TESIS DOCTORAL

\title{
MODELACIÓN MATEMÁTICA DE LA INTERACCIÓN ENTRE LA VEGETACIÓN DE RIBERA Y EL RÉGIMEN HÍDRICO DEL RÍO EN CONDICIONES SEMIÁRIDAS
}

\section{MARCO MORALES DE LA CRUZ}

Director: Dr. Félix Francés García

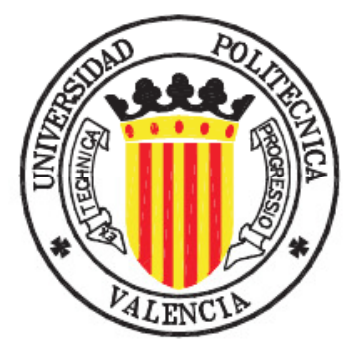

Departamento de Ingeniería Hidráulica y Medio Ambiente

Universidad Politécnica de Valencia

Diciembre de 2010. 



\section{RESUMEN}

Las interacciones bióticas y abióticas entre el río y la zona de ribera determinan procesos hidrológicos relevantes del balance hídrico y ejercen control de los tipos de vegetación característicos del corredor de ribera y laderas aledañas; las plantas responden y se adaptan a las condiciones del medio y, a su vez, controlan el ciclo hidrológico de estos ecosistemas. En las regiones semiáridas, la disponibilidad hídrica ejerce uno de los principales controles para el crecimiento y desarrollo de la vegetación, pues en el continuo suelo-planta-atmósfera son fundamentales la fluctuación de los contenidos de humedad del suelo y la profundidad del sistema de raíces; en estas condiciones, la cercanía con el río genera un gradiente de humedad que determina con mucha claridad el límite entre la ribera de vegetación exuberante y la ladera semiárida colindante.

Para enfatizar dichas condiciones y procesos ecohidrológicos, se ha diseñado y aplicado un modelo matemático de la interacción entre la vegetación de ribera y el régimen hídrico del río, denominado "Modelo de agua y vegetación de ribera RibAV", que recoge los principales avances de modelación del ecosistema a nivel mundial y que enriquece su conceptualización con base en la experiencia de campo. Esta herramienta tecnológica es de utilidad para determinar el crecimiento y respuestas de la vegetación ante condiciones variables de disponibilidad de agua de las zonas saturada y no saturada, proveniente de un balance hídrico diario controlado por el régimen del río y por los mecanismos diferenciados de adaptación al medio de los diversos tipos de vegetación presentes.

En el modelo, el régimen hídrico del río determina las fluctuaciones del nivel freático en la zona de ribera mediante una aproximación simple. La hidrología de la zona se modela mediante un balance hídrico conceptual que incluye el almacenamiento estático del suelo y los principales movimientos de agua de la ribera (lluvia, evapotranspiración, excedentes y ascenso capilar desde el nivel freático) a los que se ha añadido el del ascenso hidráulico radicular de las plantas como innovación de los modelos a escala de ribera.

Se aplicó la clasificación de la vegetación por tipos funcionales propuesta para riberas semiáridas, fortaleciendo el análisis mediante ordenación taxonómica vegetal. A partir de esta zonificación se establecieron los parámetros biofísicos característicos de la zona a modelar: bosques de ribera poco perturbados y bosques secos caducifolios de las laderas aledañas del Valle semiárido del Motagua, Guatemala. La implementación del modelo RibAV ha permitido evaluar las respuestas de los tipos de vegetación frente al régimen hídrico permanente de dos tramos de río provenientes de la Reserva de Biosfera "Sierra de las Minas" (Teculután y Uyús), cuya hidrología a escala de cuenca se determinó con modelación hidrológica distribuida.

El modelo genera las tasas de evapotranspiración de los distintos tipos de vegetación a partir de mecanismos diferenciados de respuesta y adaptación a la disponibilidad de agua del medio saturado y del almacenamiento estático; mediante la comparación de los valores respectivos se establece una escala categórica de los índices de evapotranspiración "E $\boldsymbol{T}_{\text {index" }}$ " del RibAV para predecir la ausencia / presencia de los tipos de vegetación de ribera.

El modelo se calibró, validó y evaluó utilizando uno de los índices de mayor reconocimiento en la comunidad científica de la ecología vegetal (índice "Kappa") para establecer la eficiencia de la predicción de la distribución de las plantas. De esta manera se comprobó la notable eficiencia de RibAV para zonificar los tipos de vegetación de ribera y establecer el límite entre dicha zona y la ladera aledaña; a su vez, se demostró la solidez del "E $\boldsymbol{T}_{\text {index }}$ " frente a otros índices utilizados para clasificar comunidades vegetales en ambientes semiáridos y de ribera. 



\section{AGRADECIMIENTOS}

Cómo se está de bien por aquí y a estas horas. Descansando las piernas tras el fatigoso camino lleno de montes y valles, como agua de manantial que nació pequeñita y recorrió con retumbos el cauce y bañó las riberas. Al canto de las aves le acompañan la música de guitarras acústicas y saxo acompañando las sonrisas de los hombres, de las mujeres y de los niños en paz.

No es éste un final... es un principio de más madrugadas y atardeceres en distintas sendas, con calzado nuevo y la misma vara de almendro que soporta el peso de los ideales y los recuerdos.

Es fantástico que a la dicha la llenen las sonrisas de los que están y de los que se fueron. Luces encendidas en el camino a veces oscuro, sombra de los árboles cuando abunda el sol. Palabras de aliento, café en los jardines, números frente a la computadora, pilas de papel subrayado, abrazo de los encuentros, llamada con el pensamiento viendo a través de la ventana, sereno de madrugadas en bicicleta y, de nuevo, paz.

Es el momento de escribir contento lo que ahora compartimos con lagrimitas en los ojos y sonrisas de mejillas estiradas. Como el ciego que logró ver que no veía y volvió sus pasos atrás para decirle gracias al peregrino que pasó por allí.

Gracias sí, a Dios, El que estuvo, está y estará sonriendo al mundo a través de las miradas valientes de quienes dan pasos al frente y de la laboriosa entrega de la hormiguita en el monte, tan llena de sencillez y silencio.

Gracias por supuesto a mis amados Mama Pelan y Papa Milo desde aquel día en que me ayudaron a construir mis sueños de niño, referente para partir y volver a los lugares donde se construyen el pensamiento y el sentir de los hombres.

Y ¿qué decir de tantísimas personas que allí estuvieron, y están, siempre? ¿Cómo listarlas en este folio de los recuerdos sin cerrar los ojos y sonreír de dicha? ¿Hay alguna manera en que pueda abordar con palabras lo que no se puede contabilizar con nombres y apellidos? ¿Cuál es el baremo para atreverse a poner antes a unos y después a otros? ¿Cuán capaz seré de enumerar los rostros que compartieron cada pequeño detalle, cada sonrisa justa, cada singular consejo, cada particular apoyo, cada letra en papelitos que me recordaron avanzar, cada uno de esos abrazos que dicen "aquí estamos"?

Los abordo a todos en una fotografía panorámica perfecta, abrazados y sonriendo... vienen de lejos y de cerca, partieron de países tan diversos como Guatemala, España, Colombia, México, Österreich, Francia, Honduras, Italia, Polonia, Alemania, Argentina, Chile, Bélgica...

Y allí van corriendo mis sobrinitos Emilio y Diego, llenos de esperanzas en los ojos y las mochilas cargadas de ilusión ante la atenta mirada de Mariyita y Arturo.

Y allí viene conmigo Emily, de la mano, paso a paso.

Y a esta tierra nos trajo el viento como semillitas, para vivirla con sus cimas y sus llanos, con su sequía y su verdor.

Que Dios nos acompañe y siga escribiendo hermosas historias como esta.

(Marco.

Valencia, 14 de diciembre de 2010) 



\section{ÍNDICE GENERAL}

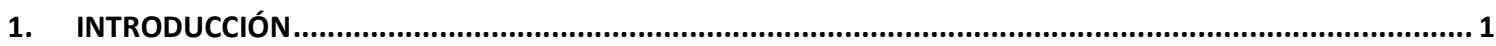

1.1 ASPECTOS INTRODUCTORIOS PARA LA MODELACIÓN ECOHIDROLÓGICA DEL ECOSISTEMA DE RIBERA.1

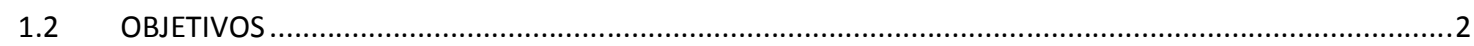

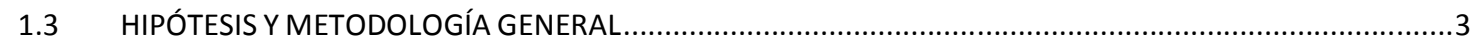

2. CONCEPTOS Y ESCALAS DE ESTUDIO DE LA ZONA DE RIBERA Y SU VEGETACIÓN.................................... 4

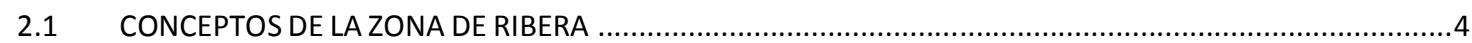

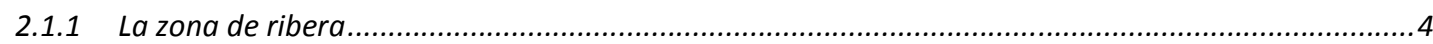

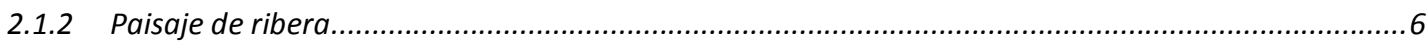

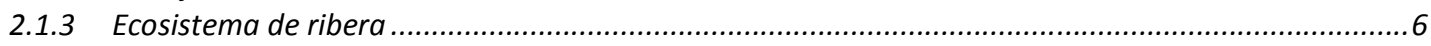

2.1.4 Vegetación de ribera: bosque de ribera y bosque de galería ...................................................6

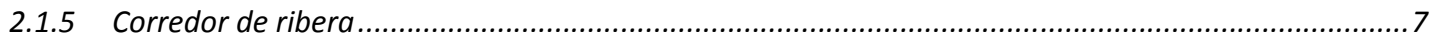

2.2 ECOLOGÍA DE LA ZONA DE RIBERA: INTERACCIÓN DE FACTORES BIÓTICOS Y ABIÓTICOS ......................8

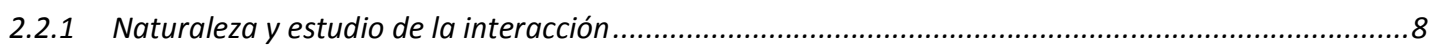

2.2.2 Efecto del régimen hídrico del río sobre la zona de ribera y su vegetación ......................................9

$2.3 \quad$ IMPORTANCIA DE LA ZONA DE RIBERA Y SU VEGETACIÓN ........................................................12

2.4 ESCALAS ESPACIAL Y TEMPORAL PARA EL ESTUDIO DE LAS INTERACCIONES EN LA ZONA DE RIBERA....13

2.4.1 Escala de ribera para el estudio de interacción de factores........................................................14

3. FUNDAMENTOS DE ECOLOGÍA, CRECIMIENTO Y DESARROLLO DE LA VEGETACIÓN ...............................18

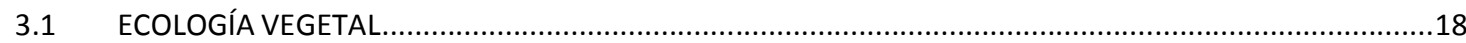

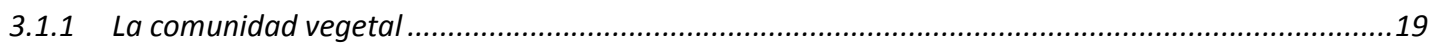

3.1.2 Clasificación de la vegetación: destacando los "tipos o grupos funcionales de vegetación".............20

3.1.2.1 Tipos o Grupos funcionales de vegetación (TFV o PFG) .........................................................................21

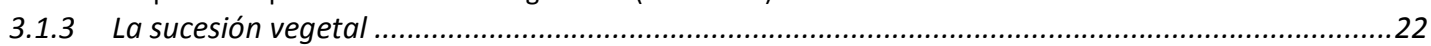

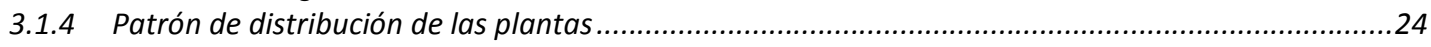

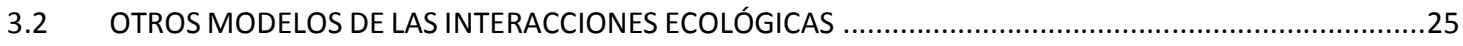

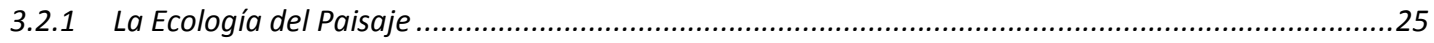

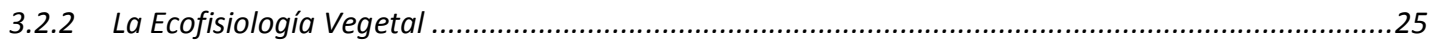

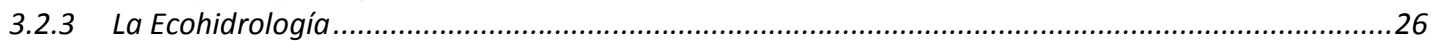

3.2.4 Otros modelos enfocados en la dinámica de la vegetación ............................................................27

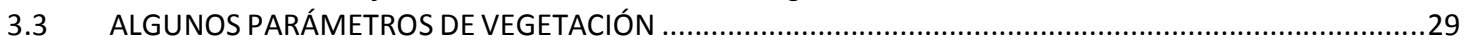

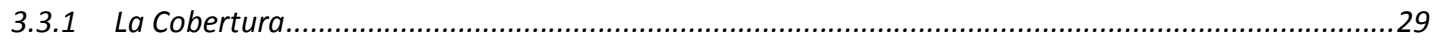

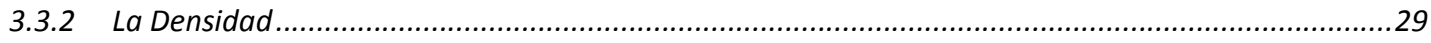

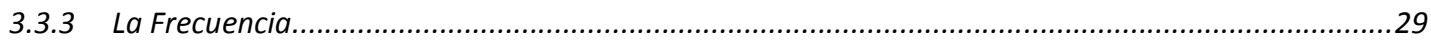

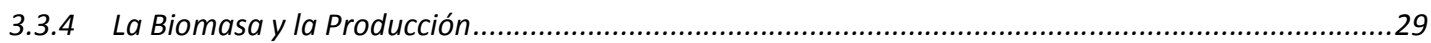

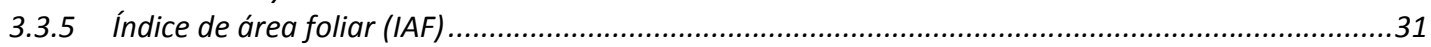

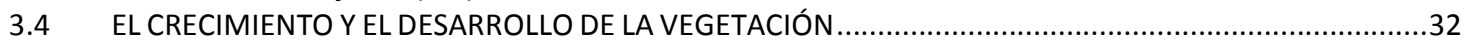

3.4.1 Efectos del estrés hídrico en el crecimiento y desarrollo de las plantas..........................................34

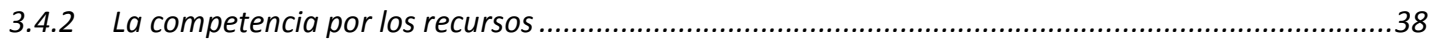

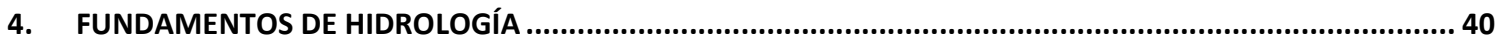

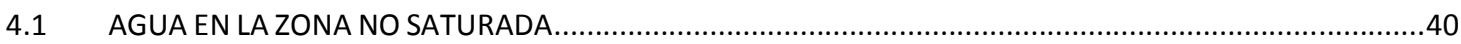

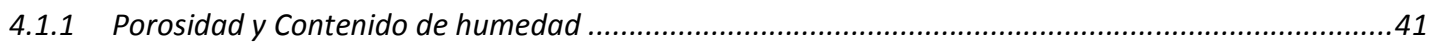

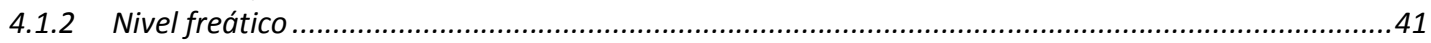

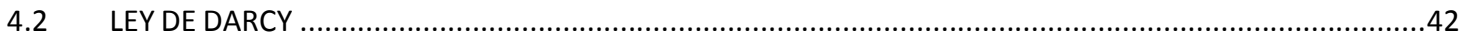

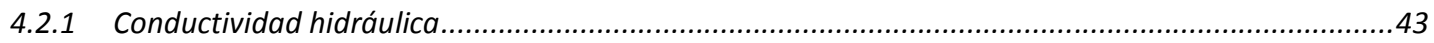

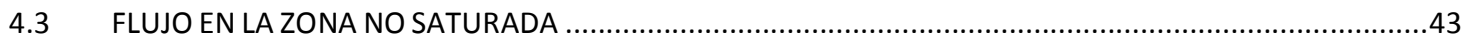

4.3.1 Curvas características de la zona no saturada: Curva de retención e Histéresis.................................44

4.3.2 Conductividad hidráulica del medio no saturado...........................................................................46

4.3.3 Almacenamiento de agua en la zona no saturada..................................................................48

4.3.4 Flujo transitorio en medio no saturado: ecuación de Richards ..................................................49 
4.4 RELACIONES AGUA - SUELO - PLANTA: USOS DEL AGUA POR LAS PLANTAS ..................................50

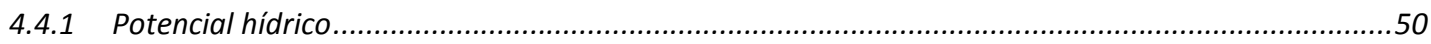

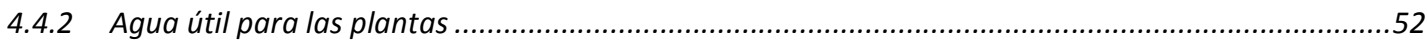

4.4.2.1 Capacidad de campo y punto de marchitez permanente ......................................................52

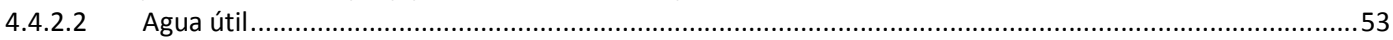

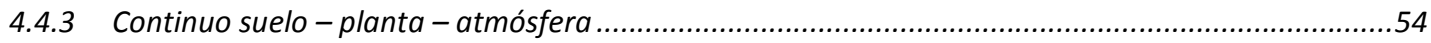

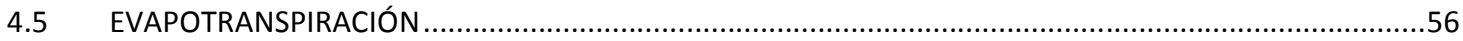

4.5.1 Evapotranspiración potencial (ETP) y su estimación .................................................................57

4.5.2 Evapotranspiración real $\left(E T_{r}\right)$ : efectos de la disponibilidad de agua del suelo..................................59

5. CONSIDERACIONES PARA MODELAR PROCESOS HIDROLÓGICOS Y DE VEGETACIÓN EN LA ZONA DE

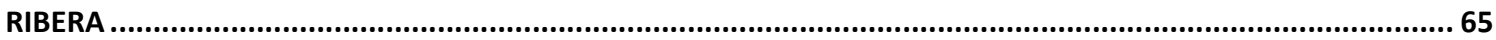

5.1 RELACIÓN ENTRE EL NIVEL DEL RÍO Y EL NIVEL FREÁTICO EN LA RIBERA .........................................66

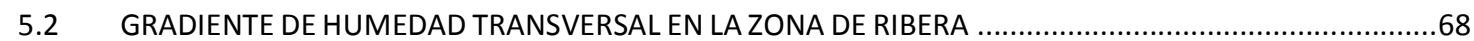

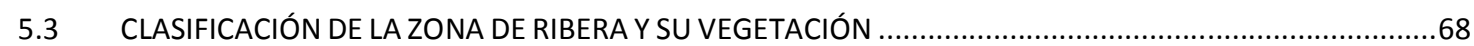

5.3.1 Los tipos funcionales de vegetación (PFT) de la ribera................................................................70

5.4 LA DISPONIBILIDAD DE AGUA EN LA RIBERA VARÍA EN FUNCIÓN DE LAS CARACTERÍSTICAS DEL SUELO,

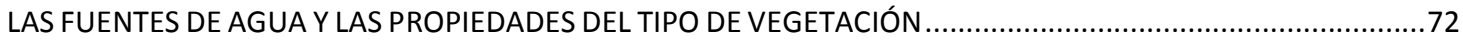

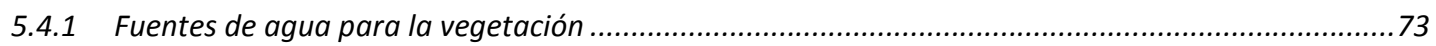

5.4.2 Anotaciones sobre los requerimientos de agua por la vegetación de ribera ....................................74

5.4.3 Efectos de los cambios en la disponibilidad de agua por variaciones del nivel freático...................... 76

5.4.4 Algunas respuestas fisiológicas de la vegetación de ribera ante cambios en la disponibilidad de

agua 77

5.4.5 Adaptaciones vegetales provenientes del sistema de raíces: relevancia del ascenso hidráulico

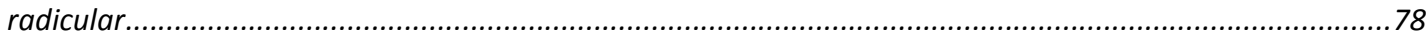

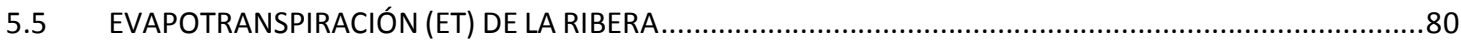

5.5.1 Métodos para estimar la ET de la ribera ..........................................................................................82

5.5.2 Método de estimación de la ET de ribera considerando los contenidos de humedad del suelo (Altier

et al, 2002; Inamdar et al, 1999; Lowrance et al, 2000).............................................................................84

5.5.3 Estimación de la ET para grupos funcionales de vegetación de ribera: el modelo RIP-ET (Baird et al,

2004; Baird y Maddock III, 2005; Maddock III y Baird, 2003) ...............................................................8.

5.6 APLICACIÓN DE SENSORES REMOTOS EN ZONA DE RIBERA: DESTACANDO LA ESTIMACIÓN DE LA ET...88

5.7 OTROS MODELOS RELEVANTES QUE ABORDAN PROCESOS INTERNOS (HIDROLOGÍA Y VEGETACIÓN) DE

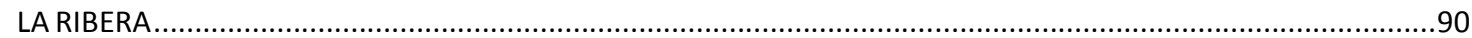

5.7.1 Modelo de vegetación - hidrología de ecosistemas de ribera de Prosopis velutina (Stromberg, 1993) 90

5.7.2 Riparian Ecosystem Management Model "REMM" (Altier et al, 2002; Inamdar et al, 1999;

Lowrance et al, 2000)

5.7.3 Modelación de las interacciones de la vegetación con el flujo del cauce en valles aluviales de la

región mediterránea (Brookes et al, 2000)..........................................................................................9.

5.8 ANOTACIONES SOBRE MODELOS ENFOCADOS EN FACTORES EXTERNOS A LA RIBERA O EN EL EFECTO

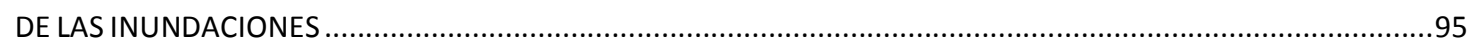

5.9 ANOTACIONES SOBRE MODELOS ENFOCADOS EN GESTIÓN FORESTAL Y RESTAURACIÓN DE LA ZONA

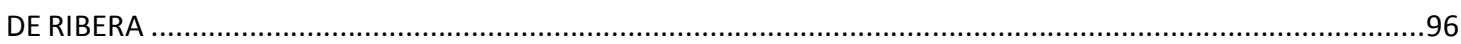

5.10 ALGUNOS SITIOS WEB RELACIONADOS CON ECOSISTEMAS DE RIBERA ........................................98

6. CONCEPTUALIZACIÓN DEL MODELO DE AGUA Y VEGETACIÓN DE RIBERA “RIBAV" .............................. 100

6.1 FUNDAMENTOS ECOLÓGICOS E HIDROLÓGICOS Y DISCRETIZACIÓN ESPACIAL DEL MODELO “RIBAV” 100

6.2 PARÁMETROS DE SUELO Y DE VEGETACIÓN DEL MODELO “RIBAV” ..............................................100

6.3 DATOS HIDROMETEOROLÓGICOS E HIDRÁULICOS DE ENTRADA DEL MODELO “RIBAV” .......................103

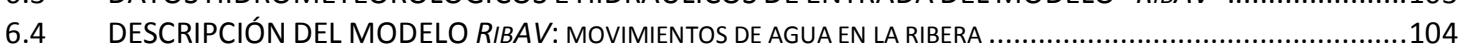

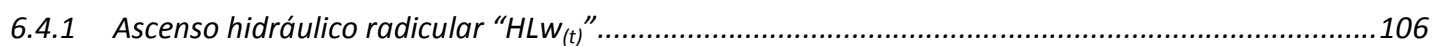

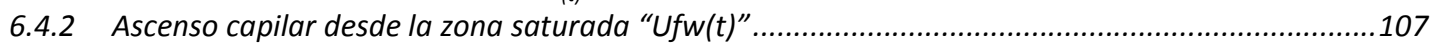

6.4.3 Evapotranspiración real "ETRtot $(t)$ "..................................................................................108

6.5 ÍNDICES DEL MODELO RIBAV PARA LA ZONIFICACIÓN DE RIBERAS DE REGIONES SEMIÁRIDAS O CON

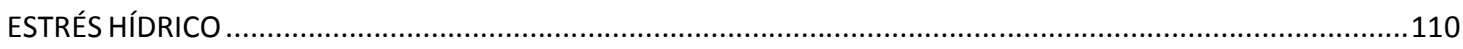

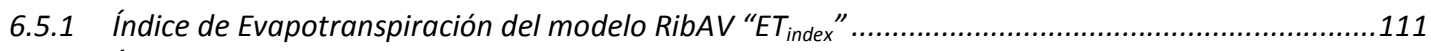

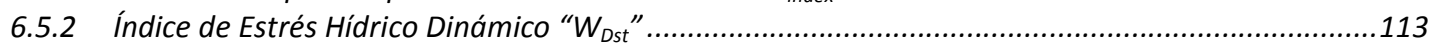


6.5.3 Índice de evapotranspiración en períodos de conectividad radicular con la zona saturada " $E T_{\text {conect }}$ 114

6.5.4 Índices de eficiencia y matriz de confusión para la calibración y validación del modelo RibAV .......115

7. APLICACIÓN DEL “MODELO RIBAV” PARA ZONIFICAR LA RIBERA EN REGIONES SEMIÁRIDAS ............... 118

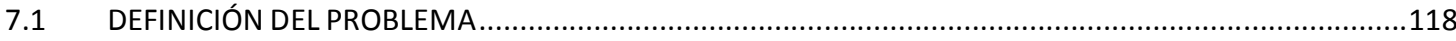

7.2 VEGETACIÓN E HIDROLOGÍA DE CUENCAS DE LA SIERRA DE LAS MINAS Y VALLE DEL MOTAGUA: Río

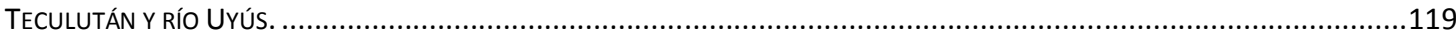

7.3 INFORMACIÓN BÁSICA Y MÉTODOS DE MUESTREO EN CAMPO DE LOS TRAMOS Y RIBERAS DE LOS RÍOS

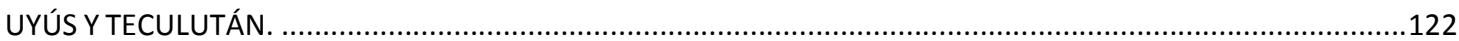

7.3.1 Ubicación de las riberas y tramos para la modelación con RibAV ..................................................123

7.3.2 Datos generales de geología y suelos del área de estudio ..........................................................124

7.3.3 Metodología para la clasificación de la vegetación de ribera: levantado de información en campo y gabinete

7.3.4 Metodología para la caracterización físico química de los suelos: levantado de información en

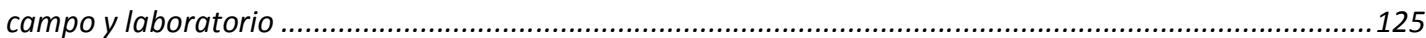

7.4 CALIBRACIÓN Y VALIDACIÓN DEL MODELO RIBAVEN TRAMOS Y RIBERAS DE LOS RÍOS UYÚS Y TECULUTÁN

7.4.1 Series hidrometeorológicas para las riberas y tramos de los ríos Uyús y Teculután.......................126

7.4.2 Tipos funcionales de vegetación de ribera de los transectos de los ríos Uyús y Teculután ..............131

7.4.2.1 Ordenación de la vegetación de ribera del río Uyús: ...............................................................................132

7.4.3 Caracterización de las secciones transversales de río y riberas de Uyús y Teculután: construcción de curvas caudal-nivel

7.4.4 Parámetros de suelo y de vegetación de los transectos de río y zonas de ribera de Uyús y Teculután 145

7.4.4.1 Parámetros de suelo:

7.4.4.2 Parámetros de vegetación:

7.4.5 Puntos de simulación de bosques de ribera y bosque seco de Uyús y Teculután para calibrar y validar el Modelo RibAV v1.0...

7.4.6 Índices de eficiencia de calibración y validación del modelo RibAV ..................................................155

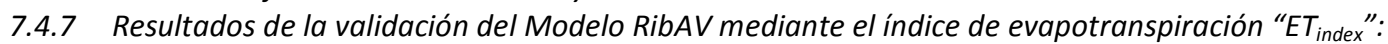

bosques de ribera y bosque seco del río Teculután.

7.4.8 Análisis del índice de evapotranspiración " $E T_{\text {index }}$ " característico de los distintos TFV simulados con RibAV 160

7.4.9.1 Breve descripción de la relevancia del ascenso hidráulico radicular para el balance hídrico en la ribera mediante modelación con RibAV:.

7.4.9.2 Comparación de resultados del " $E T_{\text {index }}$ " de RibAV con otras predicciones de ausencia/presencia de TFV basadas en índices de estrés hídrico, conectividad radicular con el nivel freático y diferencia de cota respecto al thalweg del río

7.4.9.6 Síntesis comparativa de los índices de Predicción Presencia/Ausencia analizados:.....................................174

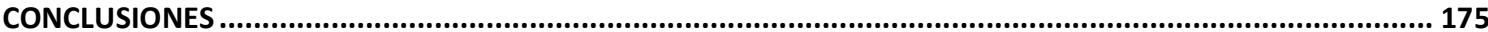

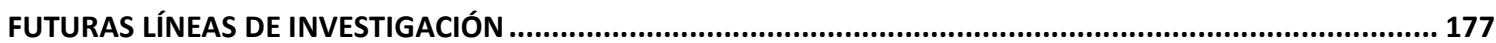

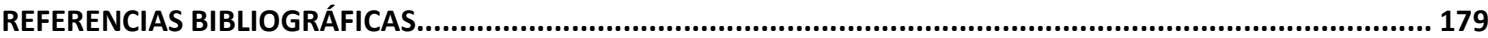





\section{INTRODUCCIÓN}

\subsection{ASPECTOS INTRODUCTORIOS PARA LA MODELACIÓN ECOHIDROLÓGICA DEL ECOSISTEMA DE RIBERA}

El dinamismo característico de los ecosistemas de ribera procede de su interacción continua con el río, y provoca múltiples adaptaciones y respuestas de su vegetación para asumir el costo energético necesario para la reproducción y el mantenimiento (Lambers et al, 1998; Malanson, 1993; Merrit et al, 2009; Naiman et al, 2005; Richards et al, 1996, 2002; Vidon y Hill, 2004).

La zona de ribera es un área muy próxima a un arroyo o río, cuyo ambiente es distintivamente influenciado por dicha proximidad y que funciona como amortiguadora de sedimentos y fuente de nutrientes para las cuencas vecinas, posibilitando mejoras de la calidad del agua que sale de la cuenca (Bren, 1993; Lowrance et.al., 1998).

Los ecosistemas vegetales influyen y a su vez son influenciados por el ciclo hidrológico. Los ecosistemas forestales de ribera son reguladores de importantes procesos hidrológicos (Lowrance et.al, 1998; Tabacchi et al, 2000). Se tiene por un lado, el clima y el suelo como controladores de la dinámica de la vegetación y por otra parte, la vegetación que ejerce una modulación importante sobre el balance total de agua, lo que a su vez la convierte en responsable, en gran medida, de los mecanismos de retroalimentación entre suelo y atmósfera (Scott et al, 2000).

Los procesos de erosión, transporte y deposición causan la perturbación y alta heterogeneidad del medio y la comunidad científica ha abordado de manera prolífica el cómo estos flujos de materia y energía entre río -inundaciones-, ribera y ladera incentivan el ciclo de sucesión vegetal y los factores bióticos de repoblación de las especies (Azami et al, 2004; Brinson y Verhoeven, 1999; Brookes et al, 2000; Choi et al, 2005; Gergel et al, 2002; Glenz, 2001; Glenz et al, 2003; McGlynn y Seibert, 2003; Ocampo et al, 2006; Shiau y Wu, 2004; Stromberg, 2001; Suzukia et al, 2002; Tabacchi et al, 1998, 2005; Wen et al, 2010; Williams et al, 1998, entre otros).

El régimen hidrológico del río a su vez es responsable del mantenimiento del ecosistema (Naiman et al, 2005) y en riberas con períodos cortos de inundación la sequía puede ser un factor incluso más limitante que la inundación misma (Heller, 1969). Por ello, otra rama importante del estudio de dicho ecosistema enfatiza el conocimiento sobre la disponibilidad del agua en la composición, estructura, distribución, crecimiento y desarrollo de la vegetación de ribera (Baird y Maddock, 2005; Horton et al, 2001; Horton y Clark, 2000; Goodwin y Tarboton, 2001; Lite et al, 2005; Maddock et al, 1998; Scott et al, 2000; Snyder y Williams, 2000; Stromberg et al, 1993; Webb y Leake, 2006; Williams et al, 1998; entre otros).

En climas áridos y semiáridos la frecuencia de ocurrencia del límite de disponibilidad de agua en el suelo es la responsable de que la vegetación entre en estado de estrés hídrico (RodríguezIturbe y Porporato, 2004; Stromberg et al, 1996). A escala de ribera el ciclo hidrológico debe estimarse con la suficiente precisión como para ser útil en la evaluación de recursos hídricos (Altier et al, 2002; Richards et al, 1996). En el caso de las riberas de los cauces, el contenido de humedad y la posición del nivel freático están marcados por el régimen hidrológico del río (Hughes et al, 2003; Richards et al, 1996), que depende tanto de la hidrología de la cuenca vertiente como de las modificaciones introducidas por el hombre a través especialmente de la construcción de embalses. 
El mejor conocimiento de las interacciones de masa y energía entre el río y el bosque de ribera con un enfoque de ecosistema es clave para dirigir acciones apropiadas de conservación y aprovechamiento de dichos recursos naturales, y particularmente como criterio para establecer el régimen del río que debe mantenerse (Glenz et al., 2003; Stromberg, 2001). La aplicación del trabajo en una zona semiárida es propicia para que se analice el agua como el recurso más limitante del desarrollo de la vegetación de ribera y requiere información de campo a detalle de diversas disciplinas (vegetación, topografía, hidráulica, hidrología, suelos, SIG, entre otros).

Se determinó aplicar la investigación en una cuenca de la Reserva de Biosfera UNESCO Sierra de las Minas, que es parte del Sistema Guatemalteco de Áreas Protegidas y fuente principal de agua para una de las zonas más productivas del país; a escala de ribera, la aplicación se desarrolla en las zonas de ribera y laderas aledañas a dos tramos de río del Valle del Motagua, que es la zona más seca y árida de Centro América, declarada de importancia nacional para su conservación (Secaira et al, 2003). El planteamiento es coherente con las iniciativas de desarrollo sostenible regional y local, pues está contemplado dentro de los planes maestros, de investigación y de conservación de dichas áreas (FDN, 2003; Secaira et al., 2003).

En este trabajo se presenta el Modelo matemático ecohidrológico de agua y vegetación de ribera "RibAV" diseñado para condiciones semiáridas, que permite analizar cómo la disponibilidad de agua ejerce uno de los principales controles del desarrollo de la vegetación de ribera. El modelo acopla avances propuestos a nivel mundial en temas de hidrología y vegetación de ribera y centra sus hipótesis en las observaciones de campo hechas en Guatemala, en bosques de ribera del Valle del Motagua que colindan con bosques secos caducifolios, una de las zonas de vida más áridas de Centro América.

\subsection{OBJETIVOS}

El objetivo general de este trabajo de tesis doctoral consiste en el desarrollo de un modelo matemático que exprese la relación entre el régimen hidrológico e hidráulico del río con la vegetación de ribera y que sea capaz de analizar el control principal que ejerce la disponibilidad de agua sobre el crecimiento y desarrollo vegetal.

Los objetivos específicos de la tesis doctoral son los siguientes:

1. Desarrollar un modelo a escala transversal de ribera para acoplar la vegetación con los procesos hidrológico-hidráulicos de ribera, para un tramo de río con discretización espacial distribuida, haciendo hincapié en el efecto de la disponibilidad de agua para el crecimiento vegetal.

2. Parametrizar el modelo a escala de ribera con base en la caracterización biofísica de campo, gabinete vegetación, suelos, topografía, hidrología y climatología recopilados en campo.

3. Aplicar el modelo de ribera en al menos dos tramos de río piloto de condiciones semiáridas, para calibrar y validar sus parámetros de vegetación efectivos y para evaluar el comportamiento de distintos tipos de vegetación frente al régimen hídrico del río.

4. Proponer y evaluar la eficiencia de al menos un índice de predicción de ausencia/presencia de tipos funcionales de vegetación de ribera.

5. Comparar la eficiencia del modelo de ribera con otros índices utilizados para la predicción de la distribución vegetal. 


\subsection{HIPÓTESIS Y METODOLOGÍA GENERAL}

Para hacer operativo un modelo de ribera es necesario disminuir el número de variables a las estrictamente condicionantes de los procesos, y en el caso de esta tesis, a las de climas áridos y semiáridos. En la actualidad, la aplicación en modelos de ribera de la celda como unidad elemental de modelización es escasa, bien sea porque estos son agregados, semidistribuidos o porque trabajan con celdas de gran tamaño dado su objetivo de conocer el balance hídrico regional a partir de la ribera; además en estos modelos se suelen considerar por separado las dos fuentes de agua para la ribera (zona saturada y no saturada). Es necesario contar con un modelo de ribera distribuido e incorporar de forma integrada los movimientos de agua que determinan la disponibilidad para la vegetación de ribera.

La metodología general de la tesis doctoral abarca cuatro grandes fases:

- El desarrollo del modelo matemático de ribera RibAV, mediante planteamiento de ecuaciones, adaptación y aplicación de modelos matemáticos a escala de ribera y que incluye: revisión del estado del arte sobre ecosistemas de ribera; desarrollo del modelo conceptual; prueba inicial del funcionamiento del programa; adaptación y aplicación de modelos a escala de ribera; entre otros.

- La generación de información base para la aplicación del modelo de ribera en los tramos de río del Valle del Motagua, Guatemala, y que incluye: trabajo de campo, gabinete y laboratorio en los temas SIG a escala de cuenca y ribera, vegetación y suelo de la zona de ribera e hidráulica y topografía de la ribera y cauce, entre otros.

- Para la generación de la serie diaria de caudales de las cuencas estudiadas de la Reserva de Biosfera Sierra de las Minas (ríos Uyús y Teculután) se utilizó modelación de lluvia - escorrentía y los siguientes elementos metodológicos: recopilación y análisis de información hidrometeorológica; preparación de mapas de parámetros en ambiente SIG a escala de cuenca; modelación mediante el programa hidrológico de cuenca Tetis v.7.2.

- La calibración y validación del modelo de ribera con base en la aplicación para al menos dos tramos de río (Teculután y Uyús) a partir de la información sobre la climatología e hidrología local, y los parámetros de suelo y de vegetación generados con información de calibración, criterio experto, revisión de literatura y observaciones o mediciones de campo y laboratorio, entre otros.

En esta tesis doctoral se trabajará con tres escalas espaciales:

- Escala Regional: El lado sur de la Reserva de Biosfera Sierra de las Minas.

- Escala de Cuenca: con énfasis en las cuencas del Río Teculután y Uyús, ubicadas al lado sur de la RBSM y que drenan al Río Motagua, con la finalidad de modelar la hidrología de las cuencas y obtener los parámetros efectivos de la calibración del modelo.

- Escala transversal de ribera: A lo largo de un tramo de río, se desarrolla el trabajo en secciones transversales perpendiculares al eje del río, obteniendo información de campo y laboratorio que permita la caracterización biofísica a escala de ribera para la modelación ecohidrológica con el modelo RibAV. Esta escala de trabajo implica la dimensión lateral / transversal desde el río hacia las laderas aledañas y la dimensión vertical de los movimientos del agua en la ribera.

Por otra parte, la escala temporal de la tesis es la siguiente:

- La modelación lluvia escorrentía a escala de cuenca se realiza en escala temporal diaria.

- La modelación a escala de ribera se realiza a escala temporal diaria pero generando indicadores de predicción de ausencia y presencia vegetal que concentran la información completa del período de simulación; además se analizará la variabilidad temporal mensual y estacional (enfatizando la época lluviosa y la época seca). 


\section{CONCEPTOS Y ESCALAS DE ESTUDIO DE LA ZONA DE RIBERA Y SU VEGETACIÓN}

\subsection{CONCEPTOS DE LA ZONA DE RIBERA}

El marco conceptual de la zona de ribera, debe ser trabajado desde su perspectiva geográfica y la lógica de los sistemas, debido a los múltiples términos y enfoque de disciplinas relacionados que refiere la literatura científica: desde el análisis del ecólogo o el geógrafo que enfocan la zona como un todo dinámico en donde interactúan muchos procesos (Bayley, 1995; Glenz et al., 2003; Lowrance et al., 1998; Malanson, 1993), el estudio que hace el ingeniero hidráulico de la resistencia al flujo por la vegetación (Arcement y Schneider, s.f.; Järvelä, 2002, 2004; Kouwen, 2003; Kummu, 2002), el estudio de los procesos hidrológicos presentes (Baird y Maddock III, 2005; Inamdar et al., 1999) o el enfoque para la restauración de la zona (Brookes y Shields, 2001; Deng y Singh, 2002; FISRWG, 1998; Hughes, 2003; Stromberg, 2001).

De acuerdo con Wenger (1999) existe una confusión especial respecto al término inglés "riparian" (ribereño), y aún parece que no existe una definición universal aceptada. Las distintas perspectivas de investigación realizada en esta zona han creado un arreglo diverso y algunas veces confuso en cuanto a definiciones basadas en hidrología, topografía, edafología y vegetación (Gregory et al., 1991). La escuela de los ecólogos y los geomorfólogos fluviales no ha llevado a un marco conceptual unificado (Malanson, 1993). Por tanto, es importante presentar algunas definiciones y conceptos relacionados con la zona de ribera, para explicar el campo de acción de la presente investigación en cuanto a la etimología empleada y teoría asociada.

De acuerdo con Naiman et al. (2000) la etimología que da origen al término "ribereño", corresponde al latín Riparius, "perteneciente a la ribera u orilla del río", referido a comunidades bióticas que viven en bordes de ríos, arroyos, estanques, lagos y algunos humedales. Esto da cabida a estudiar zonas ribereñas tanto de sistemas lóticos como lénticos (Lewis et al., 2003). Naiman et al (2005) proponen el uso del término inglés "riparian" como un adjetivo, y el término "riparia" como un sustantivo en plural o singular, para referirse a las asociaciones bióticas de las zonas de transición acuática terrestre vinculadas a las aguas lóticas, es decir, las que fluyen.

\subsubsection{La zona de ribera}

La Zona de Ribera o Ribereña (del inglés "riparian area" y "riparian zone") es un área muy próxima a un arroyo o río, cuyo ambiente es distintivamente influenciado por dicha proximidad (Bren, 1993; Lowrance et al., 1998). Entendida desde una sección transversal ideal del cauce, la zona de ribera se define como el área entre el nivel de flujo bajo del curso de agua y el punto más alto de transición entre el cauce y la llanura de inundación (Lovett y Huggan, 1998). Malanson (1993) indica que la zona de ribera es tanto un ecotono entre las zonas terrestre y acuática, como corredores a través de regiones.

Según Naiman et al (2005) las zonas de ribera son sistemas multidimensionales que se forman de acuerdo con los siguientes principios básicos: a) los gradientes de saturación hídrica determinados por la topografía, la geología y la hidrodinámica; b) los procesos biofísicos determinados por los gradientes dinámicos de energía y saturación hídrica; c) sus componentes superficiales y subsuperficiales que controlan los flujos de materia y energía; d) sus comunidades bióticas estructuradas $\mathrm{u}$ ordenadas en espacio y tiempo a lo largo de gradientes en tres dimensiones -longitudinal, lateral y vertical.

Bren (1993) considerando un estado estacionario, define la zona de ribera como el área adyacente al cauce fluvial con inundaciones periódicas; un enfoque más acorde con la ingeniería hidráulica señala que ésta es el área cubierta por una inundación en un período de retorno particular (Brookes y Shields, 2001). 


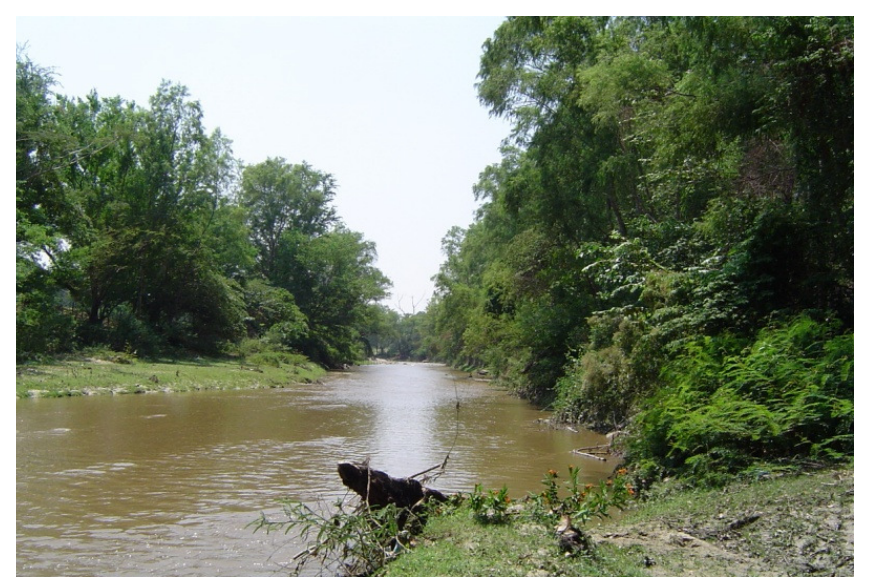

Figura 2.1. Vista de la zona de ribera en el Río Pasabién, región semiárida del Valle del Motagua, Guatemala. Foto: M. Morales (2005).

Usar el término llanura de inundación (floodplain) como sinónimo conllevaría a conclusiones erróneas, pues la zona de ribera incluye tanto áreas angostas al lado de los ríos, como extensas llanuras de inundación (Brinson y Verhoeven, 1999; Malanson, 1993). FISRWG (1998) habla de dos tipos de llanura de inundación: hidrológica o tierra adyacente al flujo base del cauce, ubicada por debajo de la elevación de la terraza de la ladera; topográfica o tierra adyacente al cauce incluyendo tanto llanura hidrológica como otras tierras por encima de un nivel definido por un caudal pico definido por un determinado período de retorno.

Con frecuencia hay que recurrir al análisis de la geomorfología de la ribera para delimitar la extensión del ambiente ribereño (García, s.f.). Una definición geomorfológica más precisa es la de Nanson y Croke (1992) que resalta la asociación genética entre los tipos de ríos y las llanuras aluviales que estos construyen.

Diversos autores enfatizan el elevado dinamismo de las zonas de ribera y sugieren no olvidar tan importante particularidad al momento de abordar los estudios (Glenz et al, 2002; Howard, 1992; Miller et al, 2003; Richards et al, 2002). Según Naiman et al (2005), el alto dinamismo de la ribera hace que exista una interacción "casi experimental" entre su organización espacial y sus procesos ecológicos.

Las zonas de ribera son tanto ecotonos entre las zonas terrestre y acuática como corredores entre regiones (Malanson, 1993). En el contexto de ecotonos y pensando el posible grado de protección que ofrece la zona, ha surgido el término "zona ribereña de amortiguamiento" (del inglés "riparian buffer zone" ó simplemente "buffer"), para expresar cómo ésta amortigua los impactos humanos de uso de la tierra sobre el río (Wenger, 1999).

Respecto a la zona de ribera entendida como un área "buffer" existe una larga lista de investigaciones que han dado paso a importantes avances, entre ellos el desarrollo del Modelo de Ribera REMM (Altier et al., 2002; Lowrance et al., 1998). Correll (1999) presenta una bibliografía con índice y anotaciones de 648 referencias de literatura mundiales con énfasis en las funciones de amortiguamiento de la zona de ribera.

La gran mayoría de estudios revisados concuerdan en expresar el carácter dinámico de la zona de ribera y su vegetación, es decir, en el cambio que siempre se produce debido a procesos continuos (Glenz et al, 2002; Howard, 1992; Miller et al, 2003; Nilsson y Berggren, 2000; Richards et al, 2002; Winward, 2000, entre otros). Las zonas de ribera son uno de los sistemas ecológicos más complejos de la biosfera y también entre los más importantes para mantener la vida del paisaje terrestre y sus ríos (Naiman et al., 2000). 


\subsubsection{Paisaje de ribera}

Malanson (1993) examina los sistemas ecológicos del margen del río y la llanura de inundación desde la perspectiva de la ecología del paisaje, define el Paisaje de Ribera (del inglés "riparian landscape") como el espacio en el que se producen las interacciones entre sus componentes bióticos y abióticos. Indica su diversidad en cuanto a estructura y función entre regiones como respuesta a los mismos factores primarios. Estudiando la estructura del paisaje se pueden encontrar diversas ecorregiones (zonas geográficas que representan grupos geográficos o asociaciones de ecosistemas funcionales semejantes) relacionadas con diversos tipos de paisajes fluviales. Presenta siete tipos de paisajes de ribera: bosques de galería en áreas semiáridas y áridas; bosques tropicales; bosques subtropicales de la llanura de inundación; bosques caducifolios húmedos; transición bosque-pastizal y pastizal; montañas; taiga y tundra. Dicha clasificación del paisaje de ribera es una referencia obligada para comprender los distintos tipos de bosque de ribera que existen asociados a diversas climatologías.

\subsubsection{Ecosistema de ribera}

El mayor enfoque del concepto está dado para zona de ribera de ríos, entendiendo al Ecosistema de ribera como la unión compleja de organismos y su ambiente adyacente y cercano al flujo de agua (Lowrance et al, 1985; Naiman et al, 2005) 0, simplemente, aquellos ecosistemas adyacentes al río (Malanson, 1993). Con una visión más funcional, Gregory et al. (1991) proponen la definición del Ecosistema de Ribera para enfocarse en los vínculos ecológicos producidos en esta interfaz entre ecosistemas terrestres y acuáticos dentro del contexto de los procesos geomorfológicos y dinámica fluvial que los crean. Dicha perspectiva se refleja en el trabajo de simulación de procesos ecológicos de la ribera del modelo "Riparian ecosystem management model, REMM" (Altier et al, 2002; Inamdar et al, 1999; Lowrance et al, 1998).

La definición funcional es generalmente la más ampliamente utilizada, debido a que refleja los procesos e interacciones que toman lugar entre el paisaje terrestre y el río; asimismo es la definición que más se acerca a los múltiples objetivos de los planes de manejo de la ribera (Lovett y Huggan, 1998).

Otro aporte importante lo hacen Brookes y Shields (2001), al mencionar que durante el Congreso Nacional de Investigación de los Estados Unidos de 1992 se recomendó hablar de "riverineriparian ecosystem" tanto para ríos grandes como para pequeños y "stream-riparian ecosystem" en relación a pequeños arroyos en donde las inundaciones son tan breves que los organismos acuáticos no han desarrollado adaptaciones para explotar la zona ribereña.

Los ecosistemas de ribera son simbólicos de los cambios de paisaje a gran escala dada su sensibilidad al régimen fluvial, y porque son la última expresión de las interacciones con el agua superficial y subterránea. Los cambios a largo plazo que se dan en su vegetación arbórea es quizás lo menos entendido de este ecosistema (Webber y Leake, 2005). También se les estudia con base en escalas temporales de minutos o más grandes (Gregory et al, 1991).

\subsubsection{Vegetación de ribera: bosque de ribera y bosque de galería}

Se han hecho intentos para definir la zona de ribera desde la bases de su vegetación, pero no ha sido un enfoque de amplio uso debido la elevada diversidad de tipos de vegetación existentes (Lovett y Huggan, 1998). Una propuesta (Winward, 2000) enfoca dicha zona como un "complejo ribereño" que se define según una clasificación por tipo de comunidad vegetal.

La vegetación ribereña es la que se cría en las riberas (margen del cauce y terrenos adyacentes). Los árboles de la zona ribereña influyen de forma directa en el agua del río o el flujo subterráneo desde o hacia el río. Por otra parte, el régimen hidráulico influye creando condiciones para la vida de ciertas plantas, principalmente mediante la variación temporal del calado, la velocidad, la erosión del lecho y los márgenes, la turbidez, etc. En el contexto relativo a latitudes mediterráneas, la vegetación ribereña es uno de los ecosistemas más heterogéneos y complejos, porque combinan los procesos de dinámica fluvial, las variaciones del régimen hidráulico, las condiciones climáticas regionales, la acción de la fauna y la acción del hombre (García, s.f.). 
En el estudio de Tabbachi et al. (1998) se tratan las temáticas del desarrollo, mantenimiento y rol de la vegetación de ribera en el paisaje ribereño a escala longitudinal. Se enfatiza en una aproximación de vegetación ribereña en la que los controles superficiales y de agua subterránea se consideran en el contexto de la ecología del ecosistema fluvial desde la escala espacial local (interna) hasta la de cuenca (regional).

Los bosques de ribera (Riparian Forests) se localizan en las llanuras aluviales de los ríos y son parte de un sistema altamente integrado que incluye al cauce, y traslapando términos son tanto "humedales de ribera" y "corredores de ribera". En términos generales y considerando que no todas las zonas de ribera tienen bosque en su estado natural, se les considera la parte vegetada del corredor de ribera (Brinson y Verhoeven, 1999). Según Treviño et al. (2001) los bosques de ribera se presentan como comunidades vegetales exuberantes en relación con su entorno, pues al desarrollarse en áreas aledañas a ríos y arroyos se propician mayor altura, densidad y en proporción, mayor cantidad de biomasa, mayor complejidad estructural y mayor número de especies siempre verdes, lo que significa un valor comercial potencialmente más grande.

Los bosques de galería (gallery forests) en los paisajes de la sabana tropical son mayormente franjas angostas forestales asociadas a quebradas y ríos; la dificultad de cuantificar su extensión y su a veces reducido tamaño, provocan que no se les considere dentro de una escala más amplia para el manejo forestal. Además, los bosques de galería son muy propensos a la fragmentación debido a la morfología de la llanura de inundación, el fuego y los impactos humanos (Veneklaas et al, 2005).

En países latinoamericanos como Cuba (Sánchez, 2001), Colombia (Veneklaas et al., 2005), Guatemala (Dix y Fernández, 2001), México (Treviño et al., 2001), entre otros, el argot técnico forestal maneja como sinónimos los términos "bosque de ribera" y "bosque de galería". En países como Estados Unidos (Lowrance et al, 1998; Stromberg et al, 1993), España (Suárez et al., 2002) y el resto de Europa (Hughes et al, 2003), suelen utilizarse con más frecuencia los términos bosque de ribera ("riparian forest"), ecosistema de ribera ("riparian ecosystem") ó bosque de la llanura de inundación ("riparian floodplain").

Para el caso de Guatemala, existe una elevada tendencia del sector profesional de los recursos naturales a utilizar el término "bosque de galería", como queda demostrado en el Inventario Nacional de Humedales (Dix y Fernández, 2001). A pesar de que la Constitución Política de Guatemala (Guatemala/Corte de Constitucionalidad, 2005) en el artículo 126 establece que "Ios bosques y vegetación en las riberas de los ríos y lagos, y en las cercanías de las fuentes de agua, gozarán de especial protección", este tipo de bosque no se menciona de forma explícita en la Ley Forestal Guatemalteca (Guatemala, 1996).

Para la utilización correcta de los términos bosques de ribera y bosques de galería, es necesario revisar los conceptos de ecología y estructura del paisaje de ribera de Malanson (1993). Allí se demuestra que el término bosque de galería es más específico para pequeñas zonas con vegetación de ribera en climas semiáridos, mientras que el término "bosque de ribera" es más genérico y adecuado pues permite involucrar a todos los tipos de bosque en el área.

\subsubsection{Corredor de ribera}

Wenger (1999) utiliza en algunas ocasiones el término zona de ribera como sinónimo de corredor de ribera, sin embargo, las connotaciones de "corredor" suelen ser más propias para enfocarse en la escala longitudinal de la ribera (ver más detalle en el tema de escalas de estudio de la zona de ribera). Los corredores son elementos angostos del paisaje que difieren de otros elementos circundantes (Malanson, 1993). Por lo tanto el término corredor de ribera está relacionado con la zona de ribera con vegetación que conecta las partes altas de las cuencas hasta las desembocaduras con los océanos y que ha sido el enfoque de diversas discusiones teóricas y estudios de diversa naturaleza (Malanson, 1993; Tabacchi et al., 1998; Winward, 2000). 
En esta conceptualización, se tratan los altos niveles de conectividad reconocidos en el corredor de ribera, que resultan mayormente de su localización como interfaz entre el río y las tierras cercanas de ladera (Tabacchi et al., 1998). Considerando la amplitud de criterios existentes, y para ser coherentes con las definiciones legales y la corrección técnica en esta tesis doctoral se utilizarán los términos "zona de ribera" y "vegetación de ribera".

\subsection{ECOLOGÍA DE LA ZONA DE RIBERA: INTERACCIÓN DE FACTORES BIÓTICOS Y ABIÓTICOS}

\subsubsection{Naturaleza y estudio de la interacción}

La interacción del cauce con la zona de ribera se produce por el vínculo lateral entre la red de drenaje de la cuenca (Malanson, 1993) y la estructura geomorfológica y de vegetación a escala local. Se han estudiado distintas facetas de la interacción entre los factores bióticos y abióticos internos de la zona de ribera, y su relación al exterior como interfaz entre los ecosistemas fluviales y terrestres aledaños. Asimismo, se han abarcado las distintas causas de dicha interacción, reflejando la complejidad del sistema en la ribera. En la presente investigación se revisan esas aproximaciones, incluyendo el enfoque de la ribera en la lógica de los sistemas (en donde la interacción se da entre factores internos y externos a la zona), y con ello poder definir dentro de qué marco resolver hipótesis planteadas.

La visión para el estudio de las interacciones ha evolucionado a lo largo de los años. En un principio se enfatizó el rol de la ribera como recurso de materia y energía para los sistemas acuáticos. Posteriormente se abordó la capacidad de la ribera para amortiguar los aportes de la ladera hacia el río. A finales de los noventas, se enfatizó en el papel del cauce sobre la vegetación, con respecto a los daños físicos que causan las perturbaciones hidrológicas a escala local (Tabacchi et al, 1998). Después de las investigaciones sobre requerimientos de flujo para mantener la fauna acuática, se sucedieron las del conocimiento de las crecidas y los flujos subsuperficiales necesarios para mantener la vegetación de ribera (sensu Stromberg, 2001).

Actualmente aún existe dificultad en la transferencia de las interacciones planta-hidrología a escalas mayores y eso constituye un destacable problema. Herramientas independientes de la escala, como los sistemas de información geográfica (SIG), siguen a la espera de contar con funciones de transferencia de escala que modelen eficientemente los patrones regionales a partir de datos de campo; sin embargo esa problemática no es exclusiva de los sistemas de ribera (Tabacchi et al, 2000) y, como se verá en este documento, existen propuestas al respecto.

Las funciones de los elementos ribereños pueden concebirse dentro de la terminología de los sistemas. Los "sistemas de ribera" son áreas semi-terrestres transicionales que se extienden de los límites de los cuerpos de agua hacia los límites de las comunidades vegetales de tierras altas (Naiman et al, 2005). Dentro del enfoque energético y de transporte de nutrientes, algunos modelos se han concentrado en un solo lugar e ignoran la estructura espacial (a diferencia de la hidrología que sí realiza consideraciones espaciales); el estudio ecológico de materia y energía de la ribera, generalmente carece de una aproximación con lógica de sistemas o considera un número limitado de factores (Malanson, 1993). Pautou y Decamps (1985) señalan que la heterogeneidad espacial de la vegetación de ribera puede entenderse como resultado de la combinación de fuerzas externas (hidráulica del cauce, erosión, sedimentación, entre otras) con procesos internos (condiciones del suelo y la hidrología).

Los factores bióticos y abióticos pueden modificar grandemente a los bosques de ribera: mientras las fuerzas físicas del medio controlan la estructura del ecosistema ribereño, dicha estructura modera las fuerzas físicas alterantes (Brinson y Verhoeven, 1999). La interacción de estos factores produce efectos sobre la biodiversidad y productividad del ecosistema (Bayley, 1995). También se ha señalado la influencia que posee la ribera sobre el cauce, desde el punto de vista de su capacidad de amortiguamiento de posibles impactos sobre la calidad del agua (Altier et al, 2002; Lowrance et al, 1998) y del favorecimiento de la estabilidad de los márgenes a partir de la adecuada función del suelo (Lewis et al., 2003) y de las características morfológicas de su vegetación (Brookes et al., 2000; Glenz et al., 2003; Winward, 2000). 
Otro concepto que se ha planteado para entender las interacciones dinámicas entre el agua y el suelo y la biota de la ribera y de la llanura aluvial es el del "Pulso de Inundación" (del inglés "flood-pulse") que aplicado a grandes ríos, demuestra que el avance y retroceso predecible del agua en la llanura aluvial, en condiciones naturales, aumenta la productividad biológica y mantiene la diversidad (Bayley, 1995; FISRWG, 1998; Middleton, 2002).

Se destaca también el control ejercido por el clima regional y los tipos de sistemas sobre los principales factores de funcionamiento de los ecosistemas de ribera. Los rasgos del ecosistema, como por ejemplo la evapotranspiración, afectan y están afectados por la composición y función de las especies vegetales dominantes (Chapin et al, 1997; Williams et al, 1998).

Una referencia que destaca por su visión integradora, es presentada por Tabacchi et al (2000), quienes revisan los impactos de la vegetación de ribera sobre algunos procesos hidrológicos internos y externos, con énfasis en la resistencia al flujo, la absorción y transpiración de agua por la vegetación, y la función de la ribera sobre la calidad del agua.

Tabacchi et al (1998) proponen analizar las interacciones dentro de un marco común, en el que la zona de ribera y ecosistema fluvial son ecosistemas dinámicamente unidos longitudinal, lateral y verticalmente por procesos hidrológicos y geomorfológicos que se suceden dentro de una jerarquía temporal. Señalan como factores geomorfológicos internos la físico química del suelo, la pendiente dentro de la zona riparia, y como externos el gradiente y área de la cuenca, el tipo de suelos, el tipo y profundidad de la roca madre, el volumen y composición de las entradas de agua subterránea, la morfología del cauce. Las características del suelo controlan el movimiento, la retención y el abastecimiento de agua para las comunidades vegetales y animales de la ribera.

Estudios como los de Brookes et al (2000), Glenz et al (2003), Gregory et al (1991), Hughes et al (2003), Lite y Stromberg (2005), Richards et al (2002), Stromberg et al (1993), Williams (1997), entre otros, también proponen abordar la problemática de la ribera con una visión integradora de procesos internos y externos. Glenz (2001) sugiere acoplar modelos hidráulicos y geomorfológicos (para simular inundación y sedimentación) con modelos de vegetación (para simular sucesión vegetal y procesos asociados). Williams (1997), señala que el "análisis y manejo ambiental adaptativo" de la ribera debe comenzar con un esfuerzo concertado para integrar la experiencia interdisciplinaria e información científica existentes en un modelo dinámico que permita hacer predicciones de los impactos de distintas alternativas. Malanson (1993) en el contexto de la Ecología del Paisaje de ribera también es una recomendable referencia.

Otros estudios en países como Japón, Corea y China (Azami et al, 2004; Choi et al, 2005; Deng y Singh, 2002; Nakamura et al, 2002; Shiau y Wu, 2004; Suzukia et al, 2002) son muestra del reconocimiento general que existe respecto a que los principales factores que determinan la composición local de especies y la diversidad forestal en la ribera son las perturbaciones del medio (por agentes externos) y las condiciones internas de sitio como su humedad, textura y profundidad del suelo. El siglo XXI ha traído consigo que la ciencia enfatice las interacciones entre las personas y los ecosistemas, los cambios en las escalas espaciales y temporales, los vínculos interdisciplinarios, y las riberas juegan un papel central para entender e ilustrar estos vínculos (Naiman et al., 2005).

\subsubsection{Efecto del régimen hídrico del río sobre la zona de ribera y su vegetación}

Las dinámicas de la vegetación dentro del corredor de ribera están clara y sustancialmente influenciadas por los cambios en el régimen hidrológico. Los vínculos superficiales y subterráneos son los controladores predominantes de la conectividad del paisaje dentro de los sistemas ribereños. Frente a cambios del régimen hídrico del río por efecto del hombre, la estructura interna del corredor de ribera juega un papel importante, ya que la vegetación controla fuertemente los vínculos entre el cauce y la llanura de inundación, y también entre el corredor de ribera y la ladera de partes altas (Tabacchi et al., 1998). 
El conocimiento combinado de los procesos fluviales y el régimen hídrico permiten explicar, al menos en parte, por qué los bosques de ribera tienen diversas asociaciones de especies. Los procesos fluviales crean condiciones heterogéneas imprescindibles para el desarrollo de la vegetación de ribera (Brinson y Verhoeven, 1999). Las interacciones dinámicas entre el agua superficial y subterránea determina la persistencia y productividad de las comunidades vegetales de ribera (Naiman et al, 2005).

Debido a que las dinámicas de la vegetación dentro del corredor de ribera están claramente influenciadas por los cambios en el régimen hidrológico (Tabacchi et al., 1998), resulta necesario el análisis del hidrograma del río conectado con la zona de ribera. Como se verá en el presente documento, en el estudio del hidrograma del río conectado con la zona de ribera, se les ha dado gran énfasis a los picos de caudales extremos, referidos a inundaciones y también a sequías. La naturaleza diversa de dichos trabajos ha aportado resultados a múltiples escalas temporales, por lo que los conceptos de escalas de estudio de la zona de ribera son importantes de conocer.

Para entender la zona de ribera se necesita también una perspectiva a escala de cuenca, pues su forma y tamaño, unido al clima y a las unidades litológicas, ejercen un control fundamental sobre los procesos hidrológicos y geomorfológicos que influeyen la ribera en cualquier punto del sistema de drenajes (Naiman et al, 2005).

Bren (1993) reconoce la importancia de contar con información de la hidrología de la ribera, haciendo especial énfasis en la descripción del régimen hidrológico "natural" del río. Los hidrogramas revelan la variabilidad estacional e interanual en los flujos de los ríos y arroyos; Naiman et al (2005) dentro de las características genéricas de los hidrogramas en distintos tipos de ribera señalan los siguientes: a) en pequeños ríos o arroyos la respuesta a las precipitaciones es bastante sensible y los hidrogramas se caracterizan por un alto número de picos a lo largo del año; b) en ríos permanentes las inundaciones se suelen concentrar en la época lluviosa; c) los ríos de zonas áridas suelen ser efímeros y con considerables períodos sin flujo y ocasionales inundaciones; d) los grandes ríos y sus ambientes de ribera son menos sensibles a eventos de lluvia individuales.

Según Stromberg (2001), la hipótesis del régimen hidrológico natural establece que las especies de ribera requieren el patrón temporal y espacial de flujo del río a los que se han adaptado a lo largo del tiempo; por tanto para mantener los ecosistemas ribereños nativos, es necesario mantener los regímenes hidrológicos regionales (incluyendo los patrones naturales de perturbación por inundaciones y dinámica fluvial). Sin embargo, en ciertas situaciones pensar en condiciones "naturales" de un río o establecer el régimen "natural", es al menos discutible, ante la imposibilidad de conocer dicho régimen en un río con condiciones altamente intervenidas o cuando se carece de información histórica. (Bren, 1993; Stromberg, 2001).

Un cuestionamiento clave relacionado con el régimen hidrológico, se refiere a los componentes del flujo "más ecológicamente sensibles o influyentes", pues una pequeña desviación en la profundidad del nivel freático o en el tiempo de inundación pueden causar un cambio mayor que, por ejemplo, una pequeña desviación en la magnitud de la inundación (Stromberg, 2001).

Los procesos hidrológicos y geomorfológicos actúan como las directrices primarias del ecosistema, pudiendo influir en los factores de control de las plantas al afectar el establecimiento y densidad de especies vegetales clave o estableciendo la base física y proveyendo de restricciones para la operación de los procesos químicos y biológicos (Tabacchi et al, 1998; Williams et al, 1998). Debido a la sensibilidad de las especies de ribera a la humedad del suelo y a las inundaciones, la alta variedad de micro hábitats dentro de un único corredor puede soportar un amplio arreglo de comunidades vegetales. En la regeneración, los caudales pico máximos sirven para crear nuevos nichos, mientras que los caudales mínimos se requieren para que las semillas o propágulos (medio de dispersión de las plantas de carácter vegetativo y no sexual, como las semillas) germinen (Brinson y Verhoeven, 1999). 
La máxima riqueza de especies suele estar en los cursos medios de los ríos, donde las alteraciones hidrológicas intermedias ocurren y, como consecuencia, donde está la máxima diversidad de hábitats (Tabacchi et al., 1998). En hábitats fluviales, la regulación hídrica y el manejo del cauce parecen acelerar la introducción de especies invasoras al corredor de ribera (Tabacchi et al, 2005). Más adelante se estudiará el papel de las especies invasoras en el balance hídrico de la ribera.

Considerando que los picos de entrada de semillas al hábitat ribereño están relacionados con los eventos de crecida, esta influencia del cauce se considera como responsable de la riqueza de especies (Tabacchi et al, 2005). El hidroperíodo (duración, frecuencia, profundidad y estacionalidad de la inundación) es el control más crítico en la composición de especies de los bosques de ribera; también es la causa de la dominancia de las especies más tolerantes a las inundaciones (Brinson y Verhoeven, 1999). El modelo agregado de Seagle y Liang (2001) es una propuesta para predecir los efectos del régimen hídrico sobre la sucesión forestal en estadios iniciales.

A largo plazo las inundaciones pueden promover o degradar los procesos que controlan la estabilidad del ecosistema ribereño y ocasionalmente proveen de microhábitats necesarios para la repoblación de ciertas especies ribereñas arbóreas clave o grupos funcionales de vegetación (Williams et al, 1998; Stromberg, 2001). Las inundaciones, y los eventos de erosión y deposición que les acompañan, contribuyen a la formación de hábitats ribereños (Tabacchi et al., 1998).

Cualquier obra hidráulica o civil que interrumpa la dinámica de la ribera, tendrá un impacto ambiental asociado. Un ejemplo son los diques, que producen impactos profundos en los ecosistemas ribereños, al interrumpir dichos ritmos de inundación, críticos para las dinámicas de dispersión de semillas, el establecimiento de las plantas, los ciclos de nutrientes, la deposición de sedimentos y el mantenimiento de la diversidad de especies (Gergel et al, 2002).

Las inundaciones pueden afectar la vegetación al causar condiciones de suelo anaeróbicas, el rompimiento mecánico de las plantas, y los procesos de erosión y deposición. Las alteraciones debidas a diques en teoría afectan, por múltiples mecanismos, la composición y estructura de comunidades forestales de la llanura de inundación. Sin embargo, la relación causa-efecto no es necesariamente lineal. Gergel et al. (2002) demostraron que existía alta correlación entre los indicadores "valor de importancia" de ciertas especies vegetales y el régimen hídrico simulado con presencia de dique, y poca correlación con el régimen simulado con remoción de dique.

Los efectos de las inundaciones en la vegetación tienden a ser eclipsados debido a que los patrones de vegetación están influidos por el régimen anual del agua y por grandes inundaciones catastróficas. El estudio de los impactos ambientales sobre la vegetación de ribera ha sido mayormente enfocado a los efectos provocados por las presas (Bendix y Hupp, 2000; Kingsford, 2000; Nilsson y Berggren, 2000; y diversos autores citados por Gergel et al, 2002). Muy pocos estudios examinan los efectos ecológicos directos de las pequeñas presas (Gergel et al. 2002; Simon y Collison, 2002).

Según Heller (1969) en las llanuras de inundación con períodos cortos de inundación, la sequía puede ser un factor más limitante que la inundación. El conocimiento de la ecología de las sequías en ríos es escaso y fragmentado, y mayormente ha surgido en estudios de zonas áridas o semiáridas. La sequía en el cauce debe verse como un agente de disturbio en donde los caudales del río caen a niveles extremadamente bajos por períodos de tiempo extensos (Lake, 2003).

Los ecosistemas ribereños de las regiones áridas y semiáridas contienen una parte desproporcionada de la biodiversidad regional y juegan un papel importante en el balance de agua y energía a esa escala, pero que son extremadamente sensibles a perturbaciones que afectan el agua subterránea y el abastecimiento de agua superficial para las plantas dominantes de la ribera (Maddock et al, 1998; Webber y Leake, 2005; Williams et al, 1998). 
Los niveles freáticos y las trayectorias del flujo subterráneo son muy relevantes debido a que un rasgo característico de la vegetación de ribera es su acceso anual al agua (Naiman et al, 2005). La importancia de los regímenes de aguas subterráneas para la vegetación ribereña se ha reportado en diversos estudios (Baird y Maddock, 2005; Maddock et al., 1998; Malanson, 1993; Webber y Leake, 2005), y sobre ellos se profundizará más adelante.

Otros estudios referidos a zonas semiáridas o áridas refuerzan estas aseveraciones, y destacan el papel de la disponibilidad del agua o humedad como el factor más limitante de la composición florística, estructural o de crecimiento del bosque de ribera (Brookes et al, 2000; Horton y Clark, 2000; Goodwin y Tarboton, 2001; Lite et al, 2005; Malanson, 1993; Scott et al, 2000; Snyder y Williams, 2000; Stromberg et al, 1993, entre otros). En el presente trabajo de investigación se dará énfasis a estos aspectos hidrológicos relacionados con la disponibilidad de agua y los procesos de vegetación asociados.

El agua y su carga disuelta se intercambian continuamente entre el río, el acuífero de ribera y el acuífero regional; la magnitud y tasa de ese intercambio depende del clima local, la forma del valle, el caudal, el material del lecho y del sustrato de la ribera, la configuración del cauce, y la variabilidad a escala de ribera de la pendiente del río (Naiman et al, 2005).

La sequía proviene tanto de eventos de periodicidad anual o "hiperanual"; sus consecuencias son la disminución o la pérdida total de la conectividad hidrológica entre la ribera y el río (a diferencia de las inundaciones que amplifican dicha conectividad) o dentro del cauce, favoreciendo el incremento de hábitats lénticos. Las sequías o períodos extensos de bajo flujo en la época seca o el verano, son fenómenos naturales que sirven como una fuerza mayor en el mantenimiento de la biodiversidad dentro del río y en su zona de ribera aledaña (Lake, 2003).

Por tanto, un paso crucial en el establecimiento de caudales ecológicos, es asegurar que el régimen hídrico restaurado no contenga períodos extensos de bajos flujos extremos o sin flujo, (Lake, 2003), así como el conocimiento del hidrograma asociado al régimen natural del río.

\subsection{IMPORTANCIA DE LA ZONA DE RIBERA Y SU VEGETACIÓN}

La vegetación de ribera juega un papel importante relacionado con la erosión, la estabilidad del cauce y la calidad del agua de los ríos, y las zonas de ribera tienen valores más directamente relacionados con los humanos, tal y como lo estético, lo recreativo y la visión de recurso natural (Malanson, 1993). Por otra parte funciona como amortiguadoras de sedimentos y fuentes de nutrientes para las cuencas vecinas, posibilitando mejorar la calidad del agua saliente, además de incrementar la estabilidad del margen y regular la temperatura del río al proveerle de sombra (Bren, 1993; Deng y Singh, 2002; Gregory et al., 1991; Hooper et.al., 1998; Lowrance et.al., 1998; Naiman et al., 2000; Weltya et.al., 2002). La vegetación ribereña facilita la remoción de los sólidos suspendidos y los nutrientes que contienen de las aguas que entran a la zona vía lateral desde la ladera y de los flujos que llegan del cauce. La resistencia al flujo por dicha vegetación y la capa de humus más superficial son las mayores responsables de la retención (Tabacchi et al., 1998).

Debido a su propiedad de regulación de los contenidos de nutrientes, la zona ribereña suele denominarse como zona "buffer" o de amortiguamiento (Altier et al., 2002). La eficiencia en dicha capacidad amortiguadora de la contaminación originada en zonas aledañas se ve reducida por la geomorfología local (Tabacchi et al., 1998; Vidon y Hill, 2004) y por la cantidad significativa de agua subterránea que conecta la ladera con el río sin pasar por el área ribereña (Lowrance et al., 1998).

La regulación de la temperatura del río se logra debido al enfriamiento por evapotranspiración de la vegetación de la ribera, fenómeno que es más abundante cuando ésta es un bosque (Tabacchi et al., 1998). Las zonas ribereñas o de ribera son importantes para el cauce fluvial por muchas razones y entre ellas, el que sirven para almacenar y regular los caudales pico transportados por el ecosistema de ribera (Brookes y Shields, 2001). 
Los desechos producidos por el bosque de ribera aportan a los cauces de los ríos de hábitats para la biota acuática (Tabacchi et al., 1998). Son a su vez ecosistemas que tienen un papel central en el mantenimiento de una variedad de organismos terrestres, que van desde microbios hasta vertebrados (Brinson y Verhoeven, 1999). Nájera (2004), Secaira et al. (2003) y Valle et al. (1999), presentan y destacan diversas evidencias de la importancia del bosque de ribera para la preservación tanto de la diversidad florística como la de insectos, aves, reptiles y mamíferos de la región semiárida del valle del Motagua en Guatemala.

Considerando la variación del ancho de la zona de ribera, se les visualiza como ecotonos y como entidades del paisaje. Tales diferencias en escala hacen difícil generalizar sobre las funciones del ecosistema y las condiciones de hábitat sin condicionar al tamaño tales consideraciones (Brinson y Verhoeven, 1999). Nuevamente, es necesario referirse a la clasificación de los tipos de zona de ribera según Malanson (1993).

A pesar de la naturaleza dinámica de los bosques de ribera, estos no son inmunes a las alteraciones por efecto de las actividades humanas. Alterar la zona de ribera y su vegetación es ir en contra de su funciones y alterar a su vez, los procesos naturales que le dan su importancia. Este es el punto en el que nace el interés por la conservación, manejo y recuperación de zonas de ribera reflejado en múltiples estudios (Brinson y Verhoeven, 1999; Hughes, 2003; Naiman et al. 2000; Richards et al., 2002; Stromberg, 2001, entre otros). Naiman et al (2005) hacen referencia al valor estético y cultural de las riberas como medios para su efectiva protección, es decir, la necesidad de incorporar principios de salud ecológica en las aspiraciones culturales y estéticas de la sociedad, como medio de obtener paisajes culturalmente sostenibles. La trascendencia de la zona de ribera y su vegetación, así como de los procesos asociados entre ecosistemas terrestre y acuático, se abarcará también de forma indirecta en el presente documento, al referir otros estudios realizados.

\subsection{ESCALAS ESPACIAL Y TEMPORAL PARA EL ESTUDIO DE LAS INTERACCIONES EN LA ZONA DE RIBERA}

La vegetación de ribera es una variable de estado, que puede ser tanto dependiente como independiente de las interacciones con el medio, por lo que los estudios se llevan a cabo en distintas escalas espaciales y temporales en función de los procesos a evaluar (Simon et al., 2004). El reconocimiento y análisis de las influencias hidrogeomorfológicas sobre la vegetación ribereña son complicados debido a las múltiples escalas de las interacciones ambientales, a la covarianza de algunas variables ambientales y la historia de las interacciones en la zona de ribera (Bendix y Hupp, 2000). De acuerdo con Naiman et al (2005), la física básica de los ríos proveniente del régimen pluvial y la geomorfología, es dinámica en las tres dimensiones espaciales -longitudinal, lateral y vertical- y produce efectos concomitantes sobre la ribera: a) la expansión o contracción del curso longitudinal del río; b) la extensión lateral de la llanura de inundación; c) las interacciones con el agua superficial y subterránea en la escala vertical.

Por ello, para definir la escala a la cual estudiar la interacción entre factores en la zona de ribera, es necesario revisar diversas propuestas recomendadas y probadas por la literatura, teniendo presente el interés que la presente investigación tiene por las interacciones en los ámbitos hidrológico, ecológico y de estructura del paisaje. Los efectos de los factores ambientales en la vegetación a lo largo de los paisajes ribereños pueden diferir en relación a la escala. Así, una inundación puede ser vista como un evento moderado a la escala de la vegetación pionera, mientras que a la escala del corredor de ribera, dicho evento puede influir significativamente en el desarrollo a medio plazo de la vegetación (Tabacchi et al., 1998). Las amplias diferencias de escala hacen difícil generalizar sobre las funciones del ecosistema de ribera y sus condiciones de hábitat sin condicionar los postulados al tamaño de las zonas (Brinson y Verhoeven, 1999).

Básicamente, los estudios de efectos a gran escala provenientes de alteraciones hidrológicas pueden tomar tres direcciones: el efecto a escala de cuenca, las diferencias entre áreas de cuencas y cambios con el tiempo (Nilsson y Berggren, 2000). 
La estructura fractal del hábitat significa que su estructura no se vuelve más simple mientras ésta se estudie con más detalle, pues los patrones y estructura de los organismos a toda escala minimizan costos energéticos (Walters y Corman, 1999).

El que existan múltiples escalas para estudiar el control interactivo entre factores bióticos y abióticos del ecosistema de ribera requiere esfuerzos para análisis en diversas escalas que permitan entender cómo mantener procesos importantes y mejorar la estabilidad de los ecosistemas de cara a las perturbaciones ambientales humanas y naturales (Chapin et al, 1997; Williams et al, 1998). Naiman et al (2005) proponen que en las zonas de ribera, los procesos lentos y de gran escala -a nivel de cuenca- son la geología y el clima, y los procesos rápidos y de pequeña escala -a nivel de tramos de río- son la geomorfología y la hidrología.

En todo caso, son necesarios los estudios a múltiples escalas, acoplando los factores regionales y locales en las tres dimensiones espaciales, a modo de entender más sintéticamente y modelar los procesos biogeoquímicos y vegetales dentro del paisaje río-zona de ribera-ladera a nivel de cuenca. La jerarquía de escalas describe las estructuras y procesos que influyen el desarrollo de los ecosistemas de ribera y las interacciones entre el cauce y los componentes de tierras más altas de la cuenca (Tabacchi et al, 1998). Es necesario incrementar los estudios en diversas escalas temporales y espaciales (Nilsson y Berggren, 2000).

Considerar la escala es un tema central para el análisis geográfico de los fenómenos naturales en general, y para la biogeografía y la ecología en particular (Bendix, 1994). En un paisaje, algunos procesos operarán a ciclos anuales distintos, mientras otros serán continuos. Algunos incluso podrían tener períodos discretos más largos (Malanson, 1993). Terradas (2001) señala que para el desarrollo de modelos con base en jerarquías de escala, deben considerarse fases como las siguientes: a) Detectar pautas a escala geográfica; b) establecer una tipología de situaciones y estratificación para muestreos en campo; c) obtener variables de campo significativas, que caractericen el comportamiento ecofisiológico de los tipos reconocidos; construir modelos de abajo arriba para los funcionamientos de los distintos tipos; d) confrontar los resultados con las pautas geográficas conocidas.

\subsubsection{Escala de ribera para el estudio de interacción de factores}

Respecto a las escalas espaciales del ambiente fluvial, Richards et al (2002) y Tabacchi et al (1998) hacen referencia a los ámbitos de estudio a nivel de cuenca, corredor, tramo, lecho del río, tamaño de partícula. Se ha dicho que a escala de tramo de ribera es donde hay más éxito en la manipulación de procesos para la conservación o restauración del ecosistema (Richards et al, 2002); a finales de los noventa se enfatizó grandemente la conectividad lateral, particularmente en término de los conceptos del "Pulso de Inundación" -del inglés flood-pulse- (Bayley, 1995; FISRWG, 1998; Middleton, 2002) y del Recruitment box -la "caja de regeneración"- (Mahoney y Rood, 1998).

Las perturbaciones por inundación y la disponibilidad de agua varían en gradientes transversales y longitudinales (Lite et al, 2005); en áreas secas se genera un gradiente de humedad muy claro hacia afuera del río que se ha tratado de cuantificar y demostrar en diversos estudios (Horton et al, 2001; Goodwin y Tarboton, 2001; Lamontagne, 2005; Stave et al, 2005; Stromberg et al, 1993, 1996), que perfectamente puede generalizarse en el eje transversal perpendicular al cauce (Malanson, 1993)

De acuerdo con Nilsson y Berggren (2000) las tres dimensiones espaciales en las que interactúan los factores bióticos y abióticos del ecosistema de ribera son las siguientes: longitudinal, transversal y vertical. Dichas dimensiones coinciden con las señaladas por Naiman et al (2005) respecto al corredor de ribera: longitudinal, lateral y vertical. 
De aquí que en el ámbito de las dimensiones de las riberas "lateral" y "transversal" son sinónimos. También se encuentra en la literatura otra terminología aplicada a esta dimensión de la ribera: "patrón", "estructura" o "sección" transversal (Malanson, 1993) "escala transversal" (Bendix, 1994); "sección transversal" o "transecto" (Altier et al, 2002; Lowrance et al, 1998; Inamdar et al, 1999); "estructura horizontal" (disposición concéntrica de diferentes tipos de vegetación respecto al cauce -bandas de vegetación-, según Lara et al, 2007).

En la presente tesis doctoral se utilizará el término "escala transversal de ribera" (Bendix, 1994) para referirse a la dimensión lateral (Naiman et al 2005) de la escala de tramo de ribera (Richards et al, 2002).

En la línea de discusión sobre las escalas de trabajo Richards et al (2002) proponen una representación jerárquica de la correlación entre los procesos fluviales y los ecológicos a diferentes escalas en el ambiente fluvial, considerando la hipótesis de que los procesos a escala de ribera son aquellos cuya manipulación puede ser más exitosa en el contexto de procesos de restauración integrada (por ser ésta la escala en donde los vínculos son más fuertes; ver Fig 2.2).

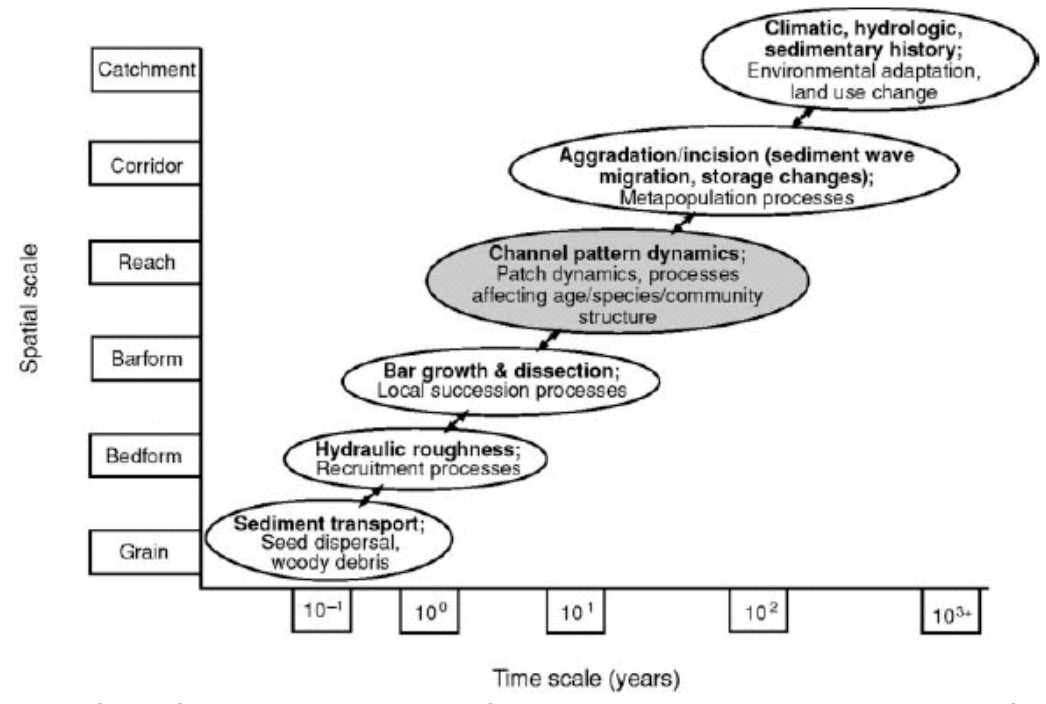

Fig. 2.2 Representación jerárquica de la correlación entre los procesos fluviales y ecológicos a diferentes escalas espaciales y temporales. Tomado de: Richards et al (2002)

La representación jerárquica expresada por Richards et al. (2002) permite diferenciar los distintos procesos en los que se relacionan la vegetación, la hidráulica y la morfología de cauces, así como las escalas de trabajo para abordar su estudio. De esta forma, cada escala espacio temporal tiene su trascendencia en función del enfoque que se le quiera proporcionar; los ambientes de ribera poseen un conjunto de características que permiten comparar los patrones de vegetación producidos como respuesta a las variables ambientales a diversas escalas (Bendix, 1994). Lo referido sugiere hacer un enfoque a escala de ribera para estudiar procesos de la dinámica de comunidades o grupos vegetales en relación con la influencia del régimen hídrico del río.

Respecto a las escalas y patrones de la zona de ribera, dos referencias fundamentales son las de Baker (1989) referidos a procesos en escalas pequeñas, y Bendix (1994), referido más específicamente a la interacción vegetación-ambiente según diversas escalas, direcciones y patrones. Las escalas micro y macro señaladas por Baker (1989) se corresponden con la escala longitudinal de ribera expresada por Bendix (1994).

Baker (1989) demostró que la influencia relativa de la escala en la composición de la vegetación ribereña varía espacialmente. Se realizó una comparación entre los factores de la escala "macro", que varían entre cuencas, y los factores de la escala "micro", que varían entre transectos. Este estudio se hizo desde una perspectiva estática y por ello solamente clarifica las variaciones espaciales en un momento dado, pero indican que las variaciones temporales son esperables. 
El estudio de Bendix (1994) sugiere utilizar una aproximación no jerárquica para la comparación escalar, pues de esa manera será más claro ver las interacciones ambientales que operan a distintas escalas, es decir, sólo se puede entender el papel relativo de factores que influyen en la vegetación si las escalas no están jerárquicamente unidas. Así, si las variables de la escala transversal son las dominantes, el patrón de vegetación exhibirá una secuencia transversal que se repetirá de sitio a sitio, o sea, un patrón franjas paralelas al río. Según Nilsson y Berggren (2000) los efectos en la escala transversal son de alguna manera mejor entendidos, debido a que están cercanamente relacionados a regímenes hídricos regulados.

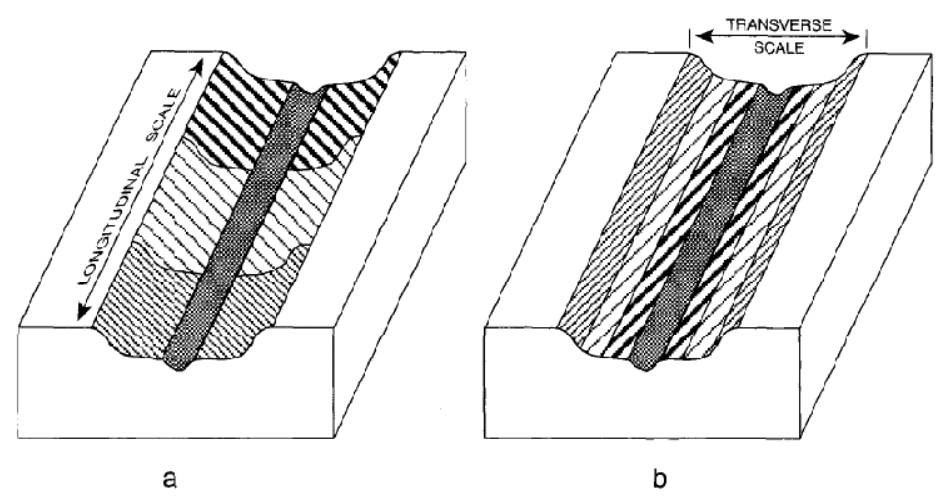

Fig. 2.3. Patrones potenciales de vegetación, resultantes de la dominancia de la escala longitudinal (a) o la escala transversal (b) para las variables ambientales. Tomado de: Bendix (1994)

De acuerdo con Bendix (1994), la escala o eje longitudinal de la ribera es evidente a escalas pequeñas de mapas (típicamente en kilómetros) mientras que la escala o eje transversal de la ribera a escalas grandes de mapas (típicamente en metros). Ambas escalas o ejes influyen en la textura resultante del patrón de vegetación y en su orientación, por lo que la dominancia de una de ellas sobre la otra determinará si el patrón es longitudinal o transversal.

Malanson (1993) concuerda en que el estudio de procesos en la zona de ribera puede hacerse a distintas escalas de investigación del paisaje (la estructura longitudinal y la transversal, concordando con lo propuesto por Bendix, 1994). Asimismo, resalta la estructura interna del ambiente ribereño como la forma de examinar las interacciones entre los patrones de la comunidad vegetal y las formas de la tierra y los procesos hidrológicos.

Naiman et al (2005) y Nilsson y Berggren (2000) señalan también la escala vertical para el estudio de las riberas (ver figura 2.4). Baker (1989) sugiere que el estudio de patrones de vegetación para una escala determinada podría ser más adecuado en zonas de baja pendiente, como los valles.

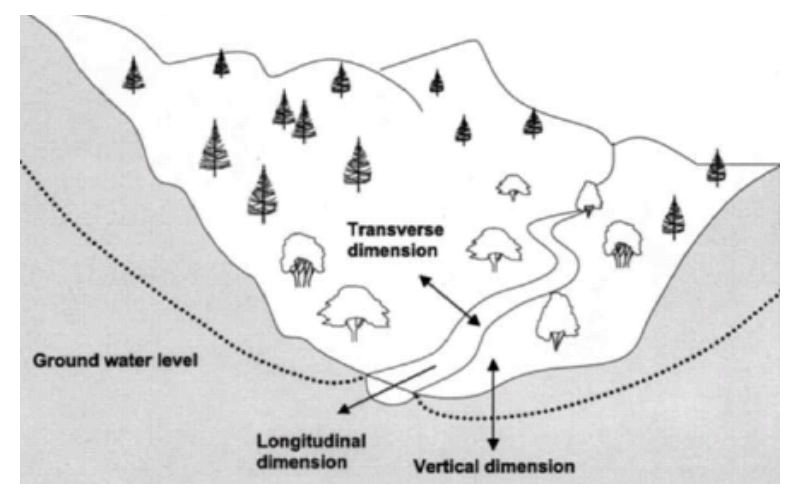

Fig. 2.4 Tres dimensiones espaciales en que se producen interacciones del ecosistema de ribera con sus ambientes hipotéticos. Tomado de Nilsson y Berggren (2000). 
Diversos tipos de estudios retrospectivos pueden emprenderse para obtener tendencias a largo plazo sobre el desarrollo de los corredores de ribera afectados por la regulación hídrica. Los modelos matemáticos son uno de estos tipos de trabajo. Sin embargo, el monitoreo de cambios a largo plazo será el único método de confianza para detectar, evaluar y validar los cambios predichos en ecosistemas ribereños (Nilsson y Berggren, 2000).

Brinson y Verhoeven (1999) proponen examinar la complejidad espacial de los bosques de ribera desde dos escalas: (i) la estructura interna del bosque que se refiere al arreglo tridimensional de los componentes vegetales (estrato vertical, altura, biomasa, riqueza de especies); (ii) la escala entre bosques de ribera y entre ambientes adyacentes, que refleja la heterogeneidad del paisaje.

Debido a las grandes diferencias entre zonas de ribera solamente puede reconocerse que hay un conjunto de controles fluviales comunes sobre la estructura y composición del bosque (Brinson y Verhoeven, 1999). De acuerdo con Walters y Korman (1999) es imposible en la práctica el desarrollar un modelo completo que exprese todas las variaciones de los factores físicos y biológicos en la zona de ribera.

FISRWG (1998) propone que la mayor parte de los ecosistemas de ribera (ubicados como corredor paralelo al río) presentan en su sección lateral tres componentes comunes: El cauce, la llanura de inundación (floodplain) y la zona de transición con la ladera. Sin embargo, tanto la discretización del espacio, como el detalle y el enfoque pueden ser distintos en función del objeto de estudio.

Tabacchi et al. (1998) proponen analizar la ribera desde un punto de vista geomorfológico y delineación longitudinal del ecosistema fluvial, incluyendo explícitamente la zonificación transversal del ecotono ribereño basado en patrones y procesos similares, pero expresados a diferente escala espacial. En la escala longitudinal sucede la conectividad en el corredor de ribera y ésta depende grandemente de la conductividad hidráulica y de la complejidad de las estructuras superficial y subsuperficial de dicho corredor. Las consecuencias de los flujos subsuperficiales en la estructura de la vegetación y sus dinámicas son las menos documentadas.

De acuerdo con Tabacchi et al. (1998), la conectividad entre el cauce y su cuenca es una función que interrelaciona la posición dentro del gradiente altitudinal, la potencia hidráulica intrínseca del cauce y el desarrollo y estabilidad de la zona ribereña. La dinámica así como la simetría de los intercambios (materia, energía, especies) varía de las partes altas hacia las partes bajas de la cuenca.

Todas las propuestas en torno a los ejes o escalas transversal y longitudinal de la zona de ribera, apuntan a encontrar el(los) gradiente(s) de vegetación como respuesta a un determinado factor ambiental (topografía, tipo de suelo, humedad, entre otros). Los conceptos que fundamentan estas consideraciones y los distintos modelos propuestos se analizarán a detalle en apartados siguientes. 


\section{FUNDAMENTOS DE ECOLOGÍA, CRECIMIENTO Y DESARROLLO DE LA VEGETACIÓN}

\subsection{ECOLOGÍA VEGETAL}

El término "ecología", convertido en argot popular a partir de los años sesenta-setenta, ha conllevado un nuevo pensamiento que ha influido y sigue influyendo en distintas disciplinas. Definido usualmente como el estudio científico de las relaciones entre organismos y su ambiente, la ecología también puede considerarse como una ciencia interdisciplinaria que se traslapa con muchos elementos de las ciencias físicas y biológicas. A la ecología se han acoplado distintos conceptos de la economía como la distribución de recursos y las razones de costo-beneficio, por lo que también puede considerársele como el estudio de la economía de la naturaleza (Smith y Smith, 2000).

La línea de pensamiento en ecología ha adoptado distintas variantes (Smith y Smith, 2000; Terradas, 2001). Entre ellas, se plantean el estudio basado en la demografía (distribución y abundancia) de organismos y poblaciones, o de la relación de los organismos con su ambiente, o del estudio de la sinergia de estos dos planteamientos; también existe una línea de ecología evolutiva que no hace énfasis en los individuos ni en los ecosistemas, sino en las especies algunas hipótesis planteadas por la ecohidrología de Eagleson (2002) poseen estas bases teóricas de la ecología evolutiva-.

Para el estudio de los factores ecológicos, la mayor unidad es el ecosistema (la comunidad y el ambiente físico). La interacción es complejísima entre los dos componentes básicos del ecosistema, la parte viva o biótica, y la física o abiótica. Por ejemplo, un bosque consiste de una parte física (atmósfera, clima, suelo y agua) y una biótica (la gran diversidad de flora y fauna que le habitan), en donde cada organismo responde al ambiente físico y al mismo tiempo se modifica, convirtiéndose a sí mismo en una parte del ambiente (Smith y Smith, 2000).

El ecosistema puede estudiarse en alguno(s) de sus muchos niveles, es decir, sus componentes forman una jerarquía. En un nivel, los organismos individuales responden a la influencia del ambiente; en el siguiente, individuos de la misma especie forman poblaciones que pueden describirse en términos de su número, crecimiento, edad; en otro nivel, la interacción de los individuos con poblaciones de su misma especie y con los de otras produce comunidades bióticas, y allí es donde se da una competencia por recursos limitados. La Ecología aborda una amplia gama de la ciencia, desde los individuos hasta los ecosistemas (Smith y Smith, 2000).

Las tasas de abastecimiento de luz, agua y nutrientes que regulan los procesos dentro del ecosistema, son función del área del terreno y el volumen de suelo. Por tanto, para relacionar los procesos en plantas individuales con aquellos a escala de ecosistema, es crítico determinar el tamaño de la planta, la densidad y la biomasa del bosque (Lambers et al., 1998).

La Ecología vegetal hace énfasis en las interacciones entre las plantas y su ambiente; en el pasado, los ecologistas vegetales han enfatizado en la complejidad del ecosistema y han despreciado los modelos simples y teóricos como simplistas y no realistas. Para el estudio de la vegetación, el de sus patrones y estructuras, se han utilizado los conceptos de individuo, población y comunidad vegetal para abarcar los diferentes niveles de organización de las plantas. La riqueza de especies de la comunidad es resultante de los procesos de inmigración y extinción; la densidad de población, del balance entre la regeneración y la mortalidad de especies individuales; el tamaño de las especies individuales resulta de los nacimientos y muertes de sus partes componentes (Crawley, 1997). 
Ciertos estudios científicos de la vegetación se han centrado en las respuestas al clima, otros en los rasgos de las plantas relacionados con condiciones ambientales, o bien partiendo de características relacionadas con la sucesión vegetal. Tanto aquellos estudios basados en grupos funcionales, como los basados en comunidades vegetales, deben reconocer que estos son construcciones intelectuales y no objetos reales (Terradas, 2001).

En la historia de la Ecología Vegetal, los documentos que muestran las correlaciones entre las características morfológicas y fisiológicas de la vegetación y las condiciones ambientales, han sido el punto de partida de muchos estudios de ecofisiología; sin embargo, dicha documentación no puede determinar la importancia relativa de la adaptación a esas condiciones ambientales y otros factores de tipo histórico - evolutivo de las especies (Lambers et al., 1998).

En general la ecología de la comunidad vegetal ha enfatizado dos grandes categorías: los procesos funcionales en las plantas y las características estructurales de las plantas. La ecología vegetal estructural estudia la forma y arreglos de las plantas dentro de la comunidad y asume que los procesos funcionales determinan el peso, el tamaño y la forma de cada planta, y el arreglo de sus hojas (Bonham, 1989).

Los criterios de aproximación al estudio de la vegetación pueden ser diferentes, desde una escala gruesa de observación, como el de los biogeógrafos y fitosociólogos, pasando por la ecología del paisaje, hasta llegar a la ecología de las comunidades. La ecología de la vegetación cubre todos los niveles que van desde la comunidad a la vegetación del planeta en su conjunto, pero muchos procesos a este nivel sólo pueden explicarse con el entendimiento de los que se dan a nivel de individuo o de población (Braun-Blanquet, 1979; Terradas, 2001).

Terradas (2001) propone el estudio de la fisiología de los ecosistemas para responder a cuestionamientos teóricos de la ecología vegetal, y la necesidad de relacionar los mecanismos tipo fisiológico - funcional, tanto con las características de los organismos y comunidades como con los cambios que ocurren en las poblaciones y comunidades a lo largo del tiempo. A pesar del incremento cuantitativo de la Ecología, ésta permanece largamente descriptiva y empírica, con el desarrollo de una teoría en estado de definición de conceptos y relaciones. Las definiciones formales de la ecología se originaron de la química y las matemáticas de transferencia de masa, o se derivaron enteramente de la teoría de la evolución y de sus propiedades implícitas (Hatton et al, 1997).

\subsubsection{La comunidad vegetal}

De acuerdo con Crawley (1997), la comunidad vegetal consiste simplemente de todas las plantas que ocupan una superficie definida por el ecólogo en función de los propósitos de su estudio. Para Terradas (2001), comunidad es un término de conveniencia que suele emplearse para designar conjuntos de plantas coexistentes en un área, desde la más simple agregación de un solo estrato hasta la más compleja; así, la comunidad estará formada por todos los organismos que se encuentran en la parcela escogida por el ecólogo, o bien tendrá un carácter más abstracto al suponer que la comunidad concreta estudiada es representación de un tipo.

La comunidad vegetal presenta una organización espacial, que corresponde a la distribución horizontal de individuos y vertical de hojas, troncos y raíces de las distintas especies, lo que está determinado por cómo se distribuyen los recursos y las respuestas de las plantas a niveles morfológicos y poblacionales. La forma de ocupar el espacio en el sentido horizontal depende del crecimiento individual y de la manera de reproducirse. La estructura temporal de la vegetación responde a su fenología -hojas caducas, floración, etc.- (Terradas, 2001).

Una de las preguntas fundamentales sobre la naturaleza de las comunidades vegetales es la forma en que las especies responden a gradientes en condiciones ambientales. Esto planteó en su momento la discusión, aún vigente, para clasificar la vegetación en comunidades vegetales discretas o en comunidades vegetales como continuamente variables (Crawley, 1997). En la línea de estas ideas, más adelante se revisarán conceptos sobre la sucesión vegetal, la distribución de las plantas y la competencia por los recursos. 


\subsubsection{Clasificación de la vegetación: destacando los "tipos o grupos funcionales de vegetación"}

La clasificación de la vegetación siguió en un principio un criterio fundamentalmente utilitario, y derivó desde las primeras propuestas sencillas hasta ganar complejidad conforme avanzó el conocimiento de la diversidad de plantas (Izco et al, 2000). Según Terradas (2001) el tema de la clasificación vegetal es "espinoso" pero necesario, pues si es deseable la extrapolación de los resultados de estudios funcionales, hace falta una clasificación y una cartografía basada en ella. Existen clasificaciones de vegetación basadas en su estructura, o en otras más detalladas que parten de criterios como la composición de especies, o las aproximaciones estadísticas que permiten clasificar u ordenar en función de uno o más criterios.

La clasificación es básica cuando se quieren aplicar los resultados de los análisis de vegetación y explicar las relaciones entre rodales ${ }^{1}$ o entre especies. Los rodales pueden clasificarse según su afinidad florística y similarmente las especies, en grupos en que sus miembros deben tener similitudes ecológicas. La clasificación es útil para la vegetación que tiene una estructura comunitaria distinguible, pero no para un continuo; por ello surge la "ordenación", cuyos resultados consisten de una serie de valores coordinados que pueden ser dibujados en una o más gráficas. Para estudios de vegetación con mucho detalle ninguna técnica analítica de clasificación u ordenación resulta aplicable, pues la rigurosidad estadística del muestreo a esta escala es especialmente alta (Causton, 1988).

La fitosociología estudia las agrupaciones de plantas, sus interrelaciones y su dependencia frente al medio ambiente vivo e inanimado y abarca todos aquellos fenómenos e investigaciones que afectan a la vida en comunidad de las plantas (Braun-Blanquet, 1979). Se estudian las interacciones entre vegetación y ambiente desde un punto de vista cualitativo, pues el objetivo es la clasificación de comunidades vegetales a nivel mundial (Causton, 1988).

Los caracteres concretos de la comunidad, referentes a las especies, que pueden aplicarse directamente al análisis fitosociológico son: a) los de naturaleza cuantitativa: número de individuos (abundancia) y densidad; grado de cobertura, volumen y peso (dominancia); forma de agrupación (sociabilidad) y distribución; frecuencia. b) los de naturaleza cualitativa: estratificación, vitalidad, fertilidad y periodicidad (Braun-Blanquet, 1979).

La taxonomía vegetal es la parte de la botánica que trata de la ordenación o clasificación de las plantas, así como de las bases, principios, métodos, normas o leyes que regulan dicha clasificación. La especie es la categoría taxonómica básica, siguiendo a ella las categorías (taxones) de género, familia, orden, clase, división y reino. Aunque lo ideal sería contar con una clasificación vegetal en donde todos y cada uno de los taxones fuesen naturales (relacionados filogenéticamente), esto es prácticamente imposible dados los conocimientos limitados que aún se tienen (Izco et al, 2000).

El carácter taxonómico de la comunidad deja de lado el hecho fundamental de que otros organismos no vegetales (animales, microorganismos, humanos) modelan y juegan roles decisivos en sus ecosistemas; por tanto hay una marcada diferencia entre definir una comunidad vegetal mediante el estudio de la taxocenosis (la taxonomía vegetal) o de la biocenosis (el de las interacciones de la vegetación con los otros elementos bióticos del ecosistema). Sin embargo la descripción de la vegetación basada en el concepto tipológico de la comunidad resulta científicamente interesante en sí mismo y puede tener algunas consecuencias aplicables (Terradas, 2001).

FAO (1994) indica que para la división del área de comunidades forestales, se utilizan los nombres de las especies arbóreas predominantes de la comunidad, para clasificar los bosques en tipos forestales. Esto puede lograrse utilizando fotografía aérea de escala media $(1: 10,000-$ 1:30,000) en combinación con comprobaciones de campo.

\footnotetext{
${ }^{1}$ Del término inglés "stand", referido al área ocupada por un grupo de árboles de similar composición, edad, y condición para ser considerado una unidad homogénea, natural o artificial, con fines de manejo o conservación
} 


\subsubsection{Tipos o Grupos funcionales de vegetación (TFV o PFG)}

Los términos "tipo funcional de vegetación (TFV)" y "grupo funcional de vegetación (PFG)" son sinónimos y se refieren a una clasificación por grupos no filogenéticos de organismos que responden de forma similar a factores ambientales y tienen efectos similares en los procesos dominantes del ecosistema (Baird y Maddock III, 2005; Smith et al, 1997). El concepto ha surgido como la forma de encontrar similitudes de funcionamiento para agrupar a las especies y así simplificar los modelos de ecosistemas o formular modelos de funcionamiento de una especie que sean extensibles a todas las especies de un mismo grupo (Terradas, 2001).

Mediante la teoría de TFV, se reduce la diversidad de especies a una diversidad de funciones y estructuras; se parte de la idea de que las dinámicas esenciales de los ecosistemas pueden capturarse mediante la agrupación de especies en un número limitado de tipos funcionales. Las estructuras pueden ser árboles, arbustos, hierbas; las funciones pueden ser tipos de procesos fotosintéticos, capacidad de minimizar pérdidas de agua y cambiar el tiempo de crecimiento (Smith et al, 1997).

Terradas (2001) señala que mediante agrupaciones de especies en función de sus similitudes de funcionamiento, es posible simplificar los modelos de ecosistemas o formular modelos de funcionamiento de una especie que sean extensibles a todas las especies del mismo grupo. El reconocimiento de grupos funcionales, cuando el investigador tiene unas bases teóricas y pragmáticas claras, es de una ayuda importante para el desarrollo de modelos, tanto conceptuales como matemáticos, innovadores y positivos.

Los diversos estudios de clasificación en tipos funcionales que existen y las diversas concepciones del término no han seguido un planteamiento teórico claro, y por ello no hay una tipología que pueda aplicarse con carácter universal (Smith et al, 1997; Terradas, 2001). Para una clasificación por tipo funcional se pueden adoptar una de las tres siguientes: a) un método subjetivo por observación; b) un método deductivo que parta de un modelo a priori de la importancia de procesos particulares en el funcionamiento del ecosistema; c) un método basado en datos y en aplicación de técnicas multivariables que lleven a una clasificación.

Lo más típico de las propuestas de clasificación por tipos funcionales de vegetación es establecer un listado de criterios diversos sobre categorías de atributos de las plantas, dar los valores correspondientes para el mayor número posible de especies y emplear una batería de análisis multidimensionales sobre estos datos hasta establecer una clasificación. Sin embargo Terradas (2001) recomienda hacer una clasificación pragmática y relativamente sencilla.

En su revisión de los TFV, Terradas (2001) indica cuatro tipos básicos de clasificaciones funcionales:

i) grupos emergentes, o grupos de especies que reflejan correlaciones naturales de atributos biológicos (desde aspectos de su ciclo de vida hasta aspectos de regeneración), pero no están relacionados directamente con funciones ecosistémicas y sus mecanismos; se parte de clasificaciones fisionómicas para encontrar correlaciones con rasgos funcionales, como tasa de crecimiento, tamaño de semilla y tamaño de la planta, por ejemplo.

ii) Estrategias, compartidas por especies que tienen atributos similares que se interpretan como adaptaciones a pautas particulares en el uso de recursos.

iii) Tipos funcionales estrictos, grupos de especies sin parentesco filogenético que tienen papeles similares en los procesos ecosistémicos, respondiendo de forma parecida a múltiples factores ambientales; para su construcción se hace una preselección subjetiva de rasgos sobre la base de conocimientos del experto y luego un análisis de correlación con gradientes ambientales.

iv) Grupos específicos de respuesta, con especies que responden de forma similar a factores ambientales específicos; trabajo con criterios regionales o de paisaje, en donde los efectos de las perturbaciones son fundamentales, haciendo tipologías en las que la respuesta a estas perturbaciones sea lo decisivo. 
Como crítica a los TFV, se señala que algunas veces, se observan marcadas diferencias de respuesta a cambios en factores ambientales por parte de las especies, mas no necesariamente por parte de los tipos. Las evidencias pueden dar lugar a pensar que las conclusiones sobre una especie no pueden ser extrapoladas a otras que, aparentemente posean una estrategia similar y que son morfológicamente muy parecidas. En todo caso, es muy común que las diferencias funcionales no se reflejen en rasgos fácilmente identificables (Terradas, 2001).

Dentro de una comunidad vegetal pueden coexistir distintos TFV en función de la fenología de las plantas, el uso de recursos, el crecimiento y también en función de su estructura espacial. La estructura vertical de la comunidad vegetal representa un conjunto de respuestas a diferentes radiaciones solares a lo alto del dosel (Terradas, 2001).

Terradas (2001) señala como atributos de tipos funcionales de vegetación asociados a cambios ambientales en los suministros de agua los siguientes: a) el tamaño y el índice de área foliar (crecimiento/competencia por agua total); b) fenología del crecimiento, duración y características de las hojas, reservas de agua y profundidad de raíces (por estacionalidad en suministros de agua); c) capacidad competitiva, biomasa y producción (distribución de agua en profundidad); d) umbral (resistencia a la sequía según un cierto grado de frecuencia del evento). Para el caso de la ribera, como se verá en capítulos siguientes, existen ya varias propuestas de TFV en función del hábito de crecimiento, la fase de desarrollo, la morfología y las tasas de transpiración (Baird y Maddock III, 2005; Brookes et al, 2000; Williams et al, 1998).

\subsubsection{La sucesión vegetal}

La Sucesión Vegetal es una teoría nacida con Clements (1916), que explica el cambio producido en el proceso de organización de las comunidades vegetales tanto en un medio nuevo (sucesión primaria) como por el efecto de una perturbación que altera el sistema (sucesión secundaria). Durante ese cambio, cada estadio de la vegetación produce una alteración gradual e inevitable del ambiente, haciéndolo menos bueno para él mismo y mejor para los elementos de la fase o etapa siguiente; el proceso continúa hasta alcanzar un estadio final llamado clímax o de equilibrio con el clima. Es una teoría que ha conformado enormemente el pensamiento en la Ecología (Terradas, 2001).

La sucesión vegetal suele explicarse teóricamente como resultante de distintos procesos. Una vertiente la explica a partir del crecimiento diferencial, la supervivencia diferencial, y tal vez, la dispersión de especies adaptadas a crecer en diferentes puntos a lo largo de gradientes de estrés. También hay quienes consideran que es un cambio secuencial en las abundancias relativas de las especies dominantes de la comunidad; otros se refieren a un proceso poblacional, una consecuencia de la variación en las tasas de reproducción, establecimiento, crecimiento y mortalidad (Terradas, 2001).

Terradas (2001) destaca cuatro procesos determinantes de la sucesión: las características de la perturbación previa; la colonización de especies; las alteraciones físicas del biotopo; competencia, alelopatías, autotoxicidad. Dichos procesos pueden afectar las tasas de establecimiento, desarrollo y supervivencia de la nueva planta, condicionando el progreso de la sucesión.

Lambers et al (1998) proponen el concepto de "filtros" para explicar la composición vegetal en un sitio determinado: la co-ocurrencia de especies en un determinado sitio resulta de un filtro histórico (migraciones de especies en el pasado), un filtro fisiológico (posibilidades de crecimiento y reproducción en las condiciones ambientales presentes) y un filtro biótico (relaciones de competencia por los recursos con otras especies y/o defensa contra agentes biológicos como patógenos o herbívoros). Para dar mayor énfasis en el "filtro histórico", desde la perspectiva de la biología evolutiva, se recomienda no equivocarse al pensar que las características de las especies en un ambiente particular son necesariamente benéficas y resultantes de la selección natural en ese ambiente (el paradigma "panglosiano" discutido en ecología vegetal), pues muchas veces éstas resultan de la historia genético- evolutiva de las especies. 
De forma general Terradas (2001) indica que los primeros estadios de la sucesión vegetal se da en especies que han tenido una "selección tipo r", o sea, individuos de pequeño tamaño, vida corta, rápido crecimiento, alta tasa de natalidad y de mortalidad. Los siguientes estadios corresponden a una "estrategia tipo K", es decir, especies de mayor tamaño, con mayor control del espacio, vida larga, que dejan pocos descendientes pero aseguran mejor su supervivencia. Especies vegetales de crecimiento rápido siguen una estrategia competitiva tipo "Grime" (de estrategias adaptativas al estrés), mientras que las de crecimiento lento siguen la estrategia de tolerancia al estrés; en condiciones de bajo régimen de perturbación (por sequías), las primeras pueden dominar, pero si aumenta el régimen de perturbación se imponen las segundas. Esto es importante, pues determina que no todas las especies responden de igual manera a alteraciones del medio y define tipos de vegetación más adaptables; no hay que olvidar tampoco los diferentes estados de desarrollo de las plantas y su relación con el medio. Los mecanismos de competencia / colonización promueven la diversidad de especies con crecimiento maduro.

Conforme las comunidades vegetales van madurando, aumenta progresivamente la competencia aérea y subterránea y una escasez también progresiva de los recursos. Asimismo, las comunidades frente a perturbaciones (de diversa intensidad y severidad) pueden tender espontáneamente a una mayor complejidad. Esto es, los ecosistemas presentan tendencias auto organizativas de variación de la biomasa, la producción primaria o el índice de área foliar, con el fin de buscar un estado más maduro y adaptarse a los recursos naturales, como estrategia de desarrollo.

En los estadios de sucesión tardía, las especies que tienen alta supervivencia en el sotobosque (la zona por debajo del dosel de las especies dominantes) suelen ser las dominantes, mientras las especies con rápido crecimiento a la sombra son las subdominantes. Esto contradice la visión tradicional de que los dominantes en el estadio final de la sucesión son competidores superiores pero pobres colonizadores, e ilustra la dificultad de hacer plantear un modelo simple que gire en torno a los procesos espaciales y de estructura por edad, que gobiernan la mayor parte de los sistemas naturales (Crawley, 1997).

Dentro del contexto de la sucesión vegetal Terradas (2001) aporta una interesante observación aplicable a los bosques de ribera, al señalar que "en un territorio determinado, aquellos lugares de condiciones extremas (junto a cursos de agua, por ejemplo) en que no se daría la convergencia hacia el estadio clímax, el estadio final sería el de comunidades permanentes (por ejemplo, los bosques de ribera) que no corresponden al clima general sino a dichas condiciones locales excepcionales".

Para el caso de la vegetación de ribera, "el proceso de sucesión es esencialmente reiniciado por la alteración hidrológica, su intensidad y frecuencia varía tanto desde aguas arriba hacia aguas abajo, como desde el cauce hacia la llanura de inundación. Por esa razón, la estructura de la vegetación de ribera se ha utilizado como un indicador de los eventos hidrológicos y geomorfológicos" (Tabacchi et al., 1998). Los árboles representan el componente más estable de la comunidad vegetal de ribera, aunque algunos de ellos sean especies pioneras adaptadas a las alteraciones del medio (Tabacchi et al., 1998). Sin embargo, los bosques cambian constantemente y por tanto su estudio debe actuar en consecuencia con este conocimiento (Terradas, 2001).

Diversos estudios han estudiado el rol de la sucesión vegetal en los procesos fluviales, llegando a la conclusión de que la frecuencia y duración de los eventos de alteración (inundaciones) determinan la probabilidad de remoción de la vegetación madura y el establecimiento de nuevas comunidades vegetales ribereñas; cuantificar esas alteraciones es clave para entender el proceso de sucesión vegetal en el ecosistema (Tabacchi et al., 1998). Gregory et al. (1991) destacan el papel de estas alteraciones naturales y el proceso de sucesión vegetal dentro del ecosistema de ribera. 


\subsubsection{Patrón de distribución de las plantas}

El agua y la temperatura son los dos determinantes más importantes de la cobertura vegetal; los climas cálidos y húmedos son los más que más favorecen la producción vegetal y las mayores tasas de biomasa por unidad de área (Crawley, 1997). El parámetro "frecuencia" describe la dispersión o distribución de las especies en el paisaje (Bonham, 1989).

Existen muchas maneras en que el agua controla la distribución de las especies a escala local, tanto en ambientes con estrés hídrico como sin él (Crawley, 1997). En la distribución de las plantas, las razones históricas son de fundamental importancia; posteriormente las interacciones bióticas ejercen un filtro adicional para eliminar muchas de las plantas que repueblan un área (Lambers et al, 1998).

El ambiente cambia de sitio a sitio y correspondientemente la vegetación altera tanto su composición en especies y la frecuencia de las especies componentes; desde una estructura espacial de la comunidad vegetal en donde se distinguen zonas claramente diferentes hasta patrones indistinguibles de vegetación. Se necesita determinar la medida en que esos patrones espaciales en la estructura de la comunidad vegetal refleja cambios en las condiciones abióticas (nutrientes, agua, etc) y en qué medida los patrones son resultado de las interacciones bióticas (competencia vegetal interespecífica, dispersión de semillas, etc) y la medida en que las condiciones abióticas alteran las interacciones bióticas (Crawley, 1997).

En la modelación de la dinámica espacial vegetal, los estudios ecológicos clásicos entienden los patrones espaciales como reflejo de condiciones heterogéneas del suelo y microclima; otros trabajos recientes proponen el estudio del patrón como no aleatorio y como fenómeno que surge de la interacción de mecanismos ordenados y procesos aleatorios, con el reto de encontrar el mecanismo desde la observación de los patrones y predecir los patrones desde la operación de los procesos conocidos (Crawley, 1997).

Smith y Smith (2000) señalan que la "homeostasis" es el momento en que las condiciones para el mantenimiento de los organismos se encuentran dentro de un rango tolerable. Estar dentro de ese rango no implica que el organismo crezca o se reproduzca; dicho rango expresado en valores mínimos y máximos determina su tolerancia ambiental.

Los rangos de tolerancia ambiental para un organismo dependen de una amplia gama de factores abióticos que interactúan entre sí. Cualquiera de estos factores tiene el potencial para limitar la supervivencia, el crecimiento y la reproducción. De acuerdo con la ley del mínimo de Leibig "el comportamiento (supervivencia, crecimiento y reproducción) de un organismo será función del factor ambiental más limitante". El concepto de que las condiciones mínimas y máximas limitan la presencia y éxito de un organismo se denomina la "ley de tolerancia" (Smith y Smith, 2000).

Esto lleva a que la distribución de los organismos sea un reflejo de la variación ambiental, entendiendo por distribución su presencia o ausencia. La abundancia de especies (número o tamaño de la población) se incrementa a medida que varían las condiciones ambientales óptimas, es decir, mientras las condiciones se acerquen más a los límites de tolerancia del organismo de una especie dada, será menor el número de individuos de dicha especie. La distribución y abundancia de organismos dependen tanto de la variación ambiental como de las tolerancias (Smith y Smith, 2000).

Las comunidades pueden ser indicadoras del ambiente físico. Esto tiene una particular importancia pues una comunidad provee de más información que una sola especie indicadora; sin embargo también es información más confusa y de interpretación más difícil. Los factores climáticos determinan las pautas geográficas en la distribución de plantas y comunidades (Malanson, 1993; Terradas, 2001). Sin embargo, sólo el análisis de la propia vegetación, de su composición específica, puede permitir caracterizar fitogeográficamente un punto de la superficie terrestre (Bolòs, 1989), esto es, porque la distribución de las plantas no obedece sólo a causas climáticas, sino a causas históricas y evolutivas. 


\subsection{OTROS MODELOS DE LAS INTERACCIONES ECOLÓGICAS}

\subsubsection{La Ecología del Paisaje}

La Ecología del Paisaje (del término inglés "landscape ecology") es una forma de estudiar el ambiente que hace énfasis en relaciones espaciales complejas, en las interacciones recíprocas entre el patrón espacial y los procesos ecológicos. Surgió inspirada en el potencial que significaba la fotografía aérea en los años cincuenta, y su origen tiene motivaciones prácticas, para poder aplicar las ideas ecológicas en el manejo del territorio, es decir, para resolver problemas reales que demandan solución de los aspectos espaciales de la ecología (Malanson, 1993; Turner, 2005).

La hipótesis básica de esta disciplina establece que las interacciones entre los componentes bióticos y abióticos del paisaje están espacialmente relacionadas. Malanson (1993) opina que su tema central consiste en que la estructura espacial controla los procesos que continuamente reproducen la estructura. A escala de paisaje diversos estudios han demostrado que los patrones de distribución de las especies y las tasas de crecimiento están relacionados con las formas del terreno y la posición dentro del paisaje, y sus consecuencias en la disponibilidad de agua para las plantas (Hatton et al, 1997). La disciplina, "goza de la fuerza de su propuesta distintiva: su énfasis en los patrones espaciales y las relaciones, escalas, heterogeneidad, fronteras, y flujos de energía y materia en el espacio" (Turner, 2005).

La ecología del paisaje es particularmente adecuada para el estudio de sistemas que no están en equilibrio, pues toma en cuenta las relaciones entre los diversos procesos de la geografía física, y porque los ambientes no equilibrados tienen distintas relaciones entre la hidrología, la geomorfología y la ecología. Los ambientes de ribera son perfectos para elucidar los principios de la ecología del paisaje, ya que se conoce su ecología, dadas sus características espaciales relativamente claras y su presencia por todo el mundo (Malanson, 1993; Naiman et al., 2005).

Naiman et al (2005) destacan que debe existir un estudio de la dimensión humana y social para que realmente se pueda generar una investigación en las riberas con carácter de ecología del paisaje. Esto es, la influencia humana sobre los paisajes de ribera, pero también la manera en que el humano los interpreta, percibe y experimenta. Como paisajes, las riberas son también una creación de la mente humana, y entender esta percepción es necesario para construir un equilibrio dinámico sostenible entre naturaleza y cultura.

\subsubsection{La Ecofisiología Vegetal}

Es el estudio de las respuestas fisiológicas al ambiente; esta interfase entre dos disciplinas, permite proveer de preguntas mediante la ecología, y de herramientas para determinar el mecanismo, mediante la fisiología. Mediante los avances en esta disciplina compuesta se han podido explicar con éxito por qué las plantas crecen en donde lo hacen. Los procesos fisiológicos vegetales tienen importantes efectos en su ambiente (por ejemplo la evapotranspiración como fenómeno que favorece la sequedad del suelo e incrementa la humedad atmosférica), que si se dan en gran magnitud, pueden servir como base mecánica para entender procesos a grandes escalas como la comunidad, el ecosistema y los procesos climáticos (Lambers et al., 1998).

En el estudio de la optimización frente al medio, los ecofisiólogos han propuesto estudiar la forma y demás características de las plantas o de sus órganos; sin embargo, el medio extremadamente complejo al que se enfrentan las plantas provoca la existencia de factores que pueden actuar de un modo independiente sobre ellas (Terradas, 2001).

Las plantas son sistemas de adquisición de información y no organismos de respuesta pasiva al ambiente. Si se trata de entender el funcionamiento de las plantas en diferentes ambientes, la información al nivel celular y molecular es de vital importancia. Por ello, "las hipótesis que han surgido en el estudio de la ecofisiología, sólo rara vez pueden ser probadas sin aproximaciones complementarias como los experimentos o monitoreos de crecimiento o análisis filogenéticos" (Lambers et al., 1998). 


\subsubsection{La Ecohidrología}

La Ecohidrología es la ciencia que estudia la interacción mutua entre el ciclo hidrológico y los ecosistemas, mediante la descripción de los mecanismos hidrológicos que existen bajo los procesos y patrones ecológicos. Tiene su enfoque en el ciclo hidrológico y otros elementos dentro del contexto de la productividad biológica de la tierra, considerando la humedad del suelo como el vínculo crucial entre la hidrología y los procesos biogeoquímicos de las plantas (Rodríguez-Iturbe y Porporato, 2004). Las bases teóricas de la ecohidrología descansan en las hipótesis del óptimo ecológico (Eagleson, 1982), pero algunas propuestas también incorporan explícitamente el estrés hídrico (Porporato et al, 2001; Rodríguez-lturbe y Porporato, 2004).

Las hipótesis del óptimo ecológico de Eagleson $(1982,2002)$ han sido las bases de la Ecohidrología, y en tres escalas temporales distintas establecen lo siguiente:

- Sobre escalas temporales cortas (una o pocas generaciones) la densidad de la vegetación se equilibrará con el clima y el suelo para minimizar el estrés hídrico de los componentes de las plantas. Se maximiza la humedad del suelo en equilibro y se minimiza la evapotranspiración.

- Sobre escalas temporales más largas (varias generaciones) la sucesión vegetal en condiciones de sequía generará una composición óptima de la comunidad en equilibrio, cuya eficiencia de transpiración maximiza la humedad del suelo en equilibrio.

- Sobre escalas temporales mucho más largas (correspondientes a las de evolución del paisaje) la vegetación alterará las propiedades físicas del suelo hasta valores de equilibrio, en donde la densidad de cobertura óptima es máxima.

Recientemente (Kerkhoff et al, 2004) se realizó una evaluación ecológica de esas hipótesis del óptimo ecológico usando datos de campo para condiciones semiáridas, y se demostró que éstas son ecológicamente defectuosas y que el comportamiento del modelo en condiciones nuevas es altamente variable y frecuentemente poco realista. No obstante, señalan que debido a que los cálculos del modelo no dependen en sí de las hipótesis, tanto el modelo como el método son valiosas herramientas para "entender" las limitaciones hídricas sobre la estructura y función de la vegetación. Algunos argumentos aportados a la discusión señalan lo siguiente:

- Maximizar la humedad disponible del suelo también deja accesible el recurso para las especies competidoras. La humedad del suelo es tanto un recurso limitante como un factor amortiguador contra el estrés; por ello, resultaría más realista considerar la situación como un intercambio, en donde los beneficios competitivos de la transpiración de la planta (crecimiento y reproducción) están en balance con los costos de mortalidad por estrés.

- Proponer que una comunidad vegetal que use menos del recurso limitante será la que domine sobre otras, contradice la mayoría del trabajo teórico y empírico realizado en sucesión vegetal. La idea de la humedad del suelo como recurso limitante implica que el sistema evolucionará a una minimización de ese factor, lo opuesto a lo planteado por Eagleson (1982). Se propone considerar la dinámica de la comunidad vegetal como un intercambio entre la producción y el estrés hídrico.

- La maximización de la humedad del suelo en equilibrio corresponde un estado sin transpiración, es decir, sin fotosíntesis. Tanto los problemas técnicos como lo concerniente a lo ecológico sugieren que la segunda hipótesis de optimización debe ser descartada.

Hatton et al (1997) destacan la importancia de la ecohidrología señalando el vínculo que se hace entre hidrología y ecología "con una aproximación dinámica - estadística que deriva un comportamiento hidrológico de gran escala basada en un equilibrio hipotético entre componentes biológicos e hidrológicos del ecosistema". Hay tres parámetros que se encuentran casi universalmente en los modelos ecohidrológicos: la profundidad del suelo, la capacidad de agua retenida disponible y la profundidad de las raíces de las plantas. Son parámetros extremadamente difíciles de estimar a lo largo del paisaje. 
La obra de Eagleson (2002), parte de una visión simplificada de los conceptos de la evolución de la vegetación (evolución darviniana de la especie y no de la comunidad de especies). Se entiende la biología eminentemente como expresión del óptimo físico, y a partir de esa idea se considera que la presión de la selección natural maximiza el éxito reproductivo de la planta mediante la maximización de la producción de biomasa; se formula ese máximo de productividad en términos de las variables físicas que definen el clima, el suelo y lo que allí denominan rasgos "óptimos" de la vegetación, en la creencia de que la cuantificación es la clave para el entendimiento.

Algunos supuestos básicos usados en Ecohidrología son los siguientes: la selección natural se expresa en cada individuo (en el árbol) y no en la comunidad (la comunidad vegetal); los grupos funcionales de plantas permiten capturar las dinámicas esenciales de los ecosistemas; (Eagleson, 2002; Hatton et al, 1997; Rodríguez-Iturbe y Porporato, 2004).

Otro de los supuestos importantes del estudio ecohidrológico de Eagleson $(1982,2002)$ es considerar los bosques como monocultivos, sin tomar en consideración los procesos laterales y las variaciones espaciales sistemáticas del flujo de agua y energía con paisajes adyacentes; esto tiene particular importancia para el trabajo de desarrollo del modelo de ribera que se está realizando, pues como señalan Hatton et al (1997) "de esta manera, se predecirán coberturas uniformes de vegetación en toda la cuenca, aún aquellas con evidentes áreas de ribera y los diversos cambios en cobertura asociados".

El modelo conceptual ecohidrológico es a menudo fino y extraño para profesiones no ingenieriles y la formalización matemática es extremadamente compleja; esa puede ser la explicación del por qué la teoría del equilibro no haya tenido mayor impacto que el de la controversia surgida en torno a ella (Hatton et al, 1997). De hecho, existen distintas aproximaciones no nacidas en esta propuesta que hacen uso del término "ecohidrología" con referencia a un enfoque hidrológico y ecológico en la ribera (Stromberg et al, 1993); la sesión específica de la EGU General Assembly 2005, denominada "Ecohydrology of riparian zones and floodplains", en donde se trataron temas diversos de las interacciones de la ribera, sin la connotación de la propuesta de Eagleson (2002), es un claro ejemplo del uso del término dentro de otras connotaciones.

\subsubsection{Otros modelos enfocados en la dinámica de la vegetación}

Terradas (2001) afirma rotundamente que no se dispone del instrumental de conceptos y métodos para entender a fondo el comportamiento de la vegetación y sus respuestas ante los cambios. Propone como más interesante el ver los errores que los aciertos de la simulación, porque este proceso puede ayudar a formular nuevas preguntas que guíen la observación de la naturaleza y crear conexiones interdisciplinarias.

La agregación conceptual es esencial para examinar las funciones ecológicas, pues sin algún grado de agrupación es imposible evaluar la respuesta de los ecosistemas dentro de un marco temporal requerido (Hatton et al, 1997). La forma más simple de formular un modelo de comunidad vegetal es quizás especificar las reglas que gobiernan el comportamiento de una planta individual durante su ciclo de vida. Dichas reglas pueden ser mecánicas (descripción de la toma y renovación de recursos) o fenomenológicas (por ejemplo, el crecimiento y supervivencia decrece con la densidad de otras plantas vecinas). Luego puede construirse un modelo del conjunto de plantas. Este tipo de modelos son biológicamente realistas, son de calibración empírica sencilla, y pueden extrapolarse a una escala espacio-temporal más allá de los límites de un programa experimental (Crawley, 1997).

Las simulaciones pueden ir del lado del tratamiento de las poblaciones como conjuntos de individuos medios, o admitiendo variaciones en tamaños individuales o reconociendo las posiciones de los individuos en el espacio. Dichos modelos pretenden predecir la evolución de la estructura, composición y/o funcionamiento de la vegetación, siendo los más comunes los siguientes: modelos de reclutamiento (germinación, propagación, etc.), crecimiento (incrementos en altura y diámetro), competencia geométrica, competencia por los recursos (factores limitantes del desarrollo de todos los individuos en una ambiente determinado) y mortalidad de individuos (Terradas, 2001). 
Muchos modelos modernos se interesan por procesos y flujos, y tratan de simular el desarrollo de la biomasa de la parcela o rodal partiendo de la ecofisiología, tomando en cuenta la estructura vertical y espacial de la comunidad y datos sobre la reproducción, crecimiento y mortalidad de árboles y competencia (Terradas, 2001). Las tasas de crecimiento vegetal están determinadas por el área foliar total por planta y por la fracción de fotosintatos (los productos de la fotosíntesis) producidos diariamente requeridos para la respiración de las plantas (Lambers et al., 1998).

También existen modelos ecológicos que se basan en la dinámica de poblaciones o individuos, interesándose por las tasas de cambio en números de individuos de una sola especie o por la productividad de una o pocas especies (Terradas, 2001).

Los modelos markovianos representan procesos estocásticos y no tratan de especies sino de estados del ecosistema, que suelen estar definidos por una especie dominante, o mediante técnicas de clasificación u ordenación; este enfoque sirve para plantear la sustitución de árboles individuales por otros, como de comunidades enteras por otras. El enfoque de comunidad es atractivo para ciertos investigadores pues no requiere gran cantidad de información demográfica y se ha usado para el estudio de cambios a lo largo del tiempo, sobre la base de mapas de uso del suelo o fotos aéreas o imágenes de satélite (Terradas, 2001).

En los modelos de transición markoviana, las tasas de cambio de un estadio a otro, pueden estimarse de formas distintas, y ante carencia de datos tomados de forma secuencial, pueden hacerse estimaciones sobre la base de la situación actual y alguna relación bien establecida para la zona o algún modelo de pronósticos. Las principales críticas a este tipo de modelos, es que la sucesión no es un proceso aleatorio, la historia es importante y los procesos no son estacionarios; sin embargo son ampliamente utilizados. Siempre que se tengan documentos de épocas distintas (mapas forestales o de vegetación, de usos o de cultivos, fotos aéreas o imágenes de satélite) pueden analizarse cambios sucedidos y calcular matrices de transición (Terradas, 2001).

Los modelos markovianos pueden servir para simular perturbaciones del medio sobre la comunidad vegetal, siendo recomendable para ello usar modelos espacialmente explícitos, por ejemplo usando autómatas celulares. Por otra parte, los modelos de paisaje se basan en la combinación de la dinámica de un conjunto de "manchas" o teselas, que pueden influirse o no mutuamente; cuando no se considera interacción entre estructura y dinámica de los elementos del mosaico, los modelos usados pueden ser de tipo markoviano, o autómatas celulares cuando sí se consideran dichas interacciones (Terradas, 2001).

Los modelos del paisaje tienen potencialmente mayor poder de predicción que los markovianos con referencia espacial, pues las probabilidades de transición suelen recibir la influencia de múltiples factores (Turner, 2005).

Para completar el tema de los distintos modelos de vegetación, Terradas (2001) nos habla de modelos combinados o integrados, a fin de combinar conocimientos precisos y detallados a escalas finas con los procesos de respuestas a escalas más globales (más directamente relacionadas con el medio y su gestión). El empleo de modelos de paisaje combinados con modelos markovianos tiene mucho interés para escalar a un ámbito territorial superior (esta aproximación requiere del uso de un SIG para el manejo de la información).

Los procesos de adaptación y aclimatación de las plantas ante factores ambientales, son procesos complejos que se reflejan en cambios de sus características particulares. Los modelos ecológicos se han usado para explorar qué tan significativo es un rasgo desde el punto de vista ecológico; pueden variar desde modelos simples de relaciones empíricas hasta complejos modelos matemáticos que incorporan muchos efectos indirectos en procesos fisiológicos o morfológicos de las plantas. En general persiguen identificar qué particular característica de la planta en determinadas condiciones permite un comportamiento óptimo, o bien, comparar los comportamientos de dos plantas que difieren en sus características (Lambers et al., 1998). 


\subsection{ALGUNOS PARÁMETROS DE VEGETACIÓN}

Los parámetros de vegetación pueden agruparse en dos grandes tipos: Los absolutos, que no dependen del método de muestreo usado, y son la densidad, la cobertura y la biomasa. Los no absolutos sí dependen del método usado y el más común es la frecuencia (Causton, 1988). La densidad, la biomasa, la cobertura y la frecuencia están expresados en cantidades por unidad de área (Bonham, 1989).

Para estimar densidad, biomasa y cobertura se usan como unidades de referencia las formas vivas de las comunidades vegetales, es decir, se requiere conocer la composición florística de la vegetación tipo (Bonham, 1989). Hay dos objetivos básicos a considerar para seleccionar la medida y las técnicas a utilizar. Uno es la evaluación de los efectos de perturbación sobre la vegetación, y el otro es describir las características de la vegetación de modo que la medida pueda usarse como un estándar o una línea base (Bonham, 1989). Cada uno de los parámetros tiene una razón de ser y un uso específico recomendado, y para ello la lectura de la obra de Bonham (1989) es una buena referencia.

\subsubsection{La Cobertura}

La cobertura de una especie se define como la proporción del suelo ocupada por una proyección perpendicular sobre él, de las partes aéreas de los individuos de la especie en consideración. Se expresa como porcentaje, y por ejemplo en un área con vegetación de muchas especies la cobertura total de todas ellas es usualmente mayor que 100\% (Causton, 1988). Eagleson (2002) define como cobertura del dosel (M) la fracción del sustrato cubierta por vegetación. El índice suele asociarse con el tipo de hábitat y los recursos disponibles y se le puede determinar usando una combinación de técnicas SIG, fotos aéreas y verificación de campo (Maddock y Baird, 2003). La cobertura puede medirse para vegetación en contacto directo con el suelo (área basal) o como una proyección perpendicular de las partes aéreas de la planta sobre el suelo (cobertura foliar) (Bonham, 1989; Causton, 1988).

\subsubsection{La Densidad}

Causton (1988) define la densidad como un número en un área dada; la densidad es el número de árboles en un área dada y puede utilizarse como un factor para escalar de estimaciones en árboles individuales a estimados por unidad de área (Maddock y Baird, 2003). En la caracterización de las hierbas la densidad es un valor más constante año a año de lo que serán la cobertura o la biomasa. La medida de densidad requiere que las plantas individuales puedan contarse. La importancia de este índice ha sido mayor para árboles y arbustos que para hierbas (Bonham, 1989).

\subsubsection{La Frecuencia}

La frecuencia de una especie se define como la probabilidad de encontrarla dentro de un cuadrado cuando el cuadrado se coloca sobre el suelo (Causton, 1988). Dado que la frecuencia es el porcentaje de especies presentes en una unidad de muestra, está influida por el tamaño y la forma de las unidades de muestreo. Puede estimarse en puntos, líneas o polígono. Es un índice útil para monitorear cambios en la cobertura de la vegetación a lo largo del tiempo y comparar diferentes comunidades vegetales (Bonham, 1989).

Se pueden usar relaciones matemáticas para estimar la frecuencia a partir de la cobertura y de la densidad de vegetación. El índice es altamente sensible a la abundancia y patrón de crecimiento vegetal (Bonham, 1989).

\subsubsection{La Biomasa y la Producción}

La biomasa es otra medida primaria de la vegetación pues indica la cantidad de recurso, como el agua, utilizada por una especie en la comunidad vegetal (Bonham, 1989). En una comunidad vegetal, la cantidad total de materia orgánica que forma parte de los organismos constituye su biomasa; normalmente la vegetación destina una importante parte de los recursos abióticos al incremento de biomasa (Terradas, 2001). Eagleson (2002) define biomasa como el peso del material vivo de la planta. 
Los datos de biomasa disponibles se refieren sobre todo a biomasa aérea, aunque también se tienen algunos de biomasa subterránea. Suelen expresarse como peso seco, es decir, después de extraer el agua secando las muestras en horno de secado. Esto implica la colecta de todos los órganos vegetales (en caso de árboles, implica la tala de la parte aérea), y posterior estimación de su materia seca (Córdova et al, 2002; Terradas, 2001).

En la ciencia forestal, la biomasa aérea suele calcularse de manera indirecta en función de otras variables como la altura y el diámetro del árbol a la altura del pecho (DAP), debido a las evidentes dificultades de medición de biomasa. El establecimiento de estas ecuaciones se hace para determinadas especies mediante un arduo trabajo de campo (Córdova et al, 2002). Por ejemplo:

Biomasa Pinus maximinoi $=\mathrm{e}^{(3.193+0.072 \text { DAP }+0.023 \text { Altura })}$

Para este caso, biomasa en kilogramos, DAP en centímetros y altura en metros. Se suele expresar la biomasa para un área determinada (toneladas por hectárea), y si ésta se estima con base en indicadores forestales como el antes señalado, el bosque debe ser de la misma especie y se debe contabilizar su cobertura. Si se quiere añadir la variación del índice en el tiempo, sería necesario el monitoreo de la masa forestal (Córdova et al, 2002; Terradas, 2001).

La mayor parte de la biomasa forestal corresponde a tejidos muertos, madera, que se acumulan con la edad del sistema y tienen una función puramente estructural y conductora. La biomasa más activa, formada por hojas y órganos reproductores, supone sólo una parte pequeña del total y es mucho menos variable. La biomasa depende del clima, la fertilidad, la disponibilidad de agua y el régimen de perturbación. La proporción de biomasas aérea / subterránea suele relacionarse con las disponibilidades hídricas ya que, a medida que disminuyen éstas, las plantas deben asignar mayor proporción de sus recursos a raíces, pero también depende de la fertilidad.

Un índice del cambio de biomasa en el tiempo se expresa a través de la tasa de crecimiento relativo ( $R G R$, del término inglés "relative growth rate").

$$
R G R=(d B / d t) / B_{o}
$$

Es decir, RGR se calcula como el cociente entre el aumento de biomasa experimentado por unidad de tiempo y la biomasa en el momento inicial $\left(\mathrm{B}_{0}\right)$ (Terradas, 2001).

Un incremento de la biomasa del bosque se asocia típicamente con un incremento en el tamaño de la planta y una reducción de su densidad (Lambers et al, 1998). Weller (1987) provee de una base empírica para extrapolar de individuos vegetales a bosques o grupos de individuos, mediante la siguiente expresión:

$\ln (b)=-3 / 2 \ln (d)$

Siendo, $b=(d)^{-3 / 2}$, y $B=b \cdot d=d^{-1 / 2}=b^{1 / 3}$. Donde $b$ es la biomasa individual (g planta ${ }^{-1}$ ), $d$ es la densidad (plantas $\mathrm{m}^{-2}$ ) y $\mathrm{B}$ es la biomasa del bosque $\left(\mathrm{g} \mathrm{m}^{-2}\right)$.

La producción primaria bruta de una comunidad es la tasa de asimilación de $\mathrm{CO}_{2}$. Desde el punto de vista de la vegetación interesan más la Producción primaria neta (NPP, del término inglés "net primary production") y la Producción neta del ecosistema (NEP).

La producción primaria neta (NPP) se define como: el carbono total asimilado por las plantas menos el que ellas mismas emplean en la respiración (Terradas, 2001); es la suma de la acumulación de biomasa vegetal verde más cualquier transferencia de carbón orgánico del "compartimiento vegetal verde" a otros compartimientos dentro del ecosistema, según la definición de Eagleson (2002); o bien, es el producto de la biomasa (B) por la tasa de crecimiento relativo (RGR) de la planta (Lambers et al, 1998):

$N P P=B \times R G R$ 
En los bosques, aunque la RGR es baja, la biomasa es grande, y es en ellos donde se da la mayor NPP. Lo contrario sucede en las comunidades herbáceas, la RGR es grande y la biomasa pequeña. Mientras que la determinación de la asimilación de carbono puede hacerse por métodos ecofisiológicos, la de la RGR suele emplear métodos de cosecha de muestras en tiempos distintos o estimaciones a partir de individuos (Terradas, 2001).

En la teoría ecohidrológica de Eagleson (2002) para el cálculo de la Productividad primaria neta (NPP), se introduce una variable independiente $\left(\beta \mathrm{L}_{t}\right)$ que está en función de parámetros por especie vegetal calculado con base en curvas, tablas y ecuaciones. Se señala que para climas extremos áridos, el $\beta L_{t}$ debe ser extremadamente pequeño a fin de conservar agua, llegando a un óptimo local NPP que es menor (debido a la limitante de agua) que su máximo global (limitado por la luz).

La producción neta del ecosistema (NEP) es la diferencia entre NPP y la respiración heterotrófica (de los animales y agentes de descomposición presentes en el ecosistema). Es difícil de estimar; mide la acumulación de carbono en el ecosistema, por lo que es interesante en relación a los cambios globales ambientales y el papel de los ecosistemas como captadores de carbono (Terradas, 2001).

\subsection{5 Índice de área foliar (IAF)}

El índice de área foliar es una variable adimensional que, según Dingman (2002) puede definirse como,

IAF $=\underline{\text { Área total de la superficie foliar por encima de una superficie de suelo } \mathrm{A}}$

A

La cantidad de hojas o densidad foliar, se expresa generalmente en términos de área foliar; para cuantificar los cambios en ambientes luminosos con incrementos de áreas foliares, se necesita definir el área de las hojas por unidad de área del suelo. El índice de área foliar "IAF" (muy comúnmente expresado como "LAl", por el término en inglés "leaf area index") expresa una relación entre una superficie foliar respecto a una superficie de suelo, por tanto es adimensional; un IAF = 3 significa que hay $3 \mathrm{~m}^{2}$ de área foliar sobre cada uno de los metros cuadrados del suelo (Smith y Smith, 2000).

Jonckheere et al. (2004) señalan que, debido a las diversas formas que pueden tener las hojas (planas, enrolladas, arrugadas, etc) se ha propuesto una definición de IAF como un área foliar proyectada, para lo cual el ángulo de proyección es clave en la estimación. Dicha área foliar proyectada se ha considerado tanto un área de proyección máxima (connotación biológica para el intercambio gaseoso, por ejemplo) como un área de total de intercepción (connotación física para la intercepción de la radiación). Además, existen más definiciones e interpretaciones del IAF que varían en función de la técnica usada para su medición; por ello conocer el método de estimación es clave para la conceptualización del término.

EI IAF sobre cualquier superficie es inversamente proporcional a la cantidad de luz que alcanza a dicha superficie, y la relación general entre la luz disponible y el IAF se describe mediante la Ley de Beer. Establece que $A L_{i}=e^{-1 A F^{*} k}$ donde $i$ se refiere a la altura vertical del dosel y $k$ es el coeficiente de extinción de la luz. Por otra parte, la cantidad de luz que alcanza el suelo en vegetación terrestre varía conforme la estación o época del año (Smith y Smith, 2000).

De acuerdo con Weis et al. (2004) el IAF es la principal variable usada para modelar distintos procesos de la vegetación, como su fotosíntesis y evapotranspiración. Los autores presentan la revisión de los principales métodos de campo utilizados para medir el IAF y las referencias respectivas de algunos estudios, señalando tanto sus ventajas como desventajas. Causton (1988) se refiere al IAF como una variante del comportamiento del parámetro de producción. 
EI IAF de la vegetación depende de la composición de especies, el estado de desarrollo, las condiciones de sitios prevalecientes, la estacionalidad y las prácticas de manejo. Es un parámetro dinámico que cambia de día a día en función de la dinámica anual del bosque. Todos estos factores sumados a los diversos métodos de medición del IAF pueden llevar a una amplia gama de valores según demuestra la literatura concerniente (Jonckheere et al., 2004).

Para la estimación del IAF pueden utilizarse métodos directos e indirectos. Dentro de los métodos indirectos con algún trabajo de campo se encuentran las técnicas "alométricas" (del término inglés "allometric techniques") para bosques, basadas en la relación entre el área foliar y alguna variable de la vegetación arbórea como el diámetro a la altura del pecho, la altura del árbol, el flujo de savia, entre otras (Jonckheere et al., 2004); los métodos ópticos que son métodos indirectos sin contacto con la planta, y que se basan en medidas de la transmisión de luz a través del dosel y que aplican la ley de Beer-Lambert tomando en cuenta que el total de radiación interceptada por el dosel depende de la radiación incidente, la estructura del dosel y las propiedades ópticas (Jonckheere et al., 2004).

De acuerdo con Eagleson (2002), el índice de área foliar puede estimarse de diversas maneras: mediante una "prueba destructiva" en la que se corta y miden las hojas de la planta; los "inclined point quadrats" que implica análisis estadístico de los contactos entre las hojas y una sonda delgada que se pasa en varios ángulos a través de la copa del árbol; y la calidad de la luz que alcanza el sustrato del dosel. En todo caso, aporta varias referencias de estudios "clásicos" desde los años treinta.

De acuerdo con Qi et al (2000) hay dos formas de estimar el IAF mediante imágenes de sensores remotos: (i) usando un índice de vegetación (el valor de importancia "Vl") que se relaciona estadísticamente con valores IAF mediante alguna de las muchas ecuaciones propuestas en la literatura; (ii) mediante modelación.

\subsection{EL CRECIMIENTO Y EL DESARROLLO DE LA VEGETACIÓN}

Los conceptos de crecimiento y desarrollo emergieron de los progresos en la producción vegetal, y actualmente son muy difundidos por la literatura agronómica, forestal, fisiológica, entre otras muchas ramas asociadas. Como se detalló en apartados anteriores, el crecimiento de la vegetación puede verse a escalas de individuo, población o comunidad. Entre las distintas vertientes teóricas algunas abogan por estudiar el crecimiento y relacionar los múltiples niveles de estudio (Lambers et al., 1998).

El Crecimiento es el aumento de tamaño de la planta, que puede ser tanto en materia seca o en dimensiones (Wild, 1992); también se define como el incremento irreversible en volumen (Taiz y Seiger, 1998). El origen del proceso es la formación de nuevas células, la expansión de las células constituyentes y la producción de asimilados. La velocidad del crecimiento se expresa como aumento de peso, volumen, área o longitud por unidad de tiempo (Wild, 1992).

Además de la definición clásica de crecimiento existe una basada en el análisis del movimiento de las células o elementos del tejido vegetal, es decir, en la cinemática. Así, mediante el estudio del movimiento de las partículas de un fluido y los cambios de forma del fluido se llega a una definición moderna del crecimiento, la cinemática, que permite describir los patrones del crecimiento de los órganos matemáticamente, en términos de los patrones de expansión de sus células componentes. Una revisión a fondo de los procesos de fisiología vegetal permite llegar al fondo de este conocimiento (Taiz y Seiger, 1998). 


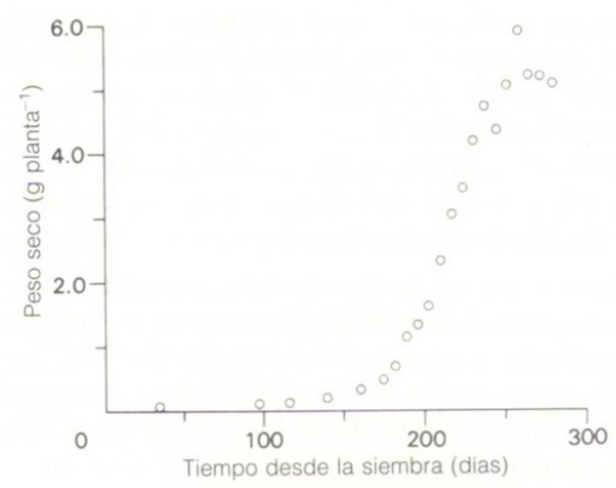

Fig. 3.1 Variación del peso de materia seca en brotes de trigo de invierno cultivados en campo. Tomado de Wild (1992).

El peso de materia seca producida por unidad de superficie por un cultivo anual, o por una planta aislada, en relación con el tiempo sigue aproximadamente una curva en forma de S (Fig. 3.1). Después de un período de crecimiento lento posterior a la emergencia de la plántula del suelo, hay un crecimiento acelerado (exponencial), seguido de otro en donde la velocidad es casi constante (lineal) que conduce a otro en que la velocidad se aproxima a cero y concluye, a causa de la senescencia, de la caída de hojas o de ambas, con un período de crecimiento negativo.

El Desarrollo es el paso de la planta, desde la germinación hasta la madurez, por una serie de fases que, en la mayor parte de los cultivos, están bien definidas. Entre esas fases están la germinación, formación de hojas e hijuelos, crecimiento de los tallos, fecundación, producción de frutos, madurez fisiológica y muerte. Cuando dichas fases están bien definidas, se tiene la base para sistemas de descripción precisa del desarrollo (Wild, 1992).

En general, los principales factores que influyen en la velocidad de desarrollo son la temperatura y el fotoperíodo, mientras que los que determinan la velocidad de crecimiento son más numerosos e incluyen, además, la luz, el $\mathrm{CO}_{2}$, los nutrientes y el agua (Wild, 1992).

Larcher (1995) señala que la actividad respiratoria y la capacidad fotosintética de las plantas no son valores constantes, no solamente en el curso del desarrollo individual sino en la conexión con fluctuaciones estacionales y diurnas de la actividad de las plantas. La capacidad fotosintética también cambia en el curso del desarrollo.

Los factores de productividad de la planta más destacados son la luz (para mantener abiertos los estomas de las hojas para la toma de $\mathrm{CO}_{2}$ y como combustible para su asimilación), el nitrógeno (para la formación del tejido vegetal), el agua (para mantener abiertos los estomas de las hojas mediante el mantenimiento de la turgencia de la planta para el transporte de nitrógeno del suelo a la planta y para regular la temperatura mediante el enfriamiento por evaporación). Eagleson (2002) presenta bases biofísicas para optimizar cada una de estas variables.

De acuerdo con Eagleson (2002), la "duración o longitud del período de crecimiento" es un tema de importante consideración, ya que "la intensidad de la radiación solar controla la tasa de producción de biomasa para un bosque y su productividad anual depende de la duración de la actividad fotosintética, que es, la longitud del período de crecimiento, T. El inicio y fin del período de crecimiento de los árboles está forzado por factores como el: (1) fotoperíodo (longitud del día), (2) la fuerte dependencia de la temperatura de la bioquímica de la fotosíntesis para las plantas arbóreas, o (3) el estrés hídrico". Las especies en fase de madurez se caracterizan por su mecanismo de intercambio (del término inglés "trade-off" utilizado en ecología vegetal) entre los fenómenos de crecimiento y supervivencia (Crawley, 1997).

De forma similar al crecimiento individual de una planta, el crecimiento de comunidades se puede caracterizar con una curva típica: cuando se inicia la sucesión vegetal se da una curva de crecimiento con una tendencia de incremento exponencial de la biomasa vegetal; luego, mientras continúa la sucesión, disminuye la tasa de crecimiento relativo pero se mantiene un incremento en la biomasa y la productividad debido a la tendencia hacia una comunidad de árboles. 
Las perturbaciones del medio determinan las proporciones relativas de los estadios de las especies, por lo que también inciden directamente en las tasas de crecimiento (Lambers et al., 1998). Desde el punto de vista de la modelación matemática del crecimiento de poblaciones vegetales, y para evitar soluciones que impliquen ecuaciones dinámicas dependientes del espacio y del tiempo, se propone la dinámica biofísica del crecimiento en términos del largo plazo (Eagleson, 2002).

Hatton et al (1997) señalan que cuando se mide la fotosíntesis, la respiración, la asimilación y la transpiración a nivel de ecosistema, se observan tasas estables y no variables en función de la sucesión, por lo cual, parece haber un elemento de auto regulación del proceso en el ecosistema, al menos hasta que se alcanza un umbral de estrés y el sistema colapsa. En apartados posteriores se hará una revisión específica de ese estrés y sus efectos sobre las plantas.

La extinción de una comunidad de plantas se da en principio por su longevidad, su ciclo de vida, y luego por accidentes mecánicos, depredación, enfermedades y otras causas ambientales. El fenómeno de las tasas de mortalidad debe estudiarse desde las distintas etapas del crecimiento de las plantas, es decir, sus aspectos demográficos (Terradas, 2001).

Un árbol puede morir súbitamente y por una causa única (rayo, sequía, viento, helada, competencia, contaminación) o más lentamente y normalmente por un conjunto de causas distintas, ya que cualquier factor que produzca estrés sostenido disminuye la fotosíntesis, las reservas y la resistencia. Las causas más frecuentes de mortalidad varían según los tipos de ambiente y también varían a lo largo de la sucesión; la mortalidad depende en gran parte de las perturbaciones y de la depredación, y no tanto de la competencia (Terradas, 2001). La estimación de las tasas anuales de incremento de especies arbóreas es virtualmente imposible ante la ausencia de datos exactos respecto a la fracción de semillas que sobreviven hasta la edad reproductiva de la planta (Crawley, 1997).

\subsubsection{Efectos del estrés hídrico en el crecimiento y desarrollo de las plantas}

Se define como estrés un factor ambiental abiótico o biótico que reduce las tasas de algún proceso fisiológico (como la fotosíntesis o el crecimiento) por debajo de un umbral máximo que de otra manera las plantas podrían sostener. Desde un punto de vista ecofisiológico estrés hídrico es cualquier limitación al funcionamiento óptimo de las plantas impuesta por una insuficiente disponibilidad de agua; Déficit hídrico es cualquier limitación en el abastecimiento de agua en los tejidos vegetales; es un término que posee carácter temporal para expresar respuestas a una disminución progresiva del agua disponible en el suelo (Lambers et al, 1998; Medrano y Flexas, 2004).

Se define una manera de estimar el déficit hídrico (DH), como el porcentaje de agua que le falta al tejido fresco para alcanzar el estado turgente (Medrano y Flexas, 2004a):

$\mathrm{DH}=(\mathrm{PT}-\mathrm{PF}) / \mathrm{PT} \times 100$

Donde PT es el peso turgente del tejido vegetal (la cantidad "máxima" experimental de agua que puede contener), PF es el peso fresco del tejido vegetal.

Porporato et al (2001) proponen un estrés hídrico estático en función del estado de cierre de los estomas, que llega a un valor máximo igual al del suelo está al nivel del cierre estomático completo; asimismo mediante un análisis estadístico de la duración y frecuencia de los períodos de déficit hídrico, introducen una dimensión temporal en la definición del estrés hídrico, definido como estrés hídrico dinámico. La referencia es obligada dado el detalle que se proporciona.

De acuerdo con Lambers et al (1998), existen tres escalas de respuesta al estrés (Fig. 3.2):

- La respuesta inmediata que es una modificación del funcionamiento de la planta en respuesta al estrés que ocurre en poco tiempo (minutos a días). 
- La aclimatación, que se refiere a un ajuste fisiológico y morfológico de las plantas individuales para compensar esa exposición al estrés. Entre ellos, los cambios en procesos específicos como la fotosíntesis, las tasas de crecimiento y la morfología de las plantas, ocurrentes siempre dentro del ciclo de vida de un individuo, es decir a escala diaria o semanal.

- La adaptación, es una respuesta evolutiva que resulta de cambios genéticos en las poblaciones, que provocan compensaciones fisiológicas y morfológicas ante el estrés. Los cambios en los procesos son similares a los de la aclimatación, y la diferencia es la escala temporal en la que ocurren, es decir, cambios sucedidos a lo largo de muchas generaciones.

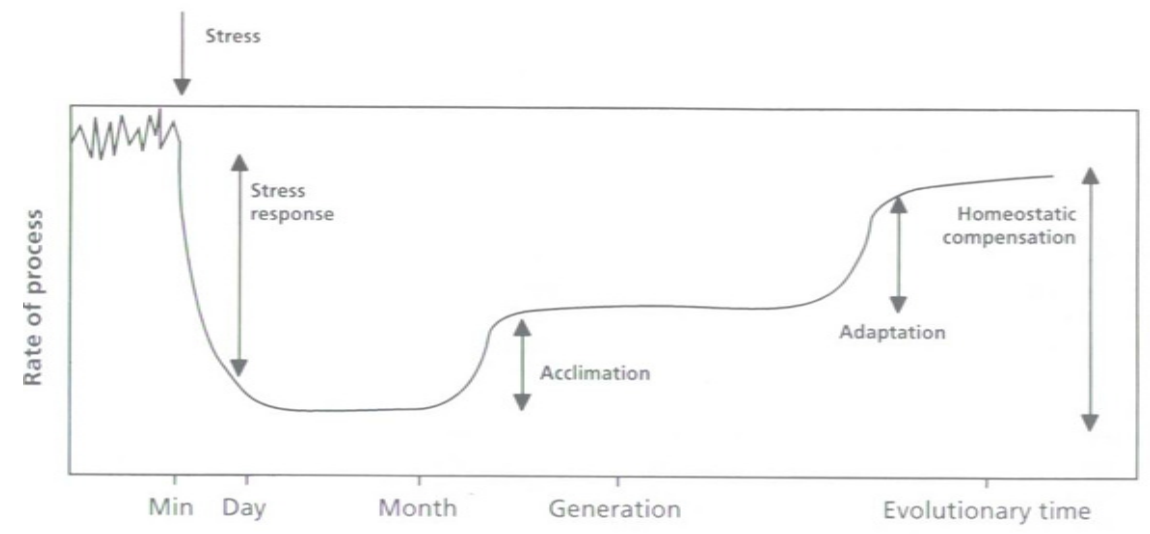

Fig. 3.2 Curso temporal típico de la respuesta de las plantas al estrés ambiental. Tomado de Lambers et al (1998)

De acuerdo con Medrano y Flexas (2004), una determinada especie puede activar diversos mecanismos de aclimatación dependiendo de su constitución genética, lo cual es un resultado del proceso de adaptación. Por ello sugieren abarcar conjuntamente los mecanismos de aclimatación y adaptación.

El estrés ambiental y las soluciones fisiológicas óptimas de las plantas pueden cambiar drásticamente en función de la fase de desarrollo en que se sucedan; el estrés hídrico debería entenderse en función de si la planta está en la fase de germinación, de brote, de crecimiento vegetativo o de reproducción. Los patrones y duración de las fases de desarrollo dependen de las condiciones ambientales y la aclimatación a ambientes específicos; también pueden variar por razones de genética vegetal reflejando aspectos de adaptación (Lambers et al., 1998).

El transporte de agua en la planta, la fotosíntesis y el crecimiento de las plantas son los tres procesos fundamentales más ampliamente estudiados desde la perspectiva ecofisiológica del estrés hídrico; uno de los más ampliamente descritos es el de la reducción del crecimiento de la parte aérea (hojas y tallos) de las plantas (Medrano y Flexas, 2004). Las compensaciones al estrés se dan mediante múltiples mecanismos que operan a diferentes escalas temporales dependiendo de la naturaleza del factor y los procesos fisiológicos que afecta (Lambers et al, 1998).

Lambers et al (1998) hablan de la habilidad de algunas especies vegetales para sobrevivir o resistir el estrés hídrico, manifestada tanto por eludirlo como por tolerarlo. También Medrano y Flexas (2004) hablan de estrategias para mejorar la capacidad de resistencia al estrés hídrico, que consisten en escapar de él, evitarlo o tolerarlo.

La estrategia de escapar al estrés se da mediante cambios en el ciclo de vida de la planta para ajustarse y propiciar una mayor probabilidad de disponer de agua del suelo. Evitar el estrés se da mediante mecanismos para reducir el gasto de agua o para mantener el abastecimiento de agua (Medrano y Flexas, 2004). 
La reducción del gasto de agua se da mediante ajustes en la estructura foliar: reducir el área foliar; la abscisión o caída de las hojas en la época seca; modificaciones del estoma de las hojas; posesión de tejido epidérmico grueso; reducción del área foliar en relación a la masa vegetal; estomas hendidos en la superficie de la hoja; orientación vertical de hojas para minimizar la radiación solar incidente; recubrimiento piloso de los tejidos vegetales (Crawley, 1997; Medrano y Flexas, 2004).

Las acciones para mantener el abastecimiento de agua son el ajuste osmótico u osmorregulación (aumento de solutos en el citoplasma de las células vegetales para disminuir el potencial osmótico e hídrico; ver Fig. 3.3) y el aumento de la extensión y profundidad del sistema radicular, almacenamiento de agua en las raíces (Medrano y Flexas, 2004).

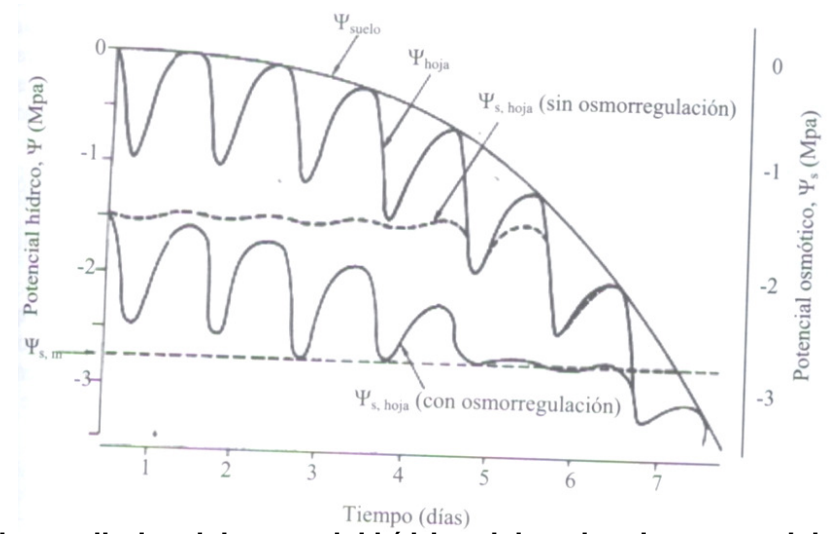

Fig.3.3 Variaciones diarias del potencial hídrico del suelo y los potenciales hídrico y osmótico de las hojas, durante el desarrollo progresivo de una sequía, de una planta que presente ajuste osmótico. Tomado de Medrano y Flexas (2004).

Terradas (2001) expone que las plantas capaces de soportar la sequía (xerófitas) pueden ser árido pasivas (son sensibles a la sequía y escapan de ella mediante adecuación fenológica), árido activas (son resistentes a la sequía debido a mejoras en la absorción y conducción de agua) y árido tolerantes (soportan importantes pérdidas de agua y son sensibles a la desecación en grados diversos).

La velocidad del estrés sobre las plantas también determina el tipo de respuesta; por ejemplo, el cierre de sus estomas para evitar pérdidas de humedad puede ser un proceso relativamente uniforme si la sequía ocurre lentamente, o no uniforme, si la exposición al fenómeno es rápida (Lambers et al., 1998). La magnitud y el tipo de respuestas dependen de la duración e intensidad del déficit hídrico (Medrano y Flexas, 2004).

Son muchos los procesos fisiológicos y metabólicos que se ven limitados por la baja disponibilidad hídrica (Medrano y Flexas, 2004). El crecimiento y la reproducción vegetal difieren en su sensibilidad al estrés hídrico. Por otra parte, la sequía inhibe más fuertemente el crecimiento que la fotosíntesis. Durante fenómenos de sequía, las plantas mediante mensajes químicos o señales hidráulicas regulan la conductividad de agua en los estomas y el crecimiento foliar; existen múltiples vías de señal - transducción en las plantas que propician reducciones en su crecimiento ante la escasez de agua (Lambers et al., 1998).

Para estudiar los efectos del estrés hídrico en las plantas, Lambers et al. (1998) hacen una revisión importante de estos fenómenos a diversas escalas desde un punto de vista netamente ecofisiológico. Se demuestra que dicho estrés produce más efectos a nivel de elongación celular foliar y síntesis de proteínas que a nivel de conductividad estomatal o fotosíntesis. Como se ve, los estudios de estrés hídrico tienden a evaluar procesos ecofisiológicos dentro de la planta. 
Smith y Smith (2000) señalan que en una planta el proceso clave que determina sus interacciones con el ambiente es la fotosíntesis, y que sus cuyos procesos físicos destacables son la difusión y transpiración. La difusión es el movimiento de moléculas según un gradiente de concentraciones (desde una mayor hacia una menor concentración), destaca el movimiento del $\mathrm{CO}_{2}$, que para el caso de las plantas terrestres está fuertemente restringido por la transpiración. La transpiración es la pérdida de agua a través de los estomas de las plantas (Crawley, 1997).

La fotosíntesis es muy sensible a variaciones de suministro de luz y $\mathrm{CO}_{2}$, los principales recursos usados durante el proceso. Las influencias de factores ambientales como la temperatura, los nutrientes, el agua y los contaminantes atmosféricos se dan a diferentes escalas de tiempo en función de las tasas de cambio en los ambientes naturales. La capacidad fotosintética de las plantas está directamente relacionada con su habilidad para captar agua, luz y nutrientes (Crawley, 1997).

Para estudiar el efecto de un solo factor limitante del crecimiento vegetal, Crawley (1997) propone contar con una curva que muestre cómo las tasas de crecimiento dependen de la disponibilidad del recurso.

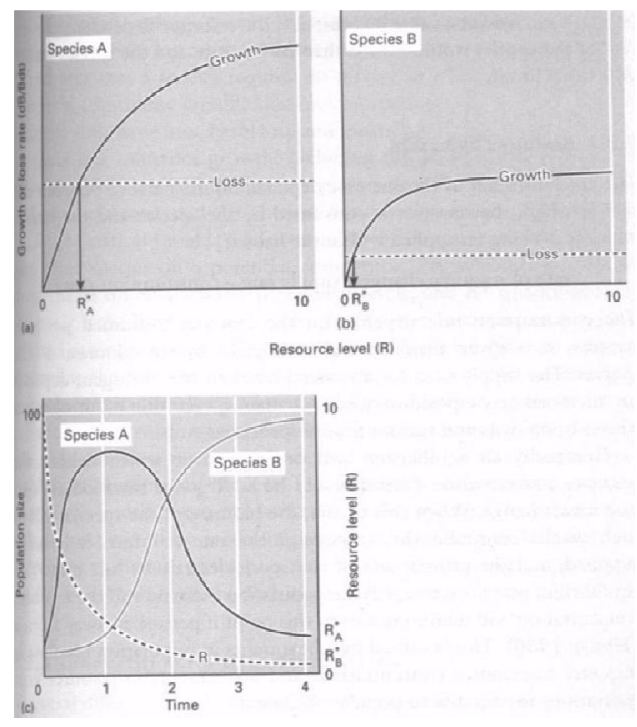

Fig. 3.4 (a) Crecimiento dependiente del recurso y pérdida para las especies $A$. $\mathbf{R}_{A}{ }^{\star}$ es la concentración del recurso a la que el crecimiento iguala la pérdida. (b) Crecimiento dependiente del recurso y pérdida para las especies $B$. (c) Dinámica de competencia por recursos entre las especies; las especies $B$, con un $\mathbf{R}^{\star}$ menor, desplazan a las especies $\mathbf{A}$ y llevan el recurso a una concentración por debajo de $\mathbf{R}_{\mathrm{B}}{ }^{*}$. Tomado de Crawley (1997)

En la Figura3.4 puede observarse una curva que representa un caso hipotético de dependencia de los recursos y la interacción de dos especies, en donde las tasas de cambio de la biomasa $\mathrm{d} B / B \mathrm{~d} t=f(\mathrm{R})-m$, donde $f(\mathrm{R})$ es una función que describe la relación dependiente entre recurso y crecimiento (como en la figura $\mathrm{X}$ ) y $m$ es la tasa de pérdida y mortalidad total, expresada en una base de biomasa específica.

La limitada aplicación de esa hipótesis en la zona de ribera para expresar el crecimiento como función de un factor limitante, es el desconocimiento de dicha función $f(R)$ para especies ribereñas individuales; además, la hipótesis planteada por Crawley (1997) se refiere a dos especies, mientras que la competencia en la zona de ribera corresponde a múltiples especies.

A nivel celular vegetal, el estrés hídrico tiene sus consecuencias. El punto nulo para intercambio de gases en la planta está determinado por el cierre total o casi total del estoma y por el efecto directo de la deficiencia de agua en el protoplasma; se alcanza solo cuando la deshidratación de las hojas está bien avanzada. Esto tiene sus implicaciones en las tasas de fotosíntesis. 
Una vez se alcanza ese punto nulo, la recuperación se retarda, pero si el secado del tejido fue demasiado severo, la capacidad fotosintética original puede, bajo ciertas condiciones, nunca recuperarse nuevamente (Ver Fig. 3.5).

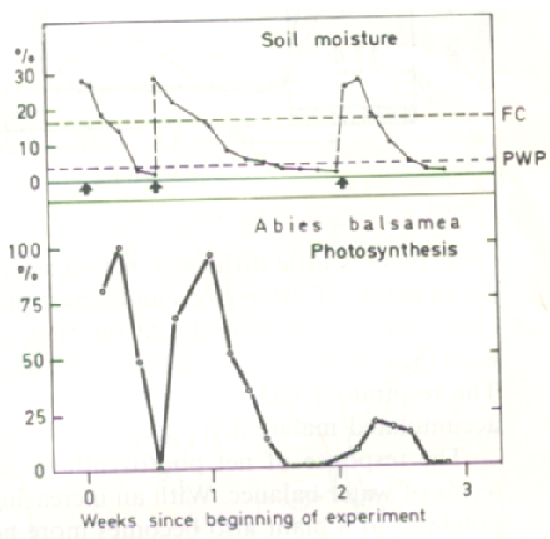

Fig. 3.5. Efecto de la sequía en la fotosíntesis neta de rebrotes de un año de edad de Abies balsamea. Como resultado del riego (flechas), el agua del suelo superaba la Capacidad de Campo (FC). Posteriormente la humedad del suelo era absorbida por debajo del Porcentaje de Marchitez Permanente (PWP). Tomado de Larcher (1995).

En la Fig. 3.5 puede observarse que después de un período de sequía, la fotosíntesis neta se recuperaba rápida y completamente, pero si el suelo permanecía por debajo del PWP por muchos días, la recuperación era incompleta (Larcher, 1995).

De acuerdo con Lambers et al (1998), a escalas regionales las variaciones en humedad y nutrientes debido a variaciones topográficas del drenaje y del material parental del suelo desempeñan un fuerte control sobre la productividad; también se destaca el papel ejercido por los factores históricos que determinan las especies presentes.

El conocimiento profundo de los mecanismos de adaptación de las plantas al estrés hídrico y el cómo ocurren en distintos tipos de vegetación es muy importante para predecir la capacidad de supervivencia y crecimiento de una determinada especie en un hábitat determinado, lo cual tiene una relevancia grande en el tema de la gestión forestal y del territorio en zonas áridas y semiáridas (Medrano y Flexas, 2004); este aspecto también es relevante desde el punto de vista de la gestión de los recursos hídricos en el caso de la zona de ribera.

Según Kerkhoff et al (2004) el estrés hídrico es uno de los factores principales en la estructuración de la vegetación en condiciones de agua limitada, y debido a ello, parece crítico considerar la transpiración de forma dependiente a la concentración de humedad del suelo. Algunos trabajos de ecohidrología consideran esa dependencia entre los factores (RodríguezIturbe y Porporato, 2004).

\subsubsection{La competencia por los recursos}

Alrededor de la teoría de la historia de la vida y el ambiente, han surgido confusiones semánticas respecto al uso del término "competidor" en función de si se sigue una u otra vertiente teórica. Según Crawley (1997) el fin la teoría de la competencia es comparar el buen estado de los fenotipos (resultado de la interacción del gen con el ambiente) que difieren en sus tasas de desarrollo o programas de fecundidad o supervivencia en circunstancias ecológicas específicas. 
En un caso hipotético las plantas individuales pueden estar fuertemente influidas por la competencia con plantas vecinas (Fig. 3.6). Existen reportes de cambios en biomasa o densidad de población de algunas especies que afectan la disponibilidad de recursos, que a su vez influyen en el crecimiento y posibilidades de supervivencia de otras especies. Así, el tipo de competencia más común entre las plantas es la que existe por los recursos. El dominio de las especies arbóreas en los ecosistemas terrestres tiene mucho que ver con la presencia de tallos maderables (tejidos con crecimiento secundario) y sus bajas tasas de crecimiento en comparación con las de las hierbas (Crawley, 1997).
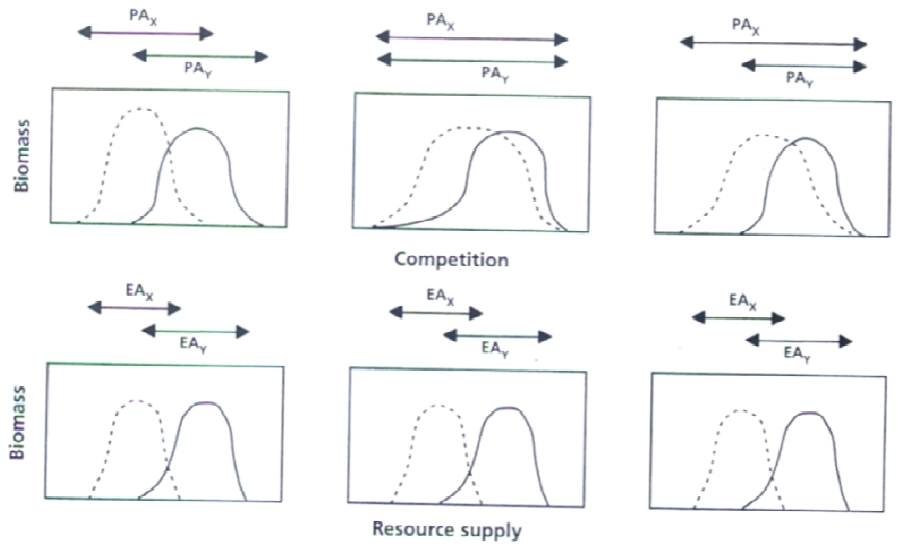

Fig. 3.6. Producción de biomasa de dos especies hipotéticas ( $\mathrm{x}$ e y) como función del abastecimiento de un recurso. Los tres paneles superiores son del rango de crecimiento para condiciones sin competencia entre especies; los inferiores, para dos especies en competencia demuestran cómo se reduce el rango de crecimiento. Tomado de Lambers et al (1998).

Todas las plantas requieren luz, agua y nutrientes; las concentraciones de estos recursos en el hábitat determinan las tasas de crecimiento de una población vegetal, medida comúnmente en términos de tasas de biomasa ( $\mathrm{d} B / B \mathrm{dt}$, donde $B$ es la biomasa vegetal por unidad de área). En general, las tasas de cambio de la biomasa de las especies es una función creciente, hasta un umbral determinado, de la concentración ambiental de ese recurso limitante. Las plantas vecinas mediante su consumo pueden reducir las concentraciones de ese recurso limitante, propiciando el decremento del crecimiento de la planta individual, operando de esta manera el mecanismo básico de competencia por recursos (Crawley, 1997).

Las hipótesis del efecto de la competencia por recursos limitados en una población vegetal pueden comprobarse cuando se cuenta con información de tasas de crecimiento de determinadas especies vegetales; dichas especies son normalmente aquellas de interés económico agrícola o forestal tal y como se observa en las múltiples referencias dadas por Crawley (1997), Lambers et al (1998), Larcher (1995), Medrano y Flexas (2004 y 2004a), entre otros. Ciertas hipótesis con filosofía de ecofisiología sólo rara vez se pueden comprobar sin monitoreos de crecimiento (Lambers et al., 1998). 


\section{FUNDAMENTOS DE HIDROLOGÍA}

\subsection{AGUA EN LA ZONA NO SATURADA}

La zona no saturada es donde se transmite el agua superficial hacia la zona saturada o donde se almacena temporalmente el agua cercana a la superficie del suelo para el uso de las plantas. También se le llama zona de aireación o zona "vadosa" o de agua poco profunda (del inglés "vadose zone"). Sin embargo, el término "zona no saturada" es uno más genérico que sirve para denotar el lugar en donde coexiste el agua o fase líquida con la fase gaseosa, es decir, los intersticios del suelo ocupados parcialmente por agua y parcialmente por aire. La fase líquida o acuosa en la zona no saturada consiste de agua y los minerales del suelo y materia orgánica que están disueltos en ella, mientras la fase gaseosa está compuesta mayormente de aire con vapor de agua y componentes volátiles de materia orgánica incorporada al suelo (Guymon, 1994; Todd y Mays, 2005).

Diversos autores (Guymon, 1994; Todd y Mays, 2005) dividen a su vez la zona no saturada en otras tres (Fig. 4. 1): la zona radicular o zona suelo-agua, la zona intermedia de agua poco profunda (del inglés "intermediate vadose zone") y la zona o margen capilar (del inglés "capillary fringe").

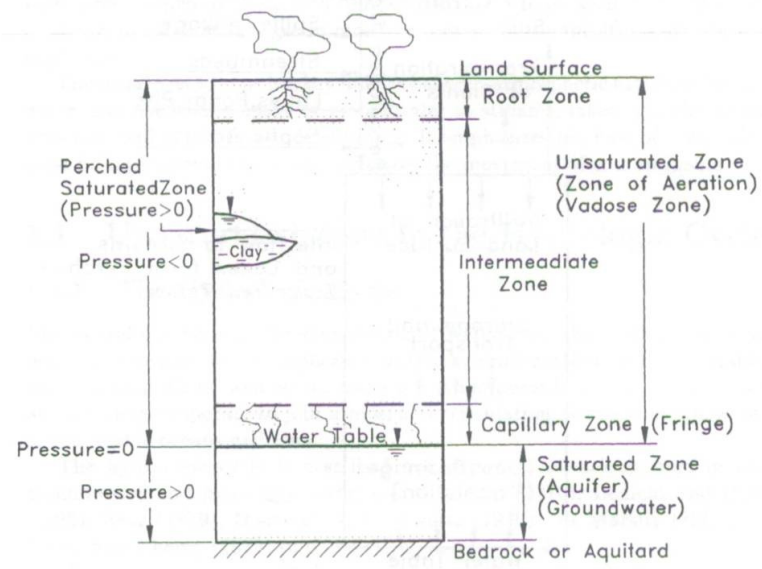

Fig. 4. 1 Clasificación del agua subsuperficial. Tomado de Guymon (1994)

No obstante, de acuerdo con Freeze y Cherry (1979) existe un problema al momento de clasificar la zona capilar (del inglés "capillary fringe") desde el punto de vista del flujo, pues sus poros están saturados de agua (como en la zona saturada) y las cargas de presión son menores que la atmosférica (como en la zona no saturada). Recomiendan desde un punto de vista físico mantener esta zona capilar como una tercera.

El agua existe en la zona radicular cuando llega por los movimientos verticales u horizontales. La zona se extiende desde la superficie del suelo hasta la zona principal radicular. En condiciones áridas se encuentra una película fina de humedad conocida como el agua higroscópica, que está adsorbida a la superficie de las partículas del suelo (Todd y Mays, 2005). El sistema radicular de las plantas en esta zona, no es el de aquellas especies de raíz profunda que pueden alcanzar el nivel freático, es decir, las denominadas plantas freatofitas. Cuando en el suelo hay más humedad disponible y el agua se matiene adherida debido a las fuerzas de tensión superficial se le denomina agua capilar. Cuando el agua capilar está en exceso por las precipitaciones se forma agua gravitacional que drena en el suelo por efecto de la gravedad (Guymon, 1994).

La zona intermedia se extiende desde el límite inferior de la zona radicular hasta el límite superior de la zona capilar. Es principalmente una región en donde el agua se debe mover verticalmente de forma descendente (agua gravitacional). También aquí se tiene agua higroscópica y capilar sin movimiento. La zona capilar se extiende del nivel freático hasta el límite del ascenso capilar de agua $\left(h_{c}\right)$ que de forma idealizada puede ser derivada de un equilibrio entre la tensión superficial del agua y el peso del agua alzada y simplificando por las constantes del agua es 
$h_{c}=0.15 / r$

Donde $r$ es el radio del tubo capilar idealizado con dimensionales en centímetros. Así, el espesor de la zona capilar variará inversamente con el tamaño del poro del suelo o roca (Guymon, 1994; Todd y Mays, 2005).

En la zona no saturada además de las fuerzas de gravedad y fricción, están las de succión que atraen al agua a las partículas del suelo mediante la tensión superficial. Esa energía (desde el punto de vista del mecanismo físico de retención) se denomina carga de succión, carga de tensión, potencial mátrico (de los términos en inglés "suction head", "tension head" y "matric potential") o presión capilar y se simboliza como $\psi$ en el flujo no saturado. Al medir la tensión $\psi$ para la zona no saturada se tiene $\psi<0$, lo cual refleja que el agua aquí permanece en los poros debido a las fuerzas de la tensión superficial (Todd y Mays, 2005; Wild, 1992).

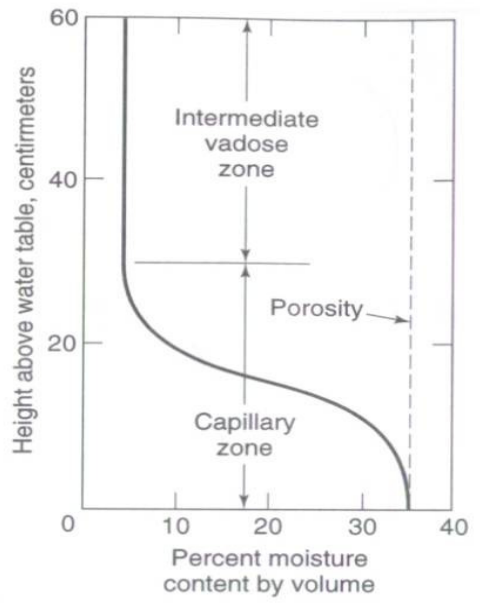

Fig. 4. 2 Distribución del agua en una arena gruesa por encima del nivel freático después del drenaje. Tomado de Todd y Mays (2005)

Puede observarse (Fig. 4. 2) que dentro de la zona capilar existe un decremento gradual en el contenido de agua con la altura, es decir, justo por encima del nivel freático casi todos los poros contienen agua capilar, y mientras se sube de ese nivel el agua estará asociada solamente a los poros más pequeños.

\subsubsection{Porosidad y Contenido de humedad}

Para una unidad de volumen de suelo $\mathrm{V}_{\mathrm{T}}$ se tiene un espacio ocupado por la porción sólida $\mathrm{V}_{\mathrm{s}} \mathrm{y}$ por los poros $V_{\mathrm{v}}$. La porosidad se define como $n=V_{V} / V_{T}$. Ésta se reporta usualmente como un porcentaje o fracción decimal (Freeze y Cherry, 1979).

Por otra parte, el volumen total de una unidad de suelo se compone de una porción sólida $V_{s}$, de un volumen de agua $\mathrm{V}_{\mathrm{w}} \mathrm{y}$ otro de aire $\mathrm{V}_{\mathrm{a}}$. El contenido volumétrico de humedad $\theta$ se define como $\theta=\mathrm{V}_{\mathrm{w}} / \mathrm{V}_{\mathrm{T}}$. Se expresa en porcentaje o fracción decimal. Para el flujo saturado $\theta=n$; para el flujo no saturado $\theta<n$ (Freeze y Cherry, 1979).

El contenido o concentración de agua se expresa de muchas formas, entre las que se incluyen la fracción de masa o de volumen, la altura de agua equivalente a la contenida en una capa del suelo en particular o en el perfil del suelo, o el déficit de agua del suelo, que es la altura de agua necesaria para volver el contenido de agua a su valor de equilibrio, es decir, la capacidad de campo (Wild, 1992). El contenido de humedad está directamente afectado por la textura del suelo, la presencia de partículas de mayor tamaño que las arenas, la densidad aparente del suelo y sus contenidosd e materia orgánica y de sales solubles (Puricelli, 2003).

\subsubsection{Nivel freático}

Comúnmente se piensa que el nivel freático es el límite entre la zona saturada y la no saturada, aunque se sepa que existe una zona capilar saturada ("capillary fringe") sobre dicho nivel. Así, Freeze y Cherry (1979) sugieren definir el nivel freático como la superficie en la que la presión del fluido $p$ en los poros de un medio poroso es exactamente la presión atmosférica, es decir, $p=0$ en el nivel freático, lo que implica que $\psi=0$, y debido a que $h=\Psi+z$, la carga hidráulica en cualquier punto de dicho nivel será la elevación $z$ del nivel freático en ese punto ( $\psi$ en metros). 
En la zona de saturación el agua llena los intersticios del suelo, por lo que la porosidad es una medida directa del contenido de agua por unidad de volumen. Para el flujo saturado $\psi>0, \theta=\mathrm{n}$, y $K=K_{s}$; donde $n$ es la porosidad (Freeze y Cherry, 1979; Todd y Mays, 2005).

\subsection{LEY DE DARCY}

La base original de esta ley es la del flujo saturado (Guymon, 1994) y por ello la revisión inicia con esa aproximación, para más adelante tratar la aplicación en la zona no saturada. Según Todd y Mays (2005), el flujo a través de los acuíferos puede ser expresado mediante la Ley de Darcy que establece que la tasa de flujo a través de un medio poroso es proporcional a la pérdida de altura e inversamente proporcional a la longitud del recorrido del flujo. La ley es válida para todo flujo de agua subterránea en cualquier dirección del espacio (Freeze y Cherry, 1979).

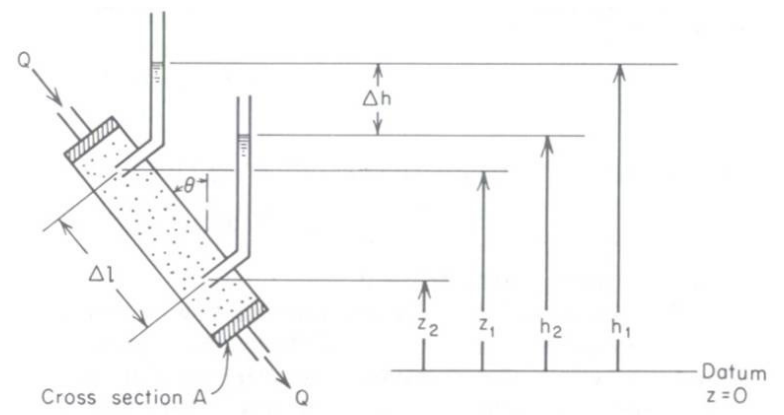

Fig. 4. 3 Aparato experimental para ilustrar la Ley de Darcy. Tomado de Freeze y Cherry (1979).

Esta verificación experimental del problema se realizó para un cilindro circular relleno de arena que recibe agua con un flujo de entrada igual al de salida, que cuenta con un nivel de referencia arbitrario $z=0$, y que presenta alturas manométricas $z_{1}$ y $z_{2}$ y elevaciones en niveles del flujo $h_{1}$ y $h_{2}$. Se define una descarga específica " $v$ " a través del cilindro o "velocidad de Darcy", como

$$
v=Q / A
$$

Considerando su proporcionalidad directa o inversa con las elevaciones del nivel del flujo y la distancia entre manómetros, la ley de Darcy puede escribirse como

$$
v=-K_{s} \frac{d h}{d l}
$$

Donde $h$ es la carga hidráulica, $d h / d l$ es el gradiente hidráulico, y $K_{s}$ es una constante de proporcionalidad denominada conductividad hidráulica saturada (o coeficiente de permeabilidad).

El signo negativo indica que el flujo de agua es en la dirección de decremento de la carga (Freeze y Cherry, 1979; Todd y Mays, 2005; Wild, 1992). Esta es una expresión en su forma unidimensional, que cambia conforme se trabaje con dos y tres direcciones (Fetter, 2001).

Y la notación vectorial de la Ley de Darcy para n-dimensiones es

$$
\vec{v}=-K_{s} \vec{\nabla} \phi
$$

En donde $\Phi=\psi+z_{o}$, es la carga hidráulica total. El gradiente hidráulico $\nabla \phi$ es negativo.

La validez de la ley está limitada por un umbral superior y otro inferior. En una forma general para el flujo en medio poroso podría ser

$$
v=-K_{s}(d h / d l)^{m}
$$


La ley de Darcy es aplicable si $m=1$, como ocurre en la mayoría de casos comunes, pues el flujo es linear. Se ha sugerido que la baja permeabilidad de materiales de grano fino podría ser un límite de gradiente hidráulico para el que no hay flujo -tema aún en discusión-; el límite superior se da a altas tasas de flujo y se identifica con la ayuda del número de Reynolds $R_{e}$, para definir si el flujo es laminar o turbulento. La experimentación ha mostrado que hay validez de la ley cuando las fuerzas de viscosidad predominan, donde $R_{e}$ son menores a valores entre 1 y 10 (Freeze y Cherry, 1979; Tindall, 1999).

\subsubsection{Conductividad hidráulica}

La conductividad hidráulica $K$ depende de las propiedades del fluido y del medio y tiene dimensionales de velocidad [m día ${ }^{-1} \circ \mathrm{m} \mathrm{seg}^{-1}$ ]. Ésta es la diferencia con el parámetro " $k$ " minúscula que sirve para expresar la permeabilidad intrínseca (o simplemente permeabilidad) que es una parte de la conductividad hidráulica y que es una función de la estructura del poro y su geometría, cuyas dimensionales son de área [m²] (Freeze y Cherry, 1979; Tindall, 1999; Todd y Mays, 2005). Esta propiedad del suelo pueda variar en un rango amplio, desde $K$ de $10^{-9} \mathrm{~cm} / \mathrm{s}$ para las arcillas hasta $1 \mathrm{~cm} / \mathrm{s}$ para arenas.

Los valores de conductividad hidráulica usualmente muestran variaciones a través del espacio dentro de una formación geológica (heterogeneidad) y variaciones en la dirección de la medición en cualquier punto de dicha formación (anisotropía). En otras palabras, si la $K$ es independiente de la posición dentro de la formación geológica, la formación es homogénea; y si $K$ es independiente de la dirección de la medida en cualquier punto de la formación geológica, la formación es isotrópica en ese punto (Freeze y Cherry, 1979).

\subsection{FLUJO EN LA ZONA NO SATURADA}

El flujo en la zona no saturada obedece principalmente al contenido de humedad, al gradiente de potencial mátrico (también conocido como potencial capilar o tensión) y al potencial gravitacional, es decir, el agua fluye en el medio no saturado bajo la influencia de un potencial matricial o de succión negativo y no constante (Tindall et al, 1999). Es importante para el flujo vertical hacia abajo (recarga natural y artificial), para el flujo vertical hacia arriba (evaporación y transpiración), para el movimiento de contaminantes en el suelo, y para el flujo horizontal en la zona capilar (Todd y Mays, 2005).

Ya que la ley de Darcy fue concebida para el flujo saturado, ésta fue extendida por Richards para el flujo en el medio poroso no saturado mediante la expresión de la conductividad hidráulica saturada $\left(K_{s}\right)$ con una función de la carga de succión o tensión $\psi$, o en función del grado de saturación (Todd y Mays, 2005). En esa línea, Freeze y Cherry (1979) añaden que hay que convertir los parámetros hidráulicos fundamentales de la zona saturada (la conductividad hidráulica $K s$ y la porosidad $n$ ) en relaciones funcionales $\theta(\Psi)$ y $K(\Psi)$.

Entonces, la ley de Darcy para la zona no saturada puede expresarse de forma general como $\vec{v}=-K(\psi) \nabla \phi$, o bien como $\vec{v}=-K(\theta) \nabla \phi$, donde el flujo está determinado por un gradiente de energía y una función de transferencia no constante del contenido del flujo o la presión hídrica (Guymon, 1994). Y aplicado a la dirección x en un suelo isotrópico como

$v_{x}=-K(\psi) \frac{\partial h}{\partial x}$

Donde se observa que la existencia de una relación $K(\Psi)$ implica que, dado un gradiente hidráulico constante, la descarga específica $v$ se incrementa con el incremento de humedad (Freeze y Cherry, 1979). 
Y ya que $h=\psi+z$, en términos del contenido de humedad se puede expresar como,

$v=-K(\theta) \frac{\partial(\psi+z)}{d z}$

Debido a que, para el flujo no saturado, tanto el contenido de humedad $\theta$ como la conductividad hidráulica $K$ son funciones de la tensión $\Psi$, es decir, para $\psi<0, \theta=\theta(\Psi)$, y $K=K(\Psi)$, el análisis del flujo en la zona no saturada resulta muy complicado (Freeze y Cherry, 1979). Para abarcar ese análisis y resolver los problemas del flujo para suelos no saturados, es necesario conocer las denominadas "curvas características suelo-agua" que expresan las relaciones entre el potencial mátrico en los poros y el contenido de flujo (Guymon, 1994).

\subsubsection{Curvas características de la zona no saturada: Curva de retención e Histéresis}

La relación entre el contenido de agua $\theta$ y la tensión $\psi$ es una propiedad muy importante de un suelo no saturado y se expresa en un par de curvas $\theta(\Psi)$ y $K(\Psi)$ que se denominan curvas características, curvas características de humedad, o más recientemente características de humedad (Freeze y Cherry, 1979; Wild, 1992). La curva $\theta(\Psi)$ se suele denominar curva de retención de humedad (Fig 4.4) y la $K(\Psi)$, curva de histéresis (Fig. 4.5). También se pueden denotar esas características con los términos "relaciones constitutivas" o "relaciones de retención" (Guymon, 1994).

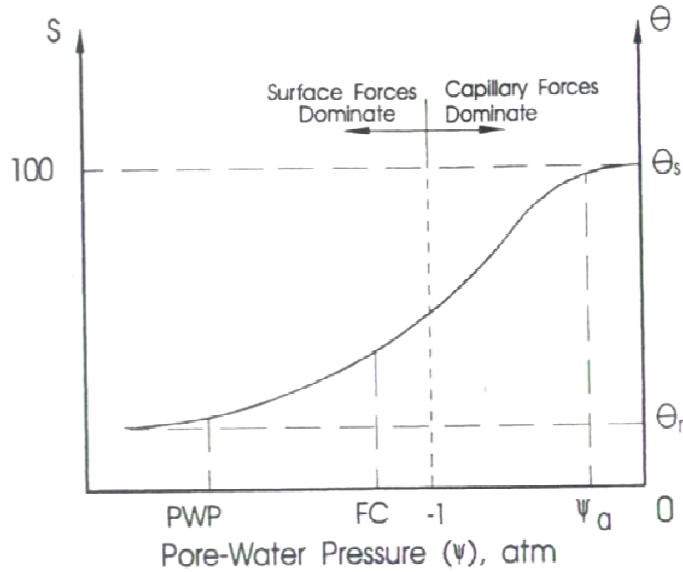

Fig 4.4 Curva característica de retención de humedad para un suelo de granos finos. PWP: punto de marchitez permanente. FC: capacidad de campo. Tomado de Guymon (1994).

La curva de retención de humedad (Fig 4. 4) tiene diversos puntos característicos. Al principio, en la saturación, $\psi=0$ y el contenido de agua $\theta=n$ (la porosidad). Para suelos de grano grueso, el contenido de humedad $\theta$ es igual a la porosidad $n$ para todo $\psi>0$, pero para suelos de grano fino esa relación se mantiene sobre un rango ligeramente largo $\psi>\psi_{a}$, donde $\psi_{a}$ es una pequeña carga de presión negativa conocida como carga de presión de aire entrante. El valor de aire entrante se define como el punto en donde el aire empieza a entrar en los poros, produciendo un medio poroso no saturado donde coexisten agua y aire. La presión $p_{a}$ correspondiente se denomina presión de aire entrante o presión de burbujeo. Para suelos de grano grueso este valor será cercano a la presión atmosférica (carga cero), y para suelos de grano fino será del orden de 0.1 atmósferas de presión (Freeze y Cherry, 1979; Guymon, 1994).

Dado que cada tensión corresponde al vaciado de poros de un cierto diámetro, puede atribuirse un intervalo de poros a cada incremento del agua extraída. Cuanto más acusada es la pendiente de la curva, mayor es el volumen de poros del tamaño correspondiente a la succión o tensión necesaria para vaciarlos (Wild, 1992). 
Otros dos puntos destacables de la curva de retención que relacionan $\theta \operatorname{con} \psi$ son la capacidad de campo y el punto de marchitez permanente o potencial de marchitez permanente, que definen el rango de agua disponible para las plantas. Se referirán con más detalle en apartados siguientes para destacarlos como propiedades que también dependen de las especies vegetales y que no son exclusivas del suelo. Posteriormente se tiene que a medida que aumentan las presiones ejercidas, se dará hasta un punto en que ya no se pueda extraer más agua; el contenido de agua en dicho punto, se conoce como contenido irreducible de agua o contenido residual de agua, que en ciertas condiciones de campo (desiertos en verano) puede ser cero, pero que en suelos profundos puede ser del orden de 0.05 para arenas y 0.1 para arcilla (Guymon, 1994).

La característica de humedad de un suelo no sólo revela así la cantidad de agua retenida en un suelo a diferentes tensiones, sino que muestra también la disponibilidad de agua en ese suelo, y su capacidad total para retener agua disponible para las plantas. Puede interpretarse como una curva de distribución de tamaño de poros, y conduce a estimaciones útiles de conductividad para todos los contenidos de agua. Da el perfil de equilibrio de contenido de agua de un suelo por encima de una capa freática, incluyendo el espesor de la zona capilar (Wild, 1992).

La relación entre el contenido de agua $\theta$ y la tensión $\psi$ es de tipo histéresis, es decir, que tiene una forma distinta cuando los suelos están húmedos o cuando están secos. A una tensión dada, el suelo retiene más agua durante el secado de la que toma al humedecerse, y las curvas de humectación y secado no coinciden, comportándose el suelo como si fuera reluctante a drenar y a rellenarse. Este fenómeno se denomina histéresis y su curva característica (Fig 15b) relaciona la conductividad hidráulica $K$ con la tensión $\Psi$ (Freeze y Cherry, 1979). En la Fig. 15a se muestra el curso que seguirán $\theta$ y $\psi$ cuando el suelo está parcialmente mojado y luego seco, o viceversa.
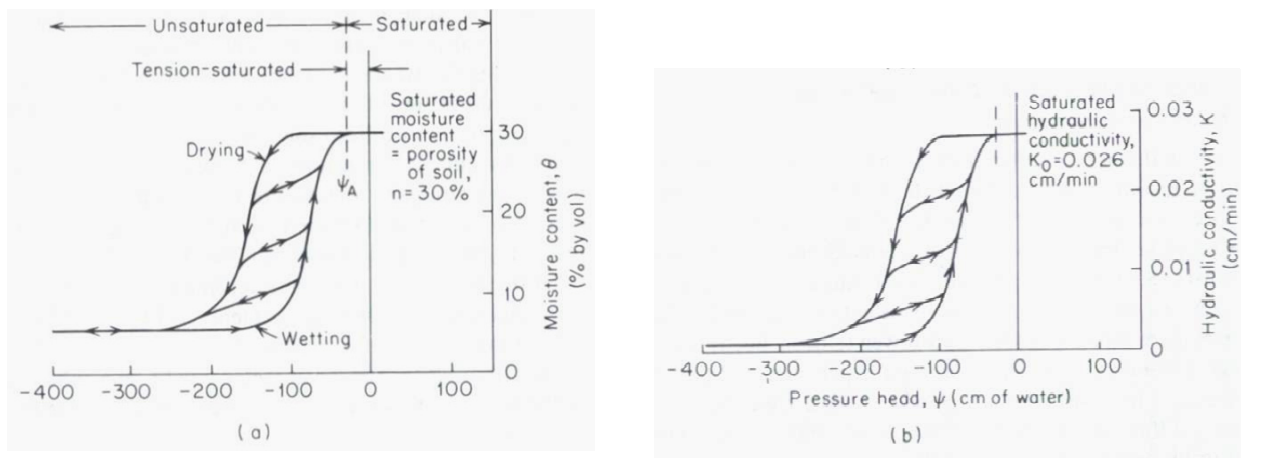

Fig. 4.5 Curvas características relacionando la tensión $\boldsymbol{\Psi}$ con el contenido de humedad $\theta$ (a) y la conductividad hidráulica $K(b)$, para un suelo arenoso en condiciones naturales. Tomado de Freeze y Cherry (1979).

Una consecuencia de la histéresis es la incertidumbre que introduce en la predicción del contenido de agua a partir del conocimiento de la tensión, y viceversa, a menos que se conozca el historial de la humedad del suelo (Wild, 1992).

La característica de humedad puede usarse también para deducir la tensión a partir de un contenido medido de humedad y viceversa, pero desde luego sólo si se conocen los antecedentes de humectación del suelo, a causa de la histéresis (Wild, 1992).

De acuerdo con Francés et al (s.f.), el dibujo de la curva de evolución de la humedad con la profundidad en un punto del suelo se conoce como el perfil de humedad, que se caracteriza por ser variable tanto en profundidad como en tiempo. En condiciones de un nivel freático suficientemente alejado de la superficie y en ausencia de lluvias, dicho perfil se hallará en una situación de equilibrio. El perfil de humedad en equilibrio es lo mismo que la curva de retención sin más que cambiar la escala vertical. 


\subsubsection{Conductividad hidráulica del medio no saturado}
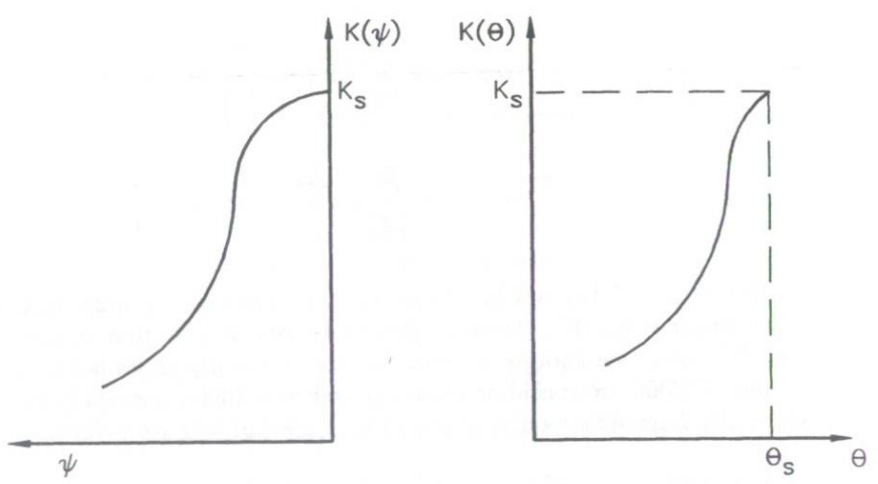

Fig 4.6 Función de la conductividad hidráulica para un flujo no saturado. Tomado de Guymon (1994).

En la Fig. 4.6 se muestra la naturaleza general de las funciones de la conductividad hidráulica no saturada de agua en términos de $\theta$ y $\psi$. La conductividad hidráulica de un suelo no saturado se incrementa con los incrementos de contenidos de humedad. Un gradiente de carga hidráulica implica un gradiente de tensión y éste a su vez implica otro gradiente de contenido de humedad (Freeze y Cherry, 1979). La conductividad hidráulica cambia mediante varios ciclos logarítmicos mientras cambia $\theta \circ \psi$, y el máximo se da en el punto de saturación $K\left(\theta_{s}\right)$ de la curva (Guymon, 1994).

Asumiendo un potencial mátrico constante en una columna en el suelo, se supone que el flujo es estacionario, ya que la columna es corta y el flujo sigue la ley de Darcy. Sin embargo, como regla, el flujo en la zona no saturada resulta de la humedad no homogénea a lo largo de una columna de suelo; consecuentemente el contenido volumétrico de agua, el potencial mátrico, y la conductividad hidráulica no saturada varían con la distancia en la columna; el potencial mátrico decrece conforme crecen el gradiente de succión y en consecuencia decrece la conductividad capilar en la columna. Así, los poros más grandes del suelo son los que primero se vacían de agua, y por ello la conductividad hidráulica no saturada decrece rápidamente conforme el contenido volumétrico de agua decrece (Tindall et al, 1999).

Ya que la relación entre la conductividad y el potencial mátrico depende de la histéresis, ésta debe considerarse en el análisis riguroso de los problemas de flujo no saturado (Tindall et al, 1999).

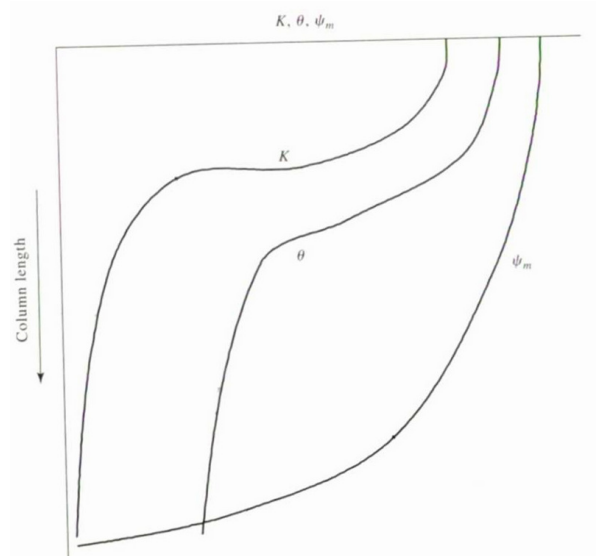

Fig 4.7 Humedad no uniforme y variación en conductividad hidráulica no saturada, $K$, contenido volumétrico de agua, $\theta, y$ potencial mátrico $\boldsymbol{\Psi}$. Tomado de Tindall et al (1999).

Dado que el gradiente hidráulico no es constante a lo largo de la columna, no se obtiene la conductividad capilar mediante dividir el flujo por el gradiente $(\Delta \mathrm{H} / \Delta \mathrm{L})$ como en el flujo saturado, sino que el flujo debe dividirse por el gradiente específico en un sitio dado, es decir, se obtiene una solución de flujo de forma iterativa (Tindall et al, 1999). 
Para el caso en el que se considere el suelo en sus diferentes estratos, es decir, un cambio en el potencial mátrico y humedad del suelo en una columna estratificada, Tindall et al (1999) presentan una muestra de una discontinuidad distintiva en el contenido de humedad en la interfaz entre las dos capas de suelo (la más profunda de ellas en contacto con un nivel freático) asumiendo un flujo estacionario y a una tasa constante (Ver Fig. 4.8).
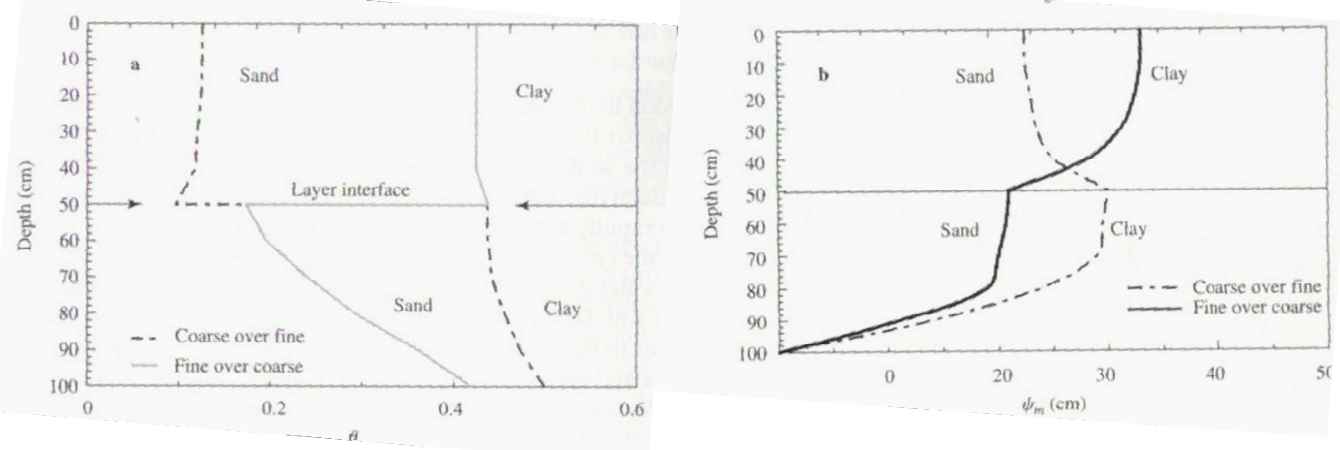

Fig. 4.8 Discontinuidad de $\theta$ en la interfaz del suelo en una columna con capas de dos texturas diferentes (a), y relación de $\boldsymbol{\theta}$ y $\boldsymbol{\Psi}$ usando los mismos suelos (b). Tomado de Tindall et al (1999).

Se observa que aunque la capa más gruesa tiene mayor conductividad hidráulica, tanto el contenido de humedad del suelo como la conductividad hidráulica no saturada decrecen más rápidamente con incrementos en la tensión que para una capa más fina (Fig 4.8a). Típicamente, la zona capilar construye una presión positiva que permite el flujo de la capa fina a la gruesa, lo que significa que el contenido hídrico volumétrico crece y el potencial mátrico, $\psi_{\mathrm{m}}$, decrece. Cada capa del suelo posee su curva de retención de humedad particular.

La conductividad hidráulica es una medida de la habilidad de los suelos para transmitir agua y depende tanto de las propiedades de los suelos (porosidad total, distribución en el tamaño de los poros, y continuidad de los poros) y de las propiedades del fluido (viscosidad y densidad). Dado que no hay disponibles relaciones universales entre la conductividad capilar y la tensión o contenido de agua en el suelo, se han propuesto relaciones matemáticas basadas en evidencia empírica y entre ellas se encuentran las siguientes (Tindall et al, 1999; Todd y Mays, 2005):

\section{Para retención de humedad en el suelo}

$$
\frac{\theta-\theta_{r}}{\phi-\theta_{r}}=\left(\frac{h_{b}}{h}\right)^{\lambda} \quad \text { (Brooks y Corey) }
$$

Donde $\theta_{r}$ es el contenido de agua residual, $\phi$ es la porosidad, $\lambda$ índice del tamaño de poros, $\mathrm{h}_{\mathrm{b}}$ es la presión capilar de burbujeo, $h$ es el potencial mátrico (también expresado como $\Psi$ ).

$$
\frac{\theta}{\phi}=\left(\frac{H_{b}}{\psi}\right)^{1 / b} \quad \text { (Campbell) }
$$

Donde $H_{b}$ es un parámetro para escalar con la dimensión de la longitud $\left(H_{b}=h_{b}\right), b$ es un valor constante.

$$
\frac{\theta-\theta_{r}}{\phi-\theta_{r}}=\left[\frac{1}{1+(\alpha h)^{n}}\right]^{m} \quad \text { (Van Genuchten) }
$$

Donde $\alpha, n, m$ son valores constantes, $h$ es el valor absoluto del potencial mátrico $(h=|\psi|)$. La correspondencia de los parámetros es $\alpha=\left(h_{b}\right)^{-1}, n=\lambda+1, m=\frac{\lambda}{\lambda+1}$ 
Para la conductividad hidráulica

$$
\frac{K(\theta)}{K_{s}}=\left(\frac{\theta-\theta_{r}}{\phi-\theta_{r}}\right)^{n}=\left(S_{e}\right)^{n} \quad \text { (Brooks y Corey) }
$$

Donde, $K_{s}$ es la conductividad hidráulica saturada $(\theta=\Phi), S_{e}$ es la saturación efectiva, y $n=3+\frac{2}{\lambda}$

$$
\frac{K(\theta)}{K_{s}}=\left(\frac{\theta}{\phi}\right)^{n} \quad \text { (Campbell) }
$$

Donde $b$ es una constante, $n=3+2 b$

$$
\frac{K(\theta)}{K_{s}}=\left(\frac{\theta-\theta_{r}}{\phi-\theta_{r}}\right)^{1 / 2}\left\{1-\left[1-\left(\frac{\theta-\theta_{r}}{\phi-\theta_{r}}\right)^{1 / m}\right]^{m}\right\}^{2} \quad \text { (Van Genuchten) }
$$

Las relaciones de Brooks y Corey y la de Campbell solamente describen la porción de la curva de retención de humedad del suelo correspondiente a potenciales mátricos menores que la presión de aire entrante $\left(\Psi_{a}\right)$, mientras que las de Van Genuchten describen la totalidad de la curva (Tindall et al, 1999).

Se han propuesto distintos métodos para la estimación de la conductividad hidráulica no saturada en función del uso de datos de retención de humedad (Campbell, 1974) o para la estimación de las características de humedad del suelo en función de funciones de pedotransferencia (Bonilla y Cancino, 2001) o de características físicas del suelo (Williams et al, 1992), entre otros. Rawls y Brakensiek incorporan tres niveles de información para predecir el agua del suelo en potenciales mátricos específicos, considerando el tamaño de las partículas y dos medidas de contenidos de humedad a tensiones de -33 y $-1500 \mathrm{kPa}$ (Maidment, 1993).

\subsubsection{Almacenamiento de agua en la zona no saturada}

Tal y como se detalló anteriormente, en un suelo no saturado, los cambios en los contenidos de humedad $\theta$, están acompañados por cambios en la tensión $\Psi$, según lo describe la relación $\theta(\Psi)$.
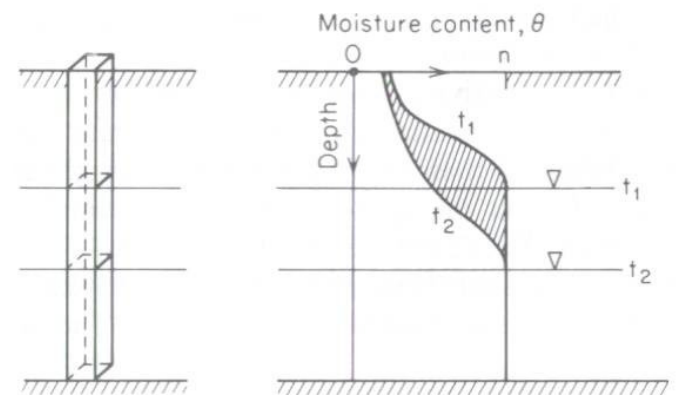

Fig. 4.9 Concepto del rendimiento especifico visto en términos de los perfiles de humedad en la zona no saturada por encima del nivel freático. Tomado de Freeze y Cherry (1979).

La pendiente de la curva característica representa la propiedad de almacenamiento no saturado del suelo. Se le denomina capacidad de humedad específica $C$ (del término inglés "specific moisture capacity") y se define como

$$
C=\frac{d \theta}{d \psi}
$$

Dado que $\theta(\Psi)$ es no lineal y posee histéresis, también C. Es una función de $\Psi$, así $C=C(\Psi)$. Las propiedades de transmisión y almacenamiento de un suelo no saturado son completamente especificadas por la curva característica $\mathrm{K}(\Psi)$ y una de las dos curvas $\theta(\Psi)$ ○ $\mathrm{C}(\Psi)$ (Freeze y Cherry , 1979). 
Otro concepto asociado a este tema es el de rendimiento específico $S_{y}$ (del inglés "specific yield) de un suelo o roca, que se define como la tasa del volumen de agua que, después de la saturación, puede ser drenada por la gravedad. Es decir,

$$
S_{y}=w_{y} / V_{T}
$$

Donde $w_{y}$ es el volumen de agua drenado y $V_{T}$ es el volumen total del suelo (Todd y Mays, 2005).

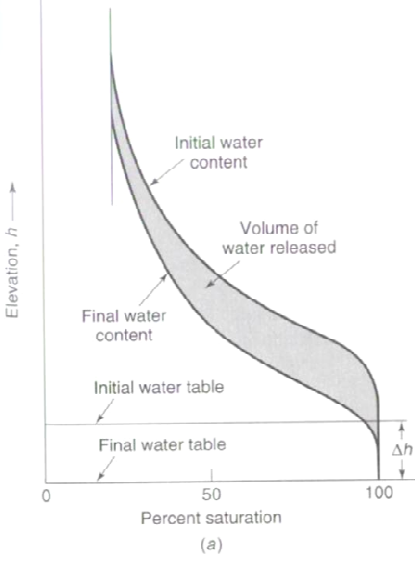

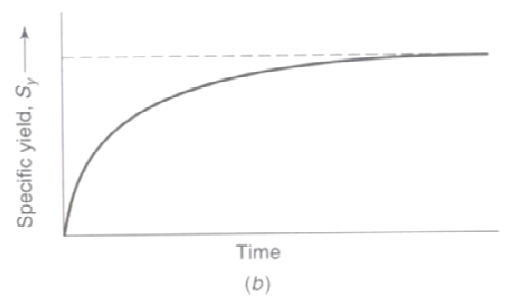

Fig. 4.10 Movimiento de agua en la zona de aireación dado el descenso del nivel freático. (a) Contenido de agua por encima del nivel freático. (b) Rendimiento específico como función del tiempo de drenaje. Tomado de Todd y Mays (2005).

En la Fig. 4.10 se puede observar una distribución típica del contenido de agua encima del nivel freático. Si el nivel desciende en $\Delta h$, entonces la zona capilar también desciende. El área sombreada de la figura es una medida del volumen de agua drenado desde encima del nivel freático, que es liberada por la percolación vertical; consecuentemente el rendimiento específico se convierte en una función asintótica del tiempo.

\subsubsection{Flujo transitorio en medio no saturado: ecuación de Richards}

El flujo transitorio ocurre cuando en cualquier punto del campo de flujo la magnitud o dirección de la velocidad del flujo cambian con el tiempo. De acuerdo con (Freeze y Cherry, 1979), para el flujo transitorio no saturado, debe definirse un grado de saturación $\theta^{\prime} \operatorname{como} \theta^{\prime}=\theta / \mathrm{n}$, donde $\theta$ es el contenido de humedad y $\mathrm{n}$ es la porosidad. Considerando la ley de conservación de masa para el flujo transitorio en un medio poroso saturado y un volumen elemental de control (sólo parcialmente saturado), la ecuación de continuidad debe revelar la tasa de cambio de contenido de humedad y la tasa de cambio de almacenamiento debido a la expansión del agua (se considera que la tasa neta de flujo es igual a la tasa de tiempo de cambio de almacenamiento de flujo dentro del elemento):

$$
-\frac{\partial\left(\rho v_{x}\right)}{\partial x}-\frac{\partial\left(\rho v_{y}\right)}{\partial y}-\frac{\partial\left(\rho v_{z}\right)}{\partial z}=n \theta^{\prime} \frac{\partial \rho}{\partial t}+\rho \theta^{\prime} \frac{\partial n}{\partial t}+n \rho \frac{\partial \theta^{\prime}}{\partial t}
$$

Simplificando la ecuación debido al poco peso de los dos términos últimos del lado derecho, y cancelando las $\rho$ 's, se inserta la forma no saturada de la ley de Darcy reconociendo que $\mathrm{n} d \theta=$ $\mathrm{d} \theta$, y se tiene

$\frac{\partial}{\partial x}\left[K(\psi) \frac{\partial \psi}{\partial x}\right]+\frac{\partial}{\partial y}\left[K(\psi) \frac{\partial h}{\partial y}\right]+\frac{\partial}{\partial z}\left[K(\psi) \frac{\partial h}{\partial z}\right]=\frac{\partial \theta}{\partial t}$ 
Esta ecuación suele expresarse en términos en que la variable es tanto $\theta$ como $\psi$. Para el último caso, es necesario multiplicar por d $\Psi$ el lado derecho de la ecuación, y considerando la definición de la capacidad de humedad específica $C$ y notando que $h=\psi+z$, se obtiene la denominada Ecuación de Richards:

$$
\frac{\partial}{\partial x}\left[K(\psi) \frac{\partial \psi}{\partial x}\right]+\frac{\partial}{\partial y}\left[K(\psi) \frac{\partial \psi}{\partial y}\right]+\frac{\partial}{\partial z}\left[K(\psi)\left(\frac{\partial \psi}{\partial z}+1\right)\right]=C(\psi) \frac{\partial \psi}{\partial t}
$$

La Ecuación de Richards es la ecuación $\psi$-basada de flujo para flujo transitorio a través de un medio poroso no saturado. Su solución requiere el conocimiento de las curvas características $\mathrm{K}(\Psi)$ y $\mathrm{C}(\Psi) \circ \theta(\Psi)$.

\subsection{RELACIONES AGUA - SUELO - PLANTA: USOS DEL AGUA POR LAS PLANTAS}

El agua se mueve verticalmente hacia arriba en las plantas debido a que el potencial hídrico total de sus hojas se vuelve negativo cuando hay pérdidas por transpiración. El agua se mueve del suelo a las raíces y de allí a las hojas mediante el tejido vegetal denominado "xilema"; la tasa de movimiento de agua no se puede predecir a partir de la diferencia del potencial hídrico, a menos que se conozca la resistencia hidráulica, es decir, la medida de la resistencia por fricción impuesta por las vías de paso del agua (Crawley, 1997).

\subsubsection{Potencial hídrico}

Actualmente la variable más utilizada para describir el estado hídrico de las plantas y del suelo es el potencial hídrico, definido como la diferencia entre el potencial químico (o energía libre) por mol de agua y el potencial químico del agua pura a iguales condiciones de presión y volumen. El potencial de agua se mide en unidades de energía (joules por mol) o de presión (MPa o Joules por volumen de agua). Algunas veces es referido en peso unitario, por lo que sus unidades son de longitud (Laio et al, 2001; Porporato et al, 2001; Terradas, 2001).

El potencial hídrico total, $\Psi$, generalmente se usa para caracterizar y comparar los niveles de energía del agua en el sistema suelo-planta-atmósfera. Como se indicó anteriormente, el potencial mátrico suelo-agua está relacionado con la humedad relativa del suelo mediante la curva de retención de humedad. Valores típicos del potencial hídrico del suelo van desde -0.01 MPa para suelos húmedos, hasta $-10 \mathrm{MPa}$ en el punto higroscópico (Laio et al, 2001; Porporato et al, 2001). Así, se tiene que

$\psi=P+\pi+\tau$

Donde $P$ es la presión hidrostática o de turgencia, $\pi$ es la presión osmótica y $\tau$ es la presión matricial.

El estado hídrico de las plantas se ha estudiado a partir de los niveles básicos celulares o de tejidos vegetales. Así, Medrano y Flexas (2004a) señalan que el potencial hídrico es una medida de la energía libre de Gibbs $(\mu)$ asociada al agua que se encuentra en un suelo o en un tejido de la planta, y referida al volumen molar del agua $(\mathrm{Vm})$. Por tanto, el potencial hídrico de un tejido equivale al trabajo que habría que ejercer sobre una unidad de masa de agua ligada al tejido para llevarla al estado energético de referencia correspondiente al agua pura a la misma temperatura y presión atmosférica $\left(\mu_{\circ}\right)$, es decir:

$\psi=\left(\mu-\mu_{0}\right) / V_{m}$

En las células vegetales, $\Psi$ está fuertemente determinado por el potencial osmótico $\left(\psi_{s}\right)$ y el potencial de presión $\left(\Psi_{\mathrm{p}}\right)$

$\psi=\psi_{s}+\psi_{p}$ 
El potencial osmótico se debe a los solutos disueltos en el agua y tiene signo negativo, siguiendo la ley de van't Hoff:

$\psi_{s}=-R T C_{s}$

Donde $\mathrm{R}$ es la constante de los gases ideales, $\mathrm{T}$ es la temperatura del tejido y $\mathrm{C}_{\mathrm{s}}$ la concentración de solutos en la solución del tejido. El $\psi_{\mathrm{p}}$ tiene valores positivos y está determinado por la presión que ejercen las paredes celulares elásticas sobre el agua en la célula.

El potencial hídrico del suelo depende de cuatro componentes de diversa importancia:

$$
\psi_{\text {suelo }}=\psi_{m}+\psi_{s}+\psi_{g}+\psi_{p}
$$

Donde $\Psi_{\mathrm{m}}$ representa el potencial mátrico producido por la capilaridad y las fuerzas de la tensión superficial, $\psi_{\mathrm{s}}$ representa el potencial osmótico producido por los solutos en el agua del suelo, $\psi_{\mathrm{g}}$ representa las fuerzas gravitacionales operando sobre el agua del suelo y $\psi_{\mathrm{p}}$ se refiere a la presión externa que a menudo se desprecia por ser cercana a la atmosférica en la zona radicular (Kramer y Boyer, 1995).

Cuando además de los tejidos vegetales, se quiere estudiar el potencial hídrico a partir del entendimiento del medio (los suelos), aparece el potencial matricial $\left(\Psi_{\mathrm{m}}\right)$ que se debe a la fuerza con que los capilares del suelo retienen el agua intersticial. Cuando se evalúa el movimiento de agua en árboles elevados, el potencial gravitacional $\left(\Psi_{\mathrm{g}}\right)$ tiene importancia y está determinado por el aumento de altura (Medrano y Flexas, 2004a).

De acuerdo con Larcher (1995), el potencial matricial $\left(\Psi_{\mathrm{m}}\right)$ puede ser particularmente alto en suelo con poros finos. El componente capilar del potencial matricial se define como:

$\psi_{\text {cap }}=-290 / d$

Donde $\Psi_{\text {cap }}$ está en Joules por kilogramo, y $d$ es el diámetro del poro (en $\mu \mathrm{m}$ ).

El potencial matricial (o tensión matricial) depende en mayor medida de la energía potencial del agua en el suelo y suele expresarse en atmósferas o $\mathrm{KPa}\left(1 \mathrm{Atm}=1.013^{*} 10^{5} \mathrm{~Pa}\right)$. Como se detalló anteriormente, la relación entre el potencial matricial y el contenido de humedad se analiza mediante la curva característica del suelo (Puricelli, 2003).

Así el potencial hídrico tiene distintas componentes en función de la naturaleza del problema analizado. Existen distintos métodos para la determinación del potencial hídrico y sus componentes en tejidos vegetales. La medida del potencial de presión es la más compleja, de manera que suele estimarse a partir del potencial hídrico y del potencial osmótico. Sin embargo, los métodos son para estudios con carácter ecofisiológico (Medrano y Flexas, 2004a).

Para usar el concepto de potencial no es necesario comprender todas las fuerzas individuales que actúan, sino sólo aquellas que no son uniformes o cuyo efecto dependen de la posición. Dado que la mayoría de fuerzas entre el agua y el suelo son atractivas, el potencial hídrico es normalmente negativo y debe tenerse cuidado en la nomenclatura. Un potencial decreciente es el que es más negativo, y corresponde a una tensión mayor. La principal ventaja del potencial como un concepto aplicado al agua del suelo es que su uniformidad en un sistema es un criterio de equilibrio mecánico. El potencial puede expresarse como energía o trabajo por unidad de volumen, o por unidad de masa o de peso. La intensidad de retención del agua en el suelo es en términos de energía termodinámica libre, o más estrictamente la energía libre parcial de Gibbs o potencial químico (Wild, 1992). 
La tensión del agua del suelo es una presión interna dentro del suelo que puede medirse fácilmente y tiene un efecto cuantitativo sobre las propiedades mecánicas del suelo. Para el movimiento del agua, los gradientes de potencial son importantes, y con altos contenidos de agua éste es principalmente gravitacional. El potencial químico o energía libre puede estar relacionado más estrechamente con la disponibilidad de agua para las raíces, incluye los efectos osmóticos, y tiene en cuenta los cambios térmicos y, por tanto, los de estado (Wild, 1992).

Al tratar la infiltración vertical lo importante es el gradiente de la suma de los potenciales matricial y gravitacional; esa suma se suele denominar el potencial hidráulico. Con bajos contenidos de humedad y para el movimiento horizontal sólo es necesario considerar el potencial matricial. Es común y conveniente atribuir a un sistema particular suelo-agua un potencial particular, pero esto puede ser engañoso a menos que sea claro a qué cero arbitrario está referido, usualmente un suelo saturado al mismo nivel, en cuyo caso es probablemente el componente capilar o matricial del potencial lo que se considera. Un gradiente de potencial osmótico genera movimiento del agua. Si el potencial hídrico sobre la columna de agua se hace más negativo en las superficies celulares que el potencial osmótico en las células, el agua sale a través de la membrana celular, se pierde turgencia y se produce la marchitez (Terradas, 2001).

\subsubsection{Agua útil para las plantas}

Antes de analizar el concepto de agua útil del suelo para la planta, es necesario recordar dos puntos de la curva característica del suelo que destacan por su concepción práctica para establecer los límites del agua disponible para la vegetación: la capacidad de campo y el punto de marchitez permanente.

\subsubsection{Capacidad de campo y punto de marchitez permanente}

La capacidad de campo (CC) es el contenido de agua o presión de succión (del término inglés "pore-water- pressure") en donde no puede drenarse el agua por gravedad con facilidad; suele tener un rango entre -2 y -3 atmósferas de presión, y en otros estudios se refieren valores de 33 kPa y $10 \mathrm{kPa}$ (Guymon, 1994; Wild, 1992). Se puede entender como el contenido máximo de agua que puede retener un suelo cuando la mayoría de los macroporos están ocupados por aire (Soil Conservation Service, 1964) y por tradición se le considera como el límite superior del contenido de agua disponible para el consumo de las plantas (Puricelli, 2003) (Fig. 4.11).

La capacidad de campo no es realmente una constante del suelo ni tampoco una característica física intrínseca del suelo. Su comportamiento es dinámico y su valor depende de las condiciones en que se mide, por lo que en términos estrictos debería analizarse en función del comportamiento del suelo como medio no saturado. Aunque algunos científicos del suelo han recomendado abandonar su estimación, el concepto se ha establecido dada la necesidad de contar con valores de referencia respecto al comportamiento hídrico del suelo y su utilidad práctica es considerable si los usuarios están concientes de sus limitaciones (Kramer y Boyer, 1995; Puricelli, 2003).

El punto de marchitez permanente (PMP) es el contenido de agua o presión de succión en el que las plantas no pueden extraer más agua para su transpiración y el agua del suelo es retenida principalmente por medio de fuerzas higroscópicas (Guymon, 1994; Soil Conservation Service, 1964). Dependiendo del tipo de planta se encuentra en el rango de entre -5 y -15 atm (Guymon, 1994), pues hay variaciones considerables entre las diferentes plantas, pero en general el PMP es menor para hierbas que para árboles, aún y cuando las hierbas llegan a condiciones de estrés antes que los árboles (Laio et al, 2001). Diversos autores (Kramer y Boyer, 1995; Puricelli, 2003; Terradas, 2001) coinciden en que cuando los potenciales matriciales del suelo llegan a $-1.5 \mathrm{MPa}$ (15 bar) se alcanza el PMP (Fig. 4.11). Sin embargo Laio et al (2001) señalan que generalmente, en condiciones naturales el punto de marchitez para plantas de ecosistemas controlados por agua es sustancialmente menor que el valor $-1.5 \mathrm{MPa}$ asumido para cultivos templados; así, valores típicos de PMP para plantas en ambientes semiáridos pueden alcanzar los $-3 \mathrm{MPa} 0$ incluso -5MPa. 
En suelos muy secos, el potencial de agua ( $\Psi$ ) puede caer debajo del punto de marchitez permanente. En este punto el potencial hídrico del suelo es tan bajo que las plantas no pueden recuperar presión de turgencia aún y cuando cese su transpiración; esto se da cuando el potencial hídrico del suelo es menor o igual que el potencial osmótico $\left(\boldsymbol{\Psi}_{\mathrm{s}}\right)$ de la planta. Dado que $\psi_{s}$ varía según las especies vegetales, el punto de marchitez permanente no es una propiedad exclusiva del suelo, sino que también depende de las especies vegetales (Taiz y Seiger, 1998). En términos estrictos y puntuales el PMP no es una característica del suelo sino una cualidad que resulta de la evolución de las relaciones agua-suelo-planta (Puricelli, 2003).
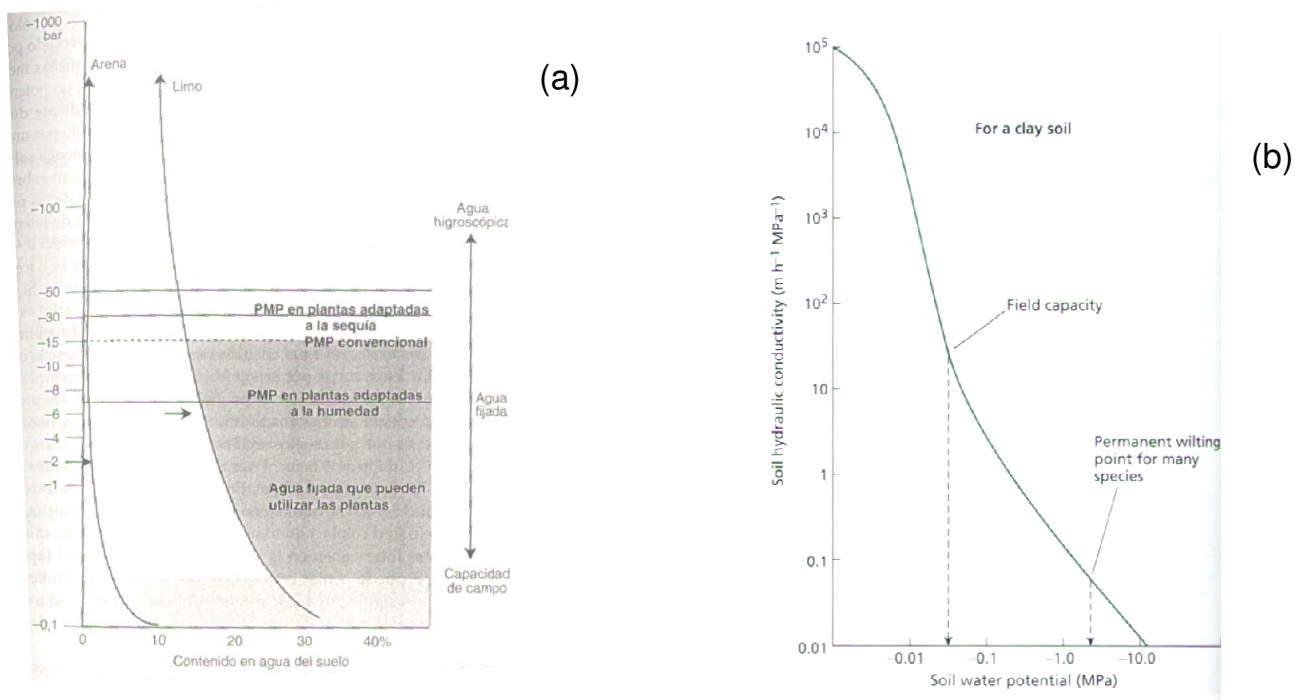

Fig. 4.11 Punto de marchitez permanente (PMP o permanent wilting point a 0.1 MPa) y capacidad de campo (CC ó field capacity) en curvas características de humedad del suelo. Tomado de Terradas (2001) y de Taiz y Seiger (1998)

\subsubsection{Agua útil}

El agua útil es una característica del suelo relacionada con la respuesta de la planta y, en su sentido más amplio, es la máxima cantidad de agua que puede extraerse por las plantas de un perfil del suelo. En un sentido más arbitrario y estático, se describe como la cantidad de agua que retiene un suelo entre su situación a capacidad de campo y su punto de marchitez permanente (Kramer y Boyer, 1995; Terradas, 2001; Wild, 1992). El contenido de agua útil es un término eficiente en función de que sea considerado como el valor de referencia del intervalo en el cual el suelo puede actuar como un reservorio dinámico de agua (Puricelli, 2003). Se calcula así:

$$
H_{u}=\frac{\rho_{b} * p *\left(H_{c c}-H_{p m p}\right)}{\rho_{w} * 100}
$$

Donde $H_{u}$ es el contenido de agua útil [mm], $H_{c c}$ es el contenido de humedad a capacidad de campo [\% en peso de suelo seco], $H_{p m p}$ es el contenido de humedad en el punto de marchitez permanente [\% en peso de suelo seco], $p$ es la profundidad del suelo considerado [m] (Puricelli, 2003).

En apartados anteriores se presentó el almacenamiento de agua en la zona no saturada, pero para referirse específicamente a la capacidad de almacenamiento de agua útil del suelo para las plantas, es necesario definir la capacidad de retención de agua disponible (CRAD) como la suma del contenido de agua útil para cada profundidad considerada del suelo (Puricelli, 2003):

$$
C R A D=\sum_{i} H u_{i}
$$


El concepto de agua útil y sus términos asociados permanece como una parte inexacta de la ciencia del suelo (Wild, 1992), es susceptible de discusión (Puricelli, 2003) y puede no describir con exactitud la situación actual en el campo (Kramer y Boyer, 1995); sin embargo, el rango de agua disponible representa aproximadamente al contenido de agua capilar del suelo (Puricelli, 2003).

Desde el punto de vista de las plantas, la disponibilidad de agua depende de las tasas de abastecimiento de agua a las raíces en relación con las demandas de agua de la planta -tanto abastecimiento como demanda son variables-. La demanda de agua de la planta depende principalmente de la tasa de transpiración y el abastecimiento depende de la longitud de raíces por volumen de suelo, la eficiencia radicular como superficie absorbente y la conductividad hidráulica del suelo (Kramer y Boyer, 1995; Wild, 1992).

Hay considerables diferencias en la cantidad de agua disponible a varias profundidades en suelos no uniformes (Fig. 4.12). Eso sugiere las plantas con raíz profunda a veces pueden compensar las limitaciones de agua disponible en la capa superficial del suelo (Kramer y Boyer, 1995).

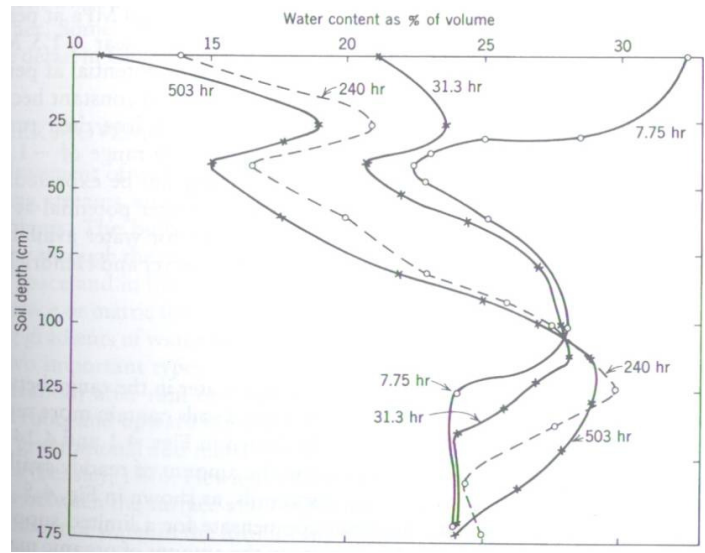

Fig. 4.12 Perfiles de contenido de agua en un suelo no uniforme después de varios tiempos de riego. Tomado de Kramer y Boyer (1995).

\subsubsection{Continuo suelo - planta - atmósfera}

El transporte de agua en el continuo suelo-planta-atmósfera, cuya naturaleza física no implica gastos energéticos de la planta para el traslado del agua (Taiz y Zeiger, 1998), fue esquematizado para expresar la variabilidad de presiones $[\mathrm{kPa}]$ existente en dicho continuo y para resaltar que el sistema radicular de la vegetación es uno de los principales factores que afectan la extracción del agua del suelo (Medrano y Flexas, 2004a). Estos conceptos permiten integrar las interacciones del agua en el suelo con las plantas, estableciendo que el flujo de agua es un proceso catenario, en el que se van dando resistencias hidráulicas. La propuesta es entender el flujo de agua en la planta similar al flujo eléctrico, análogamente con la ley de Ohm, en donde el agua circula de un punto de energía más alto (determinado por su $\Psi$ ) hacia un nivel más bajo. La resistencia total equivale a la suma de las resistencias parciales:

$J_{H_{2} \mathrm{O}}=\Delta \psi_{1} / R_{1}=\Delta \psi_{2} / R_{2}=\Delta \psi_{3} / R_{3}$

Donde $J_{\mathrm{H}_{2} \mathrm{O}}$ es el flujo de agua, $\Delta \Psi$ es el gradiente del potencial hídrico y $\mathrm{R}$ la resistencia hidráulica; el subíndice 1 representa la interfaz suelo -raíz, el subíndice 2 representa el gradiente de la planta, y el subíndice 3 representa la interfaz planta -atmósfera (Medrano y Flexas, 2004a). 


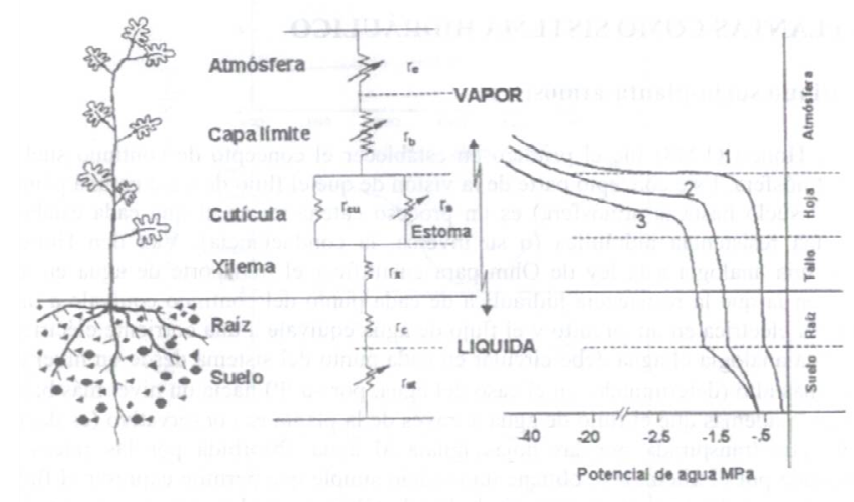

Fig. 4.13 Esquema representativo del continuo suelo -planta -atmósfera, junto con su red de resistencias en analogía a la Ley de Ohm. A la derecha se muestra una distribución típica del potencial hídrico a lo largo del continuo, en tres situaciones distintas de creciente sequía edáfica y/o atmosférica (según Joffre et al, 2001). Tomado de Medrano y Flexas (2004a).

En la figura 4.13 se observa un continuo suelo -planta -atmósfera tipo, y las variaciones típicas de $\psi$ a lo largo del continuo. Las curvas 2 y 3 representan una situación de déficit hídrico en el suelo, y la curva 3 además responde a unas condiciones de mayor demanda atmosférica (menor valor $\left.\psi_{\text {atm }}\right)$. Como se observa, los gradientes de $\psi$ entre el suelo y la planta son relativamente pequeños (entre de 1 a $10 \mathrm{MPa}$ ) en comparación con los gradientes entre la planta y la atmósfera (alcanzando incluso gradientes de 100MPa). El flujo de agua a través del sistema continuo es debido sobre todo a la demanda evaporativa de la atmósfera (Medrano y Flexas, 2004a).

El modelo análogo de la ley de Ohm es simplista, lo que implicaría considerar la planta como si tuviera una sola raíz, una sola rama-tronco y una sola hoja transpirando. Para ello se ha tratado de abordar la problemática mediante el estudio de la arquitectura hidráulica de los vegetales (Medrano y Flexas, 2004a).

Los principales factores que afectar la extracción del agua del suelo son la extensión y la profundidad de las raíces; dichos factores son función tanto de la especie vegetal como de las propiedades físicas del suelo. Para ello, es necesario referirse a la ley de Fick de la difusión de los fluidos, que para el caso del flujo de agua $\left(J_{\mathrm{H}_{2} \mathrm{O}}\right)$, considerando que el gradiente que gobierna su difusión es el de su potencial hídrico $(\Delta \Psi)$, puede expresarse como:

$$
J_{\mathrm{H}_{2} \mathrm{O}}=\Delta \psi / \mathrm{R}
$$

Resultando equivalente a la ley de Ohm, señalada anteriormente. Entonces el flujo de agua depende del gradiente de $\psi$ suelo -raíz y de la resistencia hidráulica de este sistema $(\mathrm{R}) . \Delta \psi$ será tanto menor cuanto más seco esté el suelo, por lo que en condiciones de sequía el flujo de absorción de agua es menor. La resistencia hidráulica del sistema es un factor muy complejo que depende de las resistencias de la raíz $\left(R_{r}\right)$ y el suelo $\left(R_{s}\right)$; la complejidad radica en que se necesita mucha información relacionada con la raíz de las plantas, porque las fórmulas están definidas en función de esos parámetros -extensión de las raíces, distribución de éstas en el suelo, entre otras- (Medrano y Flexas, 2004a).

Seguidamente, el transporte de agua en la planta se ha deducido a partir del conocimiento de las propiedades de anatomía vegetal (diámetros de los vasos conductores del tejido xilemático) y las propiedades físicas del agua (su viscosidad, por ejemplo). Asimismo, son necesarios los conocimientos de las variables ambientales del suelo y algunas características de la planta para calcular los flujos máximos diarios de agua en el continuo suelo -planta -atmósfera. 
El conocimiento de las fuerzas de cohesión en el continuo suelo -planta -atmósfera y de las fuerzas de tensión originadas por la transpiración de las hojas definen la captación de agua por las raíces y su transporte dentro de la planta. Diversos mecanismos de adaptación de la vegetación propician variaciones de las propiedades de velocidad de flujo, optimización de captación de agua y gasto de agua en las hojas para las diversas especies. Conocer estos procesos es imprescindible para comprender ra respuesta de las plantas a la sequía (Medrano y Flexas, 2004a).

\subsection{EVAPOTRANSPIRACIÓN}

La evapotranspiración es un término colectivo para todos los procesos en los que el agua en fase líquida o sólida, cercana a la superficie terrestre, se convierte en vapor de agua atmosférico. Incluye por tanto la evaporación del agua líquida de ríos, lagos, suelo descubierto, y superficies vegetadas; la evaporación de dentro de las hojas de las plantas (transpiración); y la sublimación de las superficies con hielo o nieve (Dingman, 2002).

Sin embargo, es frecuente el uso del término evapotranspiración para referirse a la evaporación total, y así enfatizar el proceso combinado de evaporación del suelo y las superficies con agua más la transpiración de las plantas (Ward y Robinson, 2000) considerando que en la naturaleza ambos procesos ocurren simultáneamente y no es fácil distinguirlos (Rivas, 2004). Es importante destacar que no existe una diferencia fundamental en la física de evaporación desde un cuerpo de agua, el suelo o las plantas (Shuttleworth, 1993).

"Los procesos de evaporación y transpiración dependen de la demanda evaporativa de la atmósfera, del contenido hídrico y de la naturaleza del suelo. Además, dependen de las características de la cubierta vegetal, de manera que en las primeras fases de desarrollo de un cultivo, la evapotranspiración tiene un componente mayoritario de evaporación que se va atenuando a medida que se desarrolla la cubierta vegetal (aumento del IAF y el grado de cobertura de la superficie), hasta que la transpiración prevalece totalmente sobre la evaporación" (Rivas, 2004).

Shuttleworth (1993) propone definir la evaporación como la tasa de transformación del agua líquida en vapor, desde el cuerpo de agua, el suelo desnudo o la vegetación con suelo debajo [mm de agua evaporada al día].

Según Rivas (2004), la evaporación es el proceso de difusión mediante el cual el agua se convierte en vapor para retornar a la atmósfera, y que resulta del aporte de energía (que procede fundamentalmente de la radiación solar) y que se ve afectado por otros factores atmosféricos para el transporte del vapor, como la velocidad del viento, la rugosidad de la superficie expuesta a la radiación, la humedad específica y la temperatura del aire. Si la superficie es el agua libre o el suelo, el mecanismo es fundamentalmente difusivo, pero si es una superficie vegetal, el mecanismo se combina con la transpiración.

Convencionalmente para la estimación de la evaporación se tiene un proceso de dos etapas: en la primera se estima una tasa estándar de evaporación y luego se introduce un factor multiplicativo de descuento para diferentes cultivos y/o estados de humedad. La excepción para este método de dos etapas es para la vegetación forestal alta, que es aún un tema de investigación activa, y que ha demostrado en las décadas pasadas, que hay una diferencia muy marcada entre las tasas de evaporación cuando la vegetación está húmeda y cuando está seca (Shuttleworth, 1993).

Como se señaló, para estimar la evaporación se definen dos tasas estándar de evaporación conceptuales (una para cuerpos de agua evaporación total, y una referida a un cultivo específico), en el sentido que representan situaciones idealizadas (Shuttleworth, 1993): La evaporación potencial $\left(E_{0}\right)$ [mm/día] es la cantidad de agua evaporada por unidad de área, por unidad de tiempo desde una superficie idealizada y extensa de agua libre en las condiciones atmosféricas existentes; esta entidad conceptual mide el control meteorológico sobre la evaporación de una superficie abierta de agua. 
La evaporación de un cultivo de referencia $\left(E_{r c}\right)[\mathrm{mm} /$ día], que es la tasa de evaporación de un cultivo herbáceo idealizado con una altura ajustada de cultivo de $0.12 \mathrm{~m}$, un albedo de 0.23 , y una resistencia de superficie de $69 \mathrm{~s} \mathrm{~m}^{-1}$.

La transpiración es la evaporación de agua desde el sistema vascular de una planta a la atmósfera, o bien, se define como la parte de la evaporación total que entra a la atmósfera desde el suelo a través de las plantas; en dicho proceso intervienen la absorción de agua desde el suelo por las raíces, el transporte a través del tejido vascular, desembocando en la evaporación que ocurre en los estomas (Rivas, 2004; Shuttleworth, 1993). Aunque el mecanismo de la transpiración es bien entendido, es difícil de cuantificar o de presentar en términos matemáticos (Shaw, 1994).

Es necesario entender las relaciones entre la evapotranspiración y el tipo de ecosistema para predecir la respuesta del ecosistema al cambio climático (Woodward, 1987). Además, se recomienda considerar separadamente la transpiración y la evaporación de la lluvia interceptada por el dosel del bosque. Alguna evidencia actual sugiere que la tasa de transpiración de un bosque con buena humedad es cercana al $80 \pm 10$ por ciento de la lluvia (Shuttleworth, 1993).

Considerando que la tasa de evaporación de los bosques es más difícil de describir y estimar que para otros tipos de vegetación, se han dedicado capítulos específicos de libros como el "Handbook of Hydrology" (Maidment,1993) para dar mayor detalle al respecto.

De acuerdo con Rivas (2004) indica que los modelos utilizados para calcular la evapotranspiración se pueden dividir en dos grandes grupos: los clásicos o convencionales, que usan información de tipo climático o meteorológica (escala local) y los que utilizan información captada desde satélites (escala regional). Una de las mayores limitantes con ambos tipos de modelos son los datos disponibles; a mayor precisión del método de cálculo mayor requerimiento de información por el modelo y mayor complejidad de la aplicación.

La medición directa de la evapotranspiración es muy difícil y cara, por lo que se ha optado por diversos métodos que proveen estimaciones que usan datos meteorológicos de estaciones climáticas, asumiendo que el área de evaporación es suficientemente pequeña como para que el proceso no tenga efecto en el clima regional o el movimiento del aire; muchos de esos métodos incorporan la física de la evaporación y otros principios básicos como la conservación de la masa y la energía (Dingman, 2002; Shuttleworth, 1993).

Los principios de termodinámica o balance de energía aplicados a la evaporación se relacionan con la estimación de la energía latente disponible para el cambio de estado del agua de líquido a gaseoso. Si se pudiera estimar la cantidad total de energía utilizada en evaporación, entonces conociendo el coeficiente de calor latente $\lambda$, sería relativamente simple el cálculo del monto de agua evaporada. Por otra parte, la aproximación aerodinámica o de flujo de vapor trata de la difusión hacia arriba del vapor de agua desde la superficie que evapora, y se relaciona con el "poder de secado" del aire, que comprende su humedad y la tasa a la que el vapor de agua puede difundirse hacia la atmósfera (Ward y Robinson, 2000).

\subsubsection{Evapotranspiración potencial (ETP) y su estimación}

La evapotranspiración potencial (ETP) es la tasa a la que la evapotranspiración podría ocurrir para un área grande que está cubierta de forma completa y uniforme por una vegetación creciente que tiene acceso a un abastecimiento ilimitado de agua del suelo, y sin considerar los efectos de advección o almacenamiento de calor (Dingman, 2002).

Dentro de un contexto climático, Rivas (2004) añade a la definición el hecho de la ETP es la máxima cantidad de agua que se puede evaporar desde un suelo completamente cubierto de vegetación con "desarrollo óptimo". En la práctica, la ETP está definida por el método usado para calcularla (Dingman, 2002; Shuttleworth, 1993). 
El concepto ETP introducido por Thornthwaite en 1948, es un intento de depender esencialmente del clima y ser largamente independiente de las características de la superficie; sin embargo varias características de la superficie vegetativa tiene una fuerte influencia en las tasas de evapotranspiración incluso en condiciones de agua disponible no limitada (Dingman, 2002).

Penman en 1956 redefinió la ETP como la cantidad de agua transpirada por un pequeño cultivo verde de altura uniforme, que cubre completamente el suelo, y que no tiene limitante de agua, y de esta manera surge el término evapotranspiración del cultivo de referencia $\left(E T_{0}\right)$ que se usa como sinónimo de ETP (Dingman, 2002), con la diferencia que la $\mathrm{ET}_{0}$ siempre se aplica a un cultivo específico (Rivas, 2004). Así, $\mathrm{ET}_{0}$ se define como la tasa de evapotranspiración desde un cultivo hipotético con una altura de $0.12 \mathrm{~m}$, crecimiento activo, que da una cobertura sombreada al suelo, cubre un área extensa, está bien provisto de agua y cuya resistencia de superficie es de $70 \mathrm{~s} \mathrm{~m}^{-1}$ y albedo de 0.23 (Allen et al, 1998). Se observa que la $\mathrm{ET}_{0}$ definida aquí coincide con la definición de Shuttleworth (1993) para $\mathrm{E}_{\mathrm{rc}}$.

También se trabaja con la evapotranspiración de un cultivo $\left(E T_{c}\right)$ cualquiera, a partir del coeficiente de cultivo $k_{c}$ (adimensional) y la estimación previa de $\mathrm{ET}_{0}$, según la relación (Doorenbos y Kassam, 1986):

$$
E T_{c}=k_{c} \times E T_{0}
$$

El coeficiente de cultivo expresa la relación entre la evapotranspiración del cultivo y la evaporación de referencia; su cálculo es experimental y función de factores como las características del cultivo, su estado fenológico, condiciones climáticas, disponibilidad de agua del suelo, entre otras (Rivas, 2004).

El método más utilizado a la fecha (tanto para climas húmedos como secos) es la ecuación de Penman-Monteith que combina la energía requerida para mantener la evaporación y la descripción empírica del mecanismo de difusión por el cual la energía se remueve de la superficie como vapor de agua (Dingman, 2002; Rivas, 2004; Shuttleworth, 1993). Una implementación de la ecuación de Penman-Monteith para estimar la evaporación potencial $E_{p}\left[\mathrm{~mm}\right.$ día $\left.^{-1}\right]$ es:

$E_{p}=\frac{\Delta}{\Delta+\gamma}\left(R_{n}+A_{h}\right)+\frac{\gamma}{\Delta+\gamma} \frac{6.43\left(1+0.536 U_{2}\right) D}{\lambda}$

Donde, $R_{n}$ es el intercambio de radiación neta para la superficie de agua libre [mm día ${ }^{-1}$ ]; $A_{h}$ es la energía de advección al cuerpo de agua [mm día ${ }^{-1}$ ], si es significativa; $U_{2}$ es la velocidad del viento medida a $2 \mathrm{~m} \mathrm{[m} \mathrm{s-1]}$; $D$ es el déficit de vapor de agua $e_{s}-e[\mathrm{kPa}] ; \lambda$ es el calor latente de vaporización del agua, $\Delta$ es el gradiente de la función de temperatura y $\gamma$ una constante "psicrométrica", cada una de ellas definida por ecuaciones específicas (Shuttleworth, 1993).

Históricamente se han propuesto ecuaciones conceptualmente más simples que la anterior, para la estimación de las tasas de evaporación, y que necesariamente tienen un contenido altamente empírico y su principal propósito es la estimación para un cultivo de referencia; de esta manera se tienen las ecuaciones basadas en radiación, o en temperatura o en evaporación y las ecuaciones combinadas, entre las que se pueden mencionar las de Thornthwaite en 1948, Penman en 1948, Turc en 1961, Jensen y Haise en 1963, Priestley y Taylor en 1972, Jensen en 1974, Linacre en 1973, Hargreaves y Samani en 1985, entre otras (Dingman, 2002; Rivas, 2004; Shaw, 1994; Shuttleworth, 1993).

Para climas húmedos las ecuaciones de Turc han demostrado buenos resultados. Estas ecuaciones están dadas en función de la humedad relativa $R H$ (Shuttleworth, 1993). Así, para $\mathrm{RH}$ $<50 \%$ 


$$
E=0.31 \frac{T}{T+15}\left(S_{n}+2.09\right)\left(1+\frac{50-R H}{70}\right)
$$

Y para $\mathrm{RH}>50 \%$

$$
E=0.31 \frac{T}{T+15}\left(S_{n}+2.09\right)
$$

Donde $E\left[\mathrm{~mm} \mathrm{día}^{-1}\right], T$ es la temperatura media en ${ }^{\circ} \mathrm{C}, S n$ es el equivalente de agua de la radiación solar neta [mm día ${ }^{-1}$ ], y $R H$ es la humedad relativa en porcentaje.

Considerando que en la ecuación de Penman-Monteith el primer término (radiación-dependiente) es generalmente el mayor de los dos términos, los métodos basados en la temperatura, asumen que la correlación entre radiación y temperatura es lo más importante. En general la única justificación para usar ecuaciones de estimación de este tipo es que la temperatura sea el único dato disponible, y aún en este caso no es aconsejable hacer estimaciones de evaporación para un período menor al mensual (Shuttleworth, 1993). Dentro de estas se encuentra la de Hargreaves y que puede expresarse como

$$
E_{r c}=0.0023 S_{0} \partial_{T}(T+17.8)
$$

(4.32) Donde $E_{r c}$ es la evaporación de un cultivo de referencia; $S_{0}$ es el equivalente de agua de la radiación extraterrestre $\left[\mathrm{mm}\right.$ día $\left.{ }^{-1}\right]$ para el lugar de interés; $T$ es la temperatura $\left[{ }^{\circ} \mathrm{C}\right] ; \partial_{T}$ es la diferencia entre la máxima temperatura media mensual y la mínima temperatura media mensual. Los buenos resultados de esta ecuación se explican por la incorporación de la un vínculo explícito con la radiación solar (Shuttleworth, 1993).

\subsubsection{Evapotranspiración real $\left(E T_{r}\right)$ : efectos de la disponibilidad de agua del suelo}

Debido a que el proceso de evapotranspiración producido en una superficie natural no siempre se encuentra en las condiciones hipotéticas planteadas, se ha considerado la evapotranspiración real $\left(E T_{r}\right)$ que se define como la cantidad de agua verdaderamente perdida por el suelo a través del sistema suelo-planta hacia la atmósfera. En general, la $E T_{r}$ es menor, o en el caso límite, igual a la ETP (Rivas, 2004).

Se han planteado diversas hipótesis de extracción de humedad del suelo para definir las tasas de evapotranspiración como función de la disponibilidad de agua del almacenamiento estático (Altier et al, 2002; Dingman, 2002; Grindley, 1970; Porporato et al, 2001; Rodríguez-Iturbe y Porporato, 2004; Shaw, 1994; Shuttleworth, 1993; Ward y Robinson, 2000; Wild, 1992); este comportamiento se puede aproximar a una función lineal cuando el contenido de humedad óptimo determina si la planta está estresada o no (Quevedo y Francés, 2008).

De acuerdo con Dingman (1992) uno de los métodos más extensamente usados para estimar la $E T_{r}$ hace uso de datos meteorológicos para estimar la evapotranspiración potencial mediante relaciones como las descritas previamente; así, se tiene la siguiente ecuación:

$$
E T_{r}=F\left(\theta_{r e l}\right) \times E T P
$$

Donde $F\left(\theta_{\text {rel }}\right)$ es el contenido relativo de agua en el suelo, definido como

$\theta_{r e l}=\frac{\theta-\theta_{p m p}}{\theta_{c c}-\theta_{p m p}}$ 
Donde, $\theta$ es el contenido de agua actual, $\theta_{c c}$ es la capacidad de campo y $\theta_{p m p}$ el punto de marchitez permanente en la zona radicular del suelo (Dingman, 1992).

Suele pensarse que el cálculo de la ETP es una operación más simple que la medición de la $E T_{r}$ de una superficie vegetada. Sin embargo, la pérdida de agua en una cuenca no siempre procede a la tasa potencial, ya que es dependiente de un suministro de agua continuo. Por tanto, la relación entre ETP y $E T_{r}$ depende del contenido de humedad del suelo (Shaw, 1994).

Según Dingman (2002), la relación entre la tasa $E T_{r} / E T P$ y $\theta_{\text {rel }}$ usualmente presenta una forma en la que $\mathrm{ET}_{\mathrm{r}} / \mathrm{ETP}$ se incrementa de forma cuasi-linear a medida que $\theta_{\text {rel }}$ se incrementa, $\mathrm{y}$ alcanza el valor de 1 en algún contenido de agua $\theta_{\text {crit }}$ (Fig. 4.14). Típicamente $0.5^{*} \theta_{c c} \leq \theta_{\text {crit }} \leq$ $0.8^{*} \theta_{c c}$.

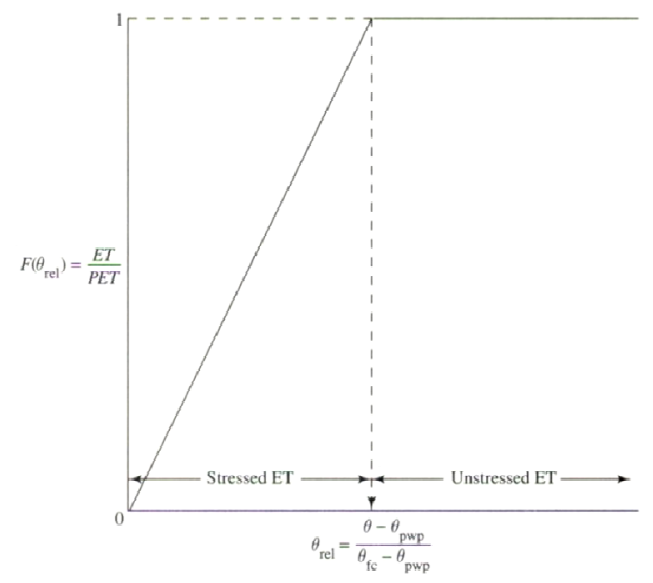

Fig. 4.14 Forma general de las relaciones entre $E_{r} / E T P$ y el contenido de humedad del suelo, $\theta$, usados para estimar la $\mathrm{ET}_{\mathrm{r}}$. Diferentes estudios han usado diferentes funciones para expresar la humedad del suelo. Cuando el contenido de humedad del suelo es variable y menor que el valor crítico $\theta_{\text {crit, }}$ la $E_{r}$ es menor que la ETP y las plantas se consideran en estrés hídrico. Tomado de Dingman (2002).

Cuando se modela el cambio en la evaporación en respuesta al estado de humedad del suelo es a menudo conveniente trabajar en términos del contenido de humedad del suelo, pero las plantas son más sensibles al potencial hídrico $\psi_{s}$. Alguna de la variabilidad en la forma funcional de $f(\theta)$ reportada en la literatura puede entonces ser causada por la variabilidad en la relación entre $\theta_{s}$ y $\psi_{s}$ para diferentes suelos. En algunas aplicaciones hidrológicas la forma precisa de $f(\theta)$ no es tan importante. En particular, en el caso de modelar los balances de recursos hídricos, el error acumulado en el almacenamiento calculado de agua se hace cero cada vez que el suelo se seca completamente o cuando éste es completamente llenado por lluvias fuertes (Shuttleworth, 1993).

Según Shuttleworth (1993), al requerir estimados de evaporación para cultivos no regados, el estado del agua del suelo puede ser importante, actuando a través de la superficie de resistencia. En la estimación de la evaporación de un cultivo de referencia, el valor de $k_{c}$ es reducido a $k_{c o}$ al incluir un factor $k_{s}(\theta)$ relacionado con el contenido volumétrico de agua del suelo $\theta$

$E=k_{c} E_{r c}=k_{s}(\theta) k_{c o} E_{r c}\left[\mathrm{~mm}\right.$ día $\left.^{-1}\right]$

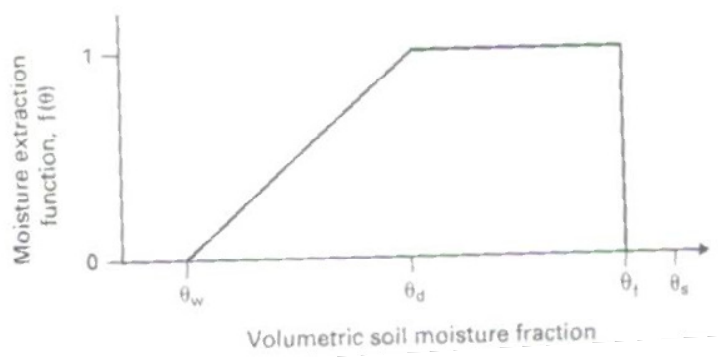

Fig. 4.15 Variación típica de la función de extracción de humedad $f(\theta)$ que modifica el coeficiente del potencial del cultivo en respuesta a cambios en el contenido volumétrico de agua $\theta$ en (porciones de) la zona radicular de las plantas. $\theta_{s}, \theta_{f}$, y $\theta_{w}$, son los valores de $\theta$ en saturación, capacidad de campo y punto de marchitez permanente respectivamente, y $(\theta \mathrm{d} / \theta \mathrm{f})$ es típicamente 0.5 a 0.8 . Estos valores están determinados por el tipo de suelo. Tomado de (Shuttleworth, 1993). 
Dyck (1983) propone diversas formas de la función de estrés por humedad del suelo $f(\theta)$ para valores diarios, cada 5 días y mensuales (Shuttleworth, 1993).

Cuando se satura el suelo, contenido de humedad $\theta_{s}$, hay agua que se drena por la gravedad y se llega luego a la capacidad de campo $\theta_{f}$. El secado procede con pocas restricciones de agua del suelo hasta que dicha humedad cae a $\theta_{d}$, cuando el contenido de humedad es típicamente 50 a 80 porciento del $\theta_{f}$; la conductividad hidráulica $k_{s}$ y la tasa de transpiración comienzan a decrecer, hasta que se alcanza el punto de marchitez cuando el contenido de agua es $\theta_{w}, y$ cuando se asume que $k_{s}=0$. Este comportamiento parece ser similar tanto para cultivos como para suelos. En condiciones de sequía prolongada los cultivos comienzan a morir y la tasa de evaporación no está controlada por las condiciones meteorológicas, sino por las características del suelo, especialmente la conductividad hidráulica (Shuttleworth, 1993).

Los modelos más realistas de restricción de la evaporación por la humedad del suelo simulan la extracción de la planta desde una serie de almacenamientos de humedad arreglados verticalmente una sobre otra en el suelo a través de la zona radicular (Shuttleworth, 1993).

Como se ha señalado con anterioridad, el tema de la disponibilidad de agua para las plantas dentro del rango capacidad de campo - punto de marchitez permanente sigue siendo susceptible a la discusión (Kramer y Boyer, 1995; Puricelli, 2003; Ward y Robinson, 2000; Wild, 1992). A pesar de ello, se han hecho numerosos intentos para relacionar la transpiración de las plantas con el estado del agua del suelo.

De acuerdo con Shaw (1994), en capacidad de campo se puede asumir que $E T_{r}=E T P$; la evapotranspiración ocurre a la tasa máxima posible determinada por las condiciones meteorológicas. Si no existen recargas del abastecimiento de agua, la humedad del suelo disminuirá gradualmente por las demandas de la vegetación para producir un déficit de humedad del suelo (DHS); mientras el DHS incrementa, la $E T_{r}$ se va haciendo incrementalmente menor que la ETP. Los valores de DHS y $E T_{r}$ varían con el tipo de suelo y vegetación, y los cambios relativos en $E T_{r}$ con incrementos en DHS han sido motivo de estudio.

Se han explorado correlaciones entre el potencial hídrico del suelo y la evaporación mediante curvas de secado que muestran tasas entre la transpiración y la transpiración sin estrés para vegetación en condiciones de poca disponibilidad de agua (Ver Fig. Siguientes). Estas curvas de secado representan un modelo de caja negra que sustituye el entendimiento detallado del complejo agua-suelo-planta; sin embargo, han permitido avances significativos en el entendimiento, medida y modelación de la evaporación de las coberturas vegetales y han constituido el medio para estimar las pérdidas de evapotranspiración real (Ward y Robinson, 2000).

Las Figuras 4.16 y 4.17 presentan distintos patrones e hipótesis surgidos para explicar las relaciones entre evaporación y el potencial hídrico del suelo que marca el grado de disponibilidad de agua del suelo. Se revisarán en un inicio las hipótesis o patrones extremos y seguidamente algunos intermedios que pueden destacarse.

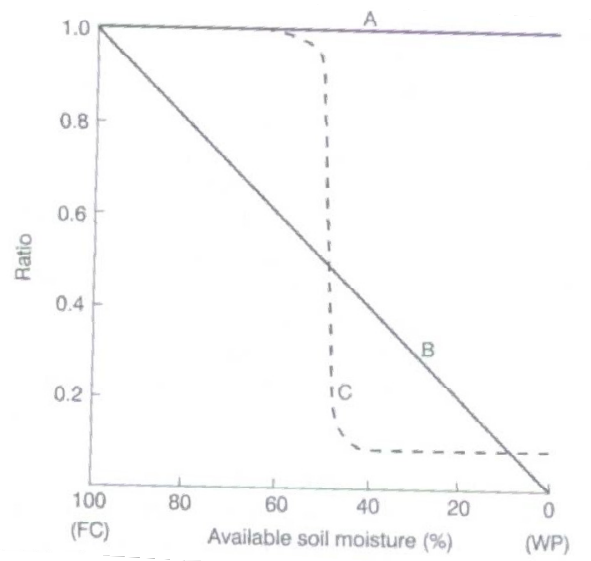

Fig. 4.16 Diversos patrones posibles de cambio de tasa de transpiración real a transpiración sin estrés para vegetación en condiciones de agua disponible desde capacidad de campo (FC) hasta punto de marchitez permanente (WP). Tomado de Ward y Robinson (2000). 
En la Fig. 4.16 (líneas $A$ y B) se tienen los dos patrones extremos que relacionan la tasa de transpiración real / transpiración potencial con la disponibilidad de humedad del suelo. En un extremo, la línea A propone que la transpiración continúa a una tasa máxima hasta que el agua disponible del suelo para la planta cae por debajo de un nivel crítico (el punto de marchitez permanente) donde no hay más toma de agua por parte de la planta. En el otro extremo, la línea $B$, expresa que la evaporación decrece a través del rango de secado de humedad del suelo, mucho antes del estado de marchitez, pues la conductividad hidráulica del suelo decrecerá con decrecimientos del contenido de humedad del suelo (Ward y Robinson, 2000).

Complementando los patrones propuestos anteriormente, Wild (1992) señala que el concepto clásico de disponibilidad de agua conduce a diversas hipótesis en cuanto a los efectos del agotamiento del agua sobre el crecimiento de las plantas (Fig 4.17). Recuerda que el sistema suelo-planta-atmósfera forma la base de las más recientes explicaciones de la disponibilidad del agua del suelo y plantea las dos hipótesis clásicas extremas en relación con la disponibilidad del agua del suelo para las plantas son: línea "a", igual disponibilidad desde capacidad de campo a marchitez -coincide con línea A de Fig 4.16-; línea "c", la disponibilidad decrece gradualmente al reducirse el contenido de humedad del suelo -coincide con línea B de Fig. 4.16-(Wild, 1992).

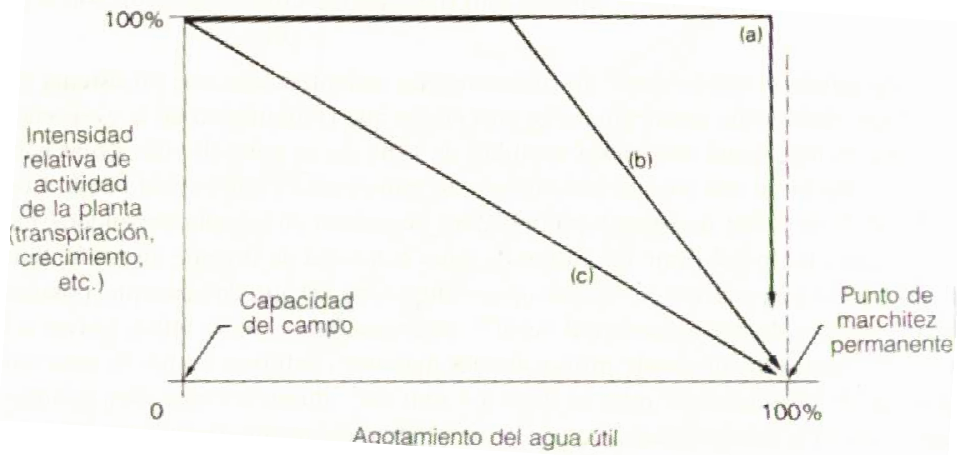

Fig. 4.17. Tres hipótesis clásicas en relación con la disponibilidad del agua del suelo para las plantas. Tomado de Wild (1992).

Entre esos extremos se han propuesto distintos patrones o hipótesis, y una de las más clásicas (línea "b" Fig 4.17) supone que hay una máxima intensidad de la actividad de la planta a una igual disponibilidad de agua desde la capacidad de campo hasta un punto de inflexión, en el que se alcanza un contenido de humedad crítica por debajo de la cual la disponibilidad disminuye. Una pista de ese punto de inflexión de la curva hipotética intermedia lo puede dar la figura de variación típica de la función de extracción de humedad $f(\theta)$ (Fig. 4.15) presentada anteriormente de acuerdo con (Shuttleworth, 1993).

En otros términos también se tiene un patrón intermedio clásico (línea C Fig 4.16), llamado la "constante radicular" propuesta por Penman en 1949, que puede describirse como el déficit máximo de humedad del suelo por debajo de la capacidad de campo que se puede construir sin controlar la transpiración (Ward y Robinson, 2000), o como un concepto que sirve para definir la cantidad de humedad del suelo ( $\mathrm{mm}$ de profundidad) que puede extraerse del suelo sin dificultad por una vegetación dada (Shaw, 1994).

La cantidad de agua del suelo disponible para las plantas depende de su profundidad radicular, que varía con el crecimiento de la vegetación, de especial interés en cultivos anuales (Shuttleworth, 1993). Por ello, de acuerdo con Shaw (1994), se proponen algunos valores típicos para el modelo de "constante radicular" (también conocido como el modelo de Grindley) que varían según los tipos de vegetación. Así, se tienen las constantes siguientes: pastos o herbáceas permanentes $75 \mathrm{~mm}$; cultivos tuberculosos, como las patatas, $100 \mathrm{~mm}$; cereales 140 $\mathrm{mm}$; bosque $200 \mathrm{~mm}$. Se asume que $E T_{r}=E T P$ para un particular tipo de vegetación hasta que el déficit de humedad del suelo (DHS) alcanza la constante radicular apropiada más un aproximado de $25 \mathrm{~mm}$, que se suma para permitir la extracción desde el suelo inmediatamente por debajo de la zona radicular. Entonces $E T_{r}$ es menor que ETP mientras la humedad se extrae con mayor dificultad. 
Mientras el DHS se hace mayor, la vegetación se marchita y la $E T_{r}$ se hace muy pequeña o insignificante. Antes del comienzo de la marchitez, la vegetación se recobrará si la humedad del suelo se vuelve a llenar, pero hay un DHS máximo para cada tipo de planta en el punto de marchitez permanente a partir del que la vegetación no se puede recuperar y muere (Shaw, 1994). La Figura 4.18 muestra dramáticamente la secuencia media del contenido de humedad del suelo relacionadas con la lluvia y la evaporación potencial en un ciclo estacional anual del Reino Unido. Es muy didáctica conceptualmente de lo que podría suceder en otras latitudes con una lógica de presencia o ausencia de lluvias. Se da un estado de humedad del suelo y la evaporación real $E T_{r}$, en términos de ETP, para cada uno de los tres tipos de vegetación.

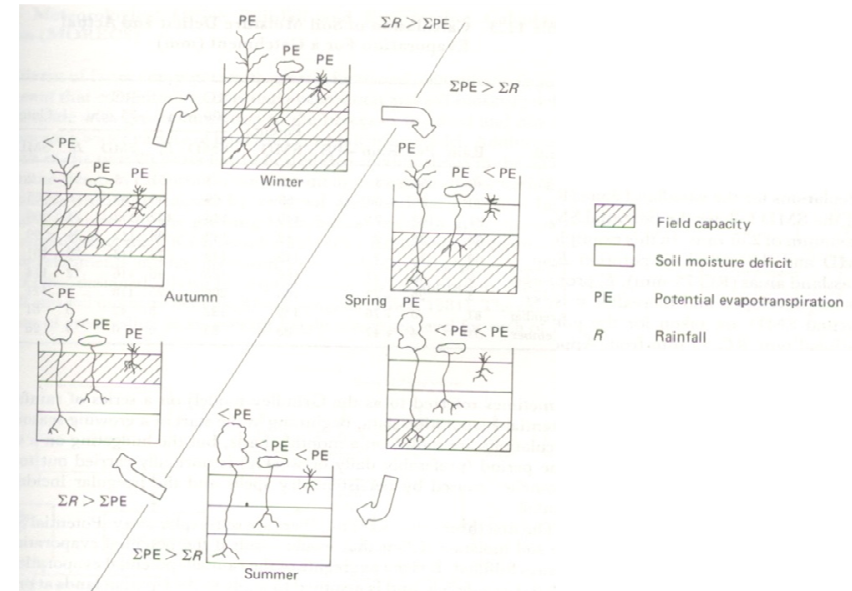

Fig. 4.18 Ciclo anual idealizado de la humedad del suelo para tres tipos de vegetación. Tomado de Shaw (1994).

Se puede hacer un balance de humedad del suelo en una base mensual para varios tipos de vegetación clasificados de acuerdo a sus constantes radiculares (CR). Se han considerado para herbáceas permanentes DHS máximo de $125 \mathrm{~mm}$, y para bosques de raíz profunda DHS máximo de $250 \mathrm{~mm}$ (Grindley, 1970).

Para evaluar el déficit de humedad del suelo y evaporación real sobre el área de una cuenca, deben conocerse las proporciones de las diferentes coberturas de vegetación. En el Reino Unido por muchos años se tomó el modelo de Penman (1950) de la siguiente manera: $20 \%$ del área de la cuenca, la tierra de ribera que bordea todos los cauces, se consideró tener un nivel freático suficientemente cercano a la zona radicular como para que la vegetación siempre transpirase a la tasa potencial; $50 \%$ del área se asumió cubierta con herbáceas permanentes y por ello se tenía una constante radicular de $75 \mathrm{~mm}$; el $30 \%$ restante del área era bosque, con un CR de $200 \mathrm{~mm}$. Este modelo simple resultó de gran ayuda para el riego y el monitoreo de crecidas en los ríos. Los cálculos se hicieron en la base mensual, pero el balance ("budgeting") en un período temporal más corto (preferiblemente diario o semanal) para evitar anomalías causadas por los períodos de sequía persistente y la incidencia irregular de la lluvia (Shaw, 1994).

En una versión del modelo hidrológico distribuido Tetis (Francés y Vélez, 2004), la evapotranspiración del agua almacenada del suelo depende de la disponibilidad de agua, de la disponibilidad de energía y de la eficiencia de la cobertura en cada celda. Se considera que la evapotranspiración real $E_{0}$ depende de la cantidad de agua disponible, de manera que cuando hay déficit de agua en el suelo la evapotranspiración es menor que la evapotranspiración potencial (Vélez, 2001). Así:

$$
E_{0}=E v p\left(\frac{\theta}{\theta_{c c}}\right)^{b_{0}}
$$

Donde $E_{0}$ es la evaporación real, Evp es la evapotranspiración potencial, $\theta$ es la humedad del suelo y $\theta_{c c}$ la humedad del suelo a la capacidad de campo. 
Entonces, la relación entre la humedad del suelo y la capacidad de campo equivale a la relación entre el agua que se encuentra en el almacenamiento estático y la capacidad máxima para ese almacenamiento (Vélez, 2001), de la siguiente forma

$E_{0}=E v p\left(\frac{S_{0}}{S m_{0}}\right)^{b_{0}}$

Actualmente una de las propuestas más avanzadas en materia de actividad de la planta frente a la dinámica de la humedad del suelo, con énfasis en el estrés hídrico, se presenta a través de un modelo complejo que considera tanto estrés estático como dinámico -dependiente de la escala temporal- (Laio et al, 2001; Porporato et al, 2001; Rodríguez-Iturbe y Porporato, 2004). El vínculo entre el estrés hídrico de la planta y las dinámicas de humedad del suelo es un problema complicado, debido tanto a la naturaleza estocástica de las dinámicas como a la complejidad de las respuestas de las plantas al estrés hídrico (Porporato et al, 2001).

Cuando la humedad es alta, la tasa de evapotranspiración depende mayormente del tipo de planta y las condiciones climáticas. Se asume una tasa máxima de evapotranspiración $E_{\max }$ cuando las condiciones de humedad del suelo son suficientes para mantener el curso normal de la fisiología de la planta (Rodríguez-Iturbe y Porporato, 2004). Con base en una amplia revisión de literatura sobre fisiología vegetal y estrés hídrico, se plantea asumir el inicio del estrés hídrico para la vegetación en el nivel de humedad del suelo correspondiente al cierre incipiente de los estomas $\left(\mathrm{S}^{*}\right)$ y que llega a una intensidad máxima en el punto de marchitez $\left(S_{w}\right)$ (Porporato et al, 2001). Así, se asumirán pérdidas diarias por evapotranspiración a una tasa constante $E_{\max }$ para $S^{*}<s<1$, y entonces un decrecimiento lineal de $s$, desde $E_{\max }$ a un valor $E_{w}$ a $S_{w}$. Debajo de $S_{w}$ solo está presente la evaporación del suelo y se asume que la tasa de périda decrece linealmente de $E_{w}$ a cero en $S_{h}$ (Fig. 4.19).

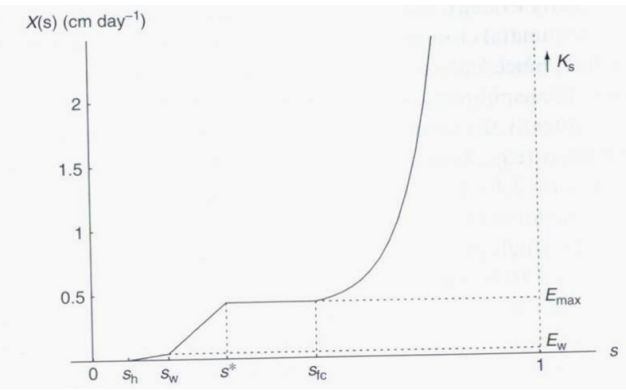

Fig. 4.19 Pérdidas de agua del suelo (evapotranspiración y percolación), $X(s)$, como función de la humedad relativa del suelo para un clima, suelo y características de vegetación típicos en ecosistemas semiáridos. Tomado de (Rodríguez-Iturbe y Porporato, 2004).

Aunque se pueden hacer estimaciones de $E_{\max }$ utilizando algunas de las expresiones basadas físicamente, como la ecuación de Penman-Monteith; sin embargo en el modelo propuesto por Rodríguez-Iturbe y Porporato (2004) se prefieren utilizar valores medidos y el uso de curvas de retención de humedad.

Los niveles de agua $S^{*}$ y Sw son dos umbrales muy importantes usados para describir de forma práctica el comportamiento de la transpiración como una función de la humedad del suelo en una escala temporal diaria. Sin embargo, no tienen un significado físico específico y esto no debe olvidarse aunque a menudo se les denomine como "punto de cierre estomático incipiente" y "punto de marchitez" respectivamente (Rodríguez-Iturbe y Porporato, 2004).

Para Porporato et al (2001) resultan importantes tanto los indicadores del estrés hídrico como las condiciones de la vegetación y destacan la relevancia del parámetro "profundidad de raíces" en el análisis de la respuesta de la vegetación ante distintas condiciones de disponibilidad de agua; propone investigar la unión de los procesos hidrológicos con las condiciones de las plantas a fin de encontrar condiciones óptimas ambientales para diferentes tipos funcionales de vegetación. 


\section{CONSIDERACIONES PARA MODELAR PROCESOS HIDROLÓGICOS Y DE VEGETACIÓN EN LA ZONA DE RIBERA}

La modelación propuesta por distintas disciplinas ha abordado múltiples causas y consecuencias (complementarias muchas veces) de dicha interacción, reflejando la complejidad del sistema en la ribera. Revisar esas aproximaciones en el contexto de ciencias básicas como la hidrología y la ecología vegetal, es la forma de encontrar y aportar respuestas útiles para su conservación, restauración y manejo. De acuerdo con Bren (1993) no hay respuestas sencillas para la complejidad de la ribera, y señala que la modelación puede tener cierta aplicabilidad, pero la verificación adecuada de los modelos es casi imposible; pese a que la modelación puede ser una herramienta poderosa para evaluar distintas hipótesis de la gestión y recuperación de la zona de ribera, dicha modelación no es substituto de la experimentación (Walters, 1997; Walters y Korman, 1999). El capítulo 7 del libro "Riparian Lanscapes" (Malanson, 1993) propone interesantes principios de la modelación de la ribera y discute las posibilidades de combinar modelos basados en hidrología, geomorfología y ecología en modelos espacialmente distribuidos diseñados para hidrología, aunque hay que considerar los problemas de calibración y validación asociados a modelos tan complejos.

De acuerdo con Walters (1997) los esfuerzos de modelación han encontrado muchas dificultades para representar los efectos de la escala transversal (de cambios hidrológicos rápidos a respuestas ecológicas de largo plazo), falta de datos en procesos clave que son difíciles de estudiar, y confusión de los factores de efecto en datos de validación. Walters y Korman (1999) destacan las percepciones disciplinarias tan distintas (hidrólogos, químicos, geomorfólogos, ecólogos) respecto a cómo estudiar las dinámicas a múltiples escalas espacio-temporales.

Probablemente la mayoría de intentos de modelación de la zona de ribera trabaja con el estudio de los diversos compartimientos ecológicos per se, en lugar de tomar en cuenta los efectos interactivos de las estructuras y procesos entre dichos compartimientos y en diferentes lugares dentro de la red de drenaje (Tabacchi et al., 1998). De acuerdo con Brookes et al (2000) existen pocos modelos de cauce que incorporen la interacción con la vegetación de ribera y los procesos hidrológicos e hidráulicos correspondientes. Sin embargo, algunos modelos empíricos que se han desarrollado para usar datos hidrológicos y de vegetación, tienen usos potenciales para el manejo de ecosistemas amenazados como la ribera (Stromberg et al, 1993). El empleo de datos históricos para la evaluación ese tipo de modelos es fundamental (Walters, 1997); desde el punto de vista de la Ecología Vegetal es recomendable reconocer patrones en el campo y desarrollar modelos simples que los describan (Crawley,1997).

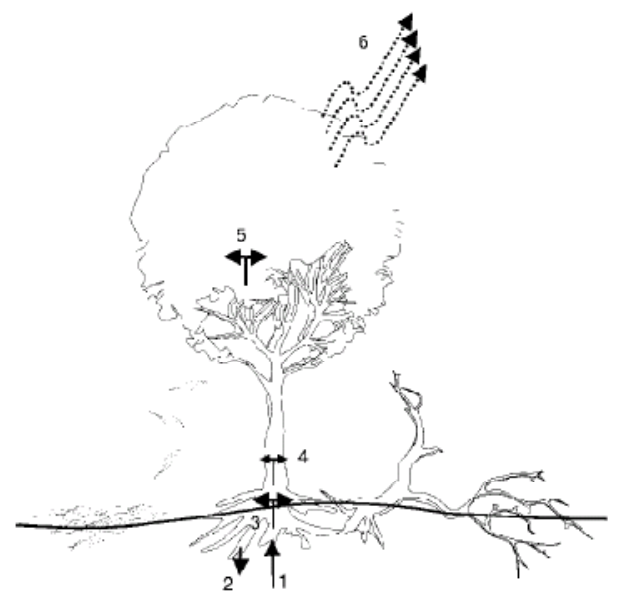

De acuerdo con Tabacchi et al (2000), el ciclo del agua en las zonas de ribera (Fig. 5.1) depende de tres relaciones importantes: el consumo y/o absorción de agua por las plantas, el almacenamiento y el retorno del agua a la atmósfera por evaporación. En el presente documento, se procurará seguir este criterio para presentar parte de la revisión del avance del conocimiento en materia de procesos hidrológicos y de vegetación de ribera.

Fig. 5.1 Principales impactos fisiológicos de la vegetación de ribera en el ciclo hidrológico: 1, ascenso hidráulico; 2, redistribución hidráulica; 3 , almacenamiento de agua en raíces; 4 , almacenamiento en tallo; 5 , almacenamientos en hojas y ramas; 6 , evapotranspiración. Tomado de Tabacchi et al (2000). 
El verdadero reto será el ver si es posible moverse más allá de aquellos casos en que la modelación de la ribera dice solamente lo que ya se sabe por experiencia, para hacer útiles predicciones sobre situaciones donde la experiencia y los datos son bastante limitados. El proceso de desarrollo de un modelo de ribera, en el largo plazo, es de tipo iterativo, incluyendo: i) la formulación de un modelo inicial y la identificación de incertidumbres; ii) implementar el manejo experimental y el monitoreo para resolver esas incertidumbres; iii) revisar el modelo basado en esos datos y continuar con el ciclo (Walters y Korman, 1999).

\subsection{RELACIÓN ENTRE EL NIVEL DEL RÍO Y EL NIVEL FREÁTICO EN LA RIBERA}

Los problemas de las interacciones entre río y acuífero son un componente crítico de la hidrología de la zona de ribera (Hantush, 2005). Los niveles del río y la topografía son las causas principales del intercambio entre agua subterránea y agua del río a través de la ribera (Lambs, 2004). Los niveles altos del río favorecen los patrones de infiltración de agua al nivel freático, mientras que si son más bajos que el nivel freático se da un drenaje de la ribera al río. En diferentes épocas del año, el movimiento del agua proveniente de la ladera o incluso de acuíferos hacia la ribera puede ser más significativo que aquella proveniente del río (Hughes et al, 2003).

De acuerdo con Naiman et al (2005), la microtopografía y la conductividad hidráulica de los depósitos aluviales rigen los intercambios entre el agua superficial y subterránea de los componentes de los sistemas de ribera.

El intercambio del agua subterránea con el río ocurre por descarga, recarga o interflujo. El intercambio de agua superficial y agua subterránea también ocurre a escala del lecho del cauce. La zona hiporreica puede definirse conceptualmente como las áreas con saturación intersticial debajo del lecho del río y en los márgenes del río (Lambs, 2004). La interacción del agua subterránea con el cauce de las zonas de ribera es controlado mayormente por las condiciones hidrogeológicas, tal y como la topografía, los suelos, y la composición, estratigrafía y características hidráulicas de los depósitos geológicos subyacentes (McGlynn et al, 1999).

Mac Nish et al (2000) desarrollan una estimación de la evapotranspiración (más detalle en apartados siguientes) a partir de las interacciones entre vegetación-río-acuífero. Usando el balance hídrico como base del análisis de dichas interacciones proponen el siguiente esquema simplificado (Fig 5.2):

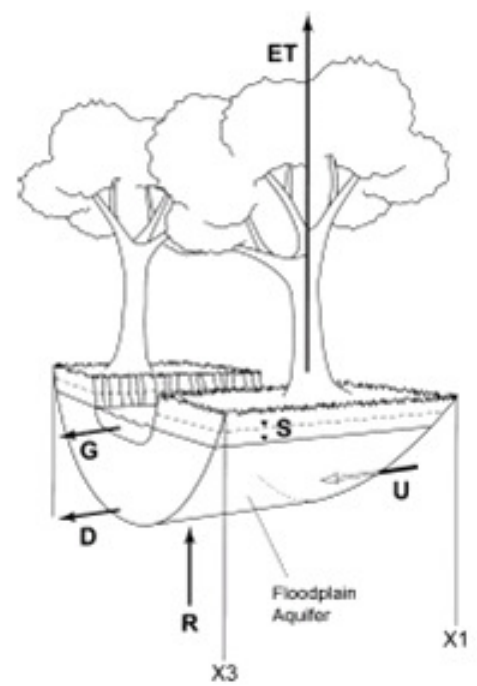

Fig. 5.2 Esquema simplificado del balance hídrico para el sistema del acuífero de la llanura de inundación. ET: evapotranspiración de árboles de ribera; R: flujo del acuífero regional; U: flujo de entrada de aguas arriba en el acuífero de la llanura de inundación en X1; D: flujo de salida del acuífero en X3; G: flujo del río ganado entre X1 y X3; S: agua liberada del almacenamiento de niveles de agua durante los descensos del nivel freático dentro del acuífero de la llanura de inundación. Tomado de Mac Nish et al (2000).

A pesar de que el modelo de Mac Nish et al (2000) está enfocado en los flujos y balance hídrico señalados anteriormente (Fig 5.2), puede resaltarse de la figura, la hipótesis de que el nivel del cauce corresponde con el del nivel freático en esa zona de ribera considerada. 
De acuerdo con Hughes et al (2003), en zonas de ribera o llanuras de inundación cuyos sustratos consisten en sedimentos aluviales gruesos, como las arenas o las gravas, el agua se infiltra y drena fácilmente y el nivel freático de la ribera es a menudo muy cercanamente asociado con el estado o nivel del río (elevación de la superficie de agua en el río). Proponen una referencia para la estimación generalizada de la interacción entre nivel del río y el freático en la ribera (Tabla 5.1).

Tabla 5.1. Referencia para la estimación generalizada del tiempo que transcurre para un cambio en el nivel freático en función de un cambio en el nivel del río. Tomado de Hughes et al (2003).

\begin{tabular}{|l|l|l|}
\hline Tipo de sedimento & $\begin{array}{l}\text { Tiempo transcurrido para ajustes } \\
\text { entre el estado del río y el nivel } \\
\text { freático a 10 metros de distancia } \\
\text { desde el río }\end{array}$ & $\begin{array}{l}\text { Tiempo transcurrido para ajustes } \\
\text { entre el estado del río y el nivel } \\
\text { freático a 100 metros de distancia } \\
\text { desde el río }\end{array}$ \\
\hline Grava & Menos de 5 minutos & Menos de 5 horas \\
\hline Arena & $\begin{array}{l}\text { Entre } 5 \text { minutos y } 5 \text { días (hay una } \\
\text { variación considerable en las tasas de } \\
\text { transferencia de agua en función de los } \\
\text { distintos tipos de arena) }\end{array}$ & Varios días \\
\hline
\end{tabular}

Las crecidas de corta duración tienen un efecto muy localizado en el nivel freático en los márgenes del cauce, pero que crecidas largas tienen un impacto más significativo en el nivel freático a lo largo de la llanura aluvial o zona de ribera (Hughes et al, 2003).

En la sección transversal del modelo conceptual de Doble et al (2004) se asume que el nivel del río corresponde con el nivel freático de la ribera hasta el punto de quiebre de la pendiente entre la llanura de inundación y la ladera, asumiendo que en ese punto el nivel freático se cruza con la superficie del suelo y forma una filtración (del término inglés "seepage"). Existen modelos de flujo subterráneo que asumen un nivel freático constante dentro de la celda (Baird et al, 2004).

De acuerdo con Lite y Stromberg (2005) en la ausencia de un modelo extensivo de aguas subterráneas, un nivel freático lineal provee de una aproximación razonable de la profundidad del agua subterránea en la llanura de inundación. La profundidad al agua subterránea a lo largo de la llanura de inundación se pude calcular a partir de la diferencia entre la superficie del suelo y las elevaciones del nivel freático. Sin embargo, en un sentido más estricto el régimen del nivel freático de la ribera está controlado por el nivel del río, el aporte de agua subterránea, la precipitación y la evapotranspiración (Andersen, 2003).

Los niveles freáticos en llanuras aluviales con capas de arcillas pueden ser más complejos, algunas veces con niveles freáticos colgados localizados. Además, el agua tarda un largo período de tiempo para moverse a través de los sedimentos arcillosos. Donde los márgenes del río se sellan debido a la deposición de sedimentos finos como las arcillas, la asociación hidráulica entre el río y el nivel freático adyacente puede cambiar radicalmente (Hughes et al, 2003). Mediante modelación de la interacción de aguas subterráneas y superficiales en la zona de ribera, se demostró que la elevación de la zona de ribera o llanura de inundación por encima del nivel del río y el ancho de dicha zona, tienen los efectos más significativos en la evapotranspiración del agua subterránea. A escala de la llanura de inundación se pudo simular con buena exactitud la ET utilizando un modelo recortado ("slice model") del Modflow@ (Doble et al, 2004).

Uno de los avances recientes en la solución matemática compleja de las interacciones ríoacuífero es la de Hantush (2005), quien propone un modelo con funciones de respuesta lineal para eventos de tormenta y períodos de flujo base. Las soluciones fueron obtenidas en términos de convoluciones de integral de las funciones lineales relacionadas con la descarga del cauce y la descarga del río-acuífero, considerando diversas condiciones del sistema en cuanto a hidrología de la ladera, tamaño de la zona de ribera y medidas de gestión del recurso hídrico; a pesar de que sus soluciones no son generalizables a cualquier condición, sí que son robustas para resolver problemas relevantes de la hidrología de la zona de ribera y la gestión conjunta de las interacción hídricas superficiales y subterráneas. 


\subsection{GRADIENTE DE HUMEDAD TRANSVERSAL EN LA ZONA DE RIBERA}

De acuerdo con Malanson (1993) el gradiente microclimático en la ribera está relacionado con la penetración de luz y la humedad del suelo, y principalmente por el efecto de la topografía; proponía que ese gradiente abiótico ejerce control sobre la distribución y abundancia de las especies vegetales y diversidad de las comunidades, mediante su influencia en la fisiología vegetal y las características morfológicas. Las inundaciones interactúan con la topografía de la llanura de inundación para crear un gradiente de humedad que influye en la composición de la vegetación y contribuyen directamente a la diversidad vegetal y de fauna asociada (Brinson \& Verhoeven, 1999).

No sólo las perturbaciones por inundación sino también la disponibilidad de agua varían a lo largo de gradientes transversales (lateral) y longitudinales (a lo largo del río), y con dependencia del tiempo. De forma transversal a medida que aumenta la distancia desde y por encima del cauce activo, decrecen la intensidad y la frecuencia de la perturbación por inundación; a lo largo de ese mismo gradiente, el estrés hídrico se puede incrementar debido a que aumenta la profundidad del agua subterránea y decrece el reabastecimiento de humedad superficial del suelo a partir de los flujos superficiales del río (Lite et al, 2005).

En áreas secas, la humedad disponible proveniente del río crea un gran contraste con las tierras aledañas, el gradiente de humedad hacia fuera del río es muy claro, y el límite entre las dos zonas también lo es (Malanson, 1993).

Diversos esfuerzos se han hecho para la cuantificación y demostración de ese gradiente (Horton et al, 2001; Goodwin y Tarboton, 2001; Lamontagne, 2005; Lite et al, 2005; Stave et al, 2005; Stromberg et al, 1993, 1996), que perfectamente puede generalizarse en el eje transversal perpendicular al cauce (Malanson, 1993). Goodwin y Tarboton (2001) proponen un modelo de cobertura vegetal basado en el equilibrio de humedad disponible del suelo que responde a esta visión. Stromberg et al (1993) señalan que el área foliar total o la masa foliar específica pueden ser indicadores de alta sensibilidad del estrés hídrico a lo largo de un hábitat basado en gradientes de humedad.

Es crítico que no se confunda el concepto del gradiente ambiental con el del transecto sobre el campo. Aunque ambos pueden coincidir en unos pocos lugares obvios, la compleja topografía e historia hidrológica local, hace que en las riberas y llanuras de inundación, la distancia al cauce no provea un gradiente para la mayoría de condiciones hidrológicas. El patrón transversal real en las áreas de ribera es mucho más complicado que un gradiente ambiental individual que espacialmente coincida con un transecto del río a la ladera (Malanson, 1993).

\subsection{CLASIFICACIÓN DE LA ZONA DE RIBERA Y SU VEGETACIÓN}

La clasificación de los tramos de ríos tiene una larga historia, pero no hay un sistema de clasificación de las riberas que sea aceptado universalmente. En general la tipología de la ribera ha surgido a partir de dos disciplinas: una geomorfológica para clasificar la dinámica y la estructura de los tramos de ríos, y otra biológica para inventariar o clasificar comunidades vegetales en zonas de ribera con distinta geomorfología o dinámica rivereña (Naiman et al, 2005).

Existen pocos protocolos para el muestreo sistemático de la vegetación de ribera, cuyos objetivos sean la precisión, la exactitud y la factibilidad de realización en campo. La mayoría de clasificaciones de vegetación de ribera utilizan áreas de muestreo entre los 4 y los $400 \mathrm{~m}^{2}$ (ColesRitchie et al., 2004). Veneklaas et al (2005) proponen un muestreo de vegetación, utilizando áreas de 20X20 metros, pues consideran que las dimensiones más grandes son inapropiadas debido a los elevados gradientes ecológicos que se dan en bosques de tan corta anchura. Pabst y Spies (1999) proponen un método de transectos para el monitoreo de regeneración y de cobertura forestal, con parcelas de $16 \mathrm{~m}^{2}$ y de $256 \mathrm{~m}^{2}$, respectivamente; mientras Samuelson y Rood (2004), con los mismos fines, proponen parcelas de $2 \mathrm{~m}^{2}$ y $100 \mathrm{~m}^{2}$ respectivamente. 
Stromberg et al (1996) usando transectos usan puntos de muestreo de 5X20 metros con el eje largo paralelo al cauce.

La Figura 5. 3, es una muestra de la diversidad florística de una zona de ribera; los distintos arreglos de vegetación y criterios empleados pueden llevar a una variedad de métodos de clasificación, basados en su taxonomía, tipología, funcionalidad, hábito, tal y como se muestra en el presente documento.
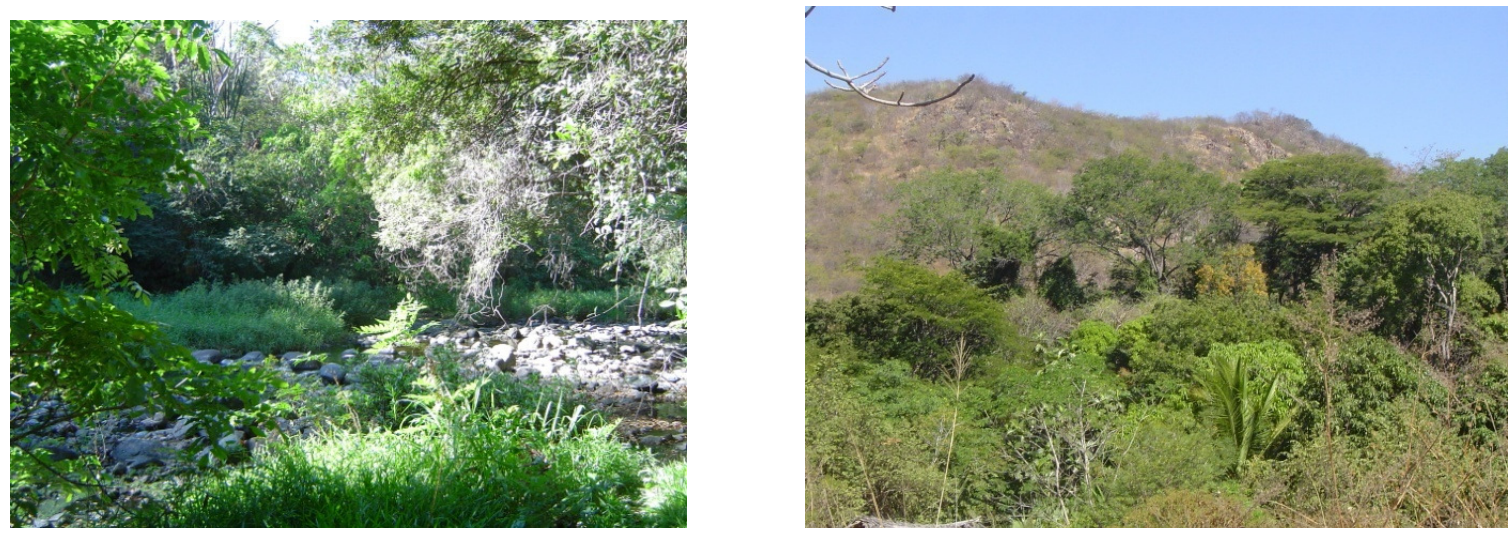

Fig 5.3 Imágenes de diversas especies de la zona de ribera del río Uyús, Valle del Motagua, Guatemala, una zona de alta diversidad florística y arreglo de vegetación con distinto hábito de crecimiento. Fotografías tomadas por Morales, M. (2005).

Existe un método de monitoreo de vegetación ribereña basado en secciones transversales de composición vegetal y medición de la evolución de la línea verde (del término inglés "greenline") aledaña al cauce (Winward, 2000). Coles-Ritchie et al (2004) realizaron un análisis de dicha propuesta y encontraron variabilidades asociadas a la difícil replicación exacta del método debido a la necesaria intervención de múltiples observadores en campo; señalan que dicho método es suficiente preciso para detectar grandes cambios (mayores del $20 \%$ ) con tamaños de muestreo factibles (menos de 13 sitios en dos poblaciones vegetales), pero que un cambio menor (10\%) requiere más muestreo, lo que puede ser impracticable para ciertos estudios; el uso de rangos para las variables de la vegetación, a menudo sirve para hacer decrecer las variaciones entre observadores en campo; sin embargo, si los cambios en la zona de ribera ocurren en un largo plazo (lo más común), los rangos de variables pueden dejar de ser útiles.

Otros sistemas de monitoreo (Dieck y Robinson, 2004) a largo plazo de vegetación de grandes llanuras de inundación, utilizan mapas de uso del suelo y un sistema de clasificación para el mapeo. Aunque sin estar enfocado en la clasificación de la vegetación vale la pena mencionar otros dos estudios: la propuesta conceptual de Rasmussen et al (2000), que presenta elementos interesantes de monitoreo integral del paisaje de ribera, mediante el uso de la herramienta SIG y la morfología de la zona; el estudio de Suárez et al (2002) para clasificar la ribera en función de un índice de calidad del bosque de ribera.

Congalton et al (2002) evaluaron la clasificación de la vegetación con base en fotografía aérea y la comparación de los resultados con mapas generados a partir de clasificación de imágenes Landsat Thematic Mapper (TM). Su estudio demostró que las clasificaciones forestales actuales basadas en imágenes Landsat TM no desempeñan una buena labor de identificación de las características estructurales de la vegetación. El trabajo de campo es inseparable de la fotointerpretación de la zona de ribera.

De acuerdo con Coles-Ritchie et al (2004) es importante buscar una clasificación por "tipos de comunidad" utilizando especies "ecológicamente equivalentes", es decir, especies dominantes que crezcan en hábitats similares y desempeñen funciones similares para poder hacer comparaciones válidas. Señalan que las diferencias taxonómicas, no siempre son importantes para tratar de entender la función del ecosistema de ribera. Además, mencionan el gran debate 
existente respecto al uso de "comunidades vegetales tipo" (del término inglés "community types") puesto que podrían no considerarse entidades reales, o determinarse consistentemente.

Enfocados en los conceptos de comunidad vegetal de ribera y especies vegetales, estudios como los de Capon (2003) y Rodríguez-González et al (2004) proponen demostrar, mediante análisis estadístico, la influencia que ejercen los pulsos de inundación para la estructura de la comunidad vegetal, 0 bien el control que ejerce el régimen hidrológico en los patrones florísticos y estructurales de la comunidad vegetal, respectivamente. En dicho contexto y referido a la vegetación de ribera en paisajes agrícolas del Mediterráneo están los de Corbacho et al (2003) y Ferreira et al (2005).

Otros estudios con perspectiva del análisis estadístico (mayormente análisis de correspondencias canónicas) de la relación entre la dinámica florística de la vegetación de ribera y factores abióticos o que tienen visión de comunidad vegetal filogenética, son los de Aguiar et al (2000), Baker y Walford (1995), Bernez et al (2004), Chauhan y Gopal (2005), Drezner et al (2001), Ferreira y Moreira (1999), Karrenberger et al (2002), Sánchez Rodríguez (2001), Stave et al (2005), Tabacchi y Planty-Tabacchi (2003), Veneklaas et al (2005).

\subsubsection{Los tipos funcionales de vegetación (PFT) de la ribera}

Los términos "tipo funcional de vegetación" (PFT del inglés "Plant functional type") y "grupo funcional de vegetación (PFG)" son sinónimos y se refieren a una clasificación por grupos no filogenéticos de organismos que responden de forma similar a factores ambientales y tienen efectos similares en los procesos dominantes del ecosistema (Baird y Maddock III, 2005; Williams et al, 1998). La descripción PFT de especies vegetales dominantes en zonas de ribera, debe reconocer las respuestas de dichas especies al ambiente y tomar en cuenta el tipo de cauce (efímero, perenne, etc) o condición de hábitat (Williams et al, 1998).

De acuerdo con Webb y Leake (2006) hay dos tipos de vegetación en la zona de ribera: las obligadas, que dependen de un abastecimiento de agua durante todo el año, y las facultativas que pueden vivir tanto en ambientes ribereños como en laderas más áridas. Ambos tipos de vegetación pueden ser freatofitas, por lo que la línea entre obligadas y facultativas puede ser borrosa. Señalan como especies nativas obligadas de ribera, las siguientes: Populus fremontii, Salix gooddingii, Fraxinus velutina, Platanus wrightii, Celtis reticulata.

Respecto a la vegetación no característica de la ribera, Tabacchi et al. (1998) presentan tres tipos: (i) las plantas exóticas, que son especies ribereñas o no ribereñas que se originan en otros países y que invaden los corredores de ribera en función de las actividades humanas; (ii) las plantas "ruderales" (especies vegetales ligadas a las actividades humanas), que se caracterizan por su adaptación al estrés bajo y alteraciones ambientales altas y que pueden ser específicas de los corredores de ribera; (iii) las "externas" que son las especies que no son ni exóticas ni "ruderales" pero que no pueden incluirse dentro de la flora ribereña usual y que pueden estar presentes en la zona de transición con la ladera y que cuando las condiciones son favorables ocasionalmente pueden colonizar la ribera.

La clasificación PFT de la ribera, con énfasis en su hidrología y sus recursos bióticos, puede basarse en rasgos útiles como las fuentes de agua de las plantas, las tasas y procesos de transpiración del dosel y el intercambio de energía, las respuestas de los estomas a cambios climáticos, la arquitectura hidráulica de la planta y la tolerancia a la sequía (Williams et al, 1998). La relativa abundancia de agua en los bosques de ribera provoca que las especies vegetales que no toleran la sequía se perpetúen en la zona (Brinson \& Verhoeven, 1999).

El concepto de la "fuente de agua utilizada por las plantas" (de lo que se dará detalle más adelante) introdujo en el pensamiento de la clasificación por tipos de vegetación, el criterio de separar aquellas especies que dependen en gran medida del agua de la zona saturada para su transpiración. Así se introdujeron dos tipos: las freatofitas obligadas y las freatofitas facultativas (Fig. 5. 5). 
Las freatofitas obligadas son las plantas que envían sus raíces hacia o debajo de la zona capilar (capillary fringe) para usar exclusivamente agua subterránea (Horton et al, 2001; Lite y Stromberg, 2005; Snyder y Williams, 2000). Muchos modelos hidrológicos ampliamente usados (Maddock III y Baird, 2003; McDonald and Harbaugh, 1988; Scott et al, 2000) asumen que los árboles de ribera derivan su agua principalmente de la zona saturada de la zona saturada del suelo; sin embargo de acuerdo con Snyder y Williams (2000) eso es claramente es una sobre simplificación (Snyder y Williams, 2000). Las freatofitas facultativas son plantas que pueden sobrevivir en ambientes de tierras altas donde el agua subterránea no está disponible; su uso de agua subterránea es de forma oportunista (Horton et al, 2001; Snyder y Williams, 2000).

En el estudio de Brookes et al (2000) se modela el comportamiento de la vegetación ribereña a nivel de categoría o tipo de vegetación, con datos de especies indicadoras para la parametrización. Se identificaron tres tipos básicos de vegetación con base en el hábito de crecimiento de las plantas, su profundidad radicular y su longevidad y estacionalidad. Los tres tipos de plantas son: herbáceas, arbustivas y freatofitas.

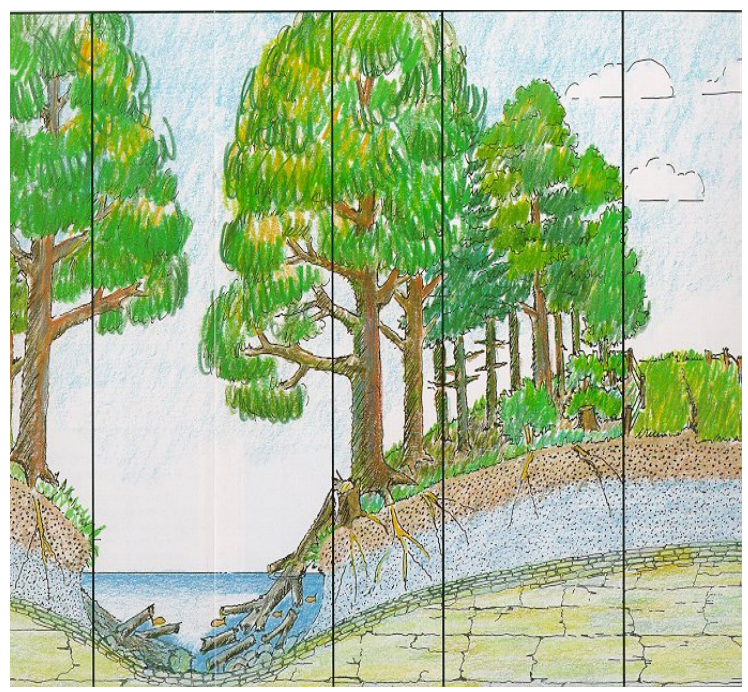

Fig 5.4 Vista parcial de sección transversal de la zona de ribera y el cauce, mostrando los tipos de vegetación utilizados para su clasificación. Tomado de Welsch (1991).

En el modelo REMM (Altier et al, 2002; Lowrance et al, 2000) se utiliza la propuesta de Welsch (1991) para clasificar por tipos de vegetación ribereña, considerando su posición en el dosel (alto o bajo) y su ubicación respecto al cauce. Los tipos de vegetación incluyen: especies herbáceas del dosel bajo (anuales y perennes); especies arbóreas de hoja ancha (caducifolias de otoño o primavera; o con hojas marcescentes); especies coníferas (con hojas de corta, mediana o larga longevidad) (Fig 5. $4)$.

Según Baird y Maddock III (2005), Maddock III y Baird (2003), Stromberg et al (1996) se pueden definir cuatro grupos funcionales de vegetación de ribera, con base en sus tasas de transpiración, profundidades radiculares, y los rangos de tolerancia de escasez o exceso de agua subterránea:

- Obligadas de humedal: plantas que requieren de suelos en condiciones de saturación o agua permanente. La mayor parte de estas especies son herbáceas, generalmente con sistemas radiculares superficiales. Algunas especies que tipifican este grupo son Typha spp, Scirpus spp., Juncus spp.

- Ribereñas de raíz poco profunda: especies normalmente herbáceas que requieren niveles freáticos poco profundos, pues el agua subterránea es la que más utilizan; sin embargo, tienen limitada tolerancia a períodos extensos de saturación del suelo. Entre las especies se encuentran: Rumex crispus, Muhlenbergia rigens, Xanthium sp., Mimulus guttatus.

- Ribereñas de raíz profunda: son especies freatofitas intolerantes a la sequía como Populus spp. y Salix spp. Dependen del nivel freático somero para el establecimiento, crecimiento y transpiración. Puede hacerse una subdivisión dentro del grupo para albergar a aquellas especies que tengan raíces mucho más profundas que el promedio, como Prosopis velutina. En general, las especies del grupo tienen tolerancia estacional limitada para períodos extensos de saturación del suelo. 
- Ribereñas de Transición o facultativas: Son especies que aunque no dependen estrictamente de niveles freáticos someros, tienen requerimientos de agua que generalmente exceden a los de especies de ladera aledañas. Existen generalmente en los márgenes exteriores de sistemas ribereños o sobre cauces efímeros. Algunos ejemplos son Sporobolus wrightii, Sambucus sp., Juglans spp., Celtis sp, Platanus $s p$.

Stromberg et al (1996) proveen un listado a detalle de posibles especies a incluir en estos cuatro grupos.

Las propuestas de Altier et al (2002), Baird y Maddock III (2005), Brookes et al (2000), Horton et al (2001) Lowrance et al (2000), Maddock III y Baird (2003), Snyder y Williams (2000), Stromberg et al (1996), Webb y Leake (2006) y Welsch (1991) sobre los PFT de ribera, muestran que es frecuente el uso del hábito de crecimiento (arbóreo, arbustivo o herbáceo), la profundidad radicular, la fuente de agua utilizada y la posición respecto al cauce, como criterios de clasificación. Un detallado análisis de cada una de las propuestas muestra coincidencias importantes que pueden utilizarse como vínculo y marco contextual para el planteamiento de hipótesis de clasificación de la vegetación ribereña según PFT.

\subsection{LA DISPONIBILIDAD DE AGUA EN LA RIBERA VARÍA EN FUNCIÓN DE LAS CARACTERÍSTICAS DEL SUELO, LAS FUENTES DE AGUA Y LAS PROPIEDADES DEL TIPO DE VEGETACIÓN}

Se ha abordado con detalle el tema del agua en la zona no saturada del suelo (capítulo 3 del presente documento), destacando el concepto de "agua útil o disponible" para las plantas, con base en dos puntos de la curva característica de humedad (el punto de marchitez permanente y la capacidad de campo); se presentaron referencias de estudios que señalan que dicha teoría sigue siendo objeto de discusión. En la revisión de los documentos enfocados en el estudio de la vegetación de ribera y su aprovechamiento del agua, los estudios de Altier et al (2002), Andersen (2003) e Inamdar et al (1999), destacan por reconocer de forma explícita el concepto de disponibilidad del agua dentro del marco de la teoría de la zona no saturada, y tratar el problema con base en curvas de retención de humedad y características de la vegetación.

En ese contexto, la falta de información a escala de ribera se aduce como una de las razones para no abordar la problemática desde esa conceptualización; sin embargo, la teoría se suele tratar de forma implícita, ya que gran cantidad de estudios consideran los contenidos de humedad del suelo como críticos para el desarrollo de la vegetación de ribera, pero parten de un marco conceptual más general.

Por otra parte, también se señaló (y se aportó un gran número de referencias; capítulo 2 del presente documento) que las plantas son sistemas de adquisición de información y no organismos de respuesta pasiva al ambiente (Lambers et al, 1998); esto es destacable para especies ribereñas, y por ello se presentan algunas de sus estrategias de respuesta, aclimatación y adaptación al estrés hídrico. La revisión de consideraciones de modelación de la ribera, mostrará que en el análisis del problema de la disponibilidad de agua en la zona ribereña, se ha considerado fuertemente la respuesta activa de la vegetación, por lo que además de enfocarse en las propiedades del suelo, también se estudian las diversas fuentes de agua, las estrategias de aprovechamiento y los requerimientos de agua de sus diferentes tipos de vegetación o especies vegetales. 


\subsubsection{Fuentes de agua para la vegetación}

Existe gran dificultad en separar conceptualmente los estudios referidos a la evapotranspiración de aquellos enfocados en la absorción de agua (Tabacchi et al, 2000), sobre todo cuando se identifican numerosas fuentes de agua para la vegetación de ribera (Goodrich et al, 2000; Lambs, 2004; Lamontagne et al, 2004; Stromberg, 2001) e incertidumbres asociadas a su predicción y variabilidad temporal (Scott et al, 2000).

Diversos estudios han identificado como fuentes principales de agua para la vegetación ribereña (Fig 5.5) al río, al acuífero de la llanura de inundación, a las lluvias locales, al acuífero regional, a la humedad atmosférica o alguna combinación de las mismas (Goodrich et al, 2000; Lambs, 2004; Lamontagne et al, 2005; Scott et al, 2000; Snyder y Williams, 2000; Stromberg, 2001; Tabacchi et al, 2000; Williams, 1998). En una clasificación más genérica (Snyder y Williams, 2000; Williams et al, 1998) se señalan como fuentes de agua, la zona no saturada del suelo (denominándola como "agua del suelo") y el agua subterránea.

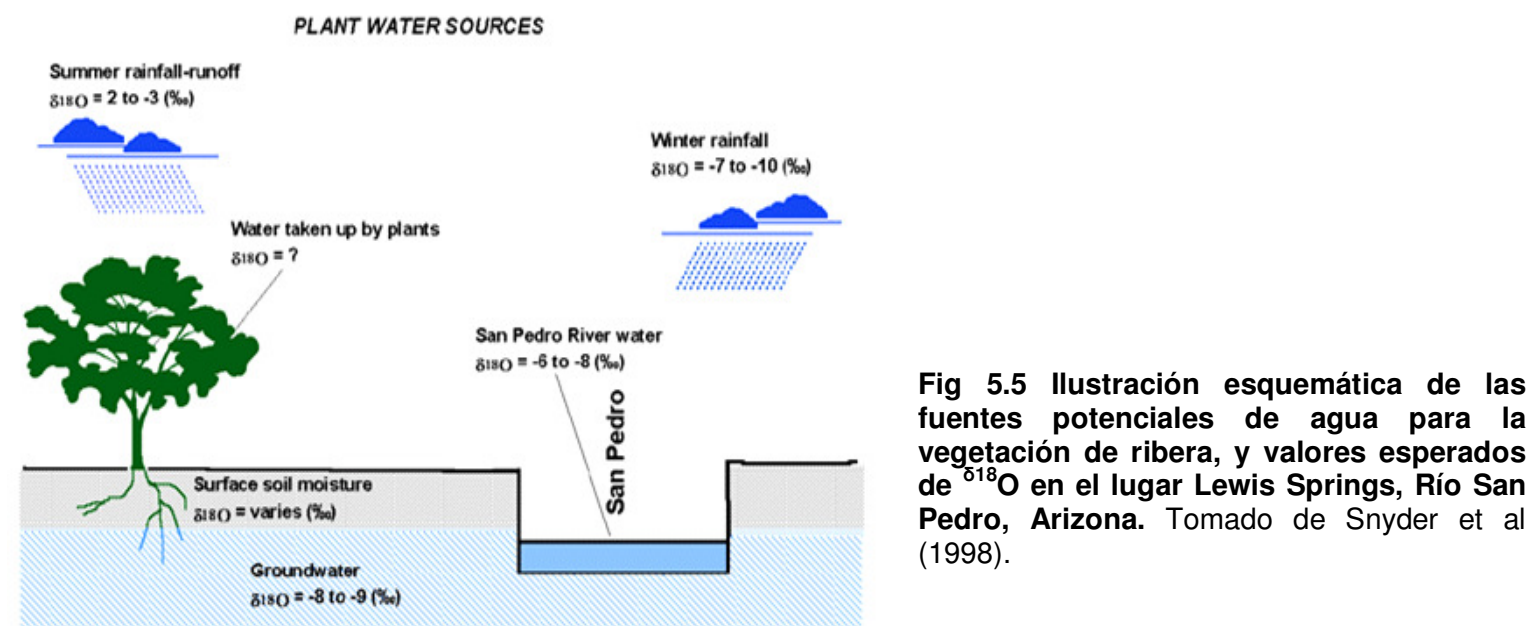

Tabacchi et al (2000) en su revisión de las diferentes fuentes de agua para la vegetación de ribera, presentan evidencias del fuerte vínculo hidrológico entre dichas fuentes, pero también señalan que en ciertas zonas semiáridas, parte del vínculo se rompe, pues agua subterránea y agua de río no se mezclan libremente (los árboles maduros alejados del río dependen más de las aguas subterráneas). También Scott et al (2000) hablan de las incertidumbres respecto a conocer las fuentes de agua y su magnitud. Por tanto, uno de los mayores problemas está en identificar la fuente de agua dominante y establecer si los patrones de absorción son estables a través del tiempo; se presentarán diversos estudios que muestran esa problemática compleja.

En zonas semiáridas, donde durante períodos extensos de tiempo la escorrentía superficial es ausente, el agua subterránea constituye la principal fuente de agua para los ecosistemas de ribera (Goodrich et al, 2000). El estrés hídrico en esas zonas está relacionado con la variabilidad interanual en el abastecimiento de agua (Dahm et al., 2002). Diversos registros de ET durante la época del crecimiento indican que el uso del agua por la vegetación de ribera es muy variable durante el año y también entre diversos años (Scott et al, 2003).

La determinación precisa de umbrales físicos para mantener unas condiciones bióticas deseadas puede ser alfo difícil. Lo primero es establecer qué condiciones bióticas se desean (Lite y Stromberg, 2005) y si son factibles de alcanzar (Hughes, 2003).

Por ello, para entender el funcionamiento del ecosistema de ribera es necesario un mejor conocimiento de las respuestas de las especies nativas y exóticas a las variaciones interanuales en la disponibilidad de agua (Horton et al, 2001). Incluso dentro de una misma especie, las variaciones genéticas tienen efectos sobre el distinto uso del agua (Fischer et al, 2004). 
El estudio de Scott et al (2006) es una importante referencia para entender el patrón de uso de agua por parte de especies de ribera de hábito herbáceo, arbustivo y arbóreo. La dominancia de las especies arbóreas por sobre las arbustivas y herbáceas, tiene que ver con el mejor aprovechamiento del agua de las capas más profundas del suelo, debido a su mayor crecimiento radicular.

Pese a que las tasas totales de ET estacional de la zona de ribera se incrementan con la abundancia de las especies arbóreas, los resultados demuestran que el mejor aprovechamiento de los recursos hídricos subterráneos no crece específicamente como una función de la abundancia de árboles. Por ello, en el cambio de cobertura de especies herbáceas a arbustivas y finalmente a arbóreas, se puede esperar una respuesta no lineal del intercambio gaseoso del ecosistema respecto a la disponibilidad de agua.

Lambs (2004) indican que el análisis de isótopos estables es una herramienta útil para rastrear el movimiento del agua; el agua del río suele estar desprovista de isótopos pesados. El método es útil para identificar la fuente y la profundidad de agua utilizada por la planta, y para determinar los componentes espaciales y temporales de las necesidades de agua (Stromberg, 2001).

En los estudios de Lamontagne et al (2005) y Snyder y Williams (2000), se utilizaron isótopos estables de hidrógeno del agua del xilema, del "agua del suelo" y del agua subterránea para la determinación de la fuente de agua utilizada por vegetación de ribera en una sabana tropical; sin embargo, es particularmente difícil establecer dicha fuente después de un fenómeno de inundación de la ribera, pues el agua que se infiltra crea una condición homogénea de isótopos estables en el primer metro del perfil del suelo (Snyder y Williams, 2000). Más adelante se mencionan otros métodos utilizados para analizar el uso de agua por la vegetación ribereña.

Lamontagne et al (2005) observaron que usos de "agua subterránea" por parte de las plantas ribereñas provienen tanto de la zona saturada como de la zona capilar ("capillary fringe"); el agua subterránea fue la fuente de más del $50 \%$ de la transpiración de la vegetación de ribera. De acuerdo con Williams et al (1998), los distintos usos del agua por las plantas dependen de si los ríos son intermitentes o perennes. Al estudiar ríos intermitentes en una región árida y semiárida y se encontró que las especies arbóreas Populus fremontii, Salix goodingii y especies arbustivas parecían utilizar mayormente agua subterránea, mientras que Prosopis velutina utilizaba una significativa proporción de "agua del suelo".

En el estudio de Snyder y Williams (2000) se ha encontrado que Salix gooddingii no toma agua de las superficie del suelo durante el período lluvioso del verano, sino solamente agua subterránea, aún en cauces efímeros con profundidades del nivel freático mayores de $4 \mathrm{~m}$; la respuesta de Prosopis velutina es de tipo lineal en la proporción del "agua de suelo" usada para transpiración a lo largo de un gradiente de mayor profundidad del agua subterránea; Populus fremontii usa mayormente agua subterránea, pero en cauces efímeros cuando hay lluvias en verano entre el 26 y el 33\% de su transpiración proviene de agua de la zona no saturada, por tanto exhibe potencialmente una respuesta tipo umbral, en contraste con la respuesta lineal de Prosopis.

Por su parte, Scott et al (2004) encontraron incrementos de la transpiración y asimilación de carbono en Prosopis velutina a partir de incrementos del agua de capas superficiales del suelo después de lluvias.

\subsubsection{Anotaciones sobre los requerimientos de agua por la vegetación de ribera}

El uso de agua por las plantas de ribera es un tema particularmente importante durante la época seca cuando los niveles del agua subterránea y del río son bajos (Tabacchi et al., 1998). De acuerdo con Sparks (1995), los requerimientos de agua no se pueden cuantificar para todas las especies del ecosistema de ribera. Sin embargo es importante conocer esa información, así como la relacionada con la distribución del recurso en tiempo y espacio (Stromberg, 2001). Además, es importante estimar tanto la cantidad como la fuente de agua para la evapotranspiración de la 
vegetación ribereña a fin de delinear qué parte del agua transpirada proviene de la zona saturada (Scott et al, 2000).

La restauración moderna de los bosques de ribera requiere establecer tanto los flujos de inundaciones que crean condiciones de sitio para regeneración, como los que recargan el agua subterránea, por tanto, se considera necesaria la restauración de las conexiones hidrológicas entre las partes altas y bajas de los ríos y entre los ríos y sus llanuras de inundación o riberas (Hughes et al, 2003).

Algunos avances de la investigación muestran que las tasas de crecimiento forestal de la ribera están fuertemente vinculadas con los patrones hidrológicos a través del año (en general las altas tasas de crecimiento corresponden a altas disponibilidad de agua y viceversa). Sin embargo esos patrones no son simples. Por ejemplo, especies del género Populus pueden hacer un uso oportunista del agua a través del año, mientras algunos del género Pinus en zonas semiáridas pueden crecer solamente durante la primavera (el resto del tiempo están en estado latente), por lo que son altamente dependientes de las lluvias durante el invierno y la duración de su período de crecimiento en primavera (Hughes et al, 2003).

La comparación del consumo de agua por los árboles ribereños, es difícil, particularmente cuando las medidas no corresponden al mismo ambiente o son de años distintos. Tampoco es claro cuál es el índice más apropiado para comparar entre árboles -altura, diámetro, área activa conductora de savia, área foliar, materia seca, volumen del dosel, o algún otro parámetro(Tabacchi et al, 2000).

De acuerdo con Stromberg (2001), los requerimientos de agua pueden determinarse mediante el examen de cómo varían los procesos demográficos de las poblaciones (regeneración, crecimiento y mortalidad) en relación con factores hidrológicos como la frecuencia de las inundaciones o la profundidad del agua subterránea. Además, es posible definir umbrales y cuantificar las relaciones entre los procesos vegetales y las condiciones hidrológicas.

En la estimación del uso de agua por la vegetación de ribera también se han utilizado mediciones del flujo de savia a través del tronco. Durante períodos de alta humedad se ha medido que un árbol de ribera de unos $30 \mathrm{~cm}$ de diámetro puede consumir entre 100 y 120 litros de agua al día; el monto exacto de agua utilizada varía en función de la edad, el diámetro del tronco, la especie y la ubicación, por lo que las estimaciones en un bosque natural es bastante complicada (Hughes et al, 2003; Mac Nish et al, 2000; Schaeffer y Williams, 1998).

Tabacchi et al (2000) señalan que las especies invasoras, pueden alterar fuertemente el balance hídrico en las áreas de ribera, a través del consumo de agua del suelo y de la zona saturada. A la especie Tamarix ramosissima se le ha denominado "tamarisk" o "saltcedar"; el concepto suele referirse a un complejo arreglo de plantas nativas del norte de África, Eurasia y China, que se considera una fuerte amenaza para los ecosistema de ribera debido a sus grandes consumos de agua (Tabacchi et al, 2000; Webb y Leake, 2006).

Se encontraron tasas de transpiración de Populus y Salix que son menores en comparación con las reportadas para Tamarix ramosissima en ambientes similares (Schaeffer et al, 2000). También el estudio de Dahm et al (2002) provee datos de las altas tasas de transpiración de la vegetación tipo "saltcedar".

Tabacchi et al (2000), señalan que se sabe poco de los requerimientos y el consumo de agua de muchas de las especies de ribera, pero sí que se tienen datos sobre los contenidos de humedad de distintos órganos de algunas plantas ribereñas, las variaciones reportadas en dichos contenidos en la época de crecimiento, y las fluctuaciones diarias como resultado de los retrasos en la extracción del agua del suelo.

La absorción de agua por las plantas (del término inglés "water uptake"), su almacenamiento y retorno a la atmósfera son fenómenos pobremente entendidos para la mayor parte de las comunidades vegetales de ribera (con excepción de algunas especies arbóreas de los Estados 
Unidos). Por ello sigue siendo dificultoso estimar la importancia del corredor de ribera en el balance hídrico a nivel regional (Tabacchi et al, 2000).

Los estudios para determinar los requerimientos de agua de la vegetación ribereña han tomado muchas direcciones, por ejemplo los centrados en la transpiración, que buscan determinar cuánta agua necesita una población o asociación vegetal mediante la estimación de cuánta agua utiliza (Stromberg, 2001). Separar conceptualmente los estudios referidos a la absorción de agua y a la evapotranspiración, es una tarea complicada (Tabbachi, 2000); por ello en el presente documento se tratan como dos temas complementarios y se presenta el tema de la evapotranspiración de ribera inmediatamente después del presente tema sobre la disponibilidad del agua.

\subsubsection{Efectos de los cambios en la disponibilidad de agua por variaciones del nivel freático}

De acuerdo con Stromberg (1993) y Stromberg et al (2005), las reducciones en el agua disponible pueden reducir la extensión de la vegetación de ribera o causar cambios en la composición, de especies mésicas (en hábitats de humedad moderada) a especies xéricas (en hábitats con deficiencia de humedad disponible). En otras palabras, según Lamontagne et al (2005), un descenso a largo plazo de los niveles freáticos puede reducir la biodiversidad en la zona de ribera al promover un cambio gradual hacia especies que dependan menos del agua subterránea.

La salud de las freatofitas obligadas puede ser la más afectada por descensos en el nivel freático; sin embargo las freatofitas facultativas pueden tener períodos de estrés hídrico más frecuentes (Lamontagne et al, 2005). De acuerdo con Scott et al (2000), para estimar el uso de agua subterránea por la vegetación del corredor de ribera, hay que concentrar esfuerzos en la estimación del uso de agua por parte de las freatofitas obligadas.

El descenso del nivel freático también puede limitar los estadios primeros de la sucesión vegetal en la ribera (Horton y Clark, 2000), pero no necesariamente comprometer la salud de los árboles con sistemas radiculares establecidos (Lamontagne et al, 2005).

Ante descensos en el nivel freático, los estadios iniciales del desarrollo de las especies Salix gooddingii y Tamarix chinensis, ven afectado el proceso de elongación de sus raíces, lo que tiene impactos sobre su establecimiento en el ecosistema. Se ha recomendado por tanto incorporar las distintas respuestas de especies en cuanto a crecimiento y supervivencia en los planes de restauración, para promover el éxito de la regeneración artificial (Horton y Clark, 2000; Horton et al, 2001).

Por ello, los modelos que relacionan la estructura de la vegetación con la profundidad del nivel freático son importantes como herramienta para la gestión de la ribera, pues aportan información sobre el rango de variabilidad inherente a las especies facultativas de ribera, y la extensión a la cual su tamaño y productividad puede estar limitada por el agua (Stromberg, 1993).

Los efectos del cambio de disponibilidad de agua por descensos en el nivel freático son complejos y diversos, pues incluso las freatofitas aprovechan de distinta manera el agua de la zona saturada en combinación con agua de la zona no saturada. Por ejemplo, según los resultados de Scott et al (2000), los árboles de la especie Prosopis velutina utilizan agua de capas más profundas del suelo, pero las fuentes pueden ser la combinación de la zona no saturada y la zona capilar. Distintas especies arbóreas de la ribera, poseen un crecimiento similar (en área basal) en los períodos de mayor disponibilidad de agua del suelo (Horton et al, 2001).

De acuerdo con las observaciones de Snyder y Williams (2000), los descensos persistentes a largo plazo de los niveles freáticos pueden limitar la presencia tanto de freatofitas obligadas como de facultativas. Señalan que dada la flexibilidad de Prosopis $s p$. en el uso de agua de diversas fuentes, es posible que ésta se convierta en especie dominante de la ribera, si hay persistencia en el descenso del nivel freático. Este tipo de predicciones aporta pistas interesantes de la funcionalidad de las especies de ribera (profundidad radicular) en presencia de estrés hídrico. 
Mediante el análisis histórico de una zona de ribera a partir de un registro de fotografías y registros hidrológicos y de intervención del cauce, se ha demostrado que la eliminación de la vegetación de ribera se relaciona con los descensos de nivel freático proveniente del impacto humano de uso de agua subterránea y/o del desvío del flujo base (Webb y Leake, 2006).

Árboles de Populus spp. se han adaptado a niveles freáticos fluctuantes al mantener a sus raíces en contacto con la zona capilar; suelen ser vulnerables a descensos repentinos de dicho nivel y a cambios a largo plazo causados por la construcción de presas (Hughes et al, 2003). Los árboles de la especie Prosopis spp pueden resistir a fluctuaciones relativamente grandes en los niveles de agua; los árboles de ribera pueden llegar al estrés cuando los niveles freáticos descienden de entre 13.7 y 15.2 metros debajo de la superficie del suelo (Webb y Leake, 2006).

\subsubsection{Algunas respuestas fisiológicas de la vegetación de ribera ante cambios en la disponibilidad de agua}

Se conocen bien las respuestas fisiológicas de especies como Populus fremontii, Salix gooddingii y Tamarix chinensis ante descensos en la disponibilidad de agua, pero se ha prestado poca atención a los cambios en la estructura de la población y la comunidad frente a esos decrementos en flujos superficiales y en los niveles freáticos. Horton et al (2001) consideran como indicadores del estrés hídrico (por descensos en el nivel freático) de Populus, Salix y Tamarix, los bajos potenciales hídricos de los rebrotes, las bajas tasas de intercambio gaseoso en las hojas y grandes cantidades de marchitez o decaimiento del dosel; la preponderancia en la zona de una especie como Tamarix chinensis, puede explicarse debido a sus mayores tasas de intercambio gaseoso, mayor crecimiento cuando el agua es abundante, tolerancia a la sequía y mantenimiento de un dosel funcional ante condiciones secas.

El buen conocimiento fisiológico no es suficiente para explicar variaciones con enfoque de comunidad vegetal; las referencias sobre estudios de la interacción biótica con factores abióticos es abundante (tal y como se mostró con anterioridad respecto a estudios enfocados en análisis estadísticos como las correspondencias canónicas). En el trabajo de Lite y Stromberg (2005), en una comparativa de umbrales de flujos superficiales y aguas subterráneas como principales controles de dos especies ribereñas, se encontró que la permanencia del flujo superficial fue la variable hidrológica que mejor explicó la varianza en la abundancia e importancia relativa de las especies; sin embargo también se señaló que existen otros factores que contribuyen a esa varianza, tal y como la fluctuación interanual del agua subterránea y su profundidad.

En el estudio de las respuestas de los bosques de ribera a cambios en el nivel freático, se han utilizado diversas escalas temporales para el monitoreo de los niveles freáticos y datos diarios, semanales o mensuales sobre el contenido volumétrico de agua. Por ejemplo, Horton et al (2001) utilizaron el muestreo mensual por transectos en puntos ubicados a diferentes alturas respecto al "thalweg" del río, y posteriormente, análisis de datos fisiológicos vegetales para los meses más secos del período analizado.

Se suele utilizar el "potencial hídrico vegetal previo al amanecer" $\left(\Psi_{p d}\right)$ como un índice de los recursos hídricos disponibles para la planta, es decir, como índice del comportamiento y desarrollo de la vegetación respecto a su disponibilidad de agua (Horton et al, 2000; Schaeffer et al, 2000; Scott et al, 2006; Snyder y Williams, 2000; Stromberg et al, 1993).

De acuerdo con Stromberg et al (1993) en el análisis de la disponibilidad de agua para vegetación de ribera, se suele usar como variable independiente el potencial hídrico de la planta (medido en distintos tejidos vegetales, pero principalmente en el follaje) y no el potencial hídrico del suelo, debido a la "dificultad de medir la disponibilidad de agua del suelo a lo largo de sistemas que usan de forma diferencial sus múltiples fuentes de agua"; se asumió que el potencial hídrico de la planta es definido principalmente por el contenido de humedad del suelo. En el estudio de Scott et al (2000), se señala que la heterogeneidad vertical del perfil del suelo, es la causa de las dificultades en la predicción de las variaciones del contenido de humedad en el suelo, tanto mediante mediciones en campo como usando una calibración en laboratorio y la curva de de calibración respectiva. 
Schaeffer et al (2000) demostraron que dichos potenciales no eran diferentes para árboles de Salix gooddingii y Populus freemontii creciendo en cauces primarios o secundarios, y señalan que eso sugiere que las diferencias en estado hídrico no son responsables de las diferencias en el flujo medio de savia basado en mediciones de área de tejido conductor. Snyder y Williams (2000) encontraron que Populus fremontii presentaba un mayor uso de agua de la zona no saturada en cauces efímeros que en cauces perennes (Fig. 5.6).

(a)
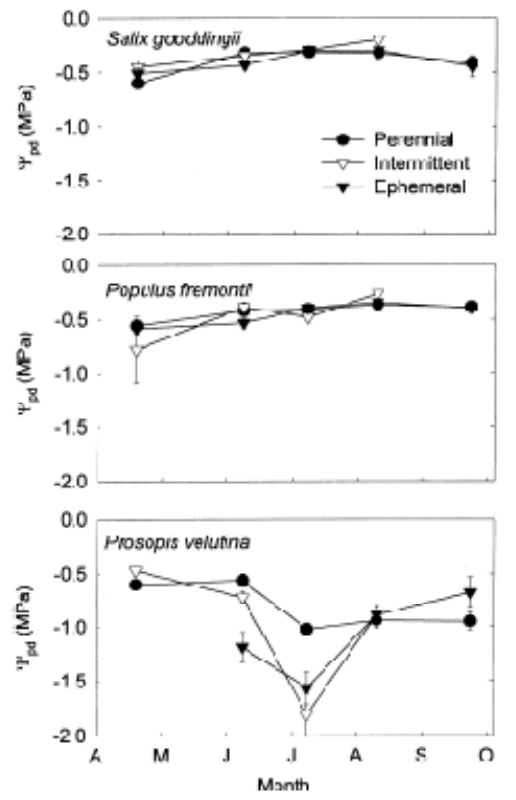

(b)

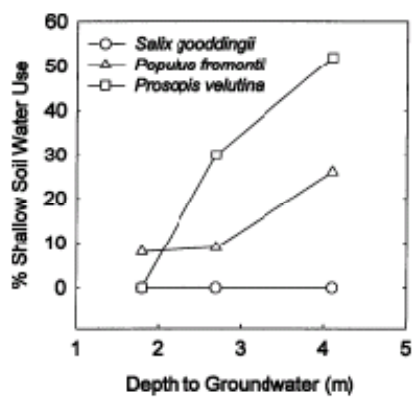

Fig. 5.6 (a) Potencial hídrico foliar medio previo al amanecer $(\Psi \mathrm{pd})$. (b) Relación entre la profundidad del agua subterránea y el porcentaje de transpiración derivada de agua poco profunda del suelo en el mes de agosto, después de un evento de tormenta del monzón. Para tres especies de ribera, en ríos perennes, intermitentes y efímeros. Tomado de Snyder y Williams (2000).

Snyder y Williams (2000) proponen estimar el estrés hídrico a partir de los potenciales hídricos de vegetación de ribera en horas antes del amanecer y del medio día. Se observa (Figuras 5.6a y 5. 6b) que en lugares donde el agua subterránea es profunda y el río es intermitente o efímero es posible promover el uso de una mayor fracción de agua de la zona no saturada (proveniente de la lluvia) por parte de Populus y Prosopis, pero no por parte de Salix. Esto confirma que las freatofitas cubren un amplio espectro de tipos funcionales que responden únicamente a la variación espacio - temporal en la distribución de agua disponible en la zona radicular.

De acuerdo con Eagleson (2002), en los climas semiáridos, considerando su baja precipitación anual o estacional, el suministro de humedad del suelo para la vegetación de ribera proviene mayormente de la recarga de agua subterránea, que está dominado por el ascenso capilar, y por tanto las propiedades del suelo son de suma importancia. El estudio de las características de adecuada función del suelo de la ribera propuesto por Lewis et al (2003), aunque hace énfasis en condiciones de saturación, es una buena referencia para comprender los procesos físicos que se suceden en este elemento del ecosistema ribereño.

\subsubsection{Adaptaciones vegetales provenientes del sistema de raíces: relevancia del ascenso hidráulico radicular}

Es relevante considerar la estrategia de crecimiento radicular de la vegetación como parte de su papel activo para favorecer la disponibilidad de agua, puesto que hay suficiente evidencia que sugiere que las raíces de las plantas pueden contribuir al ascenso vertical de agua más allá de la atribuible a la capilaridad (Burgess et al., 1998). 
La profundidad radicular ha sido descrita como un parámetro clave de los procesos ecológicos que caracteriza los distintos tipos funcionales de vegetación (Baird y Maddock III, 2005; Canadell et al, 1996; Castellanos et al, 1991; Nadezhdina, N.; Čermák, J., 2003; Schenk y Jackson, 2002a, 2002b y 2005) o taxones vegetales (Castellanos et al, 1991; Kellman y Roulet, 1990; Schulze et al, 1996) en niveles global, regional y local; recientemente, la comunidad científica ha puesto su atención en las brechas importantes de conocimiento sobre la ubicación y el funcionamiento del sistema radicular profundo para el control del ciclo hidrológico de los ecosistemas (Schenk y Jackson, 2002a; Dawson, T., 2007).

En modelación de ribera, la profundidad radicular de los tipos de vegetación se ha referido abundantemente desde la perspectiva de la disponibilidad de agua (Altier et al, 2002; Baird et al, 2004; Butler Jr. et al, 2007; Goodwin y Tarboton, 2001; Horton et al, 2001; Kranjcec et al, 1998; Lite y Stromberg, 2005; Stromberg et al, 1996). A su vez, en la visión del continuo suelo-plantaatmósfera, la profundidad de las raíces se ha señalado como uno de los principales factores que afectan la extracción del agua del suelo (Medrano y Flexas, 2004a) que debe investigarse para definir condiciones ambientales óptimas para las plantas, en conjunto con el estrés hídrico y la transpiración vegetal (Franz et al, 2010; Porporato et al, 2001).

Si existe agua subterránea con seguridad a largo plazo, los árboles de ribera pueden propiciar el desarrollo de raíces predominantemente en la zona capilar (capillary fringe) y en la zona saturada, en lugar de hacerlo a lo largo del perfil del suelo, sobre todo si la precipitación durante la época de crecimiento es incierta (Ehleringer y Dawson, 1992).

En ambientes de bosques de ribera, cuando hay estiaje del río y niveles freáticos profundos estos pueden actuar como un factor limitante para el uso del agua cuando las raíces no están en contacto con las capas húmedas del suelo o la zona saturada (Hughes et al, 2003; Kranjcec et al, 1998).

Además, la modificación de la conductividad hidráulica del suelo por efecto de las raíces de la vegetación de ribera afecta los flujos de la zona saturada y la no saturada; las raíces profundas de los árboles mejoran el drenaje o la infiltración mediante el incremento en la porosidad y capilaridad del suelo (Tabacchi et al, 2000).

Las raíces que atraviesan el suelo con distinto potencial hídrico, pueden actuar como conductos para transferir agua desde capas húmedas más profundas hacia las más secas, a través del proceso denominado "ascenso hidráulico" o "redistribución hidráulica", que puede amortiguar los efectos del estrés hídrico durante la sequía; además, este fenómeno mantiene la viabilidad de las raíces, facilita su crecimiento en suelos secos y modifica la disponibilidad de recursos (Burgess et al, 1998; Hughes et al, 2003; Tabacchi et al, 2000). El estudio de Hultine et al (2003) se aproxima con más detalle al fenómeno de redistribución hidráulica en ambientes semiáridos de ribera, mediante mediciones de flujo de savia en distintos órganos vegetales.

Se han hecho importantes avances para demostrar la relevancia del ascenso hidráulico radicular y de la redistribución hidráulica de agua en el suelo, para la disponibilidad de agua de las plantas (Caldwell y Richards, 1989; Caldwell et al, 1998; Dawson, 1993 y 1996; Hultine et al, 2003; Ryel et al, 2002 y 2003; Zheng y Wang, 2007). Recientemente se ha consolidado la necesidad de modelar la redistribución del agua del suelo propiciada por la conectividad del sistema radicular con zonas más húmedas del perfil, a través de la realización de los primeros valiosos esquemas de modelación físicamente basados (Amenu y Kumar, 2008; Lee et al, 2005; Ryel et al, 2002; Zheng y Wang, 2007;).

De acuerdo con los resultados de Amenu y Kumar (2008), durante los períodos secos del año la parte del fenómeno de redistribución hidráulica que tiene mayor relevancia es el ascenso hidráulico a través de las raíces (cuyo término original inglés es "hydraulic lift"). Zheng y Wang (2007) destacan que la investigación y modelación del fenómeno se encuentra en sus etapas iniciales, pero que ya es posible aplicarlos en modelos de clima y superficie terrestre. 


\subsection{EVAPOTRANSPIRACIÓN (ET) DE LA RIBERA}

Scott et al (2000) señalan la importancia de la evapotranspiración de los ecosistemas de ribera en los climas semiáridos. La determinación de la variabilidad interanual de las tasas de ET es útil para estimar los recursos hídricos a escala de paisaje (Goodrich et al, 2000; Scott et al., 2000); son muy pocas las medidas directas de la ET de las plantas ribereñas reportadas (Dahm et al, 2002; Moore et al, 2004).

La ET estacional de la ribera es una de las condiciones de contorno más críticas y menos cuantificadas para modelar el agua subterránea (Goodrich et al., 2000). Existen pocas estimaciones de la magnitud o de la heterogeneidad espacial y temporal de los flujos de transpiración para especies de ribera de zonas áridas y semiáridas (Schaeffer et al, 2000).

La ET varía tanto de forma estacional como diaria, de acuerdo al clima local y a la composición y estructura de la comunidad vegetal de la ribera (Tabacchi et al, 2000) y también en función de factores como la biomasa y la edad de dicha comunidad vegetal y su disponibilidad de agua (Stromberg, 2001).

De acuerdo con Tabacchi et al (2000), no existen datos en la literatura sobre la intercepción de la lluvia o el rocío por parte del bosque ribereño, a pesar de que no debería despreciarse este tipo de intercepción de humedad en la ribera. Como se verá más adelante, el modelo REMM (Altier et al, 2002), sí considera la intercepción en la ribera, y propone sus estimaciones con base en la ecuación de Thomas y Beasley (1986).

Es importante entender la hidrología de la zona de ribera para comprender su dinamismo. La ET está gobernada principalmente por factores como la vegetación, la humedad, la temperatura, el viento y la radiación solar; a su vez la vegetación de ribera también influye en el ciclo hidrológico (Tabacchi et al., 1998). Las plantas dominantes, interactuando con el cambio climático a escala regional y la hidrología local, controlan temporal y espacialmente las propiedades dinámicas del ecosistema ribereño, entre ellas la evapotranspiración (Williams et al, 1998). En las regiones áridas y semiáridas las interacciones entre el agua subterránea y superficial podrían estar intrincadamente acopladas con los procesos de evapotranspiración en los corredores de ribera (Maddock et al, 1998).

Moore et al (2004) presentan una bibliografía sobre la ET con énfasis en la de la vegetación de ribera comprendida entre los años 1940 y 2000; incluyen información sobre: métodos y técnicas utilizadas para la medición y estimación de la ET; cambios en el ecosistema de ribera y varios métodos de control y manejo de especies exóticas; requerimientos de agua para la vegetación; coeficientes de cultivo basados en unidades de calor (días de crecimiento).

El conocimiento de las respuestas específicas de las especies a la precipitación en la época de crecimiento y las restricciones de funcionamiento de las raíces profundas y superficiales para la toma de agua, facilitará las predicciones de cómo las variaciones del hábitat y decaimiento del agua subterránea afectan los patrones de transpiración en los ecosistemas de ribera (Snyder y Williams, 2000).

La transpiración de agua subterránea y de las capas no saturadas del suelo por parte de la vegetación ribereña, depende de la interacción entre las condiciones de sitio y la agrupación de especies. (Snyder y Williams, 2000). Las tasas de transpiración varían entre especies vegetales debido a diferencias morfológicas en la arquitectura de la raíz y la sensibilidad fisiológica a la disponibilidad de agua (Baird \& Maddock III, 2005).

En los bosques de las llanuras de inundación, las tasas de ET son usualmente cercanas a las de evapotranspiración potencial (ETP), mayormente en la época de crecimiento vegetal, a pesar de las fuertes fluctuaciones e insuficiente lluvia (Tabacchi et al, 2000). Algunos árboles de la ribera, incluso aquellos comúnmente asociados al agua subterránea poco profunda, pueden usar cantidades sustanciales de agua de lluvia para sus requerimientos por transpiración (Snyder y Williams, 2000). 
Los estudios de estimación de la ET han sido una forma de estudiar la fuente de agua y cantidades utilizadas por la vegetación de ribera, a partir del monitoreo de sus funciones (Goodrich et al, 2000; Schaeffer et al, 2000; Scott et al, 2000; Snyder y Williams, 2000). Se ha observado que el agua subterránea ha sido fuente de más del $50 \%$ de la transpiración de cierta vegetación de ribera (Lamontagne et al, 2005). Asimismo, se ha demostrado que mediante análisis de las tasas de transpiración junto con las de salinidad, se puede interpretar el decaimiento de la especie ribereña Populus fremontii desde el punto de vista de su funcionamiento (Pataki et al, 2005).

El estudio de Kranjcec et al (1998) sobre la transpiración de estadios iniciales del desarrollo de la vegetación de ribera, demuestra que el crecimiento de rebrotes y la transpiración aparente de especies de ribera (Populus spp.) se reducían progresivamente con el incremento de las tasas de decaimiento del nivel freático $\left(\mathrm{cm} \mathrm{día}^{-1}\right)$.

Se ha observado que en una zona de ribera, la vegetación arbórea es la que más contribuye a la ETP (herbáceas menos del 3\% de la ETP, arbustivas cerca de un 9\%, arbóreas cerca de un $88 \%$ ) para un consumo medio diario de $4.4 \mathrm{~mm}$ (Penka, 1991). Andersen (2003) aporta nuevos datos sobre tasas de ET para zonas de ribera húmedas, y se señala que la discusión y la falta de aportes concluyentes aún es algo vigente.

En el estudio de Nagler et al (2005a) se han encontrado mayores tasas de ET para Populus spp. y Salix spp., respecto a Prosopis velutina y Tamarix ramosissima; en el área evaluada las menores tasas de ET correspondían a herbáceas como Sporobolus wrightii o Pluchea sericea.

Sin embargo, no se tiene claridad en cuanto a la variación de la transpiración de Populus y Salix en función del tipo de cauce y estado de crecimiento (Schaeffer et al, 2000). Snyder y Williams (2000) aportan resultados interesantes referentes al comportamiento de la ET de ribera en cauces permanentes, efímeros e intermitentes.

Duke et al (2005) observaron pérdidas en la transpiración de la vegetación de ribera equivalentes al $70 \%$ de pérdidas anuales de agua de un sitio de ribera adyacente a un río de segundo orden. Infirieron la presencia de una zona hiporreica en la ribera debido a que el alto uso de agua por las plantas fluctuaba de forma estacional en correlación con los niveles del río. Encontraron que el desarrollo del área foliar en el dosel se relaciona cercanamente con las fluctuaciones del río y del agua subterránea.

Dahm et al (2002) encontraron buenas correlaciones entre el IAF y las tasas diarias de ET para bosques ribereños en época de verano. Señalan que las medidas de IAF en la época del crecimiento y una clasificación de la vegetación ribereña constituyen un método prometedor para mejorar los estimados de la ET total anual en la zona de ribera.

Xavier \& Vettorazzi (2003) realizaron un estudio en un bosque subtropical de ribera para medir sus índices de área foliar y dentro de sus resultados encontraron IAF de 4.90, y valores de IAF que decrecían en función de las mermas de precipitación, lo que señalan como característico de la vegetación semi decidua estudiada.

Utilizando un balance hídrico para la época de crecimiento de diferentes tipos de vegetación (arbórea, arbustiva y herbácea), Scott et al (2006), proponen la medición del "uso de agua subterránea por unidad de área dosel de freatofitas $\left(Q_{v e g}\right)$ " a partir de la relación siguiente:

$Q_{\text {veg }}=Q_{t} / f_{v}$

Donde $Q_{t}$ es el uso de agua subterránea por unidad de área de suelo $[\mathrm{mm}]$, y $f_{v}$ es la fracción de cobertura del tipo de vegetación dominante.

$Q_{t}=E T-(P-\Delta S)$ 
Donde $E T$ es la evapotranspiración de la vegetación de ribera, y el exceso de precipitación se calcula a partir de la diferencia entre la precipitación $P$, y el cambio en la humedad del suelo del metro superior del perfil del suelo $\Delta S$. Según Scott et al (2003) $Q_{t}$ es la ET en exceso de precipitación y almacenamiento de agua del suelo, asumiendo que ese exceso de humedad del suelo proviene del agua subterránea.

En el estudio de Scott et al (2006) se encontró que la ET y el intercambio neto de $\mathrm{CO}_{2}$ en el ecosistema de ribera se incrementan proporcionalmente con el incremento de la dominancia de vegetación arbórea; en otras palabras, los patrones estacionales de ET de los arbustos, herbáceas y arbóreas de la ribera son similares, pero siempre mayores en zonas dominadas por árboles (Fig. 5.7).

Scott et al (2006), explicaron que el mayor potencial hídrico $\left(\Psi_{p d}\right)$ observado para la especie arbórea Prosopis velutina se debe a la mayor presencia de raíces en contacto con agua de la zona capilar y de la zona saturada. Esto, aunado a las observaciones de la ET, explica el mejor aprovechamiento que los árboles hacen del agua subterránea en la ribera (Fig 5.7).

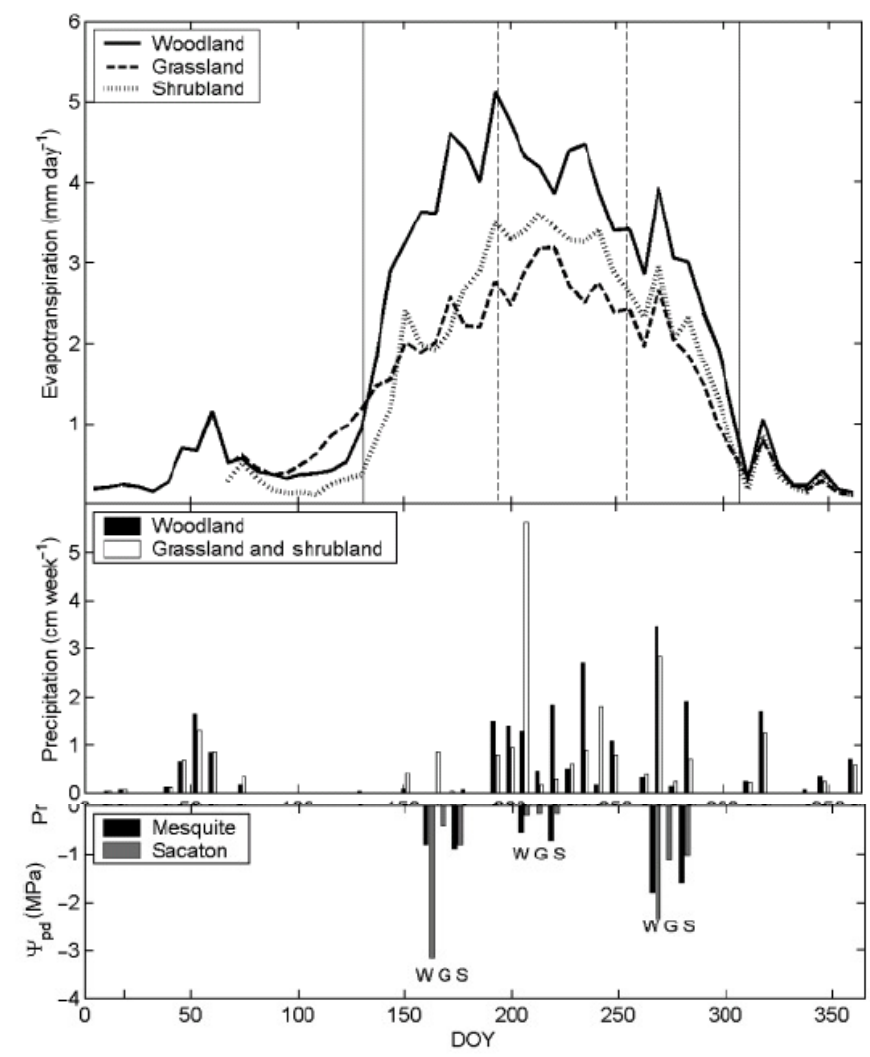

Fig. 5.7 Evapotranspiración media semanal (año 2003), precipitación semanal total (en medio) y potenciales hídricos al amanecer, $\Psi_{p d}$ (abajo) de especies arbóreas y herbáceas de ribera en diferentes zonas de ribera (W: boscosa, G: pastizal, S: matorral). El período de lluvias torrenciales se señala con las líneas discontinuas; las líneas sólidas demarcan los días de la última helada de primavera y la primera helada de otoño. Tomado de Scott et al (2006).

\subsubsection{Métodos para estimar la ET de la ribera}

Se han usado distintos métodos para estimar la evapotranspiración de la ribera, incluyendo aquellos con base en ecuaciones, mediciones de campo, datos de sensores remotos (se tratarán en un tema separado). Moore et al (2004) presentan una bibliografía que incluye documentos que describen diversos métodos y técnicas de medición y estimación de ET en la ribera. 
Algunos métodos de medición micrometeorológica para la estimación de la ET son los de la velocidad de flujo de calor, el de las tasas de flujo de Bowen y el de "eddy covariance" (Schaeffer et al, 2000). Con datos suficientes de las tasas de transpiración de las plantas y con mapas de vegetación es posible estimar las tasas totales de uso de agua a lo largo de las riberas (Goodrich et al., 2000).

Uno de los principales objetivos del programa SALSA "Semi-arid Land-Surface-Atmosphere" ha sido el mejor entendimiento y cuantificación estacional de la evapotranspiración de grandes áreas de ribera (Goodrich et al, 2000). En el contexto de dicho programa, se ha hecho un gran aporte en la estimación de la ET, mediante mediciones del flujo de savia, utilizando el método de la velocidad del pulso de calor (Schaeffer y Williams, 1998; Schaeffer et al, 2000) u otros distintos (Scott et al, 2000; Snyder y Williams, 2000; Williams et al, 1998, entre otros).

Goodrich et al (2000) desarrollaron un modelo de Penman-Monteith en combinación con datos de campo; usaron técnicas de tasas de flujo de Bowen de medición micrometeorológica (flujo de savia, potencial hídrico, conductancia estomatal, fuente de agua usada) para estimar la evapotranspiración de arbórea y herbácea de especies de ribera.

Además se usaron estimaciones de cobertura vegetal a partir de sensores remotos. Se estimó así, el uso estacional de agua de la vegetación de ribera en un corredor de ribera. Proponen estimar las tasas de evapotranspiración de la ribera para una pequeña porción de la etapa de crecimiento y extrapolar los resultados para el resto del año.

Por su parte, Scott et al (2000) proponen el uso de técnicas micro meteorológicas, a la par de medición de humedad del suelo y niveles de láminas de agua para determinar la evapotranspiración. Scott et al (2003) incorporan a lo anterior, técnicas ecofisiológicas para medir la ET de grupos funcionales de vegetación. Scott et al (2004) presentan la descripción de métodos de medición de humedad de capa superficial del suelo, evapotranspiración, entre otros.

La recomendación de Shuttleworth (1993) sobre revisar el capítulo del cambio de cobertura del suelo del libro "Handbook of Hydrology", se incorpora en algunos trabajos de la zona de ribera (revisados aquí), dada su participación cercana al grupo del programa SALSA (Scott et al, 2000 y 2004). Diversos trabajos evalúan el cambio de cobertura vegetal en la ribera como factor determinante de las tasas de ET en la zona (Baird y Maddock III, 2005; Maddock III y Baird, 2003; Scott et al, 2003 y 2006).

Scott et al (2003) desarrollaron una herramienta basada en SIG, para calcular el uso de agua subterránea ante cambios en la cobertura vegetal del corredor de ribera de regiones semiáridas de los Estados Unidos. Proponen un método en el que se combinan medidas de campo ("eddy covariance") con un mapa de vegetación en ambiente SIG, y el uso de modelos de ecosistema de ribera calibrados para proveer estimaciones a escala de cuenca.

Scott et al (2004) en el estudio de la variación interanual y estacional en los flujos de agua en un ecosistema forestal de ribera, utilizaron algunos métodos de medición de humedad de capa superficial del suelo, evapotranspiración, entre otros. Señalan que el entendimiento de cómo los factores climáticos que determinan las funciones eco hidrológicas interactúan con los cambios de demanda de la sociedad y la variabilidad climática es importante para mejorar el manejo de esos ecosistemas tan vitales.

Mac Nish et al (2000) compararon diferentes métodos de estimación de la ET de la ribera, basados en el balance hídrico (mediciones de caudal del río y de los niveles freáticos) o en medidas de flujo de savia elaborada. Se concluyó que al reducir el error en tres componentes clave (área del acuífero, aumento del caudal del río y gradiente vertical del agua subterránea) en menos del $5 \%$, la ET de la ribera podía estimarse con una exactitud de entre 20 y $25 \%$ usando el método de balance hídrico. Además, el estudio provee de un mejor entendimiento de las interacciones entre río - acuífero - vegetación. 
El estudio de Andersen (2003) utiliza el método de balance hídrico para la descripción y cuantificación de procesos hidrológicos (principalmente estimación de ET), y su implicación en los procesos de nutrientes y en la vegetación de un humedal de llanura de inundación.

Considerando el rol dinámico de la vegetación ribereña y las distintas fuentes de agua para su transpiración, a continuación se revisan dos métodos de estimación de ET que destacan por su fuerte fundamento teórico, y porque pueden verse como complementarios entre sí.

\subsubsection{Método de estimación de la ET de ribera considerando los contenidos de humedad del suelo (Altier et al, 2002; Inamdar et al, 1999; Lowrance et al, 2000)}

Dentro del modelo REMM (Altier et al, 2002; Inamdar et al, 1999; Lowrance et al, 2000), que se describirá más adelante, la transpiración se da después de que toda la humedad del dosel ha sido evaporada. La tasa potencial de la transpiración foliar se calcula usando una forma modificada de la ecuación de Penman Monteith. La tasa potencial de un determinado tipo de vegetación se ajusta en función de la humedad actual disponible para la transpiración. La cantidad de agua disponible de una capa de suelo de cada tipo de vegetación depende de la proporción de sus raíces y del contenido de humedad en dicha capa.

La tasa de transpiración máxima de una capa está limitada por su conductividad hidráulica que varía con la humedad del suelo utilizando la ecuación de Campbell (1974). Esto permite que cualquier exceso en la demanda que no se complete en una capa pueda ser transferido a una capa subyacente. La transpiración de cada tipo de vegetación para una capa del suelo dada, se determina al multiplicar el agua disponible por la proporción de la demanda total para cada combinación tipo de vegetación - capa del suelo:

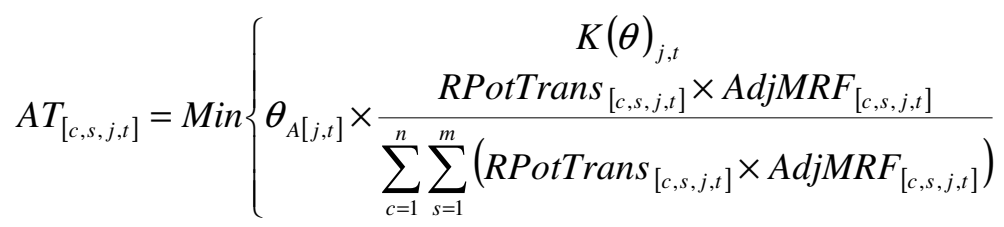

Donde, para la capa del suelo $j$ en el día $t$, AT es la absorción de agua ("water uptake") por la vegetación $s$ del dosel $c$ en la capa de suelo $j(\mathrm{~mm}) ; K(\theta)$ es la conductividad hidráulica del suelo definida por la ecuación de Campbell para la capa de suelo $j(\mathrm{~mm})$; RPotTrans es la demanda residual de transpiración potencial ("remaining potencial transpiration demand") por la vegetación $s$ del dosel $c$ en la capa de suelo $j$ después de que el agua ha sido absorbida de las capas superiores del suelo ( $\mathrm{mm}$ ); AdjMRF es un factor de humedad ajustado para la fracción de la masa radicular de la vegetación $s$ en el dosel $c$ en la capa de suelo $j$ relativa a sus raíces en las otras capas y relativa a todas las otras raíces en la capa $j$ (escalar 0-1) (Inamdar et al, 1999).

$\theta_{A}$ es el agua disponible de la capa de suelo $j(\mathrm{~mm})$ :

$$
\begin{gathered}
\theta_{A[j, t]}=0 ; \text { donde }_{[j, t]}<\theta_{W P} \\
\theta_{A[j, t]}=\left(\theta_{[j, t]}-\theta_{W P}\right) ; \text { donde } \theta_{W P} \leq \theta_{[j, t]}
\end{gathered}
$$

Donde $\theta_{W P}$ es el contenido de humedad del suelo en el punto de marchitez (mm). Así, para la primera capa del suelo, la demanda de transpiración para un tipo de vegetación dado es equivalente al potencial total de transpiración para ese tipo de vegetación. En las siguientes capas, RPotTrans es reducido por la suma de la transpiración de todas las plantas de las capas superiores (Inamdar et al, 1999).

El factor de humedad del suelo MF representa la tasa de transpiración decreciente que ocurre mientras el suelo se seca. Sería deseable contar con este factor de cambio durante cada día como el agua de las capas del suelo removida por la ET, dado que eso representa la influencia 
en la actividad estomatal así como las tasas de difusión de humedad a las raíces. Sin embargo, con una escala temporal diaria, se calcula como función del estado de humedad del suelo al final del día anterior. Como una aproximación se tiene la siguiente relación:

$$
M F_{[j, t]}=\operatorname{Minimo}\left\{\begin{array}{c}
1 \\
\frac{\theta_{[t-1]}-\theta_{W P}}{\delta\left(\theta_{F C}-\theta_{W P}\right)}
\end{array}\right.
$$

Donde $\theta_{F C}$ es la humedad del suelo a capacidad de campo $(\mathrm{mm})$, y $\delta$ es un factor específico del tipo de suelo que determina la influencia del agua del suelo limitante de la ET (Inamdar et al, 1999).

\subsubsection{Estimación de la ET para grupos funcionales de vegetación de ribera: el modelo RIP-ET (Baird et al, 2004; Baird y Maddock III, 2005; Maddock III y Baird, 2003)}

Con base en la clasificación por grupos funcionales de vegetación ribereña (presentada anteriormente), se desarrollaron curvas de transpiración para una variedad de formas vegetativas, que responden también a fluctuaciones en el nivel freático y representan separadamente la evaporación de la transpiración. El desarrollo de este modelo para la estimación de la ET de la ribera es una de las propuestas con mayor fundamento teórico encontradas, cuyos autores han trabajado conjuntamente con la mayoría de los citados, tanto en este tema de ET de la ribera como en el trabajo de clasificación de la vegetación y estudio de sus aspectos ecofisiológicos.

El modelo presenta curvas de evapotranspiración para condiciones semiáridas y para cada grupo funcional de vegetación, representado para condiciones climáticas medias, que también permiten considerar el tamaño de la planta (pequeña, mediana o grande) y/o la densidad de la población (baja, mediana o alta). En la modelación pueden tenerse desde una curva anual promedio de ET hasta cuatro o más curvas que son función de las estaciones del año. Considerando la versatilidad de dichas curvas dentro del modelo, se aconseja al modelador el crear curvas para cada tipo de condiciones climáticas o estaciones y se aportan los criterios de cómo hacerlo (Baird et al, 2003; Baird \& Maddock, 2005; Maddock III y Baird, 2003).

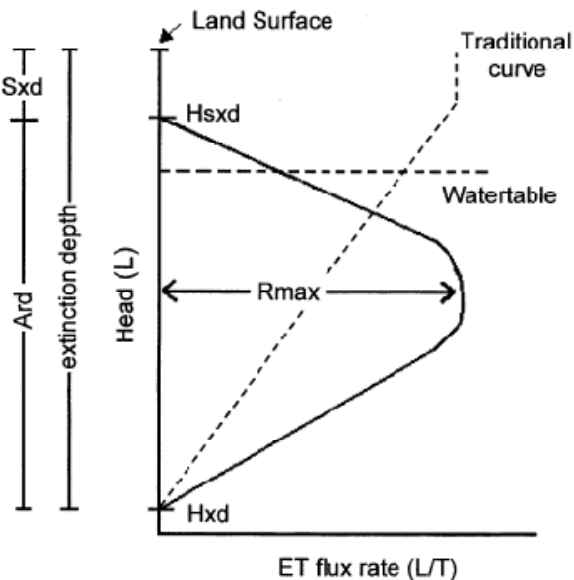

Fig 5.8 Curva genérica de tasa de flujo ET para un grupo funcional de vegetación en RIP-ET: $S x d$, profundidad de extinción por saturación; Ard, profundidad radicular activa; Hsxd, profundidad de extinción por saturación; Hxd, elevación de extinción por profundidad; HSURF, elevación de la superficie del suelo; Rmax, tasa máxima de evapotranspiración (ET). Tomado de Baird y Maddock (2005). 
En la Fig. 5.8, se observa una curva genérica de tasa de flujo ET, cuyos puntos característicos son: $\boldsymbol{H x d}$, la profundidad de extinción por elevación (del inglés extinction depth elevation) o la elevación del nivel freático debajo de la cual las raíces no pueden obtener agua y por tanto ET es cero.

Conforme el nivel freático va subiendo, el agua está disponible para las raíces y las tasas de flujo ET crecen hasta llegar al máximo ( $\boldsymbol{R m a x})$, que corresponde a la tasa máxima promedio diaria de flujo de ET, medida o estimada. La elevación del nivel freático asociada con la muerte de la planta es la profundidad de extinción por elevación saturada $(\boldsymbol{H} \boldsymbol{s} \boldsymbol{x d})$; en este punto ET es cero también. Con fines de modelación, las relaciones entre tasas de flujo y los niveles freáticos necesitan definirse como profundidades (L) o distancias relativas al nivel del suelo. La "curva tradicional" de la Figura 5.8, se usa exclusivamente para modelar la evaporación del suelo descubierto o del cuerpo de agua.

La curva genérica de flujo ET (Fig. 5.8) se reemplaza con una aproximación basada en segmentos lineales, especificados de forma adimensional (Fig. 5.9). Los segmentos de la curva se definen por los vértices $(h(k), R(k))$ y determinan la forma de la curva. $d(1) \ldots d(N)$, representan los cambios en altura sobre cada segmento, mientras $d R(1) \ldots d R(N)$ representan el cambio en flujo sobre el segmento; las profundidades características pueden aproximarse en función de la profundidad de raíces de cada tipo funcional de vegetación (Baird et al, 2004).

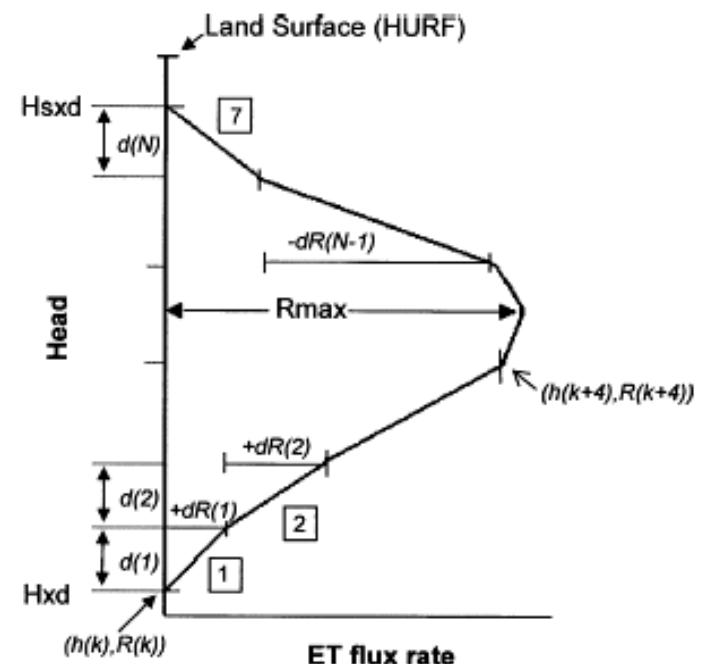

Fig. 5.9 Curva segmentada de flujo ET ilustrando una interpolación lineal usando $d(N) s$ y $d R(N) s$ : $d(1) \ldots d(N)$ representa cambio en el nivel freático en cada segmento de la curva, mientras $d R(1) \ldots d R(N)$ representa el cambio en el flujo ET en el segmento. Tomado de Baird y Maddock (2005).

En general, para $N$ segmentos, donde $1 \leq k \leq N$,

$$
\begin{aligned}
& d(k)=h(k+1)-h(k) \\
& \mathrm{y} \\
& d R(k)=d R(k+1)-d R(k)
\end{aligned}
$$

Para cada curva de sub grupo funcional (clasificación por tipo funcional y tamaño y/o densidad), la altura de cambio fraccional $(\mathrm{fdh}(k))$ y la tasa de flujo $(\mathrm{fdR}(k))$ son definidos para cada segmento adimensional como:

$$
f d h(k)=\frac{d(k)}{A r d}
$$$$
\text { y }
$$ 


$$
f d R(k)=\frac{d R(k)}{R \max }
$$

Con:

$$
\sum_{k=1}^{N} f d h(k)=1
$$

y

$$
\sum_{k=1}^{N} f d R(k)=\frac{R s x d}{R \max }
$$

Las elevaciones de extinción pueden aproximarse en función de la profundidad de raíces de las especies dentro de un determinado grupo funcional; dichos valores pueden obtenerse mediante trabajo de campo, revisión de literatura o ambos. Aunque esas elevaciones pueden no ser precisas, sí que proveen de un buen punto de inicio para representar los valores máximo y mínimo de tolerancia de agua para las especies en cuestión (Baird et al, 2003; Baird \& Maddock, 2005; Maddock III y Baird, 2003).

Las curvas de tasas de flujo ET de verano para los grupos funcionales de ribera se generaron con base en revisión bibliográfica, medidas de campo e input de investigación. Por lo tanto deben considerarse como curvas preliminares y ser sujetas a refinamiento (Baird y Maddock, 2005).

Para la modelación de los flujos ET se necesita su estimación mediante medidas de campo o bien factores de escala que suelen consistir en el área basal total que se basa en relaciones entre el diámetro a la altura del pecho del árbol y el área específica del tejido conductor de la savia. Asimismo es necesario escalar áreas, mediante la determinación del área cubierta por cada sub grupo funcional en una celda del modelo $\left(\mathrm{fSG}_{(\mathrm{i})}\right.$ ) y posteriormente el área con cobertura vegetal dentro de cada área del sub grupo funcional $\left(\mathrm{fPC}_{(\mathrm{i})}\right)$. Así, el área del $i$ sub grupo funcional vegetal que contribuye a la ET, se denomina cobertura fraccional $\left(\mathrm{fCov}_{(\mathrm{i})}\right)$ que equivale a:

$$
f \operatorname{Cov}_{(i)}=f S G_{(i)} \times f P C_{(i)}
$$

Considerando un sub grupo funcional de vegetación presente en una celda. Si $(h(k), R(k))$ y $(h(k+1)), R(k+1))$ son las coordenadas de vértices consecutivos que definen el segmento $k$-ésimo para ese subgrupo funcional de vegetación, y $h$ es la altura en la celda, entonces la tasa de flujo ET para el subgrupo, $R(h)$ está dado por,

$$
R(h)=R(k)+\frac{h-h(k)}{h(k+1)-h(k)}(R(k+1)-R(k))
$$

Para $h(k) \leq h \leq h(k+1)$

Los valores iniciales son,

$$
h(1)=H S U R F-S x d-A r d
$$

$\mathrm{y}$

$$
R(1)=0
$$


Los valores de vértices $k$ más grandes están dados por,

$$
h(k+1)=h(k)+f d h(k) A r d
$$

y

$$
R(k+1)=R(k)+f d R(k) R \max
$$

Para calcular la tasa volumétrica ET para el subgrupo funcional de vegetación, $R(h)$ se multiplica por el área de la celda (área) y por la cobertura fraccional (fCov):

$$
E T(h)=R(h)(\text { Area }) f C o v
$$

\subsection{APLICACIÓN DE SENSORES REMOTOS EN ZONA DE RIBERA: DESTACANDO LA ESTIMACIÓN DE LA ET}

Los avances en los métodos de micro meteorología y en las técnicas de sensores remotos están produciendo mejores estimaciones de importantes agotamientos de agua como la evaporación y la transpiración. Se espera que dichos avances mejoren el conocimiento del ciclo hidrológico a escala regional (Dahm et al, 2002; Scott et al, 2006).

Los sensores remotos son necesarios como herramienta complementaria para la extrapolación de las medidas micrometeorológicas y locales a escala de árbol o rodal (Goodrich et al, 2000). Los datos provenientes de sensores remotos no proveen por sí solos de información completa sobre las condiciones de la zona de ribera (Congalton et al, 2002). Lonard et al (2000) emplearon fotografía aérea color-infrarrojo (CIR) y estudio de vegetación en campo para investigar el patrón de distribución, composición de especies, y cambios anuales de la vegetación de ribera. A pesar de encontrar tonalidades similares por especies, encontraron dificultades en identificar cada una de las especies en el dosel; sin embargo, destacan que esta técnica tiene un importante valor en el monitoreo de la senescencia y la muerte de árboles en la zona de ribera entre años sucesivos.

Un componente esencial para la estimación de la ET es la determinación del área de distintos tipos o clases de vegetación dentro del corredor de ribera (Goodrich et al, 2000). Sin embargo, el estudio de Congalton et al (2002) demuestra que las imágenes Landsat TM no permiten una adecuada clasificación de la vegetación de ribera; uno de los factores más limitantes de la imaginería satelital actual para el mapeo de la ribera es la resolución espacial.

Dahm et al. (2002) estudiaron la evapotranspiración de un bosque de ribera en el Río Grande (Nuevo México, Estados Unidos) en condiciones semiáridas a escala de corredor de ribera. El método de campo usado para cuantificar la Evapotranspiración real fue el "eddy covariance" en el que los movimientos verticales del aire caracterizan los flujos de energía sobre el dosel. EI IAF se midió utilizando el instrumento LAI-2000 (Li-Cor Inc., Lincoln, NB, U.S.A.) para estimar la estructura del dosel e investigar las relaciones que habían entre la vegetación y la evapotranspiración. "El método de la eddy covariance se basa en el sólido fundamento teórico que establece que la tasa de movimiento hacia arriba del vapor de agua cercano a la superficie es proporcional al tiempo medio del producto entre las fluctuaciones instantáneas del movimiento vertical del aire y la humedad absoluta. Un desarrollo teórico completo y discusión de la instrumentación para llevar a cabo el método es dado por Brutsaert (1982)" (Dingman, 2002). Ese método también se utiliza en los estudios de Dahm et al (2002) y Scott et al (2003, 2004 y 2006).

Para la caracterización de los usos del suelo cercanos a la zona de ribera, se utilizó el Landsat 7 , del cual se observó que carecía de resolución espacial para la clasificación detallada de los tipos dominantes de vegetación que existían en el bosque ripario y las categorías arbustos-matorrales. Se cita el satélite IKONOS de resolución espacial 4-m como oportuno para mejorar la exactitud de clasificación de la zona riparia a lo lardo del corredor fluvial. Sumado a ello, la medición del 
IAF en los diversos sitios estudiados parece un método promisorio para ayudar a estratificar las diferentes coberturas del bosque (Dahm et al, 2002)

De acuerdo con Nagler et al (2005), se utilizan dos aproximaciones para la predicción de ET a partir de datos de sensores remotos: los modelos físicos y los modelos empíricos que relacionan la ET con medidas de un "índice de vegetación" (VI) en la época de crecimiento. Esas aproximación son también las más comunes para estimar el IAF a partir de imágenes satelitales; la mayor ventaja de la modelación es que es físicamente basada y es independiente del tipo de vegetación, y requiere medidas multidireccionales que están disponibles en sensores como AVHRR, VEGETATION y MISR (Qi et al, 2000).

Mediante datos del sensor remoto MODIS (Moderate Resolution Imaging Spectrometer) y datos meteorológicos de campo, Nagler et al (2005) desarrollaron un modelo de "índice de vegetación" (VI) para predecir la ET de un bosque de ribera. Las medidas en campo se hicieron mediante la técnica de "eddy covariance". La ecuación de regresión múltiple utilizada en la predicción fue:

$$
E T=0.47\left(1-\exp ^{\left(-2.28 E V I^{*}\right)}\right)\left(T_{a}-15\right)+0.77
$$

Donde ET [mm día ${ }^{-1}$ ], EVI es el índice de vegetación mejorado (calculado a partir de imágenes MODIS) y $T_{a}$ es la temperatura máxima diaria en la torre de medición micrometorológica.

Se encontraron problemas relacionados con el ancho limitado del corredor de ribera (es decir, baja resolución de los píxeles comparados con el ancho de la ribera), pues estimaciones de ET a partir de las temperaturas de la superficie del suelo de MODIS aportaron poco detalle para una medida exacta. Sin embargo, los índices de vegetación (VI) pueden usarse como herramientas de transferencia de escala para la predicción de ET siempre que se tengan medidas de campo; hasta que se tenga una relación más general entre estas dos variables, será posible usar solamente datos de sensores remotos (Nagler et al, 2005).

En el estudio de Nagler et al (2005) se pudieron predecir valores de ET sin requerir de ecuaciones específicas de especies vegetales, lo cual es significativo para zonas de vegetación mixta difícil de un mapeo a nivel de especie vegetal.

Loheide y Gorelick (2005) en el contexto de la restauración de la zona de ribera, proponen un algoritmo para el mapeo de la ET, que solamente requiere datos de flujo de calor en el suelo (proveniente de estaciones locales de campo) e imágenes térmicas de sensores remotos. La metodología propuesta permite la obtención de consumo diario de agua por ET en áreas relativamente uniformes y topografía llana para cualquier día en que se colecte información térmica de sensores remotos; dichos estimados poseen una exactitud de aproximadamente un $10 \%$ de la ETP, pero se señalan algunas restricciones.

También dentro de dicho contexto, y considerando un análisis histórico de una llanura de inundación, Oetter et al (2004), proponen un método basado en SIG para identificar lugares potenciales para restauración de la zona de ribera, utilizando recursos cartográficos y fotográficos. De forma similar, Rüger et al (2005) proponen la incorporación de un índice de hábitat ribereño (basado en geomorfología, nivel freático y régimen de inundaciones) en un SIG con el fin de contar con una herramienta más útil para la toma de decisiones.

Nagler et al (2001) estudiaron las relaciones entre tres índices de vegetación ("Vl" para sensores remotos) comúnmente utilizados, índice de área foliar "IAF", y el porcentaje de cobertura de vegetación, para encontrar correlaciones con factores del suelo en un paisaje de ribera complejo en México. Se encontró que la variabilidad del IAF global para zonas de ribera, responde más al porcentaje de cobertura, que a variaciones de IAF de las especies. Así, los índices de vegetación se relacionan de una forma más simple con el porcentaje de cobertura, que con diferencias de IAF o VI de las especies, incluso en este bioma mixto de ribera.

En el estudio de Nagler et al (2004) se utilizó el IAF para encontrar la fracción de luz incidente interceptada por vegetación de ribera $(f I R)$, utilizando el coeficiente de extinción de luz " $k$ " y de 
esta manera compararlo con el índice de vegetación de diferencia normalizada (NDVI) proveniente de fotos aéreas. La expresión utilizada es

$$
f I R=\left(1-e^{-k I A F}\right)
$$

Se probó que el NDVI es útil para determinar la fracción de cobertura vegetal y estimar las propiedades de radiación de los doseles en el bioma, y que en combinación con medidas del IAF y propiedades de reflectancia foliar, se pueden predecir los coeficientes de extinción de luz para diferentes tipos de vegetación (Nagler, 2004).

Posteriormente, Nagler et al (2005a) señalan que el uso combinado de un índice de vegetación mejorado (EVI) del satélite MODIS, con medidas de campo de ET y temperatura máxima diaria, permite estimar tasas de ET válidas tanto para grandes extensiones de hábitat ribereño como para asociaciones de plantas individuales dentro del corredor de ribera, con un error potencial aproximado de $25 \%$. Las tasas de ET estimadas fueron mucho menores que aquellas a partir de balances hídricos usando métodos de coeficientes de cultivo para la zona de estudio.

Qi et al (2000) proponen un método para estimación del IAF con base en modelos BRDF (del inglés "bidirectional reflectance distribution function") y métodos de procesamiento de índices de vegetación "VI" (de sensores remotos). Ya que la propuesta es independiente del tipo de vegetación, puede aplicarse "fácilmente" a imágenes adquiridas sobre grandes áreas si la de interés consiste de tipos de vegetación similares; por lo tanto el método está limitado a áreas de similar tipo de vegetación y fenología.

\subsection{OTROS MODELOS RELEVANTES QUE ABORDAN PROCESOS INTERNOS (HIDROLOGÍA Y VEGETACIÓN) DE LA RIBERA}

A continuación se presentarán aquellos aportes que se han considerado más trascendentes para la conceptualización del trabajo de investigación que se está realizando (además de lo ya tratado sobre el modelo RIP-ET y la ET en el modelo REMM).

\subsubsection{Modelo de vegetación - hidrología de ecosistemas de ribera de Prosopis velutina (Stromberg, 1993)}

Los modelos que integran el agua subterránea y la estructura del rodal de especies arbóreas ribereñas, permiten determinar de forma potencial los requerimientos de agua subterránea para el mantenimiento del rodal ribereño y predecir los posibles efectos en la estructura de la vegetación. Por otra parte, los modelos empíricos desarrollados con datos de potenciales hídricos de la planta son útiles para el manejo de la ribera, pues esta variable responde rápidamente a condiciones hidrológicas cambiantes, y es valiosa como un detector de advertencia de cambios (aún y cuando los efectos de los bajos potenciales hídricos no sean inmediatos). Los modelos transversales de hábitat que usan tanto el potencial hídrico como la estructura de la vegetación pueden predecir que la estructura de un sitio ribereño dado, con determinadas profundidades del nivel freático y potenciales hídricos, puede degradarse hacia una estructura de dosel típica de zonas de ladera.

Este estudio con un fuerte componente ecofisiológico y monitoreo en campo, consiste en modelos para rodales de la especie Prosopis velutina a través de un gradiente de humedad xérico a mésico. Dichos modelos expresan la altura del dosel, el área basal, el índice de área foliar y el volumen de vegetación como funciones del potencial hídrico de la planta, y expresan el potencial hídrico de la planta y la estructura del rodal de ribera como funciones de la profundidad del nivel freático. Los datos indicaron que la estructura del rodal se relacionó fuertemente con la disponibilidad de agua.

Stromberg (1993) a partir de información empírica, concluyó que para una cuenca semiárida, la riqueza y abundancia de especies de un bosque de ribera mixto deciduo variaba de una forma curvilínea y cuantificable, como función de parámetros de flujo del río. Observó que tres 
indicadores de la abundancia de vegetación de ribera (área foliar, área basal del tronco, ancho del rodal) se incrementaban significativamente con el flujo en la época de crecimiento, que es un indicador de la disponibilidad de agua. La mayor riqueza de especies se daba en ríos con inundaciones de magnitud media. Los modelos del flujo interno del río sugieren que el volumen de flujo (y atributos relacionados con la recarga del nivel freático y humedad del suelo de la llanura aluvial) es el factor principal en la regulación de la abundancia de la vegetación de ribera en el área analizada. Los resultados se expresaron como una primera aproximación de la medida de pérdida esperada de ribera a partir del desvío u otros tipos de reducción del flujo.

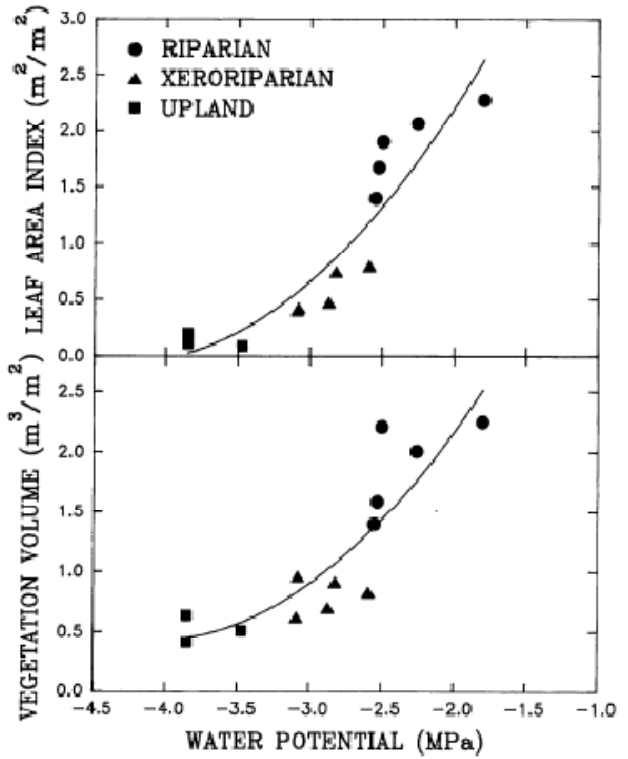

Fig 5.10 Índice de área foliar y volumen de vegetación para rodales dominados por Prosopis velutina (variables y), como función de los potenciales hídricos medios estacionales de la planta (variable $\mathbf{x}$ ). Las ecuaciones de regresión respectivas son: $y=7.9+3.8 x+0.44 x^{2} ; r^{2}=0.82, P<0.01 ; y=7.3+3.4 x+$ $0.42 x^{2} ; r^{2}=0.76, P<0.01$. Tomado de Stromberg et al (1993).

Las variables de vegetación utilizadas en este modelo incluyen el IAF y el volumen de vegetación (como indicadoras de la biomasa del rodal), la máxima altura del dosel y el área basal (como indicadoras de la estructura del rodal), y otras variables de longitud, área y número de hojas. Además se ha utilizado como variable independiente el potencial hídrico de la planta y no el del suelo, debido a la "dificultad de medir la disponibilidad de agua del suelo a lo largo de sistemas con múltiples fuentes de aguas que son usadas de forma diferencial (entre ellos precipitación, flujos efímeros del río, agua subterránea)"; se asumió que el potencial hídrico de la planta es definido principalmente por el contenido de humedad del suelo. Dichos potenciales difirieron significativamente entre todos los tipos de hábitat, con decrecimientos para especies de ribera xéricas y especies de ladera, pero manteniéndose constantes en el tiempo para árboles ribereños (Stromberg, 1993).

Posteriormente se desarrollaron métodos para relacionar estas variables con la profundidad del agua subterránea. En la Fig (5.10) se observa que las variables de la estructura del rodal variaban de forma altamente significativa como función del potencial hídrico vegetal; las relaciones entre el potencial hídrico y el IAF, el volumen de vegetación, la altura del dosel, y el área basal fueron curvilíneas (Stromberg, 1993).

Los modelos de nivel freático pueden ser inapropiados para casos en los que la especie forestal ribereña se abastezca de otras fuentes de agua diferentes a la subterránea (Stromberg, 1993).

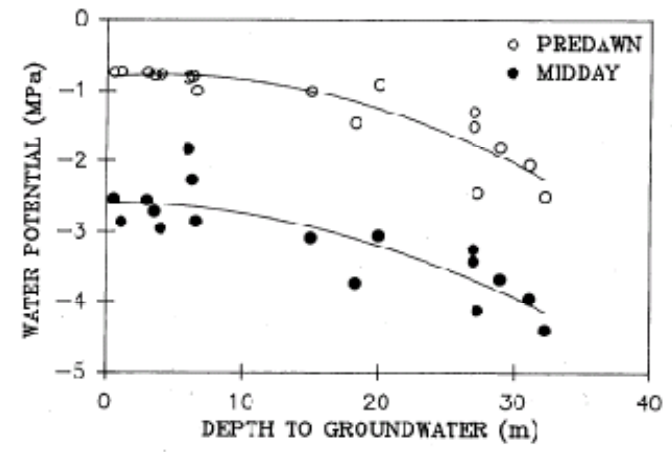

Fig 5.11. Potenciales hídricos estacionales previo al amanecer (predawn) y al medio día (midday) de Prosopis velutina (variable y) como función de la profundidad del nivel freático (variable $x$ ). Profundidades $>10 \mathrm{~m}$, resultaron del bombeo de agua subterránea. Las ecuaciones de regresión respectivas son: $y=-0.81+0.015 x+0.0018 x^{2} ; r^{2}=0.82, P<0.01 ; y=-$ $2.57+0.0016 x+0.0014 x^{2} ; r^{2}=0.73, P<0.01$. Tomado de Stromberg et al (1993). 
Los valores de potencial hídrico usados para desarrollar este tipo de modelos pueden variar con las condiciones climáticas anuales o estacionales, particularmente para rodales de ladera que crecen en un ambiente con precipitaciones de alta estocasticidad. La exactitud de las curvas deberá mejorarse mediante un mayor monitoreo de los potencial hídricos y explorando las relaciones entre el potencial hídrico y cambios en las condiciones del nivel freático (Fig. 5.11); sin embargo son útiles como una primera aproximación para evaluar el efecto de la reducción del recurso hídrico sobre el hábitat de ribera (Stromberg, 1993).

\subsubsection{Riparian Ecosystem Management Model "REMM" (Altier et al, 2002; Inamdar et al, 1999a; Lowrance et al, 2000)}

Este modelo se desarrolló para predecir la influencia de los ecosistemas forestales de ribera sobre la calidad del agua de los ríos, al reducir los aportes de nutrientes y pesticidas de las laderas agrícolas aledañas. Es un modelo altamente complejo y muy completo por su base física y procesos simulados, que requiere de una gran cantidad de información a detalle a escala de la zona de ribera (suelo y vegetación, mayormente) y del medio circundante (condiciones del tiempo y aportes provenientes de la ladera); pese a la complejidad, se logra una buena predicción de la capacidad amortiguadora de la ribera y la sensibilidad de esa respuesta a factores como la porosidad del suelo, clave de muchos de los procesos hidrológicos simulados (Altier et al, 2002; Inamdar et al, 1999a; Lowrance et al, 2000).

Su diseño corresponde a áreas de ribera que cumplen con las especificaciones sugeridas por el "Riparian Forest Buffer System" del USDA de los Estados Unidos (Welsch, 1991) y su arreglo en tres zonas características por su función y distancia al río.

La discretización espacial para el marco de los procesos simulados, corresponde a cinco capas verticales (una de vegetación, una de "litter" o capa orgánica superficial del suelo, y tres capas del suelo). La escala temporal del modelo es la diaria y está diseñado para simular la hidrología superficial y subsuperficial, la dinámica de nutrientes y el crecimiento vegetal en la zona de ribera; simula por tanto, procesos físicos y biológicos.

En este modelo, la interacción cauce-ribera se simula en aquellos momentos en donde, eventualmente, el flujo subsuperficial se mueve de la zona 1 al cauce basado en gradientes entre el nivel de agua en la zona 1 y el lecho del cauce. La escorrentía superficial puede infiltrarse con base en la capacidad de almacenamiento y en una modificación de la ecuación de Green-Ampt, y también en función de la profundidad y velocidad del flujo. La escorrentía superficial que no se infiltra se mueve hacia el cauce. Los input externos para el balance de agua incluyen la precipitación diaria y el flujo superficial y subsuperficial diario de las laderas adyacentes (Altier et al, 2002).

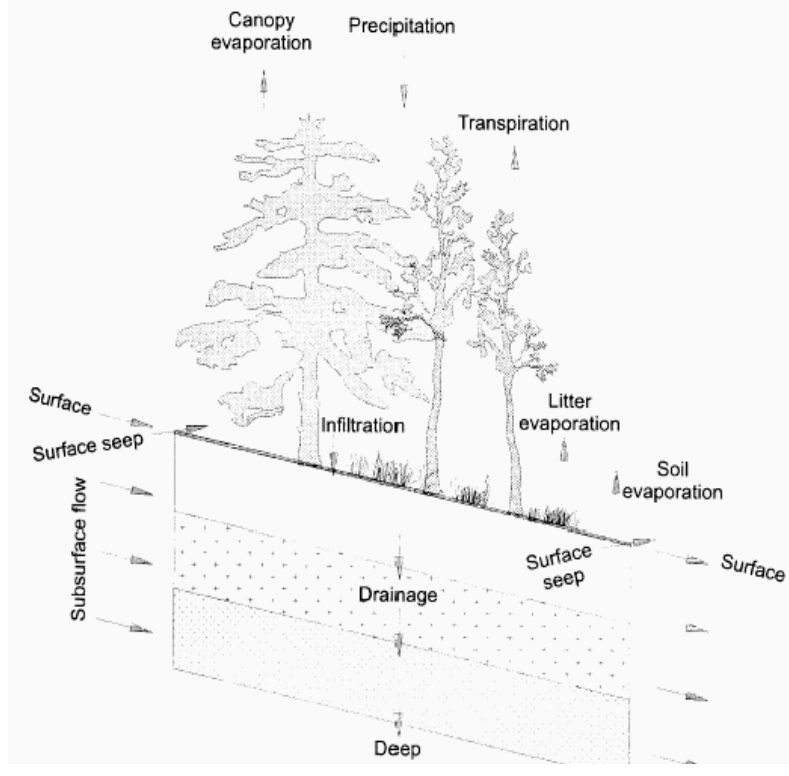

Fig 5.12. Movimientos de agua simulados por el modelo REMM. Tomado de Altier et al (2002).

En REMM se utiliza el balance hídrico para estudiar el movimiento del agua a través y el almacenamiento interno, de la zona de ribera, incluyendo consideraciones de la intercepción, evapotranspiración y flujo superficial y subsuperficial. Considerando la visión de la ribera como zona de amortiguamiento, es sin duda el modelo matemático más completo. Los movimientos de agua simulados son los descritos en la Figura 5.12; sin embargo aún no se incorporan otros movimientos que destacan otros estudios, referidos al ascenso capilar, la redistribución hidráulica por las raíces de las plantas, el movimiento de agua del cauce a la 
zona de ribera (interacción nivel del río - nivel freático).

EI REMM calcula en un principio el movimiento vertical subsuperficial, seguido de un movimiento horizontal, después de la precipitación. Los output del balance de agua simulado incluyen la evapotranspiración diaria (descrito previamente en este documento), la percolación profunda, y las pérdidas superficiales y subsuperficiales al cuerpo de agua; esas condiciones reportadas para un día en particular constituyen la variable de estado del día siguiente. La ecuación de balance de agua para cada capa de cada zona en REMM es:

$\theta_{[t]}=\theta_{[t-1]}+Q_{V-i n[t]}-Q_{V-o u t[t]}+Q_{H-\text { in }[t]}-Q_{H-o u t[t]}-E T_{[t]}$

Donde en el día $t, \theta_{\mathrm{t}}$ es la humedad del suelo $(\mathrm{mm}) ; \theta_{[t-1]}(\mathrm{mm})$ es la humedad del suelo del día precedente; $Q_{V-i n[t]}(\mathrm{mm})$ es la adición de agua debido a la infiltración; $Q_{V-o u t[t]}(\mathrm{mm})$ es el agua que drena fuera de la capa; $Q_{H-i n[t]}(\mathrm{mm})$ es la contribución debida al flujo subsuperficial lateral; $Q_{H-o u t[t]}(\mathrm{mm})$ es la salida de agua en forma de flujo subsuperficial hacia zonas más bajas; $E T_{[t]}$ (mm) es la evaportranspiración (Inamdar et al, 1999).

El drenaje vertical ocurre cuando la humedad del suelo excede la capacidad de campo. La cantidad drenada de una capa de suelo también depende de su capacidad receptora. La tasa de drenaje se iguala a la menor de las conductividades hidráulicas de las capas drenante y receptora. La conductividad no saturada se simula como función del contenido de humedad del suelo usando la ecuación de Campbell.

En presencia de un nivel freático poco somero, las capas del suelo que están por encima ("overlying") se mantienen a elevados (menos negativos) potenciales mátricos y consecuentemente elevados contenidos de humedad del suelo. Asumiendo que la capa del suelo está en equilibrio con el nivel freático, el potencial mátrico en el punto medio de una capa de suelo puede determinarse asumiendo que la carga hidráulica en aquel punto es igual en magnitud a la altura del punto encima del nivel freático. El contenido de humedad en este punto se determina entonces, usando la curva de retención de humedad, relacionando el potencial mátrico con el contenido de humedad del suelo y descrito por la ecuación de Campbell (Inamdar et al, 1999).

El flujo ascendente estacionario ocurre del nivel freático a la capa del suelo para volver a llenar las pérdidas por ET de esta capa. Dicho flujo ocurre en respuesta al gradiente de potenciales mátricos entre la capa del suelo y la superficie del nivel freático. La tasa del movimiento ascendente se determina mediante el gradiente de potencial mátrico, la conductividad hidráulica no saturada y la profundidad del nivel freático debajo de esa capa del suelo. El flujo de ET en el punto $p$, a una distancia $z$ por encima del nivel freático, puede describirse usando la ecuación de Darcy Buckingham:

$$
\frac{\partial h}{\partial z}=\frac{E}{K(h)}+1
$$

Donde, $h$ es el potencial mátrico $(\mathrm{mm})$; $z$ es la distancia (en metros) del punto al nivel freático (ascenso positivo); $\frac{\partial h}{\partial z}$ expresa el gradiente de potencial mátrico; $E$ es el flujo ascendente de agua desde el nivel freático $(\mathrm{mm}) ; K(h)$ es la conductividad hidráulica no saturada de la capa del suelo expresada como una función del potencial mátrico $h\left(\mathrm{~mm} \mathrm{hr}^{-1}\right)$ (Altier et al, 2002). 


\subsubsection{Modelación de las interacciones de la vegetación con el flujo del cauce en valles aluviales de la región mediterránea (Brookes et al, 2000)}

Este modelo se desarrolló dentro del programa de investigación MEDALUS (Mediterranean Desertification and Land Use), para simular los cambios morfológicos en cauces y llanuras de inundación de ríos efímeros sobre escalas temporales de un año hasta décadas. Se diseñó para la simulación de secuencias de eventos y condiciones en términos de la escala, tipo y distribución espacial de cambios en las características, sin buscar la predicción exacta de cambios en cada punto de la ribera.

Es un modelo espacialmente distribuido para áreas semiáridas y sub-húmedas, que integra los factores internos y externos a la ribera, y aunque se enfoca también en aspectos hidráulicos y morfológicos, sobre todo los relacionados con los eventos de crecidas, es de destacar su submodelo de vegetación de ribera acoplado al submodelo de humedad del suelo (para la incorporación de procesos hidrológicos de la ribera). Dentro del módulo de vegetación la disponibilidad de agua es un control crucial, que viene transferida desde el módulo de humedad. Las condiciones de vegetación y contenido de humedad del suelo cambian entre eventos como resultado de variaciones en temperatura y precipitación y otras condiciones del tiempo, en intervalos mensuales. La ET varía con la temperatura y el agua disponible, y se asume la misma ET para todos los tipos de vegetación y suelo descubierto.

Se clasifica la vegetación en tipos funcionales y se propone evaluar sus respuestas en términos de su crecimiento. Los PFT se subdividen a su vez en cuatro fases de crecimientos: brote, juvenil, maduro, muerto. Se plantea un límite de edad en meses para cada una de esas cuatro fases. En el análisis del módulo de vegetación se ha utilizado la herramienta Arc/Info GIS.

Posteriormente, se plantea una base conceptual para incluir el estado (o nivel de estrés) de la vegetación y su resistencia a la sequía (que se incrementa conforme se acumula el tiempo en que se superan los umbrales de estrés de humedad y temperatura); dicha base establece que bajo ciertos umbrales de temperatura y/o humedad la planta crece o no lo hace, en una especie de intercambio (o "trade-off" según Crawley, 1997); sin embargo, para umbrales menores se establece un estrés para la planta y eventualmente una muerte. En otras palabras, se tiene que:

- Ocurre el crecimiento si temperatura y humedad > umbral y no es época de latencia.

- Ocurre el estrés si la temperatura > un umbral o si la humedad < umbral (tabla 5.2).

- Ocurre la muerte si el estrés > límite de estrés (tabla 5.3); ocurre también si la edad > edad límite (elemento estocástico por tablas). Se da un cambio a estado de muerte o suelo descubierto.

Tabla 5.2. Umbrales de humedad, donde los valores están en milímetros [mm] de agua disponible. Tomado de Brookes et al (2000).

\begin{tabular}{llll} 
& Stress threshold & Growth threshold & Germination threshold \\
\hline Bare ground & $>999$ & $>999$ & $>999$ \\
Herb seedlings & $<50$ & $>50$ & $>70$ \\
Herb juveniles & $<100$ & $>100$ & $>70$ \\
Herb matures & $<100$ & $>200$ & $>70$ \\
Dead herbs & $>999$ & $>999$ & $>999$ \\
Shrub seedlings & $<100$ & $>100$ & $>150$ \\
Shrub juveniles & $<100$ & $>200$ & $>150$ \\
Shrub matures & $<50$ & $>150$ & $>150$ \\
Dead shrubs & $>999$ & $>999$ & $>999$ \\
Tamarisk seedlings & $<200$ & $>200$ & $>300$ \\
Tamarisk juveniles & $<100$ & $>100$ & $>300$ \\
Tamarisk matures & $<0$ & $>0$ & $>300$ \\
Dead tamarisk & $>999$ & $>999$ & $>999$ \\
\hline
\end{tabular}


Señalan que aunque dichos umbrales de estacionalidad y condiciones locales no estén identificados, es posible hacerlo con base en revisión de literatura, monitoreo de campo o conocimiento ecológico experto. Los coeficientes de estos procesos provienen de tablas como las que se muestran aquí (Tablas 5.2 y 5.3), y que dentro del modelo se pueden evaluar y cambiar.

Los valores de las tablas de parámetros anteriores (Tablas 5.2 y 5.3), en muchos casos, son ejemplos o los mejores estimados con los que se cuenta. Donde aún no exista una guía disponible de literatura o datos de campo, entonces se deben correr pruebas con un rango de valores. De acuerdo con los autores, la propuesta dada y los supuestos hechos son viables y apropiados para el propósito y escala de modelación llevados a cabo.

Tabla 5.3. Meses de estrés acumulado de las plantas antes de su muerte. Tomado de Brookes et al (2000).

\begin{tabular}{|c|c|c|c|c|c|c|c|c|c|c|c|c|}
\hline $\begin{array}{l}\text { Bare } \\
\text { ground }\end{array}$ & $\begin{array}{l}\text { Ilerb } \\
\text { seed- } \\
\text { lings }\end{array}$ & $\begin{array}{l}\text { Ilerb } \\
\text { juve- } \\
\text { niles }\end{array}$ & $\begin{array}{l}\text { IIero } \\
\text { matures }\end{array}$ & $\begin{array}{l}\text { Dead } \\
\text { herbs }\end{array}$ & $\begin{array}{l}\text { Shrub } \\
\text { seed- } \\
\text { lings }\end{array}$ & $\begin{array}{l}\text { Shrub } \\
\text { juve- } \\
\text { niles }\end{array}$ & $\begin{array}{l}\text { Shrub } \\
\text { matures }\end{array}$ & $\begin{array}{l}\text { Dead } \\
\text { shrubs }\end{array}$ & $\begin{array}{l}\text { Tamarisk } \\
\text { seed- } \\
\text { lings }\end{array}$ & $\begin{array}{l}\text { Tamarisk } \\
\text { juve- } \\
\text { niles }\end{array}$ & $\begin{array}{l}\text { Tamarisk } \\
\text { matures }\end{array}$ & $\begin{array}{l}\text { Dead } \\
\text { tamarisks }\end{array}$ \\
\hline 0 & 0 & 0 & 1 & 999 & 0 & 1 & 3 & 999 & 0 & 1 & 999 & 999 \\
\hline
\end{tabular}

\subsection{ANOTACIONES SOBRE MODELOS ENFOCADOS EN FACTORES EXTERNOS A LA RIBERA O EN EL EFECTO DE LAS INUNDACIONES}

Para ciertas condiciones es posible que la escorrentía de la ladera llegue directamente a la zona de ribera, tanto mediante escorrentía directa o interflujo (Tabacchi et al., 1998). Se tiene poco conocimiento de la hidrología de la zona riparia cercana a los ríos en cuencas húmedas. En el examen de aspectos espacio-temporales de los flujos en zonas de ribera durante el derretimiento de la nieve, se ha analizado el rol de la zona de ribera en la regulación de las fuentes de agua para el cauce y las interacciones complejas entre la ladera, la zona de ribera y el cauce (McGlynn et al, 1999).

Utilizando cálculo distribuido se ha demostrado que el potencial de las zonas de ribera de amortiguar la escorrentía de la ladera depende parcialmente del tamaño de dicha zona ribereña en relación al de la ladera adyacente (McGlynn y Seibert, 2003). Por su parte McGlynn y McDonnell (2003) cuantificaron las contribuciones de las laderas y las zonas de ribera para el flujo del río, en lo que ellos señalan como el primer estudio que muestra claramente esas contribuciones separadas durante un evento de crecida, en función de la hidrometría, el análisis isotópico y de solutos.

Bent (2001) evaluó los efectos que provocan actividades de manejo forestal en la ribera sobre los componentes de la escorrentía (flujo total del río, escorrentía directa y flujo base) y sobre la recarga de agua subterránea por unidad de área. A partir del flujo medio diario del río, se determinó el flujo base mediante el programa PART, y la recarga del agua subterránea mediante el programa RORA.

Se ha demostrado que asociaciones forestales de Populus fremontii y Salix gooddingii dependen ampliamente de las cantidades de agua y patrones específicos de inundación (Stromberg, 2001). Algunos modelos como el denominado "Recruitment box" (la "caja de regeneración") de Mahoney y Rood (1998), vinculan los requerimientos para el establecimiento de Populus con las tasas de recesión post inundación, estado del río y tiempo de inundación.

Phipps (1979) diseñó un programa de cómputo denominado SWAMP, para simular los efectos de la frecuencia de inundación y la profundidad del nivel freático sobre las dinámicas de bosques de humedales, incorporando características hidrológicas dentro de dicho modelo. 
Pearlstine et al (1985) modelaron los impactos que ocasionó la desviación de un río sobre una comunidad forestal (crecimiento y sucesión vegetal), mediante el desarrollo del modelo "FORFLO". Usaron parámetros hidrológicos como los controles mayores para la germinación de las semillas, el crecimiento y la mortandad forestal. Se usaron las respuestas individuales de especies a esos parámetros para predecir la sucesión (composición de especies) en los sitios simulados.

Pearlstine et al (1985) proponen la modelación de los impactos del cambio del régimen hídrico en las comunidades forestales de las tierras bajas. Se usaron parámetros hidrológicos como los principales responsables de la germinación de las semillas, el crecimiento y la muerte de los árboles y sirvieron para simular la sucesión vegetal en determinados sitios, con la ayuda de un mapeo en SIG. Proponen el modelo denominado FORFLO.

Los modelos FORFLO (Pearlstine et al, 1985) y SWAMP (Phipps, 1979) son modelos que intentan simular la sucesión vegetal en las llanuras de inundación. En ellos, se toman en cuenta de forma parcial los efectos de las inundaciones, la altura del agua de inundación, la tolerancia a la sombra, la probabilidad de muerte y la reproducción de los árboles; parten de supuestos muy simplificados para las especies, sin hacer un intercambio directo con modelos hidráulicos y geo morfológicos.

Toner y Keddy (1997) relacionaron la hidrología del río y los humedales de ribera, mediante un modelo de predicción ecológica, enfocada a ambientes húmedos templados con vegetación de ribera herbácea y arbórea de humedal. Utilizaron modelos de regresión lógica para describir la distribución del humedal arbóreo como función de todas las posibles combinaciones de siete variables hidrológicas (la profundidad, duración y temporalidad de las inundaciones). Se observó que la reducción de las inundaciones y los caudales mínimos por el río a menudo conllevaban la sucesión de ambientes herbáceos a bosques de humedal.

Dentro del alto número de modelos enfocados en la relación entre la vegetación de ribera y la geomorfología e hidráulica fluvial, algunos más recientes son los de Abernethy y Rutherfurd (1999), Bennett (2004), Brookes y Shields (2001), Fischenich (2000), Järvelä (2004), Kouwen (2003), Micheli et al (2004), Miller et al (2003), Simon et al (2004), Simon y Collison (2002). La revisión de esos avances del conocimiento rebasan los objetivos del presente trabajo.

Gautier et al (2000) demostraron una gran variabilidad espacial en la complejidad del mosaico fluvial a lo largo del corredor del río y cierta independencia entre las características del bosque y las formas de los cauces; la base de su trabajo es una aproximación metodológica basada en análisis estadístico de variables hidrogeomorfológicas y biogeográficas, complementadas por tipología de la ribera y mapeo.

Deng y Singh (2002) desarrollaron relaciones entre el patrón del cauce (caracterizado por la sinuosidad) y las funciones del río, con base en la teoría de la mínima potencia del río ("minimum stream power"), en el principio de la máxima entropía y datos de campo.

\subsection{ANOTACIONES SOBRE MODELOS ENFOCADOS EN GESTIÓN FORESTAL Y RESTAURACIÓN DE LA ZONA DE RIBERA}

Sparovek et al (2002) proponen un marco conceptual para la definición del ancho óptimo de los bosques de ribera. El marco conceptual describe los principios de un procedimiento que usa datos usualmente disponibles (mapas topográficos, de uso del suelo y datos del suelo) para determinar dicho ancho óptimo de forma cuantitativa y con una base georeferenciada.

El modelo de decisión de recursos hídricos de Hornbeck y Smith (1997) diseñado para gestores forestales, se basa en la selección de uno de seis posibles sistemas silviculturales, tomando en cuenta datos del bosque y de precipitación. Los resultados del modelo son los impactos en la calidad y cantidad de agua que ocasiona el sistema silvicultural recomendado; esos impactos se proveen en forma de texto y tablas. 
De acuerdo con Hanson et al (1990), los modelos de simulación del crecimiento forestal desarrollados a nivel de rodal, no han permitido establecer el impacto de la estructura principal del paisaje y la fragmentación forestal en la dinámica forestal en áreas extensas. Por ello proponen un modelo en el que se incluye la dispersión de las especies forestales y el vínculo con los regímenes de inundación.

Welty et al (2002) proponen el modelo RAIS (Riparian Aquatic Interaction Simulator) a través de un sistema analítico que une cuantitativamente los sistemas de monitoreo de bosques con las funciones del ecosistema de ribera de captación de grandes desechos de madera y sombra. Integra componentes "clave" de otros modelos para simular el manejo forestal de múltiples especies en cuatro bandas de ribera de ancho variable, predecir los impactos en la regeneración y evaluar cambios en la sombra al río.

Carter et al (1995), con base en mapas y SIG, estudiaron escenarios de flujo en el río para predecir espacialmente el comportamiento de las zonas de ribera en cuanto a regeneración vegetal. Se observó un descenso en la elevación de la zona de ribera comparable al descenso en el nivel medio del río y una expansión de la zona de ribera baja hacia zonas llanas del cauce.

Richards et al.(2002) aportan elementos importantes para la restauración integrada de ríos, considerando aspectos ecológicos, como respuesta a la pérdida de riqueza natural debida a las acciones para el control de avenidas, la gestión de recursos hídricos, la canalización y usos de la tierra que han separado al río de su zona de ribera y llanura aluvial.

La dinámica del cauce depende del tipo de interacciones entre el río y la llanura de inundación, lo cual puede resumirse en modelos de la arquitectura de la llanura de inundación, normalmente olvidados en la literatura ecológica. Se ha propuesto hacer una modelación simple que acople modelos hidrodinámicos-ecológicos que capturen las dinámicas del cauce y de sucesión vegetal, que pudiera servir para explorar los impactos de la gestión fluvial en la biodiversidad de la llanura de inundación (Richards et al., 2002).

Se propone una modelación de la dinámica del cauce en función del tipo de cauce, haciendo la simplificación en dos tipos: meándrico o ramificado (Richards et al., 2002). Se propone el modelo de migración de cauces y sedimentación en llanuras de inundación de Howard (1992) para ríos meándricos, que incluye componentes de flujo, topografía del lecho, transporte de sedimentos, relaciones entre la altura del margen y la velocidad de erosión.

Glenz (2001) y Glenz et al (2003), proponen la modelación de las dinámicas del bosque de ribera mediante la cuantificación de procesos hidráulicos y geomorfológicos. Señalan que los modelos ecológicos actuales de sucesión forestal, como los llamados modelos GAP del tipo JABOWA, se diseñaron para aplicaciones en tierras altas y no contabilizan adecuadamente los procesos hidráulicos y geomorfológicos de extrema importancia para ríos con elevadas energías. Existen vacíos significativos de conocimiento en procesos relevantes y valores de parámetros, especialmente relacionados a la interacción entre la geomorfología y la dinámica de vegetación. Sin embargo, se argumenta que la modelación basada en propuestas disponibles puede proveer resultados útiles, especialmente si están acompañados de un análisis cuidadoso de incertidumbre y sensibilidad.

Glenz et al (2003) proponen un conjunto de procesos relevantes y presentan un intento de acoplar distintas aproximaciones de modelación. La formulación propuesta acentúa los procesos ecológicos y adopta módulos hidráulicos y geomorfológicos relativamente simples; lo último enfatiza en la dimensión lateral, como las áreas riparias caracterizadas por gradientes laterales pronunciados de factores ambientales, procesos ecológicos y comunidades bióticas.

Según Russell et al (1997) la restauración de humedales a largo plazo requiere de la consideración de la hidrología y uso del suelo aledaño durante los procesos de selección de sitio. Proponen un criterio de selección inicial que utiliza información a escala de cuenca con base en la topografía y cobertura del suelo para calificar la viabilidad potencial de todos los sitios dentro de una cuenca tanto para preservación como para restauración. La propuesta requiere el uso de 
un sistema de información geográfica para hacer el mapa de la humedad relativa y cobertura vegetal dentro de una cuenca. Se reconocieron como sitios potenciales de preservación aquellos con valores medios o altos de humedad y vegetación existente. Zonas agrícolas o sitios baldíos con humedad media o alta se identificaron como sitios potenciales de restauración.

\subsection{ALGUNOS SITIOS WEB RELACIONADOS CON ECOSISTEMAS DE RIBERA}

Diversos grupos de investigación de universidades como de entidades estatales o de carácter internacional proveen de una vasta cantidad de información sobre la zona de ribera. Como complemento a la revisión del estado del conocimiento realizado, vale la pena mencionar algunos sitios web que aportan más información:

\section{CON ÉNFASIS EN LA GESTIÓN Y RECUPERACIÓN DE LA ZONA DE RIBERA}

El proyecto de investigación FLOBAR (Floodplain Biodiversity and Restoration), que si bien se enfoca en el tema de la restauración ha dado énfasis a investigar y discutir sobre procesos externos e internos de la ribera, con una visión multidisciplinaria y la participación multinacional de centros de investigación europeos y de Canadá:

http://www.geog.cam.ac.uk/research/projects/tlobar2/

EI USDA presenta una serie de vínculos que aportan conocimiento para la modelación y para la gestión y restauración de las zonas de ribera, tanto de los Estados Unidos como de otros países: http://www.stream.fs.fed.us/RelatedWebsites/

Dentro de la estrategia del US Forest Service para la conservación de la vida silvestre de ribera, la entidad "Colorado Division of Wildlife" ha trabajado en el mapeo mediante SIG de la zona de ribera y aporta información útil relacionada:

http://ndis1.nrel.colostate.edu/riparian/riparian.htm

EI USFWS Wetland Creation/Restoration (WCR), realizó en 1989 un compendio de literatura sobre el ecosistema de ribera enfocado a su creación y restauración, que resulta interesante para avances del conocimiento de aquella época:

http://www.npwrc.usgs.gov/resource/literatr/ripareco/ripareco.htm\#contents

La agencia federal para la restauración fluvial FISRWG aporta un documento enfocado a la restauración del corredor fluvial:

http://www.nrcs.usda.gov/technical/stream restoration/

El proyecto REAM (Riparian Ecosystem Assessment and Management) diseñado como estudio a largo plazo para la colecta y síntesis de información de diversos aspectos del ecosistema de ribera del norte de Missouri en los Estados Unidos, con enfoque de gestión de recursos naturales:

http://www.snr.missouri.edu/ream/vol2no1.html

El Programa Nacional Australiano de Tierras de Ribera R\&D (Riparian Land) ha elaborado una colección de documentos teóricos y ha desarrollado una serie de publicaciones tipo revista, dentro de lo que se ha planteado un modelo conceptual de ribera con enfoque de gestión y restauración:

http://www.rivers.gov.au/research/rlrd/zoneinteract.htm

Existe un sitio web que destaca el papel de amortiguación de la zona de ribera de nutrientes y contaminantes del agua; se presentan de forma sencilla los principales procesos relacionados con la definición espacial de la ribera, su función y diseño para proteger y mejorar la calidad de los recursos hídricos (Welsch, 1991):

http://www.na.fs.fed.us/spfo/pubs/n resource/buffer/cover.htm 


\section{CON ÉNFASIS EN LA MODELACIÓN DE PROCESOS EN LA RIBERA}

EI REMM (Riparian Ecosystem Management Model) es un modelo de simulación de la hidrología, la dinámica de nutrientes y el crecimiento de las plantas de la ribera con una visión de la zona como amortiguadora de contaminantes para la promoción de la calidad de agua del río:

http://www.tifton.uga.edu/remmwww/

El Proyecto del Río Tisza en Hungría, propone un modelo "integrado" a escala de cuenca que considera también el papel de zonas de ribera húmedas de lagos y ríos:

http://www.tiszariver.com/

EI LAMF (Lake Abitibi Model Forest) es un modelo de gestión forestal no numérico de Canadá, que provee una visión legal en el contexto de la producción y conservación forestal:

http://www.lamf.net/

El modelo RAIS (Riparian Aquatic Interaction Simulator) se creó para acoplar las prácticas de manejo forestal (productividad, crecimiento, corta, etc.) de la ribera con sus impactos en los aportes de grandes desechos al cauce y en la sombra proveída para la regulación de la temperatura del agua del río:

http://www.weyerhaeuser.com/rais.asp

El programa SALSA (Semi-Arid Land-Surface-Atmosphere Program) se ha dedicado a la evaluación de las consecuencias de los impactos humanos en ambientes semiáridos; fruto de esta visión se han hecho grandes aportes en materia de evapotranspiración y otros procesos fisiológicos de la vegetación de ribera, como se mencionó oportunamente:

http://www.tucson.ars.ag.gov/salsa/salsahome.html

Otros modelos que no se diseñaron específicamente para la zona de ribera, pero que destacan por su relación con la hidrología de la zona no saturada son los siguientes:

- El Retention Curve Computer Code, que es una herramienta de simulación y optimización, que parte de la teoría de la zona no saturada y la curva de retención de humedad:

http://eco.wiz.uni-kassel.de/model db/mdb/retc.html

- El modelo Hydrus-1D que es un modelo en ambiente "Windows" para el análisis del flujo de agua y el transporte de solutos en medios porosos de distinto grado de saturación:

http://typhoon.mines.edu/software/igwmcsoft/

El modelo PHABSIM del USGS en el contexto del sistema fluvial ("instream") y con enfoque de productividad de peces, trabaja con la vegetación de ribera en el marco de la estructura física del hábitat destacando el enfoque hidráulico. Se puede encontrar en:

http://www.mesc.usgs.gov/products/software/phabsim/phabsim.asp

Con la misma filosofía del anterior, pueden señalarse dos modelos, que aunque no traten directamente la ribera, sí que constituyen una herramienta útil para trabajar con el del ecosistema fluvial y su régimen hidrológico:

- RHABSIM (Riverine Habitat Simulation Software):

http://eco.wiz.uni-kassel.de/model db/mdb/rhabsim.html

- $\quad$ RIVMOD (Riverine Model) :

http://eco.wiz.uni-kassel.de/model db/mdb/rivmod.html 


\section{CONCEPTUALIZACIÓN DEL MODELO DE AGUA Y VEGETACIÓN DE RIBERA "RIBAV"}

\subsection{FUNDAMENTOS ECOLÓGICOS E HIDROLÓGICOS Y DISCRETIZACIÓN ESPACIAL DEL MODELO "RIBAV"}

La conceptualización del "Modelo de agua y vegetación de ribera RibAV" se desarrolla con una visión ecohidrológica de riberas de ríos de zonas semiáridas y áridas capaz de considerar la disponibilidad hídrica como el control principal del crecimiento vegetal (Altier et al., 2002; Baird \& Maddock III, 2005; Porporato et al, 2001; Scott et al., 2000) y, a su vez, considerar el papel dinámico de las raíces de las plantas como control de los factores abióticos de la zona (Canadell et al, 1996; Caldwell et al, 1998; Dawson, 1993; Schenk y Jackson, 2005; Ryel et al, 2002).

El modelo conceptual de RibAV, y su estrategia de discretización y establecimiento de parámetros principales se basan en el análisis de la arquitectura de diversos modelos bióticos y abióticos generados para la zona de ribera a nivel mundial (Altier et al, 2002; Baird y Maddock III, 2005; Bendix, 1994; Brinson y Verhoeven, 1999; Brookes et al, 2000; Horton et al, 2001; Lamontagne et al, 2005; Lite et al, 2005; Lowrance et al, 1998; Maddock III y Baird, 2003; Merrit et al, 2009; Snyder y Williams, 2000; Sparovek et al, 2002; Stave et al, 2005; Stromberg et al, 1993, 1996; Webb y Leake, 2006; Welsch, 1991).

Como se señalara, RibAV se enfoca en el análisis de la distribución vegetal y el ciclo hidrológico a escala transversal de ribera (dimensión lateral) y resuelve el balance hídrico de cada zona de forma unidimensional, al considerar únicamente movimientos verticales del agua. Para ello, se aplica discretización espacial en zonas definidas según los tipos funcionales de vegetación existentes en las cuales se generan los parámetros de suelo y vegetación respectivos.

Esta manera de entender los procesos en la ribera y de analizarlos desde la perspectiva espacial, procura intrínsecamente al RibAV de la hipótesis de la "ecología del paisaje" que establece que las interacciones entre los componentes bióticos y abióticos del paisaje están espacialmente relacionadas (Hatton et al, 1997; Malanson, 1993; Naiman et al, 2005; Terradas, 2001; Turner, 2005). Por otra parte, el diseño del modelo y planteamiento de sus principales hipótesis también tiene base en las observaciones de campo en secciones transversales de ríos, el conocimiento de la hidrología y vegetación del área de estudio y la experiencia previa en el estudio de ecosistemas de ribera (Morales-de la Cruz, 2001; Morales-de la Cruz y Polanía, 2005; Morales-de la Cruz y Fernández Bono, 2006).

\subsection{PARÁMETROS DE SUELO Y DE VEGETACIÓN DEL MODELO "RibAV"}

El modelo RibAV fundamenta sus planteamientos en el concepto del continuo suelo-plantaatmósfera y por ello, necesita contar con parámetros de vegetación y de suelo que permitan reproducir el citado marco conceptual.

Los parámetros de vegetación del modelo RibAV son los siguientes:

Conductividad máxima de agua en la interfaz raíz-suelo "Crt" [mmMPa $\left.{ }^{-1} \mathrm{hr}^{-1}\right]$ : es la máxima conductividad radial de agua entre dicha interfaz, que se estima con base en mediciones de campo o adaptando valores reportados por la literatura (Lee et al, 2005; Ryel et al, 2002; Zheng y Wang, 2007).

Factor de cobertura vegetal “Cov( $\left.\lambda_{v}\right)$ " [ ]: este factor está relacionado con la proporción del suelo que está cubierta por la proyección perpendicular del dosel del bosque o la superficie foliar de la vegetación (Causton, 1988; Eagleson, 2002). En RibAV se define con un valor mensual (por conveniencia entre 0.25 y 1) que se establece mediante observación de campo, técnicas SIG, fotos aéreas, criterio experto o revisión de literatura (Bonham, 1989, Causton, 1988, Maddock y Baird, 2003; Scott et al, 2003). 
Factores de transpiración y fuente de agua: parámetros la "preferencia/capacidad" de las plantas para transpirar agua proveniente del almacenamiento estático y/o de la zona saturada. Se divide en dos tipos de factor: el de la zona no saturada " $\boldsymbol{F}_{\text {est }}$ " [ ] (aplicable únicamente al sistema radicular ubicado por encima de la profundidad efectiva de raíces) y el de la zona saturada " $F_{\text {sat }}$ " [ ] (aplicable a todo el sistema radicular en contacto con el nivel freático). Asumen un valor entre 0 y 1 , siendo los valores más cercanos de 1 aquellos que reflejan mayor uso de una determinada fuente de agua para la transpiración: por ejemplo, un $\boldsymbol{F}_{\text {sat }}$ igual a 1, implica que la vegetación solo utiliza agua de la zona saturada, lo cual es de mucha utilidad para modelar especies freatofitas (Butler Jr. et al, 2007; Cooper et al, 2006).

Se establecen con base en observaciones de campo, criterio experto o revisión de literatura (Dawson, 1996; David et al, 2007; Horton et al, 2001; Hughes et al, 2003; Lambs, 2004; Lamontagne et al, 2005; Lite y Stromberg, 2005; Mac Nish etal, 2000; Schaeffer y Williams, 1998; Scott et al, 2006; Snyder y Williams, 2000; Sparks, 1995; Wen et al, 2010).

Presión de crecimiento vegetal óptimo "Popt" [KPa]: se define como el momento en el que la planta aún no presenta problemas de disponibilidad de agua, y que, según Eagleson (2002), corresponde a una presión de $500 \mathrm{kPa}$; en la visión ecohidrológica de Porporato et al (2001) este parámetro se define como el "punto de cierre estomático incipiente" que puede corresponder con una presión de 3,000 KPa (Laio et al, 2001).

Profundidad de extinción por saturación " $Z_{\text {sat }}$ [ [m]: establece la elevación del nivel freático a partir de la cual las raíces no pueden obtener más agua debido a la saturación del suelo; se definen para cada tipo de vegetación con base en observaciones de campo, criterio experto o referencias bibliográficas en la materia (Baird y Maddock, 2005; Maddock III y Baird, 2003; Snyder y Williams, 2000; Webb y Leake, 2006).

Profundidad efectiva de raíces "Ze" [m]: parámetro que define la capa de suelo considerada para el almacenamiento estático; se asocia al tipo de vegetación y puede establecerse mediante medición de campo o criterio experto, bases de datos o referencias bibliográficas (Castellanos et al, 1991; Canadell et al, 1996; Kellman y Roulet, 1990; Schenk y Jackson, 2002a). Esta profundidad también la controla la presencia de una capa limitante del suelo.

Profundidad máxima de raíces " $Z r$ " [m]: se define para cada tipo de vegetación con base en medición de campo o de acuerdo a criterio experto, bases de datos o referencias bibliográficas (Baird y Maddock, 2005; Canadell et al, 1996; Nadezhdina, N.; Čermák, J., 2003; Schenk y Jackson 2002b, 2005; Schulze et al, 1996). Una capa limitante también controla su magnitud.

Punto de marchitez permanente " $\boldsymbol{P}_{w p}$ " [kPa]: su valor se define con base en valores teóricos reportados por diversos autores: $1,500 \mathrm{kPa}$ como valor más generalizado (Kramer y Boyer, 1995; Puricelli, 2003; Terradas, 2001); $3000 \mathrm{kPa} 05,000 \mathrm{kPa}$ para plantas de ambientes semiáridos (Laio et al, 2001); un valor en el rango entre $506.63 \mathrm{kPa}$ y $1,519.90 \mathrm{kPa}$ (Guymon, 1994).

Los parámetros de suelo que utiliza el modelo RibAV para la definición del almacenamiento estático de agua son los siguientes:

Conductividad hidráulica saturada del suelo "Ks" [mm/hr]: parámetro medido en laboratorio u obtenido a partir de la clase textural del suelo (Saxton et al, 1986).

Contenido de humedad a capacidad de campo “ $M_{f c}\left(\theta_{f c}\right)$ " [cc/cc]: parámetro medido en laboratorio o calculado con la curva característica del suelo para la presión típica de la capacidad de campo citada por diversos autores: 33 kPa (Dingman, 2002; Kramer y Boyer, 1995; Wild, 1992); $15 \mathrm{kPa}$ (Larcher, 2003); o en el rango entre 202.65 kPa y 303.98 kPa (Guymon, 1994).

Cota de la superficie del suelo "Es" [m]: corresponde a la altitud sobre el nivel del mar (metros s.n.m.) del nivel del suelo.

Índice de la distribución del tamaño de poros “Ip ( $\lambda$ )" [ ]: se define a partir de las propiedades físicas -clase textural- del suelo (Rawls et al, 1993). 
Porosidad del suelo "Pst $(\varphi)$ " [ ]: se mide en laboratorio u obtiene a partir de las propiedades físicas -clase textural- del suelo (Rawls et al, 1993).

Presión de burbujeo " $\mathrm{Pb}\left(\boldsymbol{H}_{b}\right)$ " [ $\left.\mathrm{kPa}\right]$ : definido a partir de las propiedades físicas -clase texturaldel suelo (Rawls et al, 1993).

Profundidad máxima para considerar ascenso capilar " $Z c_{\min }$ " [m]: parámetro que en "RibAV" condiciona el ascenso capilar de agua, cuando el nivel freático está por debajo de la profundidad máxima de las raíces ( $\mathrm{Zr}$ ) más el "máximo teórico de 3 metros por debajo de la capa de suelo" señalado por Altier et al (2002).

Dado que RibAV define la interacción de los factores bióticos y abióticos en un ámbito espacial, es necesario que sus parámetros estén referenciados con la cota de la superficie del suelo. De esta manera se definen los parámetros generales siguientes:

\section{Cota de la profundidad máxima de raíces " $\mathrm{CZr}$ ” [m]:}

$$
C Z r=E s-Z r
$$

donde para cada zona a modelar, "Es" es la cota de la superficie del suelo y "Zr" la profundidad máxima de raíces de su tipo de vegetación característico.

Cota de la profundidad efectiva de raíces "CZe" [m]:

$$
C Z e=E s-Z e
$$

donde "Ze" es la profundidad efectiva de raíces del tipo de vegetación característico de cada zona a modelar.

Cota de la altura de extinción por saturación " $C P_{\text {sat }}$ " [m]:

$$
C P_{\text {sat }}=E s-Z_{\text {sat }}
$$

donde " $\boldsymbol{Z}_{\text {sat }}$ " es la profundidad de extinción por saturación del tipo de vegetación característico de cada zona a modelar.

Cota mínima para considerar ascenso capilar desde el nivel freático " $C Z c_{\min }$ " [m]:

$C Z c_{\min }=E s-Z c_{\min }$

donde para cada zona a modelar, " $Z \boldsymbol{C}_{\min }$ " es la profundidad máxima para considerar ascenso capilar desde el nivel freático a la capa de suelo del almacenamiento estático.

En el modelo conceptual de RibAV se definen los contenidos de humedad de los puntos característicos de la interacción suelo-planta mediante la curva característica de humedad de Campbell (1974), cuya aplicación práctica y validez para la modelación de ribera se ha usado en el modelo REMM (Altier et al, 2002; Inamdar et al, 1999; Lowrance et al, 1998 y 2000). Así, se establecen otros parámetros generales del modelo:

Humedad en el punto de marchitez permanente " $M_{w p}\left(\theta_{w p}\right)$ " [ ]:

$$
M_{w p}=P s t \cdot\left(\frac{P b}{P_{w p}}\right)^{I p}
$$

donde $\boldsymbol{P s t}\left[\right.$ ], Ip [ ] y $\boldsymbol{P b}$ [kPa] son parámetros de suelo de la zona a modelar, y $\boldsymbol{P}_{\boldsymbol{w p}}[\mathbf{k} \boldsymbol{P a}$ ] es el parámetro de vegetación "punto de marchitez permanente".

Humedad en el punto de presión de crecimiento vegetal óptimo " $M_{\text {opt }}\left(\theta_{\text {opt }}\right)$ " [ ]:

$$
M_{o p t}=P s t \cdot\left(\frac{P b}{P_{o p t}}\right)^{I p}
$$

donde para cada zona a modelar, $\boldsymbol{P s t}\left[\mathbf{I}, \mathbf{I p}\left[\mathbf{~}\right.\right.$ y $\boldsymbol{P b}\left[\mathbf{k P a}\right.$ ] son parámetros de suelo, y $\boldsymbol{P}_{\text {opt }}[\mathbf{k} \boldsymbol{P a}]$ es el parámetro de vegetación "presión de crecimiento vegetal óptimo".

\section{Contenido de agua equivalente al punto de marchitez permanente " $H_{w p}$ " [mm]: $H w p=M w p * Z e$}


donde para cada zona a modelar, " $\boldsymbol{M}_{\boldsymbol{w}}$ " es el contenido de humedad en el punto de marchitez permanente y " $Z \boldsymbol{Z}$ " la profundidad efectiva de raíces de su tipo de vegetación característico expresada en milímetros.

\section{Contenido de agua equivalente a la humedad de crecimiento vegetal óptimo " $H_{\text {opt }}$ [ [mm]:

$$
H_{\text {opt }}=M_{\text {opt }} * Z e
$$

donde para cada zona a modelar, " $\boldsymbol{M}_{\text {opt }}$ " es el contenido de humedad a la presión de crecimiento vegetal óptimo y "Ze" un parámetro de vegetación expresado en milímetros.

\section{Contenido de agua equivalente a la capacidad de campo " $H_{f c}$ " [mm]:}

$$
H_{f c}=M_{f c} * Z e
$$

donde para cada zona a modelar, " $\boldsymbol{M}_{\boldsymbol{f c}}$ " es el contenido de humedad a capacidad de campo.

Presión para el punto de capacidad de campo " $\boldsymbol{P}_{f c}$ " [kPa]: en los casos en donde este parámetro no se obtiene en análisis físico de laboratorio, se puede calcular con base en la curva característica de Campbell (1974):

$$
P_{f c}=\frac{P_{b}}{(M f c / P s t)^{1 / I p}}
$$

donde para cada zona a modelar, $\boldsymbol{P s t}\left[\mathbf{I}, \mathbf{I} \boldsymbol{p}\left[\mathrm{]}\right.\right.$ y $\boldsymbol{P b}\left[\mathbf{k P a}\right.$ son parámetros de suelo, y $\boldsymbol{M}_{\boldsymbol{f c}}[\mathbf{]}$ es el contenido de humedad a capacidad de campo.

Presión para el punto medio de saturación "Pm 5 " [kPa]: De acuerdo con Lee et al (2005) y Ryel et al (2002) este parámetro puede medirse en campo, provenir del análisis físico del suelo y/o calcularse con base en la curva característica de Campbell (1974):

$$
P m_{50}=\frac{P b}{(0.5 \cdot P s t)^{1 / I p}}
$$

donde para cada zona a modelar, $\boldsymbol{P s t}[]$, Ip [ ] y $\mathbf{P b}[\mathbf{k P a}]$ son parámetros de suelo.

\subsection{DATOS HIDROMETEOROLÓGICOS E HIDRÁULICOS DE ENTRADA DEL MODELO "RibAV"}

El modelo RibAV utiliza como datos de entrada la serie hidrometeorológica a escala diaria; para

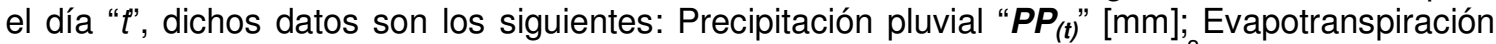
potencial "ETP( $\boldsymbol{P}_{(t)}$ " [mm]; Caudal del río de la sección transversal "Qdaily (t) $^{\text {" }}\left[\mathrm{m}^{3} / \mathrm{seg}\right]$; Cota de nivel freático "WTE $(t)$ " [m] (Fig. 1). Es posible utilizar una serie diaria de caudales "Qdaily $\boldsymbol{y}_{(t)}$ " obtenidos a partir de modelación hidrológica de cuencas, y mediante este camino se puede realizar una aproximación no jerárquica entre escalas, como sugiriera Bendix (1994) y con ello acercarnos a futuros análisis de impactos en la zona de ribera frente a distintos escenarios en la cuenca.

La evapotranspiración potencial "ETP' puede estimarse con base en alguna de las ecuaciones más referidas por diversos autores (Dingman, 2002; Rivas, 2004; Shaw, 1994; Shuttleworth, 1993).

El nivel freático de la ribera "WTE $\boldsymbol{E}_{(t)}$ " es la variable (medida o calculada) de entrada del modelo que controla la posición de la zona saturada en la zona aledaña al río y determina algunos movimientos principales del ciclo hidrológico para el ecosistema.

El régimen hidrológico diario de un tramo de río es el determinante principal de la variación de dicho nivel freático mediante una aproximación simple, de acuerdo con la hipótesis de Hughes et al (2003) y Dobble et al (2004), es decir, un nivel freático horizontal controlado principalmente por el caudal y nivel del río. Como se indicó, cuando en el subsuelo de la ribera predominan sedimentos aluviales gruesos, como las arenas o las gravas, se da un ajuste rápido (período de tiempo de minutos a horas) entre el nivel del río y el de la zona saturada de la ribera (Hughes et al, 2003); esta condición aporta un margen de tiempo propicio para la modelación a escala diaria utilizada por RibAV. 
Así, el nivel freático "WTE (t)" se calcula mediante la curva caudal - nivel de la sección de aforo/sección transversal modelada y sus cotas medidas en campo (datos de entrada del modelo): si el caudal diario del río "Qdaily $y_{(t)}$ " es igual al caudal del río "Qcurve $\boldsymbol{e}_{(j)}$ " de dicha curva, el nivel freático es igual al nivel del río correspondiente $\left(\boldsymbol{W T E}_{(t)}=\boldsymbol{H c u r v e}_{(j)}\right)$; de lo contrario se utiliza la ecuación siguiente para encontrar el nivel del río mediante interpolación:

$$
\operatorname{WTE}_{(t)}=\operatorname{Hcurve}_{(j-1)}+\left(\frac{\text { Qdaily }_{(t)}-\text { Qcurve }_{(j-1)}}{\text { Qcurve }_{(j)}-\operatorname{Qcurve}_{(j-1)}}\right) \cdot\left(\text { Hcurve }_{(j)}-\text { Hcurve }_{(j-1)}\right)
$$

donde, el caudal diario del río del día " $t$ " se interpola con los valores superior e inferior de caudal del río "Qcurve $(j)$ " y "Qcurve $(j-1)$ " $\left[\mathrm{m}^{3} / \mathrm{seg}\right]$ y sus niveles de río correspondientes "Hcurve $(j)$ " y "Hcurve ${ }_{(j-1)}$ " [m] de la curva de gasto de la sección a modelar.

Considerando la conceptualización del ámbito espacial en RibAV, la cota del nivel freático se define con la Cota de la superficie del suelo "Es" [m] y se calcula con la ecuación siguiente:

$$
C_{W T E(t)}=E s-W T E_{(t)}
$$

\subsection{DESCRIPCIÓN DEL MODELO RibAV: movimientos de agua en la ribera}

Para simular a escala diaria el movimiento y almacenamiento estático del agua se utiliza un esquema conceptual de tanque (Fig. 6.1a) fundamentado en el concepto del continuo sueloplanta-atmósfera. Los principales movimientos de agua simulados son los siguientes: Evapotranspiración real del almacenamiento estático de agua en el suelo "ETRuns" [mm]; Evapotranspiración real de la zona saturada "ETRsaf" [mm]; Ascenso capilar desde el nivel freático "UFW" [mm]; Ascenso hidráulico radicular de agua " $H L w$ ' [mm].

Además de la precipitación pluvial local "PP' [mm] (Fig. 6.1), existen otras fuentes importantes de agua para la ribera, pues su cercanía con el río le expone a recurrentes inundaciones y aportes provenientes del agua subterránea somera y/o del acuífero regional (Goodrich et al, 2000; Lambs, 2004; Lamontagne et al, 2005; Scott et al, 2000; Snyder y Williams, 2000; Stromberg, 2001; Tabacchi et al, 2000; Williams, 1998). Con base en las propuestas de Snyder y Williams (2000) y Williams et al (1998), RibAV considera como fuentes de agua para la vegetación de ribera tanto la zona saturada como la no saturada del suelo.
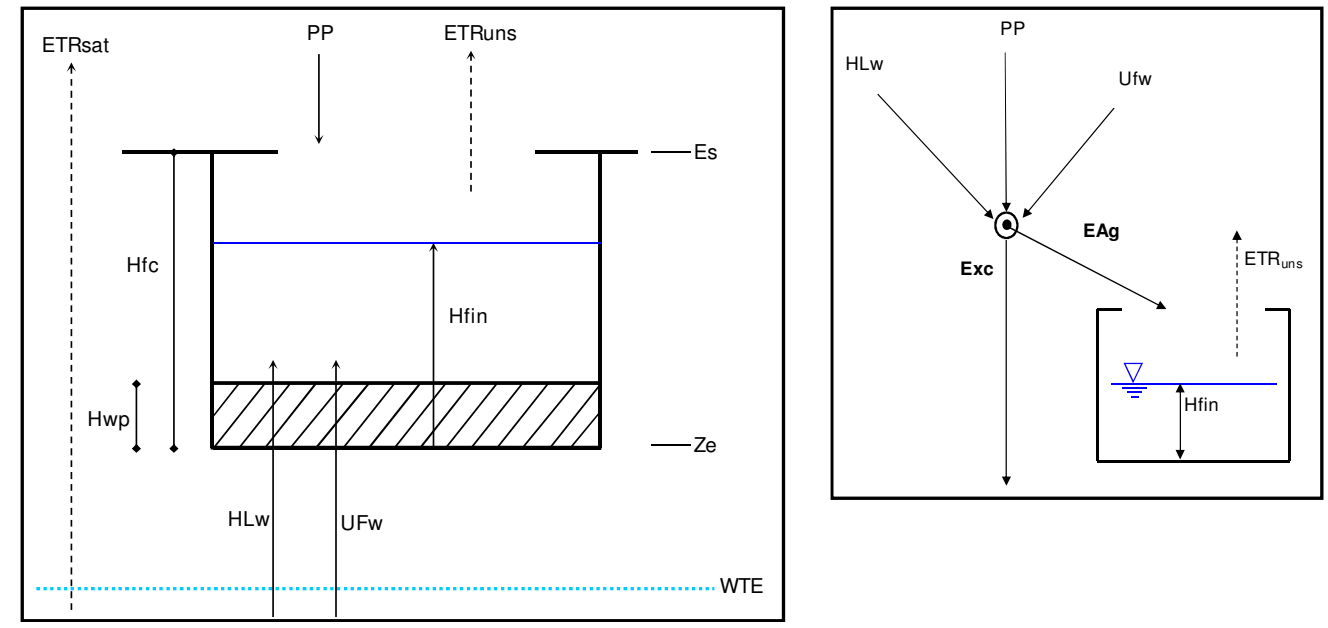

Figura 6.1. Esquema conceptual de tanque para el almacenamiento estático, variables

hidrometeorológicas y movimientos de agua simulados con RibAV: PP, precipitación pluvial; ETRsat, evapotranspiración real de la zona saturada; ETRuns, evapotranspiración real del almacenamiento estático; $H L w$, ascenso hidráulico radicular; UFw, ascenso capilar de agua; Hfc, humedad del suelo a capacidad de campo; Hwp, humedad del suelo en marchitez permanente; Hfin, almacenamiento capilar de agua; EAg, entradas de agua al sistema; Exc, excedentes de agua; WTE, nivel freático; Es, superficie del suelo. Fuente: elaboración propia. 
El esquema conceptual de RibAV (Fig. 6.1a) asume homogeneidad de los parámetros del suelo para la capa comprendida entre su superficie, "Es", y la profundidad efectiva de la raíz, "Ze"; el almacenamiento estático, "Hfin" [mm], representa el almacenamiento capilar de agua en dicha capa superior del suelo, cuya única salida es la evapotranspiración real desde la zona no saturada "ETRuns" [mm] y cuya capacidad máxima de almacenamiento está determinada por la humedad del suelo a capacidad de campo " $\boldsymbol{H}_{f c}$ " $[\mathbf{m m}]$ y en el punto de marchitez permanente " $H_{w p}$ " [mm].

$\operatorname{Hfin}_{(t)}=\operatorname{MAX} \mid \begin{aligned} & \operatorname{Hini}_{(t)}-\operatorname{ETR}_{\text {uns }(t)} \\ & H_{w p}\end{aligned}$

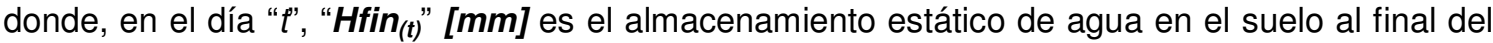
día, "Hini $i_{(t)}$ [ $[\mathbf{m m}]$ es el almacenamiento estático de agua en el suelo antes de que se produzca la evapotranspiración real, "ETRuns $(t)$ " $[\mathbf{m m}]$, y " $\boldsymbol{H}_{w p}$ " [mm] es un parámetro de vegetación.

$\operatorname{Hini}_{(t)}=E A g_{(t)}+H \operatorname{Hin}_{(t-1)}$

donde, para el día " $t$ ", el contenido de agua en el suelo "Hini ${ }_{(t)}$ [ [mm] antes de la evapotranspiración, está definido por el almacenamiento estático del día anterior "Hfin por las entradas de agua al sistema " $E A g_{(t)}$ " [mm].

Las entradas de agua "EAg" [mm] para el balance hídrico (Fig. 6.1b) se calculan con la precipitación pluvial local " $\boldsymbol{P} \boldsymbol{P}_{(t)}$ " $[\mathbf{m m}]$ y los aportes de la zona saturada de la manera siguiente:

$E A g_{(t)}=P P_{(t)}+H L w_{(t)}+U f w_{(t)}-E x c_{(t)}$

donde "Exc(t)" $[\mathbf{m m}]$ es el excedente o agua gravitacional, "HL $\boldsymbol{w}_{(t)}$ " $[\mathbf{m m}]$ es el ascenso hidráulico de agua por el sistema radicular desde la zona saturada o simplemente "ascenso hidráulico" (Ecuación 6.22) y "UFw(t)" [mm] el ascenso capilar de agua desde la zona saturada (Ecuación $6.23)$.

El Excedente "Exc(t)" [mm], para el día " $f$ ", se calcula en función de la capacidad máxima de almacenamiento estático, y otras variables ya descritas, mediante la ecuación siguiente:

$$
\operatorname{Exc}_{(t)}=\operatorname{MAX} \mid \begin{aligned}
& 0 \\
& P P_{(t)}+H L w_{(t)}+U f w_{(t)}-H_{f c}+H f i n_{(t-1)}
\end{aligned}
$$

La curva de retención de humedad utilizada en RibAV está controlada por los contenidos de agua del almacenamiento estático (Fig. 6.1) y la conectividad radicular con la zona saturada (Fig. 6.2) para calcular algunos movimientos de agua.

Así, para el día "t", y cuando el nivel freático de la ribera está por debajo de la profundidad efectiva de raíces, $\boldsymbol{C}_{W T E}<\boldsymbol{C Z e}$, (Fig. 6.2), se obtiene el valor del potencial mátrico del suelo "Pmat ${ }_{(t)}$ [ $[\mathbf{k P a}]$ con base en la curva característica de Campbell (1974):

$$
\operatorname{Pmat}_{(t)}=\frac{P_{b}}{\left(\frac{H_{f i n(t-1)}}{Z_{e} * P_{s t}}\right)^{1 / I p}}
$$

donde para cada zona a modelar, $\boldsymbol{P s t}[$ ], Ip [ ] y $\boldsymbol{P b}[\mathbf{k P a}$ ] son parámetros de suelo, "Ze" [mm] es un parámetro de vegetación y "Hfin (t-1) $^{\text {" }}[\mathbf{m m}]$ el contenido de humedad del suelo del día anterior. Si $\left.C_{W T E} \geq C Z e\right)$ entonces $P m a t(t)=P b$. 

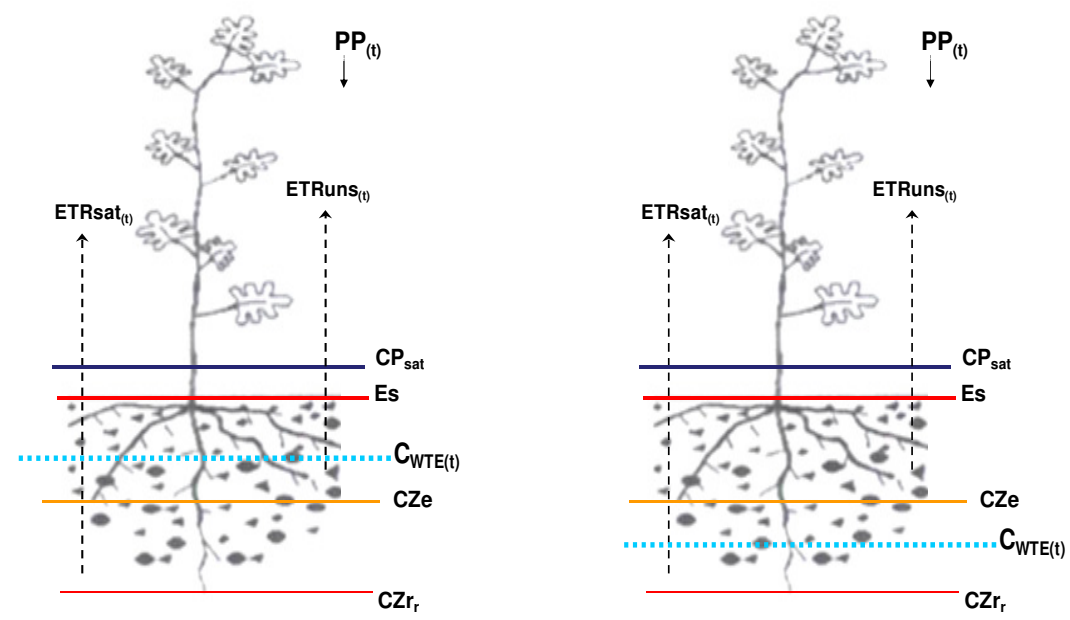

Figura 6.2. Dos casos de conectividad radicular de la vegetación de ribera con la zona saturada, definidos en función de la posición del nivel freático "C $\mathrm{WTE}$ " y de los parámetros de vegetación "CZr", "CZe" y "CP sat", que controlan alternativas de evapotranspiración real del modelo RibAV: (i) $\mathrm{C}_{W T E} \geq \mathrm{CZr}$ y $\mathrm{C}_{W T E} \geq$ CZe; (d) $\mathrm{C}_{W T E} \geq \mathrm{CZr}$ y $\mathrm{C}_{W T E}<\mathrm{CZe}$.

Toda vez calculado el potencial mátrico del suelo se puede calcular la conductividad hidráulica no saturada del suelo "K(h)$(t)$ " [mm/hr] utilizando la ecuación de Campbell (1974):

$K(h)_{(t)}=K s \cdot\left(\frac{P_{b}}{\text { Pmat }_{(t)}}\right)^{3 \cdot I_{p}+2}$

donde $\mathbf{K s}[\mathbf{m m} / \mathbf{h r}]$, Ip [ ] y $\mathbf{P b}$ [kPa] son parámetros de suelo de la zona modelada.

\subsubsection{Ascenso hidráulico radicular " $H L w_{(t)}$ "}

Modelar este fenómeno dentro del contexto de la hidrología y ecología de las zonas de ribera es una innovación trascendental que se desarrolla en RibAV. La simulación del ascenso hidráulico radicular " $H \boldsymbol{L} \boldsymbol{w}$ " desde la zona saturada hasta la capa de suelo del almacenamiento estático se realiza mediante una aproximación simple (Ecuación 6.22) basada en el trabajo de Ryel et al (2002) y en algunas consideraciones planteadas por Lee et al (2005) y Zheng y Wang (2007): se plantea el ascenso hidráulico radicular entre las capas del suelo "i, $j$ " $\left(q_{H R(i, j)}\right)$ como función de la máxima conductividad radial suelo-raíz $\left(C_{R T}\right)$, de la diferencia del potencial mátrico entre dichas capas $\left(\Delta \psi_{m}\right)$, de la conductividad relativa raíz-suelo $\left(C_{j}\right)$, de la eficiencia de la conductividad radicular expresada en términos de la distribución de raíces en el perfil $\left(F_{\text {root }}\right)$ y de un factor de control de ocurrencia del fenómeno ( $S_{\text {time }}$ que tiene valor 1 durante la noche, y 0 durante el día):

$q_{H R(i, j)}=-C r t * \Delta \psi_{m} * c_{j^{*}}\left[\frac{\operatorname{Froot}_{(i)} \operatorname{Froot}_{(j)}}{1-\operatorname{Froot}_{(j)}}\right] * S_{\text {time }}$

Se procedió a la adaptación de la propuesta de la Ecuación 6.20 con base en el modelo conceptual de RibAV: para la modelación a escala diaria se asumió un valor 1 para $S_{\text {time }}$ desde la consideración de que " $H L w$ " es un fenómeno que usualmente ocurre de noche (Amenu y Kumar, 2008; Caldwell y Richards, 1989; Caldwell et al, 1998; Dawson, 1993; Hultine et al, 2003); se tomó como parámetro de ecuación la duración de 10 horas al día que se ha reportado (Ryel et al, 2002).

La "distribución acumulada de raíces, Froof' es un parámetro con valores entre 0 y un máximo acumulado igual a 1 (Ryel et al, 2002), y como RibAV simula el ascenso hidráulico desde la zona 
saturada "WTE' hacia la única capa de almacenamiento estático, es posible simplificar el cuarto término de la Ecuación 6.20 y dejarlo expresado en función de la fracción de raíces de la capa de suelo más profunda $\left(F r_{0 o t}\right)$ y considerar como eficiencia del sistema radicular el factor de captación de agua de la zona saturada (factor " $F_{\text {sat }}$ "). De aquí la necesidad de que, en el futuro, se aborde la equivalencia / complemento de los parámetros de "distribución acumulada de raíces" en el perfil del suelo con los factores de eficiencia de transpiración y fuente de agua " $F_{\text {est }}$ " y " $F_{\text {sat }}$ ".

La eficiencia en la conductividad raíz-suelo $\left(C_{j}\right)$ asume valores entre 0 y 1 y sigue la relación empírica siguiente (Ryel et al, 2002; Zheng y Wang, 2007):

$$
C_{j}=\frac{1}{1+\left(\psi_{(t)} / \psi_{50}\right)^{b}}
$$

La estimación experimental de los parámetros de la Ecuación 6.21 determinó que " $b$ " asume un valor de 3.22 y que $\psi_{50}$ es el potencial mátrico del suelo [MPa] al que se reduce la conductividad hidráulica del suelo en un 50\% y tiene un valor de -1 MPa (Lee et al, 2005; Ryel et al, 2002). En RibAV pueden adoptarse estos valores constantes de los parámetros, y para el caso de $\psi_{50}$ también se le puede calcular con base en la Ecuación 6.11 del parámetro de suelo " $\boldsymbol{P m}_{50}$ ".

Para simular el ascenso hidráulico en presencia de agua subterránea, en RibAV se toma en consideración la hipótesis de Ryel et al (2002), quienes asumen que en estas condiciones el contenido volumétrico de agua en la capa más profunda del perfil se mantiene a capacidad de campo. Por otra parte Ryel et al (2002) estimaron mediante experimentos el valor del parámetro $C_{R T}$ en $0.097 \mathrm{~cm} \mathrm{MPa}^{-1} \mathrm{~h}^{-1}$, y Zhen y Wang (2007) utilizaron este valor en su análisis del fenómeno de redistribución hidráulica de agua en el suelo.

Por tanto, simplificando la ecuación 6.20, para el día " $t$ ', y cuando el nivel freático de la ribera de la noche anterior " $t-1$ " está por debajo de la profundidad efectiva de raíces $\left(\boldsymbol{C}_{W T E(t-1)}<C Z e\right)$ y en conectividad con el sistema radicular de la vegetación $\left(\boldsymbol{C}_{\text {WTE (t-1) }} \geq \boldsymbol{C Z r}\right.$ ) (Fig. 6.2), el ascenso hidráulico radicular " $H L w_{(t)}$ " se calcula con la ecuación siguiente:

$$
H L w_{(t)}=M A X \mid-\frac{C r t * 10}{1000} *\left(P_{f c}-\operatorname{Pmat}_{(t)}\right) *\left[\frac{1}{1+\left(\operatorname{Pmat}_{(t)} / \mathrm{Pm}_{50}\right)^{3.22}}\right] * F_{s a t}
$$

en donde, para cada zona a modelar en el día " $t$ ", " $\boldsymbol{P m _ { 5 0 }}$ " [kPa] y " $\boldsymbol{P}_{f c}$ " $[\mathbf{k P a}$ ], son parámetros del suelo, "Crt" [mmMPa-1 $\boldsymbol{h}^{-1}$ ] y " $\boldsymbol{F}_{\text {sat }}$ " [ ] son parámetros de la vegetación, y "Pmat $t_{(t)}$ " [kPa] es el potencial mátrico del suelo. Si $C_{W T E(t-1)} \geq C Z e$ y $C_{W T E(t-1)}<C Z r$, entonces $H L w_{(t)}=0$.

\subsubsection{Ascenso capilar desde la zona saturada "Ufw(t)"}

Diversos estudios han resaltado la importancia del ascenso capilar de agua para el suministro de humedad para la vegetación de ribera (Eagleson, 2002; Inamdar et al, 1999; Lewis et al, 2003; Lowrance et al, 1998 y 2000). En RibAV, para simular este proceso se adaptó la propuesta de modelación de Altier et al (2002) del flujo estacionario ascendente hacia las capas superficiales del suelo en presencia de un nivel freático poco profundo (entre 1 y $3 \mathrm{~m}$ debajo de la zona radicular). La citada restricción en cada zona a modelar se establece mediante la profundidad máxima para considerar ascenso capilar desde el nivel freático " $\boldsymbol{C} Z \boldsymbol{C}_{\min }$ ", definida como la cota

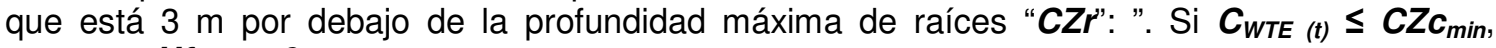
entonces $\boldsymbol{U} f \boldsymbol{w}_{(t)}=\mathbf{0}$. 
De acuerdo con Altier et al (2002) es posible describir el ascenso capilar en las zonas de ribera utilizando la ecuación de Darcy (Skaggs 1978), de tal forma que la tasa del movimiento de agua está determinada por el gradiente de potencial mátrico entre la capa del suelo "Pmat $(t)$ " y la superficie del nivel freático ( $\boldsymbol{\Psi = 0}$, según Freeze y Cherry, 1979), la conductividad hidráulica no saturada " $\boldsymbol{K}(\boldsymbol{h})_{(t)}$ ", y la profundidad del nivel freático debajo de la capa de suelo. Con ello se plantea la ecuación siguiente:

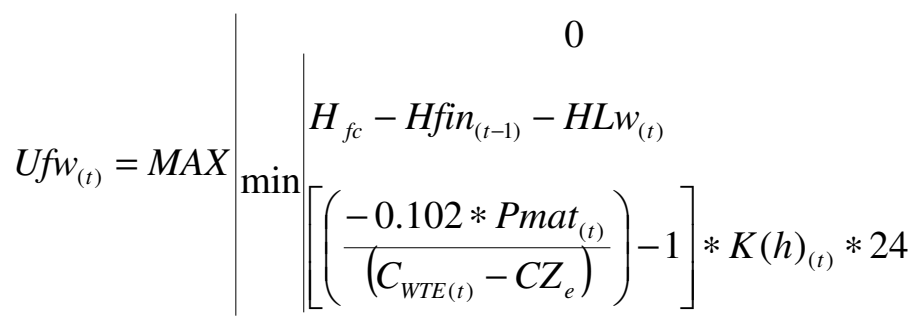

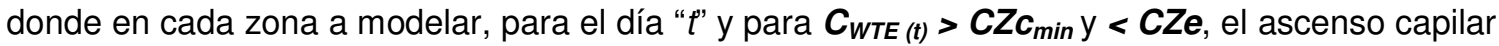
de agua desde la zona saturada "Ufw $\boldsymbol{w}_{(t)}$ " [mm], se calcula en función de la capacidad de almacenamiento estático, del potencial mátrico del suelo, la cota del nivel freático y parámetros de suelo y vegetación definidos previamente. En la ecuación 6.23 se usan dos valores para corrección de dimensionales: [0.102 m columna de agua / kPa] y [24 horas/día].

Para el caso en que la cota del nivel freático es ligeramente superior a la cota de la zona radicular efectiva, es decir, $\boldsymbol{C}_{\text {WTE (t) }}>\boldsymbol{C} \boldsymbol{C} \boldsymbol{c}_{\min } \mathrm{y} \geq \boldsymbol{C Z e}$ (Fig. 6.2), se asume la hipótesis de que el ascenso capilar es suficiente como para llenar el tanque de almacenamiento estático hasta la capacidad de campo y se calcula con la ecuación siguiente:

$$
U f w_{(t)}=H_{f c}-H f i n_{(t-1)}-H L w_{(t)}
$$

\subsubsection{Evapotranspiración real "ETRtot $(t)$ "}

En RibAV la evapotranspiración real "ETRtot" está determinada por la saturación del suelo, por la conectividad de las raíces con el nivel freático (Baird et al, 2004; Baird y Maddock III, 2005; Maddock III y Baird, 2003) y por los contenidos de humedad del suelo (Altier et al, 2002; Dahm et al, 2002; Inamdar et al, 1999); a su vez, esas variables están controladas por la posición del nivel freático y por los aportes de agua hacia el suelo a escala diaria (Fig. 6.1 y 6.2).

Como se citó, el modelo trabaja con dos fuentes de agua para la vegetación (Snyder y Williams, 2000; Williams et al, 1998): la zona saturada (que los autores denominan "agua subterránea") y la zona no saturada (denominada "agua del suelo"); por esta razón la evapotranspiración real "ETRtot $(t)$ [ [mm] del ecosistema de ribera se estima con base en la ecuación siguiente:

$$
\operatorname{ETRtot}_{(t)}=\operatorname{ETRun}_{(t)}+\operatorname{ETRsat}_{(t)}
$$

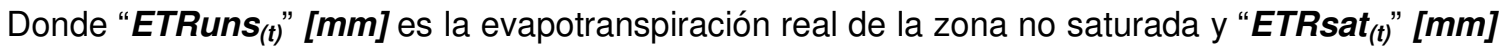
es la evapotranspiración real de la zona saturada.

De esta manera, RibAV rescata e integra las fortalezas de cuantificar y analizar la evapotranspiración de la vegetación de ribera desde la perspectiva de las aguas subterráneas (Baird et al, 2004; Baird y Maddock III, 2005; Horton et al, 2001; Horton y Clark, 2000; Lamontagne et al, 2005; Lautz, 2007; Mac Nish et al, 2000; Maddock III y Baird, 2003; Schilling y Kiniry, 2007; Stromberg et al, 1996) y de la disponibilidad de agua de la zona no saturada en presencia o no de niveles freáticos someros (Altier et al, 2002; Andersen, 2003; Dahm et al, 2002; Goodrich et al, 2000; Inamdar et al, 1999; Lowrance et al, 1998 y 2000; Scott et al, 2000)

Para estimar la evapotranspiración real "ETRtot", se parte de la tasa potencial de evapotranspiración "ETP(t)" [mm], que es la manera más simple y tradicional de representar la 
disponibilidad energética y las condiciones atmosféricas para el proceso (Butler Jr. et al, 2007; Quevedo y Francés, 2008). El ajuste de la "ETP' para calcular la evapotranspiración real se realiza con base en parámetros de suelo y vegetación que definen la disponibilidad de agua y acceso a diversas fuentes.

Como se citó, la fuente de agua para la transpiración de los tipos funcionales de vegetación está definida en RibAV por los factores que controlan la capacidad/preferencia de captar agua del almacenamiento estático y/o del nivel freático, $\boldsymbol{F}_{\text {est }}\left[\mathbf{[}\right.$ y $\boldsymbol{F}_{\text {sat }}$ (Fig. 6.2).

El control de la evapotranspiración de ribera ejercido por el nivel freático, se ha establecido con base en el conocimiento y adaptación de las curvas de evapotranspiración de tipos funcionales de vegetación de ribera propuestos por Baird et al (2004), Baird y Maddock III (2005) y Maddock III y Baird (2003).

Por conveniencia de cálculo en RibAV, las "profundidades" se trabajan como "cotas" -altitud sobre el nivel del mar- y curva de "evapotranspiración/posición del nivel freático" se adapta mediante dos segmentos lineales: i) el primero, una función lineal creciente que inicia en el vértice de valor 0 de ET en la "profundidad de extinción por elevación" (definido por "CZr") y que finaliza en el vértice de valor "ETP( $(t)$ en la profundidad efectiva de raíces (definido por "CZe"); ii) el segundo, una función lineal decreciente desde el vértice de valor "ETP(t)" en "CZe" hasta el vértice de valor 0 en el "punto de extinción por elevación saturada" (definido por el parámetro de vegetación "CP sat").

La "extinción" (valor igual a cero) del proceso de evapotranspiración real del modelo se simula cuando existe desconexión entre el nivel freático y el sistema radicular -muy notorio en plantas freatofitas- o cuando el suelo se satura hasta un nivel intolerable por las plantas. El primer caso es específico para la "evapotranspiración real de la zona saturada" y se define con la "profundidad de extinción por elevación" (Maddock III y Baird, 2003): si $\boldsymbol{C}_{W T E ~(t)}<\boldsymbol{C Z r}$, entonces $\boldsymbol{E T R s a t}_{(t)}=\mathbf{0}$. En estas condiciones la evapotranspiración de la zona no saturada "ETRuns $(t)$ " solamente está determinada por el contenido de agua del suelo (Ecuación 6.26).

El segundo caso de "extinción de la evapotranspiración", parte del hecho de que la duración, frecuencia, profundidad y estacionalidad de las inundaciones son un control crítico de la composición de las especies de ribera y de la dominancia de aquellas más tolerantes al fenómeno (Brinson y Verhoeven, 1999; Tabacchi et al, 2005), pues la saturación del suelo genera condiciones anaeróbicas que afectan la fisiología vegetal (Gergel et al, 2002). Para ello se trabaja con el parámetro de vegetación "Profundidad de extinción por saturación, $\mathbf{C P}_{\text {sat }}$ " (Baird et al, 2004) que establece la elevación del nivel freático $\left(\boldsymbol{C}_{W T E}\right)$ a partir del cual las raíces no pueden captar más agua debido a la saturación del suelo: si $\boldsymbol{C}_{W T E(t)} \geq C \boldsymbol{P}_{\text {sat }}$, entonces $\boldsymbol{E T R u n s}_{(t)}=\mathbf{0}$ y ETRsat $_{(t)}=0$.

Cuando el nivel freático se ubica entre el punto de extinción por saturación " $\boldsymbol{C} \boldsymbol{P}_{\text {sat }}$ " y la

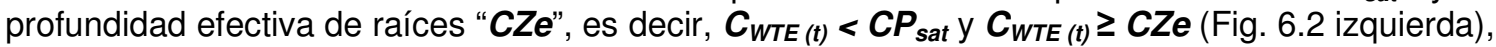
la evapotranspiración real está definida por el segmento lineal decreciente de la curva de evapotranspiración, por la cobertura vegetal de la zona a modelar, y por la eficiencia de captación de agua, considerando las ecuaciones siguientes:

$\operatorname{ETRuns}_{(t)}=F_{e s t} * \operatorname{Cov}_{(m)} * \operatorname{ETP}_{(t)} *\left(1-\left(\frac{C_{W T E(t)}-C Z e}{C P_{s a t}-C Z e}\right)\right)$

donde, para cada zona modelar y para el día " $f$ ", "ETRuns $\boldsymbol{s}_{(t)}$ " [mm] es la evapotranspiración real

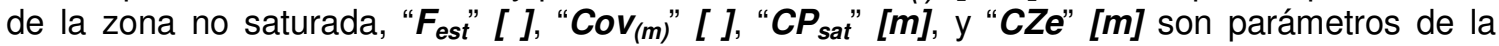
vegetación, "ETP(t)" $[\mathbf{m m}]$ es la evapotranspiración potencial, y $\boldsymbol{C}_{W T E(t)}$ es la cota del nivel freático.

La evapotranspiración real de la zona saturada "ETRsat(t)" [mm] se calcula siguiendo la misma lógica, pero acotando su valor con la disponibilidad energética que queda después de la evapotranspiración real de la zona no saturada, de acuerdo con la siguiente ecuación: 
$\operatorname{ETRsat}_{(t)}=\operatorname{MIN} \mid \begin{aligned} & \operatorname{Cov}_{(m)} * \operatorname{ETP}_{(t)}-\operatorname{ETRuns}_{(t)} \\ & F_{s a t} * \operatorname{Cov}_{(m)} * \operatorname{ETP}_{(t)} *\left(1-\left(\frac{C_{W T E(t)}-C Z e}{C P_{s a t}-C Z e}\right)\right)\end{aligned}$

donde para cada zona modelar y para el día " $f$ ", además de los parámetros ya descritos, " $\boldsymbol{F}_{\text {sat }}$ [ [ ] es un parámetro de vegetación.

Cuando el nivel freático se ubica por debajo de la profundidad efectiva de raíces " $C Z \mathbf{Z}^{\text {", }}$ es decir, $\boldsymbol{C}_{\text {WTE (t) }}<\boldsymbol{C Z e}$ (Fig. 6.2 derecha), la "ETRuns $(t)$ " [mm] está determinada por los contenidos de agua del almacenamiento estático, por la cobertura vegetal y por la eficiencia de captación de agua, de acuerdo con la ecuación siguiente:

$$
\operatorname{ETRuns}_{(t)}=\operatorname{MIN} \mid \begin{aligned}
& \operatorname{Hini}_{(t)}-H_{w p} \\
& F_{e s t} * \operatorname{Hrel}_{(t)} * \operatorname{Cov}_{(m)} * \operatorname{ETP}_{(t)}
\end{aligned}
$$

donde, para el día " $t$ ", "Hini $\mathbf{i}_{(t)}$ [ $[\mathbf{m m}]$ es el contenido de agua del suelo, " $\boldsymbol{H}_{\boldsymbol{w p}}$ " [mm] es un parámetro de suelo y vegetación, " $F_{\text {est }}$ " [ ] y " $\operatorname{Cov}_{(m)}$ " [ ] son parámetros de la vegetación y $H_{r e l}(t)$ [ ] es la humedad relativa del suelo.

En RibAV se asume que las plantas crecen sin estrés hídrico a partir del "contenido de agua del crecimiento vegetal óptimo, $\boldsymbol{H}_{\text {opt }}$ " (Eagleson, 2002) y que, a contenidos de agua por debajo de dicho punto, la evapotranspiración se reduce hasta llegar a un valor 0 en el punto de marchitez permanente. Así, la humedad relativa se determina de la manera siguiente:

$$
\operatorname{Hrel}_{(t)}=\operatorname{MIN}\left(\frac{1}{H_{o p t}-H_{w p}}\right)
$$

Donde para el día " $t$ ", además de los parámetros y variables ya descritos, " $\boldsymbol{H}_{\text {opt }}$ [ [mm] es un parámetro de suelo y vegetación. Si $\boldsymbol{H i n i}_{(t)}<\boldsymbol{H}_{w p}$ entonces $\boldsymbol{H r e l}_{(t)}=\mathbf{0}$.

Finalmente, para el cálculo de la evapotranspiración real de la zona saturada "ETRsat $(t)$ [ [mm] cuando el nivel freático se ubica entre la profundidad efectiva de raíces " $C Z \boldsymbol{Z}^{\text {" y la profundidad }}$ máxima de raíces " $\boldsymbol{C Z r}$ ", es decir, $\boldsymbol{C}_{W T E(t)}<\boldsymbol{C Z e}$ y $\boldsymbol{C}_{W T E(t)} \geq \boldsymbol{C Z r}$ (Fig. 6.2 derecha), se utiliza el segmento lineal creciente de la curva de evapotranspiración (Maddock III y Baird, 2003), los factores de cobertura vegetal y la eficiencia de captación de agua, con corrección de la disponibilidad energética después de la evapotranspiración real de la zona no saturada. Para ello se plantea la ecuación siguiente:

$$
\operatorname{ETRsat}_{(t)}=\operatorname{MIN} \mid \begin{aligned}
& \operatorname{Cov}_{(m)} * \operatorname{ETP}_{(t)}-\operatorname{ETRuns}_{(t)} \\
& F_{s a t} * \operatorname{Cov}_{(m)} * \operatorname{ETP}_{(t)} *\left(\frac{C_{W T E(t)}-C Z r}{C Z e-C Z r}\right)
\end{aligned}
$$

\section{5 ÍNDICES DEL MODELO RIBAV PARA LA ZONIFICACIÓN DE RIBERAS DE REGIONES SEMIÁRIDAS O CON ESTRÉS HÍDRICO}

El agua es tanto recurso limitante como factor amortiguador contra el estrés y, por ello, la vegetación establece un balance/intercambio entre el beneficio competitivo de su transpiración (crecimiento/reproducción) y los costos de la muerte por estrés (Brookes et al, 2000; Crawley, 1997; Franz et al, 2010; Kerkhoff et al, 2004; Porporato et al, 2001). Se han identificado el crecimiento vegetal, la competencia por agua, la fenología, la profundidad radicular, la capacidad 
de producción y la resistencia al estrés hídrico como atributos de los tipos funcionales de vegetación asociados a cambios ambientales en los suministros de agua (Terradas, 2001).

Diversos estudios de "ecohidrología" específicos para condiciones áridas y semiáridas con un abundante fundamento ecofisiológico que recalcan la relevancia del estrés hídrico para el crecimiento y desarrollo vegetal (Porporato et al, 2001; Quevedo y Francés, 2008; RodríguezIturbe y Porporato, 2004). Esto le da sentido al planteamiento de índices de distribución vegetal en escenarios de poca disponibilidad de agua.

Sin embargo, en las zonas de ribera de las regiones semiáridas la cercanía al río brinda condiciones favorables de disponibilidad hídrica provenientes de las múltiples fuentes de agua de la zona saturada y no saturada del suelo que determinan la composición florística, estructural o de crecimiento del bosque de ribera (Brookes et al, 2000; Horton y Clark, 2000; Goodwin y Tarboton, 2001; Lite et al, 2005; Maddock et al, 1998; Scott et al, 2000; Snyder y Williams, 2000; Williams et al, 1998). Esa cercanía al río crea un gradiente de humedad hacia afuera que permite identificar con claridad el límite entre las tierras aledañas y la zona de ribera de vegetación exuberante (Malanson, 1993; Treviño et al, 2001).

Se ha citado que la ley del mínimo de Leibig establece que la supervivencia, el crecimiento y la reproducción vegetal son función del factor ambiental más limitante y que "la ley de tolerancia" establece que el rango de condiciones mínimas y máximas limita la presencia y éxito de un organismo (Smith y Smith, 2000). Así, en RibAV la disponibilidad del agua de la zona saturada y no saturada, el estrés hídrico por humedad del suelo o por saturación, y la conectividad radicular con la zona saturada son las variables fundamentales que determinan el crecimiento y la tolerancia de los tipos de vegetación de ribera.

Se han diseñado índices del modelo que responden a estas premisas. Para cada tipo funcional de vegetación en función de sus mecanismos diferenciados de adaptación y respuesta vegetal para captar agua disponible del medio saturado y no saturado, el RibAV genera índices basados en lo siguiente: tasas características de evapotranspiración real y rachas de conectividad radicular con la zona saturada y de estrés hídrico dinámico.

Se clasifican los tipos de vegetación comparando y jerarquizando los valores de su índice respectivo, para predecir la zonificación de la ribera y el límite entre ésta y la ladera aledaña, y establecer la respuesta vegetal ante potenciales cambios provenientes del clima local y/o del régimen hídrico del río / nivel freático.

\subsection{1 Índice de Evapotranspiración del modelo RibAV "ET index"}

Con frecuencia se utilizan las tasas máximas de evapotranspiración como una medida del crecimiento y productividad de las plantas (Kramer y Boyer, 1995; Laio et al, 2001a; Quevedo y Francés, 2008; Smith y Smith, 2000) y como indicador de condiciones ambientales óptimas para los diversos tipos de vegetación en zonas semiáridas (Porporato et al, 2001).

La secuencia temporal de las tasas de evapotranspiración de diferentes tipos de vegetación se puede utilizar como una medida indirecta del uso del agua (Laio et al, 2001a; Lautz, 2007) y de la resistencia vegetal a la saturación de la zona radicular (Baird y Maddock, 2005); es necesario entender las relaciones entre la evapotranspiración y el tipo de vegetación para predecir la respuesta del ecosistema al cambio climático (Woodward, 1987).

En esa línea, se plantea un índice basado en la evapotranspiración de cada tipo funcional de vegetación, y que en el modelo RibAV se denominará " $E T_{\text {index }}$ ", como una medida adimensional de la interacción de factores abióticos y bióticos en la ribera que se define como la tasa de evapotranspiración real de la vegetación con relación a su cobertura vegetal y la evapotranspiración potencial. La cuantificación del índice se hace con base en la ecuación siguiente: 


$$
E T_{\text {index }}=\sum_{t=1}^{n} \frac{\operatorname{ETRtot}_{(t)}}{\operatorname{ETP}_{(t)} \cdot \operatorname{Cov}_{(m)}}
$$

donde, para el período de simulación comprendido entre el día " $t=1$ " y el día " $n$ " y para cada zona y tipo de vegetación modelado, "ET $\boldsymbol{T}_{\text {index }}$ [ ] es el índice o tasa de evapotranspiración obtenido a partir de la relación entre la sumatoria de la evapotranspiración real diaria "ETRtot $(t)$ [mm] y la sumatoria de la evapotranspiración potencial "ETP(t)" [mm] y su cobertura vegetal mensual correspondiente "Cov $(m)$ " [ ].

Por su utilidad para análisis de resultados, el índice de evapotranspiración de RibAV también se calcula a escala diaria:

$$
E T_{\text {index }(t)}=\frac{\operatorname{ETRtot~}_{(t)}}{\operatorname{ETP}_{(t)} * \operatorname{Cov}_{(m)}}
$$

donde, para el día " $t$ "' y para cada zona y tipo de vegetación modelado, "E $\boldsymbol{T}_{\text {index }(t)}$ " [ ] es el índice o tasa de evapotranspiración diario.

El "E $\boldsymbol{T}_{\text {index }}$ " asume valores entre 0 y 1 , siendo 1 el valor al cual la vegetación evapotranspira a la tasa máxima equivalente a la evapotranspiración potencial "ETP' (Rivas, 2004; Shaw, 1994), dadas las respectivas condiciones de humedad del suelo (Ec. (6.28)), saturación y conectividad radicular con la zona saturada (Ec. $(6.26,6.27$ y 6.30)). Se establece por tanto que aquel tipo de vegetación con el valor más alto de " $\boldsymbol{E} \boldsymbol{T}_{\text {index" }}$ será el que presente una mejor respuesta/adaptación a la variabilidad del medio en cada zona (respecto de otros tipos funcionales de vegetación simulados en las mismas condiciones y durante el mismo período).

Como se dijo, la clasificación se hace comparando los valores de los índices entre los tipos de vegetación; un criterio similar de valoración enfocado en estrés hídrico lo han propuesto Fernández-Illescas y Rodríguez-Iturbe (2003).

El " $\boldsymbol{E} \boldsymbol{T}_{\text {index }}$ " surge tanto a nivel de la función de extracción de humedad del almacenamiento estático (Dingman, 2002; Grindley, 1970; Porporato et al, 2001; Rodríguez-Iturbe y Porporato, 2004; Shaw, 1994; Wild, 1992) como a nivel de la transpiración desde el nivel freático en las zonas de ribera (Baird et al, 2004; Butler Jr. et al, 2007; Horton y Clark, 2000; Kranjcec et al, 1998; Lamontagne et al, 2005; Lautz, 2007; Schilling y Kiniry, 2007; Stromberg et al, 1996; Scott et al, 2006), es posible generar índices específicos para analizar el aprovechamiento del agua de ambas zonas:

$$
\text { ETuns }_{\text {index }(t)}=\frac{\operatorname{ETRuns}_{(t)}}{\operatorname{ETP}_{(t)} * \operatorname{Cov}_{(m)}}
$$

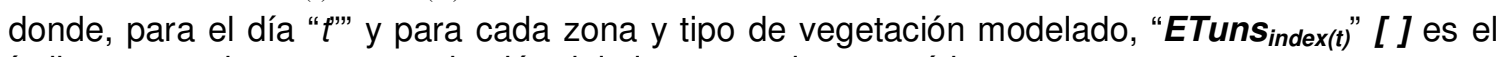
índice o tasa de evapotranspiración del almacenamiento estático.

$$
\text { ETsat }_{\text {index }(t)}=\frac{\operatorname{ETRsat}_{(t)}}{\operatorname{ETP}_{(t)} * \operatorname{Cov}_{(m)}}
$$

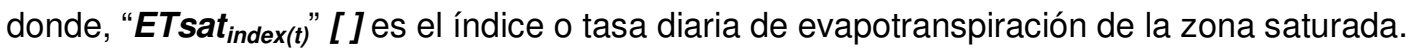

El uso potencial del " $\boldsymbol{E} \boldsymbol{T}_{\text {index }}$ " y de las ecuaciones (6.33) y (6.34), permitirá analizar el crecimiento vegetal en la ribera y el aprovechamiento de las distintas fuentes de agua de manera conjunta y evitar las limitaciones de analizar la evapotranspiración de la zona saturada y del almacenamiento estático por separado; de esta manera, RibAV provee de una herramienta que diversos estudios han señalado como necesaria (Hughes et al, 2003; Lamontagne, 2005; Lautz, 2007; Mac Nish et al, 2000; Schaeffer y Williams, 1998; Scott et al, 2000; Snyder y Williams, 2000; Tabacchi et al, 2000). 


\subsection{2 Índice de Estrés Hídrico Dinámico " $W_{D s t "}$}

El estrés hídrico se utiliza como un indicador de la supervivencia de las plantas y junto con la transpiración determina la época de crecimiento y la dinámica de captación de agua (Quevedo y Francés, 2008). Lambers et al (1997) y Medrano y Flexas (2004) señalan que un factor ambiental puede provocar estrés y reducir las tasas de crecimiento vegetal cuando supera un determinado valor umbral; en el capítulo de parámetros de vegetación se ha citado que el umbral de inicio del estrés hídrico lo establece el potencial mátrico "óptimo" (Eagleson, 2002; Porporato et al, 2001).

El cálculo del índice de estrés hídrico estático " $W_{s t}$ [ ], se hace de acuerdo a la definición de Porporato et al (2001), como se ha hecho en otras aplicaciones (Fernández-Illescas y RodríguezIturbe, 2003; Franz et al, 2010; Quevedo y Francés, 2008). La ecuación es la siguiente:

$W_{s t(t)}=\left[\frac{M_{o p t}-M_{(t)}}{M_{o p t}-M_{w p}}\right]^{q}$

donde, para el día " $t$ ", " $W_{\text {stt }(t)}$ " [ ] es el índice de estrés hídrico estático, " $M_{\text {opt }}$ " [ ] es la humedad en el punto de presión de crecimiento vegetal óptimo, " $\boldsymbol{M}_{\boldsymbol{w}}$ " [ [ ] es la humedad en el punto de marchitez y " $\boldsymbol{M}_{(t)}$ " [ ] es la humedad del suelo calculada con la Ecuación de Campbell (1974) utilizando el contenido de agua del suelo "Hini $(t)$ [ $\mathbf{m m}$ ]. El parámetro "q" [ ] mide la no linealidad del déficit sobre las condiciones vegetales y asume un valor entre 1 y 3 (Porporato et al, 2001). El estrés hídrico estático es 0 cuando la humedad del suelo está por encima del punto de crecimiento vegetal óptimo, y es 1 cuando se llega al punto de marchitez permanente. Es decir, $\boldsymbol{W}_{\boldsymbol{s t}}=0$ para $\boldsymbol{M}_{(t)}>\boldsymbol{M}_{\text {opt }}$, y $\boldsymbol{W}_{\boldsymbol{s t}}=1$ para $\boldsymbol{M}_{(t)}<\boldsymbol{M}_{\boldsymbol{w p}}$.

Para que este índice sea dinámico es necesario incluir las características temporales de los períodos de estrés hídrico $>0$ y establecer la duración y frecuencia de dichos períodos; a estos períodos $\left(\boldsymbol{M}_{(t)} \leq \boldsymbol{M}_{\text {opt }}\right)$ en RibAV se les denomina "rachas de estrés hídrico" y que en la programación del modelo se les puede calcular como salida. Se utiliza la definición del estrés hídrico dinámico " $\boldsymbol{W}_{\boldsymbol{D s t}}$ " [ ] de Porporato et al (2001):

$W_{D s t}=\left(\frac{\bar{W}_{s t}^{\prime} * T_{\text {Mopt }}}{k * T_{\text {seas }}}\right)^{1 / \sqrt{n_{\text {Mopt }}}}$

donde para cada zona a modelar y para el total de rachas de estrés hídrico, " $\bar{W}_{s t}^{\prime}$ " [ ] es el valor medio del estrés hídrico dado que la planta está en estrés, " $\boldsymbol{T}_{\text {Mopt }}$ [día] es la duración media de las rachas de estrés hídrico, " $n_{\text {Mopt }}$ " [ ] es el número de rachas en estrés hídrico durante el período de crecimiento, " $\boldsymbol{T}_{\text {seas }}$ " [día] es la longitud del período de crecimiento, " $\boldsymbol{k}$ " [ ] representa un índice de resistencia vegetal al estrés hídrico.

Ante ausencia de información se suele asumir un valor $k=0.5$ para todas las especies (Porporato et al, 2001) o se le calibra. Si $\bar{W}^{\prime}{ }_{\text {st }}{ }^{*} \boldsymbol{T}_{\text {Mopt }} \geq k^{*} \boldsymbol{T}_{\text {seas }}$ entonces $\boldsymbol{W}_{\text {Dst }}=1$.

Para calcular el valor medio del estrés hídrico, dado que la planta está en estrés “ $\bar{W}^{\prime}$ ' " se utiliza la ecuación siguiente (Porporato et al, 2001):

$\bar{W}_{s t}^{\prime}=\frac{\bar{W}_{s t}}{P\left(M_{\text {opt }}\right)}$

donde, para el total de rachas de estrés hídrico, " $\bar{W}_{s t}$ " [ ] es el promedio de los valores diarios de estrés hídrico estático (Ec. (35)) y " $\boldsymbol{P}\left(\boldsymbol{M}_{\text {opt }}\right.$ " [ ] es la probabilidad de estar por debajo del punto de crecimiento vegetal óptimo, y que en RibAV se calcula dividiendo el número total de días en racha de estrés hídrico entre el total de días del período de crecimiento.

El estrés hídrico dinámico " $W_{D s t}$ " [ ] asume valores entre 0 (sin estrés) y 1 (valor máximo del estrés en el punto de marchitez permanente). Porporato et al (2001) y Laio et al (2001a) hacen referencia a la posibilidad de analizar las rachas de estrés hídrico máximo, es decir, cuando $\boldsymbol{M}_{(t)} \geq$ $\boldsymbol{M}_{\text {wp }}$. 
Al igual en el anterior índice, se comparan los valores obtenidos para los distintos tipos funcionales de vegetación y, siguiendo el criterio de Fernández-Illescas y Rodríguez-Iturbe (2003), se establece que aquella comunidad vegetal con los valores más bajos de " $\boldsymbol{W}_{\boldsymbol{D} \text { s" }}$ " respecto a las otras simuladas en igualdad de condiciones, será la más adaptada a la variabilidad abiótica del medio.

No obstante, se ha observado que el estrés hídrico mínimo no es un indicador suficiente para definir las condiciones óptimas de la vegetación (Quevedo y Francés, 2008) y por ello debe analizarse en conjunto con indicadores de la transpiración vegetal (Porporato et al, 2001) debido a que el crecimiento vegetal es uno de los procesos fundamentales de la ecofisiología del estrés hídrico (Lambers et al, 1998; Medrano y Flexas, 2004; Rodríguez-Iturbe y Porporato, 2004). Algunos resultados muestran que la bondad de ajuste de modelos de distribución vegetal está más influenciada por el uso del agua que por el escape al estrés, pero la predicción de la ausencia/presencia de las especies debe considerar ambas variables (Franz et al, 2010).

Por esta razón y para contribuir en un mejor análisis de la distribución vegetal, en RibAV es posible generar el índice de evapotranspiración en estrés hídrico dinámico "E $\boldsymbol{T}_{\boldsymbol{D s t}}$ " a través de la ecuación siguiente:

$$
E T_{D s t}=\left(\frac{E T_{\text {index }}^{\prime} * T_{\text {Mopt }}}{k * T_{\text {seas }}}\right)^{1 / \sqrt{\sqrt{\text { Mopt }}}}
$$

donde para cada zona a modelar y para el total de rachas de estrés hídrico, " $E \bar{T}_{\text {index }}^{\prime}$ "[ ] es el

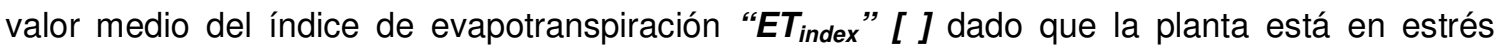
hídrico; el resto de parámetros se definieron previamente.

El valor de " $\bar{E} \bar{T}_{\text {index }}$ "se calcula incorporando las características temporales de las ecuaciones (6.36) y (6.37) propuestas por Porporato et al (2001):

$$
\bar{E} \bar{T}^{\prime}{ }_{\text {index }}=\frac{\bar{E} \bar{T}_{\text {indexST }}}{P\left(M_{\text {opt }}\right)}
$$

Donde " $E \bar{T}_{\text {indexsT }}$ " [ ] es el promedio de los valores diarios del índice de evapotranspiración (Ec. (6.32)) en los días de la racha de estrés hídrico.

\subsection{3 Índice de evapotranspiración en períodos de conectividad radicular con la zona saturada " $E T_{\text {conect" }}$}

Respecto a la conectividad radicular se ha señalado que los vínculos superficiales y subterráneos son los controladores predominantes de la conectividad del paisaje dentro de los sistemas de ribera (Tabacchi et al, 1998). La capacidad amortiguadora de la ribera para atrapar nutrientes de la cuenca y mejorar la calidad del agua del río se ve reducida por la cantidad significativa de agua subterránea que conecta la ladera con el río, y viceversa, sin pasar por el área de ribera (Lowrance et al, 1998). También se ha señalado que la sequía provoca la disminución o la pérdida total de la conectividad hidrológica entre la ribera y el río (Lake, 2003).

Por tanto, en zonas semiáridas y áridas es crítico evaluar la conectividad radicular de la ribera con la zona saturada, en atención de su rol como zona amortiguadora de la calidad del agua y reguladora del balance hídrico. En RibAV la interacción del régimen hídrico del río con el nivel freático se desarrolla con una aproximación simple y determina la conectividad del sistema de raíces de la ribera con la zona saturada para simular la evapotranspiración real de la zona saturada (Horton y Clark, 2000; Lamontagne et al, 2005; Lautz, 2007; Maddock III y Baird, 2003) y el ascenso hidráulico radicular (Burgess et al, 1998; Dawson, 1993; Ryel et al, 2002). 
Por tanto, con base en la conectividad radicular de los tipos de vegetación de ribera, la variabilidad diaria del nivel freático y con la salida del modelo RibAV "ET index", es posible generar el índice de evapotranspiración en períodos de conectividad radicular con la zona saturada

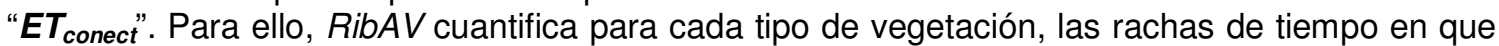
el nivel freático está por encima o por debajo de su profundidad radicular máxima "Zr" y reporta el índice " $\boldsymbol{E} \boldsymbol{T}_{\text {index" }}$ " promedio durante dichas rachas. Entoces, si $\boldsymbol{C}_{W T E(t)} \geq \boldsymbol{C Z r}$, el índice " $\boldsymbol{E} \boldsymbol{T}_{\text {conect }}$ " se calcula así:

$$
E T_{\text {conect }}=\left(\frac{\bar{E} T_{\text {indexC }}^{\prime} * T_{\text {conect }}}{T_{\text {seas }}}\right)^{1 / \sqrt{n_{\text {conect }}}}
$$

donde, para cada zona a modelar y para el total de rachas de conectividad radicular con la zona saturada, " $E \bar{T}_{\text {indexC }}^{\prime}$ "[ ] es el valor medio del índice de evapotranspiración en racha de

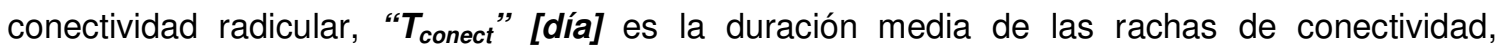
" $n_{\text {conect }}$ [ [ ] es el número de rachas de conectividad durante el período de crecimiento, " $\boldsymbol{T}_{\text {seas }}$ " [día] es la longitud del período de crecimiento. Si $\boldsymbol{C}_{\text {WTE (t) }}<C Z r$ entonces $E T_{\text {conect }}=0$.

El valor de " $E T^{\prime}$ indexC "se calcula incorporando las características temporales de las ecuaciones (36) y (37) propuestas por Porporato et al (2001):

$$
\bar{E} \bar{T}^{\prime}{ }_{\text {indexC }}=\frac{\bar{E} \bar{T}_{\text {indexC }}}{P\left(E T_{\text {conect }}\right)}
$$

donde " $E \bar{T}_{\text {indexc }}$ " [ ] es el promedio de los valores diarios del índice de evapotranspiración " $E T_{\text {index" }}$ durante las rachas de conectividad radicular y " $P\left(E T_{\text {conect) }}\right.$ [ ] es la probabilidad de que el nivel freático esté conectado al sistema radicular por encima de su profundidad radicular máxima " $Z r$ " (calculado en RibAV dividiendo el número total de días en racha de conectividad entre el total de días del período de crecimiento).

\subsection{4 Índices de eficiencia y matriz de confusión para la calibración y validación del modelo RibAV}

Se han descrito para el área de estudio las variables de entrada y parámetros para modelación con RibAV y se detalló el procedimiento para generar sus índices para cada tipo de vegetación (" $E T_{\text {index }}$ ", "W $\boldsymbol{W}_{\text {Dst }}$ " y " $E T_{\text {conect }}$ ) y el método para establecer la presencia/ausencia de las plantas por jerarquización de valores. La estrategia de establecer variables categóricas a partir de índices para distintos TFV se ha utilizado en otro estudio de modelación de vegetación (FernándezIllescas y Rodríguez-Iturbe, 2003); en el caso de RibAV se asignan valores categóricos para representar ausencia (valor 0 ) y presencia (valor 1) de los tipos de vegetación en la zona de ribera, procediendo de la manera siguiente:

- valor 1 para la vegetación con el "E $\boldsymbol{T}_{\text {index }}$ " mayor y valor 0 para el resto;

- valor 1 para el tipo con el " $W_{D s}$ " menor y 0 para el resto;

- valor 1 para el "E$T_{\text {conect" }}$ mayor y valor 0 para el resto.

En el desarrollo de modelos de ausencia/presencia vegetal es necesario contar con sólidos procedimientos para su entrenamiento y evaluación, basados en índices de eficiencia (Manel et al, 2001; Mouton et al, 2010). En los últimos años incrementó la publicación de este tipo de modelos y del uso de índices de eficiencia para su evaluación: durante el período 1989-1999, se demostró que solamente el $52 \%$ de ese tipo de modelos $(n=57)$ evaluaban la eficiencia de la predicción (Manel et al, 2001); mientras, durante el período 1998-2007 se determinó que el 67\% de los modelos ( $n=257$ ) utilizaron datos para su evaluación (Mounton et al, 2010). 
Cuando el modelo genera predicciones discretas se pueden sintetizar en una matriz de confusión (Manel et al, 2001) para calcular a detalle los acuerdos entre predicciones del modelo y datos observados (Liu et al, 2009; Mouton et al, 2010; Wen et al, 2010) y para describir los fallos en la clasificación (Chen et al, 2010; Congalton, 1991). Una matriz de confusión para modelos de presencia-ausencia identifica los casos positivos verdaderos (a), falso positivos (b), falso negativos (c) y negativos verdaderos (d) predichos por cada modelo.

Con la matriz de confusión se puede calcular una alta variedad de índices estadísticos para el análisis de consistencia de los modelos. Los más utilizados para evaluar modelos de distribución vegetal son el "porcentaje de instancias clasificadas correctamente, CCl", el "índice Kappa" y el "área debajo de la curva ROC, AUC". Aún no existe acuerdo sobre cuál índice tiene más ventajas; en la práctica $\mathrm{CCl}$ es el más utilizado, y otros refieren que el más recomendable es "Kappa" (Manel et al, 2001; Chen et al, 2010), pese a que hay un creciente interés por explorar la ventajas de "AUC" (Mounton et al, 2010).

Para calibrar y validar el modelo RibAV se utilizan los índices de eficiencia "CCl" y "Kappa":

- Índice de porcentaje de casos correctamente clasificados "CCl" (Fielding y Bell, 1997): en donde, siendo " $n$ " el número total de casos (Tabla 21) se puede calcular con la ecuación siguiente (Manel et al, 2001; Mounton et al, 2010):

$$
C C I=(a+d) / n
$$

- I Índice de Kappa (Cohen, 1960), que según Manel et al (2001) se puede calcular así:

$$
\text { kappa }=\frac{[(a+d)-(((a+c)(a+b)+(b+d)(c+d)) / n)]}{[n-(((a+c)(a+b)+(b+d)(c+d)) / n)]}
$$

El índice Kappa es la medida más popular de las predicciones de ausencia/presencia (Mounton et al, 2010), pues aporta la proporción de todos los posibles casos que se predicen correctamente con el modelo después de contabilizar los efectos del azar (Manel et al, 2001); es una buena alternativa para la clasificación cuando el tamaño de la muestra es limitado y porque se ve menos afectado por la distribución del error entre clases (Chen et al, 2010).

Kappa se ha usado mucho para pruebas de diagnóstico médico y psiquiátrico (Cohen, 1960; Landis y Koch, 1977) y, más recientemente, para evaluar modelos de distribución de comunidades vegetales utilizando sensores remotos (Chen et al, 2010; Franz et al, 2010; Kokaly et al, 2003; Liu et al, 2009; Niclòs Corts et al, 2010), para mapeo de humedales (Biondini y Kandus, 2006; Nielsen et al, 2008; Peters et al, 2008) e incluso para evaluar un modelo de riberas enfocado en los efectos de las inundaciones sobre la vegetación (Wen et al, 2009).

Pese a la controversia sobre el rigor estadístico de la escala de calificación del índice Kappa (Landis y Koch, 1977), ésta ha sido utilizada abundantemente y es la siguiente: 0.0 - 0.4 indica una eficiencia débil o regular del modelo, $0.4-0.6$ una eficiencia moderada, $0.6-0.8$ una eficiencia substancial, 0.8 - 1.0 una eficiencia casi perfecta.

En el proceso de cálculo de estos índices de eficiencia del modelo, se construye una matriz de confusión para contabilizar aciertos y fallos, visualizar los resultados de los pasos de la calibración y extraer información para su evaluación, como se ha hecho en recientes aplicaciones para modelos de distribución vegetal (Chen et al, 2010; Liu et al, 2009; Wen et al, 2010).

La matriz de confusión RibAV está conformada por columnas que representan los valores simulados de cada tipo funcional de vegetación y filas que representan los tipos de vegetación observados (Tabla 6.1), y con ella se identificarán los casos positivos verdaderos, falso positivos, falso negativos y negativos verdaderos predichos por el modelo. 
Tabla 6.1. Matriz de confusión para la calibración y validación del Modelo RibAV, con los TFV simulados y observados del río Uyús y Teculután, Valle del Motagua, Guatemala. RH: herbáceas obligadas de ribera; RA: arbóreas de ribera húmeda; RF: arbóreas facultativas de ribera; BS: bosque seco.

\begin{tabular}{|c|c|c|c|c|c|c|}
\hline & \multirow{2}{*}{ TFV } & \multicolumn{4}{|c|}{ SIMULADOS } & \multirow{2}{*}{$\begin{array}{c}\text { Total } \\
\text { Observados }\end{array}$} \\
\hline & & RH & $\mathbf{R A}$ & RF & BS & \\
\hline \multirow{5}{*}{ 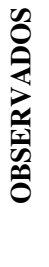 } & RH & & & & & \\
\hline & $\mathbf{R A}$ & & & & & \\
\hline & $\mathbf{R F}$ & & & & & \\
\hline & BS & & & & & \\
\hline & Simu & & & & & \\
\hline
\end{tabular}

En la presente versión del RibAV se simulan únicamente tipos funcionales de vegetación "puros" representados por aquel TFV con el valor categórico de ausencia/presencia más alto. Por ello, la matriz de confusión de los resultados para riberas y bosque seco de los ríos Uyús y Teculután se centrará en el análisis de TFV puros, y la evaluación de la predicción de zonas mixtas de TFV se realizará en posteriores versiones del modelo.

El establecimiento del acierto de predicción en la matriz de confusión (Tabla 6.1) se basa en la comparación del "TFV simulado con RibAV" con el "TFV observado en campo". A medida que se van obteniendo resultados de cada punto de simulación se añaden valores unitarios en las celdas cuyos índices de filas y columnas coinciden con las clases observadas y simuladas respectivamente (Francés et al, 2009).

Dicha matriz tiene cuatro columnas y otras tantas filas, es decir, 16 celdas en las que coinciden los valores simulados y observados exclusivamente para los tipos funcionales puros. En ella se ha resaltado en gris la diagonal principal, pues en este conjunto de celdas se ubican los valores simulados que coinciden con los observados; al calibrar el modelo se espera que estos valores sean lo más alto posible a costa de reducir los valores de las demás celdas (especialmente de las más alejadas de la diagonal). La columna y fila de valores totales facilita el cálculo de los índices de bondad globales del modelo, y el valor de dicha celda tiene que ser igual al número total de puntos observados y simulados. 


\section{APLICACIÓN DEL "MODELO RIBAV" PARA ZONIFICAR LA RIBERA EN REGIONES SEMIÁRIDAS}

\subsection{DEFINICIÓN DEL PROBLEMA}

Se ha mencionado el gradiente de humedad en la dimensión lateral, del río hacia fuera, con vegetación de ribera exuberante en regiones semiáridas y áridas; el régimen del río determina la dinámica de la ribera y representa la principal fuente de agua durante la época seca, al controlar el nivel freático local.

En estos ambientes, la presencia/ausencia de los tipos de vegetación está controlada por su capacidad de responder y adaptarse al estrés hídrico en la época seca, a los períodos de saturación del suelo y a la variabilidad espacio temporal de las fuentes de agua. La disponibilidad hídrica de la zona saturada y no saturada ejerce un control principal del crecimiento vegetal, mientras que el sistema radicular de las plantas controla el balance hídrico de la zona.

Conociendo la variabilidad ambiental y su interacción con los parámetros locales de suelo, topografía y vegetación, es posible simular los principales movimientos de agua en el continuo suelo-planta-atmósfera que determinan las tasas de crecimiento vegetal (expresada por la evapotranspiración) y de estrés hídrico dinámico. La modelación ecohidrológica de la zona de ribera debe ser eficiente para establecer una sólida zonificación de las comunidades vegetales basada en la respuesta de los diversos tipos de vegetación al medio local.

Por ello es primordial medir la bondad de ajuste de modelos de distribución de las plantas para establecer el alcance de su predicción respecto a posibles impactos de la derivación de agua del cauce del río o la variabilidad climática. En esta línea, y para evaluar la aplicación de RibAV se establecieron la variabilidad climática y los parámetros biofísicos de dos cuencas y zonas de ribera de la Reserva de Biósfera UNESCO "Sierra de las Minas" y del Valle del Río Motagua (Morales-de la Cruz y Francés, 2007, 2008 y 2009), ubicadas al noreste de Guatemala (Fig. 7.1).

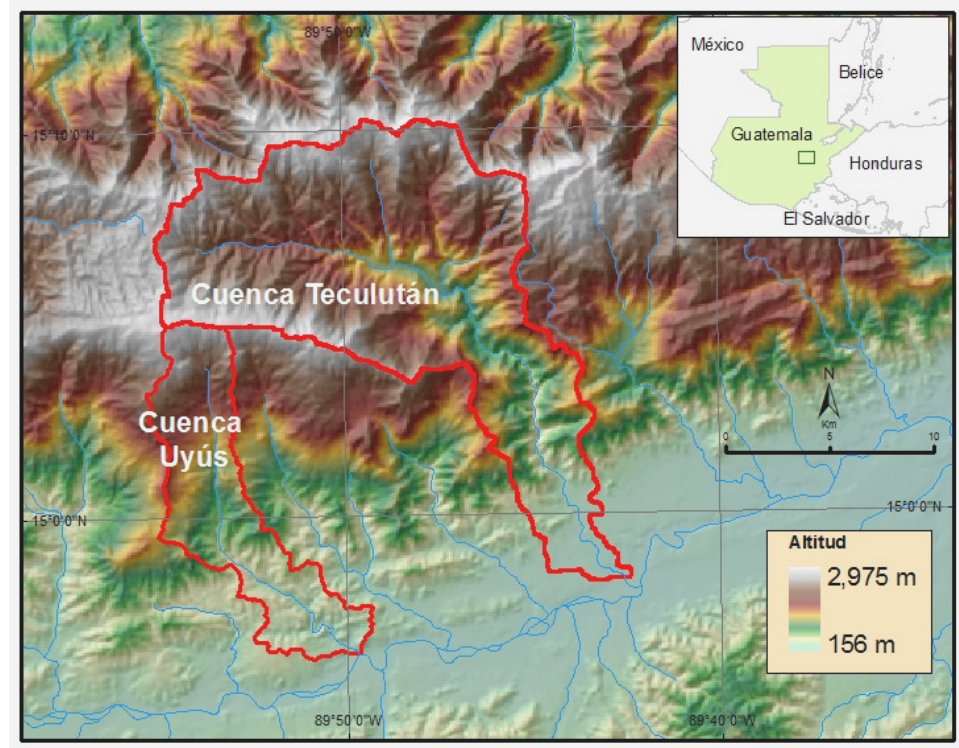

Figura 7.1 Ubicación de las cuencas de los ríos Teculután y Uyús, Guatemala: parte alta en la Sierra de las Minas y desembocadura en el Valle del río Motagua (debajo de los 300 m s.n.m.). Fuente: Base digital de Guatemala, MAGA (2001 y 2002). 


\subsection{VEGETACIÓN E HIDROLOGÍA DE CUENCAS DE LA SIERRA DE LAS MINAS Y VALLE DEL MOTAGUA: río Teculután y río Uyús.}

La Reserva de Biósfera UNESCO "Sierra de las Minas" es parte del Sistema Guatemalteco de Áreas Protegidas, pues constituye una de las fuentes hídricas más importantes del país, de donde nacen 63 ríos que poseen una estacionalidad definida tanto por el régimen de precipitaciones como por el fenómeno de lluvia horizontal originado en sus bosques nubosos (Brown et al, 1996; FDN, 2003; Holder, 2002 y 2004; Morales-de la Cruz y Francés, 2007). Las laderas del lado sur de la Sierra, a través de sus principales ríos de régimen permanente (entre ellos, los ríos Teculután, Pasabien, Uyús, Hato, Hondo), abastecen de agua al Valle del Motagua, una de las zonas más productivas del país y, paradójicamente, la más árida y seca de Centroamérica, declarada de interés para conservación (Secaira et al., 2003; Valle et al, 1999).

La parte alta de las cuencas de la "Sierra de las Minas" (con una altitud máxima de 3,015 m s.n.m.) está caracterizada por sus bosques nubosos y latifoliados de gran riqueza florística (Vargas, 1999), representada por más de 400 especies y 35 familias de vegetación ${ }^{2}$; la causa de la riqueza de flora con alto endemismo es el aislamiento geográfico y la variabilidad de elevaciones del terreno (Succhini, 2001). Esto también se presenta en el valle del Motagua, que incluye al bosque seco subtropical y al monte espinoso subtropical o bosque muy seco subtropical $^{3}$ (de la clasificación de zonas de vida de Holdridge), cuya distribución alcanza en condiciones normales altitudes máximas de 400 m s.n.m. en la Sierra de las Minas, aunque se ha registrado incluso a los 1200 m s.n.m. (Castañeda, 2004; Véliz et al, 2003).
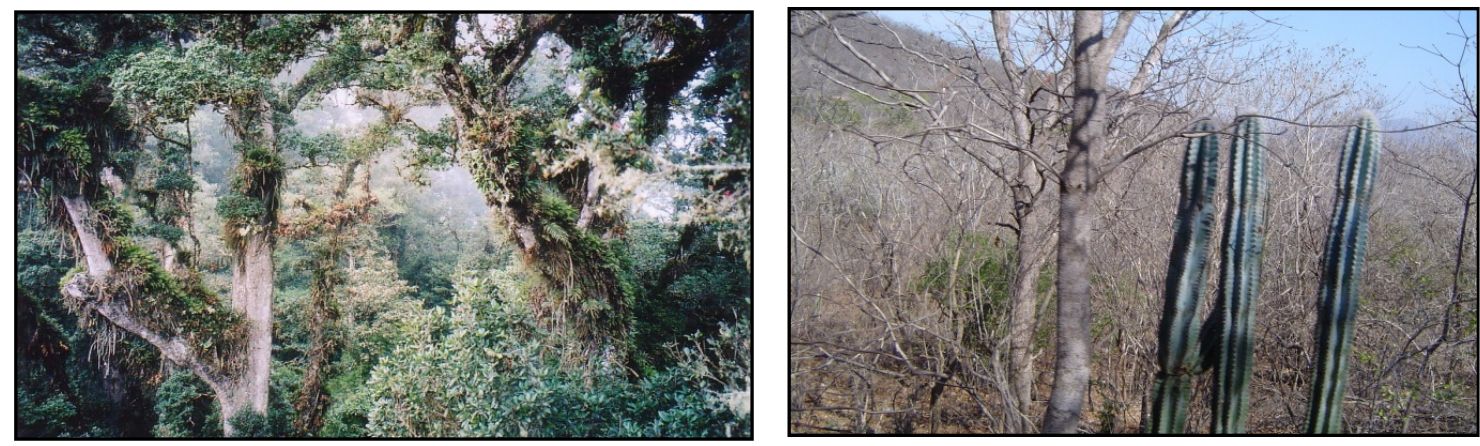

Figura 7.2. Vegetación del bosque de la Sierra de las Minas (bosque nuboso, izquierda) y del Valle del río Motagua (bosque seco, derecha), Guatemala. Fotos: J.M. Vargas y M. Morales, 2006.

La distribución de vegetación en las cuencas del área de estudio (Fig 7.2) está determinada por la disponibilidad de agua proveniente del régimen de lluvias. A nivel regional, la orografía permite describir que las lluvias decrecen en dirección este - oeste, y la presencia de una "sombra de lluvia" sobre las laderas del sur (que drenan al valle del Motagua), pues las nubes descargan en la cara norte y partes altas de las cuencas y provoca las bajas precipitaciones de mayo a octubre (Brown et al, 1996; FDN, 2003; Holder, 2002 y 2004). En el ámbito de la cuenca se han estudiado y descrito incrementos de la cantidad de lluvia con la altitud (FDN, 2003; Morales-de la Cruz, 2007 y 2008).

Basados en el conocimiento del área y en las recomendaciones técnicas de instituciones y diversos expertos se realizaron intensas visitas de reconocimiento del área comprendida entre las cuencas del río Hato y Río Hondo (superficie aproximada de $950 \mathrm{~km}^{2}$; rectángulo Fig. 7.1), cuya riqueza vegetal y variabilidad de clima permitieron identificar ríos permanentes en régimen natural (Uyús y Teculután) con zonas de ribera siempreverdes, poco disturbadas y claramente diferenciadas del bosque seco aledaño en estado natural; al lado de las mismas se puede observar un bosque seco caducifolio que permite definir con claridad el límite entre ribera y ladera (Fig. 7.3).

\footnotetext{
${ }^{2}$ Comunicación personal con Jorge Mario Vargas, profesor de biología y vegetación del bosque de la Universidad de San Carlos de Guatemala.

${ }^{3}$ Por conveniencia, en esta tesis se denominará "bosque seco" a estas dos zonas de vida.
} 

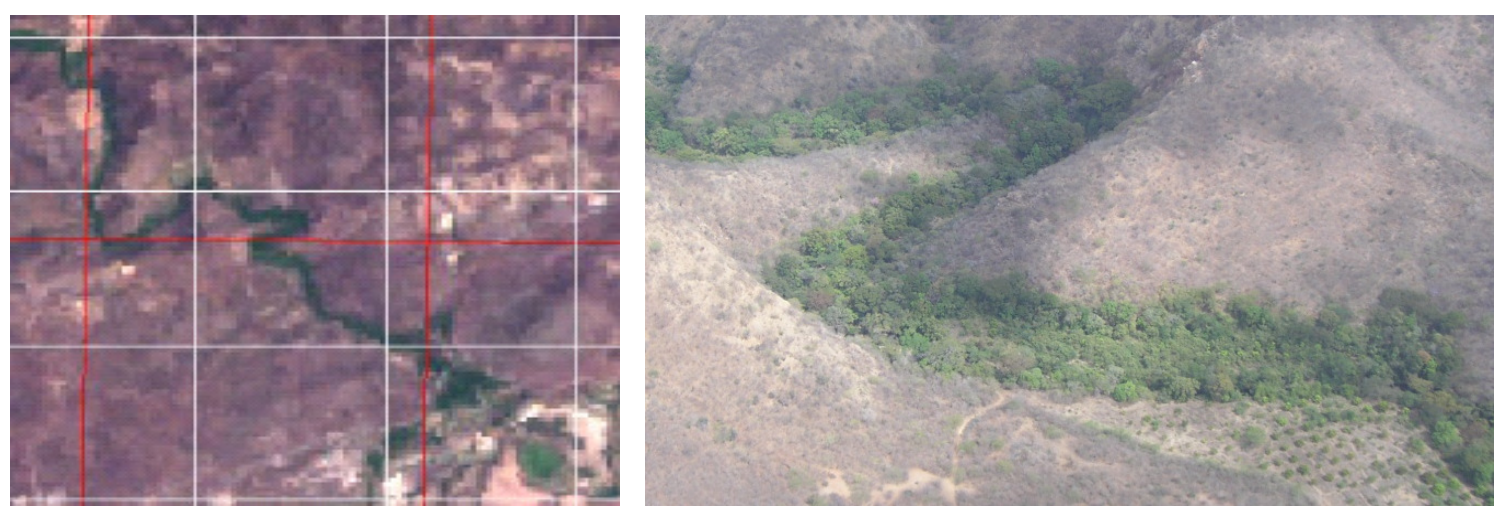

Figura 7.3. Vista de la entrada del río Uyús al Valle del Motagua durante la época seca (tonos verde del bosque de ribera y marrón-grisáceo del bosque seco): (i) sección de imagen satelital Landsat 7 ETM (14/04/2003); (d) vista aérea del tramo de río y zona para modelación (31/01/2005). Foto: S. Alvarado, 2005.

La poca disponibilidad de datos hidroclimáticos, edafológicos y geológicos es la mayor limitante para entender la hidrología compleja de las cuencas de la Sierra de las Minas. Para el área de estudio hay una cobertura media de $237 \mathrm{~km}^{2} /$ estación meteorológica y solamente 3 tributarios del río Motagua con registros de caudal (período de datos continuos de 1990 a 2004). La información disponible es mayoremente lluvia y temperatura y es irregular el control de calidad de la misma (Morales-de la Cruz y Francés, 2007 y 2008). Las estaciones son operadas por el Instituto Nacional de Sismología, Vulcanología, Meteorología e Hidrología (INSIVUMEH) y por el Instituto Nacional de Electrificación (INDE), entidades que donaron la información para esta tesis doctoral.

En Centroamérica la falta de información a escala de cuenca impide resolver preguntas clave sobre procesos hidrológicos (Morales-de la Cruz y Francés, 2007). De las dos cuencas y zonas de ribera seleccionadas por sus ideales condiciones de sitio, únicamente Teculután posee un registro de caudales (estación las Minas, INDE, a 300msn), pero ninguna tiene estación climática (Fig. 7.4); debido a que la extrapolación de datos climáticos de cuencas vecinas es una práctica común en la región (SINAFIP y EDESA, 2004) se utilizaron los registros de aquellas más cercanas: Pasabien (260 m s.n.m.), San Lorenzo (1720 m s.n.m.) y Albores (1900 m s.n.m.).

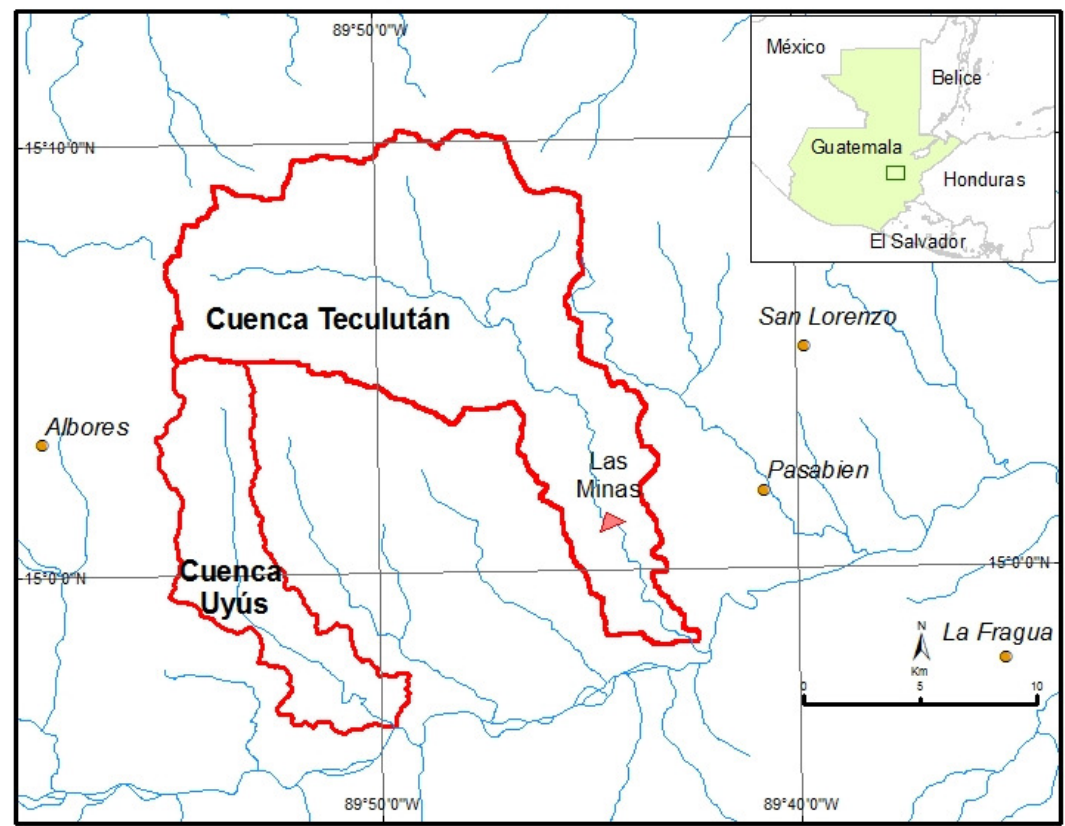

Figura 7.4. Estaciones INDE e INSIVUMEH Albores, Pasabien, San Lorenzo, La Fragua (climáticas; punto naranja) y Las Minas (hidrométrica; triángulo rojo) para el estudio hidrológico de las cuencas del río Uyús $\left(62 \mathrm{~km}^{2}\right)$ y del río Teculután $\left(187 \mathrm{~km}^{2}\right)$, Guatemala. Fuente: MAGA $(2001,2002)$. 
La evapotranspiración potencial (ETP) se estimó con la ecuación de Hargreaves ${ }^{4}$ (Hargreaves, 1975; 1977; Hargreaves y Allen, 2003) para la estación Pasabien (la única con datos de humedad relativa mensual); la ETP también se calculó con la ecuación de Thornthwaite y un factor de corrección ajustado, mediante comparación simple entre este método y el de Hargreaves, para las estaciones San Lorenzo y Albores (que solo poseen datos diarios de temperatura).

La generación de mapas de parámetros -almacenamiento capilar de agua, conductividad hidráulica saturada del suelo, conductividad hidráulica saturada del sustrato- de las cuencas se hizo mediante método simple y eficiente de estimación (Francés et al., 2002; Puricelli, 2003), con la información digital y bases de datos siguientes: a) el modelo de elevación digital con tamaño de celda de $100 \mathrm{~m}$; b) geología, cobertura vegetal y suelo a escala 1:50,000 -información parcial para el área estudiada- (MAGA, 2001 y 2002; SINAFIP y EDESA, 2004).

Tras estimar las características hidrológicas de las cuencas de Teculután y Uyús, se estudió su hidrología a escala temporal diaria (Morales-de la Cruz y Francés, 2007 y 2008) utilizando el conocido modelo hidrológico distribuido Tetis v. 7.2, y obteniendo factores correctores óptimos del modelo (Francés et al., 2007; Vélez, 2001). Así, se estableció el recurso hídrico y el régimen diario de la cuenca del río Teculután (Fig. 7.5) y se generó la serie de caudales en la cuenca sin aforo del río Uyús (Fig. 7.6): nótese el régimen permanente de estos dos ríos.

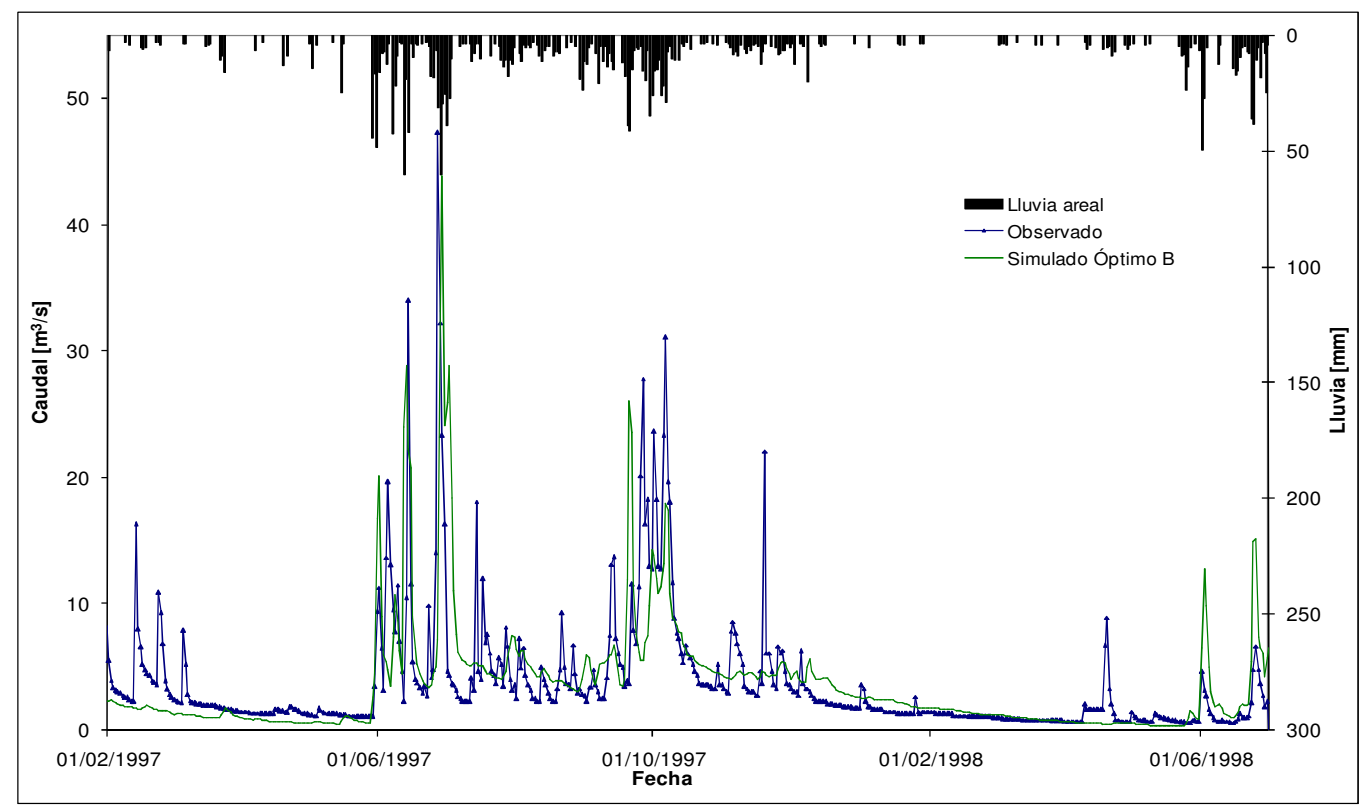

Figura 7.5. Caudales diarios simulados y observados (estación INDE Las Minas) del río Teculután. Período del 01/03/1999 al 31/08/2001. Fuente: elaboración propia.

Pese a la carencia de información se pudieron simular satisfactoriamente dos eventos singulares de la precipitación pluvial en las cuencas objeto de estudio (Morales-de la Cruz y Francés, 2007 y 2008): la tasa de incremento de lluvia con la altitud (Tabla 7.1) y la estimación de la lluvia horizontal provocada por la presencia de los bosques nubosos en la parte alta (Fig. 7.5). Esto constituye el primer resultado necesario para la modelación de los bosques de ribera con RibAV, y con ella se representan condiciones de régimen permanente en una cuenca aforada (río Teculután, Fig. 7.5) y en otra sin medición de caudal (río Uyús).

La generación de la serie diaria de caudales con un modelo hidrológico a escala de cuenca (Tetis $v 7.2)$ y su utilización en otro a la de ribera (RibAV v1.0) permitirá realizar una aproximación no jerárquica entre ambas (Bendix, 1994) y potencialmente analizar impactos en la zona de ribera frente a distintos escenarios en la cuenca.

${ }^{4}$ Garavito (1989) ha registrado resultados satisfactorios de esta ecuación para las condiciones de Guatemala . 
Tabla 7.1. Tasa de incremento de la precipitación con la altitud $[\mathrm{mm} / \mathrm{m}]$ para mediciones de campo (3 estaciones pluviométricas) y simulaciones (5 altitudes). Fuente: Morales-de la Cruz y Francés, 2007

\begin{tabular}{|c|c|c|c|c|c|c|c|}
\hline $\begin{array}{c}\text { Punto } \\
\text { simulado }\end{array}$ & $\begin{array}{l}\text { Alt (m } \\
\text { s.n.m.) }\end{array}$ & $\begin{array}{c}P P \\
(m m / a \tilde{n} o)\end{array}$ & $\begin{array}{c}\text { Tasa de } \\
\text { incremento } \\
\text { medio Simulado } \\
\text { "PP /Alt" } \\
{[\mathrm{mm} / \mathrm{m}]}\end{array}$ & Estación & $\begin{array}{l}\text { Alt (m } \\
\text { s.n.m.) }\end{array}$ & $\begin{array}{c}P P \\
(m m / a \tilde{n} o)\end{array}$ & $\begin{array}{c}\text { Tasa de } \\
\text { incremento } \\
\text { medio } \\
\text { Observado } \\
\text { "PP } / \text { Alt" } \\
{[\mathrm{mm} / \mathrm{m}]}\end{array}$ \\
\hline A & 1511.00 & 3047.09 & \multirow{5}{*}{1.39} & Albores & 1900.00 & 2423.30 & \multirow{3}{*}{1.41} \\
\hline $\mathrm{B}$ & 1020.00 & 2669.44 & & San Lorenzo & 1720.00 & 1779.50 & \\
\hline $\mathrm{C}$ & 668.00 & 2234.53 & & Pasabién & 260.00 & 1116.70 & \\
\hline $\mathrm{D}$ & 395.00 & 1751.89 & & \multirow{2}{*}{\multicolumn{4}{|c|}{$\begin{array}{l}P P: \text { precipitación; } \text { Alt } \text { : altitud. Simulación realizada } \\
\text { con el modelo hidrológico Tetis v7.2, utilizando un } \\
\text { factor de corrección de la precipitación } \beta=0.00739\end{array}$}} \\
\hline $\begin{array}{c}\text { Estación } \\
\text { Las Minas }\end{array}$ & 300.00 & 1527.74 & & & & & \\
\hline
\end{tabular}

El parámetro "incremento de la lluvia con la altitud", de gran sensibilidad para la modelación hidrológica de Teculután, permite representar la distribución de la lluvia que determina el gradiente altitudinal de comunidades vegetales observadas en las cuencas (Fig. 7.2): esto se considerará para el establecimiento de los regímenes de lluvia a escala local de ribera.

La "lluvia horizontal" es un fenómeno difícil de cuantificar, debido a sub registros en pluviómetros tradicionales del aporte de agua de la condensación de la niebla y de la lluvia casi horizontal dirigida por el viento (Bruijnzeel, 2001; Bruijnzeel et al, 2006). Para estimarla en Teculután y Uyús se usó un método simple basado en trabajos previos (Frumau et al, 2006; Hölscher et al, 2004) e información de campo de la Sierra de las Minas (Brown et al, 1996; Holder, 2002). Se calculó un aporte de la lluvia horizontal de 2.2 [mm/día] (aproximadamente $600 \mathrm{~mm}$ en 44 semanas) durante la época seca (mediados de noviembre a finales de abril).

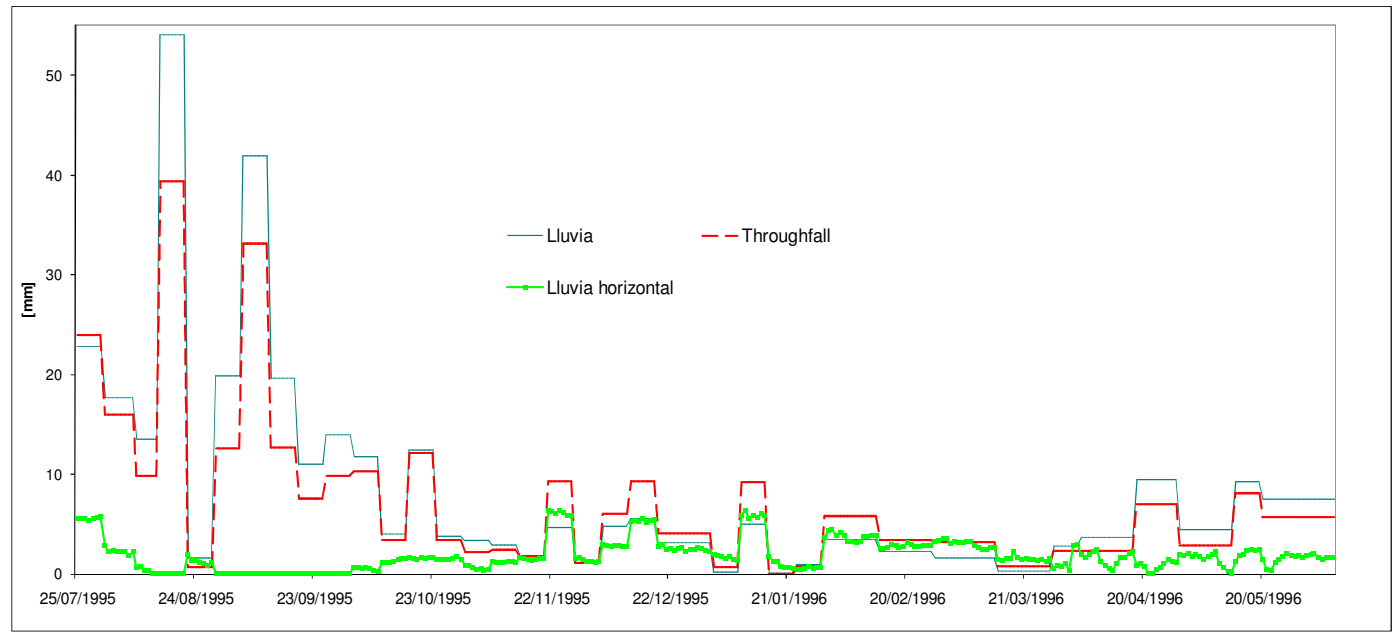

Figura 7.6. Lluvia horizontal estimada con un modelo simple y registros semanales de lluvia y

"throughfall" de un bosque nuboso de la Sierra de las Minas (Morales-de la Cruz y Francés, 2008).

\subsection{INFORMACIÓN BÁSICA Y MÉTODOS DE MUESTREO EN CAMPO DE LOS TRAMOS Y RIBERAS DE LOS RÍOS UYÚS Y TECULUTÁN.}

Se ha citado que el desarrollo del RibAV tiene fuerte fundamento en las intensas observaciones de campo y en la aplicación de métodos de caracterización biofísica del suelo, la topografía y la vegetación del bosque. Se trabajó localmente en secciones transversales de ribera (separación mínima de $50 \mathrm{~m}$ ) seleccionados de forma preferencial en los tramos de seleccionados por su bosque de ribera maduro y siempreverde, con parcelas en estado natural y claramente diferenciadas del bosque seco aledaño; se procuró representatividad de los tipos funcionales de vegetación, accesibilidad y presencia de especies relevantes para la conservación/protección (Castañeda, 2004; Secaira et al., 2003). 


\subsubsection{Ubicación de las riberas y tramos para la modelación con RibAV}

Los tramos y riberas seleccionados (Tabla 7.2; Figuras 7.7 y 7.8) se encuentran en la transición del pie de monte de la Sierra de las Minas a la región fisiográfica del Valle del Río Motagua, con vegetación que representa un rango de altitudes de 98 a118 m s.n.m. (en Teculután) y de 240 a 340 m s.n.m. (en Uyús). La zona semiárida del Valle del Motagua posee una precipitación promedio anual entre 500 y $650 \mathrm{~mm}$, humedad relativa entre el 60 y $72 \%$ y evapotranspiración potencial entre 600 a 800 mm anuales (Castañeda, 1997; Secaira et al., 2003).

Tabla 7.2.Ubicación de tramos estudiados, Valle del Motagua, Guatemala. Fuente: Datos de campo sistema de coordenadas WGS1984, UTM zona 15N (Celis, 2008); Ortofotos de la República de Guatemala (IGN, 2006).

\begin{tabular}{|c|c|c|c|c|c|c|c|c|}
\hline & Tramo & & Cuenca & Régimen & $\begin{array}{l}\text { Número } \\
\text { de } \\
\text { transectos }\end{array}$ & $\begin{array}{c}\text { Longitud } \\
\text { del tramo } \\
{[\mathrm{m}]} \\
\end{array}$ & $X$ & $\mathrm{Y}$ \\
\hline & Uyús & & Uyús & Natural & 5 & 950 & 839931 & 1655373 \\
\hline Teculután & Teculután & Natural & 3 & 270 & 850555 & \multicolumn{2}{|c|}{1662980} & \\
\hline
\end{tabular}

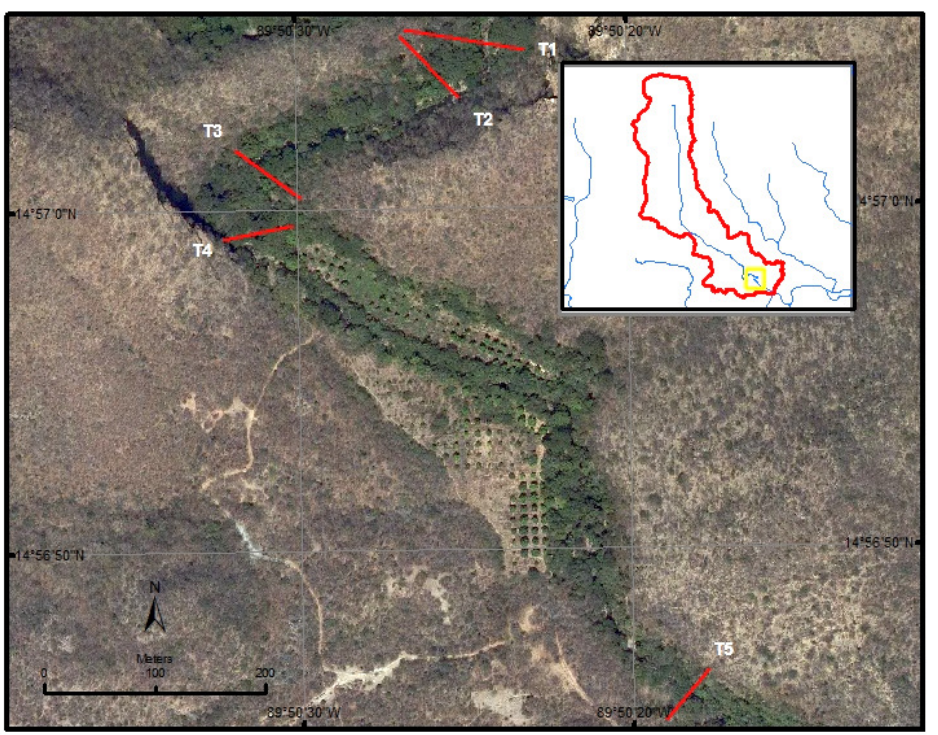

Figura 7.7. Transectos del tramo y zonas de ribera del río Uyús, Valle del Motagua, Guatemala, para la modelación con RibAV. Fuente: Î́dem Tabla 7.2.

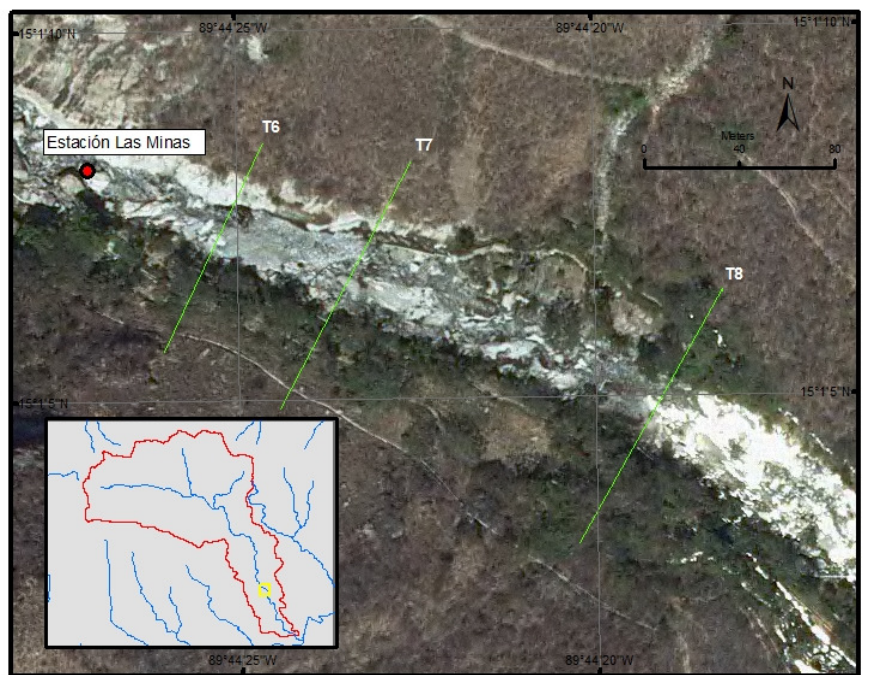

Figura 7.8. Transectos del tramo y zonas de ribera del río Teculután, Valle del Motagua.

Fuente: Ídem Tabla 7.2. 
El río Uyús ocupa la jurisdicción de los municipios San Cristóbal Acasaguastlán (El Progreso) y Usumatlán (Zacapa). Su dirección es de norte a sureste, con la cabecera de cuenca al este del paraje Pinal Ralo, Sierra de Las Minas; descarga al sur del cerro Uyús en el río Motagua. La información cartográfica del área se encuentra en los mapas topográficos a escala 1:50,000 siguientes: Hoja El Cimiento Código 2261 III y Hoja San Agustín Acasaguastlán Código 2260 IV. Sus bosques de ribera se encuentran entre los mejor conservados del Valle del Motagua (Secaira et al, 2003), por lo que allí se levantaron 5 transectos para caracterización de campo.

La cuenca del río Teculután se encuentra en los municipios de Teculután (Zacapa) y San Agustín Acasaguastlán (El Progreso), asentada mayoritariamente en la región fisiográfica Tierras Altas Cristalinas y con una pequeña porción al sur en la depresión del Motagua. La cuenca posee un desnivel de 2,758 m en una distancia horizontal aproximada de $23 \mathrm{~km}$ (SINAFIP y EDESA, 2004). Se seleccionaron 3 transectos cercanos a la estación hidrométrica INDE "Las Minas" que representan una zona con un impacto medio del cambio de uso del suelo en el pasado, pero que posee vegetación de bosque maduro exuberante y que colinda con bosque seco poco disturbado.

Los ecosistemas de ribera del Motagua se caracterizan por especies típicas de ecosistemas más húmedos, que alcanzan grandes tallas; estos presentan alteraciones por su conversión a huertos frutales, donde predominan aguacates, zapotes, cítricos y mango (Secaira et al, 2003).

\subsubsection{Datos generales de geología y suelos del área de estudio}

La región semiárida de Guatemala se encuentra principalmente en la depresión del río Motagua. Está constituida por aluviones cuaternarios y rocas ultrabásicas de edad desconocida. El paisaje fisiográfico está caracterizado por meandros antiguos y bien desarrollados, que están abandonados; pendientes muy poco pronunciadas $(<5 \%)$, aunque rodeada de topografía muy accidentada (Castañeda, 1997).

Las cuencas del río Teculután y Uyús se ubican en uno de los segmentos del sistema de fallas del Motagua; poseen características geomorfológicas típicas de fallas de desplazamiento horizontal, que incluyen el desplazamiento de cuencas y cauces de ríos, el hundimiento de terrenos llanos formando lagunetas, la formación de depósitos coluviales y aluviales al pie de las laderas, entre otros (Castañeda, 1997). Los suelos del área pertenecen a tres grandes grupos: aluviones cuaternarios, rocas ultrabásicas de edad desconocida y rocas volcánicas que incluyen colada de lava, material lahárico y edificios volcánicos (MAGA, 2001 y 2002).

Se pueden identificar las formas del terreno siguientes: topografía abrupta ubicada en la ladera de la Sierra de las Minas; zona transicional de menor relieve, localizada entre la alta pendiente y la planicie; zona plana formada del valle aluvial del Motagua ubicada en el pie de monte constituido por el coluvión y el relleno aluvial de los ríos Motagua y Teculután y Uyús, el drenaje es poco denso y está centralizado prácticamente en el cauce del río (SINAFIP y EDESA, 2004).

El aluvión reciente está constituido por fragmentos de gran tamaño así como guijarros, grava, arena, limo y arcilla y se encuentran en los actuales cauces de los ríos Motagua, Teculután y Uyús. Por otra parte, el aluvión de edad cuaternaria está constituido por fragmentos de los diferentes tipos litológicos que afloran dentro de los límites de la cuenca, los tamaños son bloques, guijarros, grava, arena, limo y arcilla, también contiene esta unidad fragmentos de pómez "retrabajados" por agua, así como cenizas bastante consolidadas (tobas). Estos depósitos están formando abanicos aluviales del río Teculután y Uyús (SINAFIP y EDESA, 2004).

El tramo del río Uyús se encuentra sobre dos unidades geológicas: las rocas volcánicas metamorfoseadas (formación El Tambor) y las serpentinitas de cizalla. El tramo del río Teculután se encuentra en la zona de transición entre el gneis granítico cataclástico y migmatitas (formación San Agustín) y el aluvión del cuaternario (MAGA, 2001 y 2002; SINAFIP y EDESA, 2004). 


\subsubsection{Metodología para la clasificación de la vegetación de ribera: levantado de información en campo y gabinete}

Mediante un método subjetivo por observación del hábitat de crecimiento vegetal, cercanía al río y profundidad radicular (Baird y Maddock III, 2005; Brookes et al, 2000; Terradas, 2001), se realizó una clasificación preliminar por tipos funcionales de vegetación de las diversas "zonas" de cada sección transversal; esto sirvió para identificar sitios idóneos para levantar transectos de muestreo de suelo y vegetación de ribera y ladera aledaña. Se hizo identificación con estacas marcadas y georreferencia con GPS; la longitud del transecto fue variable, incluyendo tanto el cauce, la ribera completa y al menos $10 \mathrm{~m}$ por dentro del bosque seco aledaño.

Los pasos a seguir en la caracterización biofísica son los siguientes:

Muestreo de la vegetación: siguiendo el método de parcelas intensivas y parcelas modificadas de Whittaker (Barnett y Stohlgren, 2003; Stohlgren et al, 1995). Las dimensiones de muestreo se definen en $1000 \mathrm{~m}^{2}$ para el estrato arbóreo (en promedio, $50 \mathrm{~m}$ de largo y $20 \mathrm{~m}$ de ancho, según la longitud variable de la zona de ribera), $100 \mathrm{~m}^{2}$ para el estrato arbustivo (20 m de largo y $5 \mathrm{~m}$ de ancho) y $10 \mathrm{~m}^{2}$ para el estrato herbáceo (10 parcelas de $1 \mathrm{~m}^{2}$ a partir de la orilla del río hasta completar los $10 \mathrm{~m}^{2}$ ). El área definida para el estrato arbóreo se ubicó al centro de los transectos, dividida en dos partes iguales por el eje central y con el lado más largo de la parcela a favor de la pendiente; las de $100 \mathrm{~m}^{2}$ y las de $10 \mathrm{~m}^{2}$ en el eje central de la parcela mayor.

Tamaño de la muestra: con base en la media acumulada del número de plantas colectadas en cada una de las parcelas y el número total de parcelas, se definió que la intensidad mínima de muestreo es de 11 parcelas (Barnett y Stohlgren, 2003; Stohlgren et al, 1995). Este análisis solo se realizó para el río Uyús, pues en el caso de Teculután solamente se tomaron puntos de control vegetal considerando el conocimiento taxonómico y de campo ganado para el área de estudio.

Levantamiento de parcelas para elaborar diagramas fisonómicos-estructurales de los bosques de ribera: En las parcelas de $1000 \mathrm{~m}^{2}$, se hizo un transecto de $50 \mathrm{~m}$ de longitud sobre su centro; éste se dividió en cinco segmentos de $10 \mathrm{~m}$ a partir del punto 0 -thalweg del río- y luego se procedió a listar y contar las especies que entraban dentro de cada segmento y dentro de los límites del ancho de 10 metros a cada lado del transecto.

Trabajo de especímenes en herbario: se colectaron especímenes de herbario en las parcelas, se les secó y determinó (Standley y Steyermark, 1946-1977), siguiendo el protocolo del Herbario de la Escuela de Biología de la Universidad de San Carlos de Guatemala, en donde quedaron depositadas las muestras. Posteriormente se elaboró una lista de especies incluyendo la siguiente información sobre familia, nombre científico y nombre común.

Preparación de datos para el análisis de la ordenación de la vegetación: se elaboró una matriz de densidad promedio (especie-distancia al thalweg) para la ordenación vegetalmediante métodos de análisis multivariables.

Con base en este conocimiento, se generó una clasificación por tipos funcionales de vegetación de ribera, útil para la modelación con RibAV (Celis, 2008; Morales-de la Cruz y Francés, 2009), con fundamentos taxonómico filogenéticos y agrupación no filogenética.

\subsubsection{Metodología para la caracterización físico química de los suelos: levantado de información en campo y laboratorio}

Se colectaron muestras de suelo en cada transecto para representar como mínimo los parámetros de la zona de ribera y del bosque seco aledaño (Celis, 2008). La cantidad mínima de muestreo fue $125 \mathrm{~g}$, almacenada y tratada según el protocolo definido por el Laboratorio de Suelos de la Facultad de Agronomía de la Universidad de San Carlos de Guatemala (FAUSAC). El análisis físicoquímico de las muestras (Tabla 7.3) se realizó en el citado laboratorio (Celis, 2008) definiendo los parámetros siguientes: clase textural del suelo, porosidad, densidad aparente, densidad real del suelo, materia orgánica y contenidos de humedad a cinco diferentes presiones (33 kPa, $101.3 \mathrm{kPa}, 506.6 \mathrm{kPa}, 1013 \mathrm{kPa}, 1500 \mathrm{kPa})$. 
Tabla 7.3.Métodos de análisis de las muestras de suelo de los ríos Uyús y Teculután. Fuente: Información del Laboratorio de Suelos FAUSAC, año 2006.

\begin{tabular}{|c|c|}
\hline Análisis & Método \\
\hline Textura del suelo & $\begin{array}{l}\text { Hidrómetro de Bouyoucos calibrado a } 68^{\circ} \mathrm{F} \text { con } \\
\text { medición de partículas con escala USDA modificada }\end{array}$ \\
\hline $\begin{array}{l}\text { Contenidos de } \\
\text { humedad }\end{array}$ & $\begin{array}{l}\text { Picnómetro de aire diferencial con aplicación de aire a } \\
\text { presión durante un período de entre } 16 \text { y } 24 \text { horas }\end{array}$ \\
\hline $\begin{array}{l}\text { Densidad } \\
\text { aparente y real }\end{array}$ & Analítico o de laboratorio con uso de probetas \\
\hline Materia orgánica & $\begin{array}{l}\text { Walkley-Black modificado (digestión con dicromato } \\
\text { ácido y valoración con } \mathrm{FeSO}_{4} \cdot 7 \mathrm{H}_{2} \mathrm{O}\end{array}$ \\
\hline
\end{tabular}

Además, se realizaron observaciones de campo en cortes naturales encontrados en el área de estudio (Fig. 7.9), para definir tanto la profundidad del suelo como la profundidad efectiva y máxima de las raíces para cada tipo de vegetación (se estableció como profundidad media para muestreo el rango de entre $0-20 \mathrm{~cm}, 0-40 \mathrm{~cm}$ y $0-50 \mathrm{~cm}$ ).
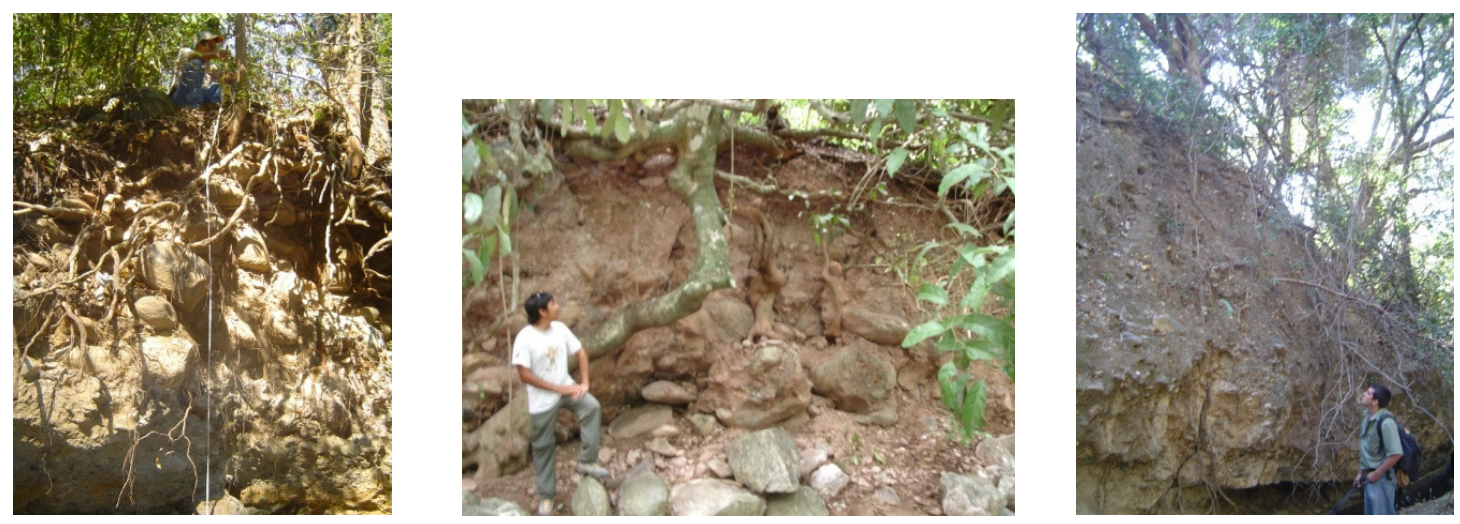

Figura 7.9. Vista de algunos perfiles naturales de suelo de las márgenes del río Uyús, para analizar profundidades características de horizontes del suelo y del sistema radicular de las plantas. Fotos: M. Morales (2006 y 2008), F. Francés (2007).

\subsection{CALIBRACIÓN Y VALIDACIÓN DEL MODELO RIBAV EN TRAMOS Y RIBERAS DE LOS RÍOS UYÚS Y TECULUTÁN.}

\subsubsection{Series hidrometeorológicas para las riberas y tramos de los ríos Uyús y Teculután}

Tras la revisión exhaustiva de la climatología local para los tramos y riberas a modelar con RibAV se determinó utilizar el período estudiado para la hidrología de Teculután y Uyús comprendido entre el 01/01/1995 y el 30/06/2003 (Morales-de la Cruz y Francés, 2008); este es el período con menor cantidad de datos faltantes, coincidencia en el registro de las estaciones del área y que ya fue utilizado para la modelación hidrológica de las cuencas.

Datos de precipitación pluvial y caudal:

Para completar los datos diarios faltantes de la estación Pasabien se utilizaron los datos de temperatura y precipitación de una estación fuera del área de estudio, pero cuya ubicación (en el Valle del Motagua y zona de vida "Bosque Seco"), altitud y estadísticos característicos son similares: La Fragua (Tabla 7.4). 
Tabla 7.4. Estaciones INSIVUMEH empleadas en el cálculo de lluvias y temperaturas de los tramos y riberas del río Uyús y del río Teculután, Guatemala.

\begin{tabular}{lllllllll}
\hline Tramo & Descripción & $\begin{array}{l}\text { Nombre de la } \\
\text { estación }\end{array}$ & Código & $\begin{array}{c}\text { Altitud } \\
{[\mathbf{m}} \\
\text { s.n.m.] }\end{array}$ & $\begin{array}{l}\text { Longitud } \\
{\left[{ }^{\mathbf{0}},{ }^{\prime}\right]}\end{array}$ & $\begin{array}{l}\text { Latitud } \\
{\left[{ }^{\mathbf{0}},{ }^{\prime \prime}\right]}\end{array}$ & $\begin{array}{l}\text { Período de } \\
\text { datos de } \\
\text { lluvia y } \\
\text { temperatura }\end{array}$ & Departamento \\
\hline & $\begin{array}{l}\text { Tramos del } \\
\text { río Uyús y del } \\
\text { río Teculután } \\
\text { en el Valle } \\
\text { del Motagua }\end{array}$ & Lasabien & 220701 & 260 & 150148 & 894048 & $01 / 70-12 / 04$ & Zacapa \\
$\begin{array}{l}\text { Uyús y } \\
\text { Teculután }\end{array}$ & 220301 & 210 & 145751 & 893504 & $01 / 72-12 / 04$ & \\
\hline
\end{tabular}

Los datos de la estación Pasabien completados son los siguientes: a) precipitación pluvial diaria de febrero de 2003; b) temperatura media diaria de marzo de 1999 y febrero de 2003. Se consideraron los valores medios de registro de los meses señalados y el valor correspondiente de la estación La Fragua.

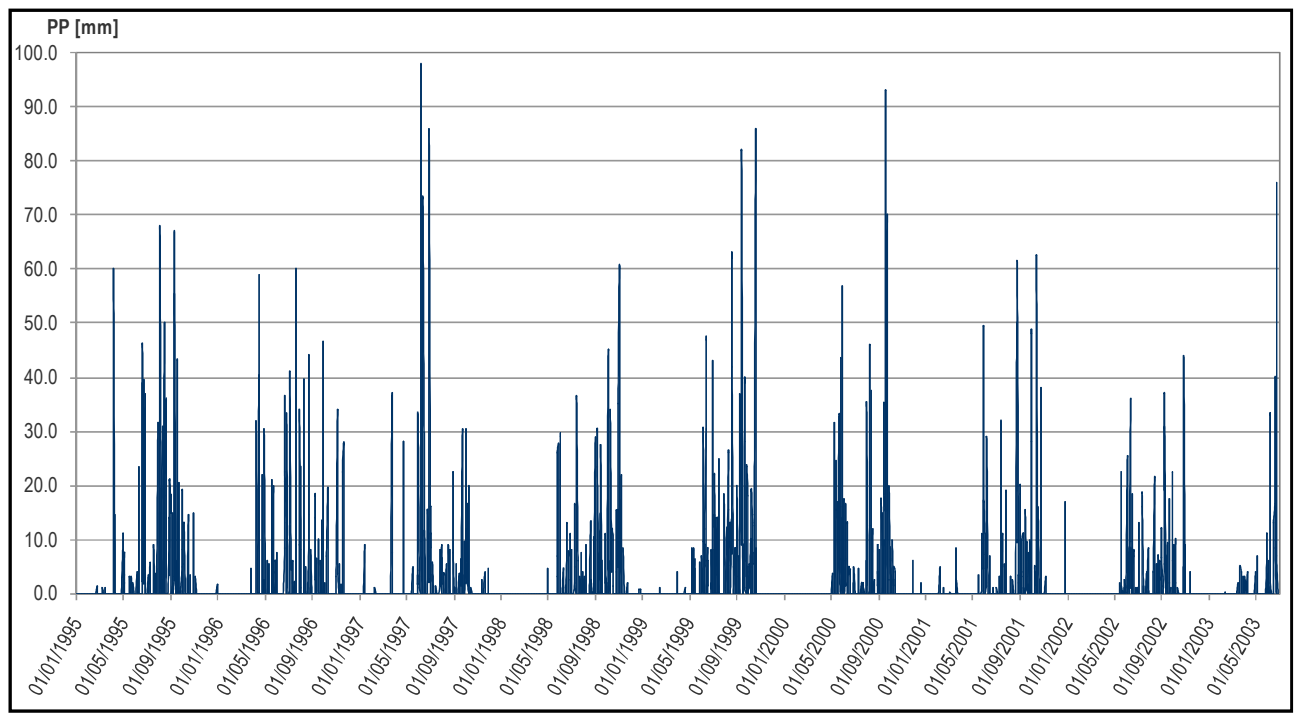

Figura 7.10. Registro de datos diarios de precipitación pluvial del tramo y riberas del río Uyús. Estación de Pasabien, período del 01/01/1995 al 30/06/2003.

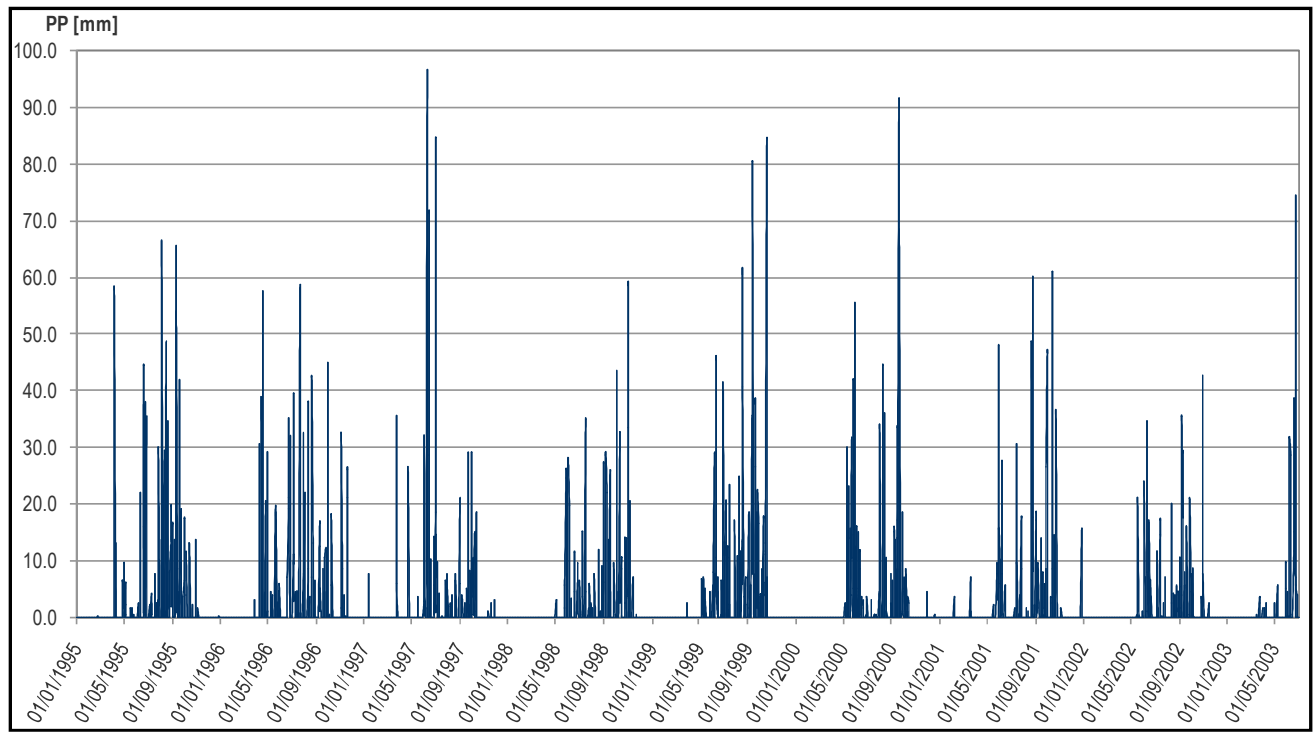

Figura 7.11. Registro de datos diarios de precipitación pluvial del tramo y riberas del río Teculután. Estación de Pasabien, período del 01/01/1995 al 30/06/2003. 
Se usó la serie diaria de caudales de la estación INDE Las Minas (Tabla 7.5 y Fig. 7.12) ubicada a escasos metros (aproximadamente $80 \mathrm{~m}$ ) del inicio del tramo y riberas del río Teculután.

Tabla 7.5. Estación INDE Las Minas para la medición de caudales del río Teculután, Guatemala.

\begin{tabular}{|c|c|c|c|c|c|c|c|c|}
\hline Tramo & Descripción & $\begin{array}{l}\text { Nombre } \\
\text { de la } \\
\text { estación }\end{array}$ & Código & $\begin{array}{l}\text { Altitud } \\
\text { [m } \\
\text { s.n.m.] }\end{array}$ & $\begin{array}{l}\text { Longitud } \\
{\left[{ }^{\circ},, 9\right]}\end{array}$ & $\begin{array}{l}\text { Latitud } \\
{\left[{ }^{\circ},, 9\right]}\end{array}$ & $\begin{array}{l}\text { Período de } \\
\text { registro caudales } \\
\text { diarios }\end{array}$ & Departamento \\
\hline Teculután & $\begin{array}{l}\text { Tramos del } \\
\text { río Teculután } \\
\text { en el Valle } \\
\text { del Motagua }\end{array}$ & $\begin{array}{l}\text { Las } \\
\text { Minas }\end{array}$ & 220901 & 300 & 150105 & 894430 & 1994-2005 & Zacapa \\
\hline
\end{tabular}

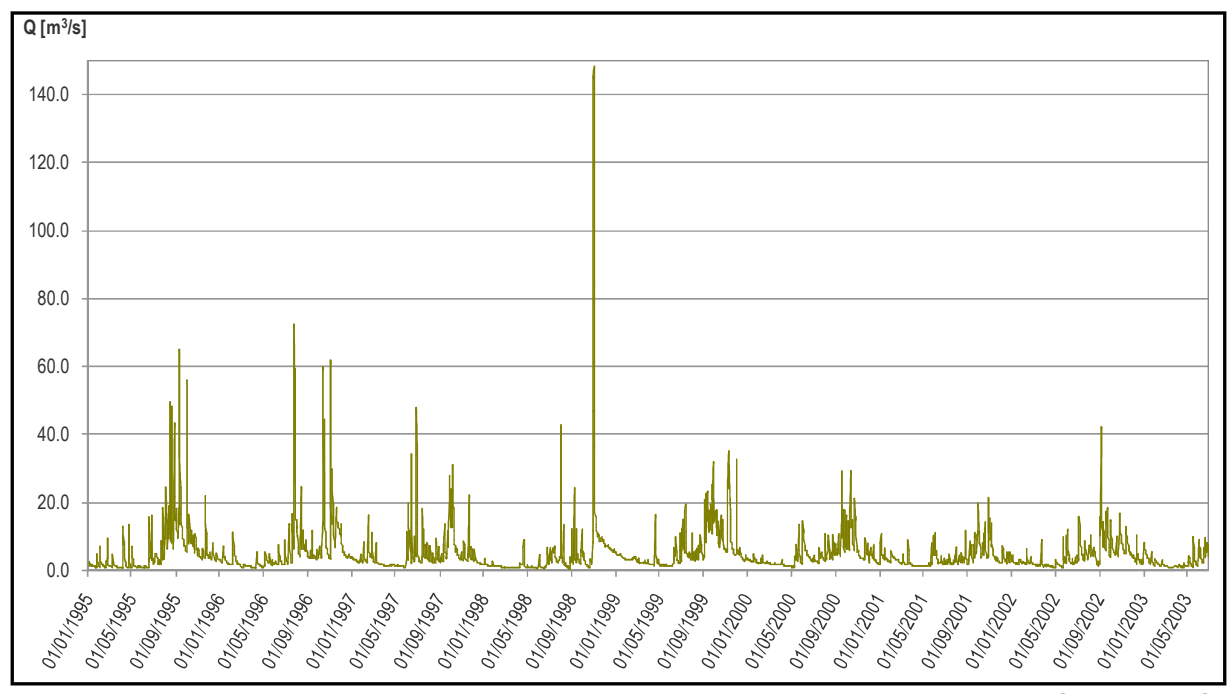

Figura 7.12. Registro de datos diarios de caudales del tramo y riberas del río Teculután. Fuente: Estación INDE Las Minas, período del 01/01/1995 al 30/06/2003.

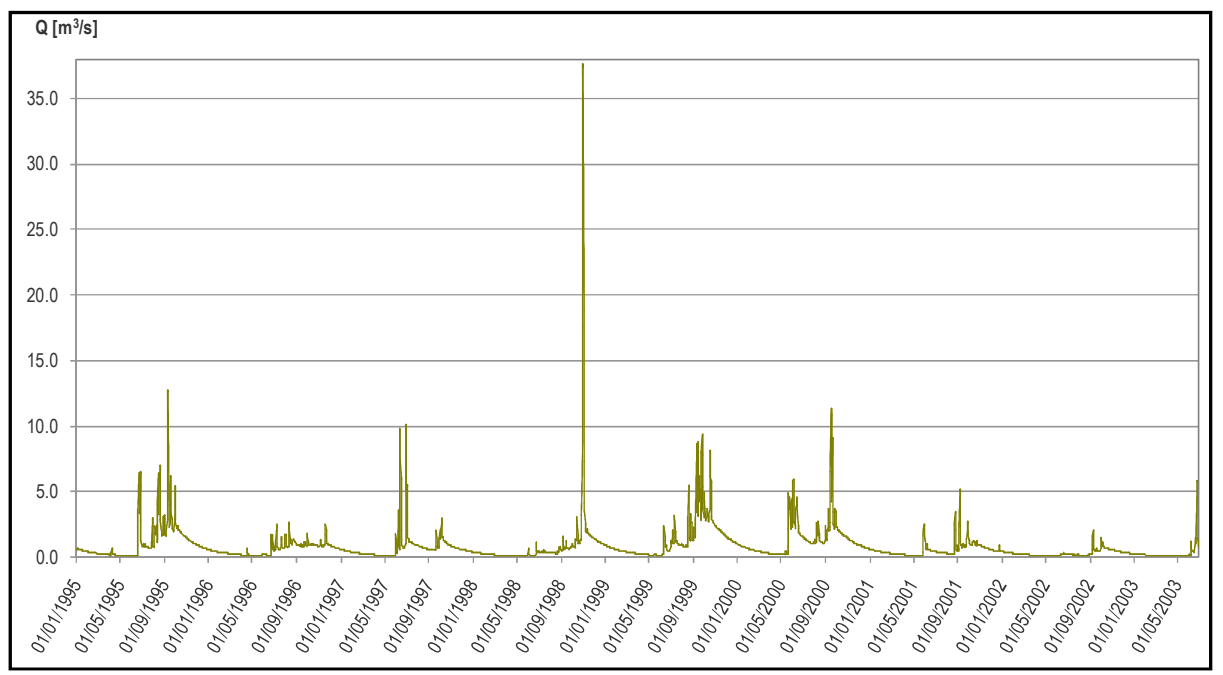

Figura 7.13. Caudales diarios del río Uyús simulados con el modelo Tetis v7.2 y los parámetros regionales efectivos de las cuencas de las Sierra de las Minas. Período del 01/01/1995 al 30/06/2003.

La variabilidad climática del área responde a la estacionalidad de las lluvias para la Sierra de las Minas y el Valle del Motagua: i) las lluvias se dan entre mayo y octubre con un comportamiento bimodal; ii) la época seca es entre noviembre y abril, pero aún en los meses más secos (diciembre a marzo), los ríos Uyús y Teculután presentan caudales por encima de los $0.15 \mathrm{~m}^{3} / \mathrm{seg}$ y $1.70 \mathrm{~m}^{3} / \mathrm{seg}$, respectivamente, lo que demuestra su régimen permanente. 

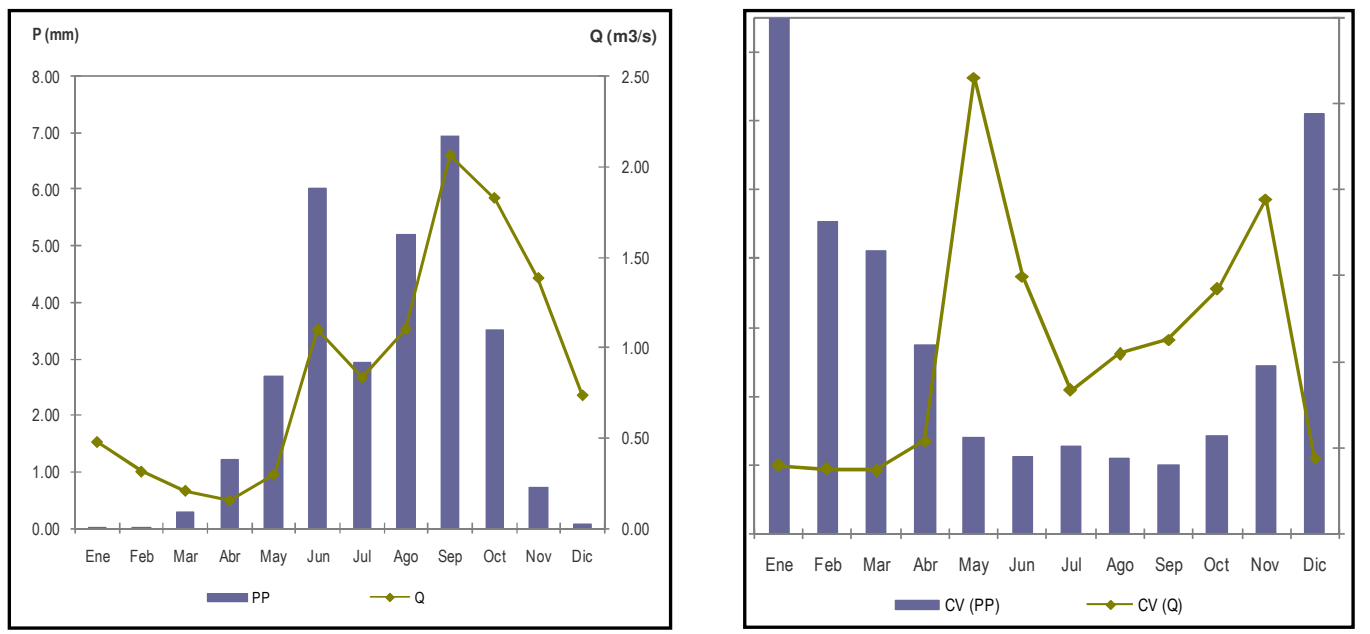

Figura 7.14. Tramo y riberas del río Uyús (Registros del período 1995-2003): (i) precipitaciones [mm] y caudales medios mensuales [ $\mathrm{m}^{3} / \mathrm{s}$ ]; (d) Coeficientes de variación (CV) de las precipitaciones (PP) y caudales medios mensuales (Q). Fuente: Estación INSIVUMEH Pasabien y caudales simulados del río Uyús (Morales-de la Cruz y Francés, 2008).

En la comparación de la variabilidad de la lluvia y de los caudales del río en Uyús (Fig. 7.14 derecha) y en Teculután (Fig. 7.15 derecha) se observa que el régimen hídrico del río no se corresponde con la climatología local del valle del Motagua pues, como ya se demostró (Moralesde la Cruz y Francés, 2007 y 2008), la hidrología de estas cuencas está definida por la climatología característica de la Sierra de las Minas, del incremento de la lluvia con la altitud y la presencia de un bosque nuboso productor de lluvia horizontal. El caudal de ambos ríos recargan el acuífero del valle en su paso hacia el río Motagua.
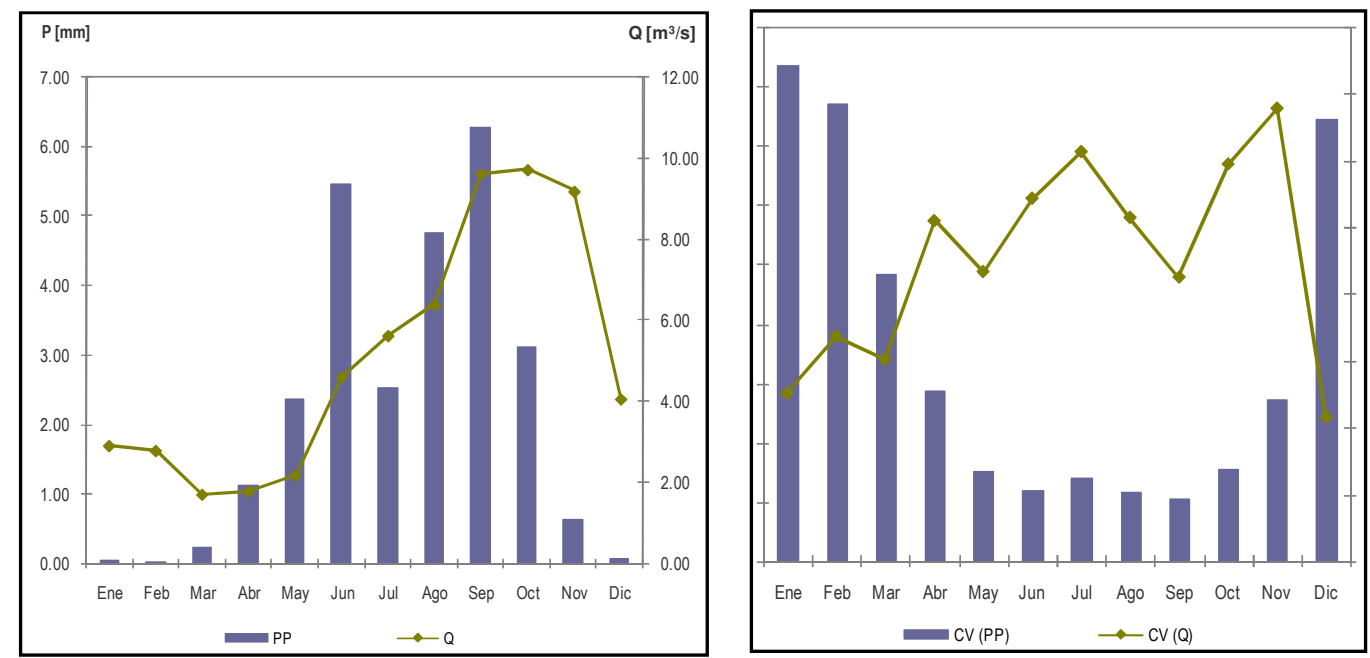

Figura 7.15. Tramo y riberas del río Teculután (Registros del período 1995-2003): (i) precipitaciones [mm] y caudales medios mensuales [m3/s]; (d) Coeficientes de Variación (CV) de las precipitaciones (PP) y caudales medios mensuales (Q). Fuente: Ídem Figura 15.

\section{Evapotranspiración potencial:}

En Guatemala se ha utilizado recurrentemente para el cálculo de la evapotranspiración potencial la ecuación modificada de Hargreaves (Hargreaves, 1975 y 1977), con resultados satisfactorios para múltiples condiciones locales definidas por el relieve y el régimen climático (Garavito, 1989). En dicha ecuación adaptada a Centroamérica se incluye la estimación del porcentaje de posibilidad de sol con base en una relación media entre éste y la humedad relativa media (Hargreaves y Allen, 2003); Garavito (1989) registra una tabla mensual de referencia para Guatemala con valores de radiación media extraterrestre [mm/día] de acuerdo con la latitud 15N. La ecuación es la siguiente: 


$$
E T P=0.0075 * 0.075 R M M * \sqrt{12.5 * \sqrt{(100-R H)}} *(9 / 5 * T m+32)
$$

donde "ETP' [mm/día] es la evapotranspiración potencial, "RMM' [mm/día] es la radicación media extraterrestre [mm/día], " $\boldsymbol{R} \boldsymbol{H}^{[}[\%]$ es la humedad relativa media mensual y " $\mathbf{T m}$ " ${ }^{\mathbf{}} \boldsymbol{C}$ ] es la temperatura media.

La serie de evapotranspiración potencial (ETP) del río Uyús y del río Teculután (Fig. 7.16) se calculó con el registro de temperatura diaria y humedad relativa mensual de la estación Pasabien y de los valores de radiación media extraterrestre indicados para el país.

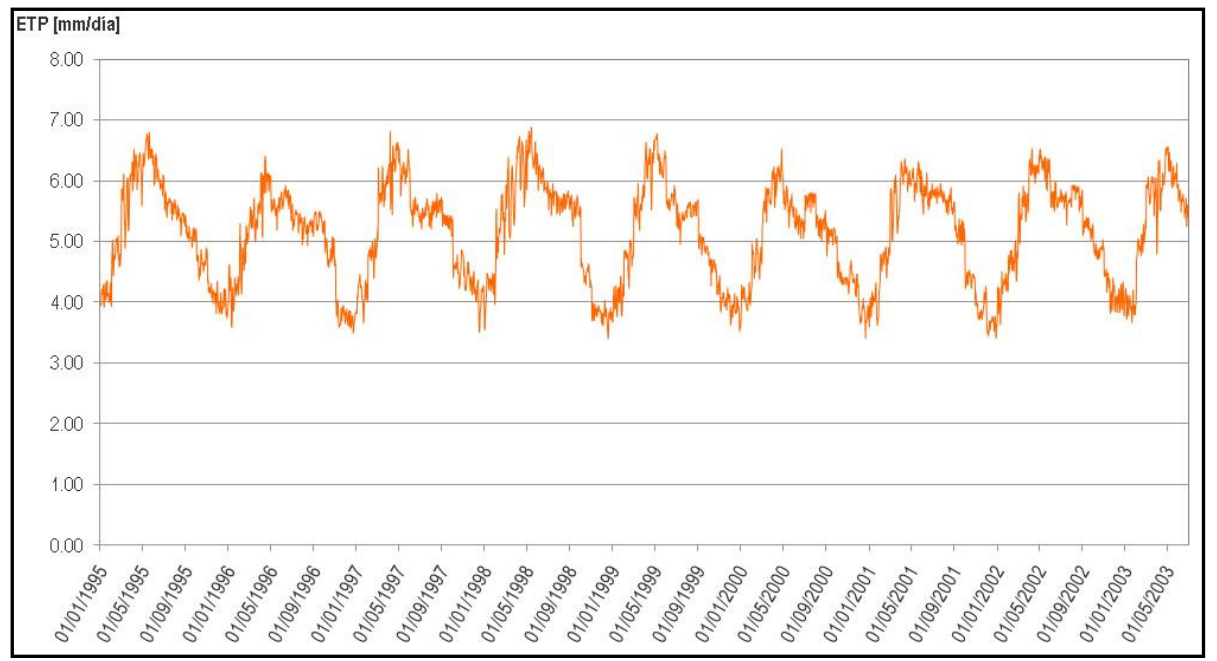

Figura 7.16. Registro de datos diarios de evapotranspiración potencial de los tramos y riberas de Uyús y Teculután. Estación de Pasabien, INSIVUMEH, período del 01/01/1995 al 30/06/2003.

El régimen de ETP corresponde con el de temperaturas y, por ello, los valores máximos de ETP se alcanzan durante los meses más cálidos (Fig. 7.17 izquierda). No obstante, la comparación de los coeficientes de variación de la temperatura y de la ETP (Fig. 7.17 derecha) no muestra correspondencia clara entre ambos fenómenos; esto se debe a que el comportamiento de la ETP en la zona también está determinado por la humedad relativa del ambiente, cuyos valores más altos se dan durante la época lluviosa (comprendida entre mayo y octubre de cada año).
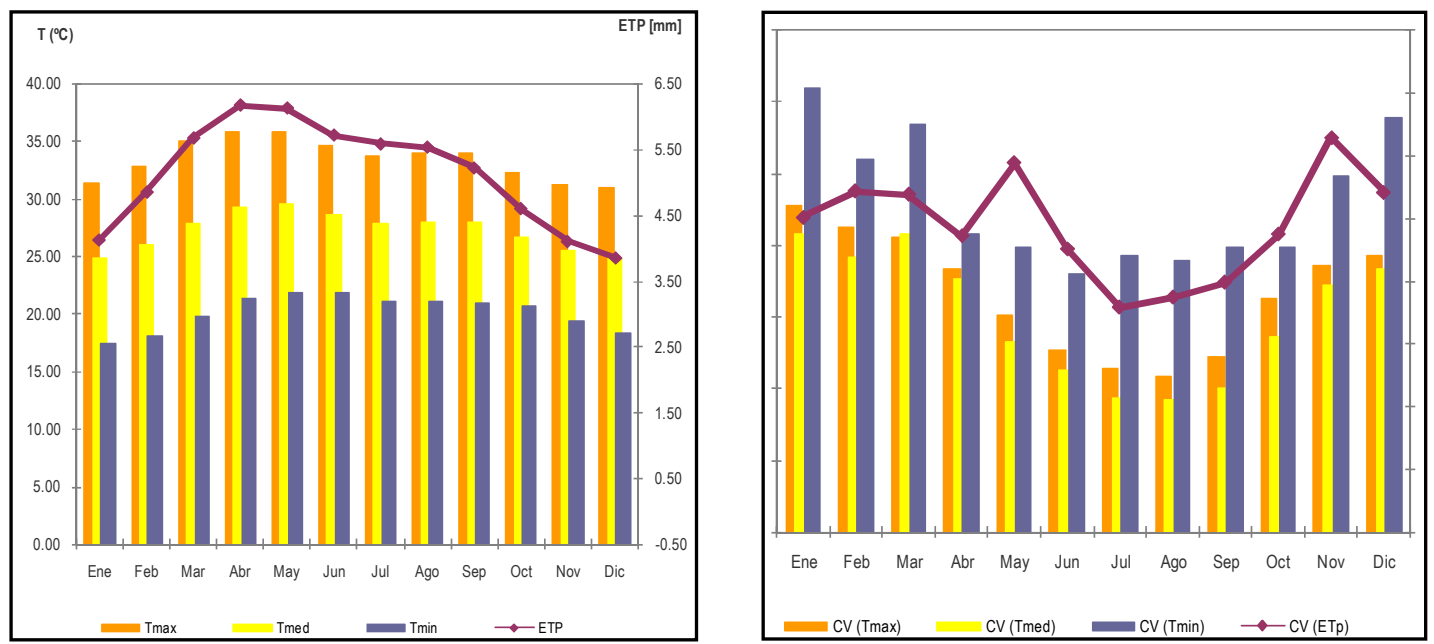

Figura 7.17. Tramo y riberas de Uyús y Teculután (Registros del período 1995-2003): (i) temperaturas [을 y evapotranspiración potencial media mensual [mm]; (d) coeficientes de variación (CV) de las temperaturas y evapotranspiración potencial media mensual. Fuente: Estación INSIVUMEH Pasabien. 


\subsubsection{Tipos funcionales de vegetación de ribera de los transectos de los ríos Uyús y Teculután}

La clasificación preliminar de la vegetación en campo por tipos funcionales de vegetación (TFV) basados en hábitat de crecimiento vegetal, cercanía al río y profundidad radicular dio como resultado 3 TFV de ribera y 1 terrestre (Morales-de la Cruz y Francés, 2008a y 2009):

- Herbáceas obligadas de ribera $(\mathrm{HOb})$ : incluye especies freatofitas obligadas y facultativas (Horton et al, 2001; Snyder y Williams, 2000) que pertenecen al grupo denominado "obligadas de humedal" (sensu Baird y Maddock III 2005; Stromberg et al 1996).

- Arbóreas de riberas húmedas (RA): incluye freatofitas obligadas y facultativas exuberantes (Horton et al, 2001; Snyder y Williams, 2000) que pueden corresponderse con el grupo "vegetación arbórea obligada de humedal de raíz poco profunda" (Baird y Maddock III, 2005; Stromberg et al, 1996).

- Arbóreas facultativas de transición de ribera (RF): con vegetación freatofita facultativa (Horton et al, 2001; Snyder y Williams, 2000) que pertenece al grupo denominado "ribera de transición / arbórea facultativa de humedal de raíz profunda" (Baird y Maddock III, 2005; Stromberg et al, 1996).

- Bosque Seco (BS): vegetación caducifolia en época seca característica del Valle del río Motagua, Guatemala, descrita por Castañeda (2004), Standley y Steyermark (1946-1977) y Véliz et al (2003).

Aunque también se observó el TFV "arbustos y regeneración (Rg)" del sotobosque, que corresponde a plantas facultativas de humedal / especies de ribera de raíz superficial (Baird y Maddock III, 2005; Stromberg et al, 1996), dicha comunidad vegetal está dominada por el estrato arbóreo (RA y RF) y, por tanto, no se modeló como parte de los tipos de vegetación característicos (dominantes) de una zona, y las especies se incluyeron asociadas a los otros TFV señalados (Morales-de la Cruz y Francés, 2008a).

La riqueza florística de las riberas Uyús (Tabla 7.6) se puede describir de forma genérica así: a) el estrato arbóreo se encuentra integrado por 22 familias, 30 géneros y 32 especies de plantas; $b$ ) el estrato arbustivo indica una riqueza integrada por 9 familias 11 géneros y 11 especies; c) el estrato herbáceo está integrado por 10 familias, 13 géneros y 13 especies.

Tabla 7.6. Composición florística del bosque de ribera del río Uyús, Valle del Motagua: Familias, Géneros (Gen) y Especies (Esp) de los hábitos arbóreos, arbustivos y herbáceos. Fuente: Celis (2008). ÁRBOLES

\begin{tabular}{|c|c|c|c|c|c|c|c|c|c|c|c|}
\hline \multicolumn{4}{|c|}{ ARBOLES } & \multicolumn{4}{|c|}{ ARBUSTOS } & \multicolumn{4}{|c|}{ HIERBAS } \\
\hline No. & Familia & Gen & Esp & No. & Familia & Gen & Esp & No. & Familia & Gen & Esp \\
\hline 1 & Simaruobaceae & 1 & 1 & 1 & Piperaceae & 1 & 1 & 1 & Rubiaceae & 1 & 1 \\
\hline 2 & Bombacaceae & 1 & 2 & 2 & Cactaceae & 2 & 2 & 2 & Poaceae & 3 & 3 \\
\hline 3 & Rhamnaceae & 1 & 1 & 3 & Zygophylaceae & 1 & 1 & 3 & Bromeliaceae & 1 & 1 \\
\hline 4 & Mimosaceae & 4 & 4 & 4 & Theophrataceae & 1 & 1 & 4 & Acanthaceae & 1 & 1 \\
\hline 5 & Caelsalpinaceae & 1 & 1 & 5 & Euphorbiaceae & 1 & 1 & 5 & Arecaceae & 2 & 2 \\
\hline 6 & Annonaceae & 1 & 2 & 6 & Bignoniaceae & 1 & 1 & 6 & Lamiaceae & 1 & 1 \\
\hline 7 & Bignoniaceae & 1 & 1 & 7 & Arecaceae & 1 & 1 & 7 & Ciperaceae & 1 & 1 \\
\hline 8 & Zapotaceae & 2 & 2 & 8 & Apocynaceae & 2 & 2 & 8 & Malvaceae & 1 & 1 \\
\hline 9 & Anacardeaceae & 2 & 2 & 9 & Sterculiaceae & 1 & 1 & 9 & Fabaceae & 1 & 1 \\
\hline 10 & Cecropiaceae & 1 & 1 & & & & & 10 & Schizaeaceae & 1 & 1 \\
\hline
\end{tabular}

11 Sapindaceae 22

12 Sn 11

13 Fabaceae 22

14 Sterculiaceae 11

15 Moraceae 11

16 Meliaceae 1

17 Ulmaceae 11

18 Lauraceae 22

19 Hipppocrateaceae $1 \quad 1$

20 Burceraceae 11

21 Anacardeaceae $2 \quad 2$ 
Estos corredores de ribera de Uyús y Teculután poseen segmentación y alteración de la vegetación en un grado bajo y medio, respectivamente, que proviene de huertos frutícolas, monocultivos, ganadería de bajo impacto, pequeñas derivaciones de agua para riego y tala de bosque para leña en las cercanías de los mismos (Celis, 2008). La riqueza de especies de las riberas del río Uyús (Tabla 7.6) y su estado de conservación satisfactorio (Secaira et al, 2003), provocan que este tramo sea de especial interés y referente del Valle del Motagua para el establecimiento de estrategias de protección de sus recursos genéticos vegetales. Esto hace pertinente la aplicación de la modelación ecohidrológica con RibAV en el citado ecosistema.

\subsubsection{Ordenación de la vegetación de ribera del río Uyús:}

Para acoplar el conocimiento de taxonomía vegetal a la clasificación por tipos funcionales de vegetación (TFV), ha sido necesario estudiar estadísticamente la ordenación de las comunidades vegetales del río Uyús (Celis, 2008). La ordenación se utiliza en ecología para describir un patrón dominante o comprobar hipótesis de distribución vegetal, mediante el arreglo de la vegetación a lo largo de uno o múltiples ejes; también permite encontrar cómo varía la abundancia vegetal con relación a un gradiente ambiental y suele sintetizar la complejidad subyacente de esta relación mediante una expresión gráfica (Gauch, 1982; McCune y Grace, 2002; Vargas, 1999). Para el río Uyús se analizó con énfasis el gradiente de humedad de la sección transversal.

Con los datos del muestreo de vegetación se construyó una matriz de ausencia/presencia y otra de densidad promedio de las especies para el análisis multivariable de ordenación (Celis, 2008). Se trabajó con el software PC-ORD (McCune y Mefford, 1997) y la herramienta DECORANA ${ }^{5}$ para analizar la correspondencia entre las especies de ribera y el gradiente de humedad (eje 1, representado indirectamente por las clases "distales" correspondientes a distancias cada $10 \mathrm{~m}$ a partir del thalweg del río) o la geomorfología local (eje 2, representado por la posición fisiográfica de la zona -llanura de inundación, terraza reciente, escarpe o paredón rocoso-).

En el resultado de la ordenación de "ausencia/presencia vegetal" (Tabla 7.7) se puede observar que el código de cada especie de ribera muestreada está seguido del valor de ordenación o media ponderada para cada uno de los ejes de ordenación utilizados: el gradiente transversal de humedad (eje 1) y la geomorfología local (eje 2). En el segmento central y derecho de la citada tabla, se indican los autovalores "EIG." de cada eje y se ordenan las especies con base en un valor adimensional para representar la intensidad del gradiente. El autovalor de 0.908 demuestra que la distribución de la vegetación de la ribera del río Uyús está determinado principalmente por el eje 1 "gradiente transversal de humedad", con lo que es posible corroborar la hipótesis de distribución vegetal que responde al gradiente ambiental de ribera (Malanson, 1993).

Posteriormente, se generó un análisis gráfico (Fig. 7.18) con PC-ORD para conocer cómo se distribuyen las especies vegetales / TFV de ribera a lo largo del gradiente de humedad, y con ello establecer cómo agruparlos en función de su cercanía al lecho del río conforme su asusencia/presencia (Celis, 2008). Los tipos de vegetación "obligada de humedal" (mayormente herbáceas freatofitas) y "bosque seco" poseen una distribución aglutinada en los extremos del gradiente de humedad, es decir, en zonas saturadas cercanas al río y en zonas alejadas del río de menor tendencia a la saturación, respectivamente. Las otras especies y TFV de ribera tienen un amplio espectro de presencia/ausencia a lo largo del transecto que provoca que sus distribuciones sean coincidentes y difíciles de separar.

También se hizo el análisis con los datos de densidad de las especies, obteniéndose un resultado similar, en el que el autovalor de 0.904 del eje 1 "gradiente transversal de humedad" evidencia que éste determina la distribución vegetal en la ribera (Fig. 7.19). Con esto se vuelve a observar la ubicación de las especies herbáceas obligadas de humedal en las cercanías del cauce y del bosque seco en las zonas exteriores de la ribera. Los TFV arbóreos obligados y de transición de la ribera nuevamente muestran una distribución que se traslapa.

\footnotetext{
${ }^{5}$ Nombre del programa de cómputo original para el análisis de correspondencias (McCune y Grace, 2002).
} 


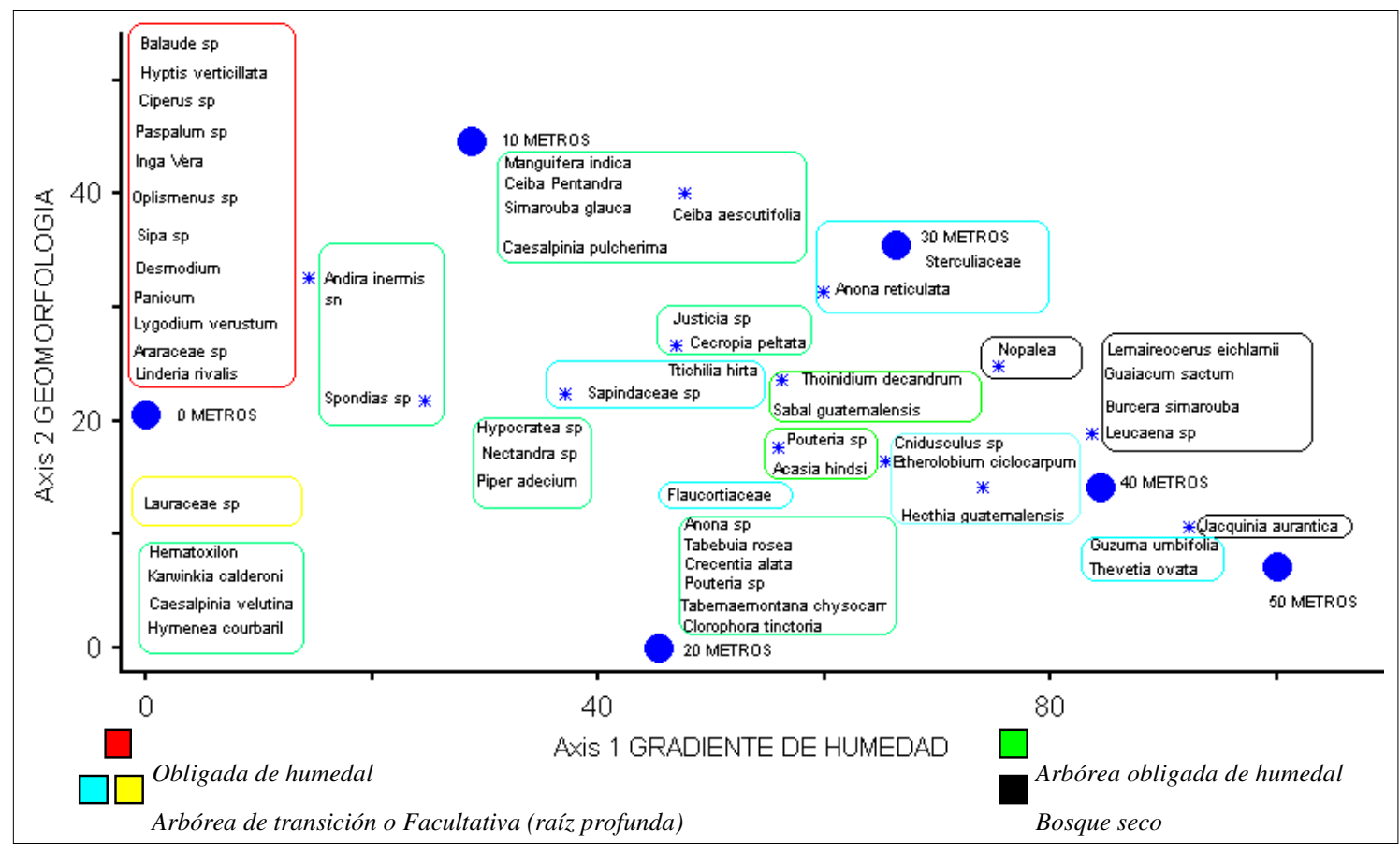

Figura 7.18. Ordenación de especies y TFV de riberas Uyús, mediante valores ponderados de ausenciapresencia en los ejes de variación "gradiente de humedad" y "geomorfología". Fuente: Celis (2008).

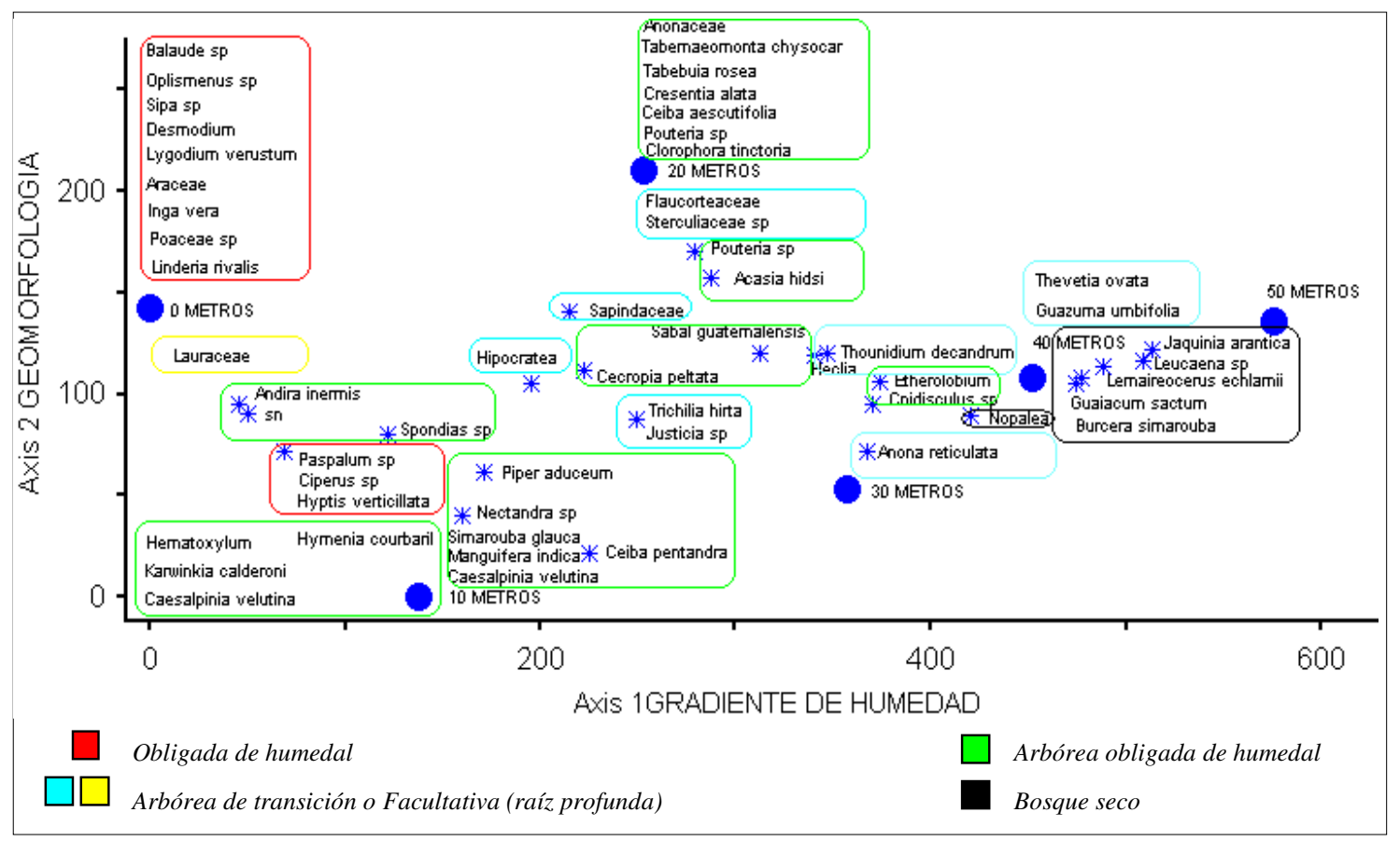

Figura 7.19. Ordenación de especies y TFV de riberas Uyús, mediante valores ponderados de densidad vegetal en los ejes de variación "gradiente de humedad" y "geomorfología". Fuente: Celis (2008). 
Tabla 7.7. Ponderaciones realizadas con PC-ORD DECORANA (McCune y Mefford, 1997) para la ordenación de la vegetación con base en los datos de ausencia-presencia de las especies vegetales muestreadas en las riberas del río Uyús. Fuente: Celis (2008).

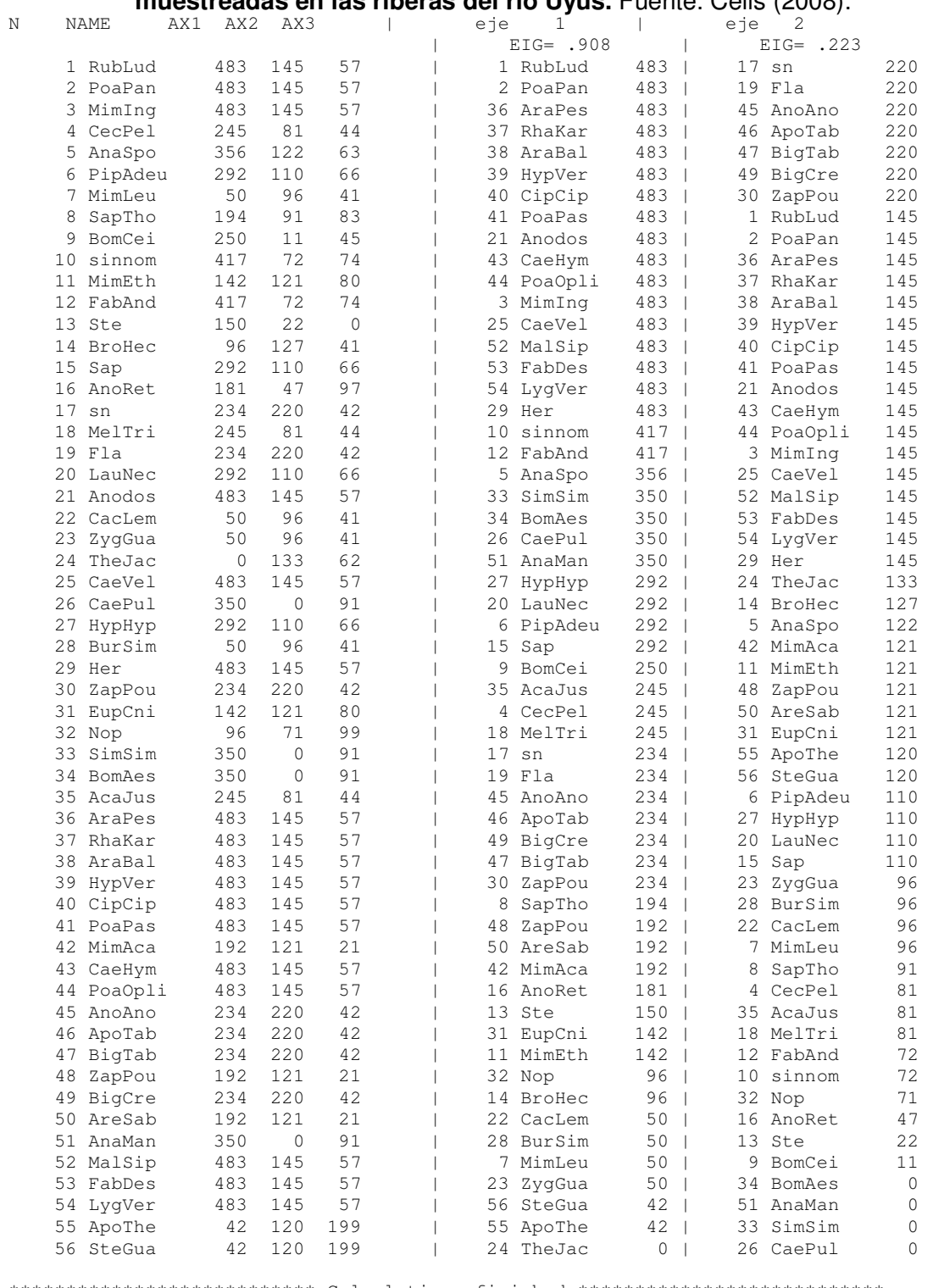

Considerando la ordenación, el estudio taxonómico (Celis, 2008), las anotaciones de campo y la clasificación preliminar por TFV (Morales-de la Cruz y Francés, 2008a y 2009), se pudo establecer qué especies y/o familias de plantas caracterizan los TFV de ribera (Tabla 7.8): a) Herbáceas obligadas de ribera "RH": 9 familias, 12 géneros y 12 especies (Fig. 7.20); b) Arbóreas de riberas húmedas "RA": 21 familias, 27 géneros y 27 especies (Fig. 7.21); c) Arbóreas facultativas o de transición de ribera "RF": 10 familias, 11 géneros y 11 especies (Fig. 7.22); d) Bosque Seco "BS": las 5 familias, 6 géneros y 6 especies colectadas en los transectos de estudio (Fig. 7.23) más la riqueza florística descrita por Castañeda (2004) y Véliz et al (2003).

Estos resultados son la base taxonómica vegetal y de referencia para el establecimiento de otros tipos funcionales de vegetación de las riberas del Valle del Motagua, tal y como las del río Teculután -objeto de modelación con RibAV-. Además, se realizó una revisión exhaustiva para establecer las características morfológicas, fenológicas, fitosociológicas y ecofisiológicas de las especies vegetales de la ribera y el bosque seco del Valle del Motagua (Castañeda, 1997 y 2004; Nájera, 2009; Secaira et al., 2003; Standley y Steyermark, 1946-1977; Valle et al, 1999; Vargas, 1999; Véliz et al, 2003). 
Tabla 7.8. Composición florística del bosque de ribera del río Uyús, Valle del Motagua: Familias, Géneros (Gen) y Especies (Esp) de los hábitos arbóreos (a), arbustivos (b) y herbáceos (h). Fuente: Celis (2008), Morales-de la Cruz y Francés (2008a, 2009).

\begin{tabular}{|c|c|c|c|c|c|c|}
\hline No. & NOMBRE COMÚN & NOMBRE CIENTIFICO & FAMILIA & HÁBITO & CODIGO & TFV \\
\hline 1 & Jazmín de agua & Lindenia rivales Benth & Rubiaceae & $\mathrm{h}$ & RubLud & $\mathrm{RH}$ \\
\hline 2 & & Panicum sp. & Poaceae & $\mathrm{h}$ & PoaPan & $\mathrm{RH}$ \\
\hline 3 & & & $S n$ & a & sinnom & $\mathrm{RH}$ \\
\hline 4 & & Justicia sp. & Acanthaceae & $\mathrm{h}$ & AcaJus & $\mathrm{RH}$ \\
\hline 5 & Cola de pescado & & Arecaceae & $\mathrm{h}$ & AraPes & $\mathrm{RH}$ \\
\hline 6 & Palma & Bactris sp & Arecaceae & $\mathrm{h}$ & AraBal & $\mathrm{RH}$ \\
\hline 7 & Verbena & Hyptis verticillata autoridad Jacq & Lamiaceae & $\mathrm{h}$ & HypVer & $\mathrm{RH}$ \\
\hline 8 & & Ciperus sp. & Ciperaceae & $\mathrm{h}$ & CipCip & $\mathrm{RH}$ \\
\hline 9 & & Paspalum sp & Poaceae & $\mathrm{h}$ & PoaPas & $\mathrm{RH}$ \\
\hline 10 & & Oplismenus sp. & Poaceae & $\mathrm{h}$ & PoaOpli & $\mathrm{RH}$ \\
\hline 11 & Sipa & Sida $s p$ & Malvaceae & $\mathrm{h}$ & MalSip & $\mathrm{RH}$ \\
\hline 12 & Helecho & Lygodium venustum & Schizaeaceae & $\mathrm{h}$ & LygVer & $\mathrm{RH}$ \\
\hline 13 & Inga & Inga Vera & Mimosaceae & a & MimIng & RA \\
\hline 14 & Guarumo & Cecropia peltata $L$. & Cecropiaceae & a & CecPel & RA \\
\hline 15 & Jocote & Spondias sp & Anacardeaceae & $a, b$ & AnaSpo & RA \\
\hline 16 & Cordoncillo & Piper aduncun $L$ & Piperaceae & $\mathrm{b}$ & PipAdeu & RA \\
\hline 17 & Ceiba & Ceiba pentandra ( I.) Gaerth & Bombacaceae & a & BomCei & RA \\
\hline 18 & Almendro de río & Andira inermes (Swartz) $H B K$. & Fabaceae & a & FabAnd & RA \\
\hline 19 & Aguacatillo & Nectandra sp. & Lauraceae & a & LauNec & RA \\
\hline 20 & & Hippocratea sp. & Hippocrateaceae & a & НурНур & RA \\
\hline 21 & & Hematoxylum sp. & Fabaceae & a & Her & RA \\
\hline 22 & Jocote de Mico & Simarouba glauca DC & Simaroubaceae & $\mathrm{a}$ & SimSim & RA \\
\hline 23 & & Karwinskia sp. & Rhamnaceae & a & RhaKar & RA \\
\hline 24 & Ixcanal o cacho toro & Acacia hindsii Benth & Mimosaceae & a & MimAca & RA \\
\hline 25 & Guapinol & Hymenaea courbaril $L$. & Caelsalpinaceae & a & CaeHym & RA \\
\hline 26 & Anona & & Anonaceae & $\mathrm{a}$ & AnoAno & RA \\
\hline 27 & Chapupo & Tabernaemontana chysocarr Blake. & Apocynaceae & $\mathrm{b}, \mathrm{a}$ & ApoTab & RA \\
\hline 28 & Matilisguate & Tabebuia rosea (Bertol) DC. & Bignoniaceae & $\mathrm{a}$ & BigTab & RA \\
\hline 29 & Morro & Crescentia alata $H B K$ & Bignoniaceae & $\mathrm{b}$ & BigCre & RA \\
\hline 30 & Sabal & Sabal guatemalensis Beccari. & Arecaceae & $\mathrm{b}$ & AreSab & RA \\
\hline 31 & Mango & Manquifera indica $L$ & Anacardeaceae & $\mathrm{a}$ & AnaMan & RA \\
\hline 32 & & Desmodium sp. & Fabaceae & $\mathrm{h}$ & FabDes & RA \\
\hline 33 & Zorrillo & Thouinidium decandrum (Humb \& Bonpl) & Sapindaceae & a & SapTho & $\mathrm{RF}$ \\
\hline 34 & Piñuelón & Hechtia guatemalensis Mez. & Bromeliaceae & $\mathrm{h}$ & BroHec & $\mathrm{RF}$ \\
\hline 35 & Zapote & Pouteria sp & Zapotaceae & a & ZapPou & $\mathrm{RF}$ \\
\hline 36 & Moral o Ceibillo & Ceiba aescutifolia $H B K \&$ Baker & Bombacaceae & a & BomAes & $\mathrm{RF}$ \\
\hline 37 & Ficus & Ficus sp. & Moraceae & $\mathrm{a}$ & Ficu & $\mathrm{RF}$ \\
\hline 38 & Conacaste & Etherolobium cyclocarpum (Jacq.) Grisseb. & Mimosaceae & a & MimEth & $\mathrm{RF}$ \\
\hline 39 & & & Sterculiaceae & a & Ste & $\mathrm{RF}$ \\
\hline 40 & & & Sapindaceae & a & Sap & $\mathrm{RF}$ \\
\hline 41 & Anona & Annona reticulata $L$ & Anonaceae & a & AnoRet & $\mathrm{RF}$ \\
\hline 42 & Mora o Moral & Clorophora tinctoria (L) Gaud. & Moraceae & a & sn & $\mathrm{RF}$ \\
\hline 43 & Quesillo & Trichilia hirta $L$ & Meliaceae & a & MelTri & $\mathrm{RF}$ \\
\hline 44 & Cabalero & Celtis iguanaza (Jacq) Sarg & Ulmaceae & a & Fla & $\mathrm{RF}$ \\
\hline 45 & & & Lauraceae & $\mathrm{a}$ & Anodos & $\mathrm{RF}$ \\
\hline 46 & Chichicaste de caballo & Cnidosculos tubulosos (Muelll Agr.) I.M. Johnston & Euphorbiaceae & $\mathrm{b}$ & EupCni & $\mathrm{RF}$ \\
\hline 47 & Chilindrón & Thavetia ovata (Cav) A. DC. & Apocynaceae & $\mathrm{b}$ & ApoThe & $\mathrm{RF}$ \\
\hline 48 & Caulote & Guazuma umbifolia Lam & Sterculiaceae & $\mathrm{b}, \mathrm{a}$ & SteGua & $\mathrm{RF}$ \\
\hline 49 & Jiote & Bursera simaruba (L) Sarg & Burseraceae & a & BurSim & $\mathrm{RF}$ \\
\hline 50 & Aripín & Caesalpinia velutina (Britt \& Rose) Standl & Caesalpinaceae & a & CaeVel & BS \\
\hline 51 & Santa Rosa & Caesalpinia pulcherima ( L) Swart & Caesalpinaceae & a & CaePul & BS \\
\hline 52 & Yaje & Leucaena sp & Mimosaceae & a & MimLeu & BS \\
\hline 53 & Tuno & Lemarireocerus echlamii Britt. \& Rose & Cactaceae & $\mathrm{b}$ & CacLem & BS \\
\hline 54 & Guayacán & Guaiacum sanctum $L$. & Zygophylaceae & $\mathrm{b}$ & ZygGua & BS \\
\hline 55 & Duruche & Jacquinia aurantiaca Ait & Theophrataceae & $\mathrm{b}$ & TheJac & BS \\
\hline 56 & Nopal & Nopalea guatemalensis Rose & Cactaceae & $\mathrm{b}$ & Nop & BS \\
\hline
\end{tabular}

RH: Herbáceas obligadas de ribera

RF: Arbóreas facultativas o transición de ribera

RA: Arbóreas obligadas de ribera

BS: Bosque seco 

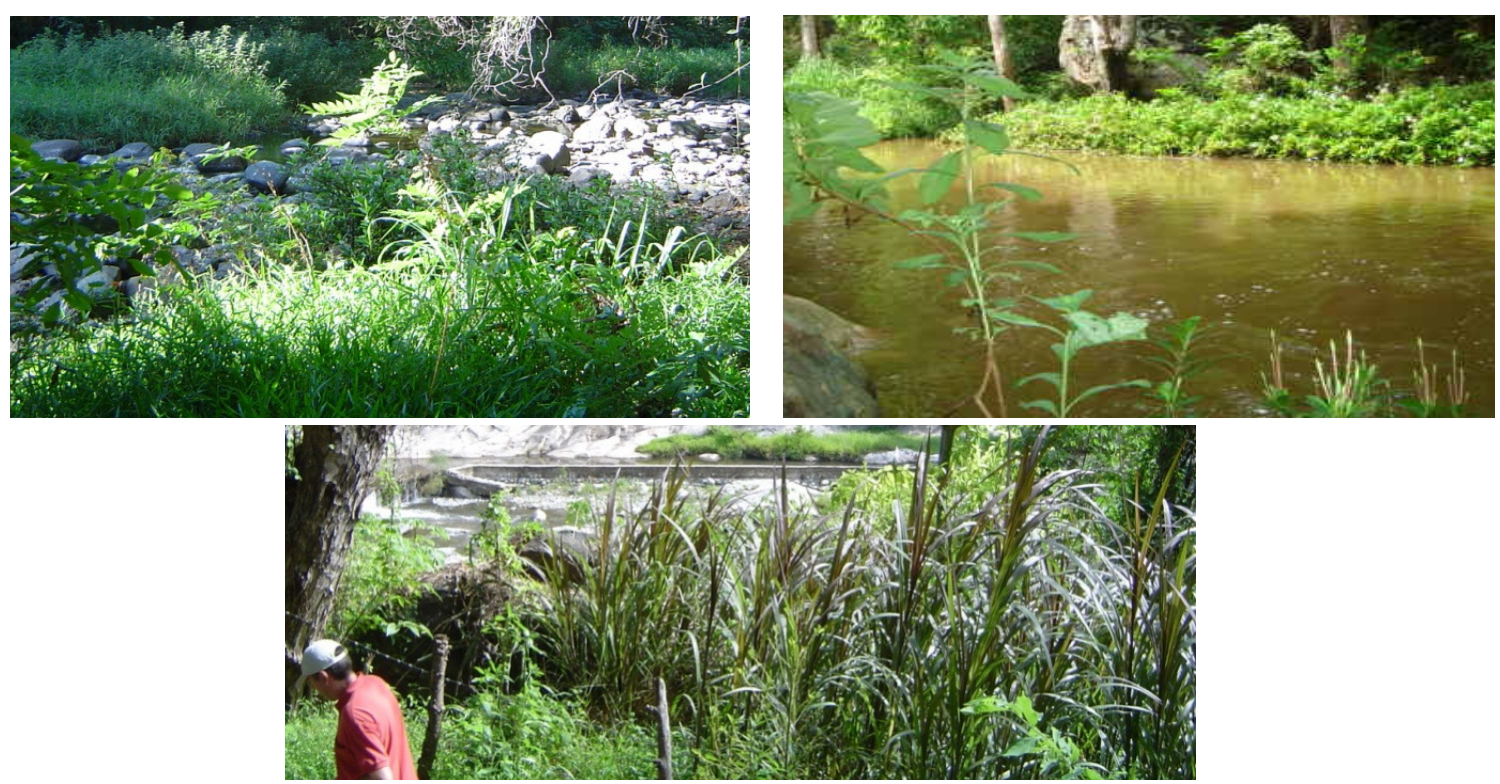

Figura 7.20. Especies de las familias Poaceae y Rubiaceae del TFV "Herbáceas obligadas de ribera, RH" presentes en el río Uyús (arriba) y Teculután (abajo). Fotos: M. Morales (2006, 2007), J. Vargas (2007).
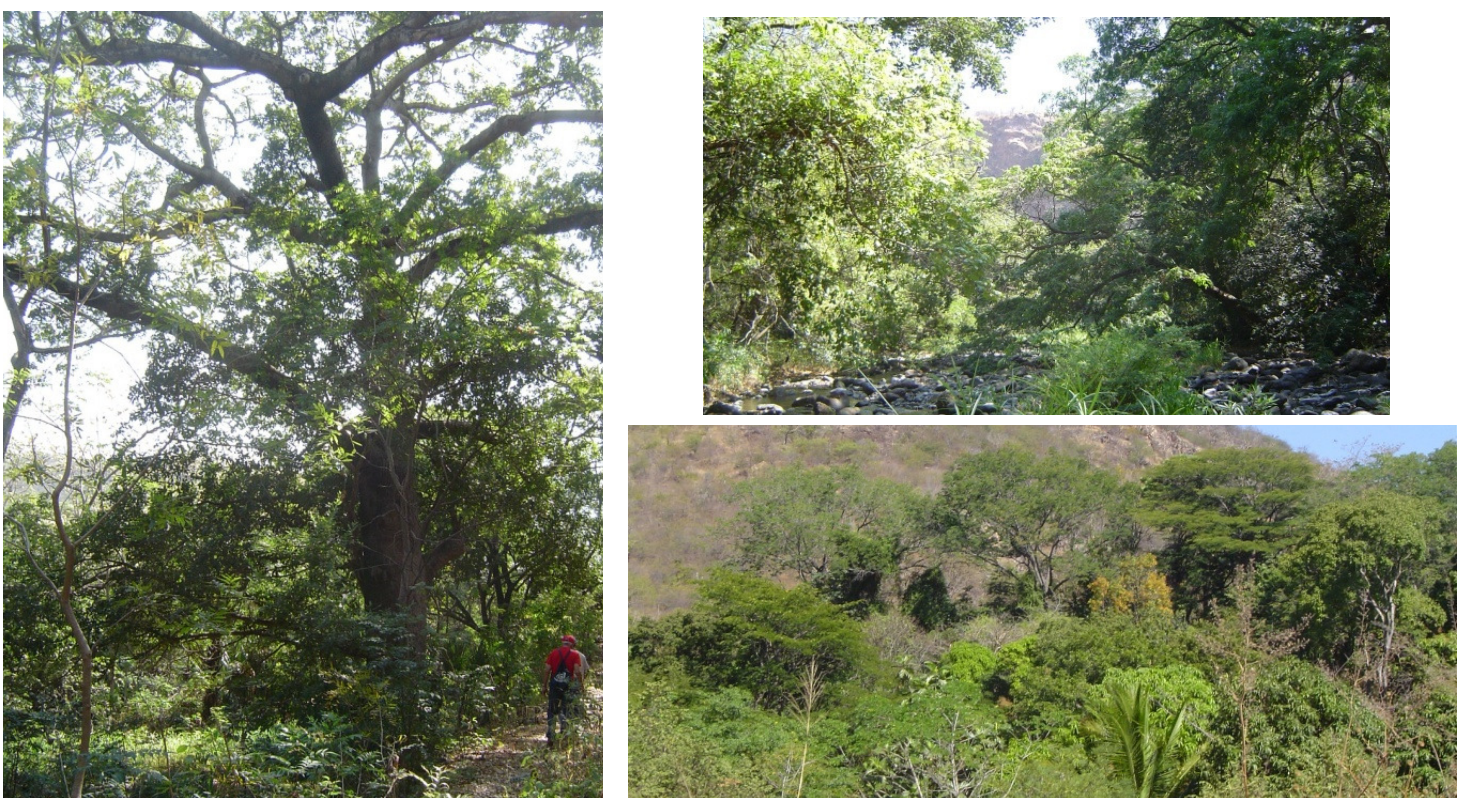

Figura 7.21. Especies de las familias Anacardeaceae, Bombacaceae, Fabaceae, Simaroubaceae, entre otras -ver tabla 7.8- del TFV “Arbóreas de ribera húmeda, RA”, presentes en transectos del río Uyús. Fotos: M. Morales (2006, 2008). 

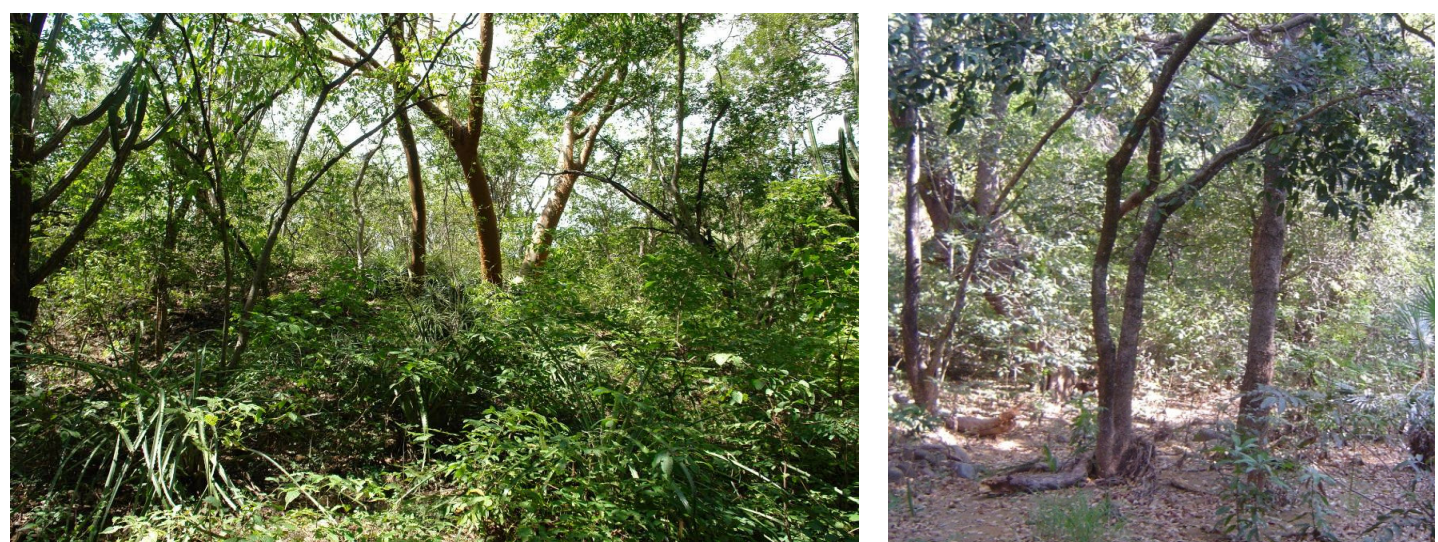

Figura 7.22. Especies de las familias Sterculiaceae, Moraceae, Sterculiaceae, entre otras -ver tabla 7.8- del TFV "Arbóreas facultativas de transición de ribera, RF” presentes en el río Uyús.

Fotos: J. Vargas (2007), M. Morales (2008).
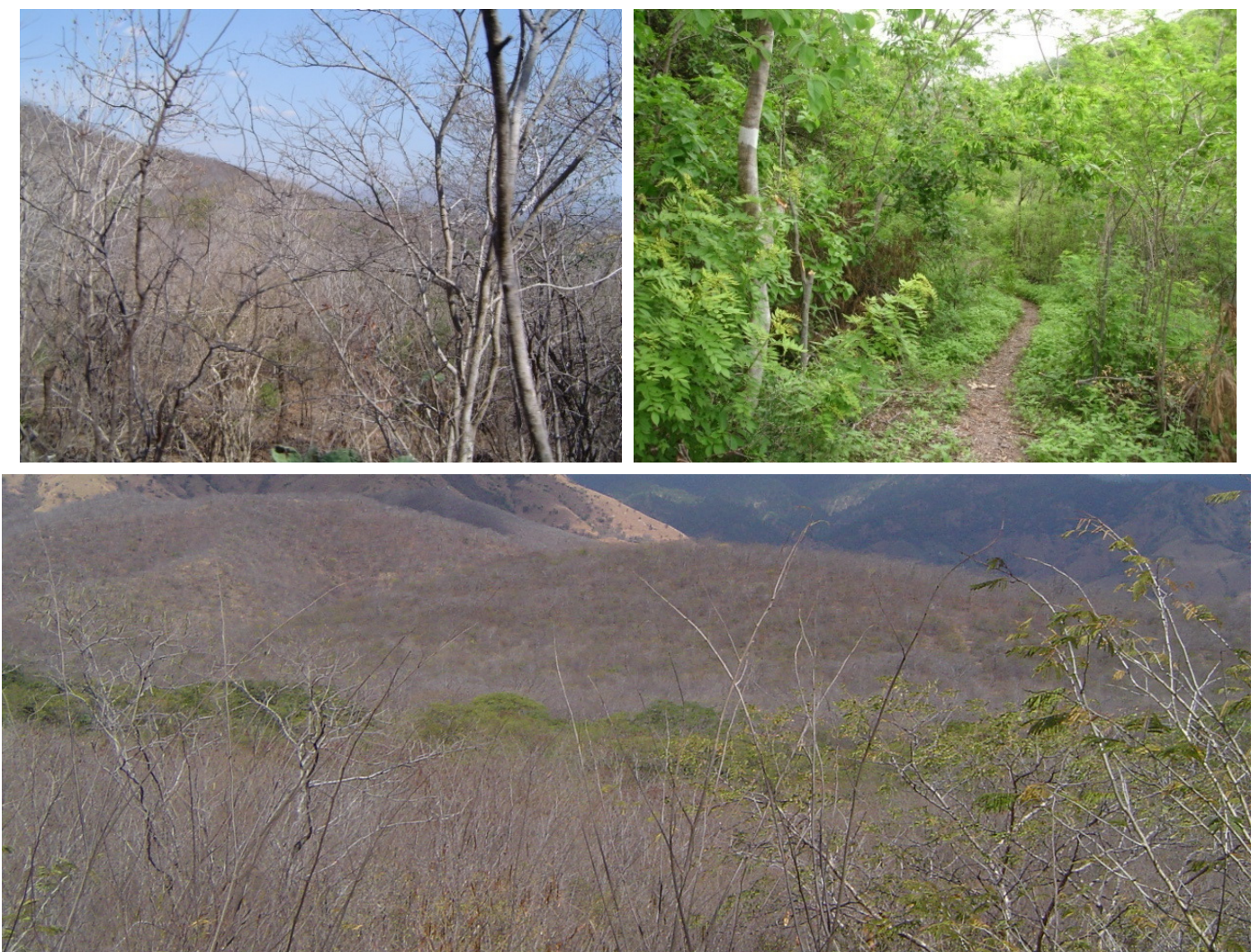

Figura 7.23. Especies de las familias Mimosaceae, Zygophylaceae, Theophrataceae, entre otras del TFV "Bosque seco, BS" -ver tabla 7.8- presente en laderas aledañas a las riberas del río Uyús y Teculután: Arriba, superficie foliar (i) caduca en la época seca (02/02/2006) y (d) verde durante la época lluviosa

(31/07/2007). Abajo, vista del BS del Valle Motagua rodeando un tramo de bosque de ribera. Fotos: M. Morales (2006 y 2007). 


\subsubsection{Caracterización de las secciones transversales de río y riberas de Uyús y Teculután: construcción de curvas caudal-nivel}

Se tomaron datos topográficos (puntos de distancia y elevación) para la modelación hidráulica de cada sección utilizando estación total; se buscó representar la variabilidad topográfica del río, de las zonas de ribera y bosque seco y los puntos de transición entre éstas (Fig. 7.24). Esta información de campo se procesó en gabinete utilizando Autocad(O. Los transectos y puntos de transición se marcaron en campo con estacas, y se tomaron georreferencias mediante GPS en sistema de coordenadas WGS1984, UTM zona 15N para su mapeo en SIG (Fig. 7.7 y 7.8 ).
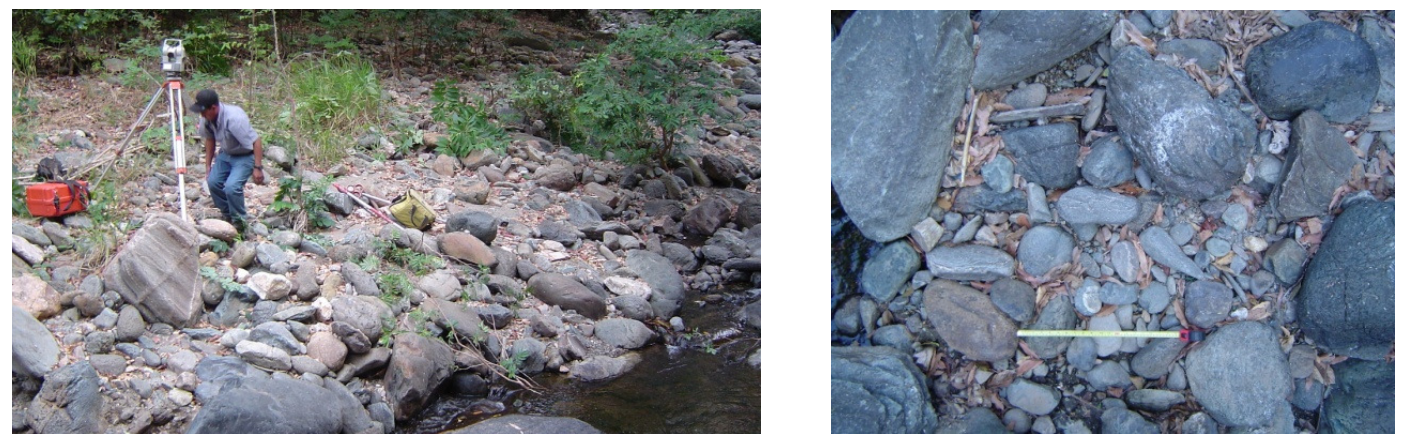

Figura 7.24. (i) Trabajo de levantamiento de información topográfica con Estación total en el transecto 2 del río Uyús. (d) Vista del material del lecho del transecto 3 del río Uyús y escala de referencia de $0.5 \mathrm{~m}$ para estimar su tamaño promedio. Fotos: M. Morales (2006).

Para obtener la curva de gasto de las secciones transversales de los ríos Uyús y Teculután se estimó la rugosidad total de cada una de las zonas de dicho transecto, siguiendo el método y recomendaciones del "US Geological Survey" (Arcement y Scheider, 1989) que incluye correcciones del valor de la rugosidad con base en el tamaño del material del fondo, las irregularidades de la superficie, las variaciones en forma y tamaño de la sección transversal, obstrucciones al flujo, vegetación (en el cauce, en la ribera, en el bosque seco ${ }^{6}$ ) y sinuosidad. El método se apoya en fotografías, tablas y observaciones de campo; se interpretaron también las fotografías de los tramos de estudio (Figuras 7.20 a 7.24).

Se observaron en el río Uyús tamaños promedio del material del lecho $>300 \mathrm{~mm}$, con grava o suelo firme, irregularidad de grado entre moderado y severo, obstrucciones entre escasas y menores, y vegetación entre mediana y extrema que influyen fuertemente en el orden de magnitud de la rugosidad. Por su parte, el río Teculután, posee en general, un material del lecho con tamaño $>300 \mathrm{~mm}$, que varía entre grava y suelo firme, con irregularidad entre moderada y severa, obstrucciones que pueden ser entre insignificantes y apreciables, y que pueden carecer de vegetación o poseerla en cantidad extrema.

Esta información de campo es una de las claves para conocer la distribución de los tipos funcionales de vegetación (TFV), y provee la base para que el modelo RibAV estudie las interacciones recíprocas entre el patrón espacial y los procesos ecológicos de la ribera y, con ello, aplicar las ideas ecológicas en el manejo del territorio (zonificación). A continuación se presentan los transectos y TFV de los ríos Uyús (Fig. 7.25 y 7.26) y Teculután (Fig. 7.27).

\footnotetext{
${ }^{6}$ Para establecer la cantidad de vegetación en cada zona del transecto la zonificación con base en los TFV es primordial (ver Fig. 24 a 26)
} 
Transecto 1, río Uyús

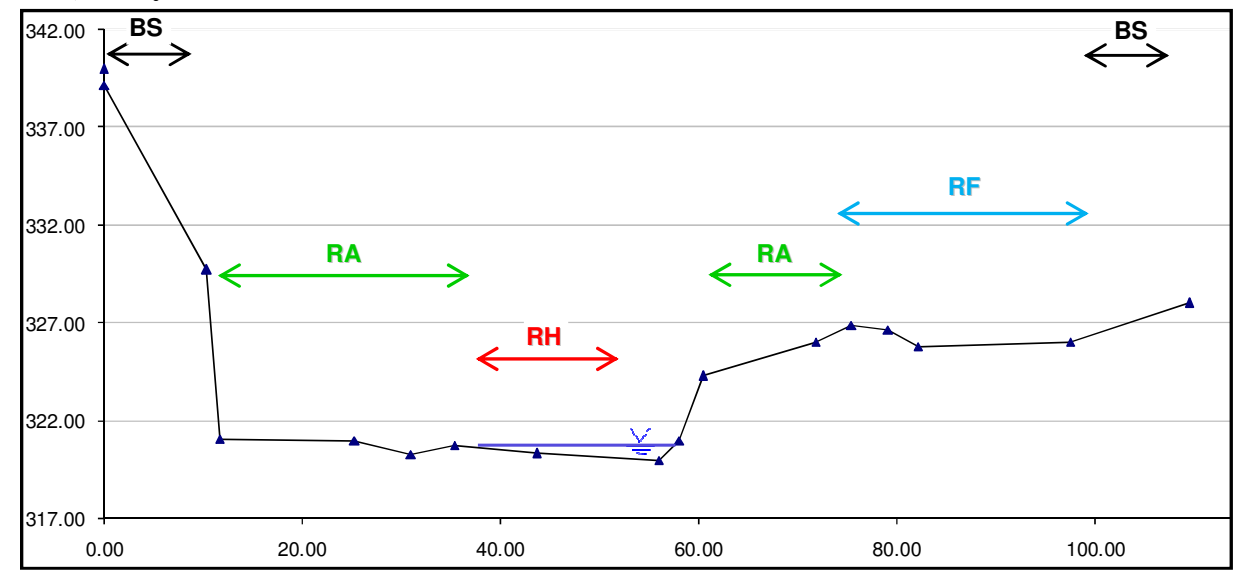

(b) Transecto 2, río Uyús

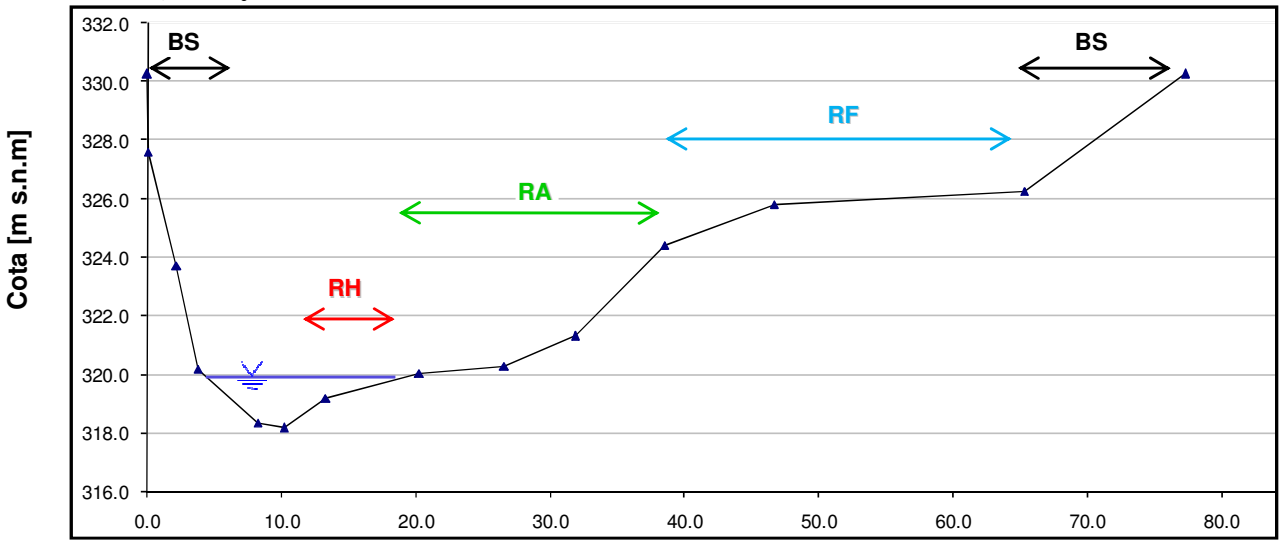

(c) Transecto 3, río Uyús

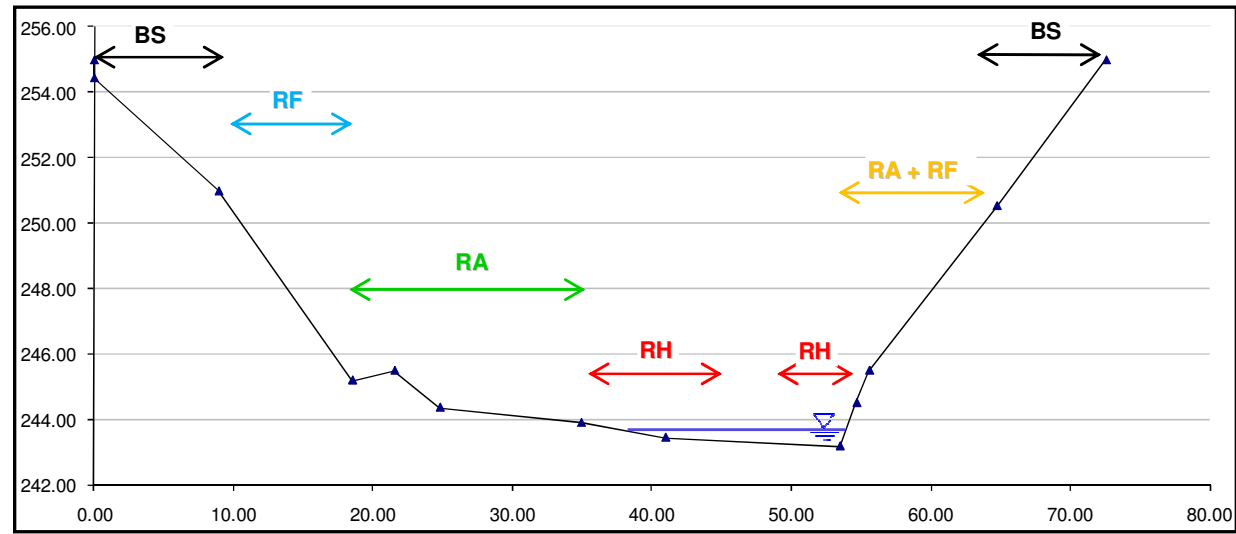

Distancia horizontal [m]

Figura 7.25. Transectos 1, 2 y 3 del río Uyús y descripción del TFV característico de cada zona: $\mathbf{R H}$, herbácea obligada de ribera; RA, Arbórea de ribera húmeda; RF, Arbórea facultativa de ribera; BS, Bosque seco. 
(d) Transecto 4, río Uyús

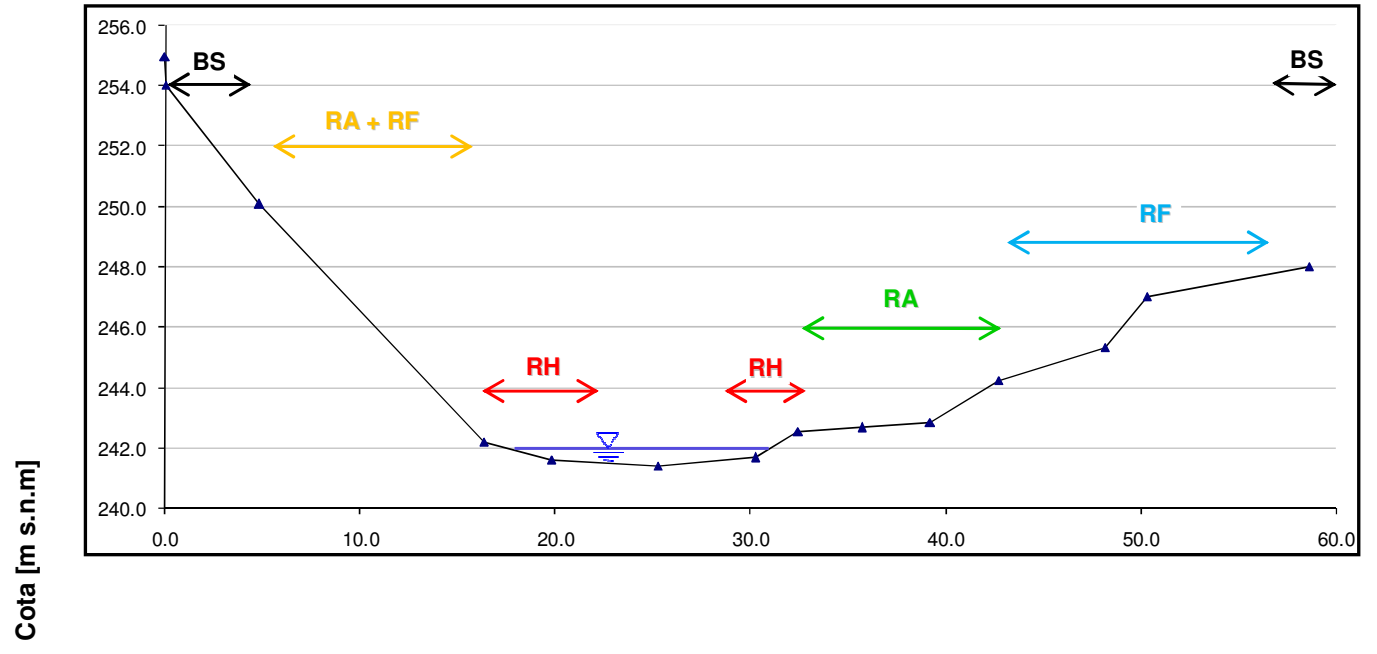

(e) Transecto 5, río Uyús

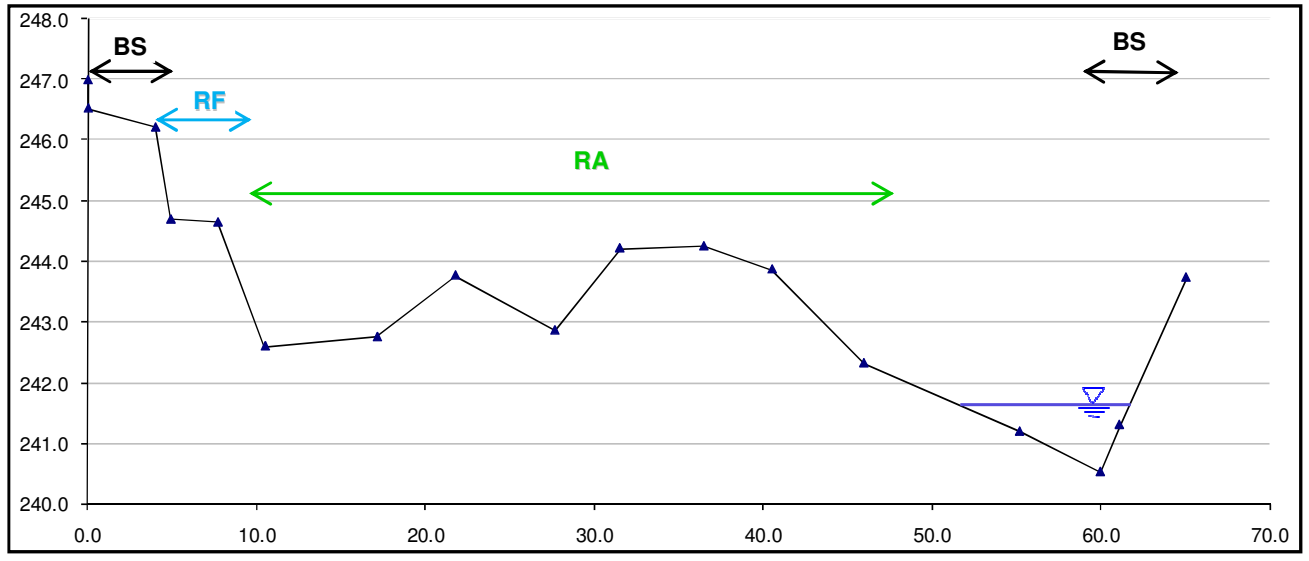

Distancia horizontal $[\mathrm{m}]$

Figura 7.26. Transectos 4 y 5 del río Uyús y descripción del TFV característico de cada zona: $\mathrm{RH}$, herbácea obligada de ribera; RA, Arbórea de ribera humeda; RF, Arbórea facultativa de ribera; BS, Bosque seco. 
Transecto 6, río Teculután

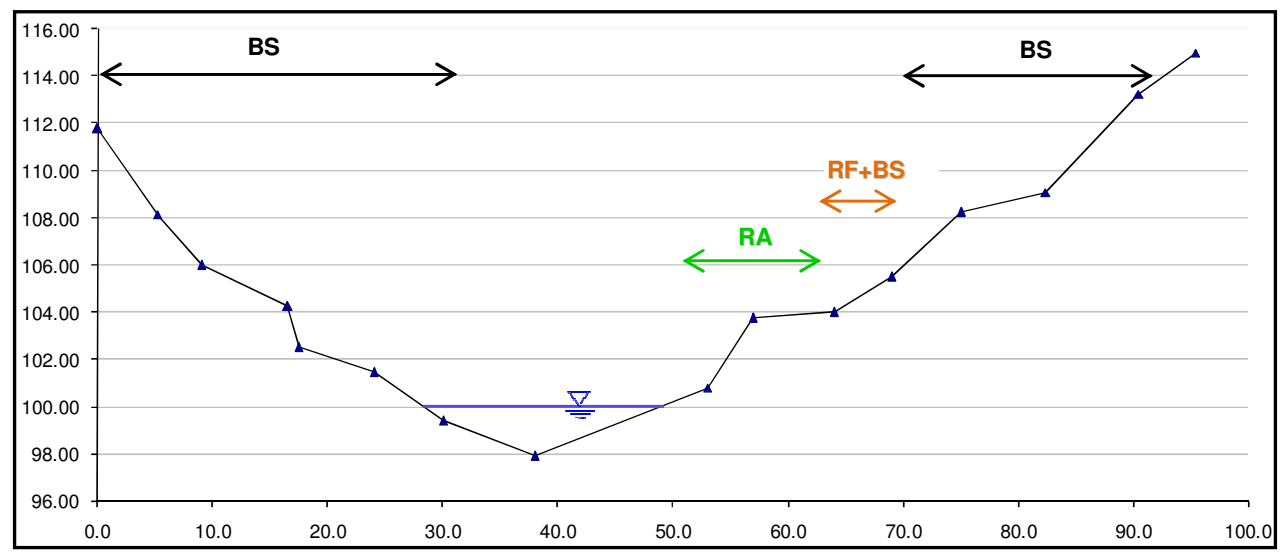

(g) Transecto 7, río Teculután

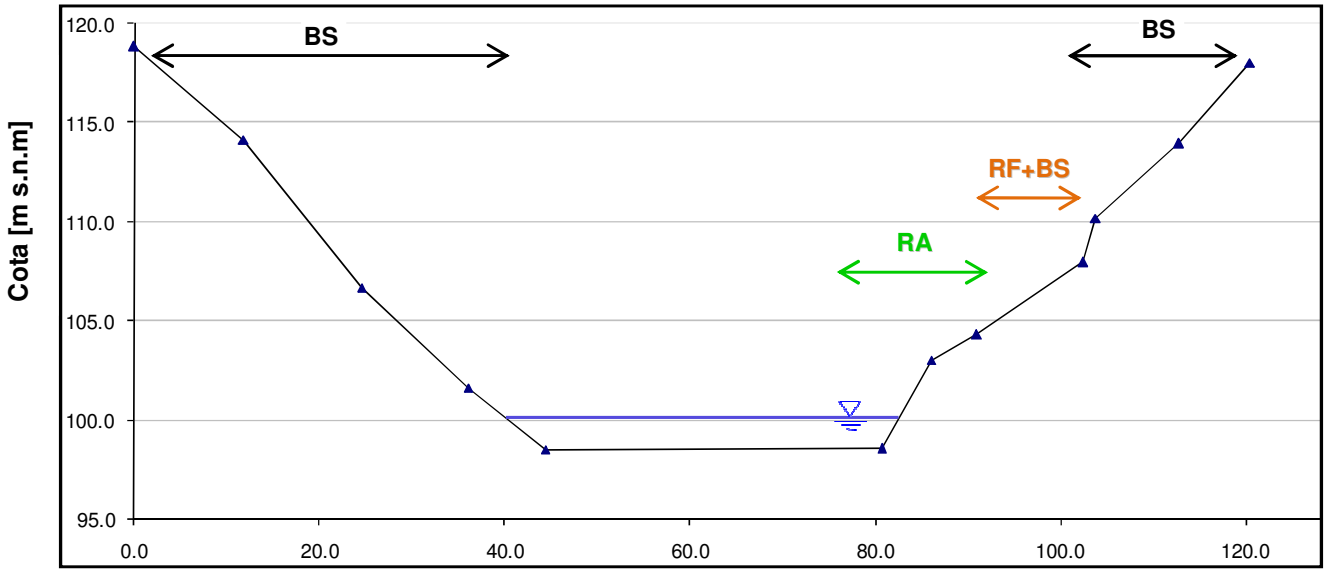

(h) Transecto 8, río Teculután

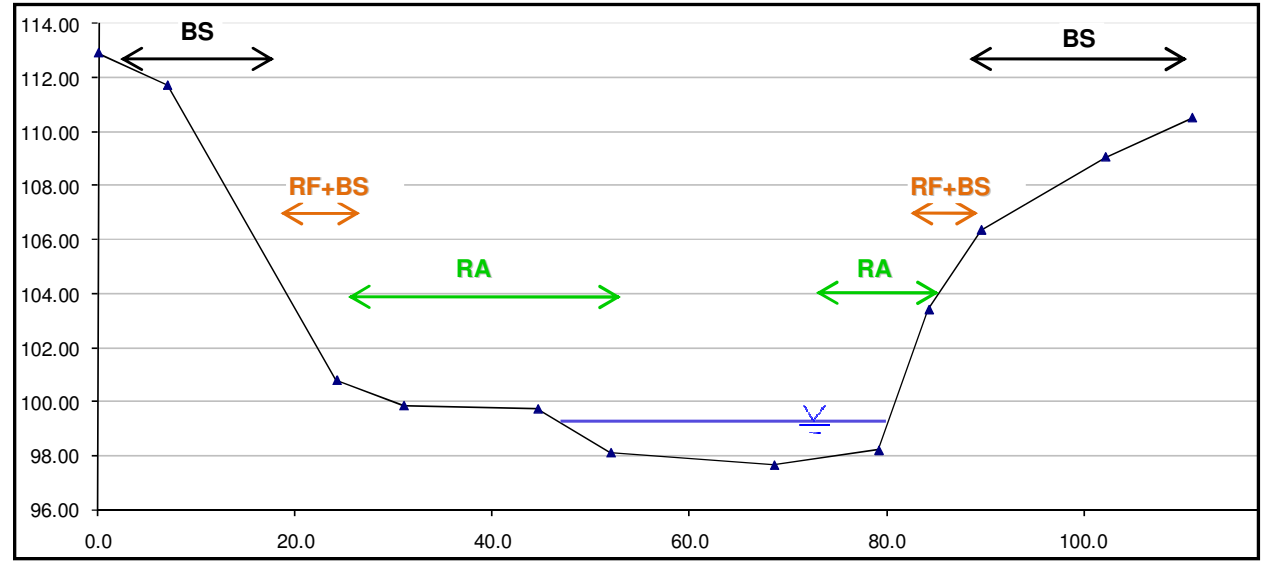

Distancia horizontal [m]

Figura 7.27. Transectos 6,7 y 8 del río Teculután y descripción del TFV característico de cada zona: RA, RF y BS. 
Posteriormente, utilizando la información topográfica de las secciones transversales, sus valores estimados de rugosidad y la serie de caudales de los tramos de estudio, se obtuvo la curva caudal-nivel mediante modelación con FlowMaster Student Edition v5.15@. Para establecer la bondad de esta modelación, los niveles predichos se compararon gráficamente con los registros anotados en libreta de campo sobre marcas de inundaciones, altura de depósito de sólidos y grandes desechos del bosque, y la presencia ausencia de vegetación y/o su sistema radicular. El ajuste fue adecuado.

Asimismo, se estableció la serie diaria de niveles de río con el modelo RibAV (Ecuación (6.12)), utilizando para ello la serie de caudales de Uyús y Teculután (Morales-de la Cruz y Francés, 2007) y sus curvas caudal-nivel respectivas (Fig. 7.28, 7.29 y 7.30 ).

Curva de gasto Transecto 1, río Uyús

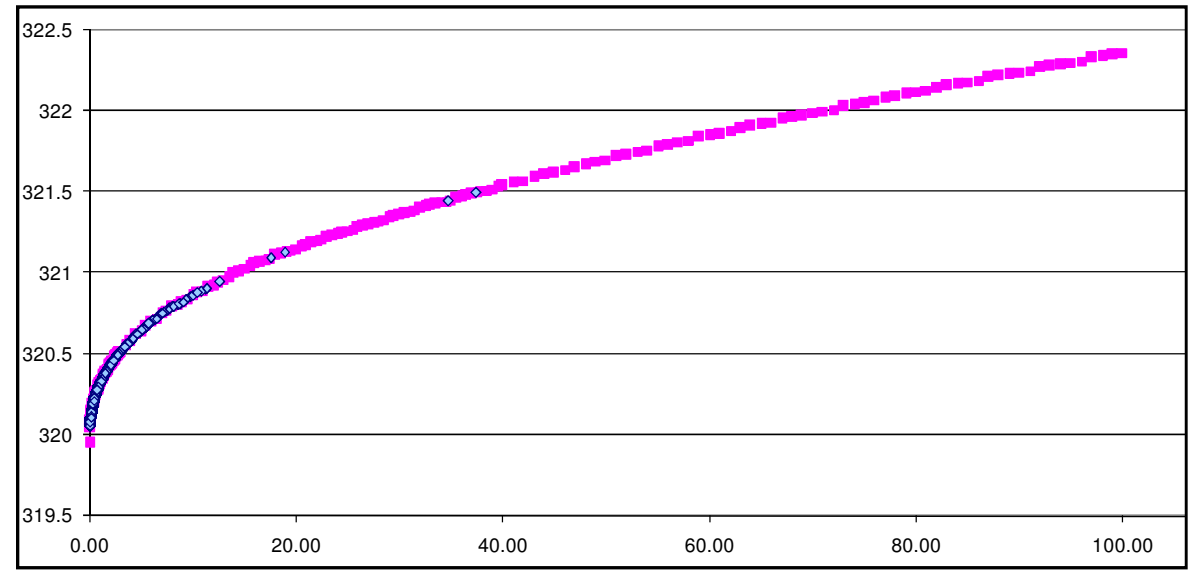

(b) Curva de gasto Transecto 2, río Uyús

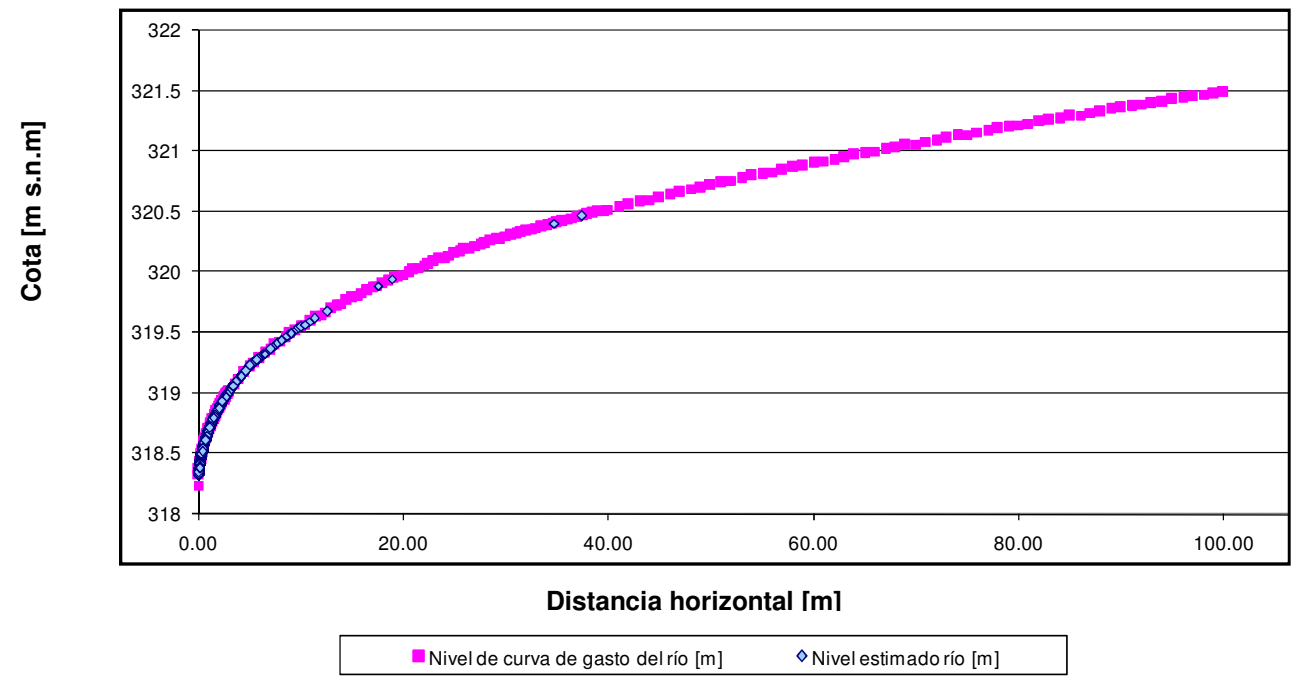

Figura 7.28. Curvas de gasto de los Transectos 1 y 2 obtenidos con FlowMaster v5.15 y datos de campo del río Uyús; niveles de río estimados con el modelo RibAV (Ecuación (12)) a partir de la serie de caudales (Morales-de la Cruz y Francés, 2007) y la curva caudal-nivel respectiva. 
(c) Curva de gasto Transecto 3, río Uyús

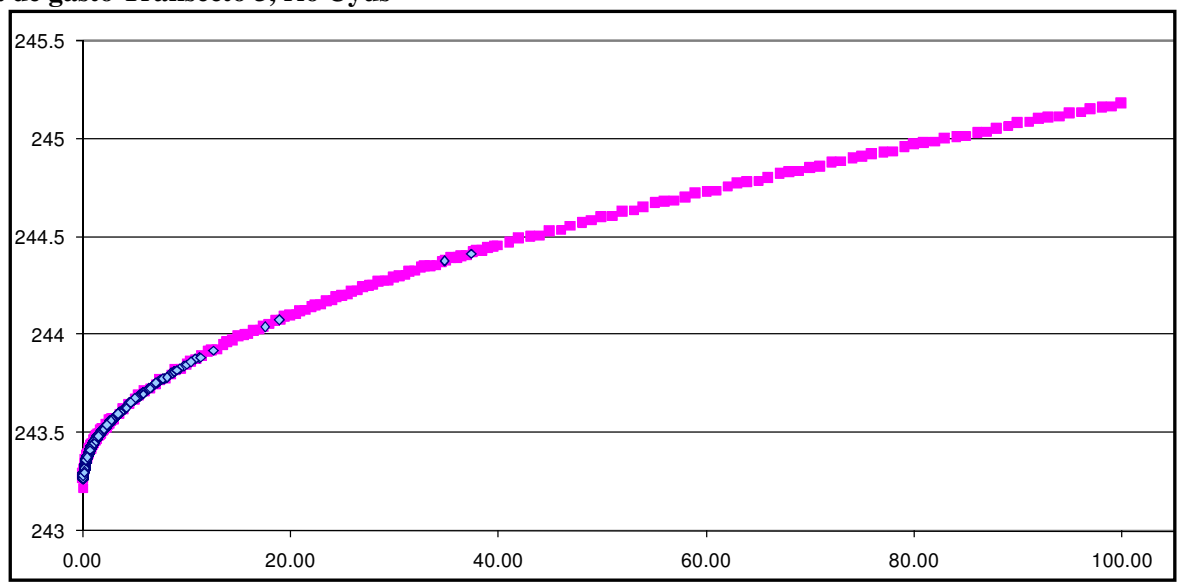

(d) Curva de gasto Transecto 4, río Uyús

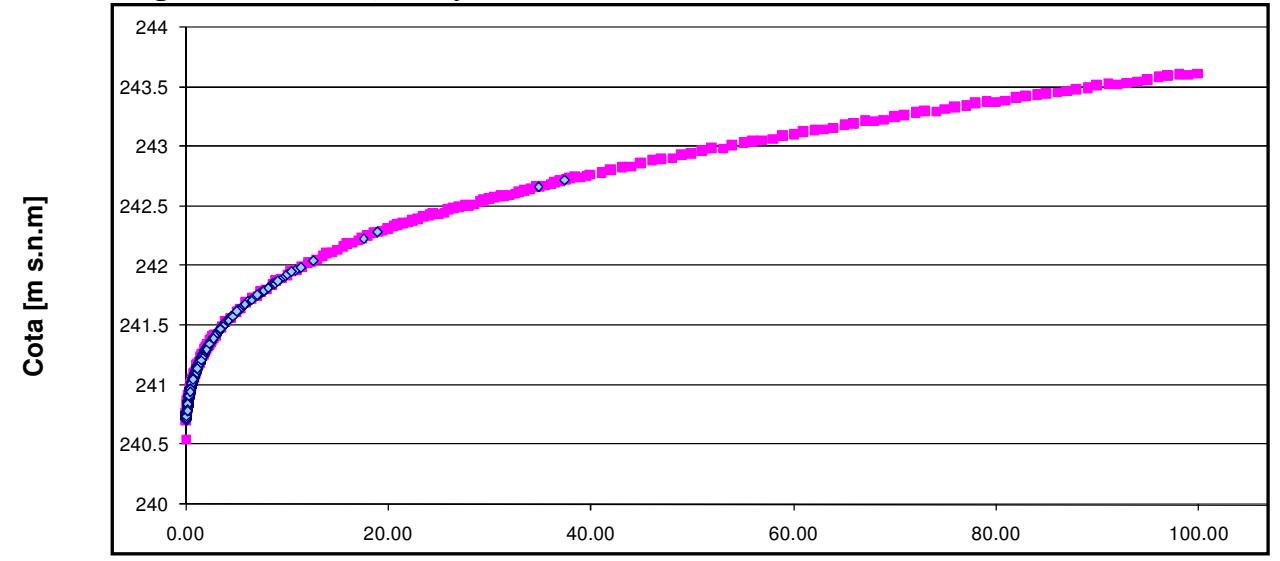

(e) Curva de gasto Transecto 5, río Uyús

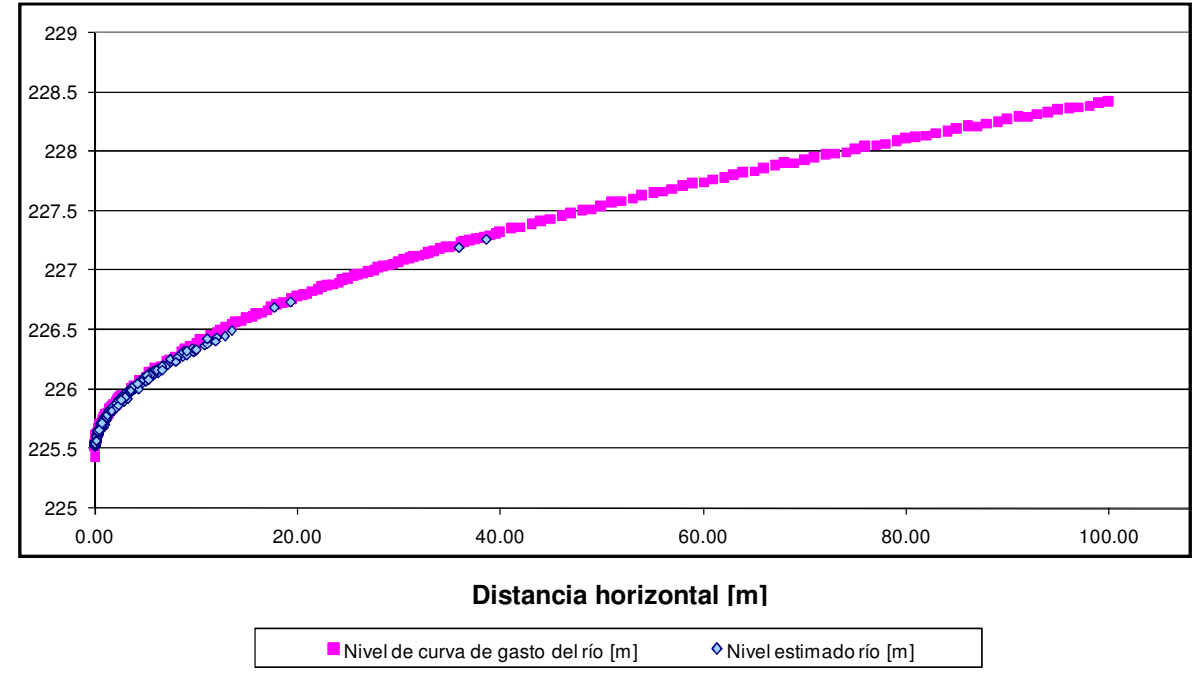

Figura 7.29. Curvas de gasto de los Transectos 3, 4 y 5 obtenidos con FlowMaster v5.15 y datos de campo del río Uyús; niveles de río estimados con el modelo RibAV (Ecuación (12)) a partir de la serie de caudales (Morales-de la Cruz y Francés, 2007) y la curva caudal-nivel respectiva. 
(f) Curva de gasto Transecto 6, río Teculután

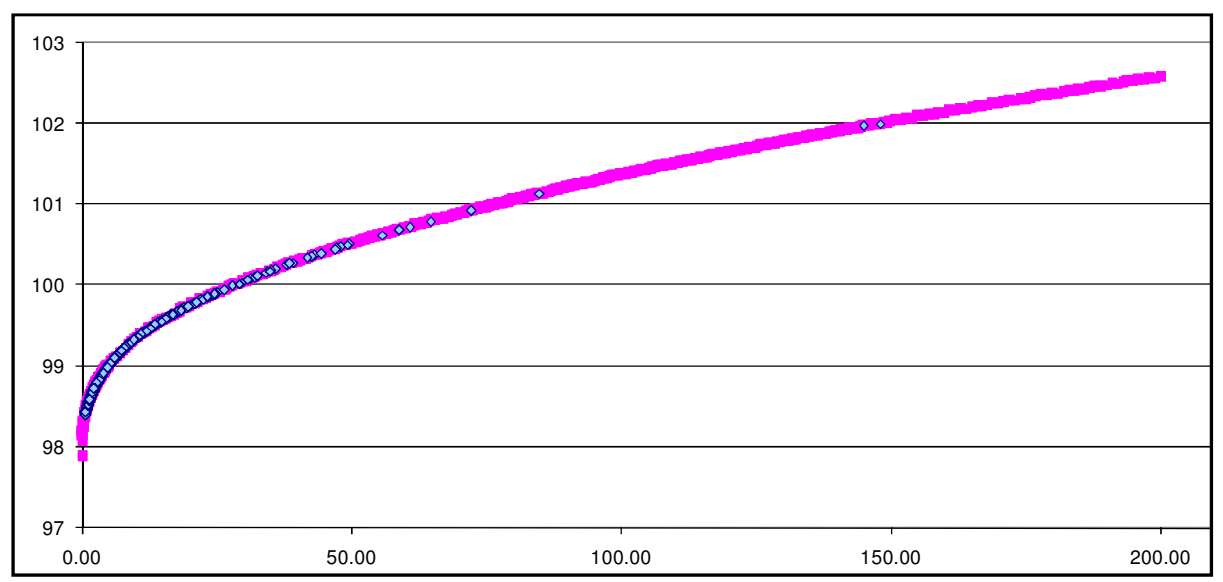

(g) Curva de gasto Transecto 7, río Teculután

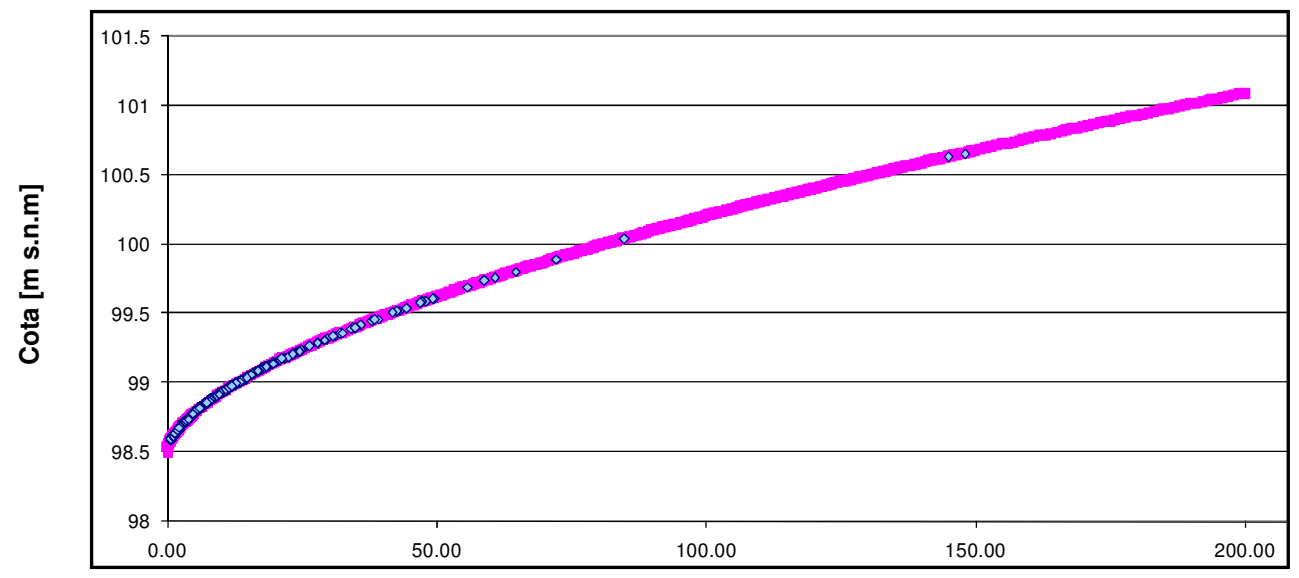

(h) Curva de gasto Transecto 8, río Teculután

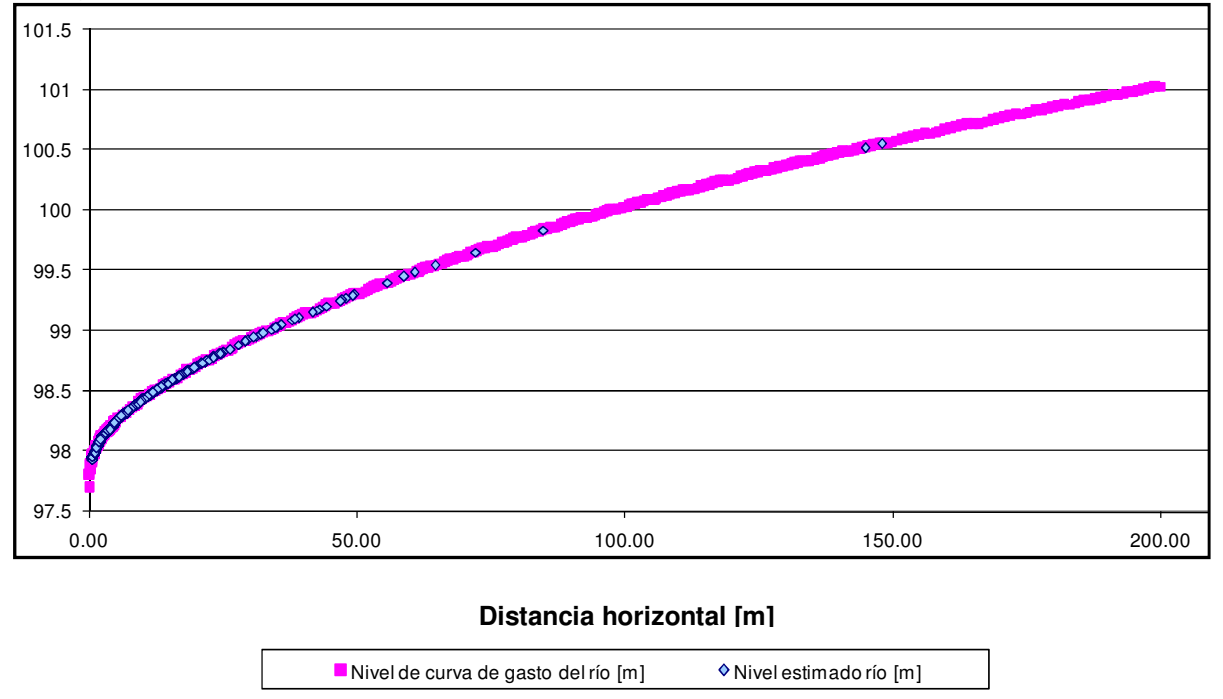

Figura 7.30. Curvas de gasto de los Transectos 6,7 y 8 obtenidos con FlowMaster v5.15 y datos de campo del río Teculután; niveles de río estimados con el modelo RibAV (Ecuación (12)) a partir de la serie de caudales de la Estación INDE “Las Minas” y la curva caudal-nivel respectiva. 


\subsubsection{Parámetros de suelo y de vegetación de los transectos de río y zonas de ribera de Uyús y Teculután}

\subsubsection{Parámetros de suelo:}

Se obtuvieron los parámetros de suelo de 21 muestras de la zona de ribera y bosque seco del río Uyús (Tabla 7.9) y cinco muestras del río Teculután (Tabla 7.10).

Tabla 7.9. Valores de los parámetros de suelo del tramo del río Uyús.

\begin{tabular}{|c|c|c|c|c|c|c|c|}
\hline $\begin{array}{l}\text { Código } \\
\text { del tipo }\end{array}$ & Textura del suelo & Porosidad $^{o b s}$ & $\begin{array}{c}\text { Índice de } \\
\text { distribución } \\
\text { de poros }^{a}\end{array}$ & $\begin{array}{l}\text { Presión de } \\
\text { burbujeo }^{a}\end{array}$ & $\begin{array}{c}\text { Conductividad } \\
\text { hidráulica } \\
\text { saturada }^{b}\end{array}$ & $\begin{array}{c}\text { Humedad a } \\
\text { capacidad de } \\
\text { campo }^{o b s}\end{array}$ & $\begin{array}{c}\text { Profundidad } \\
\text { máxima para } \\
\text { ascenso } \\
\text { capilar }^{c a l} \\
\end{array}$ \\
\hline & & $\begin{array}{l}\text { Pst } \\
{[\text { ] }}\end{array}$ & $\begin{array}{l}\text { Ip } \\
\text { [ ] }\end{array}$ & $\begin{array}{c}\mathbf{P b} \\
{[\mathrm{kPa}]}\end{array}$ & $\begin{array}{c}\mathbf{K s} \\
{[\mathrm{mm} / \mathrm{hr}]}\end{array}$ & $\begin{array}{c}\text { Mfc } \\
{[\mathrm{cc} / \mathrm{cc}]}\end{array}$ & $\begin{array}{c}\mathbf{Z c}_{\min } \\
{[\mathrm{m}]}\end{array}$ \\
\hline 1 & Suelo franco arenoso & 0.469 & 0.175 & 0.03 & 54.06 & 0.139 & 10 \\
\hline 2 & Suelo franco arenoso & 0.433 & 0.221 & 0.15 & 45.73 & 0.138 & 10 \\
\hline 3 & Suelo arenoso franco & 0.518 & 0.217 & 0.12 & 19.18 & 0.157 & 10 \\
\hline 4 & Arenoso franco & 0.440 & 0.265 & 1.78 & 26.16 & 0.214 & 10 \\
\hline 5 & Franco limoso arcilloso & 0.420 & 0.286 & 2.54 & 15.60 & 0.216 & 10 \\
\hline 6 & Arenoso & 0.407 & 0.694 & 0.71 & 61.97 & 0.053 & 10 \\
\hline 7 & Franco limoso arcilloso & 0.427 & 0.154 & 0.13 & 31.92 & 0.182 & 10 \\
\hline 8 & Arenoso franco & 0.467 & 0.378 & 1.44 & 22.31 & 0.109 & 10 \\
\hline 9 & Franco limoso arcilloso & 0.440 & 0.290 & 2.75 & 19.78 & 0.221 & 10 \\
\hline 10 & Franco arcilloso & 0.506 & 0.167 & 0.92 & 6.84 & 0.290 & 10 \\
\hline 11 & Franco limoso arcilloso & 0.446 & 0.226 & 3.79 & 8.17 & 0.284 & 10 \\
\hline 12 & Arenoso franco & 0.417 & 0.240 & 3.14 & 32.40 & 0.247 & 10 \\
\hline 13 & Arenoso franco & 0.413 & 0.263 & 1.93 & 23.43 & 0.206 & 10 \\
\hline 14 & Franco arenoso & 0.426 & 0.553 & 0.85 & 69.69 & 0.076 & 10 \\
\hline 15 & Arcilloso & 0.428 & 0.293 & 18.36 & 2.79 & 0.438 & 10 \\
\hline 16 & Arcilloso & 0.484 & 0.089 & 18.36 & 0.25 & 0.464 & 10 \\
\hline 17 & Arenoso franco & 0.448 & 0.211 & 0.05 & 51.34 & 0.113 & 10 \\
\hline 18 & Franco limoso arcilloso & 0.506 & 0.116 & 0.29 & 11.15 & 0.297 & 10 \\
\hline 19 & Franco limoso arcilloso & 0.539 & 0.143 & 0.3 & 6.10 & 0.280 & 10 \\
\hline 20 & Arenoso franco & 0.476 & 0.200 & 0.18 & 33.99 & 0.171 & 10 \\
\hline 21 & Franco limoso arcilloso & 0.465 & 0.177 & 0.21 & 18.16 & 0.191 & 10 \\
\hline
\end{tabular}

Tabla 7.10. Valores de los parámetros de suelo del tramo del río Teculután.

\begin{tabular}{|c|c|c|c|c|c|c|c|}
\hline \multirow[t]{2}{*}{$\begin{array}{l}\text { Código } \\
\text { del tipo } \\
\text { de suelo }\end{array}$} & \multirow[t]{2}{*}{ Textura del suelo } & Porosidad $^{o b s}$ & $\begin{array}{c}\text { Índice de } \\
\text { distribución } \\
\text { de poros }^{a}\end{array}$ & $\begin{array}{l}\text { Presión de } \\
\text { burbujeo }^{a}\end{array}$ & $\begin{array}{l}\text { Conductividad } \\
\text { hidráulica } \\
\text { saturada }^{b}\end{array}$ & $\begin{array}{c}\text { Humedad a } \\
\text { capacidad de } \\
\text { campo }^{c}\end{array}$ & \multirow{2}{*}{$\begin{array}{c}\text { Profundidad } \\
\text { máxima para } \\
\text { ascenso } \\
\text { capilar }^{c a l} \\
\mathbf{Z c}_{\text {min }} \\
{[\mathbf{m}]} \\
\end{array}$} \\
\hline & & $\begin{array}{l}\text { Pst } \\
{[\text { ] }}\end{array}$ & $\begin{array}{l}\text { Ip } \\
{[]}\end{array}$ & $\begin{array}{c}\mathbf{P b} \\
{[\mathrm{kPa}]}\end{array}$ & $\begin{array}{c}\mathrm{Ks} \\
{[\mathrm{mm} / \mathrm{hr}]}\end{array}$ & $\begin{array}{c}\text { Mfc } \\
{[\mathrm{cc} / \mathrm{cc}]}\end{array}$ & \\
\hline 22 & Franco arenoso & 0.437 & 0.553 & 0.85 & 32.65 & 0.058 & 10 \\
\hline 23 & Arena & 0.437 & 0.694 & 0.71 & 88.08 & 0.031 & 10 \\
\hline 24 & Arenoso Franco & 0.453 & 0.378 & 1.44 & 20.22 & 0.139 & 10 \\
\hline 25 & Franco arenoso & 0.437 & 0.553 & 0.85 & 38.45 & 0.058 & 10 \\
\hline 26 & Arena & 0.437 & 0.694 & 0.71 & 87.94 & 0.031 & 10 \\
\hline \multicolumn{8}{|c|}{$\begin{array}{l}\text { Fuente: }{ }^{\text {obs }} \text { estimado en laboratorio; }{ }^{a} \text { Rawls et al (1993) y calibración curva característica }(\text { Campbell, } 1974) ;{ }^{b} \text { Saxton et al } \\
\text { (1986); }{ }^{c} \text { curva característica calibrada (Campbell, 1974); }{ }^{\text {cal }} \text { valor calibrado a partir de Canadell et al (1996) y Altier et al }\end{array}$} \\
\hline
\end{tabular}


Otra fuente de información para estimación de parámetros de suelo es el modelo SWC (Saxton et al, 1986). A partir de la clasificación de textura del suelo y sus contenidos de materia orgánica, se calculó la conductividad hidráulica saturada "Ks" para la modelación con RibAV; el modelo SWC también permite obtener los contenidos de humedad a distintas presiones características.

La profundidad máxima para considerar ascenso capilar " $Z c_{\min }$ " se calibró con $R i b A V$ a partir de la suma de la máxima profundidad radicular esperada $(\mathbf{Z r})$ y un parámetro teórico de entre 1 y 3 metros propuesto por Altier et al (2002). También se consideró que el valor máximo posible de profundidad radicular de los TFV arbóreos es en promedio $7 \pm 1.2 \mathrm{~m}$ (sensu Canadell et al, 1996).

\subsubsection{Parámetros de vegetación:}

Para establecer los parámetros de los TFV estudiados (Tabla 7.11) ha sido necesario combinar conocimientos provenientes de múltiples fuentes: el marco conceptual del modelo, la caracterización de campo y criterio experto (Morales-de la Cruz y Francés, 2008a y 2009), el estudio de ordenación e inventario de la riqueza florística de los taxones presentes (Celis, 2008) y la revisión exhaustiva de la morfología, fenología, fitosociología y ecofisiología de las especies vegetales de la ribera y el bosque seco del Valle del Motagua (Castañeda, 1997 y 2004; Celis, 2008; Nájera, 2009; Standley y Steyermark, 1946-1977; Valle et al, 1999; Véliz et al, 2003).

El primer resultado de este apartado queda descrito en el listado de especies vegetales presentes y clasificación por TFV de la ribera y bosque seco aledaño de los tramos de río Uyús y Teculután (Tabla 7.11).

Por otro lado, los parámetros característicos de los TFV en las riberas de Uyús y Teculután se resumen en la Tabla 7.12. Cabe destacar que la base para establecer la profundidad radicular máxima "Zr" son los trabajos de Baird y Maddock III (2005) y Canadell et al (1996), que caracterizan rangos de profundidad máxima de raíces para diversos TFV a escala de ribera de ríos en condiciones semiáridas y otras vegetaciones del bosque; este parámetro se calibró con el RibAV, a partir de las referencias de literatura de las especies, de las observaciones de campo del sistema radicular y de la presencia o ausencia de capas limitantes.

Los valores de "Zr" característicos de los TFV de ribera y bosque seco calibrados para los ríos Uyús y Teculután (Tabla 7.12) se encuentran dentro del rango reportado en la literatura y son coherentes con los órdenes de magnitud característicos de TFV de similar hábito de crecimiento (Schenk y Jackson, 2002a; Kellman y Roulet, 1990): los TFV arbóreos RA y RF poseen las mayores profundidades radiculares, seguidos del bosque seco de hábito matorral y monte espinoso BS, y finalmente las herbáceas de ribera $\mathrm{RH}$. El valor de profundidad radicular máxima del bosque seco que produjo la mejor calibración de RibAV es coincidente con el valor citado para especies y condiciones climáticas coincidentes (Kellman y Roulet, 1990).

Por otra parte, para establecer la profundidad radicular efectiva "Ze" (Tabla 7.13), Canadell et al (1996) refieren que un enorme número de estudios demuestran que la mayor parte de la biomasa radicular ocurre dentro de los primeros $50 \mathrm{~cm}$ del suelo, y proponen que, para entender el papel de las raíces sobre la estructura y función del ecosistema, basta con estudiar el perfil del suelo hasta dicha profundidad. Por su parte, Schenk y Jackson (2002a) también refieren una profundidad efectiva radicular de $50 \mathrm{~cm}$ con base en el análisis de 475 perfiles para establecer la biogeografía global de las raíces; diversos estudios de ecología vegetal refieren que entre el $90 \%$ y $95 \%$ de la biomasa radicular se encuentra en el rango de los 30 y $60 \mathrm{~cm}$ del suelo (Castellanos et al, 1991; Kellman y Roulet, 1990; Schenk y Jackson, 2005; Schulze et al, 1996).

Las observaciones de campo sobre la profundidad efectiva de las raíces y el desarrollo del suelo (Fig. 7.9 y 7.31) y los antecedentes de la geología del valle Motagua (SINAFIP y EDESA, 2004) hacen referencia a que las riberas de Uyús y Teculután poseen suelos poco desarrollados, que corresponden a aluviones recientes constituidos por fragmentos de gran tamaño. Con esto, se corrobora la fundamentación teórica expresada en el párrafo anterior y se confirmó el valor de parámetro teórico "Ze" de 0.5 m (Tabla 7.12). 
Tabla 7.11. Especies vegetales presentes en los cinco transectos del río Uyús y en los tres del Teculután. Fuente: Celis (2008), Morales-de la Cruz y Francés (2008a, 2009).

\begin{tabular}{|c|c|c|c|c|c|c|c|c|c|c|c|c|}
\hline \multirow{2}{*}{ No. } & \multirow{2}{*}{$\begin{array}{l}\text { NOMBRE } \\
\text { COMÚN }\end{array}$} & \multirow{2}{*}{ NOMBRE CIENTIFICO } & \multirow{2}{*}{ CODIGO } & \multirow{2}{*}{ TFV } & \multicolumn{8}{|c|}{$\begin{array}{c}\text { PRESENCIA (X) DE LA ESPECIE EN TRANSECTOS DE } \\
\text { UYÚS (U) Y TECULUTÁN (T) }\end{array}$} \\
\hline & & & & & UT1 & UT2 & UT3 & UT4 & UT5 & TT6 & TT7 & TT8 \\
\hline 1 & Jazmín de agua & Lindenia rivales Benth & RubLud & RH & $\mathrm{X}$ & $\mathrm{X}$ & $\mathrm{X}$ & & & & & \\
\hline 2 & & Panicum sp. & PoaPan & RH & $\mathrm{X}$ & & $\mathrm{X}$ & & & & & \\
\hline 3 & & & sinnom & RH & $\mathrm{X}$ & & & & $\mathrm{X}$ & & & \\
\hline 4 & & Justicia sp. & AcaJus & $\mathrm{RH}$ & & & $\mathrm{X}$ & & $\mathrm{X}$ & & & $\mathrm{X}$ \\
\hline 5 & Cola de pescado & & AraPes & RH & & $\mathrm{X}$ & & & & & & \\
\hline 6 & Palma & Bactris sp & AraBal & $\mathrm{RH}$ & & & $\mathrm{X}$ & $\mathrm{X}$ & & & & \\
\hline 7 & Verbena & Hyptis verticillata autoridad Jacq & HypVer & $\mathrm{RH}$ & & & $\mathrm{X}$ & & & & & \\
\hline 8 & & Ciperus sp. & CipCip & RH & & $\mathrm{X}$ & $\mathrm{X}$ & & $\mathrm{X}$ & $\mathrm{X}$ & & $\mathrm{X}$ \\
\hline 9 & & Paspalum sp & PoaPas & $\mathrm{RH}$ & & & $\mathrm{X}$ & & & & & \\
\hline 10 & & Oplismenus sp. & PoaOpli & $\mathrm{RH}$ & $\mathrm{X}$ & & & & $\mathrm{X}$ & & & \\
\hline 11 & Sipa & Sida $s p$ & MalSip & RH & & $\mathrm{X}$ & & & & & & \\
\hline 12 & Helecho & Lygodium venustum & LygVer & $\mathrm{RH}$ & & & $\mathrm{X}$ & & $\mathrm{X}$ & & & \\
\hline 13 & Inga & Inga Vera & MimIng & RA & & $\mathrm{X}$ & $\mathrm{X}$ & & $\mathrm{X}$ & & & $\mathrm{X}$ \\
\hline 14 & Guarumo & Cecropia peltata $L$. & CecPel & RA & $\mathrm{X}$ & $\mathrm{X}$ & $\mathrm{X}$ & & & $\mathrm{X}$ & $\mathrm{X}$ & $\mathrm{X}$ \\
\hline 15 & Jocote & Spondias sp & AnaSpo & RA & $\mathrm{X}$ & $\mathrm{X}$ & $\mathrm{X}$ & $\mathrm{X}$ & $\mathrm{X}$ & $\mathrm{X}$ & $\mathrm{X}$ & $\mathrm{X}$ \\
\hline 16 & Cordoncillo & Piper aduncun $L$ & PipAdeu & RA & $\mathrm{X}$ & & & & & & & \\
\hline 18 & Ceiba & Ceiba pentandra ( I.) Gaerth & BomCei & RA & $\mathrm{X}$ & & & $X$ & $\mathrm{X}$ & $\mathrm{X}$ & & \\
\hline 19 & Almendro de río & Andira inermes (Swartz) HBK. & FabAnd & RA & $\mathrm{X}$ & $\mathrm{X}$ & $\mathrm{X}$ & $\mathrm{X}$ & $\mathrm{X}$ & $\mathrm{X}$ & $\mathrm{X}$ & \\
\hline 21 & Aguacatillo & Nectandra sp. & LauNec & RA & $\mathrm{X}$ & & & & & & & \\
\hline 24 & & Hippocratea sp. & НурНур & RA & & $\mathrm{X}$ & & & & & & \\
\hline 25 & & Hematoxylum sp. & Her & RA & & $\mathrm{X}$ & & & & & $\mathrm{X}$ & $\mathrm{X}$ \\
\hline 27 & Jocote de Mico & Simarouba glauca DC & SimSim & RA & & & $\mathrm{X}$ & & & & & \\
\hline 29 & & Karwinskia sp. & RhaKar & RA & & & $\mathrm{X}$ & & & & & \\
\hline 30 & Ixcanal o cacho toro & Acacia hindsii Benth & MimAca & RA & & & $\mathrm{X}$ & & & $\mathrm{X}$ & $\mathrm{X}$ & $\mathrm{X}$ \\
\hline 31 & Guapinol & Hymenaea courbaril $L$. & CaeHym & RA & & & $\mathrm{X}$ & & & & & \\
\hline 32 & Anona & & AnoAno & RA & $\mathrm{X}$ & & & $\mathrm{X}$ & & & & \\
\hline 33 & Chapupo & Tabernaemontana chysocarr Blake. & ApoTab & RA & & & & $\mathrm{X}$ & & & & \\
\hline 34 & Matilisguate & Tabebuia rosea (Bertol) DC. & BigTab & RA & & & & $\mathrm{X}$ & & & & $\mathrm{X}$ \\
\hline 36 & Morro & Crescentia alata $H B K$ & BigCre & RA & & & & & $\mathrm{X}$ & & $\mathrm{X}$ & \\
\hline 37 & Sabal & Sabal guatemalensis Beccari. & AreSab & RA & & & & & $\mathrm{X}$ & $\mathrm{X}$ & & $\mathrm{X}$ \\
\hline 38 & Mango & Manquifera indica $L$ & AnaMan & RA & & & & & $\mathrm{X}$ & & $\mathrm{X}$ & \\
\hline 39 & & Desmodium sp. & FabDes & RA & $\mathrm{X}$ & & & & & & & \\
\hline 17 & Zorrillo & Thouinidium decandrum (Humb \& Bonpl) & SapTho & RF & $\mathrm{X}$ & $\mathrm{X}$ & $\mathrm{X}$ & & $\mathrm{X}$ & $\mathrm{X}$ & & $\mathrm{X}$ \\
\hline 20 & Piñuelón & Hechtia guatemalensis Mez & BroHec & RF & $\mathrm{X}$ & $\mathrm{X}$ & $\mathrm{X}$ & & & & $\mathrm{X}$ & \\
\hline 26 & Zapote & Pouteria sp & ZapPou & RF & & $\mathrm{X}$ & & $\mathrm{X}$ & $\mathrm{X}$ & & & \\
\hline 28 & Moral o Ceibillo & Ceiba aescutifolia $H B K \&$ Baker & BomAes & RF & & & $\mathrm{X}$ & & & & & \\
\hline 35 & Ficus & Ficus sp. & Ficu & RF & $\mathrm{X}$ & & $\mathrm{X}$ & $\mathrm{X}$ & $\mathrm{X}$ & & & \\
\hline 40 & Conacaste & Etherolobium cyclocarpum (Jacq.) Grisseb. & MimEth & RF & $\mathrm{X}$ & & $\mathrm{X}$ & $\mathrm{X}$ & $\mathrm{X}$ & & & \\
\hline 41 & & & Ste & RF & & & & & & & $\mathrm{X}$ & \\
\hline 42 & & & Sap & $\mathrm{RF}$ & & $\mathrm{X}$ & & & & & & \\
\hline 43 & Anona & Annona reticulata $L$ & AnoRet & RF & $\mathrm{X}$ & & $\mathrm{X}$ & $\mathrm{X}$ & & $\mathrm{X}$ & & \\
\hline 44 & Mora o Moral & Clorophora tinctoria (L) Gaud. & sn & $\mathrm{RF}$ & $\mathrm{X}$ & & & & & & $\mathrm{X}$ & $\mathrm{X}$ \\
\hline 45 & Quesillo & Trichilia hirta $L$ & MelTri & $\mathrm{RF}$ & $\mathrm{X}$ & & & & & & & \\
\hline 46 & Cabalero & Celtis iguanaza (Jacq) Sarg & Fla & $\mathrm{RF}$ & $\mathrm{X}$ & & & & & & & \\
\hline 47 & & & Anodos & $\mathrm{RF}$ & & & & & & & & $\mathrm{X}$ \\
\hline 48 & Chichicaste de caballo & Cnidosculos tubulosos (Muell Agr.) I.M. Johnston & EupCni & $\mathrm{RF}$ & & $\mathrm{X}$ & $\mathrm{X}$ & & & & $\mathrm{X}$ & $\mathrm{X}$ \\
\hline 49 & Chilindrón & Thavetia ovata (Cav) A. DC. & ApoThe & $\mathrm{RF}$ & & & $\mathrm{X}$ & $\mathrm{X}$ & & $\mathrm{X}$ & & \\
\hline 50 & Caulote & Guazuma umbifolia Lam & SteGua & $\mathrm{RF}$ & & & & & & & $\mathrm{X}$ & $\mathrm{X}$ \\
\hline 55 & Jiote & Bursera simaruba (L) Sarg & BurSim & RF & & $\mathrm{X}$ & $\mathrm{X}$ & & $\mathrm{X}$ & $\mathrm{X}$ & & $\mathrm{X}$ \\
\hline 22 & Aripín & Caesalpinia velutina (Britt \& Rose) Standl & CaeVel & BS & & $\mathrm{X}$ & $\mathrm{X}$ & & $\mathrm{X}$ & & & $\mathrm{X}$ \\
\hline 23 & Santa Rosa & Caesalpinia pulcherima ( $L$ ) Swart & CaePul & BS & & $\mathrm{X}$ & & & $\mathrm{X}$ & & & \\
\hline 51 & Yaje & Leucaena sp & MimLeu & BS & $\mathrm{X}$ & $\mathrm{X}$ & $\mathrm{X}$ & $\mathrm{X}$ & & $\mathrm{X}$ & $\mathrm{X}$ & $\mathrm{X}$ \\
\hline 52 & Tuno & Lemarireocerus echlamii Britt. \& Rose & CacLem & BS & $\mathrm{X}$ & & $\mathrm{X}$ & $\mathrm{X}$ & & $\mathrm{X}$ & $\mathrm{X}$ & $\mathrm{X}$ \\
\hline 53 & Guayacán & Guaiacum sanctum $L$. & ZygGua & BS & $\mathrm{X}$ & $\mathrm{X}$ & $\mathrm{X}$ & $\mathrm{X}$ & & & & \\
\hline 54 & Duruche & Jacquinia aurantiaca Ait & TheJac & BS & $\mathrm{X}$ & $\mathrm{X}$ & $\mathrm{X}$ & & & & & $\mathrm{X}$ \\
\hline 56 & Nopal & Nopalea guatemalensis Rose & Nop & BS & & $\mathrm{X}$ & & $\mathrm{X}$ & & & & \\
\hline
\end{tabular}

RH: Herbáceas obligadas de ribera

RA: Arbóreas obligadas de ribera

RF: Arbóreas facultativas o transición de ribera

BS: Bosque seco 
Tabla 7.12. Valores de los parámetros de los tipos funcionales de vegetación (TFV) de ribera y bosque seco presentes en las secciones transversales de los ríos Uyús y Teculután, para modelación con RibAV.

\begin{tabular}{|c|c|c|c|c|c|c|c|c|c|}
\hline \multirow{2}{*}{$\begin{array}{c}\text { Código } \\
\text { del } \\
\text { TFV }\end{array}$} & \multirow{2}{*}{$\begin{array}{c}\text { Acrónimo y } \\
\text { Descripción del } \\
\text { TFV }\end{array}$} & $\begin{array}{l}\text { Profundidad } \\
\text { máxima } \\
\text { radicular }^{\text {call }}\end{array}$ & $\begin{array}{c}\text { Profundidad } \\
\text { efectiva } \\
\text { radicular }^{b}\end{array}$ & $\begin{array}{c}\text { Profundidad } \\
\text { de extinción } \\
\text { por } \\
\text { saturación }^{\text {cal } 2}\end{array}$ & $\begin{array}{c}\text { Factor de } \\
\text { transpiración } \\
\text { de zona no } \\
\text { saturada }^{\text {cal3 }}\end{array}$ & $\begin{array}{c}\text { Factor de } \\
\text { transpiración } \\
\text { de zona } \\
\text { saturada }^{\text {cal3 }}\end{array}$ & $\begin{array}{l}\text { Conductividad } \\
\text { máxima } \\
\text { interfaz raíz- }^{{ }^{d}} \\
\text { suelo }^{d}\end{array}$ & $\begin{array}{c}\text { Punto de } \\
\text { marchitez } \\
\text { permanente }^{e}\end{array}$ & $\begin{array}{c}\text { Punto de } \\
\text { crecimiento } \\
\text { vegetal } \\
\text { óptimo }^{g}\end{array}$ \\
\hline & & $\begin{array}{r}\mathbf{Z r} \\
{[\mathrm{m}]}\end{array}$ & $\begin{array}{r}\mathbf{Z e} \\
{[\mathrm{m}]}\end{array}$ & $\begin{array}{l}\mathrm{Z}_{\mathrm{sat}} \\
{[\mathrm{m}]}\end{array}$ & $\begin{array}{l}\mathbf{F}_{\text {est }} \\
{[\text { ] ] }}\end{array}$ & $\begin{array}{c}\mathbf{F}_{\text {sat }} \\
\text { [ ] }\end{array}$ & $\begin{array}{c}\text { Crt } \\
{\left[\mathrm{mmMPa}^{-1} h^{-1}\right]}\end{array}$ & $\begin{array}{c}\mathbf{P}_{\mathrm{wp}} \\
{[\mathrm{kPa}]}\end{array}$ & $\begin{array}{c}\mathbf{P}_{\text {opt }} \\
{[\mathbf{k P a}]}\end{array}$ \\
\hline 1 & $\begin{array}{l}\text { RH, herbácea } \\
\text { obligada de } \\
\text { ribera }\end{array}$ & 0.66 & 0.50 & -0.85 & 0.80 & 0.50 & 0.97 & 1500 & 500 \\
\hline 2 & $\begin{array}{l}\text { RA, arbórea } \\
\text { obligada de } \\
\text { ribera }\end{array}$ & 5.60 & 0.50 & -0.10 & 0.42 & 0.72 & 0.97 & 1500 & 500 \\
\hline 3 & $\begin{array}{c}\mathrm{RF} \text {, arbórea } \\
\text { facultativa de } \\
\text { ribera }\end{array}$ & 7.43 & 0.50 & 0.09 & 0.73 & $0.29^{\text {cal } 3}$ & 0.97 & 1500 & 500 \\
\hline 4 & $\begin{array}{c}\text { BS, bosque } \\
\text { seco }\end{array}$ & $1.40^{a}$ & 0.50 & 0.10 & $0.91^{c}$ & $0.09^{c}$ & 0.97 & $3000^{f}$ & 500 \\
\hline $\begin{array}{r}\text { Fue } \\
\text { suelo } \\
\text { cal }\end{array}$ & $\begin{array}{l}\text { nte: }{ }^{a} \text { Kellman y } \\
{ }^{c} \text { Castellanos e } \\
\text { valor calibrado }\end{array}$ & $\begin{array}{l}\text { Roulet }(1990 \\
\text { t al (1991); } \\
\text { a partir de Bo } \\
\text { (2005); }\end{array}$ & $\begin{array}{l}\text { banadell } \\
\text { yel et al }(20 \\
\text { y Maddoct } \\
\text { valor calibr }\end{array}$ & $\begin{array}{l}\text { al (1996) y } \\
\text { e); }{ }^{e} \text { Guym } \\
I(2005) \text { y } \\
\text { o a partir a }\end{array}$ & $\begin{array}{l}\text { enk y Jacksc } \\
\text { 1994) y Krat } \\
\text { adell et al (1 } \\
\text { llman y Ror }\end{array}$ & $\begin{array}{l}\text { 2002a) con } \\
\text { y Boyer (1 } \\
6) ;{ }^{\text {cal } 2} \text { valor } \\
\text { (1990) y Sc }\end{array}$ & $\begin{array}{l}\text { ificación de } \\
) ;{ }^{f} \text { Laio et } \\
\text { ibrado a par } \\
\text { ze et al (199 }\end{array}$ & $\begin{array}{l}\text { po durant } \\
\text { O01) } ;{ }^{g} \mathrm{Ea} \\
\text { de Baird y }\end{array}$ & $\begin{array}{l}\text { uestreo de } \\
\text { son (2002); } \\
\text { ddock III }\end{array}$ \\
\hline
\end{tabular}
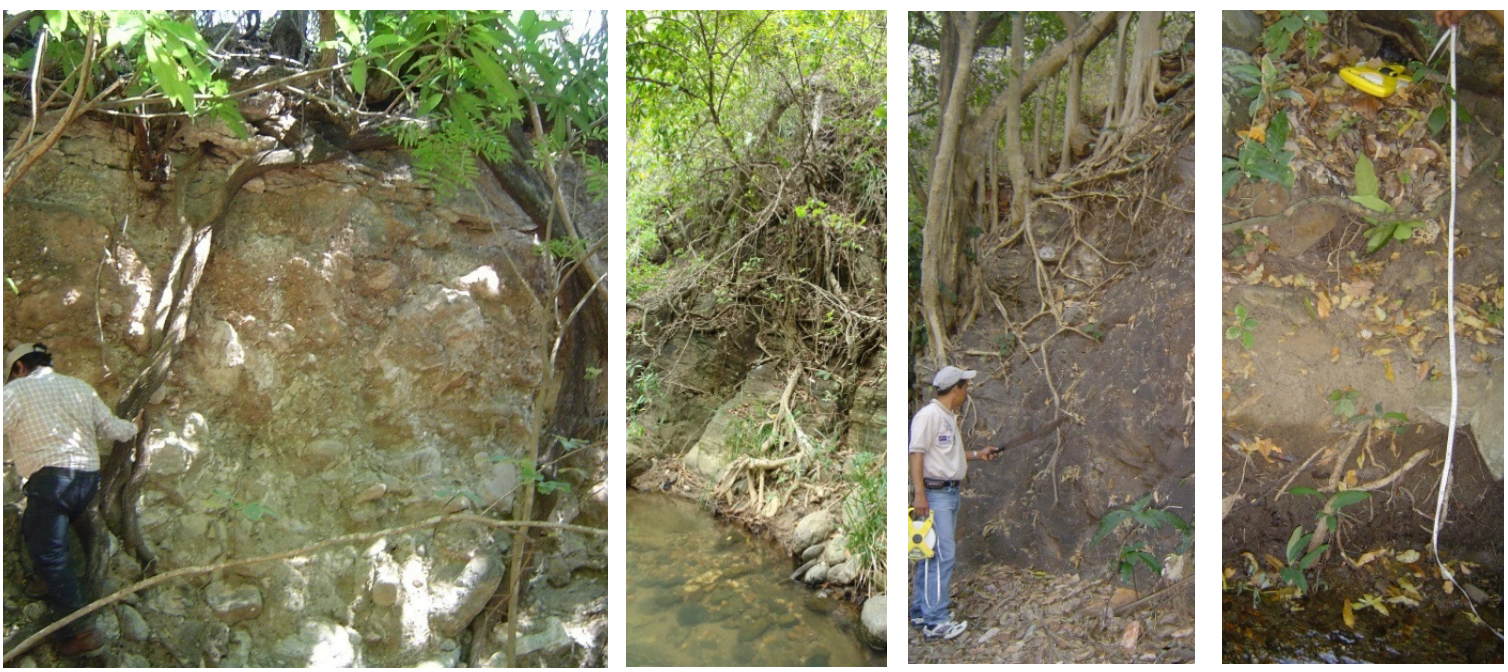

Figura 7.31. Vistas de perfiles de suelo y de sistemas radiculares de especies obligadas y facultativas de ribera del río Uyús y Valle del Motagua. Fotos: M.Morales (2006, 2007 y 2008).

En RibAV, la presencia de una capa limitante determina la profundidad máxima " $Z \boldsymbol{r}$ " y efectiva "Ze" del sistema de raíces. La profundización del sistema radicular está limitada por una variedad de factores como la presencia de rocas consolidadas poco profundas ${ }^{7}$, capas horizontalmente estratificadas de pizarras o arcillas, permafrost, y el nivel freático (sensu Canadell et al, 1996).

Un análisis preliminar para condiciones semiáridas del mediterráneo español (Francés et al, 2009) demostró que los parámetros más sensibles del $R i b A V$ son $Z r, Z e, F_{\text {est }}$ y $\boldsymbol{F}_{\text {sat }}$.

${ }^{7}$ Este factor se observó en algunas zonas de la ribera de Uyús y Teculután (Fig. 7.32). 

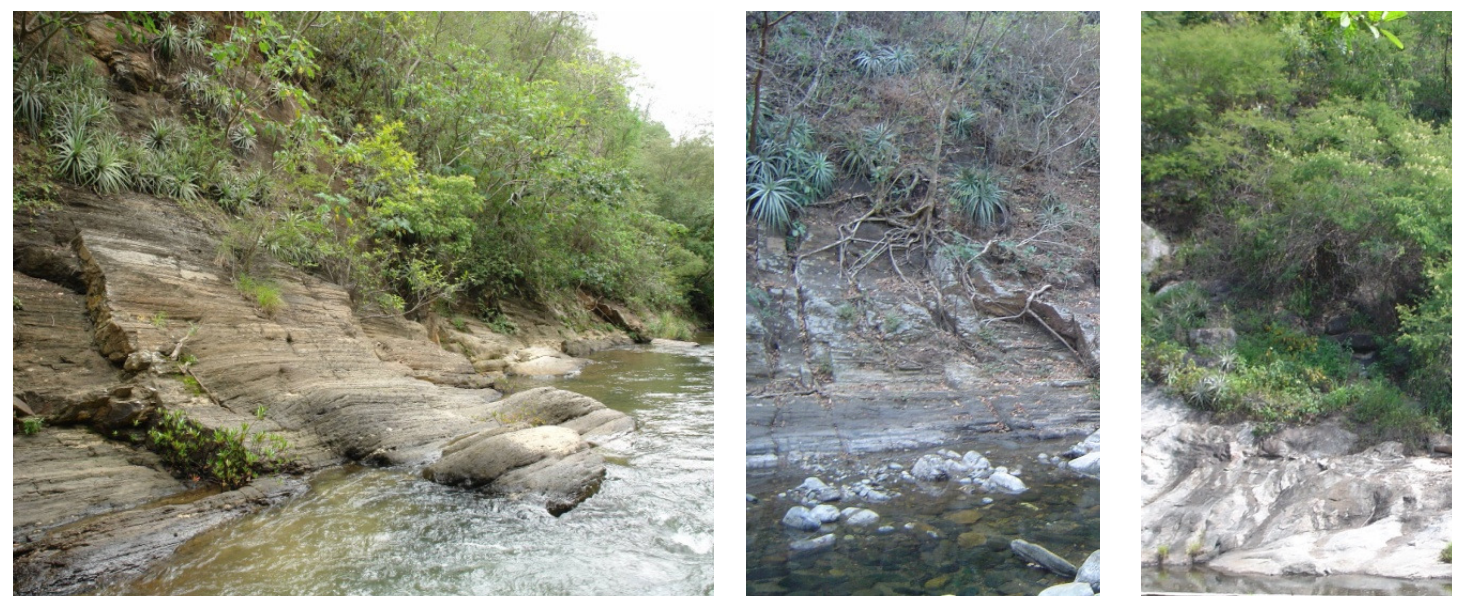

Figura 7.32. Bosque seco colindante con el río desarrollado en zonas de ribera con presencia de capa rocosa limitante para la profundización del sistema radicular. Observaciones en los transectos siguientes:

T2 y T4 del río Uyús; T6 y T7 del río Teculután. Fotos: (i) J. Vargas (2006), (d) M. Morales (2006 y 2007).

Para identificar la fuente de agua para la vegetación se han establecido valores del factor de transpiración de la zona no saturada " $\boldsymbol{F}_{\text {est }}$ " y saturada " $\boldsymbol{F}_{\text {sat }}$ " (Tabla 7.12) siguiendo una estrategia de diferenciación entre especies freatofitas obligadas y facultativas y no freatofitas (Butler Jr. et al, 2007; Cooper et al, 2006) y comparando las especies observadas con bibliografía (Castellanos et al, 1991; Kellman y Roulet, 1990; Schulze et al, 1996). Finalmente se obtuvieron valores calibrados con RibAV, de los cuales, los del bosque seco se corresponden con el dato teórico extraído observado en bosques caducifolios (Castellanos et al, 1991), y los de los árboles RA y RF se corresponden con lo reportado por Kellman y Roulet (1990).

La profundidad de extinción por saturación " $\boldsymbol{Z}_{\text {sat }}$ " (Tabla 7.12) se estableció con base en el valor teórico de referencia para TFV de ribera (Baird y Maddock III, 2005; Maddock III y Baird, 2003) y mediante calibración con RibAV; el resultado permite diferenciar claramente entre la vegetación obligada de ribera -normalmente cerca de la zona saturada y con valores menores de " $\boldsymbol{Z}_{\text {sat }}$ "- y la de los bosques de transición y seco aledaño -con los valores mayores del parámetro-.

El parámetro de "conductividad máxima de agua en la interfaz raíz-suelo, Crt" en RibAV, se establece a partir del valor estimado por experimentación de campo por Ryel et al (2002): 0.97 $\left[\mathrm{mm} \mathrm{MPa}{ }^{-1} \mathrm{~h}^{-1}\right]$; dicho parámetro teórico se utilizó para modelar la redistribución hidráulica de agua en el suelo en el estudio de Zhen y Wang (2007).

El parámetro de punto de marchitez permanente " $\boldsymbol{P}_{\boldsymbol{w}}$ " (Tabla 7.12) de los TFV de ribera (RH, RA y RF) se estableció con base el valor de presión de 1,500 kPa de diversos estudios (Guymon, 1994; Kramer y Boyer, 1995; Puricelli, 2003; Terradas, 2001). Para el bosque seco caducifolio del Valle del Motagua se asumió la presión de 3,000 kPa, referido por Laio et al (2001) para plantas de ambientes semiáridos. Estos órdenes de magnitud son coherentes con los citados por Larcher (2003) cuando se refiere a presiones características de marchitez para especies hidrófitas (las que colonizan sitios muy húmedos), árboles, plantas mesófitas y xerófitas.

El valor del parámetro "presión de crecimiento vegetal óptimo $\boldsymbol{P}_{\text {opt }}$ " tras la calibración con RibAV, para los TFV de Uyús y Teculután corresponde al dato teórico de Eagleson (2002).

El "factor de cobertura vegetal Cov" (Tabla 7.13) se estableció a partir de las observaciones de campo (Fig. 7.2, y 7.19 a 7.21), de las de imágenes de sensores remotos disponibles (Fig. 7.3, 7.8 y 7.9) y con base en el conocimiento recabado en la revisión de las características morfológicas, fenológicas, fitosociológicas y ecofisiológicas de las especies vegetales de la ribera y el bosque seco del Valle del Motagua. De manera general, el comportamiento del dosel de los bosques observados se puede describir con factores de cobertura $=1$ para las especies siempreverdes de las zonas de ribera y con una cobertura variable para el bosque seco caducifolio adelaño. 
Tabla 7.13. Valores del parámetro de cobertura vegetal "Cov" para los tipos funcionales de vegetación (TFV) de ribera y bosque seco presentes en las secciones transversales de los ríos Uyús y Teculután.

\begin{tabular}{|c|c|c|c|c|c|c|c|c|c|c|c|c|c|}
\hline \multirow{2}{*}{$\begin{array}{l}\text { Código del } \\
\text { TFV }\end{array}$} & \multirow{2}{*}{$\begin{array}{c}\text { Acrónimo y } \\
\text { Descripción del } \\
\text { TFV }\end{array}$} & \multicolumn{12}{|c|}{$\begin{array}{l}\text { Factor de cobertura vegetal } \\
\text { "Cov }[] "\end{array}$} \\
\hline & & En & Feb & Mar & Abr & May & Jun & Jul & $\mathbf{A g}$ & Sept & Oct & Nov & Dic \\
\hline 1 & $\begin{array}{l}\text { RH, herbácea } \\
\text { obligada de } \\
\text { ribera }\end{array}$ & 1.0 & 1.0 & 1.0 & 1.0 & 1.0 & 1.0 & 1.0 & 1.0 & 1.0 & 1.0 & 1.0 & 1.0 \\
\hline 2 & $\begin{array}{l}\text { RA, arbórea } \\
\text { obligada de } \\
\text { ribera }\end{array}$ & 1.0 & 1.0 & 1.0 & 1.0 & 1.0 & 1.0 & 1.0 & 1.0 & 1.0 & 1.0 & 1.0 & 1.0 \\
\hline 3 & $\begin{array}{c}\mathrm{RF} \text {, arbórea } \\
\text { facultativa de } \\
\text { ribera }\end{array}$ & 1.0 & 1.0 & 1.0 & 1.0 & 1.0 & 1.0 & 1.0 & 1.0 & 1.0 & 1.0 & 1.0 & 1.0 \\
\hline 4 & $\begin{array}{l}\text { BS, bosque } \\
\operatorname{seco}^{a}\end{array}$ & 0.7 & 0.7 & 0.7 & 0.9 & 1.0 & 1.0 & 1.0 & 1.0 & 1.0 & 1.0 & 0.9 & 0.7 \\
\hline nte: ${ }^{\text {obs }}$ & vaciones empi & 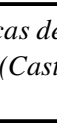 & $S c$ & , & 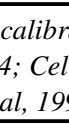 & 96) & 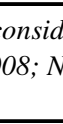 & (2) & & 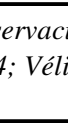 & Ont & & po \\
\hline
\end{tabular}

El bosque seco del Valle del Motagua pierde sus hojas al inicio de la estación seca (Castañeda, 2004; Nájera, 2004), pero no se conoce un registro (semanal o mensual) de dicha caducidad del follaje, salvo alguna información indirecta proveniente de observaciones de campo durante la mayor época de floración -febrero a mayo- (Véliz et al, 2003). Para calibrar la variabilidad temporal del parámetro "Cov" del bosque seco y establecer su magnitud (Tabla 7.13), se usó el conocimiento promedio mensual de la climatología local (Fig. 7.15 y 7.16), y referencias de bosques deciduos en condiciones semiáridas y áridas (Schulze et al, 1996).

\subsubsection{Puntos de simulación de bosques de ribera y bosque seco de Uyús y Teculután para calibrar y validar el Modelo RibAV v1.0}

Las ecuaciones de RibAV se han programado en el lenguaje de Microsoft Visual Studio $2008 \AA$ para facilitar cálculos y su calibración y validación (Francés et al, 2009; Real et al, 2010). El resultado ha sido una interfaz que facilita las aplicaciones en zonas de ribera con múltiples registros de suelo, curvas de caudal-nivel, series hidrometeorológicas, tipos de vegetación, y puntos de simulación a escala transversal de ribera, y que permite obtener los principales índices descritos en apartados previos (Fig. 7.33).

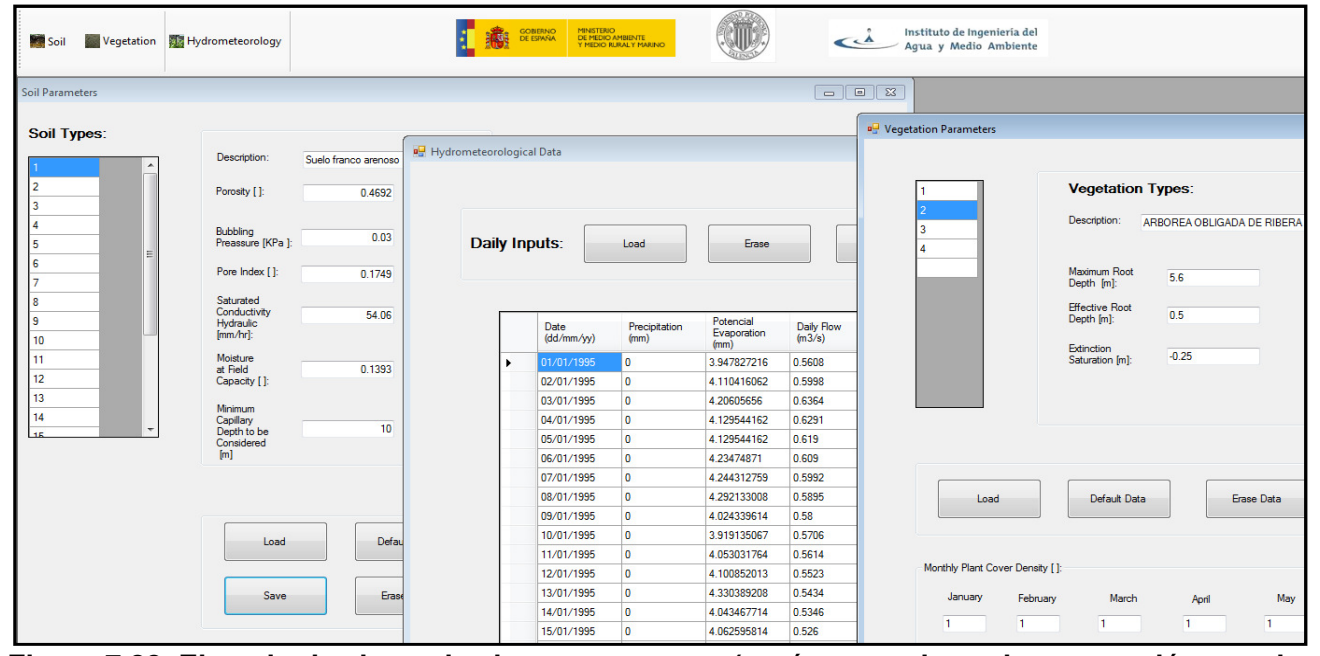

Figura 7.33. Ejemplo de vistas de algunas ventanas (parámetros de suelo, vegetación y series hidrometeorológicas) del modelo RibAV versión 1.0. 
A continuación, con base en los TFV observados, se resume la información de los 153 puntos de simulación de las secciones transversales del río Uyús en el formato requerido por el programa RibAV versión 1.0 (Tablas 7.14, 7.15, 7.16 y 7.17).

Tabla 7.14. Información resumida de los 12 puntos de simulación en riberas del río Uyús en donde se observó el TFV Herbáceas obligadas de ribera (RH).

\begin{tabular}{ccccccc}
\hline $\begin{array}{c}\text { Punto de } \\
\text { Simulación }\end{array}$ & $\begin{array}{c}\text { Cota [m } \\
\text { s.n.m] }\end{array}$ & $\begin{array}{c}\text { Tipo de } \\
\text { suelo }\end{array}$ & Transecto & $\begin{array}{c}\text { Distancia } \\
\text { horizontal al } \\
\text { thalweg [m] }\end{array}$ & $\begin{array}{c}\text { Código } \\
\text { TFV }\end{array}$ & TFV \\
\hline 1_1_RH & 320.3 & 1 & 1 & 0 & 1 & RH \\
2_2_RH & 319.1 & 6 & 2 & 5 & 1 & RH \\
2_2_RH2 & 319.6 & 6 & 2 & 5 & 1 & RH \\
3_1_RH & 243.4 & 9 & 3 & 5 & 1 & RH \\
3_5_RH & 243.8 & 9 & 3 & 0 & 1 & RH \\
3_5_RH2 & 244.3 & 9 & 3 & 0 & 1 & RH \\
3_5_RH3 & 244.8 & 9 & 3 & 0 & 1 & RH \\
3_5_RH4 & 245.3 & 9 & 3 & 0 & 1 & RH \\
5_1_RH & 225.6 & 14 & 5 & 6 & 1 & RH \\
5_1_RH2 & 226.1 & 14 & 5 & 6 & 1 & RH \\
5_4_RH & 225.5 & 17 & 5 & 5 & 1 & RH \\
5_4_RH2 & 226.0 & 17 & 5 & 5 & 1 & RH \\
\hline
\end{tabular}

Tabla 7.15. Información resumida de los 29 puntos de simulación en riberas del río Uyús en donde se observó el TFV Arbóreas de ribera húmeda (RA).

\begin{tabular}{|c|c|c|c|c|c|c|}
\hline $\begin{array}{c}\text { Punto de } \\
\text { Simulación }\end{array}$ & $\begin{array}{c}\text { Cota [m } \\
\text { s.n.m] }\end{array}$ & $\begin{array}{l}\text { Tipo de } \\
\text { suelo }\end{array}$ & Transecto & $\begin{array}{c}\text { Distancia } \\
\text { horizontal al } \\
\text { thalweg }[\mathrm{m}]\end{array}$ & $\begin{array}{c}\text { Código } \\
\text { TFV }\end{array}$ & TFV \\
\hline 1_2_RA & 320.7 & 2 & 1 & 15 & 2 & RA \\
\hline 1_2_RA2 & 321.2 & 2 & 1 & 15 & 2 & RA \\
\hline 1_4_RA & 324.3 & 4 & 1 & 5 & 2 & RA \\
\hline 1_4_RA2 & 324.8 & 4 & 1 & 5 & 2 & RA \\
\hline 1_4_RA3 & 325.3 & 4 & 1 & 5 & 2 & RA \\
\hline 1_4_RA4 & 325.8 & 4 & 1 & 5 & 2 & RA \\
\hline 1_4_RA5 & 326.3 & 4 & 1 & 5 & 2 & RA \\
\hline 2_3_RA & 320.0 & 7 & 2 & 15 & 2 & RA \\
\hline 2_3_RA2 & 320.5 & 7 & 2 & 15 & 2 & RA \\
\hline 2_3_RA3 & 321.0 & 7 & 2 & 15 & 2 & RA \\
\hline 2_3_RA4 & 321.5 & 7 & 2 & 15 & 2 & RA \\
\hline 2_3_RA5 & 322.0 & 7 & 2 & 15 & 2 & RA \\
\hline 2_3_RA6 & 322.5 & 7 & 2 & 15 & 2 & RA \\
\hline 2_3_RA7 & 323.0 & 7 & 2 & 15 & 2 & RA \\
\hline 2_3_RA8 & 323.5 & 7 & 2 & 15 & 2 & RA \\
\hline 2_3_RA9 & 324.0 & 7 & 2 & 15 & 2 & RA \\
\hline 3_2_RA & 243.9 & 10 & 3 & 18 & 2 & RA \\
\hline 3_2_RA2 & 244.4 & 10 & 3 & 18 & 2 & RA \\
\hline 3_2_RA3 & 244.9 & 10 & 3 & 18 & 2 & RA \\
\hline 3_2_RA4 & 245.4 & 10 & 3 & 18 & 2 & RA \\
\hline 4_1_RA & 242.3 & 20 & 4 & 15 & 2 & RA \\
\hline 4_1_RA2 & 242.8 & 20 & 4 & 15 & 2 & RA \\
\hline 4_1_RA3 & 243.3 & 20 & 4 & 15 & 2 & RA \\
\hline 4_1_RA4 & 243.8 & 20 & 4 & 15 & 2 & RA \\
\hline 4_1_RA5 & 244.3 & 20 & 4 & 15 & 2 & RA \\
\hline 5_5_RA & 226.5 & 18 & 5 & 8 & 2 & RA \\
\hline 5_5_RA2 & 227.0 & 18 & 5 & 8 & 2 & RA \\
\hline 5_5_RA3 & 227.5 & 18 & 5 & 8 & 2 & RA \\
\hline 5_5_RA4 & 228.0 & 18 & 5 & 8 & 2 & RA \\
\hline
\end{tabular}


Tabla 7.16. Información resumida de los 31 puntos de simulación en riberas del río Uyús en donde se observó el TFV Arbóreas facultativas de transición de ribera (RF).

\begin{tabular}{|c|c|c|c|c|c|c|}
\hline $\begin{array}{c}\text { Punto de } \\
\text { Simulación }\end{array}$ & $\begin{array}{c}\text { Cota [m } \\
\text { s.n.m] }\end{array}$ & $\begin{array}{c}\text { Tipo de } \\
\text { suelo }\end{array}$ & Transecto & $\begin{array}{c}\text { Distancia } \\
\text { horizontal al } \\
\text { thalweg }[\mathrm{m}]\end{array}$ & $\begin{array}{c}\text { Código } \\
\text { TFV }\end{array}$ & TFV \\
\hline 1_5_RF & 326.9 & 4 & 1 & 15 & 3 & $\mathrm{RF}$ \\
\hline 1_5_RF2 & 327.4 & 4 & 1 & 15 & 3 & $\mathrm{RF}$ \\
\hline 1_5_RF3 & 327.9 & 4 & 1 & 15 & 3 & $\mathrm{RF}$ \\
\hline 2_4_RF & 324.4 & 7 & 2 & 30 & 3 & $\mathrm{RF}$ \\
\hline 2_4_RF2 & 324.9 & 7 & 2 & 30 & 3 & $\mathrm{RF}$ \\
\hline 2_4_RF3 & 325.4 & 7 & 2 & 30 & 3 & $\mathrm{RF}$ \\
\hline 2_4_RF4 & 325.9 & 7 & 2 & 30 & 3 & $\mathrm{RF}$ \\
\hline 3_3_RF & 245.5 & 10 & 3 & 35 & 3 & $\mathrm{RF}$ \\
\hline 3_3_RF3 & 246.0 & 10 & 3 & 35 & 3 & $\mathrm{RF}$ \\
\hline 3_3_RF4 & 246.5 & 10 & 3 & 35 & 3 & $\mathrm{RF}$ \\
\hline 3_3_RF5 & 247.0 & 10 & 3 & 35 & 3 & $\mathrm{RF}$ \\
\hline 3_3_RF6 & 247.5 & 10 & 3 & 35 & 3 & $\mathrm{RF}$ \\
\hline 3_3_RF7 & 248.0 & 10 & 3 & 35 & 3 & $\mathrm{RF}$ \\
\hline 3_3_RF8 & 248.5 & 10 & 3 & 35 & 3 & $\mathrm{RF}$ \\
\hline 3_3_RF9 & 249.0 & 10 & 3 & 35 & 3 & $\mathrm{RF}$ \\
\hline 3_3_RF10 & 249.5 & 10 & 3 & 35 & 3 & $\mathrm{RF}$ \\
\hline 3_3_RF11 & 250.0 & 10 & 3 & 35 & 3 & $\mathrm{RF}$ \\
\hline 3_3_RF12 & 250.5 & 10 & 3 & 35 & 3 & $\mathrm{RF}$ \\
\hline 4_2_RF & 244.7 & 21 & 4 & 37 & 3 & $\mathrm{RF}$ \\
\hline 4_2_RF2 & 245.2 & 21 & 4 & 37 & 3 & $\mathrm{RF}$ \\
\hline 4_2_RF3 & 245.7 & 21 & 4 & 37 & 3 & $\mathrm{RF}$ \\
\hline 4_2_RF4 & 246.2 & 21 & 4 & 37 & 3 & $\mathrm{RF}$ \\
\hline 4_2_RF5 & 246.7 & 21 & 4 & 37 & 3 & $\mathrm{RF}$ \\
\hline 5_6_RF & 228.2 & 18 & 5 & 18 & 3 & $\mathrm{RF}$ \\
\hline 5_6_RF2 & 228.7 & 18 & 5 & 18 & 3 & $\mathrm{RF}$ \\
\hline 5_6_RF3 & 229.2 & 18 & 5 & 18 & 3 & $\mathrm{RF}$ \\
\hline 5_6_RF4 & 229.7 & 18 & 5 & 18 & 3 & $\mathrm{RF}$ \\
\hline 5_6_RF5 & 230.2 & 18 & 5 & 18 & 3 & $\mathrm{RF}$ \\
\hline 5_6_RF6 & 230.7 & 18 & 5 & 18 & 3 & $\mathrm{RF}$ \\
\hline 5_6_RF7 & 231.2 & 18 & 5 & 18 & 3 & $\mathrm{RF}$ \\
\hline 5_6_RF8 & 231.7 & 18 & 5 & 18 & 3 & $\mathrm{RF}$ \\
\hline
\end{tabular}


Tabla 7.17. Información resumida de algunos de los 81 puntos de simulación en riberas del río Uyús en donde se observó el TFV Bosque seco (BS)

\begin{tabular}{|c|c|c|c|c|c|c|}
\hline $\begin{array}{l}\text { Punto de } \\
\text { Simulación }\end{array}$ & $\begin{array}{c}\text { Cota [m } \\
\text { s.n.m] }\end{array}$ & $\begin{array}{c}\text { Tipo de } \\
\text { suelo }\end{array}$ & Transecto & $\begin{array}{c}\text { Distancia } \\
\text { horizontal al } \\
\text { thalweg [m] }\end{array}$ & $\begin{array}{c}\text { Código } \\
\text { TFV }\end{array}$ & TFV \\
\hline 1_3_BS & 330.0 & 3 & 1 & 45 & 4 & $\overline{B S}$ \\
\hline 1_3_BS2 & 330.5 & 3 & 1 & 45 & 4 & BS \\
\hline 1_3_BS3 & 331.0 & 3 & 1 & 45 & 4 & BS \\
\hline 1_3_BS16 & 337.5 & 3 & 1 & 45 & 4 & BS \\
\hline 1_3_BS17 & 338.0 & 3 & 1 & 45 & 4 & BS \\
\hline 1_3_BS18 & 338.5 & 3 & 1 & 45 & 4 & BS \\
\hline 1_3_BS19 & 339.0 & 3 & 1 & 45 & 4 & BS \\
\hline 1_3_BS20 & 339.5 & 3 & 1 & 45 & 4 & BS \\
\hline 1_6_BS & 328.0 & 5 & 1 & 50 & 4 & BS \\
\hline 1_6_BS2 & 328.5 & 5 & 1 & 50 & 4 & BS \\
\hline 1_6_BS3 & 329.0 & 5 & 1 & 50 & 4 & BS \\
\hline 1_6_BS4 & 329.5 & 5 & 1 & 50 & 4 & BS \\
\hline 1_6_BS5 & 330.0 & 5 & 1 & 50 & 4 & BS \\
\hline 2_5_BS & 326.3 & 8 & 2 & 55 & 4 & BS \\
\hline 2_5_BS2 & 326.8 & 8 & 2 & 55 & 4 & BS \\
\hline 2_5_BS8 & 329.8 & 8 & 2 & 55 & 4 & BS \\
\hline 2_5_BS9 & 330.3 & 8 & 2 & 55 & 4 & BS \\
\hline 3_4_BS & 250.9 & 11 & 3 & 45 & 4 & BS \\
\hline 3_4_BS2 & 251.4 & 11 & 3 & 45 & 4 & BS \\
\hline 3_4_BS7 & 253.9 & 11 & 3 & 45 & 4 & BS \\
\hline 3_4_BS8 & 254.4 & 11 & 3 & 45 & 4 & BS \\
\hline 3_7_BS & 250.9 & 13 & 3 & 12 & 4 & BS \\
\hline 3_7_BS2 & 251.4 & 13 & 3 & 12 & 4 & BS \\
\hline 3_7_BS9 & 254.9 & 13 & 3 & 12 & 4 & BS \\
\hline 3_7_BS10 & 255.4 & 13 & 3 & 12 & 4 & BS \\
\hline 4_3_BS & 247.0 & 21 & 4 & 40 & 4 & BS \\
\hline 4_3_BS2 & 247.5 & 21 & 4 & 40 & 4 & BS \\
\hline 4_3_BS3 & 248.0 & 21 & 4 & 40 & 4 & BS \\
\hline 4_3_BS4 & 248.5 & 21 & 4 & 40 & 4 & BS \\
\hline 4_3_BS5 & 249.0 & 21 & 4 & 40 & 4 & BS \\
\hline 4_3_BS6 & 249.5 & 21 & 4 & 40 & 4 & BS \\
\hline 4_3_BS7 & 250.0 & 21 & 4 & 40 & 4 & BS \\
\hline 5_3_BS & 234.1 & 16 & 5 & 21 & 4 & BS \\
\hline 5_3_BS2 & 234.6 & 16 & 5 & 21 & 4 & BS \\
\hline 5_3_BS3 & 235.1 & 16 & 5 & 21 & 4 & BS \\
\hline 5_3_BS4 & 235.6 & 16 & 5 & 21 & 4 & BS \\
\hline 5_3_BS5 & 236.1 & 16 & 5 & 21 & 4 & BS \\
\hline 5_3_BS6 & 236.6 & 16 & 5 & 21 & 4 & BS \\
\hline 5_3_BS7 & 237.1 & 16 & 5 & 21 & 4 & BS \\
\hline 5_3_BS8 & 237.6 & 16 & 5 & 21 & 4 & BS \\
\hline 5_3_BS9 & 238.1 & 16 & 5 & 21 & 4 & BS \\
\hline 5_3_BS10 & 238.6 & 16 & 5 & 21 & 4 & BS \\
\hline 5_3_BS11 & 239.1 & 16 & 5 & 21 & 4 & BS \\
\hline 5_7_BS & 232.0 & 19 & 5 & 34 & 4 & BS \\
\hline 5_7_BS2 & 232.5 & 19 & 5 & 34 & 4 & BS \\
\hline 5_7_BS3 & 233.0 & 19 & 5 & 34 & 4 & BS \\
\hline 5_7_BS4 & 233.5 & 19 & 5 & 34 & 4 & BS \\
\hline 5_7_BS5 & 234.0 & 19 & 5 & 34 & 4 & BS \\
\hline 5_7_BS6 & 234.5 & 19 & 5 & 34 & 4 & BS \\
\hline 5_7_BS7 & 235.0 & 19 & 5 & 34 & 4 & BS \\
\hline 5_7_BS8 & 235.5 & 19 & 5 & 34 & 4 & BS \\
\hline 5_7_BS9 & 236.0 & 19 & 5 & 34 & 4 & BS \\
\hline 2_1_BS & 325.4 & 3 & 2 & 5 & 4 & BS \\
\hline 5_4_BS & 242.5 & 3 & 5 & 2 & 4 & $\mathrm{BS}$ \\
\hline
\end{tabular}


A continuación, con base en los TFV observados se resume la información de los 119 puntos de simulación de las secciones transversales del río Teculután en el formato requerido por el programa RibAV versión 1.0 (Tablas 7.18 y 7.19 ).

Tabla 7.18. Información resumida de los 43 puntos de simulación en riberas del río Teculután en donde se observó el TFV Arbóreas obligadas de ribera (RA).

\begin{tabular}{|c|c|c|c|c|c|c|}
\hline $\begin{array}{c}\text { Punto de } \\
\text { Simulación }\end{array}$ & Cota [m s.n.m] & Tipo de suelo & Transecto & $\begin{array}{c}\text { Distancia } \\
\text { horizontal al } \\
\text { thalweg }[\mathrm{m}]\end{array}$ & Código TFV & TFV \\
\hline 6_2_RA & 100.78 & 23 & 6 & 15 & 2 & RA \\
\hline 6_2_RA2 & 101.28 & 23 & 6 & 15 & 2 & RA \\
\hline 6_2_RA3 & 101.78 & 23 & 6 & 15 & 2 & RA \\
\hline 6_2_RA4 & 102.28 & 23 & 6 & 15 & 2 & RA \\
\hline 6_2_RA5 & 102.78 & 23 & 6 & 15 & 2 & RA \\
\hline 6_2_RA6 & 103.28 & 23 & 6 & 15 & 2 & RA \\
\hline 6_2_RA7 & 103.78 & 23 & 6 & 15 & 2 & RA \\
\hline 7_2_RA & 98.53 & 26 & 7 & 36 & 2 & RA \\
\hline 7_2_RA2 & 99.03 & 26 & 7 & 36 & 2 & RA \\
\hline 7_2_RA3 & 99.53 & 26 & 7 & 36 & 2 & RA \\
\hline 7_2_RA4 & 100.03 & 26 & 7 & 36 & 2 & RA \\
\hline 7_2_RA5 & 100.53 & 26 & 7 & 36 & 2 & RA \\
\hline 7_2_RA6 & 101.03 & 26 & 7 & 36 & 2 & RA \\
\hline 7_2_RA7 & 101.53 & 26 & 7 & 36 & 2 & RA \\
\hline 7_2_RA8 & 102.03 & 26 & 7 & 36 & 2 & RA \\
\hline 7_2_RA9 & 102.53 & 26 & 7 & 36 & 2 & RA \\
\hline 7_2_RA10 & 103.03 & 26 & 7 & 36 & 2 & RA \\
\hline 7_2_RA11 & 103.53 & 26 & 7 & 36 & 2 & RA \\
\hline 7_2_RA12 & 104.03 & 26 & 7 & 36 & 2 & RA \\
\hline 7_2_RA13 & 104.53 & 26 & 7 & 36 & 2 & RA \\
\hline 8_1_RA & 98.12 & 25 & 8 & 17 & 2 & RA \\
\hline 8_1_RA2 & 98.62 & 25 & 8 & 17 & 2 & RA \\
\hline 8_1_RA3 & 99.12 & 25 & 8 & 17 & 2 & RA \\
\hline 8_1_RA4 & 99.62 & 25 & 8 & 17 & 2 & RA \\
\hline 8_1_RA5 & 100.12 & 25 & 8 & 17 & 2 & RA \\
\hline 8_1_RA6 & 100.62 & 25 & 8 & 17 & 2 & RA \\
\hline 8_1_RA7 & 101.12 & 25 & 8 & 17 & 2 & RA \\
\hline 8_1_RA8 & 101.62 & 25 & 8 & 17 & 2 & RA \\
\hline 8_1_RA9 & 102.12 & 25 & 8 & 17 & 2 & RA \\
\hline 8_1_RA10 & 102.62 & 25 & 8 & 17 & 2 & RA \\
\hline 8_1_RA11 & 103.12 & 25 & 8 & 17 & 2 & RA \\
\hline 8_1_RA12 & 103.62 & 25 & 8 & 17 & 2 & RA \\
\hline 8_4_RA & 98.21 & 23 & 8 & 11 & 2 & RA \\
\hline 8_4_RA2 & 98.71 & 23 & 8 & 11 & 2 & RA \\
\hline 8_4_RA3 & 99.21 & 23 & 8 & 11 & 2 & RA \\
\hline 8_4_RA4 & 99.71 & 23 & 8 & 11 & 2 & RA \\
\hline 8_4_RA5 & 100.21 & 23 & 8 & 11 & 2 & RA \\
\hline 8_4_RA6 & 100.71 & 23 & 8 & 11 & 2 & RA \\
\hline 8_4_RA7 & 101.21 & 23 & 8 & 11 & 2 & RA \\
\hline 8_4_RA8 & 101.71 & 23 & 8 & 11 & 2 & RA \\
\hline 8_4_RA9 & 102.21 & 23 & 8 & 11 & 2 & RA \\
\hline 8_4_RA10 & 102.71 & 23 & 8 & 11 & 2 & RA \\
\hline 8_4_RA11 & 103.21 & 23 & 8 & 11 & 2 & RA \\
\hline
\end{tabular}


Tabla 7.19. Información resumida de algunos de los 59 puntos de simulación en riberas del río Teculután en donde se observó el TFV Bosque seco (BS).

\begin{tabular}{|c|c|c|c|c|c|c|}
\hline $\begin{array}{l}\text { Punto de } \\
\text { Simulación }\end{array}$ & Cota $[\mathrm{m}$ s.n.m] & Tipo de suelo & Transecto & $\begin{array}{c}\text { Distancia } \\
\text { horizontal al } \\
\text { thalweg [m] }\end{array}$ & Código TFV & TFV \\
\hline 6_4_BS & 107.23 & 24 & 6 & 35 & 4 & BS \\
\hline 6_4_BS2 & 107.73 & 24 & 6 & 35 & 4 & BS \\
\hline 6_4_BS3 & 108.23 & 24 & 6 & 35 & 4 & BS \\
\hline 6_4_BS4 & 108.73 & 24 & 6 & 35 & 4 & BS \\
\hline 6_4_BS5 & 109.23 & 24 & 6 & 35 & 4 & BS \\
\hline 6_4_BS11 & 112.23 & 24 & 6 & 35 & 4 & BS \\
\hline 6_4_BS12 & 112.73 & 24 & 6 & 35 & 4 & BS \\
\hline 6_4_BS13 & 113.23 & 24 & 6 & 35 & 4 & BS \\
\hline 7_4_BS & 107.53 & 24 & 7 & 56 & 4 & BS \\
\hline 7_4_BS2 & 108.03 & 24 & 7 & 56 & 4 & BS \\
\hline 7_4_BS3 & 108.53 & 24 & 7 & 56 & 4 & BS \\
\hline 7_4_BS4 & 109.03 & 24 & 7 & 56 & 4 & BS \\
\hline 7_4_BS10 & 111.7 & 24 & 7 & 56 & 4 & BS \\
\hline 7_4_BS11 & 112.2 & 24 & 7 & 56 & 4 & BS \\
\hline 7_4_BS12 & 112.7 & 24 & 7 & 56 & 4 & BS \\
\hline 7_4_BS13 & 113.2 & 24 & 7 & 56 & 4 & BS \\
\hline 7_4_BS14 & 113.7 & 24 & 7 & 56 & 4 & BS \\
\hline 7_4_BS15 & 114.2 & 24 & 7 & 56 & 4 & BS \\
\hline 8_3_BS & 105.12 & 24 & 8 & 52 & 4 & BS \\
\hline 8_3_BS2 & 105.62 & 24 & 8 & 52 & 4 & BS \\
\hline 8_3_BS3 & 106.12 & 24 & 8 & 52 & 4 & BS \\
\hline 8_3_BS4 & 106.44 & 24 & 8 & 52 & 4 & BS \\
\hline 8_3_BS5 & 106.94 & 24 & 8 & 52 & 4 & BS \\
\hline 8_3_BS6 & 107.44 & 24 & 8 & 52 & 4 & BS \\
\hline 8_3_BS15 & 111.94 & 24 & 8 & 52 & 4 & BS \\
\hline 8_3_BS16 & 112.44 & 24 & 8 & 52 & 4 & BS \\
\hline 8_3_BS17 & 112.94 & 24 & 8 & 52 & 4 & BS \\
\hline 8_6_BS & 105.71 & 24 & 8 & 21 & 4 & BS \\
\hline 8_6_BS2 & 106.21 & 24 & 8 & 21 & 4 & BS \\
\hline 8_6_BS3 & 106.36 & 24 & 8 & 21 & 4 & BS \\
\hline 8_6_BS4 & 106.86 & 24 & 8 & 21 & 4 & BS \\
\hline 8_6_BS11 & 110.36 & 24 & 8 & 21 & 4 & BS \\
\hline 8_6_BS12 & 110.86 & 24 & 8 & 21 & 4 & BS \\
\hline 6_1_BS & 106.52 & 22 & 6 & 20 & 4 & BS \\
\hline 7_1_BS & 101.57 & 22 & 7 & 9 & 4 & BS \\
\hline
\end{tabular}

\subsection{6 Índices de eficiencia de calibración y validación del modelo RibAV}

Para la calibración del modelo RibAV v1.0, se trabajó con datos de las riberas y laderas aledañas del río Uyús considerando 151 puntos de simulación con parámetros biofísicos y variables climáticas conocidos. Un intenso análisis para entender la interacción de los parámetros de vegetación y suelo y las variables climáticas y un elevado número de simulaciones con el RibAV, han permitido obtener el conjunto más aceptable de parámetros de vegetación (Tablas 7.12 y 7.13) y sus índices de evaluación de la eficiencia (índices CCI y Kappa).

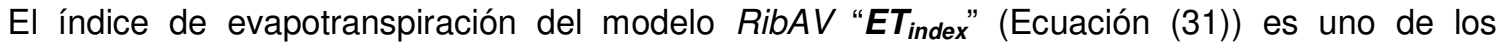
indicadores centrales para calibrar los parámetros, porque en su conceptualización integra la respuesta de los distintos tipos de vegetación a la disponibilidad de agua de la zona saturada y no saturada. La primera de las salidas del modelo RibAV (Tabla 7.20) es justamente el valor de " $E T_{\text {index }}$ " para cada uno de los TFV observados y simulados del río Uyús (RH, RA, RF y BS). 
Tabla 7.20. Salida del RibAVv 1.0 (columnas 1 a 6) y categorización Presencia/Ausencia (columnas 7 a 10) para una muestra de 28 puntos de simulación en zonas de ribera y bosque seco del río Uyús.

\begin{tabular}{|c|c|c|c|c|c|c|c|c|c|}
\hline \multirow{2}{*}{$\begin{array}{l}\text { Punto } \\
\text { simulado }\end{array}$} & \multirow{2}{*}{ TFV } & \multicolumn{4}{|c|}{ ET $_{\text {index }}$ de los TFV } & \multicolumn{4}{|c|}{$\begin{array}{l}\text { Categoría Presencia (1) / } \\
\text { Ausencia (0) de los TFV }\end{array}$} \\
\hline & & Etind_RH & Etind_RA & Etind_RF & Etind_BS & $\mathbf{R H}$ & RA & $\mathbf{R F}$ & BS \\
\hline 1_1_RH & $\mathrm{RH}$ & 0.854 & 0.294 & 0.066 & 0.050 & 1 & 0 & 0 & 0 \\
\hline 1_2_RA & RA & 0.642 & 0.862 & 0.598 & 0.452 & 0 & 1 & 0 & 0 \\
\hline 1_2_RA2 & RA & 0.308 & 0.835 & 0.559 & 0.359 & 0 & 1 & 0 & 0 \\
\hline 1_3_BS & BS & 0.310 & 0.220 & 0.297 & 0.332 & 0 & 0 & 0 & 1 \\
\hline 1_3_BS2 & BS & 0.310 & 0.220 & 0.297 & 0.332 & 0 & 0 & 0 & 1 \\
\hline 1_3_BS19 & BS & 0.310 & 0.220 & 0.297 & 0.332 & 0 & 0 & 0 & 1 \\
\hline 1_3_BS20 & BS & 0.310 & 0.220 & 0.297 & 0.332 & 0 & 0 & 0 & 1 \\
\hline $1 \_4 \_\mathrm{RA}$ & RA & 0.338 & 0.605 & 0.506 & 0.361 & 0 & 1 & 0 & 0 \\
\hline 1_4_RA2 & RA & 0.338 & 0.534 & 0.484 & 0.360 & 0 & 1 & 0 & 0 \\
\hline 1_4_RA5 & RA & 0.338 & 0.242 & 0.422 & 0.360 & 0 & 0 & 1 & 0 \\
\hline 1_5_RF & $\mathrm{RF}$ & 0.338 & 0.242 & 0.396 & 0.360 & 0 & 0 & 1 & 0 \\
\hline 1_5_RF2 & $\mathrm{RF}$ & 0.338 & 0.242 & 0.375 & 0.360 & 0 & 0 & 1 & 0 \\
\hline 1_5_RF3 & $\mathrm{RF}$ & 0.338 & 0.242 & 0.326 & 0.360 & 0 & 0 & 0 & 1 \\
\hline 1_6_BS & BS & 0.342 & 0.244 & 0.329 & 0.364 & 0 & 0 & 0 & 1 \\
\hline 1_6_BS2 & BS & 0.342 & 0.244 & 0.328 & 0.364 & 0 & 0 & 0 & 1 \\
\hline 1_6_BS5 & BS & 0.342 & 0.244 & 0.328 & 0.364 & 0 & 0 & 0 & 1 \\
\hline 2_2_RH & $\mathrm{RH}$ & 0.502 & 0.804 & 0.526 & 0.370 & 0 & 1 & 0 & 0 \\
\hline 2_2_RH2 & $\mathrm{RH}$ & 0.282 & 0.798 & 0.517 & 0.308 & 0 & 1 & 0 & 0 \\
\hline 2_3_RA & $\mathrm{RA}$ & 0.304 & 0.992 & 0.847 & 0.373 & 0 & 1 & 0 & 0 \\
\hline 2_3_RA2 & $\mathrm{RA}$ & 0.303 & 0.936 & 0.827 & 0.325 & 0 & 1 & 0 & 0 \\
\hline 2_3_RA9 & RA & 0.302 & 0.388 & 0.682 & 0.324 & 0 & 0 & 1 & 0 \\
\hline 2_4_RF & $\mathrm{RF}$ & 0.302 & 0.223 & 0.665 & 0.324 & 0 & 0 & 1 & 0 \\
\hline 2_4_RF2 & $\mathrm{RF}$ & 0.302 & 0.215 & 0.644 & 0.324 & 0 & 0 & 1 & 0 \\
\hline 2_4_RF4 & $\mathrm{RF}$ & 0.302 & 0.215 & 0.445 & 0.324 & 0 & 0 & 1 & 0 \\
\hline 2_5_BS & BS & 0.298 & 0.212 & 0.287 & 0.318 & 0 & 0 & 0 & 1 \\
\hline 2_5_BS2 & BS & 0.298 & 0.212 & 0.286 & 0.318 & 0 & 0 & 0 & 1 \\
\hline 2_5_BS9 & BS & 0.298 & 0.212 & 0.286 & 0.318 & 0 & 0 & 0 & 1 \\
\hline 3_1_RH & $\mathrm{RH}$ & 0.862 & 0.288 & 0.036 & 0.025 & 1 & 0 & 0 & 0 \\
\hline
\end{tabular}

Tabla 7.21. Matriz de confusión "Presencia/Ausencia de TFV" observada y simulada con el modelo RibAV v1.0 (en 151 puntos) con base en parámetros biofísicos y variables climáticas de transectos del río Uyús.

\begin{tabular}{|c|c|c|c|c|c|c|}
\hline \multicolumn{2}{|c|}{$\mathbf{E T}_{\text {index }}$} & \multicolumn{4}{|c|}{ SIMULADOS } & \multirow{2}{*}{$\begin{array}{c}\text { Total } \\
\text { Observados }\end{array}$} \\
\hline & & RH & RA & $\mathbf{R F}$ & BS & \\
\hline \multirow{5}{*}{ 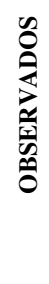 } & RH & 7 & 5 & 0 & 0 & 12 \\
\hline & RA & 0 & 22 & 7 & 0 & 29 \\
\hline & $\mathbf{R F}$ & 0 & 7 & 23 & 1 & 31 \\
\hline & BS & 0 & 0 & 6 & 73 & 79 \\
\hline & $\begin{array}{c}\text { Total } \\
\text { Simulados }\end{array}$ & 7 & 34 & 36 & 74 & 151 \\
\hline
\end{tabular}

Tabla 7.22. Matrices de confusión "Presencia/Ausencia" readecuadas para cada uno de los TFV observados y simulados con el RibAV v1.0 (en 151 puntos). Estudio de caso en transectos del río Uyús.

\begin{tabular}{|c|c|c|c|}
\hline \multirow{2}{*}{\multicolumn{2}{|c|}{$\begin{array}{c}T F V \text { "RH", } \\
\text { Transectos Río Uyús }\end{array}$}} & \multicolumn{2}{|c|}{ SIMULADOS } \\
\hline & & PRESENTE & AUSENTE \\
\hline \multirow{2}{*}{ OBSERVADOS } & PRESENTE & 7 & 5 \\
\hline & AUSENTE & 0 & 139 \\
\hline \multirow{2}{*}{\multicolumn{2}{|c|}{$\begin{array}{c}T F V \text { "RF", } \\
\text { Transectos Río Uyús }\end{array}$}} & \multicolumn{2}{|c|}{ SIMULADOS } \\
\hline & & PRESENTE & AUSENTE \\
\hline \multirow{2}{*}{ OBSERVADOS } & PRESENTE & 23 & 8 \\
\hline & AUSENTE & 13 & 107 \\
\hline
\end{tabular}

\begin{tabular}{|c|c|c|c|}
\hline \multirow{2}{*}{\multicolumn{2}{|c|}{$\begin{array}{c}T F V \text { "RA", } \\
\text { Transectos Río Uyús }\end{array}$}} & \multicolumn{2}{|c|}{ SIMULADOS } \\
\hline & & PRESENTE & AUSENTE \\
\hline \multirow{2}{*}{ OBSERVADOS } & PRESENTE & 22 & 7 \\
\hline & AUSENTE & 12 & 110 \\
\hline \multirow{2}{*}{\multicolumn{2}{|c|}{$\begin{array}{c}\text { TFV "BS", } \\
\text { Transectos Río Uyús }\end{array}$}} & \multicolumn{2}{|c|}{ SIMULADOS } \\
\hline & & PRESENTE & AUSENTE \\
\hline \multirow{2}{*}{ OBSERVADOS } & PRESENTE & 73 & 6 \\
\hline & AUSENTE & 1 & 71 \\
\hline
\end{tabular}


Se resaltan con gris las celdas que contienen el número de acuerdos entre predicciones del modelo y datos observados en campo (Tabla 7.21 y 7.22), con el agregado de que para los diferentes TFV se contabilizan tanto los casos observados y simulados de "presencia" como los de "ausencia". Así, se incorpora mayor información para la calibración del modelo y para evaluar su eficiencia de predicciones tanto de "presencia" como de "ausencia" de los TFV.

Arreglando la información de salida del RibAV en el formato descrito (Tabla 7.23) es posible generar los índices "CCl" y "Kappa" de los TFV; de esta manera el modelo permite generar dos indicadores de eficiencia útiles para su sólida calibración, y se suma a los recientes esfuerzos por evaluar la bondad de las predicciones sobre distribución vegetal "presencia/ausencia" (Biondini y Kandus, 2006; Chen et al, 2010; Franz et al, 2010; Kokaly et al, 2003; Liu et al, 2009; Niclòs Corts et al, 2010; Nielsen et al, 2008; Peters et al, 2008; Wen et al, 2009).

Tabla 7.23. "Porcentaje de casos correctamente clasificados, $\mathrm{CCl}$ e "Índice Kappa" utilizados en RibAV para la calibración y para medir la eficiencia de predicción del modelo. Estudio de caso río Uyús.

\begin{tabular}{|c|c|c|c|c|c|c|}
\hline TFV & $\begin{array}{c}\text { PRESENTES } \\
\text { Simuladas }\end{array}$ & $\begin{array}{c}\text { AUSENTES } \\
\text { Simuladas }\end{array}$ & $\begin{array}{c}\text { PRESENTES } \\
\text { Observadas }\end{array}$ & $\begin{array}{c}\text { AUSENTES } \\
\text { Observadas }\end{array}$ & CCI & Kappa \\
\hline RH & 7 & 139 & 12 & 139 & 0.97 & 0.72 \\
\hline $\mathbf{R A}$ & 22 & 110 & 29 & 122 & 0.87 & 0.62 \\
\hline RF & 23 & 107 & 31 & 120 & 0.86 & 0.60 \\
\hline \multirow[t]{2}{*}{ BS } & 73 & 71 & 79 & 72 & 0.95 & 0.91 \\
\hline & & & & $\begin{array}{c}3 \text { TFV de } \\
\text { Ribera }\end{array}$ & 0.90 & 0.64 \\
\hline
\end{tabular}

Para los cuatro TFV simulados con RibAV, el valor del "porcentaje de casos correctamente clasificados, CCl" está por encima del $85 \%$, lo que permitiría asumir un buen comportamiento del modelo debido al ajuste estadístico de los datos. Sin embargo, se ha demostrado (Manel et al, 2001) que este índice falla en tomar en cuenta los efectos de la predominancia o frecuencia de ocurrencia de las especies, y más adelante se analizará este argumento. Los resultados (Tabla 7.23) demuestran que el modelo permite predecir con una eficiencia substancial la presencia/ausencia de los TFV de ribera $\mathrm{RH}(\mathrm{Kappa}=0.72)$ y RA $(\mathrm{Kappa}=0.62)$, con una eficiencia entre moderada y substancial la presencia/ausencia de RF (Kappa $=0.6)$ y con una eficiencia casi perfecta la presencia/ausencia de BS $(K a p p a=0.91)$ para el caso del río Uyús.

A partir de los resultados de la ordenación de la vegetación observada en los transectos del río Uyús (Celis, 2008) mediante PC-ORD, se tiene evidencia que las especies arbóreas dominantes de la ribera (RA y RF) poseen una distribución amplia en las secciones transversales, lo que explicaría la mayor dificultad para estimar la distribución de esta vegetación y la relativa menor eficiencia de predicción con RibAV para dichos TFV.

La ordenación de la vegetación de Uyús también demuestra que la distribución de RH y BS está restringida hacia los extremos del gradiente de humedad en los transectos, donde se representan las condiciones de mayor saturación o no saturación del suelo (Celis, 2008). El modelo RibAV captura y simula también esa realidad observada de condiciones biofísicas y tipos de vegetación características de los extremos del gradiente, pues genera los índices "CCl" y "Kappa" más altos para $\mathrm{RH}$ y BS (Tabla 7.23) que explican fuertemente la distribución de dichos TFV.

Por tanto, a partir de estos resultados de la calibración se puede afirmar de manera general que utilizando el "índice de evapotranspiración, $\boldsymbol{E T}_{\text {index" }}$ del modelo RibAV se puede simular con mucha consistencia el límite entre la zona de ribera y la ladera aledaña (Kappa de los tres TFV de ribera $=0.64$, y Kappa del $B S=0.91$ ), situación que ha sido descrita ampliamente por Malanson (1993) y Treviño et al (2001) con base en información empírica de riberas de ambientes semiáridos o secos. También se puede afirmar de manera general que el "índice de evapotranspiración, $\boldsymbol{E} \boldsymbol{T}_{\text {index }}$ " del modelo RibAV permite predecir con eficiencia, entre substancial y casi perfecta, la ausencia/presencia de los TFV característicos en el gradiente de humedad. 
Estas evidencias obtenidas con una de las salidas más importantes del RibAV, el "E $\boldsymbol{T}_{\text {index }}$ ", demuestran a su vez la validez del conjunto de parámetros de vegetación que se calibró con base en la experiencia de campo, las referencias bibliográficas y las múltiples iteraciones del modelo matemático (Tablas 7.12 y 7.13 ).

\subsubsection{Resultados de la validación del Modelo RibAV mediante el índice de evapotranspiración " $E T_{\text {index" }}$ ": bosques de ribera y bosque seco del río Teculután}

Con base en los parámetros de vegetación calibrados en el tramo del río Uyús y habiéndose comprobado la eficiencia del modelo RibAV para la predicción de la ausencia/presencia de TFV en el área, se procedió a generar los " $\boldsymbol{E} \boldsymbol{T}_{\text {index" }}$ en Teculután para su validación con base en el análisis de eficiencia del modelo (índices CCl y Kappa). Cabe señalar en el Teculután solamente se observaron TFV puros (dominantes) de RA y BS, pero se simuló la presencia de los 4 TFV calibrados en Uyús; a su vez, considerando el alcance de la actual versión del RibAV v1.0, en esta validación tampoco se considerarán las zonas mixtas observadas.

Tabla 7.24. Salida del RibAV v 1.0 (columnas 1 a 6) y categorización Presencia/Ausencia (columnas 7 a 10) para una muestra de 29 puntos de simulación en zonas de ribera y bosque seco del río Teculután

\begin{tabular}{|c|c|c|c|c|c|c|c|c|c|}
\hline \multirow{2}{*}{$\begin{array}{c}\text { Punto } \\
\text { simulado }\end{array}$} & \multirow{2}{*}{ TFV } & \multicolumn{4}{|c|}{ ET $_{\text {index }}$ de los TFV } & \multicolumn{4}{|c|}{$\begin{array}{l}\text { Categoría Presencia (1) / } \\
\text { Ausencia (0) de los TFV }\end{array}$} \\
\hline & & Etind_RH & Etind_RA & Etind_RF & Etind_BS & RH & $\mathbf{R A}$ & $\mathbf{R F}$ & BS \\
\hline 6_2_RA & RA & 0.228 & 0.688 & 0.447 & 0.239 & 0 & 1 & 0 & 0 \\
\hline 6_2_RA2 & RA & 0.224 & 0.620 & 0.426 & 0.236 & 0 & 1 & 0 & 0 \\
\hline 6_2_RA7 & RA & 0.223 & 0.269 & 0.321 & 0.235 & 0 & 0 & 1 & 0 \\
\hline 6_4_BS & BS & 0.321 & 0.229 & 0.308 & 0.342 & 0 & 0 & 0 & 1 \\
\hline 6_4_BS2 & BS & 0.321 & 0.229 & 0.307 & 0.342 & 0 & 0 & 0 & 1 \\
\hline 6_4_BS12 & BS & 0.321 & 0.229 & 0.307 & 0.342 & 0 & 0 & 0 & 1 \\
\hline 6_4_BS13 & BS & 0.321 & 0.229 & 0.307 & 0.342 & 0 & 0 & 0 & 1 \\
\hline 7_2_RA & RA & 0.612 & 0.004 & 0.000 & 0.000 & 1 & 0 & 0 & 0 \\
\hline 7_2_RA2 & RA & 0.974 & 0.738 & 0.517 & 0.432 & 1 & 0 & 0 & 0 \\
\hline 7_2_RA13 & RA & 0.223 & 0.173 & 0.285 & 0.235 & 0 & 0 & 1 & 0 \\
\hline 7_4_BS & BS & 0.321 & 0.229 & 0.307 & 0.342 & 0 & 0 & 0 & 1 \\
\hline 7_4_BS2 & BS & 0.321 & 0.229 & 0.307 & 0.342 & 0 & 0 & 0 & 1 \\
\hline 7_4_BS14 & BS & 0.321 & 0.229 & 0.307 & 0.342 & 0 & 0 & 0 & 1 \\
\hline 7_4_BS15 & BS & 0.321 & 0.229 & 0.307 & 0.342 & 0 & 0 & 0 & 1 \\
\hline 8_1_RA & RA & 0.761 & 0.180 & 0.019 & 0.013 & 1 & 0 & 0 & 0 \\
\hline 8_1_RA2 & RA & 0.770 & 0.836 & 0.620 & 0.495 & 0 & 1 & 0 & 0 \\
\hline 8_1_RA11 & RA & 0.271 & 0.290 & 0.366 & 0.287 & 0 & 0 & 1 & 0 \\
\hline 8_1_RA12 & RA & 0.271 & 0.220 & 0.345 & 0.287 & 0 & 0 & 1 & 0 \\
\hline 8_3_BS & BS & 0.321 & 0.229 & 0.329 & 0.342 & 0 & 0 & 0 & 1 \\
\hline 8_3_BS2 & BS & 0.321 & 0.229 & 0.311 & 0.342 & 0 & 0 & 0 & 1 \\
\hline 8_3_BS16 & BS & 0.321 & 0.229 & 0.307 & 0.342 & 0 & 0 & 0 & 1 \\
\hline 8_3_BS17 & BS & 0.321 & 0.229 & 0.307 & 0.342 & 0 & 0 & 0 & 1 \\
\hline 8_4_RA & RA & 0.841 & 0.309 & 0.092 & 0.071 & 1 & 0 & 0 & 0 \\
\hline 8_4_RA2 & RA & 0.551 & 0.823 & 0.547 & 0.396 & 0 & 1 & 0 & 0 \\
\hline 8_4_RA11 & RA & 0.223 & 0.251 & 0.316 & 0.235 & 0 & 0 & 1 & 0 \\
\hline 8_6_BS & BS & 0.321 & 0.229 & 0.309 & 0.342 & 0 & 0 & 0 & 1 \\
\hline 8_6_BS2 & BS & 0.321 & 0.229 & 0.307 & 0.342 & 0 & 0 & 0 & 1 \\
\hline 8_6_BS3 & BS & 0.321 & 0.229 & 0.307 & 0.342 & 0 & 0 & 0 & 1 \\
\hline 8_6_BS12 & BS & 0.321 & 0.229 & 0.307 & 0.342 & 0 & 0 & 0 & 1 \\
\hline
\end{tabular}

Posteriormente, al igual que durante la calibración, se generó la matriz de confusión de RibAV (Tabla 7.24) y su reacomodo en la matriz de confusión ausencia/presencia (Tabla 7.25) para calcular los acuerdos entre predicciones del modelo y datos observados en campo (celdas de color gris). 
Tabla 7.25. Matriz de confusión "Presencia/Ausencia de TFV" observada y simulada con el modelo RibAV v1.0 (en 100 puntos). Estudio de caso en transectos del río Teculután.

\begin{tabular}{|c|c|c|c|c|c|c|}
\hline \multicolumn{2}{|c|}{$\mathbf{E T}_{\text {index }}$} & \multicolumn{4}{|c|}{ SIMULADOS } & \multirow{2}{*}{$\begin{array}{c}\text { Total } \\
\text { Observados }\end{array}$} \\
\hline & & RH & RA & $\mathbf{R F}$ & BS & \\
\hline \multirow{5}{*}{ 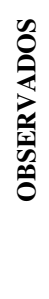 } & RH & $\mathbf{0}$ & 0 & 0 & 0 & 0 \\
\hline & $\mathbf{R A}$ & 4 & 29 & 10 & 0 & 43 \\
\hline & $\mathbf{R F}$ & 0 & 0 & $\mathbf{0}$ & 0 & 0 \\
\hline & BS & 0 & 0 & 0 & 57 & 57 \\
\hline & $\begin{array}{c}\text { Total } \\
\text { Simulados }\end{array}$ & 4 & 29 & 10 & 57 & 100 \\
\hline
\end{tabular}

Un dato debe observarse en la Tabla 7.25: el RibAV predice la presencia de los TFV herbáceas obligadas de ribera $(\mathrm{RH})$ y arbóreas facultativas de ribera durante 4 y 10 casos, respectivamente, cuando éstas no se observaron como TFV dominantes de la ribera (lo cual se considera un fallo en la modelación). No obstante, los datos de campo recogen la presencia (aunque dominada) de RF y RH en Teculután (Tabla 7.11), lo que indica que ciertamente hay condiciones en la ribera para la presencia de esas especies. Establecer la manera de modelar TFV mixtos es una línea de trabajo necesaria a futuro para mejorar el modelo.

Tabla 7.26. Matrices de confusión "Presencia/Ausencia" readecuadas para los dos TFV observados y simulados con el modelo RibAV v1.0 (en 100 puntos). Estudio de caso en transectos del río Teculután.

\begin{tabular}{|c|c|c|c|}
\hline \multirow{2}{*}{\multicolumn{2}{|c|}{$\begin{array}{c}T F V \text { "RA", } \\
\text { Transectos Río Uyús }\end{array}$}} & \multicolumn{2}{|c|}{ SIMULADOS } \\
\hline & & PRESENTE & AUSENTE \\
\hline \multirow{2}{*}{ OBSERVADOS } & PRESENTE & 29 & 14 \\
\hline & AUSENTE & 0 & 57 \\
\hline
\end{tabular}

\begin{tabular}{|c|c|c|c|}
\hline \multirow{2}{*}{\multicolumn{2}{|c|}{$\begin{array}{c}T F V \text { "BS", } \\
\text { Transectos Río Uyús }\end{array}$}} & \multicolumn{2}{|c|}{ SIMULADOS } \\
\hline & & PRESENTE & AUSENTE \\
\hline \multirow{2}{*}{ OBSERVADOS } & PRESENTE & 57 & 0 \\
\hline & AUSENTE & 0 & 43 \\
\hline
\end{tabular}

Con base en la información de salida del RibAV en el formato de la matriz de confusión (Tabla 7.26) se generaron los índices "CCl" y "Kappa" de los TFV para medir la eficiencia del modelo para predecir la ausencia y presencia vegetal. El resultado se muestra a continuación:

Tabla 7.27. "Porcentaje de casos correctamente clasificados, CCl" e "Índice Kappa" utilizados para la validación del modelo RibAV. Estudio de caso de riberas y ladera aledaña al río Teculután.

\begin{tabular}{ccccccc}
\hline TFV & $\begin{array}{c}\text { PRESENTES } \\
\text { Simuladas }\end{array}$ & $\begin{array}{c}\text { AUSENTES } \\
\text { Simuladas }\end{array}$ & $\begin{array}{c}\text { PRESENTES } \\
\text { Observadas }\end{array}$ & $\begin{array}{c}\text { AUSENTES } \\
\text { Observadas }\end{array}$ & CCI & Kappa \\
\hline RA & 29 & 57 & 43 & 57 & $\mathbf{0 . 8 6}$ & $\mathbf{0 . 7 0}$ \\
BS & 57 & 43 & 57 & 43 & $\mathbf{1 . 0 0}$ & $\mathbf{1 . 0 0}$ \\
\hline
\end{tabular}

El índice "CCl" generado para los tipos de vegetación RA y BS del río Teculután (Tabla 7.27) posee un valor mayor que $86 \%$, reflejando que en esta fase de validación del modelo hay un aceptable ajuste estadístico de los datos. Los resultados de la simulación con el RibAV de 100 puntos de control para validar la bondad de ajuste del modelo demuestran nuevamente que el modelo es capaz de predecir con una eficiencia substancial la presencia/ausencia del tipo de vegetación de ribera RA (Kappa $=0.70)$ y con una eficiencia casi perfecta la presencia/ausencia de BS (Kappa =1.0). Estos resultados obtenidos en el tramo de río Teculután son ligeramente mejores que los obtenidos durante la calibración con datos del río Uyús, considerando los índices Kappa obtenidos y su escala de calificación (Landis y Koch, 1977).

Con esto se reafirma que el "índice de evapotranspiración, $\boldsymbol{E} \boldsymbol{T}_{\text {index }}$ " del modelo RibAV permite categorizar la ausencia/presencia de los TFV de ribera de forma satisfactoria, identificando de manera consistente el límite entre la zona de ribera y la ladera aledaña 
Así, se tienen evidencias suficientes de la validación de los parámetros de vegetación calibrados con los datos del otro tramo analizado del Valle del Motagua (Tablas 7.12 y 7.13 ).

Con la finalidad de considerar aciertos y fallos en la predicción de RibAV de los 4 TFV observados, tanto en Uyús como en Teculután, se acumularon los resultados de ausencia/presencia de las simulaciones hechas con el modelo, y se presenta a continuación la matriz de confusión resultante (Tabla 7.28) que resume las predicciones logradas.

Tabla 7.28. Índices "CCl” y "Kappa” de los resultados de calibración y validación del RibAV, con datos de riberas y laderas aledañas al río Uyús y al río Teculután.

\begin{tabular}{ccccccc}
\hline TFV & $\begin{array}{c}\text { PRESENTES } \\
\text { Simuladas }\end{array}$ & $\begin{array}{c}\text { AUSENTES } \\
\text { Simuladas }\end{array}$ & $\begin{array}{c}\text { PRESENTES } \\
\text { Observadas }\end{array}$ & $\begin{array}{c}\text { AUSENTES } \\
\text { Observadas }\end{array}$ & CCI & Kappa \\
\hline RH & 7 & 235 & 12 & 239 & $\mathbf{0 . 9 6}$ & 0.59 \\
RA & 51 & 167 & 72 & 179 & 0.87 & 0.67 \\
RF & 23 & 197 & 31 & 220 & $\mathbf{0 . 8 8}$ & 0.53 \\
BS & 130 & 114 & 136 & 115 & $\mathbf{0 . 9 7}$ & $\mathbf{0 . 9 4}$ \\
\hline & & & & $\begin{array}{c}\text { 3 TFV de } \\
\text { Ribera }\end{array}$ & $\mathbf{0 . 9 0}$ & $\mathbf{0 . 6 3}$ \\
\hline
\end{tabular}

El análisis permite descubrir algunos argumentos de los dos índices de evaluación utilizados. En primer lugar, comparando los índices CCl "acumulados" con los obtenidos para los casos particulares de Uyús y Teculután, se observa que no hay variaciones de órdenes de magnitud en el índice y se mantienen muy similares, indicando que el CCI no considera la inclusión de nuevos casos de fallo o acierto en la matriz de confusión. En segundo lugar, cuando se comparan los índices Kappa los dos TFV que cambian notoriamente con la inclusión de unos fallos de la predicción son el $\mathrm{RH}$ y el RF, por lo que a las bondades de este índice hay que añadirle que es más sensible que el CCI para evaluar nuevos casos de fallo o acierto del modelo.

\subsubsection{Análisis del índice de evapotranspiración " $E T_{\text {index" }}$ característico de los distintos TFV simulados con RibAV}

En los procesos de calibración y validación del modelo RibAV, se analizó cuantitativamente el índice " $E T_{\text {index }}$ ". A partir del análisis de los 3103 datos diarios para el río Uyús (comprendidos entre el 01/01/1995 y el 30/06/2003), se construyeron estadísticos mensuales "ET index" característicos de los 4 TFV observados (Figuras 35 y 36) durante la calibración (caso del río Uyús con $\mathrm{RH}, \mathrm{RA}, \mathrm{RF}$ y $\mathrm{BS}$ ); con la misma cantidad de datos para el río Teculután se estimaron esos estadísticos para los 2 TFV observados durante la validación del modelo (RA y BS). Todo ello se resumió en gráficos de diagrama de caja (box and whisker plot) para visualizar los valores mínimo y máximo, el menor cuartil (Q1) y el mayor (Q3), la mediana y la media del "E $\boldsymbol{T}_{\text {index", para }}$ conocer la distribución y dispersión de los datos e identificar la presencia de valores atípicos.

Para una comprensión de la variabilidad espacial (a lo largo del gradiente de humedad en la ribera) del crecimiento vegetal se presentan de manera conjunta los diagramas de los distintos TFV observados, pues con ello es posible comparar similitudes o diferencias entre los mismos, y, a su vez, analizar el comportamiento de la salida del modelo " $\boldsymbol{E} \boldsymbol{T}_{\text {index" }}$ por época del año -seca y lluviosa- y por su ubicación en la ribera -zona RA, RH, RF o BS, de acuerdo al TFV observado como dominante en campo- de los ríos Uyús (Fig. 7.34) y Teculután (Fig. 7.35).

En términos generales, se observa (Fig. 7.34 y 7.35) que los valores más elevados de "E $\boldsymbol{T}_{\text {index }}$ " se dan en las zonas más cercanas al río y que van disminuyendo conforme se avanza hacia las laderas semiáridas aledañas; esto representa numéricamente el gradiente de humedad decreciente que se ha descrito con bases empíricas en riberas de regiones semiáridas. 

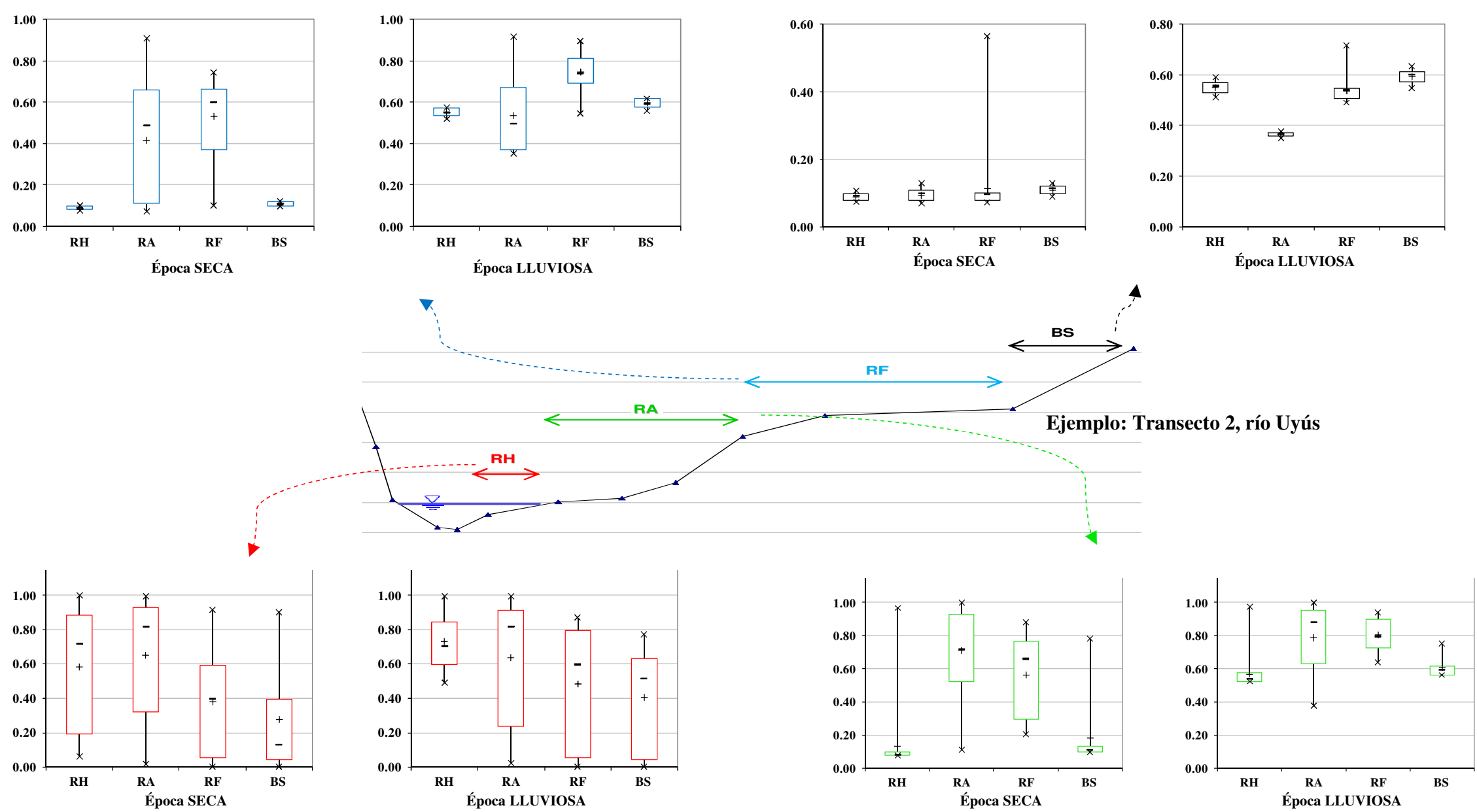

Figura 7.34. Comportamiento estacional del Índice de evapotranspiración "ET index" promedio simulado con el RibAV para los 4 TFV en los 5 Transectos del río Uyús: herbáceas obligadas de ribera $(\mathrm{RH})$, arbóreas de ribera húmeda (RA), arbóreas facultativas de ribera (RF) y bosque seco (BS). 

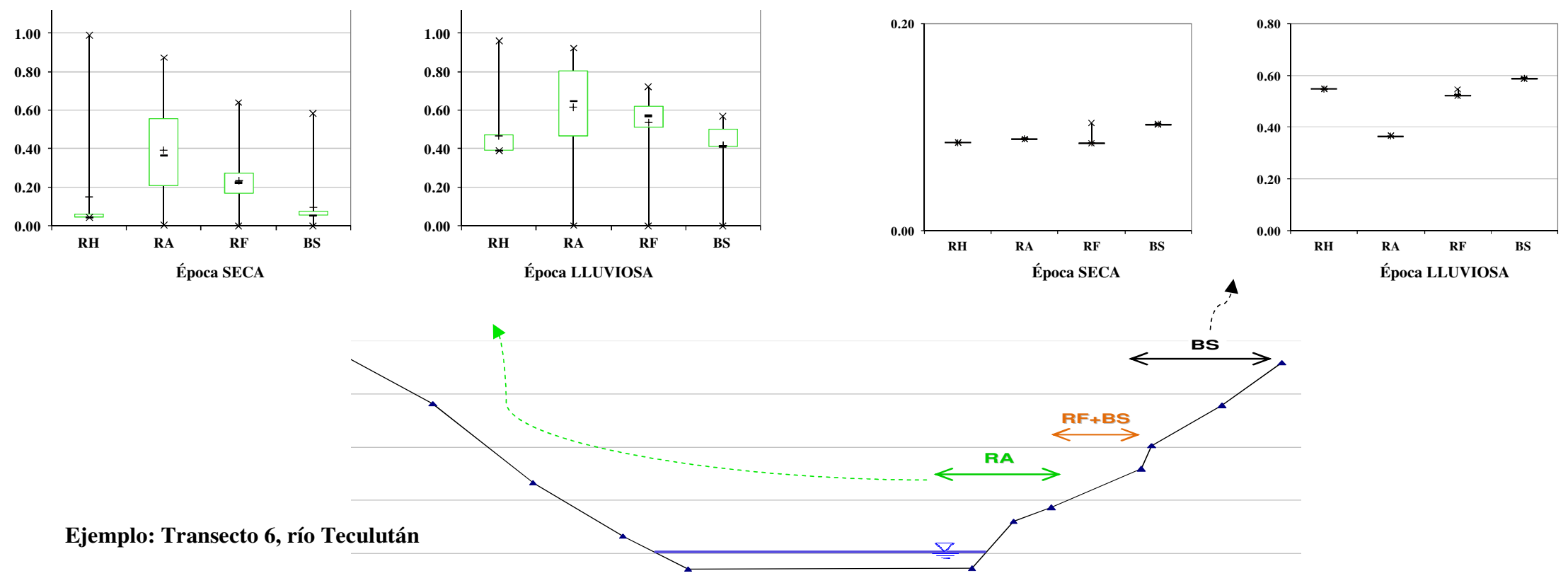

Figura 7.35. Comportamiento estacional del Índice de Evapotranspiración “ET index” promedio simulado con el RibAV para los 4 TFV en los 3 Transectos del río Teculután: herbáceas obligadas de ribera $(\mathrm{RH})$, arbóreas de ribera húmeda $(\mathrm{RA})$, arbóreas facultativas de ribera $(\mathrm{RF})$ y bosque seco $(\mathrm{BS})$. 
En el caso del río Uyús (Fig. 7.34) se puede observar para cada una de las zonas de ribera y laderas aledañas características, el comportamiento simulado de los cuatro TFV observados tanto en época seca como en la lluviosa:

- En la zona RH (color rojo), el RibAV simula los valores más elevados de "ET index" para el TFV $\mathrm{RH}$ durante la época lluviosa (>0.7); en esta zona el tipo de vegetación "competidor" más fuerte es RA con tasas de transpiración que superan los 0.6 durante todo el año (Fig. 34a). Los índices simulados para los 4 TFV son de distribución asimétrica y de amplia dispersión.

- En la zona RA (color verde) se simularon para el tipo RA las tasas de "E $\boldsymbol{T}_{\text {index }}$ " más elevadas, mayores que el resto durante todo el año y con especial notoriedad durante la época seca; solamente en la época de lluvias el TFV que compite más fuertemente, RF, posee tasas similares e incluso ligeramente superiores (ver también Fig. 34b).

- En la zona RF (color azul) el RibAV simula como claro TFV predominante al RF, cuya tasa de evapotranspiración es notoriamente mayor que el resto durante todo el año; se observa que el competidor más cercano es el tipo RA y que durante la época seca se generan tasas similares entre ambos.

- En la zona BS (color negro) se observa con mucha claridad la simetría y poca dispersión de los datos simulados, con dos claras ventajas para el TFV BS; por un lado, los índice más altos corresponden al BS durante la época lluviosa y es notoria la ausencia de crecimiento $\left(\boldsymbol{E} \boldsymbol{T}_{\text {index }}<0.1\right)$ para los cuatro TFV, lo que genera la pérdida de hojas por parte de diversas especies del bosque seco (es evidente que esta condición es característica y favorable para categorizar la presencia de dicho bosque caducifolio). Cabe señalar la presencia de algún valor atípico simulado para RF, producto de un punto de fallo en la simulación con RibAV.

Por otra parte, los resultados del río Teculután (Fig. 7.35) reafirman el comportamiento de los 4 TFV en la zona RA y BS descrito para el caso del río Uyús, pero con una menor dispersión de los

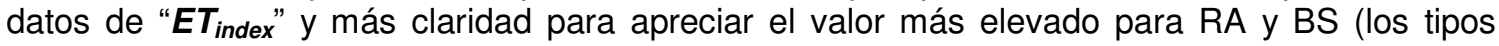
dominantes en las zonas respectivas).

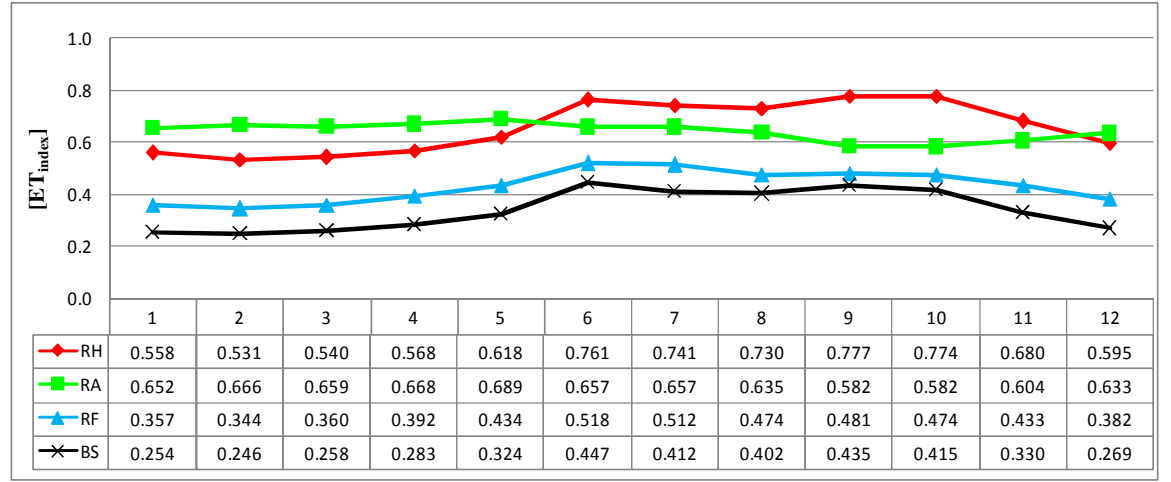

a. Comportamiento en zona RH

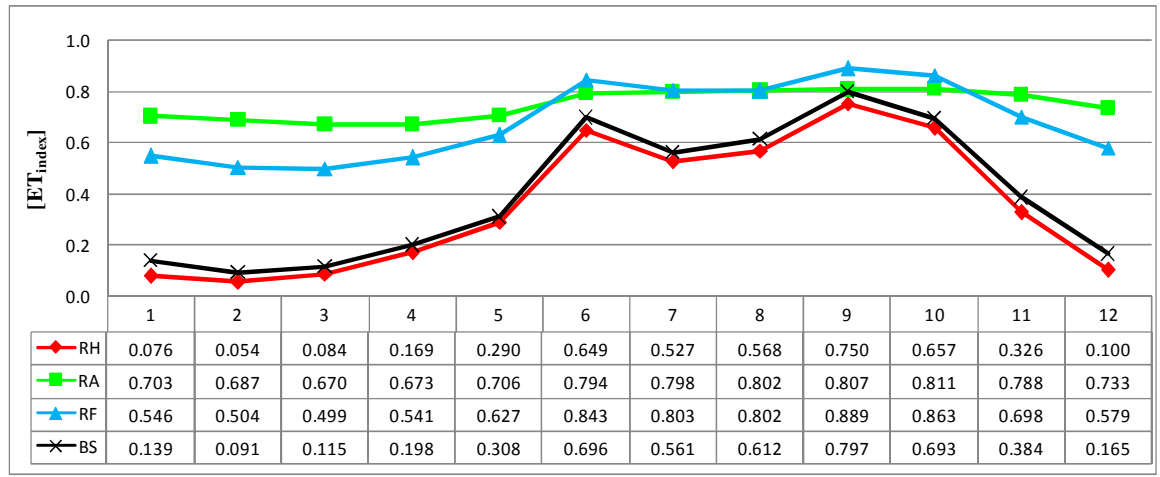

b. Comportamiento en zona RA

Figura 7.36. Comportamiento mensual del Índice de evapotranspiración " $E T_{\text {index" promedio simulado con }}$ el RibAV para los 4 TFV en los 5 Transectos del río Uyús: a. Simulaciones en Zona de Herbáceas obligadas de ribera (RH); b. Simulaciones en Zona de Arbóreas de ribera húmeda (RA). 
La zona más cercana al río y que recibe mayor influencia de sus niveles diarios es la zona de herbáceas obligadas de ribera, $\mathrm{RH}$. Se ha obtenido la variabilidad mensual de los " $\boldsymbol{E} \boldsymbol{T}_{\text {index }}$ " de $\mathrm{RH}$ y RA para describir y analizar el comportamiento del crecimiento vegetal dadas las condiciones de cercanía y mayor influencia del régimen del río. En la Figura 7.36a, zona $\mathrm{RH}$, se observa que durante la época seca se dan condiciones favorables para la evapotranspiración de las plantas más freatofitas de la ribera (RA y $\mathrm{RH}$ ), lo que se simula con valores promedio de "E $\boldsymbol{T}_{\text {index" }}$ de aproximadamente 0.6. Esto se explica a partir de los factores de transpiración de la zona saturada " $\boldsymbol{F}_{\text {sat }}$ ", cuyos valores más altos corresponden precisamente a $\mathrm{RH}(0.5)$ y a RA (0.72).

Durante la época seca es posible notar (Fig. 7.36a) la relativa debilidad de "predicción ausencia/presencia $\mathrm{RH}$ " que posee el RibAV (Kappa $\mathrm{RH}=0.72$; se simula bien la ausencia, pero solamente se simulan bien 7 de 12 presencias del tipo $\mathrm{RH}$ ); no obstante, durante la época lluviosa, cuando es mayor el efecto de los niveles de río, se simulan condiciones mucho más favorables para las plantas adaptadas a la saturación (controlado por el parámetro de extinción por saturación " $\boldsymbol{Z}_{\text {sat }}$ "), que son las del tipo $\mathrm{RH}$, con los mayores " $E \boldsymbol{T}_{\text {index }}$ " $(>0.73)$.

En el caso del tipo RA (Fig. 7.36b) se observa la preponderancia de los valores "E $\boldsymbol{T}_{\text {index" }}$ correspondientes a RA, salvo excepciones en los meses más lluviosos, en donde el tipo RF posee una tasa más elevada. Esto se puede explicar entendiendo los factores de transpiración de la zona no saturada " $F_{\text {est }}$ " de los TFV, que para el caso de RA es 0.42 y para RF es 0.73 , es decir, se simula una mejor adaptación de los árboles facultativos de ribera para aprovechar el agua de lluvia del almacenamiento estático.

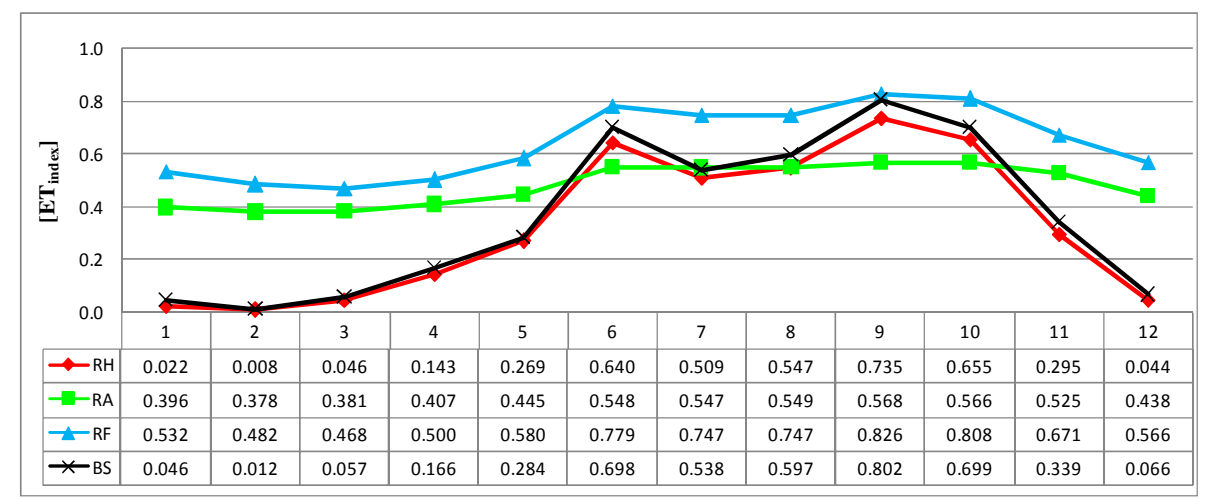

a. Comportamiento en zona $\mathbf{R F}$

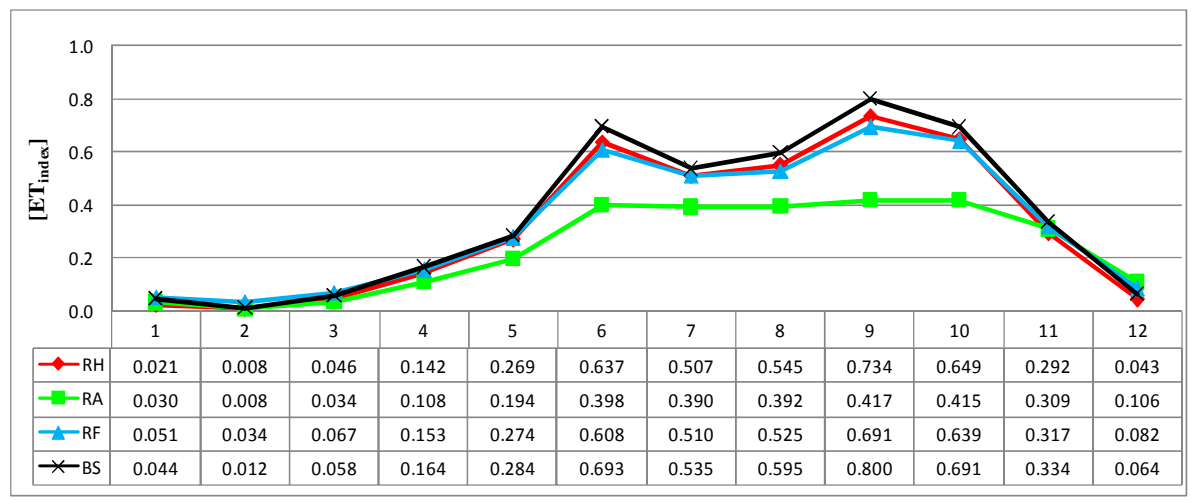

b. Comportamiento en zona BS

Figura 7.37. Comportamiento mensual del Índice de evapotranspiración " $E T_{\text {index }}$ " promedio simulado con el RibAV para los 4 TFV en los 5 Transectos del río Uyús: a. Simulaciones en Zona de Arbóreas Facultativas de transición de ribera (RF); b. Simulaciones en Zona de Bosque Seco

Analizando los fallos de la predicción del tipo RA (Fig. 7.36b) se observa que el competidor más fuerte es justamente el tipo RF, pero que a pesar de ello, el RibAV predice con una eficiencia substancial $(K a p p a=0.62)$ la ausencia/presencia de los árboles obligados de ribera $(R A)$. 
Estos dos tipos de vegetación poseen una distribución prácticamente traslapada entre sí cuyos límites son un tanto difíciles de discernir tanto mediante modelación como con base en observaciones de campo (Celis (2008).

También se han presentado resultados para RF y BS. En la Fig. 7.37a se observa que las tasas simuladas de "E $\boldsymbol{T}_{\text {index }}$ " más altas corresponden al TFV RF (que es el observado de campo); dicha tendencia se mantiene a lo largo del año, por lo cual el RibAV posee un potencial de predicción de eficiencia substancial (Kappa $=0.60)$ de la ausencia/presencia de los árboles facultativos de ribera $(\mathrm{RF})$. Respecto a los valores de los índices de evapotranspiración en la zona del bosque seco (Fig. 7.37b) se puede observar que los TFV poseen un comportamiento muy similar y con tasas bastante parecidas, a excepción de la especie más freatofita (RA) que se simuló con eficiencia media para aprovechar el agua de la zona no saturada $\left(\boldsymbol{F}_{\text {est }}=0.42\right)$.

Estas observaciones se explican a partir de la la humedad del suelo de la zona BS, cuyo único aporte proviene del agua de lluvia, que no muestra variación en el nivel local (indistintamente del TFV simulado). El espíritu de la simulación y parámetros calibrados refleja que será el TFV más eficiente para aprovechar el agua de lluvia quien posea los " $\boldsymbol{E} \boldsymbol{T}_{\text {index }}$ " más elevados; en este caso, es precisamente el BS (TFV observado de campo) quien posee parámetros más adaptados a esas condiciones de disponibilidad hídrica $\left(\boldsymbol{F}_{\text {est }}=0.91\right.$; punto de marchitez permanente típico de condiciones semiáridas de $3000 \mathrm{kPa}$ ).

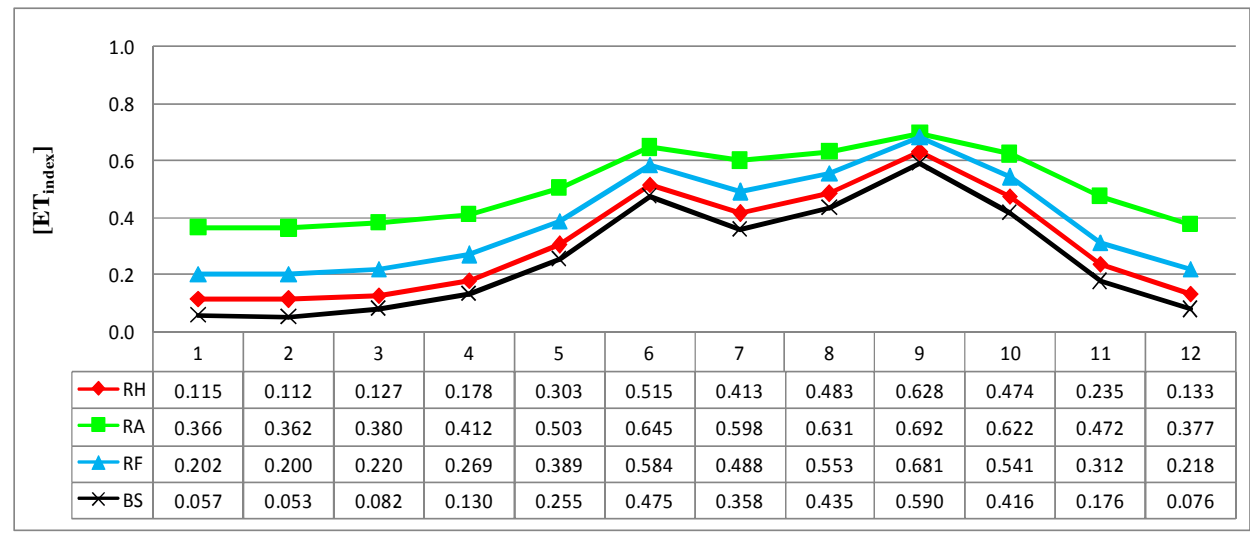

a. Comportamiento en zona RA

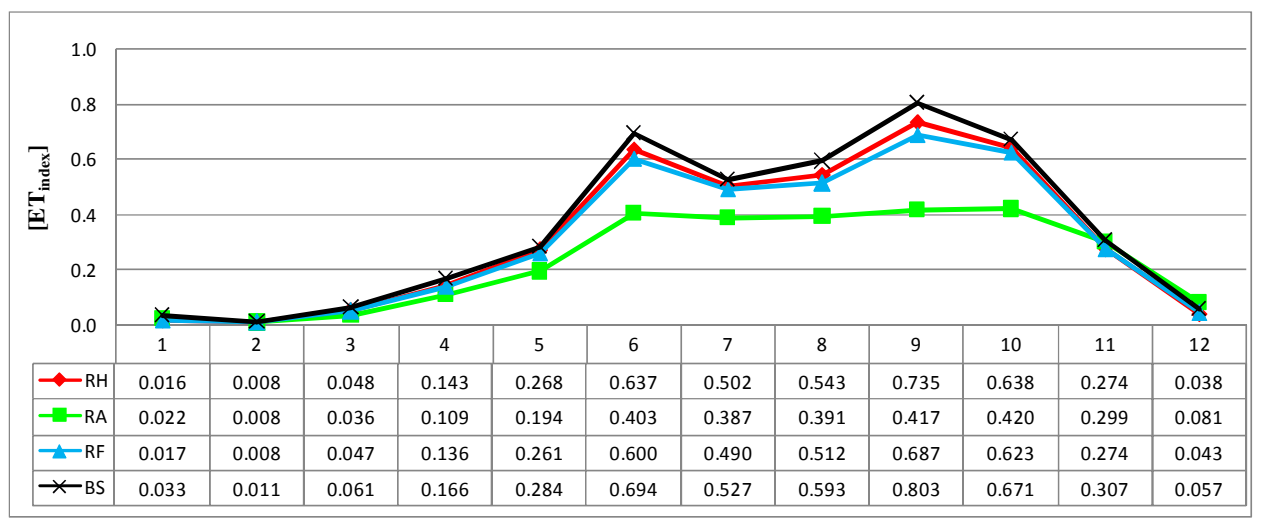

b. Comportamiento en zona BS

Figura 7.38. Comportamiento mensual del Índice de evapotranspiración " $E T_{\text {index }}$ " promedio simulado con el $R i b A V$ para los 4 TFV en los 3 Transectos del río Teculután: a. Simulaciones en Zona de Arbóreas Obligadas de ribera (RA); b. Simulaciones en Zona de Bosque Seco 
Con base en el índice de eficiencia Kappa se demostró la validación de los parámetros calibrados con RibAV y que es factible su aplicación en riberas del Valle del Motagua. Sin embargo, para demostrar la solidez numérica del modelo RibAV también es posible observar una validación con base en las tasas de "ET $\boldsymbol{T}_{\text {index }}$ " predichas para las zonas RA y BS de riberas y laderas aledañas del río Teculután (Fig. 7.38). En el caso del TFV "RA" (Fig. 7.38a) se observa que las predicciones del tipo dominante RA mejoran en la aplicación de los parámetros para el río Teculután; esto sustenta también el incremento del valor del índice de eficiencia Kappa, de la predicción con Uyús (Kappa RA $=0.62$ ) a la realizada en Teculután (Kappa RA $=0.7$ ).

Para el caso del bosque seco (Fig. 7.38b) se valida la observación hecha para Uyús respecto a la similitud de las tasas de evapotranspiración considerando únicamente la variabilidad de los parámetros de vegetación a la climatología local. Cabe destacar, sin embargo, el bajísimo valor del " $E T_{\text {index }}$ " durante los meses más secos del año: en promedio los tres TFV de ribera están más de dos meses (enero a marzo) con tasas de evapotranspiración inferiores a 0.03 , lo cual es evidentemente inferior a las tasas características dentro de la ribera; esta situación demarca ya la escasa aptitud de la zona para el crecimiento de especies adaptadas a fuentes de agua disponible durante todo el año, y recalca el papel de adaptación del bosque seco caducifolio típico de esos meses.

\subsubsection{Breve descripción de la relevancia del ascenso hidráulico radicular para el balance hídrico en la ribera mediante modelación con RibAV:}

En este apartado, mediante un análisis preliminar de los datos, se esboza el comportamiento del ascenso hidráulico radicular " $H \boldsymbol{L} \boldsymbol{w}$ " en la lógica del modelo RibAV, para matizar su relevancia en el contexto del papel que juegan las raíces para el control del ciclo hidrológico de los ecosistemas, tema declarado de interés por la comunidad científica de ecólogos vegetales y ecofisiólogos (Canadell et al, 1996; Castellanos et al, 1991; Dawson, T., 2007; Kellman y Roulet, 1990; Schenk y Jackson, 2002b; Schulze et al, 1996). Durante la calibración del RibAV, y mediante el análisis gráfico de sus variables a escala diaria, fue posible observar que el ascenso hidráulico radicular modelado era especialmente relevante para los TFV arbóreas de ribera húmeda (RA) y arbóreas facultativas de ribera (RF), especialmente en época seca (Fig. 7.39).

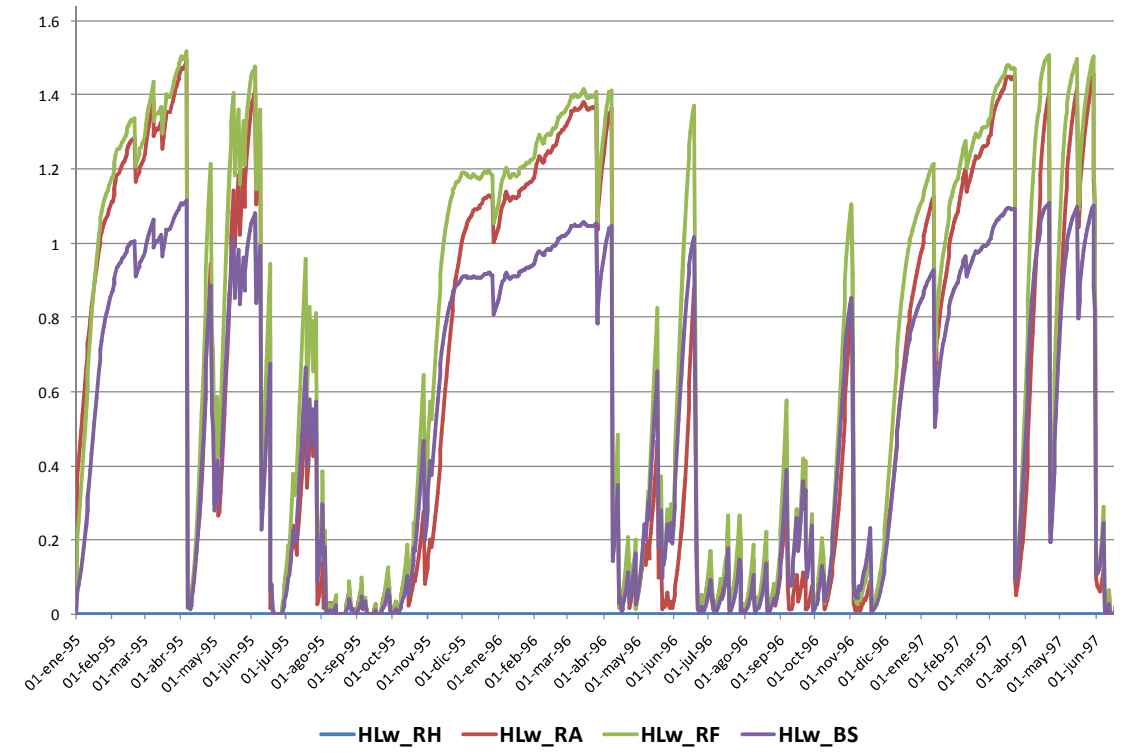

Figura 7.39. Ascenso hidráulico radicular " $H L w$ " diario de los $4 T F V(R H, R A, R F$ y BS) del río Uyús, simulado con el RibAV v.1.0 para el período del 01/01/1995 al 15/06/1997.

Con esa observación en mente, y toda vez finalizada la calibración y validación del modelo, se procedió a calcular el valor promedio diario del ascenso hidráulico radicular simulado en un período de estudio de 2922 días. Los resultados se muestran a continuación (Tabla 7.29). 
Tabla 7.29. Ascenso hidráulico radicular "HLw" diario [mm/día] simulado con el modelo RibAV v.1.0 para 4TFV del río Uyús, durante el período del 01/04/1995 al 31/03/2003.

\begin{tabular}{|c|c|c|c|c|c|c|c|c|c|c|c|c|c|c|c|c|}
\hline \multirow[b]{2}{*}{ Época } & \multicolumn{4}{|c|}{ Zona RH } & \multicolumn{4}{|c|}{ Zona RA } & \multicolumn{4}{|c|}{ Zona RF } & \multicolumn{4}{|c|}{ Zona BS } \\
\hline & RH & $\mathbf{R A}$ & RF & BS & $\mathbf{R H}$ & $\mathbf{R A}$ & RF & BS & RH & $\mathbf{R A}$ & $\mathbf{R F}$ & BS & RH & RA & RF & BS \\
\hline SECA & 0.00 & 0.06 & 0.00 & 0.00 & 0.20 & 1.22 & 1.05 & 0.00 & 0.05 & 1.36 & 1.77 & 0.11 & 0.00 & 0.14 & 0.00 & 0.00 \\
\hline LLUVIOSA & 0.00 & 0.03 & 0.00 & 0.00 & 0.06 & 0.44 & 0.33 & 0.00 & 0.05 & 0.68 & 0.82 & 0.06 & 0.01 & 0.08 & 0.00 & 0.00 \\
\hline TOTAL & 0.00 & 0.04 & 0.00 & 0.00 & 0.13 & 0.83 & 0.69 & 0.00 & 0.05 & 1.02 & 1.29 & 0.08 & 0.00 & 0.11 & 0.00 & 0.00 \\
\hline
\end{tabular}

De acuerdo con Caldwell et al (1998) el ascenso hidráulico radicular no está restringido exclusivamente a las regiones áridas y semiáridas ni a un determinado tipo de vegetación o especie. En la Tabla 7.29 se observa que, salvo en las condiciones extremas de saturación del suelo (zona $\mathrm{RH}$ ), en el resto de zonas se da el proceso y que RibAV lo simula para los cuatro TFV; en el otro extremo, en la región de mayor alejamiento del área de influencia del río (zona BS) este movimiento de agua es escaso.

Uno de los beneficios de este movimiento de agua es facilitar las tasas de transpiración en condiciones de alta demanda evaporativa (Caldwell y Richards, 1989). En este sentido es de resaltar que el " $H \boldsymbol{L} \boldsymbol{w}$ " simulado para la época seca es mayor que el correspondiente a la época de lluvias, lo que se explica en función de la demanda evaporativa en mención y de los potenciales mátricos del suelo característicos de períodos con ausencia de lluvia: en total, las tasas de ascenso hidráulico radicular simuladas con RibAV están entre 0.83 y $1.02 \mathrm{~mm} /$ día para RA y 0.69 y $1.29 \mathrm{~mm} /$ día para RF, durante el período de simulación de 2922 días. Estas cantidades se encuentran dentro del rango preliminar que citan algunos autores (Hultine et al, 2003; Ryel et al, 2002), aunque aún se están perfeccionando los métodos de estimación de este movimiento de agua.

\subsubsection{Comparación de resultados del "ET index" de RibAV con otras predicciones de ausencia/presencia de TFV basadas en índices de estrés hídrico, conectividad radicular con el nivel freático y diferencia de cota respecto al thalweg del río}

En este capítulo se comparará la fortaleza del modelo RibAV y su índice " $E T_{\text {index" }}$ para predecir ausencia/presencia de TFV de ribera y laderas aledañas de climas semiáridos, con otras predicciones obtenidas mediante tres líneas de trabajo recurrentemente utilizadas para estudiar la distribución vegetal: el estrés hídrico, la conectividad radicular de las plantas con la zona saturada y la distancia vertical de las zonas respecto al thalweg. Las primeras dos aproximaciones se basan en resultados obtenidos con RibAV y la tercera consiste en un abordaje basado en datos medidos en campo (cotas y presencia/ausencia); se presenta una comparación de estos resultados con los obtenidos con RibAV y se discuten fortalezas y debilidades de tales alternativas de modelación.

\section{a. Índice de Estrés Hídrico Dinámico del RibAV:}

Para analizar el estrés hídrico dinámico se preparó de manera externa al código del modelo RibAV una adaptación de las ecuaciones de Porporato et al (2001), ecuaciones (6.35), (6.36) y (6.37), para calcular el índice de Estrés Hídrico Dinámico " $W_{D s t}$ " con base en parámetros de vegetación y los contenidos variables de humedad del suelo obtenidos con el RibAV.

Utilizando el programa del RibAV es posible calcular las rachas de estrés hídrico para los distintos TFV, a partir de la estimación del número de días por debajo del umbral de humedad óptima para el crecimiento vegetal (definido por el parámetro de vegetación " $\boldsymbol{P}_{\text {opt }}$ " para cada TFV); a su vez, con base en los parámetros calibrados y variables definidos en la modelación RibAV del río Uyús, se obtuvieron los índices de transpiración " $E T_{\text {index }}$ " correspondientes a cada día de la racha de estrés hídrico. 
Para este análisis se utilizaron los datos de los ríos Uyús y Teculután correspondientes a los años hidrológicos comprendidos entre el 01/04/1995 y el 31/03/2003 (período de 2922 días). A partir de la simulación diaria con RibAV y la programación ad hoc para establecer las rachas de estrés hídrico, se pudo generar la información siguiente:

- $\quad$ Longitud Total de racha en estrés hídrico durante el período de simulación "Twstr tot" [día].

- Longitud Promedio de la racha en estrés hídrico durante el período de simulación "Twstr media" [día].

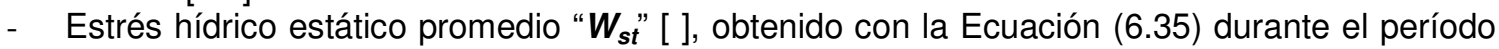
de simulación.

- Número de períodos de estrés hídrico durante la época de crecimiento [ ].

- Índice de transpiración promedio "ETxmean wst" [mm] en períodos de estrés hídrico.

- Estrés hídrico dinámico "W $\boldsymbol{W}_{\boldsymbol{D s t}}$ " [ ] obtenido con la Ecuación (6.36) durante el período de simulación.

En esta revisión de índices se descubrió que la ecuación (6.36) es bastante sensible al parámetro " $k$ " que se define como un índice de resistencia vegetal al estrés hídrico y que ante ausencia de información se suele asumir un valor $k=0.5$ para todas las especies (Porporato et al, 2001). Los resultados obtenidos sin la calibración de dicho parámetro " $k$ " fueron bastante pobres para todos los TFV (índices Kappa inferiores a 0.29 , es decir una débil eficiencia del modelo según la clasificación de Landis y Koch, 1977).

Con base en la revisión de los aspectos alrededor del planteamiento de este parámetro y procurando dar relevancia a su sentido físico, se procedió a su calibración por prueba y error, con la finalidad de obtener las mejores predicciones posibles (mayores índices Kappa).

Tabla 7.30. Parámetro “ $k$ ”, índice de resistencia vegetal al estrés hídrico (Porporato et al, 2001), calibrado para las condiciones de las riberas y laderas del río Uyús y Teculután: comparación con el parámetro " $F_{\text {est }}$, factor de transpiración de la zona no saturada del modelo RibAV v1.0.

\begin{tabular}{|c|c|c|c|}
\hline \multirow{2}{*}{$\begin{array}{l}\text { Código } \\
\text { del } \\
\text { TFV }\end{array}$} & \multirow{2}{*}{ Acrónimo y Descripción del TFV } & $\begin{array}{l}\text { Factor de } \\
\text { transpiración de zona } \\
\text { no saturada }\end{array}$ & $\begin{array}{l}\text { Índice de resistencia } \\
\text { vegetal al estrés } \\
\text { hídrico }^{\text {cal }}\end{array}$ \\
\hline & & $\begin{array}{c}\mathbf{F}_{\text {est }} \\
\text { [ ] }\end{array}$ & $\begin{array}{c}\boldsymbol{k} \\
{[\text { ] }}\end{array}$ \\
\hline 1 & $\mathrm{RH}$, herbácea obligada de ribera & 0.80 & 0.79 \\
\hline 2 & RA, arbórea obligada de ribera & 0.42 & 0.46 \\
\hline 3 & $\mathrm{RF}$, arbórea facultativa de ribera & 0.73 & 0.73 \\
\hline 4 & BS, bosque seco & $0.91^{a}$ & 0.87 \\
\hline \multicolumn{4}{|c|}{$\begin{array}{c}\text { Fuente: }{ }^{a} \text { Castellanos et al (1991); }{ }^{\text {call }} \text { valor calibrado a partir de Kellman y Roulet } \\
\text { (1990) y Schulze et al (1996); }{ }^{\text {cal2 }} \text { valor calibrado a partir de Porporato et al (2001) y } \\
\text { Laio et al (2001a) }\end{array}$} \\
\hline
\end{tabular}

Como se puede observar (Tabla 7.30), se encontró una equivalencia muy cercana entre el parámetro " $k$ " de la teoría del estrés hídrico y el factor de transpiración de la zona no saturada " $F_{\text {est }}$ " utilizada en el modelo RibAV como parte de una estrategia de diferenciación entre especies freatofitas obligadas y facultativas y no freatofitas (Butler Jr. et al, 2007; Cooper et al, 2006).

Lo anterior puede explicarse con base en el conocimiento de la visión de estrés hídrico y lo aprendido mediante la modelación con RibAV. La teoría señalada del estrés hídrico tiene una visión muy fuerte de plantas "no freatofitas", es decir, aquellas cuya fuente de agua es mayormente la del almacenamiento estático, y por ello el tema de los potenciales mátricos del suelo, el agua de lluvia, entre otros, son factores de especial interés. 
En este contexto, una manera de establecer el parámetro " $k$ " podría basarse en las estrategias de la vegetación para escapar a dicho estrés hídrico del almacenamiento estático; en el caso de RibAV, esta estrategia está dada por un aprovechamiento tanto del agua de la zona no saturada como de la saturada, y las estrategias de ascenso hidráulico radicular, considerando la relativa cercanía de niveles freáticos provenientes de la interacción con el río. En otras palabras, es posible dimensionar el parámetro " $k$ " a partir del entendimiento de la dependencia de las plantas al agua de la zona no saturada, que en RibAV se define como el parámetro " $\boldsymbol{F}_{\text {est }}$ ".

Vale la pena por tanto, explorar más esta equivalencia, y recomendar a los autores con la visión de estrés hídrico dinámico las consideraciones hechas aquí respecto al parámetro " $F_{\text {est }}$ " y la manera de entenderlo dentro de la teoría de la distribución vertical del sistema radicular.

Así, con base en el parámetro " $k$ " calibrado y a partir del resto de información obtenida con RibAV, fue posible establecer los valores de estrés hídrico dinámico "W $W_{D s t}$ y su categoría ausencia/presencia respectiva (Tabla 7.31).

Tabla 7.31. Categoría ausencia/presencia (columnas 7 a 10) obtenida a partir del Índice de Estrés Hídrico Dinámico " $W_{D s t}$ " (columnas 1 a 6) y datos obtenidos con el Modelo RibAV v 1.0: muestra de 28 puntos de simulación en zonas de ribera y bosque seco del río Uyús.

\begin{tabular}{|c|c|c|c|c|c|c|c|c|c|}
\hline \multirow{2}{*}{$\begin{array}{l}\text { Punto } \\
\text { simulado }\end{array}$} & \multirow{2}{*}{ TFV } & \multicolumn{4}{|c|}{$\mathrm{W}_{\text {Dst }}$ de los TFV } & \multicolumn{4}{|c|}{$\begin{array}{l}\text { Categoría Presencia (1) / } \\
\text { Ausencia (0) de los TFV }\end{array}$} \\
\hline & & $\mathbf{W}_{\text {Dst__ }} \mathbf{R H}$ & $\mathbf{W}_{\text {Dst__ }} \mathbf{R A}$ & $\mathbf{W}_{\text {Dst_-RF }}$ & $\mathbf{W}_{\text {Dst_BS }}$ & RH & RA & $\mathbf{R F}$ & BS \\
\hline 1_1_RH & $\overline{\mathrm{RH}}$ & 0.000 & 0.000 & 0.000 & 0.000 & 0 & 0 & 0 & 0 \\
\hline 1_2_RA & RA & 0.560 & 0.570 & 0.560 & 0.534 & 0 & 0 & 0 & 1 \\
\hline 1_2_RA2 & RA & 0.602 & 0.578 & 0.595 & 0.579 & 0 & 1 & 0 & 0 \\
\hline $1 \_3 \_B S$ & BS & 0.590 & 0.577 & 0.589 & 0.568 & 0 & 0 & 0 & 1 \\
\hline 1_3_BS2 & BS & 0.590 & 0.577 & 0.589 & 0.568 & 0 & 0 & 0 & 1 \\
\hline 1_3_BS3 & BS & 0.590 & 0.577 & 0.589 & 0.568 & 0 & 0 & 0 & 1 \\
\hline 1_3_BS19 & BS & 0.590 & 0.577 & 0.589 & 0.568 & 0 & 0 & 0 & 1 \\
\hline 1 _3_BS20 & $\mathrm{BS}$ & 0.590 & 0.577 & 0.589 & 0.568 & 0 & 0 & 0 & 1 \\
\hline 1_4_RA & RA & 0.559 & 0.464 & 0.542 & 0.546 & 0 & 1 & 0 & 0 \\
\hline 1_4_RA2 & RA & 0.559 & 0.464 & 0.542 & 0.546 & 0 & 1 & 0 & 0 \\
\hline 1_4_RA5 & RA & 0.559 & 0.555 & 0.543 & 0.545 & 0 & 0 & 1 & 0 \\
\hline 1_5_RF & $\mathrm{RF}$ & 0.559 & 0.555 & 0.543 & 0.545 & 0 & 0 & 1 & 0 \\
\hline 1_5_RF3 & $\mathrm{RF}$ & 0.559 & 0.555 & 0.554 & 0.545 & 0 & 0 & 0 & 1 \\
\hline 1_6_BS & BS & 0.557 & 0.552 & 0.553 & 0.545 & 0 & 0 & 0 & 1 \\
\hline 1_6_BS2 & BS & 0.557 & 0.552 & 0.553 & 0.545 & 0 & 0 & 0 & 1 \\
\hline 1_6_BS5 & BS & 0.557 & 0.552 & 0.553 & 0.545 & 0 & 0 & 0 & 1 \\
\hline $2 \_2 \_\mathrm{RH}$ & RH & 0.624 & 0.635 & 0.625 & 0.627 & 1 & 0 & 0 & 0 \\
\hline 2_2_RH2 & $\mathrm{RH}$ & 0.665 & 0.654 & 0.662 & 0.666 & 0 & 1 & 0 & 0 \\
\hline $2 \_3 \_$RA & RA & 0.590 & 0.000 & 0.538 & 0.567 & 0 & 1 & 0 & 0 \\
\hline 2_3_RA2 & RA & 0.590 & 0.000 & 0.538 & 0.569 & 0 & 1 & 0 & 0 \\
\hline 2_3_RA3 & RA & 0.590 & 0.000 & 0.538 & 0.569 & 0 & 1 & 0 & 0 \\
\hline 2_3_RA8 & RA & 0.590 & 0.000 & 0.538 & 0.569 & 0 & 1 & 0 & 0 \\
\hline 2_3_RA9 & RA & 0.590 & 0.528 & 0.538 & 0.569 & 0 & 1 & 0 & 0 \\
\hline $2 \_4 \_R F$ & $\mathrm{RF}$ & 0.590 & 0.575 & 0.538 & 0.569 & 0 & 0 & 1 & 0 \\
\hline 2_4_RF2 & $\mathrm{RF}$ & 0.590 & 0.576 & 0.538 & 0.569 & 0 & 0 & 1 & 0 \\
\hline 2_5_BS & BS & 0.603 & 0.584 & 0.599 & 0.581 & 0 & 0 & 0 & 1 \\
\hline 2_5_BS9 & BS & 0.603 & 0.584 & 0.599 & 0.581 & 0 & 0 & 0 & 1 \\
\hline $3 \_1 \_\mathrm{RH}$ & $\mathrm{RH}$ & 0.000 & 0.000 & 0.000 & 0.000 & 0 & 0 & 0 & 0 \\
\hline
\end{tabular}

De la misma manera en que se hizo para el análisis de la calibración y validación del RibAV, se procedió a la construcción de las matrices de confusión para el cálculo del número de acuerdos entre predicciones del modelo y datos observados en campo (celdas de color gris). 
Tabla 7.32. Matriz de confusión "Presencia/Ausencia de TFV" observada y simulada con el Índice de Estrés Hídrico Dinámico " $W_{D s t}$ " (en 151 puntos) con RibAV

\begin{tabular}{|c|c|c|c|c|c|c|}
\hline & \multirow[t]{2}{*}{$\mathbf{W}_{\text {Dst }}$} & \multicolumn{4}{|c|}{ SIMULADOS } & \multirow{2}{*}{$\begin{array}{c}\text { Total } \\
\text { Observados }\end{array}$} \\
\hline & & RH & RA & $\mathbf{R F}$ & BS & \\
\hline \multirow{5}{*}{ 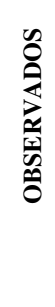 } & RH & 1 & 3 & 0 & 2 & $6(6)$ \\
\hline & $\mathbf{R A}$ & 0 & 26 & 2 & 1 & 29 \\
\hline & $\mathbf{R F}$ & 0 & 17 & 13 & 1 & 31 \\
\hline & BS & 0 & 0 & 6 & 73 & 79 \\
\hline & $\begin{array}{c}\text { Total } \\
\text { Simulados }\end{array}$ & 1 & 46 & 21 & 77 & 145 \\
\hline
\end{tabular}

Como puede observarse (Tabla 7.32) del total de 151 puntos simulados solamente se obtuvo predicción para 145, es decir, existen seis puntos (identificados entre paréntesis en la celda superior derecha) que no fue posible predecir con el índice " $W_{D s t}$ ": por ejemplo, véanse la primera y última líneas de la Tabla 7.31, en donde se observa que los 4 TFV poseen valores " $W_{D s t}$ " iguales a cero, debido a que no hay un solo día en el período de estudio en que la simulación detecte déficit hídrico en las zonas $\mathrm{RH}$ en mención.

Dichos fallos, corresponden a zonas de ribera muy cercanas al río $(\mathrm{RH})$, en donde la saturación constante del suelo genera otro tipo de estrés y no necesariamente el de ausencia del recurso; esto evidencia una limitación fuerte de aplicar la teoría del "estrés hídrico dinámico" de manera generalizada en la ribera de los ríos (más adelante se aporta otra evidencia).

El resto de resultados obtenidos y su análisis mediante el índice de eficiencia Kappa ${ }^{8}$ se presenta a continuación (Tabla 7.33).

Tabla 7.33. "Índice Kappa" de los resultados de zonificación de los TFV de ribera y ladera aledaña a partir del Índice de Estrés Hídrico Dinámico " $W_{D s t "}$ " Estudio de caso río Uyús.

\begin{tabular}{cccccc}
\hline TFV & $\begin{array}{c}\text { PRESENTES } \\
\text { Simuladas }\end{array}$ & $\begin{array}{c}\text { AUSENTES } \\
\text { Simuladas }\end{array}$ & $\begin{array}{c}\text { PRESENTES } \\
\text { Observadas }\end{array}$ & $\begin{array}{c}\text { AUSENTES } \\
\text { Observadas }\end{array}$ & Kappa \\
\hline RH & 1 & 139 & 6 & 139 & $\mathbf{0 . 2 8}$ \\
RA & 26 & 96 & 29 & 116 & $\mathbf{0 . 5 9}$ \\
RF & 13 & 106 & 31 & 114 & $\mathbf{0 . 4 0}$ \\
BS & 73 & 62 & 79 & 66 & $\mathbf{0 . 8 6}$ \\
\hline & & & & 3 TFV de & $\mathbf{0 . 5 2}$ \\
\hline
\end{tabular}

Los índices Kappa obtenidos (Tabla 7.33) y la magnitud del estrés hídrico dinámico para las diversas zonas de ribera, demuestran que la zonificación basada en el modelo de estrés hídrico dinámico permite predecir con una eficiencia débil la ausencia/presencia del TFV RH (Kappa = 0.28), tal y como se había descrito previamente. Por otra parte, se observa que este indicador posee una eficiencia moderada para predecir la presencia/ausencia RA (Kappa $=0.59$ ) y RF $(\mathrm{Kappa}=0.4)$, y una eficiencia casi perfecta para predecir la presencia/ausencia de BS (Kappa = 0.89 ) en las secciones transversales del río Uyús.

El resultado permite observar que la fortaleza del índice se va perdiendo en la medida en que se trabaja con zonas de ribera más influenciadas por la zona saturada y la influencia del régimen hídrico del río; sin embargo, en el análisis gráfico (Fig. 7.40) se observa que no es tan fácil de apreciar la diferencia numérica del " $W_{D s t}$ " de los distintos TFV (comparar con Fig. 7.39).

\footnotetext{
${ }^{8}$ Se consideró suficiente hacer el análisis con este índice, dadas sus fortalezas de aplicación para el caso de las riberas de Uyús y Teculután con RibAV
} 

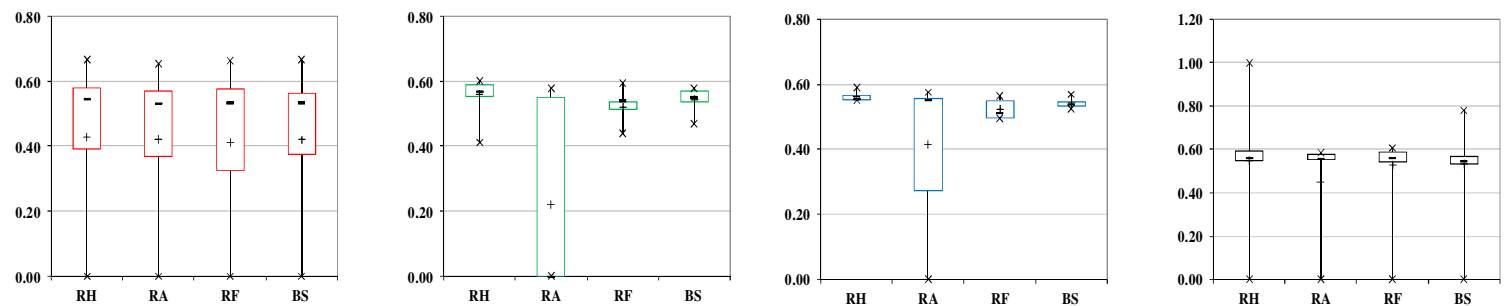

Figura 7.40. Índices de Estrés Hídrico Dinámico " $W_{D s t}$ ” obtenidos para los 4 TFV en zonas de herbáceas obligadas de ribera (RH, en rojo), arbóreas de ribera húmeda (RA, en verde), arbóreas facultativas de ribera (RF, en azul) y bosque seco (BS, en negro) del río Uyús (período del 01/04/1995 al 31/03/2003).

Para la validación de los resultados obtenidos con el índice de estrés hídrico dinámico " $W_{D s}$ ", se trabajó con el estudio de caso del río Teculután. Los resultados se muestran a continuación:

Tabla 7.34. "Índice Kappa" de los resultados de zonificación de los TFV de ribera y ladera aledaña a partir del Índice de Estrés Hídrico Dinámico “W $W_{D s t}$ ". Estudio de caso río Teculután.

\begin{tabular}{cccccc}
\hline TFV & $\begin{array}{c}\text { PRESENTES } \\
\text { Simuladas }\end{array}$ & $\begin{array}{c}\text { AUSENTES } \\
\text { Simuladas }\end{array}$ & $\begin{array}{c}\text { PRESENTES } \\
\text { Observadas }\end{array}$ & $\begin{array}{c}\text { AUSENTES } \\
\text { Observadas }\end{array}$ & Kappa \\
\hline RA & 37 & 57 & 39 & 57 & $\mathbf{0 . 9 6}$ \\
BS & 57 & 38 & 57 & 39 & $\mathbf{0 . 9 8}$ \\
\hline
\end{tabular}

De manera similar al resultado obtenido durante la validación del RibAV, se observa que el índice de estrés hídrico dinámico permite con una eficiencia casi perfecta para predecir la presencia/ausencia de RA (Kappa $=0.96)$ y BS (Kappa $=0.89)$, lo que también comprueba fortaleza de esta teoría para zonificar dos de los tipos de vegetación observados.

Por otra parte, los resultados de predicción ausencia/presencia mostraron índices de eficiencia Kappa por debajo del 0.52, razón para considerarlos de poca validez para estos análisis. También se hizo el ejercicio de predecir la distribución vegetal con base en el "ET index" de las rachas de estrés hídrico detectadas; los resultados se muestran a continuación (Tabla 7.35).

Tabla 7.35. "Índice Kappa” de los resultados de zonificación de los TFV de ribera y ladera aledaña a partir del Î́ndice de Estrés Hídrico Dinámico “ $W_{D s t}$ ". Estudio de caso río Teculután.

\begin{tabular}{cccccc}
\hline TFV & $\begin{array}{c}\text { PRESENTES } \\
\text { Simuladas }\end{array}$ & $\begin{array}{c}\text { AUSENTES } \\
\text { Simuladas }\end{array}$ & $\begin{array}{c}\text { PRESENTES } \\
\text { Observadas }\end{array}$ & $\begin{array}{c}\text { AUSENTES } \\
\text { Observadas }\end{array}$ & Kappa \\
\hline RH & 0 & 138 & 6 & 139 & $-\mathbf{0 . 0 1}$ \\
RA & 7 & 110 & 29 & 116 & $\mathbf{0 . 2 4}$ \\
RF & 28 & 91 & 31 & 114 & $\mathbf{0 . 5 7}$ \\
BS & 74 & 60 & 79 & 66 & $\mathbf{0 . 8 5}$ \\
\hline & & & & $\begin{array}{c}\text { 3 TFV de } \\
\text { Ribera }\end{array}$ & $\mathbf{0 . 4 5}$ \\
\hline
\end{tabular}

Con base en el comportamiento de estos indicadores de evapotranspiración " $E T_{\text {index }}$ " del RibAV durante las rachas de estrés hídrico, cabe destacar la validez de esta visión para predecir los TFV de zonas más dependientes del agua del almacenamiento estático (BS y RF); sin embargo, nuevamente se observa que la teoría se debilita conforme se acerca hacia zonas con mayor saturación de los suelos. 


\section{b. Índice de Evapotranspiración en períodos de conectividad radicular con la zona saturada "ET conect":}

Otra cara de la moneda para la predicción de la distribución vegetal en las riberas de los ríos la aportan los estudios que resaltan la visión de las plantas freatofitas (Butler Jr. et al, 2007; Cooper et al, 2006) y de la evapotranspiración real con visión de aguas subterráneas (Horton y Clark, 2000; Lamontagne et al, 2005; Lautz, 2007; Mac Nish et al, 2000; Maddock III y Baird, 2003; Schilling y Kiniry, 2007; Stromberg et al, 1996) y el ascenso hidráulico radicular (Burgess et al, 1998; Caldwell y Richards, 1989; Dawson, 1993; Hultine et al, 2003; Ryel et al, 2002).

Para este análisis se utilizaron los mismos datos que para el análisis de estrés hídrico dinámico. Se pudo generar la información siguiente:

- Longitud Total de racha de conectividad radicular con la zona saturada durante el período de simulación "Tconect tot" [día].

- Longitud Promedio de la racha de conectividad radicular durante el período de simulación "Tconect media" [día].

- Número de períodos de conectividad radicular con la zona saturada durante la época de crecimiento [ ].

- Índice de Evapotranspiración promedio [mm] del RibAV durante los períodos de conectividad radicular con la zona saturada "ET conect", Ecuación (6.40).

Los resultados de esta propuesta muestran una eficiencia entre débil y moderada para la predicción de la ausencia/presencia de los TFV, como se muestra a continuación (Tabla 7.36 y 7.37).

Tabla 7.36. "Índice Kappa" de los resultados de zonificación de los TFV de ribera y ladera aledaña a partir del Índice de Conectividad radicular con la zona saturada " $E T_{\text {conect" }}$. Estudio de caso río Uyús.

\begin{tabular}{cccccc}
\hline TFV & $\begin{array}{c}\text { PRESENTES } \\
\text { Simuladas }\end{array}$ & $\begin{array}{c}\text { AUSENTES } \\
\text { Simuladas }\end{array}$ & $\begin{array}{c}\text { PRESENTES } \\
\text { Observadas }\end{array}$ & $\begin{array}{c}\text { AUSENTES } \\
\text { Observadas }\end{array}$ & Kappa \\
\hline RH & 5 & 130 & 12 & 138 & $\mathbf{0 . 3 5}$ \\
RA & 8 & 111 & 28 & 122 & $\mathbf{0 . 2 2}$ \\
RF & 22 & 84 & 31 & 119 & $\mathbf{0 . 3 2}$ \\
BS & 50 & 60 & 79 & 71 & $\mathbf{0 . 4 7}$ \\
\hline & & & & 3 TFV de & $\mathbf{0 . 3 2}$ \\
\hline
\end{tabular}

Tabla 7.37. "Índice Kappa" de los resultados de zonificación de los TFV de ribera y ladera aledaña a partir del Índice de Conectividad radicular con la zona saturada " $E T_{\text {conect }}$ ". Estudio de caso río Teculután.

\begin{tabular}{cccccc}
\hline TFV & $\begin{array}{c}\text { PRESENTES } \\
\text { Simuladas }\end{array}$ & $\begin{array}{c}\text { AUSENTES } \\
\text { Simuladas }\end{array}$ & $\begin{array}{c}\text { PRESENTES } \\
\text { Observadas }\end{array}$ & $\begin{array}{c}\text { AUSENTES } \\
\text { Observadas }\end{array}$ & Kappa \\
\hline RA & 19 & 56 & 43 & 57 & $\mathbf{0 . 4 5}$ \\
BS & 37 & 36 & 57 & 43 & $\mathbf{0 . 4 7}$ \\
\hline
\end{tabular}

En el análisis de las rachas de conectividad radicular, no se observó que ésta fuese n criterio de discriminación muy fuerte de los distintos RFV observados; tampoco el valor del " $E \boldsymbol{T}_{\text {index" }}$ " durante dichas rachas aporta demasiadas fortalezas para el análisis, demostrando eficiencias entre débiles y moderadas para los ríos Uyús (Kappa < 0.47) y Teculután (Kappa < 0.45). Estos resultados preliminares no deben demeritar la fortaleza de la visión de especies freatofitas ni de las múltiples comprobaciones de la evapotranspiración a partir del abastecimiento de agua desde la zona saturada. 


\section{c. Índice de la Diferencia de Cota respecto al thalweg del río "I $\mathrm{I}_{\text {cota": }}$}

Una de las variables que se ha utilizado para clasificar y abordar los temas de la distribución vegetal de las riberas con base estadística, es la distancia horizontal y/o la diferencia de altitud (cota) entre la especie o TFV observado y el thalweg del río.

Por ello se calculó el índice de diferencia de cota "Icot" a partir de 4 modelos lineales sencillos para predecir la cota de las zonas TFV usando datos observados en campo (elevación del thalweg y del suelo). Se construyeron ecuaciones lineales a partir de dos parámetros calibrados con datos observados en el río Uyús, mediante la función Solver de Excel@ y reducción del error expresado en diferencias al cuadrado; las ecuaciones obtenidas son las siguientes:

$Y_{R H}=$ CotaThalwe $g * 1.0025+0.20757$

$Y_{R A}=$ CotaThalwe $g * 1.0222-3.15203$

$Y_{R F}=$ CotaThalwe $g * 1.02832-1.89172$

$Y_{B S}=$ CotaThalwg $* 1.0312+2.51094$

Con base en estos modelos se calculó la cota esperada de cada TFV $\left(Y_{R H}, Y_{R A}, Y_{R F}, Y_{B S}\right)$ y se estableció la diferencia con la cota observada de cada TFV. Para la categorización de ausencia presencia, se seleccionó aquella predicción de TFV que reportara la menor diferencia al cuadrado entre cota observada y cota simulada con los modelos lineales. Con ello, se construyó la matriz de confusión respectiva a partir de 152 puntos observados en el río Uyús (Tabla 7.38).

Tabla 7.38. Matriz de confusión "Presencia/Ausencia de TFV" observada y simulada con el Índice de Cota "Icota" (en 152 puntos) con base en parámetros biofísicos y variables climáticas de transectos del río Uyús.

\begin{tabular}{|c|c|c|c|c|c|c|}
\hline & \multirow[t]{2}{*}{$\mathbf{I}_{\text {cota }}$} & \multicolumn{4}{|c|}{ SIMULADOS } & \multirow{2}{*}{$\begin{array}{c}\text { Total } \\
\text { Observados }\end{array}$} \\
\hline & & $\mathbf{R H}$ & RA & RF & BS & \\
\hline \multirow{5}{*}{ 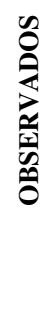 } & RH & 9 & 2 & 0 & 0 & 11 \\
\hline & RA & 7 & 18 & 4 & 0 & 29 \\
\hline & $\mathbf{R F}$ & 0 & 4 & 27 & 0 & 31 \\
\hline & BS & 0 & 0 & 12 & 69 & 81 \\
\hline & $\begin{array}{c}\text { Total } \\
\text { Simulados }\end{array}$ & 16 & 24 & 43 & 69 & 152 \\
\hline
\end{tabular}

Considerando que los modelos lineales sencillos se construyeron con datos observados del río Uyús, hay un buen ajuste de la predicción, con una eficiencia entre substancial y casi perfecta de la presencia/ausencia de los TFV (sensu Landis y Koch, 1977; Tabla 7.39).

Tabla 7.39. "Índice Kappa” de los resultados de zonificación de los TFV de ribera y ladera aledaña a partir del Índice de Cota "I cota". Estudio de caso río Uyús.

\begin{tabular}{cccccc}
\hline TFV & $\begin{array}{c}\text { PRESENTES } \\
\text { Simuladas }\end{array}$ & $\begin{array}{c}\text { AUSENTES } \\
\text { Simuladas }\end{array}$ & $\begin{array}{c}\text { PRESENTES } \\
\text { Observadas }\end{array}$ & $\begin{array}{c}\text { AUSENTES } \\
\text { Observadas }\end{array}$ & Kappa \\
\hline RH & 9 & 134 & 11 & 141 & $\mathbf{0 . 6 4}$ \\
RA & 18 & 117 & 29 & 123 & $\mathbf{0 . 6 1}$ \\
RF & 27 & 105 & 31 & 121 & $\mathbf{0 . 6 5}$ \\
BS & 69 & 71 & 81 & 71 & $\mathbf{0 . 8 4}$ \\
\hline & & & & 3 TFV de & $\mathbf{0 . 6 4}$ \\
\hline
\end{tabular}


Para comprobar la validez de estos modelos se usaron datos del río Teculután, comprobándose que no son estables en la predicción de TFV de ribera y ladera aledaña, y que posee una eficiencia débil para predecir el TFV RA $($ Kappa $=0)$ y una eficiencia moderada para el BS $($ Kappa $=0.48)$.

Esto demuestra que el parámetro de cota y el índice de diferencia de altitud del TFV respecto al thalweg tienen fortaleza de aplicación local (cuando el modelo se construye con datos observados de la localidad), pero que posee limitaciones fuertes para regionalizar los parámetros, demostrando con estos resultados preliminares la relativa debilidad de esta aproximación.

\subsubsection{Síntesis comparativa de los índices de Predicción Presencia/Ausencia analizados:}

A manera de síntesis, se resumen los índices de eficiencia de los distintos modelos de predicción de ausencia/presencia de vegetación que se compararon con los resultados de la predicción con el modelo RibAV (Tabla 7.41). Como se observa, a partir del "índice de Evapotranspiración, "ET $T_{\text {index }}$ " del modelo RibAV se obtienen eficiencias de predicción de la ausencia/presencia de los TFV de ribera de forma satisfactoria y consistente, tanto en la calibración (caso Río Uyús) como en la validación (caso Río Teculután), con eficiencias de predicción entre substancial y casi perfecta de acuerdo con la calificación de Landis y Koch (1977) del índice de Kappa.

El resto de modelos poseen índices de Eficiencia de Predicción "Kappa" inferiores o como máximo iguales a los obtenidos con el modelo RibAV (Tabla 7.40), con los matices particulares de predicción que se señaló para cada indicador en su momento oportuno.

Tabla 7.40. "Índice Kappa” de los resultados de zonificación de los TFV de ribera y ladera aledaña obtenidos a partir de 4 índices de predicción ausencia/presencia que se compararon con el índice de evapotranspiración " $E T_{\text {index }}$ " del modelo RibAV.

\begin{tabular}{|c|c|c|c|c|c|c|c|c|c|c|}
\hline \multirow[b]{2}{*}{ TFV } & \multicolumn{5}{|c|}{$\begin{array}{l}\text { Índices de Kappa obtenidos mediante calibración de modelos: } \\
\text { estudio de caso Río Uyús }\end{array}$} & \multicolumn{5}{|c|}{$\begin{array}{c}\text { Índices de Kappa obtenidos mediante validación de modelos: } \\
\text { estudio de caso Río Teculután }\end{array}$} \\
\hline & $\begin{array}{c}E T_{\text {index }} \\
\text { (modelo } \\
\text { RibAV) } \\
\text { [ ] }\end{array}$ & $\begin{array}{c}W_{D s t} \\
\text { (Estrés } \\
\text { hídrico } \\
\text { dinámico) } \\
\text { [ ] }\end{array}$ & $\begin{array}{c}I_{\text {cota }} \\
\text { (Diferencia } \\
\text { de cota al } \\
\text { thalweg) } \\
\text { [ ] }\end{array}$ & $\begin{array}{c}E T_{W d s t} \\
\left(E T_{i n d e x} \text { en }\right. \\
\text { racha de } \\
\text { estrés hídrico) } \\
\text { [ ] }\end{array}$ & $\begin{array}{c}E T x_{\text {conec }} \\
\left(E T_{\text {index }}\right. \\
\text { durante } \\
\text { conectividad } \\
\text { radicular) [ ] }\end{array}$ & $\begin{array}{c}E T_{\text {index }} \\
\text { (modelo } \\
\text { RibAV) } \\
\text { [ ] }\end{array}$ & $\begin{array}{c}W_{D s t} \\
\text { (Estrés } \\
\text { hídrico } \\
\text { dinámico) } \\
\text { [ ] }\end{array}$ & $\begin{array}{c}I_{\text {cota }} \\
\text { (Diferencia } \\
\text { de cota al } \\
\text { thalweg) } \\
\text { [ ] }\end{array}$ & $\begin{array}{c}E \boldsymbol{T}_{W d s t} \\
\left(E T_{\text {index }} \text { en }\right. \\
\text { racha de estrés } \\
\text { hídrico) } \\
\text { [ ] }\end{array}$ & $\begin{array}{c}E T x_{\text {conect }} \\
\quad\left(E T_{\text {index }}\right. \\
\text { durante } \\
\text { conectividad } \\
\text { radicular) [ ] }\end{array}$ \\
\hline RH & 0.72 & 0.28 & 0.64 & -0.01 & 0.45 & - & - & - & - & - \\
\hline RA & 0.62 & 0.59 & 0.61 & 0.24 & 0.28 & 0.70 & 0.96 & 0.00 & 0.87 & 0.17 \\
\hline $\mathrm{RF}$ & 0.60 & 0.40 & 0.65 & 0.57 & 0.33 & - & - & - & - & - \\
\hline BS & 0.91 & 0.86 & 0.84 & 0.85 & 0.47 & 1.00 & 0.98 & 0.48 & 1.00 & 0.45 \\
\hline $\begin{array}{l}3 \mathrm{TFV} \text { de } \\
\text { ribera }\end{array}$ & 0.90 & 0.52 & 0.64 & 0.45 & 0.36 & - & - & - & - & - \\
\hline
\end{tabular}

La mayor solidez de las predicciones TFV se obtuvo con el índice de evapotranspiración " $E \boldsymbol{T}_{\text {index }}$ " del modelo RibAV considerando los resultados de la validación y las mejoras notables en los índices de eficiencia de predicción (Kappa). El siguiente modelo más estable y válido a nivel regional es el del índice de estrés hídrico dinámico " $W_{D s}$ ", seguido de los índices obtenidos a partir de la diferencia de cota al thalweg y la conectividad radicular con la zona saturada (Tabla 7.40). Se han presentado argumentos que refuerzan la hipótesis planteada en otros estudios, respecto a que el estrés hídrico mínimo no es un indicador suficiente para definir las condiciones óptimas de la vegetación por sí solo y que se le debe analizar no sólo desde la visión del escape al estrés sino considerando el uso del agua (Franz et al, 2010) y otros indicadores de la transpiración vegetal (Fernández-Illescas y Rodríguez-Iturbe, 2003; Porporato et al, 2001; Quevedo y Francés, 2008). 


\section{CONCLUSIONES}

Se ha desarrollado el modelo ecohidrológico de ribera de ríos "RibAV", que predice con eficiencia la zonificación de los TFV en ecosistemas de ribera de regiones semiáridas, puesto que incluye fortalezas provenientes del conocimiento de múltiples disciplinas que consideran el crecimiento vegetal desde la perspectiva del agua disponible del almacenamiento estático y de la zona saturada.

El modelo está integrado por un submodelo hidráulico para predecir el nivel del río con base en la curva de gasto, un submodelo hidrológico que genera niveles freáticos a partir de una hipótesis sencilla dependiente del nivel del río y que integra la variabilidad climática local, un submodelo de suelo y vegetación que genera la variabilidad de contenidos de humedad del suelo a partir del papel del sistema radicular de las plantas, en su aprovechamiento del agua disponible del almacenamiento estático y de aguas subterráneas accesibles. La versión RibAV 1.0 se encuentra programada en Microsoft Visual Studio $2008 \AA$, lo que facilita su interacción con el usuario y el manejo eficiente de los datos numéricos de entrada y salida del modelo.

En el desarrollo de RibAV se generó una metodología de campo, laboratorio y gabinete para la caracterización biofísica de las zonas de ribera, y se presentó como uno de los resultados de la tesis doctoral, enfocado en la obtención de parámetros característicos de suelo y vegetación.

La aplicación del modelo para su calibración y validación en la zona más árida de Guatemala y Centroamérica (el Valle del Motagua) ha permitido establecer el comportamiento de los distintos tipos de vegetación de ribera y realizar la zonificación correspondiente, con índices de eficiencia aceptables, que permiten asegurar que es capaz de definir con claridad el límite entre la zona de ribera y la ladera del bosque seco aledaño.

En la evaluación de la eficiencia de predicción de ausencia/presencia del modelo, se utilizó uno de los índices de mayor reconocimiento en la comunidad de científicos de la ecología vegetal: el índice Kappa. Este índice ha demostrado fortalezas para evaluar modelos de distribución vegetal, y de acuerdo a su escala de calificación, se diagnosticaron eficiencias substanciales y casi perfectas para la predicción de la distribución vegetal en la ribera a través del RibAV. Con este proceder, el modelo se suma a los recientes esfuerzos por evaluar la bondad de las predicciones sobre distribución vegetal "presencia/ausencia" con base en el indicador Kappa.

Se propuso y se comprobó la fortaleza del Índice de Evapotranspiración "E$T_{\text {index }}$ " del modelo para predecir la distribución vegetal; con base en los resultados comparados con otros índices de predicción de ausencia / presencia, se demostró que dicho índice del RibAV es muy eficiente y el que mejor logra predecir los tipos de vegetación observados, tanto en calibración como en validación. El segundo índice más notable para la predicción de los TFV observados es el de estrés hídrico dinámico " $W_{D s t}$ ", seguido de los índices obtenidos a partir de la diferencia de cota al thalweg y la conectividad radicular con la zona saturada.

Durante esta evaluación del modelo, se han presentado argumentos que refuerzan la hipótesis planteada en otros estudios, respecto a que el estrés hídrico mínimo no es un indicador suficiente para definir las condiciones óptimas de la vegetación por sí solo y que se le debe analizar tanto desde la visión del escape al estrés como considerando el uso del agua y otros indicadores de la transpiración vegetal.

Existen por tanto, puntos de encuentro entre la conceptualización del RibAV y la teoría de las rachas de estrés hídrico dinámico para predecir la distribución de las especies; no obstante, el RibAV abunda en el marco conceptual, abordando tanto el estrés por falta de agua como por saturación del suelo, y dando relevancia a distintos mecanismos de adaptación vegetal (mayormente del sistema radicular) para facilitar la disponibilidad de agua (tanto del almacenamiento estático como de la zona saturada). 
Pese a que los resultados del índice de conectividad radicular con la zona saturada no muestran una predicción satisfactoria, la fortaleza de la visión de las fuentes de agua subterránea para las plantas de ribera no está en discusión, considerando tanto la enorme cantidad de referencias que sustentan dicha visión como los resultados obtenidos con RibAV.

El uso potencial del " $E T_{\text {index }}$ " y de las ecuaciones de evapotranspiración del RibAV permitirán analizar el crecimiento vegetal en la ribera y el aprovechamiento de las distintas fuentes de agua de manera conjunta y evitar las limitaciones de analizar la evapotranspiración de la zona saturada y del almacenamiento estático por separado; de esta manera, el modelo provee de una herramienta que diversos estudios han señalado como necesaria.

Esta conceptualización y aportes al conocimiento desde el RibAV, también ha sido posible gracias a las observaciones de campo acerca de la riqueza de la dinámica biótica y abiótica del ecosistema de ribera estudiado. El modelo conceptual del RibAV también se acopla a las múltiples observaciones del gradiente de humedad en zonas de ribera de condiciones semiáridas y del límite entre la zona de ribera y las laderas aledañas con menor disponibilidad de agua.

Finalmente, se ha demostrado una vez más la importancia del sistema de raíces para el balance hidrológico en las riberas, y se han encontrado indicios de que el ascenso hidráulico radicular puede jugar un papel importante en el control de las tasas de transpiración. 


\section{FUTURAS LÍNEAS DE INVESTIGACIÓN}

Desde el punto de vista de los parámetros del modelo y sus variables internas, es preciso señalar algunas acciones futuras que deberán tratarse:

- Respecto a parámetros de vegetación, en futuras versiones de RibAV se deberá analizar la equivalencia y/o complemento de los factores de transpiración y fuente de agua $\left(\boldsymbol{F}_{\text {est }}\right.$ y $\left.\boldsymbol{F}_{\text {sat }}\right)$ con otros parámetros del sistema radicular: su distribución en el perfil, la discretización del sistema radicular y sus respectivas profundidades (Castellanos et al, 1991; Kellman y Roulet, 1990; Ryel et al, 2002; Schenk y Jackson, 2002a, 2002b, 2005; Schulze et al, 1996). Abundar en el conocimiento de los parámetros de profundidad radicular característicos de los distintos TFV es una línea de investigación de la comunidad científica internacional que deberá seguirse atentamente en el mejoramiento del modelo.

- Es importante que se afinen los parámetros relacionados con la fuente de agua para la vegetación, en función de su preferencia por el agua del nivel freático o del almacenamiento estático; para ello, será necesario actualizar el banco de datos de especies vegetales estudiadas, teniendo especial interés en los avances de identificación de especies freatofitas obligadas o facultativas.

- Considerando los avances muy recientes de modelación del ascenso hidráulico radicular, es fundamental para la mejor predicción de los contenidos de agua del suelo, que se les tengan presentes y se analicen órdenes de magnitud y tasas características del citado movimiento de agua reportadas con base en mediciones de campo.

- Por otra parte, es necesario continuar el análisis para encontrar una metodología de clasificación de tipos funcionales de vegetación de ribera que sea tanto práctica para optimizar los recursos disponibles para el trabajo de campo como basada en criterios autoecológicos que enriquezcan la zonificación de la ribera.

En cuanto a los temas de la predicción de la ausencia/presencia o zonificación de la vegetación es importante citar las siguientes acciones concretas de trabajo futuro:

- Será necesario abundar en los criterios de modelación de la interacción del nivel del río con el nivel freático, sobre todo considerando que la presente versión del RibAV se especializa en ríos que mantienen los niveles freáticos someros de la ribera. Esta línea de investigación deberá ir de la mano del análisis para incorporar nuevos movimientos de agua en la ribera, como pueden ser el flujo subsuperficial y la escorrentía.

- El siguiente paso es calibrar el modelo con base en tasas de evapotranspiración real medidas en campo. Sin embargo, como han citado diversos autores, este es un dato poco común a escala de corredor de ribera, y más aún a escala transversal y para cada tipo funcional de vegetación observado. El seguimiento del avance en la predicción de estas tasas por parte de los distintos grupos de especialistas citados en este documento, es un tema obligado para las posibles mejoras.

- Durante el análisis del comportamiento simulado para los distintos tipos de vegetación se

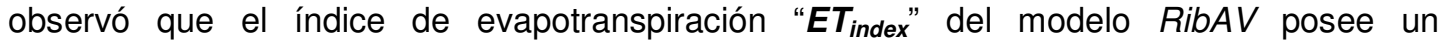
comportamiento estacional, es decir, las evidencias sugieren que el índice predice mejor el tipo RH y RF durante la época lluviosa y el tipo RA durante la época seca, por lo que será necesario explorar más a fondo esta tendencia, y estudiar las variables internas del modelo para una posible predicción de ausencia/presencia basada en "E $\boldsymbol{T}_{\text {index }}$ " de época seca y lluviosa. Asimismo, es de interés encontrar tasas de "E$T_{\text {index }}$ " provenientes del aprovechamiento de agua de la zona saturada y del almacenamiento estático, sobre todo porque el RibAV ya está generando esos valores internamente, y algunas observaciones preliminares sugieren que este es un buen camino para el fortalecimiento del índice propuesto. 
- Por otra parte, pese a que se ha demostrado que el índice de evapotranspiración del RibAV es más sólido para la predicción de la vegetación que el índice de estrés hídrico dinámico, es importante notar que dicha teoría se hace fuerte en la medida en que la transpiración depende menos de la zona saturada y por tanto es de mucho interés explorar las mejoras al modelo para predicciones de abatimiento del nivel freático o derivaciones fuertes del recurso hídrico del río.

- Dado que con RibAV es posible determinar las condiciones abióticas del medio saturado y no saturado (nivel del río, nivel freático, entre otros) características de las distintas zonas de ribera, se tiene el potencial de complementar otros modelos que enfatizan procesos originados con las inundaciones y perturbaciones mecánicas de creación de nuevos hábitat. Para ello, se puede explorar el campo de conocimiento de la hidráulica bidimensional o tridimensional del flujo de materia y energía en las riberas; es recomendable seguir la base conceptual de los trabajos de Fathi-Maghadam y Kouwen (1997), Glenz et al (2003), Järvelä (2002 y 2004), Kouwen (2003), Kummu (2002), Mason (2003), Micheli et al (2004), Simon y Collison (2002). Para esta interacción con la dimensión longitudinal será necesario adecuar los procesos fluviales y ecológicos de mayor interés a la escala espacial y temporal más conveniente.

- Finalmente, el tema de las posibles aplicaciones del modelo RibAV para predecir ausencia/presencia de tipos funcionales de vegetación a partir de cambios en potenciales escenarios de uso del agua a escala local y en el ámbito de la cuenca hidrográfica tributaria, es una de las asignaturas pendientes, que ya se está preparando para próximas versiones del modelo. Profundizar en estas aplicaciones generando múltiples escenarios de cambio climático o de intensidad de uso de los recursos hídricos es, sin duda, parte obligada de las líneas de investigación futuras con el modelo RibAV. 


\section{REFERENCIAS BIBLIOGRÁFICAS}

Abernethy, B.; Rutherfurd, I. 1999. Guidelines for stabilising streambanks with riparian vegetation. Technical report 99/10. Cooperative Research Centre for Catchment Hydrology. 30 p.

Acker, S.A.; Gregory, S.V.; Lienkaemper, G.; McKee, W.A.; Swanson, F.J.; Miller, S.D. 2003. Composition, complexity, and tree mortality in riparian forests in the central Western Cascades of Oregon. Forest Ecology and Management 173: 292-308

Aguiar, F.C.; Ferreira, M.T.; Moreira, I.S.; Albuquerque, A. 2000. Riparian types on a Mediterranean basin. Aspects of Applied Biology 58: 1-12.

Allen, R.G.; Jensen, M.E.; Wright, J.L.; Burman, R.D. 1989. Operational estimates of evapotranspiration. Agronomy Journal, 81: 650-662.

Allen, R.G.; Pereira, L.S.; Raes, D.; Smith, M. 1998. Crop evapotranspiration: guidelines for computing crop water requirements. FAO Irrigation and Drainage Paper No. 56. 300 p.

Altier, L.S.; Lowrance, R.; Williams, R.G.; Inamdar, S.P.; Bosch, D.D.; Sheridan, J.M.; Hubbard, R.K.; Thomas, D.L. 2002. Riparian Ecosystem Management Model: simulator for ecological processes in riparian zones. USDA, Conservation Research Report 46. 216 p.

Andersen, H.E. 2003. Hydrology, nutrient processes and vegetation in floodplain wetlands. PhD thesis. National Environmental Research Institute, Denmark. 36 p.

Arcement, G.J.; Schneider, V.R. 1989. Guide for selecting Manning's roughness coefficients for natural channels and flood plains: metric version. USGS Water-supply Paper 2339. USA. s.n.

Azami, K.; Suzuki, H.; Toki, S. 2004. Changes in riparian vegetation communities below a large dam in a monsoonal region: Futase dam, Japan. River Res. Applic. 20: 549-563.

Baird, K.J.; Dragoo, C.A.; Maddock III, T. 2004. Pre-Rip-ET: a preprocessor for RIP-ET. Department of Hydrology and Water Resources, University of Arizona.

Baird, K.J.; Maddock III, T. 2005. Simulating riparian evapotranspiration: a new methodology and application for groundwater models. Journal of Hydrology 312: 176-190.

Baker, W.L.; Walford, G.M. 1995. Multiple Stable States and Models of Riparian Vegetation Succession on the Animas River, Colorado. Annals of the Association of American Geographers 85(2), pp. 320-338.

Barnett, D.T.; Stohlgren, T.J. 2003. A nested-intensity design for surveying plant diversity. Biodiversity and Conservation (12): 255-278.

Bayley, P. 1995. Understanding large river-floodplain ecosystems. BioScience 45(3):154. In: FIRSWG. 1998. Stream Corridor Restoration.

Bendix, J. 1994. Scale, direction, and pattern in riparian vegetation-environment relationships. Annals of the Association of American Geographers, 84(4), 1994, 652-665 p.

Bendix, J.; Hupp, C.R. 2000. Hydrological and geomorphological impacts on riparian plant communities. Hydrol. Process. 14, 2977-2990 p.

Bennett, S.J. 2004. Effects of emergent riparian vegetation on spatially averaged and turbulent flow within an experimental channel. American Geophysical Union, 10.1029/008WSA03. pp. 29-41. 
Bent, G.C. 2001. Effects of forest-management activities on runoff components and ground-water recharge to Quabbin Reservoir, central Massachussets. Forest Ecology and Management 143: 115129.

Bernez, I.; Daniel, H.; Haury, J.; Ferreira, M.T. 2004. Combined effects of environmental factors and regulation on macrophyte vegetation along three rivers in western France. River Res. Applic. 20: 4359.

Biondini, M.; Kandus, P. 2006. Transition matrix analysis of land-cover change in the accretion area of the lower delta of the Paraná River (Argentina) reveals two succession pathways. Wetlands 26(4):981991.

Bolòs, O. 1989. Bioclimatología y geografía botánica. Mem R Acad Ciencias y Artes Barcelona 867: 423-444. In:

Bonham, C.D. 1989. Measurements for terrestrial vegetation. John Wiley \& Sons, U.S.A. 338 p.

Bonilla, C.; Cancino, J. 2001. Estimación del contenido de humedad del suelo mediante el empleo de funciones de pedotransferencia. Agric. Téc., Vol 61, No. 3, 326-338 p.

Braun-Blanquet, J. 1979. Fitosociología: bases para el estudio de las comunidades vegetales. Trad. por: Jorge Lalucat Jo., H. Blume Ediciones, España. 820 p.

Bren, L. 1993. Riparian zone, stream, and floodplain issues: a review. Journal of Hydrology, Vol 150, Issues 2-4, 277-299 p.

Brinson, M.M.; Verhoeven, J. 1999. Riparian forests. In: Hunter, M.L. 1999. Maintaining biodiversity in forest ecosystems. NY, USA, Cambridge University Press. 265 - 299 p.

Brookes, C.J.; Hooke, J.M.; Mant, J. 2000. Modelling vegetation interactions with channel flow in river valleys of the Mediterranean region. Catena 40:93-118.

Brookes, A.; Shields, F (Eds). 2001. River channel restoration: guiding principles for sustainable projects. John Wiley \& Sons. $433 \mathrm{p}$.

Brown, M.B.; de la Roca, I.; Vallejo, A.; Ford, G.; Casey, J.; Aguilar, B.; Haacker, R.1996. A valuation analysis of the role of cloud forests in watershed protection: Sierra de las Minas Biosphere Reserve, Guatemala and Cusuco National Park, Honduras. RARE / FDN / Fundación Ecologista Hector Rodrigo Pastor Fasquelle / TNC. Guatemala. 134 p.

Bruijnzeel, L.A. 2001. Hydrology of tropical montane cloud forests: a reassessment. Land Use and Water Resources Research 1: $1.1-1.18 \mathrm{p}$.

Bruijnzeel, L.A.; Burkard, R.; Carvajal, A.; Frumau, A.; Köhler, L.; Mulligan, M.; Schellekens, J.; Schmid, S.; Tobón, C. 2006. Hydrological impacts of converting tropical montane cloud forest to pasture, with initial reference to northern Costa Rica. Final Technical Report DFID-FRP Project no. R7991. 1-52 p.

Burgess, S.S.O.; Adams, M.A.; Turner, N.C.; Ong, C.K. 1998. The redistribution of soil water by tree root systems. Oecologia 115: 306-311. Citado por Tabacchi et al, 2000.

Butler Jr., J.J.; Kluitenberg, G.J.; Whittemore, D.O.; Loheide II, S.P.; Jin, W.; Billinger, M.A.; Zhan, X. 2007. A field investigation of phreatophyte-induced fluctuations in the water table. Water Resources Research, Vol. 43, W02404, doi:10.1029/2005WR004627.

Campbell, G.S. 1974. A simple method for determining unsaturated conductivity from moisture retention data. Soil Science, Vol. 117, No. 6, 311-314 p.

Canadell, J.; Jackson, R.B.; Ehleringer, J.R.; Mooney, H.A.; Sala, O.E.; Schulze, E.D. Maximum rooting depth of vegetation types at the global scale. Oecologia 108: 583-595. 
Capon, S.J. 2003. Plant community responses to wetting and drying in a large arid floodplain. River Res. Applic. 19: 509-520.

Carter J., W.; Dixon, M.D.; Simons, R.; Jenson, S. ; Larson, K. 1995. Mapping the response of riparian vegetation to possible flow reductions in the Snake River, Idaho. Geomorphology 13 (1995) 159-173.

Castañeda Salguero, C. 1997. Impacto de los diferentes sistemas de producción en la biodiversidad de las regiones semiáridas de Guatemala.Universidad de San Carlos de Guatemala. Dirección General de Investigación. 72 p.

Castañeda Salguero, C. 2004. Árboles y arbustos de los bosques secos de Guatemala. Instituto Nacional de Bosques de Guatemala. 199 p.

Causton, D.R. 1988. Introduction to vegetation analysis: principles, practice and interpretation. Unwin Hyman Ltd., Londres. 342 p.

Celis Barrios, J.A. 2008. Caracterización del bosque de ribera de las subcuencas del río Uyús, EI Progreso y Río Hondo, Zacapa en la Región Semiárida del Valle del Motagua. Tesis de grado de ingeniero agrónomo, Facultad de Agronomía Universidad de San Carlos de Guatemala. 196 p.

Clements, F. 1916. Plant succession: an analysis of the development of vegetation. Carnegie Inst Publ 242. Washington DC. In: Terradas, J. 2001. Ecología de la vegetación: de la ecofisiología de las plantas a la dinámica de comunidades y paisajes. España, Ediciones Omega. p. 23.

Chapin III, F.S.; Walker, B.H.; Hobbs, R.J.; Hooper, D.U.; Lawton, J.; Sala, O.; Tilman, D. 1997. Biotic Control over the functioning of Ecosystems. Science, 277: 500-504 p.

Chauhan, M.; Gopal, B. 2005. Vegetation structure and dynamics of a floodplain wetland along a subtropical regulated river. River Res. Applic. 21: 513-534.

Choi, S.-U.; Yoon, B.; Woo, H. 2005. Effects of dam-induced flow regime change on downstream river morphology and vegetation cover in the Hwang river, Korea. River Res. Applic. 21: 315-325.

Cohen, J. 1960. A coefficient of agreement for nominal scales. Educational and psychological measurement, Vol XX, No. 1: 37-46.

Coles-Ritchie, M.C.; Henderson, R.; Archer, E.K.; Kennedy, C.; Kershner, J.L. 2004. Repeatability of riparian vegetation sampling methods: how useful are these techniques for broad-scale, long-term monitoring? USDA General Technical Report RMRS-GTR-138. 18 p.

Congalton, R.G. 1991. A review of assessing the accuracy of classifications of remotely sensed data. Remote Sensing of Environment 37: 35-46.

Congalton, R.G.; Birch, K.; Jones, R.; Schriever, J. 2002. Evaluating remotely sensed techniques for mapping riparian vegetation. Computers and Electronics in Agriculture 37: 113-126.

Corbacho, C.; Sánchez, J.M.; Costillo, E. 2003. Patterns of structural complexity and human disturbance of riparian vegetation in agricultural landscapes of a Mediterranean area. Agriculture, Ecosystems and Environment 95 (2003) 495-507.

Córdova, L.; Cano, E.; Estrada, R. 2002. Estimación de biomasa y carbono para Pinus oocarpa Schiede, $P$. maximinoi H.E. Moore y $P$. caribeae Morelet. Var hondurensis, en algunos bosques de Guatemala. Tikalia 20 (2): 7-24.

Correll, D. 1999. Vegetated Stream Riparian Zones: Their Effects on Stream Nutrients, Sediments, and Toxic Substances. Smithsonian Environmental Research Center Edgewater, Maryland, USA 210370028.

Crawley, M.J (Ed). 1997. Plant ecology. 2a. edición. Blackwell Science Ltd, UK. 717 p. 
Dahm, C.N.; Cleverly, J, R.; Allred, J.; Thibault, J.R.; Mcdonnell, D.; Gilroy, D. 2002. Evapotranspiration at the land/water interface in a semi-arid drainage basin. Freshwater Biology (2002) $47,831-843$.

Dawson, T.E. 2007. Linking roots and rhizospheres to hydrological processes. In American Geophysical Union Fall Meeting, San Francisco, CA, USA, Session "Vegetation controls over ecosystem water cycling I", B23E-01.

Deng, Z.; Singh, V.P. 2002. Optimum channel pattern for environmentally sound training and management of alluvial rivers. Ecological Modelling 154 (2002) 61-74.

De Chant, L.J. ; De Chant, C.J. 2004. Development of an elementary quantitative competing species model: potential guidelines for exotic/weed plant species control and ecosystem restoration programs. Ecological Engineering 22: 67-75.

Dieck, J.J.; Robinson, L.R. 2004. General Classification Handbook for Floodplain Vegetation in Large River Systems. Geological Survey La Crosse Wi Upper Midwest Environmental Sciences Center. Chapter 1 of Book 2, Collection of Environmental Data.

Dingman, S.L. 2002. Physical hydrology. New Jersey, U.S.A., Prentice Hall. 646 p.

Dix, M.; Fernández, J. (Eds). 2001. Inventario Nacional de los Humedales de Guatemala. UICNMesoamérica / CONAP / USAC. Costa Rica. 176 p.

Doble, R.; Simmons, C.; Jolly, I.; Walker, G. 2004. Spatial modelling of groundwater discharge patterns to predict floodplain salinisation and impacts on vegetation health. CSIRO Land and Water Technical Report No. 1/04

Doorenbos, J.; Kassam, A. 1986. Efectos del agua sobre el rendimiento de los cultivos. Estudios FAO serie riego y drenaje 33, Roma, $212 \mathrm{p}$.

Drezner, T.D.; Fall, P.L.; Stromberg, J.C. 2001. Plant distribution and dispersal mechanisms at the Hassayampa River Preserve, Arizona, USA. Global Ecology \& Biogeography, 10: 205-217.

Duke, J.R., J.D. White, P.M. Allen, R.S. Muttiah. 2005. Riparian Influence on Hyporheic-zone Formation Downstream of a Small Dam in the Blackland Prairie Region of Texas. Hydrological Processes (Aceptado para publicación).

Dwire, K.; Kauffman, J. 2003. Fire and riparian ecosystems in landscapes of the western USA. Forest Ecology and Management 178 (2003) 61-74.

Dyck, S. 1983. Overview on the present status of the concepts of water balance models. IAHS Publ. 148, Wallingford. p. 3-19. Citado en: Shuttleworth, W.J. 1993.

Eagleson, P.S. 1982. Ecological optimality in water-limited natural soil-vegetation systems. 1. Theory and hypothesis. Water Resources Research 18: 325-340.

Eagleson, P.S. 2002. Ecohydrology: Darwinian expression of vegetation form and function. Cambridge University Press, United Kingdom. 443 p.

EGU. 2005. European Geosciences Union: geophysical research abstracts. Volume 7, 2005, EGU General Assembly 2005.

Ehleringer, J.R.; Dawson, T.E. 1992. Water uptake by plants: perspectives from stable isotope composition. Plant Cell Environ. 15, 1073-1082. Citado por Snyder y Williams, 2000.

FAO (ITALIA). 1994. Directrices para la ordenación de los manglares. Chile. Estudio FAO Montes no. 117. $345 \mathrm{p}$.

FDN. 2003. III Plan Maestro de la Reserva de Biosfera Sierra de las Minas. Guatemala, FDN, 81 p. 
Fernandez-Illescas, C.P.; Rodríguez-Iturbe, I. 2003. Hydrologically driven hierarchical competitioncolonization models: the impact of interannual climate fluctuations. Ecological Monographs 73(2): 207222.

Ferreira, M.T.; Moreira, I.S. 1999. River plants from an Iberian basin and environmental factors influencing their distribution. Hydrobiologia 415: 101-107.

Fetter, C.W. 2001. Applied hydrogeology. 4a. edición. Prentice Hall, U.S.A. 598 p.

Fielding, A.H.; Bell, J.F. 1997. A review of methods for the assessment of prediction errors in conservation presence/absence models. Environmental Conservation (24): 38-49.

Fischenich, C. 2000. Resistance Due to Vegetation. ERDC TN-EMRRP-SR-07.

Fischer, D. G.; Hart, S.C.; Whitham, T.G.; Martinsen, G.D.; Keim, P. 2004. Ecosystem implications of genetic variation in water-use of a dominant riparian tree. Oecologia (2004) 139: 288-297.

Fischer, R.A. 2004. Using Soil Amendments to Improve Riparian Plant Survival in Arid and Semi-arid Landscapes. Engineer Research and Development Center Vicksburg Ms, Report Number A231224.

FISRWG. 1998. Stream Corridor Restoration: Principles, Processes, and Practices. GPO Item No. 0120-A; SuDocs No. A 57.6/2:EN 3/PT.653.

Francés, F.; Albentosa, E.; Bellver, V.; Marco, J. s.f. Hidrología básica para ingenieros: para la asignatura de hidráulica e hidrología de $2^{\circ}$ del PIE-IC. DIHMA / Universidad Politécnica de Valencia. Ref. 2006.871. 162 p.

Francés, F.; Vélez, J.I.; Vélez, J.J. 2007. Split-parameter structure for the automatic calibration of distributed hydrological models. Journal of Hydrology 332: 226- 240.

Francés, F.; Martínez, F.; Garófano, V.; Morales-de la Cruz, M.; Real, J.; García, A.; García, J.; Muñoz, R.; Soares, R.; Villanueva, J. 2009. Proyecto RIBERA, modelación matemática de ecosistemas de ribera para la determinación de regímenes ecológicos en el río: informe de l+D+i. Ministerio de Medio Ambiente y Medio Rural y Marino / IIAMA / UPV / IGIC. 448 p.

Franz, T.E.; Caylor, K.K.; Nordbotten, J.M.; Rodríguez-Iturbe, I.; Celia, M.A. 2010. An ecohydrological approach to predicting regional woody species distribution patterns in dryland ecosystems. Advances in Water Resources 33: 215-230.

Freeze, R.A.; Cherry, J. A. 1979. Groundwater. Prentice Hall, UK. 604 p.

Frumau, K.F.; Bruijnzeel, L.A.; Tobon, C. 2006. Hydrological measurement protocol for montane cloud forest. Annex 2, Final Technical Report DFID-FRP Project R7991. Vrije Universiteit: Amsterdam, 1-105 p.

Garavito, F. 1989. Balances hídricos agrícolas. In: I Congreso guatemalteco de agrometeorología. INSIVUMEH - PNUD, Guatemala, 352-360.

García, J. s.f. Vegetación riparia y régimen de caudales. EUIT Forestal, Universidad Politécnica de Madrid.

Gauch, H.G. 1982. Multivariate analysis in community ecology. EEUU, Cambridge University Press. $298 \mathrm{p}$.

Gautier, E. ; Piégay, H.; Bertain, P. 2000. A methodological approach of fluvial dynamics oriented towards hydrosystem management: case study of the Loire and Allier rivers. Geodinamica Acta 1 (2000) 29-43.

Gergel, S.; Dixon, M.; Turner, M. 2002. Consequences of human-altered floods: levees, floods, and floodplain forests along the Wisconsin river. Ecological Applications, 12(6): 1755-1770 p. 
Glenz, C. 2001. Predicting floodplain vegetation development considering ecological, geomorphological and hydraulic processes: case of 3rd. Rhône Correction in Valais. Research Plan of GECOS not publicated, $13 \mathrm{p}$.

Glenz, C.; lorgulescu, I.; Kienast, F.; Schlaepfer, R. 2003. Modelling the dynamics of riparian forests by accounting for hydraulic and geomorphological processes. In: EGS - AGU - EUG Joint Assembly, Abstract \#8875, Nice, France, 6 - 11 April 2003,

Goodrich, D.C.; Scott, R.; Qi, J.; Goff, B.; Unkrich, C.L.; Moran, M.S.; Williams D.; Schaeffer, S.; Snyder, K.; MacNish, R.; Maddock, T.; Pool, D.; Chehbouni, A.; Cooper, D.; Eichinger, W.; Shuttleworth, W.; Kerr, Y.; Marsett, W.; Ni, W. 2000. Seasonal estimates of riparian evapotranspiration using remote and in-situ measurements. Journal of Agricultural and Forest Meteorology, 105: 281-309.

Goodwin, C.N.; Tarboton, D.G. 2001. An ecohydrological approach for modelling vegetation cover based upon equilibrium soil moisture availability. AGU Chapman Conference on State-of-the-Art Hillslope Hydrology. Sunriver, Oregon, October 8-12, 2001.

Gregory, S.V.; Swanson, F.; McKee, A.; Cummins, K. 1991. An ecosystem perspective of riparian zones. BioScience 41, 540-550.

Grindley, J. 1970. Estimation and mapping of evaporation. IASH Pub. No. 92. World Water Balance, Vol 1., 200-213. In: Shaw. 1994.

Guatemala / Congreso de la República de Guatemala. 1996. Ley forestal: Decreto número 101-96. 36 p.

Guatemala / Corte de Constitucionalidad. 2005. Constitución Política de la República de Guatemala: reforma aprobada por referéndum en 1993. Guatemala, 105 p.

Guymon, G.L. 1994. Unsaturated zone hydrology. Prentice Hall, U.S.A. 210 p.

Hanson, J.S.; Malanson, G.P.; Armstrong, M.P. 1990. Landscape fragmentation and dispersal in a model of riparian forest dynamics. Ecological Modelling Volume 49, Issues 3-4, Pages 277-296.

Hantush, M.M. 2005. Modeling stream-aquifer interactions with linear response functions. Journal of Hydrology 311 (2005) 59-79.

Hargreaves, G. H. 1975. 'Moisture availability and crop production. Trans. ASAE, 18(5): 980-984.

Hargreaves, G. H. 1977. 'World water for agriculture. Agency for international development, 177 p.

Hargreaves, G. H.; Allen R. G. 2003. History and Evaluation of Hargreaves Evapotranspiration Equation. Journal of Irrigation and Drainage Engineering 129 (1): 53-63.

Hatton, T.J.; Salvucci, G.D.; Wu, H.I. 1997. Eagleson's optimality theory of an ecohydrological equilibrium: quo vadis? Functional Ecology 11: $665-674$.

Heller, H. 1969. Lebensbedingungen und Abfolge der Flussauenvegetation in der Schweiz. Mitteilungen Schweizerische Anstalt für das forstliche Versuchswesen 45(2): 1-124. Citado por: Glenz, C. 2001.

Holder, C.D. 2002. Fog precipitation in the Sierra de las Minas Biosphere Reserve, Guatemala. Hydrol. Process. (17): 2001-2010.

Holder, C.D. 2004. Rainfall interception and fog precipitation in a tropical montane cloud forest of Guatemala. Forest Ecology and Management (190): 373-384.

Hölscher, D.; Köhler, L.; van Dijk, A.I.; Bruijnzeel, L.A. 2004. The importance of epiphytes to total rainfall interception by a tropical montane rain forest in Costa Rica. Journal of Hydrology (292): 308322. 
Horton, J.L., Clark, J.L., 2001. Water table decline alters growth and survival of Salix gooddingii and Tamarix chinensis seedlings. Forest Ecology and Management 140, 243-251.

Horton, J.L.; Kolb, T.E.; Hart, S.C. 2001. Responses of riparian trees to interannual variation in ground water depth in a semi arid river basin. Plant, Cell and Environment 24, 293-304.

Hornbeck, J.W.; Smith, R.B. 1997. A water resources decision model for forest managers. Agricultural and Forest Meteorology Volume 84, Issues 1-2: 83-88.

Howard A.D. 1992. Modelling channel migration and floodplain sedimentation in meandering streams. In: Lowland Rivers: Geomorphological Perspectives (Eds P.A. Carling \& G.E. Petts), pp. 1-41. John Wiley \& Sons Ltd, Chichester.

Hughes, F. (Ed.) 2003. The Flooded Forest: guidance for policy makers and river managers in Europe on the restoration of floodplain forests. FLOBAR 2 Project / UE, Department of Geography, Univesrity of Cambridge.

Hughes, F.; Barsoum, N.; Belleudy, P.; Lambs, L.; Marigo, G.; Muller, E.; Nilsson, C.; Rood, S. 2003. What are the key hydrological processes? In: Hughes, F. (Ed.) 2003. The Flooded Forest: guidance for policy makers and river managers in Europe on the restoration of floodplain forests. FLOBAR 2 Project / UE, Department of Geography, Univesrity of Cambridge.

Hultine, K.R.; Williams, D.G.; Burgess, S.S.O.; Keefer, T.O. 2003. Contrasting patterns of hydraulic redistribution in three desert phreatophytes. Oecologia (2003) 135:167-175.

Inamdar, S.P.; Sheridan, J.M.; Williams, R.G.; Bosch, D.D.; Lowrance, R.R.; Altier, L.S.; Thomas, D.L. 1999. Riparian ecosystem management model (REMM): I. Testing of the hydrologic component for a coastal plain riparian system. American Society of Agricultural Engineers. Vol 42(6): 1679-1689.

Inamdar, S.P.; Lowrance, R.R.; Altier, L.S.; Williams, R.G.; Hubbard, R.K. 1999a. Riparian ecosystem management model (REMM): II. Testing of the water quality and nutrient cycling component for a coastal plain riparian system. American Society of Agricultural Engineers. Vol 42(6): 1691-1707.

Instituto Geográfico Nacional de Guatemala -IGN-. 2006. Ortofotos 1:5,000 de la República de Guatemala. Sistema de coordenadas GTM, factor de escala 0.9998, falso Este 500,000, falso Norte 0, meridiano Central -90.5.

Jansson, R.; Zinko, U.; Merritt, D. 2005. Hydrochory increases riparian plant species richness: a comparison between a free-flowing and a regulated river. Journal of Ecology 93: 1094-1103.

Järvelä, J. 2004. Determination of flow resistance caused by non-submerged woody vegetation. Intl. J. River Basin Management Vol. 2, No. 1 (2004): 1-10.

Jonckheere, I.; Fleck, S.; Nackaerts, K.; Muysa, B.; Coppin, P.; Weiss, M.; Baret, F. 2001. Review of methods for in situ leaf area index determination Part I. Theories, sensors and hemispherical photography. Agricultural and Forest Meteorology 121 (2004) 19-35.

Inamdar, S.P.; Sheridan, J.M.; Williams, R.G.; Bosch, D.D.; Lowrance, R.R.; Altier, L.S.; Thomas, D.L. 1999. Riparian ecosystem management model (REMM): I. Testing of the hydrologic component for a coastal plain riparian system. American Society of Agricultural Engineers. Vol 42(6): 1679-1689.

Izco, J., Barreno, E.; Brugués, M.; Costa, M.; Devesa, J.; Fernández, F.; Gallardo, T.; Llimona, X.; Salvo, E.; Talavera, S.; Valdés, B. 2000. Botánica. McGraw-Hill, Interamericana de España. 781 p.

Karrengerger, S.; Edwards, P.J.; Kollmann, J. 2002. The life history of Salicaceae living in the active zone of floodplains. Freshwater Biology 47: 733-748.

Kellman, M.; Roulet, N. 1990. Nutrient Flux and Retention in a Tropical Sand-Dune Succession. The Journal of Ecology, Vol. 78 (3): 664-676. 
Kerkhoff, A.J.; Martens, S.N.; Milne, B.T. 2004. An ecological evaluation of Eagleson's optimality hypotheses. Functional Ecology 18: 404-413.

Kingsford, R.T. 2000. Ecological impacts of dams, water diversions and river management on floodplain wetlands in Australia. Austral Ecology 25: 109-127

Kokaly; R.F.; Despain; D.G.; Clark, R.N.; Livo, K.E. 2003. Mapping vegetation in Yellowstone National Park using spectral feature analysis of AVIRIS data. Remote Sensing of Environment 84: 437-456.

Kouwen, N. 2003. Using vegetation properties to predict flow resistance and erosion rates. International Workshop on Riparian forest vegetated channels: Hydraulic, Morphological and Ecological Aspects. Trento, Italy, 20-22 February 2003.

Kramer, P.J.; Boyer, J.S. 1995. Water relations of plants and soils. Academic Press Ltd, U.S.A. 495 p.

Kranjcec, J.; Mahoney, J.M; Rood, S.B. 1998. The responses of three riparian cottonwood species to water table decline. Forest Ecology and Management 110: 77-87.

Laio, F.; Porporato, A.; Ridolfi, L.; Rodríguez-Iturbe, I. 2001. Plants in water-controlled ecosystems: active role in hydrologic processes and response to water stress; II Probabilistic soil moisture dynamics. Advances in Water Resources 24: 707-723.

Laio, F.; Porporato, A.; Fernandez-Illescas, C.P.; Rodriguez-Iturbe, I. 2001a. Plants in water-controlled ecosystems: active role in hydrologic processes and response to water stress; IV Discussion of real cases. Advances in Water Resources 24: 745-762.

Lake, P.S. 2003. Ecological effects of perturbation by drought in flowing waters. Freshwater Biology 48, $1161-1172$

Lambers, H.; Chapin III, F.S.; Pons, T.L. 1998. Plant physiological ecology. U.S.A. Springer. 540 p.

Lambs, L. 2004. Interactions between groundwater and surface water at river banks and the confluence of rivers. Journal of Hydrology 288: 312-326.

Lamontagne, S.; Cook, P.C.; O'Grady, A.; Eamus, D. 2005. Groundwater use by vegetation in a tropical savanna riparian zone (Daly River, Australia). Journal of Hydrology 310: 280-293.

Larcher, W. 1995. Physiological plant ecology: ecophysiology and stress physiology of functional groups. U.S.A. Springer, 3a. edición. 506 p.

Lautz, L.K. 2007. Estimating groundwater evapotranspiration rates using diurnal water-table fluctuations in a semi-arid riparian zone. Hydrogeology Journal, DOI 10.1007/s10040-007-0239-0.

Lewis, L. Clark, L.; Krapf, R. Manning, M. Staats, J.; Subirge, T.; Townsend, L.; Ypsilantis, B. 2003. Riparian - Wetland Soils: riparian area management. USDA, Technical reference 1737-19 2003. 86 p.

Lite, S.J.; Stromberg, J.C. 2005. Surface water and ground-water thresholds for maintaining PopulusSalix forests, San Pedro River, Arizona. Biological Conservation 125: 153-167.

Lite, S.J.; Bagstad, K.J.; Stromberg, J.C. 2005. Riparian plant species richness along lateral and longitudinal gradients of water stress and flood. Journal of Arid Environments 63: 785-813.

Liu, H.; Wang, L.; Yang, J.; Nakagoshi, N.; Liang, C.; Wang, W.; Lv, Y. 2009. Predictive modeling of the potential natural vegetation pattern in northeast China.

Lonard, R.I.; Judd, R.W.; Everitt, J.H.; Escobar, D.E.; Davis, M.R.; Crawford, M.M.; Desai, M.D. 2000. Evaluation of color-infrared photography for distinguishing annual changes in riparian forest vegetation of the lower Rio Grande in Texas. Forest Ecology and Management 128: 75-81. 
Loheide II, S.P.; Gorelick, S.M. 2005. A local-scale, high resolution evapotranspiration mapping algorithm (ETMA) with hydroecological applications at riparian meadow restoration sites. Remote Sensing of Environment 98: 182-200.

Lovett, S.; Huggan, H. (Eds). 1998. Riparian zones: what are they? Australia, LWRRDC, Issue 11, December 1998. $19 \mathrm{p}$.

Lowrance, R.; Leonard, R.; Sheridan, J. 1985. Managing riparian ecosystems to control nonpoint pollution. Journal of Soil and Water Conservation 40(1): 87-91.

Lowrance, R.; Altier, L.; Williams, R.; Inambar, S.; Bosch, D.; Sheridan, J.; Thomas, D.; Hubbard, R. 1998. The riparian ecosystem management model: simulator for ecological processes in buffer systems. In: Proceedings of the First Federal Interagency Hydrologic Modeling Conference, Las Vegas NV. p. 1-81 a 1-88.

Lowrance, R.; Altier, L.S.; Williams, R.G.; Inamdar, S.P.; Sheridan, J.M.; Bosch, D.D.; Hubbard, R.K.; Thomas, D.L. 2000. REMM: the riparian ecosystem management model. Journal of Soil and Water Conservation Vol. 55, No. 1, pp. 27 - 34.

Mac Nish, R.D.; Unkrich, C.L.; Smythe, E.; Goodrich, D.C.; Maddock III, T. 2000. Comparison of riparian evapotranspiration estimates based on a water balance approach and sap flow measurements. Agricultural and Forest Meteorology 105: 271-279.

Maddock III, T.; Baird, K.J. 2003. A riparian evapotranspiration package for Modflow-96 and Modflow2000. Department of Hydrology and Water Resources, University of Arizona. 60 p.

Maddock III, T.; Mac Nish, R. D.; Goodrich, D. C.; Williams, D. G.; Shuttleworth, W. J.; Goff, B. A.; Scott, R. L.; Moran, M. S.; Cooper, D. I.; Hipps, L. E.; Chehbouni, A. G. 1998. The overview of atmospheric and surface water coupling to regional groundwater models in semi-arid basins. American Meteorological Society, Special Symposium on hydrology, Arizona, 11-16 Enero 1998. Sesión 1, Artículo 1.10.

Mahoney J.M. \& Rood S.B. (1998) Streamflow requirements for cottonwood seedling recruitmentan integrative model. Wetlands, 18, 634-645. Citado por Stromberg, 2001.

Maidment, D.R. (Ed.). 1993. Handbook of hydrology. McGraw-Hill, U.S.A. p.

Malanson, G.P., 1993. Riparian Landscapes. Cambridge University Press.

Manel, S; Ceri Williams, H.; Ormerod, S.J. 2001. Evaluating presence-absence models in ecology: the need to account for prevalence. Journal of Applied Ecology (38): 921-931.

Mouton, A.M; De Baets, B.; Goethals, P.L.M. 2010. Ecological relevance of performance criteria for species distribution models. Ecological Modelling (221): 1995-2002.

Mathooko, J.M.; Kariuki, S.T. 2000. Disturbances and species distribution of the riparian vegetation of a Rift Valley stream. Afr. J. Ecol. 38: 123-129.

McCune, B; Mefford, M.J. 1997. PC-ORD. Multivariate analysis of ecological data, version 3.0. MjM software, Gleneden Beach, Oregon, USA.

McCune, B; Grace, J.B. 2002. Analysis of ecological communities. MjM Software Design, USA. ISBN 0-9721290-0-6. $300 \mathrm{p}$.

McDonald, M.G.; Harbaugh, A.W., 1988. A modular three dimensional finite difference groundwater flow model. Techniques of Water-Resources Investigations, 06-A1, US Geological Survey. Citado por Snyder y Williams, 2000.

McGlynn, B.; McDonnell, J.; Shanley, J.; Kendall, C. 1999. Riparian zone flowpath dynamics during snowmelt in a small headwater catchment. Journal of Hydrology 222: 75-92. 
McGlynn, B.; McDonnell, J. 2003. Quantifying the relative contributions of riparian and hillslope zones to catchment runoff. Water Resources Research, Vol. 39, No. 1, SWC 2.

McGlynn, B.; Seibert, J. 2003. Distributed assessment of contributing area and riparian buffering along stream networks. Water Resources Research, Vol. 39, No. 4, TNN 2.

McMahon, T.A.; Finlayson, B.L. 2003. Droughts and anti-droughts: the low flow hydrology of Australian rivers. Freshwater Biology (2003) 48, 1147-1160.

Medici, C.; Butturini, A.; Bernal, S.; Vázquez, E; Sabater, F. ; Vélez, J.I.; Francés, F. 2008. Modelling the non-linear hydrological behaviour of a small Mediterranean forested catchment. Hydrol. Process. (2008) DOI: 10.1002/hyp.6991.

Medrano, H.; Flexas, J. 2004. Respuesta de las plantas al estrés hídrico. In: Reigosa, M.; Pedrol, N.; Sánchez, A., eds. 2004. La ecofisiología vegetal: una ciencia de síntesis. España. Thomson. 253 $286 \mathrm{p}$.

Medrano, H.; Flexas, J. 2004a. Relaciones hídricas de las plantas. In: Reigosa, M.; Pedrol, N.; Sánchez, A., eds. 2004. La ecofisiología vegetal: una ciencia de síntesis España. Thomson. 1141 $1174 \mathrm{p}$.

Merritt, D.M.; Scott, M.L.; Poff, N.L.; Auble, G.T.; Lytle, D.A. 2009. Theory, methods and tools for determining environmental flows for riparian vegetation: riparian vegetation-flow response guilds. Freshwater Biology (2009). Doi:10.1111/j.1365-2427.2009.02206.x

Middleton, B.A. (Ed.). 2002. Flood Pulsing in Wetlands: restoring the natural hydrological balance. John Wiley \& Sons, Inc. 1-10 p.

Micheli, E.; Kirchner, J.; Larsen, E. 2004. Quantifying the effect of riparian forest versus agricultural vegetation on river meander migration rates, central Sacramento river, California, USA. River Res. Applic. 20: 537-548 (2004).

Miller, D.; Luce, C.; Benda, L. 2003. Time, space, and episodicity of physical disturbance in streams. Forest Ecology and Management 178 (2003) 121-140.

Ministerio de Agricultura, Ganadería y Alimentación, Guatemala -MAGA-. 2001. Base digital de la República de Guatemala Escala 1:250,000. ESPREDE-BID-MAGA-CATIE-PEDN. 106 p.

Ministerio de Agricultura, Ganadería y Alimentación, Guatemala -MAGA-. 2002. Atlas temático de la República de Guatemala. UPGGR, Guatemala. 127 p.

Moore, J.L.; King, J.P.; Salim Bawazi, A.A.; Sammis, T.W. 2004. A bibliography of evapotranspiration with special Emphasis on riparian vegetation. New Mexico Water Resources Research Institute / New Mexico State University. WRRI Miscellaneous Report No. M28 January 2004.

Morales-de la Cruz, M.V. 2001. Estudio de factores que determinan la población y distribución del mangle comprendido entre Puerto Viejo (Iztapa) y Zunzo (Taxisco). Guatemala, Tikalia 19(4): 65-116.

Morales-de la Cruz, M.; Polanía, J. 2005. Factors that determine population and distribution of mangrove ecosystem in the Pacific coast of Guatemala. European Geosciences Union General Assembly 2005, Viena, Austria. HS-40 EGU05-A-02087.

Morales-de la Cruz, M.; Fernández Bono, J. 2006. Aspectos relevantes de la interacción entre la vegetación de ribera, la hidráulica y la morfología de cauces. III Congreso ICITEMA, España. 15 p.

Morales-de la Cruz, M.; Fráncés, F. 2007. Water Resources Estimation of the Biosphere Reserve "Sierra de las Minas" in Guatemala, by Using a Distributed Hydrological Model and Considering Lack of Data. In American Geophysical Union Fall Meeting, San Francisco, CA, USA. H21A-0183-AGU-2566. 
Morales-de la Cruz, M.; Fráncés, F. 2008. Hydrological modelling of the Sierra de las Minas in Guatemala, by using a conceptual distributed model and considering the lack of data. In: Mander, U.; Brebbia, C.; Martin-Duque,J. 2008. Proceeding of Geo-Environment and Landscape Evolution III. Southampton, U.K. doi: 10.2495/GEO080101.

Morales-de la Cruz, M.; Fráncés, F. 2008a. Modelo de agua y vegetación de la zona de ribera aplicado a condiciones semiáridas. In: Memorias Técnicas XXIII Congreso Latinoamericano de Hidráulica, Cartagena de Indias, Colombia. ISBN: 978-958-719-075-5

Morales-de la Cruz, M.; Fráncés, F. 2009. Vegetation and water use modelling in a semi-arid riparian zone in Guatemala, by coupling basin and river reach hydrological processes. In: Proceeding of The International Conference of Science and Information Technologies for Sustainable Management of Aquatic Ecosystems, Concepción, Chile, ISE-1B2-PH1 (conf187a223), p. 93.

Nagler, P.L.; Glenn, E.P.; Huete, A.R. 2001. Assessment of spectral vegetation indices for riparian vegetation in the Colorado River delta, Mexico. Journal of Arid Environments 49: 91-110

Nagler, P.L.; Glenn, E.P.; Thompson, T.L.; Huete, A. 2004. Leaf area index and normalized difference vegetation index as predictors of canopy characteristics and light interception by riparian species on the Lower Colorado River. Agricultural and Forest Meteorology 125 (2004) 1-17.

Nagler, P.L.; Cleverly, J.; Glenn, E.; Lampkin, D.; Huete, A.; Wan, Z. 2005. Predicting riparian evapotranspiration form MODIS vegetation indices and meteorological data. Remote Sensing of Environment 94: 17-30.

Nagler, P.L.; Scott, R.L.; Westenburg, C.; Cleverly, J.R.; Glenn, E.P.; Huete, A.R. 2005a. Evapotranspiration on western U.S. rivers estimated using the Enhanced Vegetation Index from MODIS and data from eddy covariance and Bowen ratio flux towers. Remote Sensing of Environment 97 (2005) $337-351$.

Naiman, R. J.; Bilby, R. E.; Bisson, P.A. 2000. Riparian ecology and management in the Pacific Coastal Rain Forest. BioScience, November 2000 / Vol. 50 No. 11, 996-1011.

Naiman, R. J.; Décamps, H.; McClain, M.E. 2005. Riparia: ecology, conservation, and management of streamside communities. Elsevier, Academic Press, UK. 430 p.

Nájera, A. (Ed.) 2004. Seminario de investigación para la conservación de la región semiárida del valle del Motagua: libro de resúmenes. Guatemala, FDN / TNC / USAID. 38 p.

Nakamura, F.; Jitsu, M.; Kameyama, S.; Mizugaki, S. 2002. Changes in riparian forests in the Kushiro Mire, Japan, associated with stream channelization. River Res. Applic. 18: 65-79.

Niclòs Corts, R.; Estrela, M.J.; Valiente, J.A.; Barberá, M.J. 2010. Clasificación periódica de coberturas terrestres a escala regional con imágenes MODIS. GeoFocus (Artículos) 10: 1-17. ISSN: 1578-5157

Nielsen, E.M.; Prince, S.D.; Koeln, G.T. 2008. Wetland change mapping for the U.S. mid-Atlantic region using an outlier detection technique. Remote Sensing of Environment 112: 4061-4074.

Nilsson, C.; Berggren, K. 2000. Alterations of riparian ecosystems caused by river regulation. BioScience Vol. 50 No. 9: 783-792 p.

Oetter, D.R.; Ashkenas, L.R.; Gregory, S.V.; Minear, P.J. 2004. GIS Methodology for characterizing historical conditions of the Willamette River Flood Plain, Oregon: research article. Transactions in GIS 8(3): 367-383.

Ocampo, C.J.; Sivapalan, M.; Oldham, C. 2006. Hydrological connectivity of upland-riparian zones in agricultural catchments: Implications for runoff generation and nitrate transport. Journal of Hydrology 331: $643-658$.

Pabst, R.J.; Spies, T.A. 1999. Structure and composition of unmanaged riparian forests in the coastal mountains of Oregon, U.S.A. Can. J. For. Res. 29: 1557-1573. 
Pataki, D.E.; Bush, S.E.; Gardner, P.; Solomon, D.K.; Ehleringer, J.R. 2005. Ecohydrology in a colorado river riparian forest: implications for the decline of Populus fremontii. Ecological Applications, 15(3), 2005, pp. 1009-1018.

Pautou, G.; Decamps, H. 1985. Ecological interactions between alluvial forests and hydrology in the Upper Rhone. Archiv für Hydrobiologie 104: 13-37. (Citado por Glenz, 2001).

Pearlstine, L; McKellar, H; Kitchens, W. 1985. Modelling the impacts of a river diversion on bottomland forest communities in the Santee River Floodplain, South Carolina. Ecological Modelling, vol. 29, no. 14, pp. 283-302.

Penka M. 1991. The water relations of the herb, shrub and tree layers in the - oodplain forest. In Floodplain Forest Ecosystem. Vol II: After Water Management Measures, Penka M, Vyskot M, Klimo E, Vasicek F (eds). Academia: Praha, 419-448.

Peters, J.; Verhoest, N.E.C.; Samson, R.; Boeckx, P.; De Baets, B. 2008. Wetland vegetation distribution modelling for the identification of constraining environmental variables. Landscape Ecol 23:1049-1065.

Phipps, R.L. 1979. Simulation of wetlands forest vegetation dynamics. Ecological Modelling Volume 7 , Issue 4 , October 1979, Pages 257-288.

Politti, E.M. 2008. Riparian Ecosystems Dynamic Model. Fachhochschule Technikum Kärnten - Master of Science Spatial Decision Support Systems. 102 p.

Porporato, A.; Laio, F.; Ridolfi, L.; Rodríguez-lturbe, I. 2001. Plants in water controlled ecosystems: active role in hydrologic processes and response to water stress, III vegetation water stress. Advances in Water Resources 24: 725-744.

Puricelli, M. 2003. Estimación y distribución de parámetros del suelo para la modelación hidrológica. Tesis doctoral DIHMA / Universidad Politécnica de Valencia. 435 p.

Qi, J.; Kerr, Y. H.; Moran, M. S.; Weltz, M.; Huete, A.R.; Sorooshian, S.; Bryant, R. 2000. Leaf area index estimates using remotely sensed data and BRDF models in a semiarid region. Remote Sens. Environ. 73:18-30 (2000).

Quevedo, D.; Francés, F. 2008. A conceptual dynamic vegetation-soil model for arid and semiarid zones. Hydrol. Earth Syst. Sci., 12, 1175-1187.

Rasmussen, G.A.; Goodwin, C.N.; Dobrowolski, J.P. 2000. A conceptual approach to integrating upland, riparian, and stream monitoring at an intermediate sized watershed scale. Poster presented at the Society for Range Management Annual Meeting in Boise, Idaho, February 12-18, 2000.

Rawls, W. J., L.R. Ahuja, D. Brakensiek, and A. Shirmohammadi. 1993. Infiltration and soil water movement. p. 5.1-5.51. In: D. Maidment (ed.) Handbook of hydrology. McGraw-Hill, New York.

Real, J.; Morales-de la Cruz, M.; García, A.; Garofano, V.; Martínez-Capel, F.; Francés, F. 2010. Mathematical modeling of riparian vegetation zonation in semiarid conditions based on a transpiration index. European Geosciences Union General Assembly 2010, Viena, Austria. Geophysical Research Abstracts, Vol. 12, EGU2010-5482-1.

Richards, K.S.; Hughes, F.M.R.; El-Hames, A.S.; Harris, T.; Pautou, G.; Peiry, J.-L.; Girel, J. 1996. Integrated field, laboratory and numerical investigations of hydrological influences on the establishment of riparian tree species. p. 611-635. In: Anderson, M.; Walling, D.; Bates, P. 1996 (Ed). Floodplain processes. John Wiley \& Sons Ltd.

Richards, K.; Brasington, J.; Hughes, F. 2002. Geomorphic dynamics of floodplains: ecological implications and potential modelling strategy. Freshwater Biology (2002) 47, 559-579. 
Rivas, R.E. 2004. Propuesta de un modelo operativo para la estimación de la evapotranspiración. Tesis doctoral Facultad de Física / Universidad de Valencia. 140 p.

Rodríguez-González, P.M.; Ferreira, M.T.; Rego, P. R. 2004. Vegetation types and within-stand structure. Forest Ecology and Management 203: 261-272.

Rodríguez-Iturbe, I.; Porporato, A. 2004. Ecohydrology of water-controlled ecosystems: soil moisture and plant dynamics. Cambridge University Press. $442 \mathrm{p}$.

Rüger, N.; Schlüter, M.; Matthies, M. 2005. A fuzzy habitat suitability index for Populus euphratica in the Northern Amudarya delta (Uzbekistan). Ecological Modelling 184 (2005) 313-328.

Russell, G D; Hawkins, C P; O'Neill, M P. 1997. The role of GIS in selecting sites for riparian restoration based on hydrology and land use. Restoration Ecology. Vol. 5, no. 4 Suppl, pp. 56-68.

Ryel R.J., Caldwell M.., Yoder C.K., Or D., Leffler A.J. 2002. Hydraulic redistribution in a stand of Artemisia tridentata: evaluation of benefits to transpiration assessed with a simulation model. Oecologia 130: 173-184.

Sánchez Rodríguez, Y. 2001. Estado de conservación del bosque de galería del Jardín Botánico Cupaynicu. Revista Electrónica Granma Ciencia. Vol.5, No. 2, Mayo-Agosto del 2001.

Saxton, K. E., W. J. Rawls, J. S. Romberger and R. I. Papendick. 1986. Estimating generalized soil water characteristics from texture. Trans. Amer. Soc. Agri. Engr., 50(4):1031-1035.

Skaggs, R.W. 1978. A water management model dor shallow water table soils. Water Resources Research Institute, University of North Carolina Report No. 134.

Schaeffer, S.M.; Williams, D.G. 1988. Transpiration of desert riparian forest canopies estimated from sap flux. American Meteorological Society, Special Symposium on Hydrology, Phoenix, Arizona, 11-16 Jan 1998. Session 1, Paper-P2.10.

Schaeffer, S.M.; Williams, D.G.; Goodrich, D.C. 2000. Transpiration of cottonwood / willow forest estimated from sap flux. Agricultural and Forest Meteorology 105: 257-270.

Schenk, H.J.; Jackson, R.B. 2002. The global biogeography of roots. Ecological Monographs 72 (3): 311-328.

Schenk, H.J.; Jackson, R.B. 2002a. Rooting depths, lateral root spreads and below-ground / aboveground allometries of plants in water-limited ecosystems. Journal of Ecology (90): 480-494.

Schenk, H.J.; Jackson, R.B. 2005. Mapping the global distribution of deep roots in relation to climate and soil characteristics. Geoderma (126): 129-140

Schilling, K.E, Kiniry, J.R. 2007. Estimation of evapotranspiration by reed canarygrass using field observations and model simulations. Journal of Hydrology (2007) 337, 356- 363.

Schulze, E.D.; Mooney, H.A.; Sala, O.E.; Jobbagy, E.; Buchmann, N.; Bauer, G.; Canadell, J.; Jackson, R.B.; Loreti, J.; Oesterheld, M.; Ehleringer, J.R. 1996. Rooting depth, water availability, and vegetation cover along an aridity gradient in Patagonia. Oecologia Vol 108, (3): 503-511.

Scott, R.L., Shuttleworth, W.J., Goodrich, D.C., Maddock, T., 2000. The water use of two dominant vegetation communities in a semiarid riparian ecosystem. Agric. For. Meteorol. 105, 241-256.

Scott, R.L., Goodrich, D.C., Levick, L.R. 2003. A Gis-Based Management Tool to Quantify Riparian Vegetation Groundwater Use. Proceedings First Interagency Conference on Research in the Watersheds. Oct. 27-30, 2003. Benson, AZ., Pp. 222-227.

Scott, R.; Edwards, E.; Shuttleworth, W.; Huxmanc, T.; Watts, C.; Goodrich, D. 2004. Interannual and seasonal variation in fluxes of water and carbon dioxide from a riparian woodland ecosystem. Agricultural and Forest Meteorology 122 (2004) 65-84 
Scott, R.L.; Huxman, T.E.; Williams, D.G.; Goodrich, D.C. 2006. Ecohydrological impacts of woodyplant encroachment: seasonal patterns of water and carbon dioxide exchange within a semiarid riparian environment. Global Change Biology (2006) 12, 311-324.

Seagle, S.W.; Liang, S-Y. 2001. Application of a forest gap model for prediction of browsing effects on riparian forest succession. Ecological Modelling 144 (2001) 213-229.

Secaira, E.; Prado, P.; Pérez, S. 2003. Plan de conservación de la región semiárida del Valle del Motagua. FDN / TNC / USAID. Guatemala, 61 p.

Shaw, E.M. 1994. Hydrology in practice. 3ª. Ed., Stanley Thornes, U.K. 569 p.

Shiau, J.-T.; Wu, F.-C. 2004. Assessment of hydrologic alterations caused by Chi-Chi diversion weir in chou-shui creek, taiwan: opportunities for restoring natural flow conditions. River Res. Applic. 20: 401412.

Shuttleworth, W.J. 1993. Evaporation. In: Maidment, D.R. (Ed.). 1993. Handbook of hydrology. McGraw-Hill, U.S.A. p. $4.1-4.53$.

Simon, A.; Bennett, S.J.; Neary, V.S. 2004. Riparian vegetation and fluvial geomorphology: problems and opportunities. American Geophysical Union, 10.1029/008WSA01. pp. 1-10.

Simon, A.; Collison, A. 2002. Quantifying the mechanical and hydrologic effects of riparian vegetation on streambank stability. Earth Surf. Process. Landforms 27, 527-546.

SINAFIP; EDESA. 2004. Estudio de factibilidad y diseño final para el ordenamiento y plan de manejo integrado del área de la cuenca del río Teculután, comprendida en el municipio de Teculután, departamento Zacapa. SINAFIP - BID, contrato No. 117-2003. Tomo I, Cap 1-11 y Anexos. 269 p.

Smith, T.M.; Shugart, H.H.; Woodward, F.I. (Eds). 1997. Plant functional types: their relevance to ecosystem properties and global change. Cambridge University Press / International Geosphere Biosphere Programme book series. $369 \mathrm{p}$.

Smith, R.L; Smith, T.M. 2000. Elements of Ecology. 4a. edición. Addison Wesley Longman, Inc., U.S.A. 567 p.

Snyder, K.A.; Williams, D.G.; Gempko, V.L. 1998. Water source determination in cottonwood/ willow and mesquite forests on the San Pedro River in Arizona. American Meteorological Society, Special Symposium on Hydrology, Phoenix, Arizona, 11-16 Jan 1998. Session 1, Presentado en Poster.

Snyder, K.A., Williams, D.G., 2000. Water sources used by riparian trees varies among stream types on the San Pedro River. Arizona Agric. For. Meteorol. 105, 227-240.

Soil Conservation Service. 1964. Irrigation. USDA, SCS engineering handbook, section 15. In: Puricelli, M. 2003.

Souto, C. 2004. Factores que afectan a la productividad en ecosistemas forestales. In: Reigosa, M.; Pedrol, N.; Sánchez, A., eds. 2004. La ecofisiología vegetal: una ciencia de síntesis. España. Thomson. $997-1015 \mathrm{p}$.

Sparks, R.E. 1995. Need for ecosystem management of large rivers and their floodplains. BioScience, 45: 168-182. Citado por Stromberg, 2001.

Sparovek, G., Lima Ranieri, S.; Gassner, A.; De Maria, I.; Schnug, E.; Ferreira dos Santos, F.; Joubert, A. 2002. A conceptual framework for the definition of the optimal width of riparian forests. Agriculture, Ecosystems and Environment 90 (2002) 169-175.

Standley, P.; Steyermark, J. 1946-1977. Flora of Guatemala. Chicago Natural History Museum, Fieldiana Botany, Vol. 24, Pt. I - XIII. 
Stave, J.; Oba, G.; Stenseth, N.C.; Nordal, I. 2005. Environmental gradients in the Turkwel riverine forest, Kenya: Hypotheses on dam-induced vegetation change. Forest Ecology and Management 212 (2005) 184-198.

Stohlgren, T.J.; Falkner, M.B.; Schell, L.D. 1995. A Modified-Whittaker Nested Vegetation Sampling Method. Vegetatio 117(2):113-121.

Stromberg, J. 2001. Restoration of riparian vegetation in the south-western United States: importance of flow regimes and fluvial dynamism. Journal of Arid Environments (2001) 49: 17-34.

Stromberg, J.C. 1993. Instream Flow Models for Mixed Deciduous Riparian Vegetation within a Semiarid Region. Regulated Rivers Research \& Management, Vol. 8, No. 3, p 225-235.

Stromberg, J.C.; Wilkins, S.D.; Tress, J.A. 1993. Vegetation-Hydrology Models: implications for management of Prosopis velutina (Velvet Mesquite) Riparian Ecosystems. Ecological Applications: Vol. 3, No. 2, pp. 307-314. Año 1993.

Stromberg, J.C.; Tiller, R.; Richter, B. 1996. Effects of Groundwater Decline on Riparian Vegetation of Semiarid Regions: The San Pedro, Arizona. Ecological Applications, Vol. 6, No. 1, pp. 113-131.

Stromberg, J. 2001. Restoration of riparian vegetation in the south-western United States: importance of flow regimes and fluvial dynamism. Journal of Arid Environments (2001) 49: 17-34.

Stromberg, J.C.; Bagstad, K.J.; Leenhouts, J.M.; Lite, S.J.; Making, E. 2005. Effects of stream flow intermittency on riparian vegetation of a semiarid region river (San Pedro River, Arizona). River Res. Applic. 21: 925-938 (2005).

Suárez, M.L.; Vidal-Abarca, M.; Sánchez-Montoya, M.; Alba-Tercedor, J.; Álvarez, M.; Avilés, J.; Bonada, N.; Casas, J.; Jáimez-Cuéllar, P.; Munné, A.; Pardo, I.; Prat, N.; Rieradevall, M.; Salinas, M; Toro, M.; Vivas, S. 2002. Las riberas de los ríos mediterráneos y su calidad: el uso del índice QBR. Limnetica 21(3-4): 135-148.

Succhini Farfán, A.E. 2001. Estudio del endemismo florístico en la Reserva de Biosfera Sierra de las Minas. Centro de Estudios Conservación de la Universidad San Carlos de Guatemala. CONCYT/FONACYT. Guatemala. s.n.

Suzukia, W.; Osumi, K.; Masaki, T.; Takahashi, K.; Daimaru, H.; Hoshizaki, K. 2002. Disturbance regimes and community structures of a riparian and an adjacent terrace stand in the Kanumazawa Riparian Research Forest, northern Japan. Forest Ecology and Management 157 (2002) 285-301

Tabacchi, E., Correll, D.L., Hauer, R., Pinay, G., Planty-Tabacchi, A., Wissmar, R.C., 1998. Development, maintenance and role of riparian vegetation in the river landscape. Freshwater Biol. 40, 497-516.

Tabacchi, E.; Lambs, L.; Guilloy, H.; Planty-Tabacchi, A.; Muller, E.; Décamps, H. 2000. Impacts of riparian vegetation on hydrological processes. Hydrol. Process. 14: 2959-2976.

Tabacchi, E.; Planty-Tabacchi, A.-M. 2003. Recent changes in riparian vegetation: possible consequences on dead wood processing along rivers. River Res. Applic. 19: 251-263.

Tabacchi, E.; Planty-Tabacchi, A-M; Roques, L.; Nadal, E. 2005. Seed inputs in riparian zones: implications for plant invasion. River Res. Applic. 21: 299-313.

Taiz, L.; Zeiger, E. 1998. Plant physiology. Estados Unidos, Sinauer Associates, Inc., Publishers, 2a . Edición. 792 p.

Terradas, J. 2001. Ecología de la vegetación: de la ecofisiología de las plantas a la dinámica de comunidades y paisajes. España, Ediciones Omega. 703 p.

Tindall, J.; Kunkel, J.; Anderson, D. 1999. Unsaturated zone hydrology for scientists and engineers. Prentice Hall, U.S.A. 624 p. 
Todd, D.K.; Mays, L.W. 2005. Groundwater hydrology. 3ra. Edición. John Wiley \& Sons, Inc. U.S.A. $636 \mathrm{p}$.

Toner, M; Keddy, P. 1997. River hydrology and riparian wetlands: A predictive model for ecological assembly. Ecological Applications. Vol. 7, no. 1, pp. 236-246.

Treviño, E.J.; Cavazos, C.; Aguirre, O.A. 2001. Distribución y estructura de los bosques de galería en dos ríos del centro sur de Nuevo León. Madera y Bosques 7(1):13-25.

Turner, M.G. 2005. Landscape ecology: what is the state of the science? Annu. Rev. Ecol. Evol. Syst. 36: 319-344.

Valle, L.; Soto, R.; Negreros, M.; Pérez, S.; Castañeda, C. 1999. Áreas prioritarias para la conservación en el sector norte del matorral espinoso del Valle del río Motagua. Guatemala, FDN / PROARCA - CAPAS. $168 \mathrm{p}$.

Van Coller, A.L.; Rogers, K.H.; Heritage, G.L. 1997. Linking riparian vegetation types and fluvial geomorphology along the Sabie River within the Kruger National Park, South Africa. Afr. J. Ecol. 1997, Volume 35, pages 194-212.

van der Honert, T.H. 1948. Water transport in plants as a catenary process. Discussion Faraday Soc. 3: 146-153. In: Medrano, H.; Flexas, J. 2004a. Relaciones hídricas de las plantas.

Vargas Ponce, J.M. 1999. Caracterización de las comunidades vegetales asociadas a las familias Lophosoriaciae, Dicksoniaceae y Cyatheaceae, en el bosque nublado de la microcuenca " Rio el Naranjo", en la sierra de las minas.

Vélez Upegui, J.I. 2001. Desarrollo de un modelo hidrológico conceptual y distribuido orientado a la simulación de las crecidas. Tesis doctoral DIHMA / Universidad Politécnica de Valencia. 266 p.

Véliz Pérez, M.E.; Ramírez, F.J.; Cobar Carranza, A.J.; García, M.J. 2003. La diversidad florística del Monte Espinoso de Guatemala: informe final. Proyecto 2-55, DIGI, Universidad de San Carlos de Guatemala. $51 \mathrm{p}$.

Veneklaas, E.J.; Fajardo, A.; Obregon, S.; Lozano, J. 2005. Gallery forest types and their environmental correlates in a Colombian savanna landscape. Ecography 28: 236-252.

Viaud, V.; Durand, P.; Merot, P.; Sauboua, E. ; Saadi, Z. 2005. Modeling the impact of the spatial structure of a hedge network on the hydrology of a small catchment in a temperate climate. Agricultural Water Management 74: 135-163.

Walters, C., 1997. Challenges in adaptive management of riparian and coastal ecosystems. Conserv. Ecol. [online]1 (2): 1.

Walters, C.; Korman, J. 1999. Cross-scale modelling of riparian ecosystem responses to hydrologic management. Ecosystems 2: $411-421$.

Ward, R.C.; Robinson, M. 2000. Principles of hydrology. 4a. Ed. McGraw-Hill, U.K. 450 p.

Webb, R.H.; Leake, S.A. 2006. Ground-water surface-water interactions and long-term change in riverine riparian vegetation in the southwestern United States. Journal of Hydrology 320 (2006) 302323.

Weiss, M.; Baret, F.; Smith, G.J.; Jonckheere, I.; Coppin, P. 2004. Review of methods for in situ leaf area index (LAI) determination Part II. Estimation of LAI, errors and sampling. Agricultural and Forest Meteorology 121 (2004) 37-53.

Weller, D.E. 1987. A reevaluation of the $-3 / 2$ power rule of plant self-thinning. Ecol. Monogr. 57:23-43. In: Lambers, H.; Chapin III, F.S.; Pons, T.L. 1998. 
Welty, J., Beechie, T., Sullivan, K., Hyink, D., Bilby, R., Andrus, C., Pess, G. 2002. Riparian aquatic interaction simulator (RAIS): a model of riparian forest dynamics for the generation of large woody debris and shade. Forest Ecology and Management 162 (2002) 299-318.

Wen, L.; Ling, J.; Saintilan, N; Rogers, K. 2009. An investigation of the hydrological requirements of River Red Gum (Eucalyptus camaldulensis) Forest, using Classification and Regression Tree modelling. Ecohydrol. 2: 143-155.

Wenger, S. 1999. A review of the scientific literature on riparian buffer width, extent and vegetation. Institute of Ecology, University of Georgia. $59 \mathrm{p}$.

Wild, A. 1992. Condiciones del suelo y desarrollo de las plantas según Russell. Trad. por P. Urbano Terron y C. Rojo Hernández. Ediciones Mundi-Prensa. 1045 p.

Williams, D.G.; Brunel, J.; Schaeffer, S.M.; Snyder, K.A. 1998. Biotic controls over the functioning of desert riparian ecosystems. American Meteorological Society, Special Symposium on hydrology, Arizona, 11-16 Enero 1998. Sesión 1, Artículo 1.11.

Williams, R.D.; Ahuja, L.R.; Naney, J.W. 1992. Comparison of methods to estimate soil water characteristics from soil texture, bulk density, and limited data. Soil Science, Vol. 153, No. 3, 172-184 p.

Winward, A.H. 2000. Monitoring the vegetation resources in riparian areas. Gen. Tech. Rep. RMRSGTR-47. Ogden, UT: USDA, Forest Service, Rocky Mountain Research Station. 49 p.

Woodward, F.I. 1987. Climate and plant distribution. Cambridge University Press, U.K. In: Dingman, S.L. 2002.

Xavier, A.C.; Vettorazzi, C.A. 2003. Leaf area index of ground covers in a subtropical watershed. Sci. agric. (Piracicaba, Braz.), 2003, vol.60, no.3, p.425-431. ISSN 0103-9016. 